\title{
APLICAÇÃO DA MECÂNICA DE FRATURA À ANÁLISE DE FUNDAÇÕES DE BARRAGENS DE CONCRETO FUNDADAS EM ROCHA
}

Dissertação apresentada à Escola de Engenharia de São Carlos da Universidade de São Paulo, como parte dos requisitos para a obtenção do Título de Mestre em Geotecnia.

Orientador: Prof. Dr. Tarcísio Barreto Celestino

São Carlos

2005 
Ficha catalográfica preparada pela Seçăo de Tratamento da Informaçăo do Serviço de Biblioteca - EESC/USP

\footnotetext{
Herrera López, Rossana Aplicação da mecânica de fratura à análise de fundaçōes de barragens de concreto fundadas em rocha / Rossana Herrera López. -- são Carlos, 2005.

Dissertaçăo (Mestrado) -- Escola de Engenharia de São Carlos-Universidade de São Paulo, 2005.

Area: Geotecnia.

Orientador: Prof. Dr. Tarcisio Barreto Celestino.
}

1. Mecânica da fratura. 2. Barragem. 3. Fundaçảo rochosa. 4. Modelo do Dano. 5. propagaçào da fratura. 6. Zona tracionada. I. Titulo. 
Candidata: Engenheira ROSSANA HERRERA LÓPEZ

Dissertação defendida e julgada em 01-07-2005 perante a Comissão Julgadora:

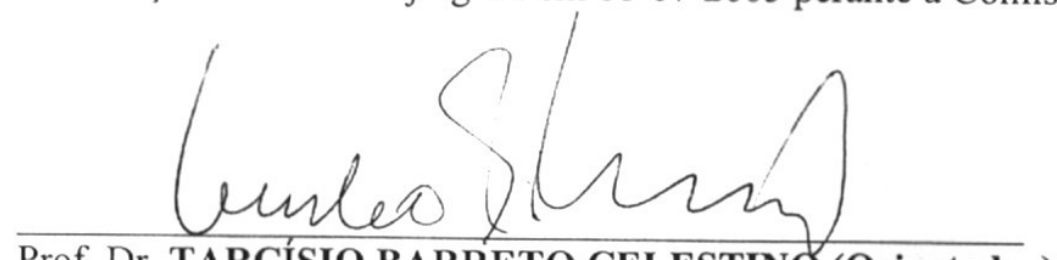

Prof. Dr. TARCÍSIO BARRETO CELESTINO (Orientador)

(Escola de Rngenharia de São Carlos/USP)

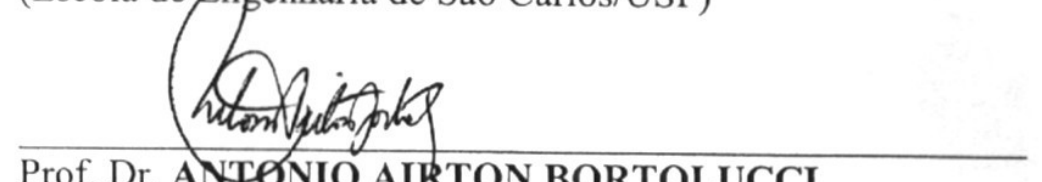

Prof. Dr. ANTONIO AIRTON BORTOLUCCI

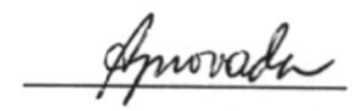

(Escola de Engenharia de São Carlos/USP)

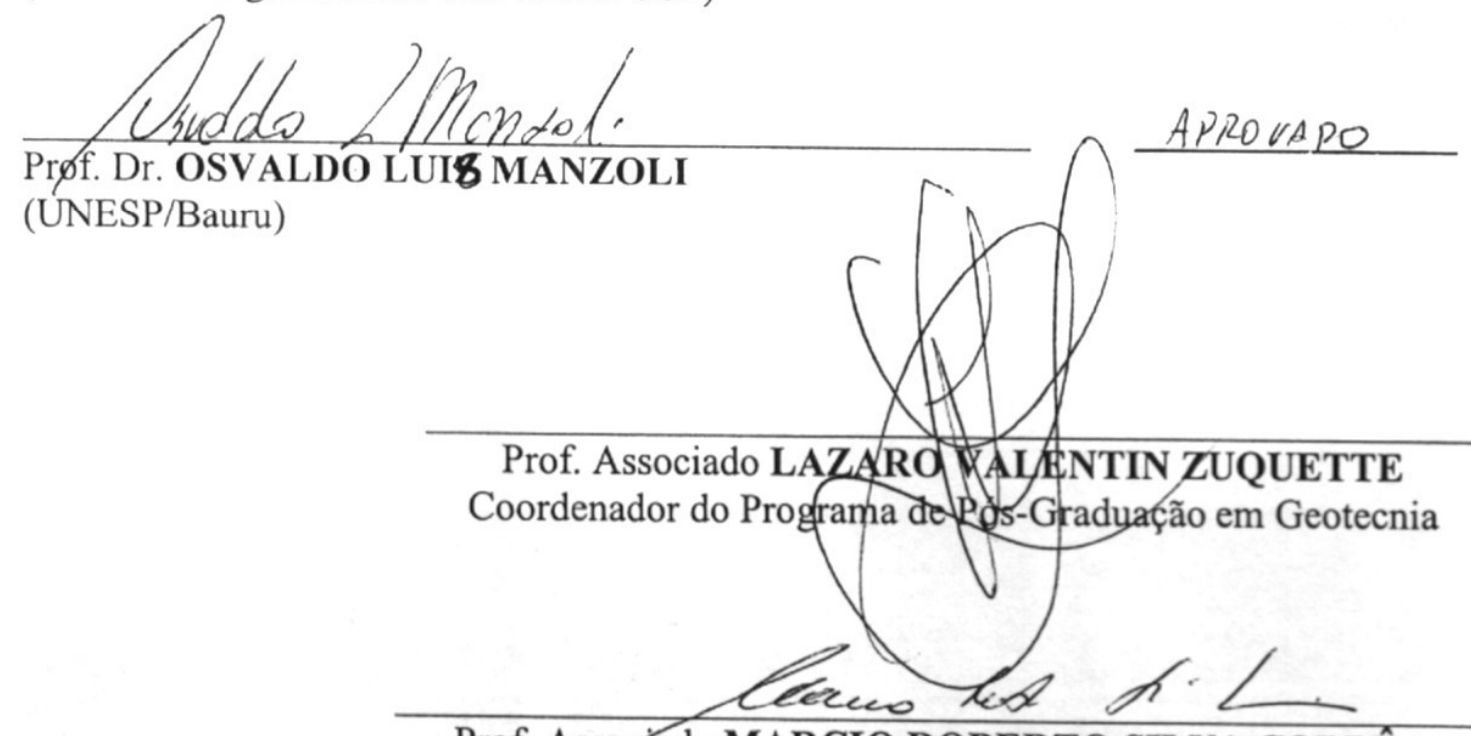

Prof. Associado MARCIO ROBERTO SILVA CORREA

Vice-Presidente da Comissão de Pós-Graduação, em Exercício 

A minha mãe Alejandra, que com seu amor, valentia e exemplo de trabalho orientou e motivou a minha vida. E as minhas irmãs Carmen e Rut pelo apoio desmedido na minha formação. 


\section{AGRADECIMENTOS}

A Deus pela minha vida e a oportunidade de estudar e compartilhar com o próximo.

A CNPq pela oportunidade e financiamento na realização da pesquisa.

Ao Prof. Dr. Tarcísio B. Celestino, pela orientação, ensinamentos e críticas que contribuíram muito na minha formação de Mestre.

Ao Prof. Dr. Osvaldo L. Manzoli pelo continuo apoio, orientação e amizade na realização deste trabalho.

Ao Prof. Dr. Antonio Airton Bortolucci e ao Prof. Dr. Edmundo Esquivel pelo grande e constante apoio durante a realização do trabalho.

Ao geólogo Giácomo Re e à engenheira Kênia Damaseno pelo generoso apoio técnico. Aos professores do Departamento de Geotecnia da Escola de Engenharia de São Carlos que contribuíram para o meu aperfeiçoamento profissional e elaboração deste trabalho, em especial aos Profs. Dr. José C. Cintra, Prof. Dr. Orencio Monje Vilar, Prof. Dr. José E. Rodrigues, ao Prof. Dr. Nelson Aoki, ao Prof. Dr. João B. Nogueira, ao Prof. Dr. Lázaro Valentin Zuquette e ao Prof. Dr. Benedito de Souza Bueno.

Aos Drs. Philippe Martin, Dr. C. Wei, ao engenheiro amigo Jorge Bustamante Dawson que me deram muito apoio no aperfeiçoamento profissional. E aos meus professores Mijail Shteinberg, Victor Dorozhkin e Constantin Karadzhi pela sua dedicação e ensino na minha formação profissional no Instituto de Engenharia de Construção de Odessa.

A todos meus colegas pela amizade e contribuição na realização deste trabalho em especial Heraldo N. Pitanga, Leonardo Silveira, Sara Rodrigues, Miguel Alfaro, Eliana Martins, Kleber, Enrique, Mauricio, Jean Carlo, Ivan, Clóvis. E a Héctor Velásquez pela sua amizade e motivação.

Às secretarias Maristela e Neiva pela ajuda generosa, ao engenheiro Herivelto Moreira dos Santos pelos múltiplos socorros no uso da informática.

Ao povo brasileiro, amigo e generoso, pela acolhida fraterna. E às minhas amigas Maribel Funes, Daniane Vicentini e Marly Monma pela amizade e apoio. 


\section{RESUMO}

HERRERA, R.L (2005). Aplicação da Mecânica da Fratura à análise de fundações de barragens de concreto fundadas em rocha. Dissertação (Mestrado) - Escola de Engenharia de São Carlos, Universidade de São Paulo, São Carlos, 2005.

O presente trabalho de pesquisa está relacionado à análise do progresso do fraturamento na zona tracionada de fundações rochosas de barragens de concreto e suas conseqüências nas avaliações de estabilidade global. Tomou-se como exemplo a barragem de Porto Primavera de propriedade da CESP (Companhia Energética de São Paulo), situada entre os Estados de São Paulo e Mato Grosso do Sul, Brasil. Com a ajuda de modelos elaborados com elementos finitos e sob a ótica da Mecânica da Fratura não linear e da Mecânica do Dano, analisa-se o desenvolvimento da fratura mediante uma avaliação iterativa tensão-deformação e carga hidráulica. Devido ao carregamento progressivo de água, realiza-se a análise iterativa baseada no avanço da fratura e na aplicação de pressão hidráulica, até quando a fratura deixa de progredir. A simulação numérica proposta tem o objetivo de estudar o desenvolvimento de fraturas, determinar as deformações ocorridas sob a ação das forças de empuxo d’água, de subpressão, do peso próprio e das pressões de água na fratura do maciço rochoso fraturado. As deformações calculadas são comparadas com registros da instrumentação na fundação efetuados durante o enchimento do reservatório, o que permitirá o ajuste dos parâmetros adotados na simulação, assim como estabelecer as reais características da fundação.

Palavras-chave: Mecânica da Fratura, barragem, fundação rochosa, Modelo do Dano, propagação da fratura, zona tracionada. 


\begin{abstract}
HERRERA, R.L. (2005). The application of Rock Mechanics to the analysis of rock foundations of concrete dams. M.Sc. Dissertation. Escola de Engenharia de São Carlos, Universidade de São Paulo, São Carlos, 2005.
\end{abstract}

This study is related to the analysis of crack propagation in the tensioned zone of concrete dam foundation. The example of Porto Primavera dam owned by CESP (São Paulo State Power Company) Brazil is presented. Fracture growth is analyzed by mean iterative stress-strain and hydraulic head analysis with codes based on finite elements incorporating non-linear fracture mechanics and damage models. Due to progressive load of water, a step-by-step analysis is performed, based on the development of fracture and application of forces due of hydraulic pressure. The proposed numerical simulation has the purpose of studying the development of fracture, determining deformations due to the action of uplift pressure, self-weight and hydraulic pressure on the fracture walls. The computed deformations are compared with instrumentation data, obtained during the impoundment of the reservoir, from devices installed in the foundation, which will allow to adjust the adopted parameters in the simulation and to determine the real characteristics of the foundation.

Keywords: Fracture Mechanics, dam, rock foundation, Damage model, fracture propagation, tension zone. 


\section{LISTA DE FIGURAS}

Figura 2.1 - Tomada de água e casa de força da barragem Água Vermelha (Celestino, 1983). .7

Figura 2.2 - Instrumentação do vertedouro da barragem de Ilha Solteira (Celestino, 1983).

Figura 2.3 - Relação entre deslocamentos calculados e medidos (extensômetros longos).

Figura 2.4 - Esquema dos índices usados na análise de Cruz (1978). 15

Figura 2.5 - Esquema de subpressão no contato concreto-rocha (Cruz, 1978)................16

Figura 2.6 - Esquema de subpressões na fundação com descontinuidade (Cruz, 1978). 16 Figura 2.7 - (a) Subpressão na fundação do vertedouro de fundo da barragem Jupiá. (b)

Na fundação da barragem de Capivara (Cruz,1978). 18

Figura 2.8 - Leituras piezométricas da subpressão na base das barragens com $B=0,7 \mathrm{H}$ a $1,0 \mathrm{H}$. 19

Figura 2.9 - Leituras piezométricas da subpressão nas descontinuidades da fundação de barragens com $\mathrm{B}=0,7 \mathrm{H}$ a $1,0 \mathrm{H}$.

Figura 2.10 - Diagrama de subpressão proposto na base da barragem sob condições normais.

Figura 2.11 - Diagrama de subpressão proposto em descontinuidades sob condições normais

Figura 2.12 - Variações na permeabilidade com a profundidade (Apud Cruz e Silva, 1978).

Figura 2.13 - Critério proposto para a redução do empuxo de água (Cruz e Silva, 1978). 
Figura 2.14 - Fraturas no pé de montante da barragem Kölbrein (Linsbauer et al., 1989).

Figura 2.15 - Fraturas no pé da barragem (Linsbauer et al., 1989).....

Figura 2.16 - Esquemas dos quatro modelos para fraturamentos ao lado da montante: (a) Modelo de fratura em ângulo; (b) Modelo sem interligação barragem-maciço;

(c) Modelo de rigidez variável da base e (d) Modelo de junta de fundação. 24

Figura 2.17 - Esquema de carregamento (Linsbauer et al. 1989) .25

Figura 2.18 - Detalhe da zona de propagação da fratura (modelo de fratura em ângulo).

Figura 2.19 - Detalhe da malha após dois intervalos de avanço da fratura (modelo sem interligação barragem-maciço). 26

Figura 2.20 - Seção transversal da barragem com a instrumentação Piezodex e

Micrômetros deslizantes, as juntas S, L e o selo de neoprene. 28

Figura 2.21 - Perfis da deformação ao longo das duas perfurações (Kóvari e Bergamin, 1994). 29

Figura 2.22 - Desenvolvimento da deformação na junta ativa S (medida da posição

GM.1.46) devido à variação do nível de água. 30

Figura 2.23 - Comparação dos valores de pressão calculados com as leituras no nível 2162m (Kóvari e Bergamin, 1994).

Figura 2.24 - Energia e variação da energia em função do tamanho da fratura

(Bortolucci, 1994) 33

Figura 2.25 - Modos de propagação da fratura. 34

Figura 2.26 - Curva uniaxial tensão-deformação para o modelo de degradação (Olivier et al., 1990). 36

Figura 2.27 - Superfície limite inicial do dano no espaço das tensões principais efetivas biaxial. 38

Figura 2.28 - Esquema de Cálculo de Andrade (1988). 43

Figura 2.29 - Definição da subpressão média (Sd) segundo Andrade (1988). 43

Figura 2.30 - Consideração do fator de forma, l (Andrade, 1988).................................44

Figura 2.31 - Tipos de abertura ou descontinuidade (Andrade, 1980). 46 
Figura 2.32 - Substituição do modelo real (A) pelo modelo teórico (B) .........................46

Figura 3.1 - Seção de análise do vertedouro sob carga máxima atual de água...............50

Figura 3.2 - Seção de análise da casa de força sob a carga máxima de água...................51

Figura 3.3 - Localização em planta do vertedouro BV-6...............................................51

Figura 3.4 - Localização em planta da zona da tomada de água e da casa de força U-10. 52

Figura 3.5 - Esquema de carregamento hidráulico do vertedouro. ................................55

Figura 3.6 - Esquema do carregamento hidráulico na tomada e casa de força...............55

Figura 3.7 - Esquema de cálculo das forças nodais equivalentes. ................................56

Figura 3.8 - Esquema de cálculo da carga de água a jusante do vertedouro....................57

Figura 3.9 - Esquema de cálculo das forças a jusante da casa de força...........................58

Figura 3.10 - Esquema de aplicação da carga na entrada do conduto e na zona de saída.

Figura 3.11 - Esquema para o cálculo das forças equivalentes na fenda do vertedouro. 60

Figura 3.12 - Esquema para o cálculo das forças nodais na fenda................................60

Figura 3.13 - Malha de análise do vertedouro (Programa GID). ..................................67

Figura 3.14 - Malha de análise da casa de força. .........................................................67

Figura 3.15 - Pressão de água na fratura (Reich et al. 1994)........................................68

Figura 3.16 - Orientação da fratura e ângulos de inclinação das forças. ........................69

Figura 3.17 - Esquema da aplicação das forças nodais nos elementos danificados........69

Figura 3.18 - Modelo de análise para calcular as forças equivalentes da subpressão no vertedouro (Programa SEEP/W) ................................................................ 70

Figura 3.19 - Discretização da zona de fratura para o cálculo da subpressão..................71

Figura 3.20 - Modelo de análise para calcular as forças equivalentes da subpressão na

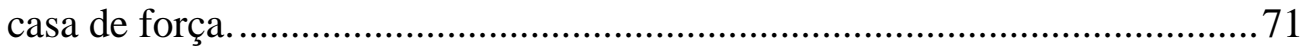

Figura 3.21 - Discretização da zona de fratura para o cálculo da subpressão..................72

Figura 4.1 - Desenvolvimento da fratura: (a) sob carga do nível 242m e (b) sob a aplicação da carga do mesmo nível na fratura...................................73

Figura 4.2 Avanço da fratura sob carga do nível de água 244m...................................74 
Figura 4.3 Avanço da fratura sob carga do nível de água 247m................................. 74

Figura 4.4 Avanço da fratura sob carga do nível de água 250m.................................. 74

Figura 4.5 Avanço da fratura sob carga do nível de água 253m.................................. 75

Figura 4.6 Avanço da fratura sob carga do nível de água $257 \mathrm{~m}$.................................. 75

Figura 4.7 Extensômetros e Piezômetros existentes na seção de análise do vertedouro.79

Figura 4.8 Extensômetros e Piezômetros existentes na seção de análise da casa de força.

Figura 4.9 Comparação dos deslocamentos calculados e medidos da haste 1 do EH-261.

Figura 4.10 Comparação dos deslocamentos calculados e medidos da haste 2 do EH261.

Figura 4.11 Comparação dos deslocamentos calculados e medidos da haste 3 do EH261.

Figura 4.12 Comparação dos deslocamentos calculados e medidos da haste 1 do EH262

Figura 4.13 Comparação dos deslocamentos calculados e medidos da haste 2 do EH262

Figura 4.14 Comparação dos deslocamentos calculados e medidos da haste 3 do EH262

Figura 4.15 Comparação dos deslocamentos calculados e medidos da haste 1 do EH566.

Figura 4.16 Comparação dos deslocamentos calculados e medidos da haste 2 do EH566

Figura 4.17 Comparação dos deslocamentos calculados e medidos da haste 3 do EH566.

Figura 4.18 Comparação dos deslocamentos calculados e medidos da haste 1 do EH567.

Figura 4.19 Comparação dos deslocamentos calculados e medidos da haste 2 do EH567. 
Figura 4.20 Comparação dos deslocamentos calculados e medidos da haste 3 do EH567 86

Figura 4.21 Comparação dos deslocamentos calculados e medidos da haste 1 do EH568. 87

Figura 4.22 Comparação dos deslocamentos calculados e medidos da haste 2 do EH568. 87

Figura 4.23 Comparação das vazões dos drenos do bloco BV-6 e as respectivas vazões calculadas. 88

Figura 4.24 Comparação das vazões dos drenos da U-10 e as respectivas vazões calculadas. 88

Figura 4.25 Deslocamentos das hastes no tempo do enchimento em relação ao nível de água do reservatório. 90

Figura 4.26 Deslocamentos das hastes em relação à temperatura média. 91

Figura 4.27 Deslocamentos das hastes no tempo em relação ao nível de água do reservatório 91

Figura 4.28 Deslocamentos das hastes em relação à temperatura média. 92

Figura 4.29 Deslocamentos das hastes no tempo em relação ao nível de água. 93

Figura 4.30 Deslocamentos das hastes do EH-566 em relação à temperatura média.....93

Figura 4.31 Deslocamentos das hastes no tempo em relação ao nível de água. 94

Figura 4.32 Deslocamentos das hastes do EH-568 no tempo em relação ao nível de água.

Figura 4.33 Deslocamentos das hastes do EH-568 em relação à temperatura média.....95

Figura 4.34 Comparação das hastes 1 dos extensômetros 261 e 262..............................95

Figura 4.35 Comparação das hastes 2 dos extensômetros 261 e 262..............................96

Figura 4.36 Comparação das hastes 3 dos extensômetros 261 e 262..............................96

Figura 4.37 Comparação das hastes 1 dos extensômetros 566 e 567..............................97

Figura 4.38 Comparação das hastes 2 dos extensômetros 566 e 567.............................97

Figura 4.39 Comparação das hastes 3 dos extensômetros 566 e 567 ...............................98

Figura 4.40 Desenvolvimento da fratura a montante do vertedouro..............................99 
xvi

Figura 4.41 Desenvolvimento da fratura a montante da estrutura tomada de água-casa de força. 99

Figura 4.42 Leituras dos piezômetros a montante em relação ao nível de água............ 100

Figura 4.43 Localização da fratura em relação aos piezômetros na seção BV-2........... 100

Figura 4.44 Leituras dos piezômetros PZ-221, PZ-222, PZ-223, PZ-224, PZ-225 e PZ226 no vertedouro BV-2. 101

Figura 4.45 Subpressão calculada sem fratura e com fratura na fundação do vertedouro. 101

Figura 4.46 Comparação dos critérios de projeto e o resultado da simulação numérica. 


\section{LISTA DE TABELAS}

Tabela 1. Parâmetros característicos dos materiais para a simulação do vertedouro.......53

Tabela 2. Parâmetros característicos dos materiais para a simulação da casa de força. .53

Tabela 3 Valores calculados da Energia de fratura para o basalto................................ 54

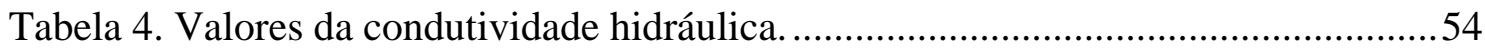

Tabela 5. Pressões a montante e a jusante, e cargas pontuais no vertedouro..................59

Tabela 6. Pressões de água a montante e a jusante da casa de força................................59

Tabela 7. Deslocamentos das hastes do extensômetro EH-261 no vertedouro................76

Tabela 8. Deslocamentos das hastes do extensômetro EH-262 no vertedouro.................76

Tabela 9. Deslocamentos das hastes do extensômetro EH-566 na casa de força. ...........77

Tabela 10. Deslocamentos das hastes do extensômetro EH-567 na casa de força. .........77

Tabela 11. Deslocamentos das hastes do extensômetro EH-568 na casa de força. .........77

Tabela 12. Cota de instalação dos extensômetros e dos piezômetros do vertedouro......79

Tabela 13. Cota de instalação dos extensômetros e dos piezômetros da casa de força. .80 
xviii

\section{LISTA DE SÍMBOLOS}

$A^{+} \quad$ Parâmetro de abrandamento.

A Área onde ocorre o escoamento na unidade de largura.

$A_{\mathrm{d}} \quad$ Superfície da circunferência do dreno.

a Semi comprimento da fratura.

$a_{\mathrm{d}} \quad$ Distância entre furos de drenagem.

B Largura da base da barragem.

$b \quad$ Distância do dreno até a face de jusante.

$\overline{C D}$ Coluna de água no dreno.

$D_{0} \quad$ Tensor constitutivo elástico linear de quarta ordem.

$d^{+} \quad$ Variável interna do dano de tração.

$d^{-} \quad$ Variável interna do dano de compressão.

d Variável de dano.

E Módulo de elasticidade.

$E_{d} \quad$ Eficiência de drenagem.

$\mathrm{E}_{\mathrm{X}} \quad$ Módulo de deformabilidade na direção x.

$\mathrm{E}_{\mathrm{y}} \quad$ Módulo de deformabilidade na direção y.

e Abertura nominal da fratura.

$e_{1}, e_{2}, e_{3}$ Altura de aplicação das cargas nodais equivalentes.

$\varepsilon \quad$ Deformação específica.

$F_{1}, F_{2}, F_{3}$ Forças nodais equivalentes.

$F_{e q}$ Força equivalente.

$f_{0}^{+}, f_{0}^{-}$Limites de proporcionalidade.

$f_{\mathrm{t}} \quad$ Resistência à tração.

$f \quad$ Fator de escoamento.

$\phi \quad$ Diâmetro do furo de drenagem.

$\gamma \quad$ Energia específica de superfície livre. 
$\gamma_{c} \quad$ Peso específico do concreto.

$\gamma_{\mathrm{m}} \quad$ Peso específico do maciço saturado.

$\gamma_{n} \quad$ Peso específico do maciço em condição natural.

$\gamma_{\mathrm{w}}$ Peso específico da água.

G Variação da liberação de energia.

Gc Energia de ruptura critica.

$G_{\mathrm{F}} \quad$ Energia de fratura do material.

g Aceleração da gravidade.

$H_{\mathrm{m}} \quad$ Carga hidráulica a montante.

$H_{\mathrm{j}} \quad$ Carga hidráulica a jusante.

$H_{\mathrm{d}} \quad$ Carga de água na boca do dreno.

$H_{\mathrm{dr}}$ Profundidade do dreno.

$\mathrm{H}_{1}, \mathrm{H}_{2}, \mathrm{H}_{3}$ Altura da zona de influencia das cargas a jusante.

$h_{1}, h_{2}, h_{3}$ Altura dos níveis de carga de água.

i Gradiente hidráulico.

K Fator de intensidade de tensão.

Kc Tenacidade à fratura.

$k_{\mathrm{d}} \quad$ Condutividade hidráulica do dreno.

$\mathrm{k}_{\mathrm{h}} \quad$ Condutividade hidráulica horizontal.

$\mathrm{k}_{\mathrm{v}} \quad$ Condutividade hidráulica vertical.

$k_{x} \quad$ Condutividade hidráulica na direção $\mathrm{x}$.

$k_{\mathrm{y}} \quad$ Condutividade hidráulica na direção y.

K Coeficiente de empuxo.

$k_{f} \quad$ Condutividade da fratura.

$k_{\mathrm{t}} \quad$ Condutividade total o ponderada do elemento danificado.

L Comprimento da circunferência do dreno.

l Distância de um ponto qualquer até o dreno.

$l_{e} \quad$ Largura do elemento.

$\lambda \quad$ Fator de forma da linha de drenos.

n Número de elemento.

$\mu \quad$ Viscosidade dinâmica.

$p, p_{1}$ Pressões de água.

$v \quad$ Viscosidade cinemática de água. 
Q Vazão do meio.

$Q_{\mathrm{d}} \quad$ Vazão no dreno.

$Q_{t} \quad$ Vazão total do elemento danificado.

$Q_{f} \quad$ Vazão da abertura da fratura.

$Q_{m} \quad$ Vazão da zona do elemento sem fratura.

$q \quad$ Vazão do meio descontínuo.

$q_{\mathrm{m}} \quad$ Vazão que penetra a montante.

$q_{\mathrm{d}} \quad$ Vazão que sai pelo dreno.

$q_{\mathrm{j}} \quad$ Vazão que sai por jusante.

$\mathrm{q}_{1}, \mathrm{q}_{2}, \mathrm{q}_{3}$ Pressões de água.

$r^{+} \quad$ Limite corrente de dano de tração.

$r^{-} \quad$ Limite corrente de dano de compressão.

$r_{0}^{+}, r_{0}^{-}$Limites correntes de dano iniciais.

$r_{d} \quad$ Raio do dreno.

$\sigma \quad$ Tensão.

$\sigma_{\mathrm{cr}}$ Tensão crítica para ruptura.

$\bar{\sigma} \quad$ Tensão efetiva.

$\bar{\sigma}^{+}$Tensão efetiva de tração.

$\bar{\sigma}^{-} \quad$ Tensão efetiva de compressão.

$\sigma_{\mathrm{h}}$ Tensão horizontal.

$\sigma_{\mathrm{v}}$ Tensão vertical.

$S \quad$ Área total.

$S_{D} \quad$ Área das microfissuras e cavidades.

$S_{d} \quad$ Subpressão média.

s Distância do dreno até a face de montante.

$s_{1}, s_{2}, s_{3}$ Pressões de água.

$\bar{\tau}^{+} \quad$ Norma de tensão efetiva de tração.

$\bar{\tau} \quad$ Norma de tensão efetiva de compressão.

$U_{\mathrm{e}} \quad$ Energia de deformação.

$U_{\mathrm{s}} \quad$ Energia de superfície.

$U_{\mathrm{t}} \quad$ Energia total.

$v_{\mathrm{m}} \quad$ Velocidade média. 
$v \quad$ Coeficiente de Poisson. 
xxii 


\section{SUMÁRIO}

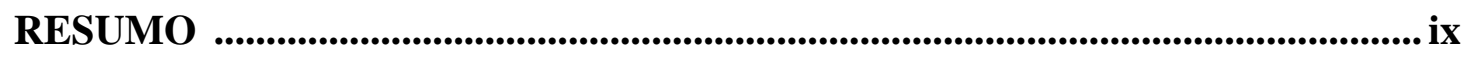

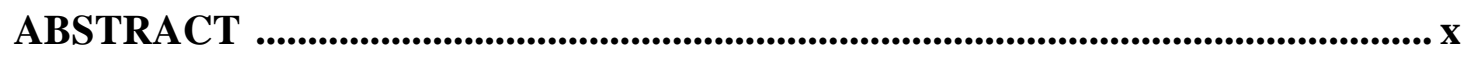

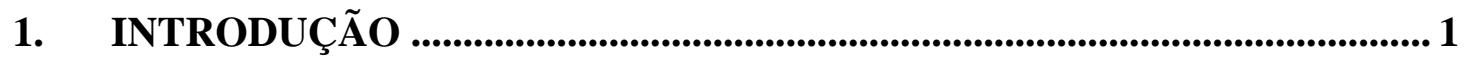

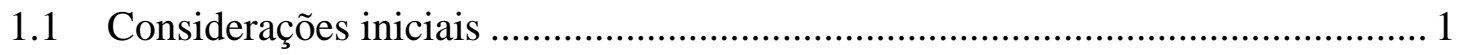

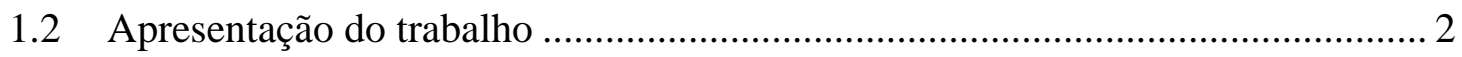

2. REVISÃO BIBLIOGRÁFICA ................................................................... 4

2.1 Antecedente de estudos de barragens no Brasil............................................... 4

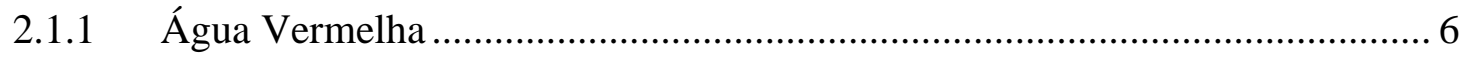

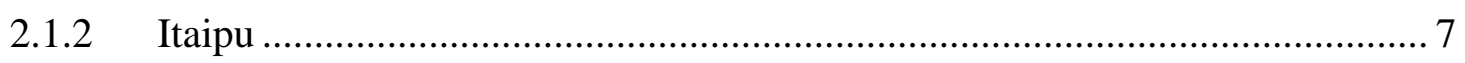

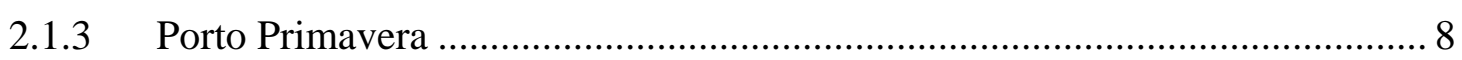

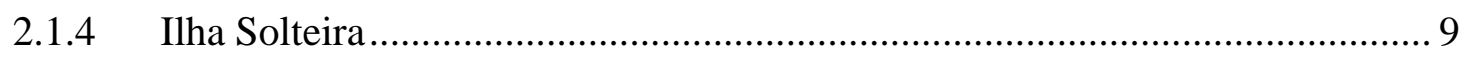

2.2 Antecedente de estudos de barragens no exterior ............................................. 22

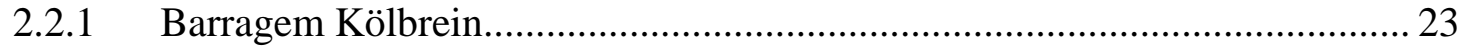

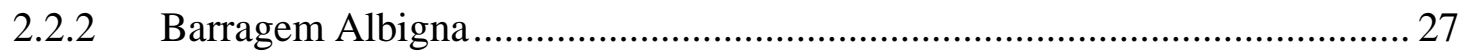

2.3 A mecânica de Fratura ....................................................................................... 31

2.3.1 Balanço Energético de Griffith ..................................................................... 31

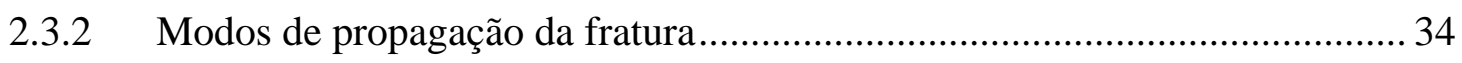

2.4 Modelo de Propagação de Fratura ...................................................................... 35

2.5 Determinação da Subpressão ............................................................................. 39

2.5.1 Determinação da subpressão média ............................................................. 41

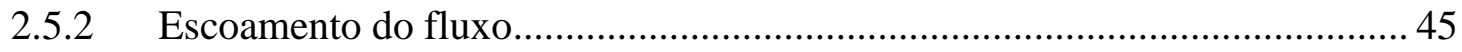

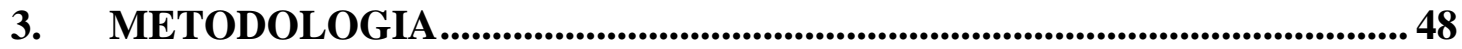

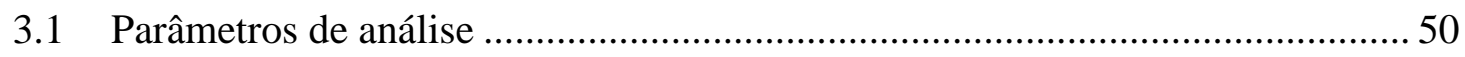

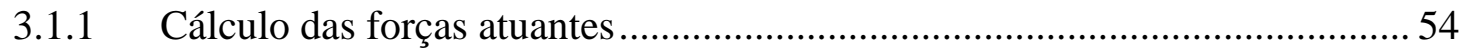

3.1.2 Subpressão e Pressão Média ........................................................................ 60 
xxiv

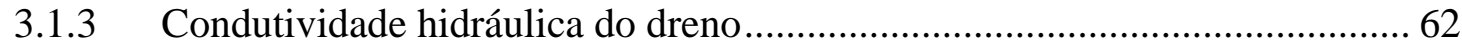

3.1.4 Cálculo da condutividade hidráulica na fratura .......................................... 63

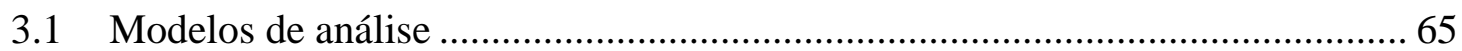

3.2.1 Modelo Tensão-Deformação e Pressão de água ............................................ 65

3.2.2 Modelo de análise de fluxo e subpressão..................................................... 69

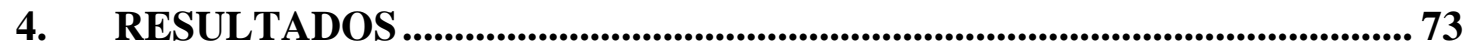

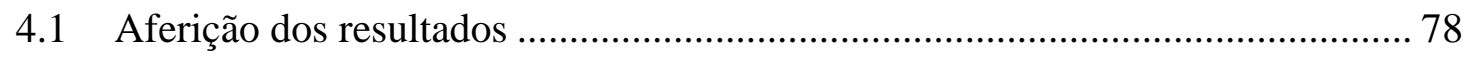

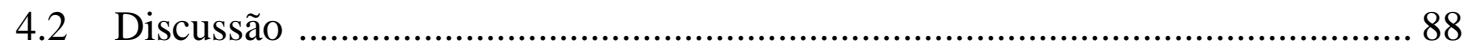

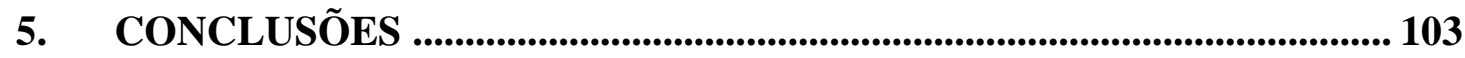

REFERÊNCIAS BIBLIOGRÁFICAS ............................................................... 105

ANEXO A

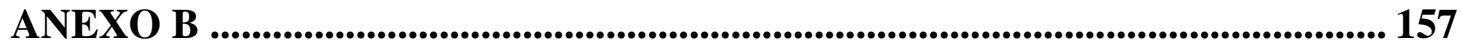




\section{INTRODUÇÃO}

\subsection{Considerações iniciais}

As estruturas de barragens são geralmente as obras mais caras construídas pelo homem. Isto se vê refletido no grande esforço que os engenheiros fazem para garantir que sejam projetadas, construídas e mantidas sob critérios de vanguarda e tecnologia. Durante muito tempo, os projetos de barragens foram analisados com métodos clássicos que não permitiam distinguir quando e por que se produz o fraturamento das estruturas e suas fundações. A grande preocupação em manter a segurança das barragens de concreto tem motivado a realização de inúmeros estudos com o intuito de determinar os fatores que influem a formação e desenvolvimento das fraturas. As barragens de concreto assentadas nos maciços rochosos e submetidas a empuxos de água experimentam fraturamento tanto no próprio corpo da estrutura, como também na fundação, sendo esta zona objeto do presente estudo.

Devido às tensões de tração impostas pelo carregamento de empuxo a montante, fendas se formam na rocha do pé da barragem. A presença destas fraturas ou fendas, como já é conhecido, pode originar uma série de problemas no que concerne ao funcionamento normal das estruturas hidráulicas, produzindo, principalmente, grandes vazamentos ou a desestabilização da estrutura, o que, em muitos casos, pode levá-la ao colapso.

Como exemplo, podemos citar os estudos efetuados na barragem de Itaipu relatados no trabalho de Rosso et al. (1997), em que, devido à presença de fendas no concreto, foram constatadas grandes vazões de infiltração, observando-se a dependência das vazões em relação às fraturas originadas pelas variações da temperatura-ambiente. Salienta-se, porém, que o fator temperatura não é o único. Em barragens, como a de Kolbrein na Áustria, segundo o estudo de Linsbauer et al. (1989), o aparecimento das fraturas se deu devido à ação das cargas hidráulicas ou de empuxo, assim como devido 
ao peso próprio e às tensões na base da barragem. Outro caso digno de ser citado é a barragem de Albigna na Suíça, onde Kovári e Bergamin (1994) com ajuda de instrumentação conseguiram descobrir a existência de fissuras, na fundação de montante, que originavam deformações na estrutura e mudanças da permeabilidade devido à variação do nível de água.

É importante aclarar que as forças de percolação e os sismos também são fatores que influem na estabilidade do sistema barragem-fundação-água.

A problemática das fraturas em concreto e em rocha tem sido um dos objetivos de estudo da Mecânica da Fratura, cujos princípios tornam possível a análise de situações de tensões em zonas onde o critério clássico da resistência dos materiais não funciona.

A Mecânica da Fratura, cujos princípios permitem conhecer e controlar a propagação das fraturas, pode ser aplicada com a ajuda de modelos numéricos, os que trabalham principalmente com elementos finitos. Modelos numéricos, como o Modelo de Dano, são empregados na análise do desenvolvimento da fratura em rochas ou em concreto. Mas, embora as técnicas de análise ajudem muito na representação matemática da estrutura interagindo com a fundação e a água do reservatório, ainda não se consegue fazer a fiel representação do sistema barragem-fundação-água. Detalhes da caracterização do contorno do modelo e do material ainda sofrem simplificações que permitam viabilizar a análise e obter conclusões razoáveis.

\subsection{Apresentação do trabalho}

O presente trabalho tenta desenvolver uma metodologia que, baseada em um modelo matemático, permita realizar uma análise iterativa do estado de tensãodeformação do maciço e a consideração da pressão hidrostática na fratura após o carregamento progressivo d'água durante o enchimento do reservatório.

No desenvolvimento do trabalho, apresenta-se, num primeiro momento, a revisão bibliográfica relacionada ao estudo, onde são expostos antecedentes de estudos realizados em barragens no Brasil e no exterior. Seguidamente, trata-se de dar uma abordagem simples e concisa do fundamento teórico da Mecânica da Fratura e sua aplicação na Mecânica das Rochas. Igualmente, apresentam-se os conceitos principais da Teoria da Mecânica do Dano, na qual se baseia o Modelo de propagação de fratura que foi usado na análise e que fornece os deslocamentos que ocorrem na rocha de fundação. Apresenta-se uma breve resenha dos estudos de subpressão e o critério de 
cálculo para determinação da pressão média assim como também os estudos relacionados à lei cúbica de vazão, através de fraturas individuais.

Num segundo momento, apresenta-se no item 03 a metodologia adotada e seguida, a qual descreve o roteiro da obtenção dos parâmetros necessários para a análise, o enfoque e o procedimento da análise, a quantificação dos valores de saída e a análise dos resultados.

No mesmo item 03, apresentam-se as características das seções da estrutura da barragem e os parâmetros necessários para o cálculo, tanto os utilizados no projeto original, como os obtidos com base nos ensaios de laboratório. São parte deste item o modelo de análise de tensão-deformação e de pressão de água, assim como o modelo de análise de subpressão afetado pela presença de fratura no pé de montante da barragem. O processamento do modelo tensão-deformação e de pressão de água é realizado com a ajuda do Modelo de propagação da Fratura, no qual são consideradas as componentes de tração das tensões principais.

Os resultados obtidos, que são os deslocamentos produzidos na fundação, são mostrados no item 04, onde se faz a aferição dos resultados em relação aos registros da instrumentação existente na fundação da barragem e se expõem as discussões relacionadas ao tema.

Por fim, no item 05, são apresentadas as conclusões a que se chegou com base na aferição dos dados. Também são apresentadas algumas sugestões identificadas como relevantes à continuidade da pesquisa, propondo-se mais variáveis a serem consideradas, as quais não foram usadas neste trabalho, em decorrência do tempo limitado. 


\section{REVISÃO BIBLIOGRÁFICA}

\subsection{Antecedente de estudos de barragens no Brasil}

Um grande número de barragens, no Brasil tem sido estudado para analisar sua segurança e estabilidade. A necessidade de se realizarem análises localizadas de deformações e fraturas deu passo ao emprego de modelos matemáticos com ajuda de métodos numéricos.

Celestino (1983) aborda o tema pertinente ao uso de métodos numéricos com exemplos de aplicação em barragens da Bacia do Alto Paraná, explicando com detalhe as evoluções, principalmente nas hipóteses de cálculo, e os aspectos de aferição dos modelos numéricos com resultados de instrumentação, dando importância à representação da ação da água na fundação. Neste último caso, o emprego de ações impostas como o uso do diagrama de subpressão obtido de observações de outras obras cede lugar a uma análise de fluxo, acoplada à análise de tensão-deformação. Salienta-se que as duas análises são interdependentes, no sentido de que as pressões de água modificam as tensões efetivas, que por sua vez modificam localmente a permeabilidade.

Segundo Celestino (1983), os modelos matemáticos envolvem simplificações nas propriedades dos materiais, na geometria e no carregamento. Nas análises, assume-se geralmente um comportamento elástico linear sob compressão. Isto se dá para rochas típicas aceitas como material de fundação das barragens do Alto Paraná, onde as tensões atuantes são relativamente baixas e o material intacto trabalha dentro de seu limite de linearidade. Mas, em situações como a fundação da barragem de Porto Primavera, por motivos econômicos, foi necessário que se trabalhasse sobre um maciço basáltico de peso específico bastante baixo e de resistência bem inferior aos materiais usuais para tal fim. Diante uma situação de concentração de tensões que atingia a resistência do basalto leve, as análises levaram em conta o critério de ruptura do material intacto.

Os parâmetros correspondentes ao módulo de elasticidade e ao coeficiente de 
Poisson necessários para a análise linear podem ser determinados mediante a aferição de modelos matemáticos com resultados de instrumentação.

Em relação à segurança das barragens, Celestino (1983) considera que os níveis de tensão numa rocha intacta situam-se sempre abaixo dos limites de linearidade dos materiais, porém isto não ocorre com as descontinuidades. Análises mais precisas devem considerar estas feições e representar seu comportamento elasto-plástico. Ele referencia resultados de ensaios in-situ, onde se concluiu que o critério de um coeficiente de segurança imposto de 1,5 (condições normais de operação de barragens) para o atrito das descontinuidades seria como impor que a fundação trabalhasse abaixo do ponto de cedência, ou seja, em regime linear, o que resulta na tendência de procurar maior tensão normal ou maior altura da barragem em análise.

Em relação à permeabilidade, Celestino (1983) explica que os maciços têm sido representados como heterogêneos, anisotrópicos, porém contínuos. Ante a necessidade de parâmetros, tomam-se coeficientes de permeabilidade válidos para certas regiões do maciço. Aquele autor chama a atenção, também para os limites de modelos analisados, principalmente aqueles onde se realizam análises acopladas de fluxo e tensãodeformação. A extensão de uma malha para percolação deve ser determinada em função do comprimento impermeável da base da barragem e da profundidade da zona permeável da fundação, contudo, para tensão-deformação, o critério usual se baseia na altura da barragem. Devido à presença de drenos que reduzem a zona impermeável da base, a profundidade da zona permeável é um parâmetro determinante, o que leva a considerar comprimentos da malha de cerca do dobro da profundidade, para montante e jusante, porém, em casos de forte anisotropia $\left(k_{\mathrm{h}}>>k_{\mathrm{v}}\right)$, este critério pode ser insuficiente. Com relação à geometria, é na análise plana que se tem maior simplificação de efeitos tridimensionais. Isto pode ser complicado quando se trata de percolação porque a variação espacial da permeabilidade parece ser maior do que as propriedades mecânicas. As diferenças no tratamento das fundações e a disposição geométrica das estruturas de uma usina originam componentes de fluxo significativos que não são representados em análises planas. Guidicini (1983) mostra que o efeito de convergência do fluxo na casa de força gera, em sua vizinhança, linhas de fluxo quase paralelas ao eixo da barragem.

Outro aspecto importante que ressalta Celestino (1983) corresponde aos efeitos de $\underline{\text { arqueamento da estrutura em vales estreitos que somente podem ser considerados em }}$ 
análises tridimensionais. Um exemplo de consideração foi o caso da Usina de Itaipu, onde, graças a um modelo reduzido tridimensional, comprovou-se que o carregamento de ruptura era o dobro daquele encontrado em análises planas.

Com o objetivo de mostrar a aplicação das hipóteses de cálculo, Celestino (1983) cita como exemplos alguns casos reais.

\subsection{1 Água Vermelha}

O projeto de Água Vermelha foi o primeiro nas obras do Alto Paraná que analisou a fundação das estruturas, considerando o comportamento elasto-plástico das descontinuidades do maciço rochoso.

Uma hipótese importante foi a consideração de pressões totais do reservatório na fundação a montante da cortina de vedação, devido à ação da água. Esta zona, que antes foi chamada de trinca de tração, deu margem a confusão. Isto pode ser explicado pelas deformações impostas ao maciço imediatamente a montante da barragem, o que tenderá a aumentar a abertura das fissuras, por onde percola a água e em decorrência sua condutividade hidráulica. Como é sabido, a vazão através de uma fissura individual depende do cubo de sua abertura, o que influi na permeabilidade média do maciço em dependência da abertura média das fissuras, e também, indiretamente, nas tensões efetivas atuantes. A figura 2.1 apresenta a seção da tomada de água - casa de força da barragem.

Vale dizer que na determinação das pressões atuantes, são importantes os valores relativos de permeabilidades das diversas zonas e não seus valores absolutos. Outro ponto a considerar é que a zona imediata a jusante, que sofre deformações de extensão (zona de aumento de permeabilidade), é caracterizada pela presença da cortina de vedação e elevadas tensões de compressão, devido ao peso próprio da barragem, o que contribui para a diminuição da permeabilidade. O contraste de permeabilidade leva a um aumento das pressões de percolação, na zona imediata a montante da cortina de vedação. A quantificação deste aumento de pressões não é tão simples.

Para a tomada de água e a casa de força, foram realizadas análises considerandose as não linearidades decorrentes da variação dos parâmetros de deformação da junta com a tensão normal atuante. No final, não houve diferenças sensíveis. 


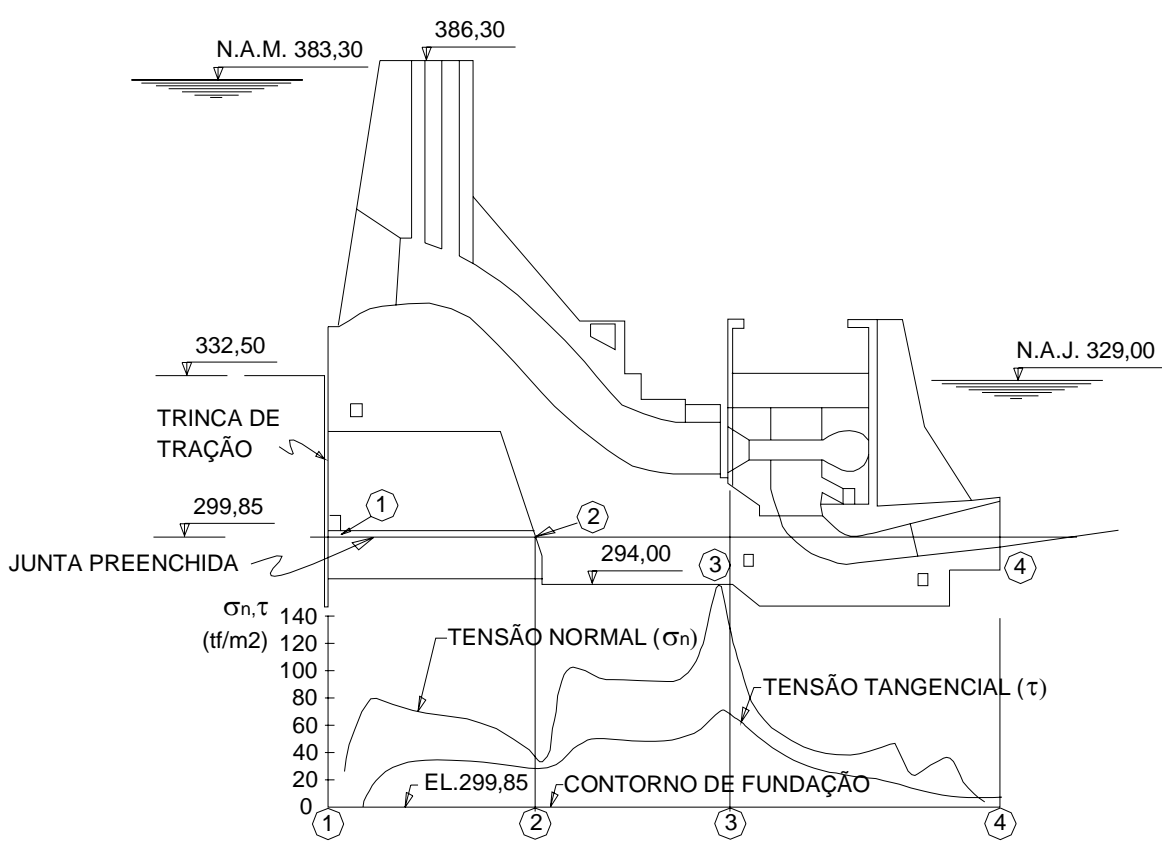

Figura 2.1 Tomada de água e casa de força da barragem Água Vermelha (Celestino, 1983).

\subsubsection{Itaipu}

A obra foi objeto de várias análises, muitas delas nas fundações. Celestino (1983) comenta uma em especial por seu aspecto inovador quanto à hipótese de ação da água na fundação.

Na análise realizada, não se considerou a imposição prévia de uma trinca de tração, e o maciço foi tratado como um material sem nenhuma resistência à tração, seguindo o modelo de redistribuição de tensões, proposto por Zienkiewicz et al. (1968).

A zona tracionada, após cálculos iterativos de redistribuição do excedente de tensões que o maciço não tinha capacidade de suportar, convergiu para uma configuração estável a uma profundidade máxima, no topo da camada de brecha basáltica.

Não se considerou a ação de água como subpressão ou como pressão a montante da cortina de vedação. Realizando-se uma análise de percolação acoplada à análise de tensão-deformação, desenvolveu-se um processo iterativo que consistiu nos seguintes passos: 
1. Análise inicial de tensões, considerando-se a construção das estruturas de concreto. Com o estado de tensões da zona a montante da cortina, determina-se a permeabilidade correspondente.

2. Análise de percolação, usando-se os valores da permeabilidade da zona a montante da cortina de vedação determinados no passo anterior. A isto seguiu-se o cálculo das forças de percolação.

3. Análise de tensões efetivas, usando-se as forças de percolação e diagramas de subpressão determinadas no passo 2.

4. Determinação dos novos valores de permeabilidade, compatíveis com as tensões calculadas no passo 3. Se a diferença de permeabilidade em relação aos valores adotados na última análise for menor que uma tolerância estabelecida, o processo converge e os resultados finais são os da última análise de percolação e de tensões. Caso contrário, adotam-se os novos valores de permeabilidade e retornase ao passo 2.

A análise convergiu com 3 iterações, tendo-se como resultado uma grande diferença entre os valores adotados da permeabilidade da cortina de vedação e o maciço vizinho. Isto talvez causou pressões elevadas a montante da cortina.

Celestino (1983) ressalta outro aspecto importante a considerar, a saber, o valor das tensões horizontais iniciais, atuando em planos paralelos ao eixo da barragem. As tensões finais, após a construção da barragem e enchimento do reservatório, serão tanto maiores quanto maiores foram as tensões iniciais e, conseqüentemente, tanto menor será a permeabilidade vertical e tanto menor será a pressão de água a montante da cortina de vedação.

\subsubsection{Porto Primavera}

Em vista da importância do estado inicial de tensões, realizaram-se duas análises. Uma considerou $K=\sigma \mathrm{h} / \sigma \mathrm{v}=0,3$, determinado a partir de um estado de tensões puramente gravitacional. Na outra, adotou-se $K=0,7$, admitindo-se a existência de tectonismo.

Uma análise da eclusa foi realizada sob os mesmos princípios de acoplamento entre análises de percolação e tensões. Destaca-se que uma análise com ações impostas a priori seria menos confiável que para barragens, porque não são usuais os diagramas de subpressão para eclusas, devido às particularidades do sistema de drenagem. 


\subsubsection{Ilha Solteira}

Tomou-se como exemplo um bloco instrumentado, onde se pretendeu analisar a coerência de resultados dos extensômetros de grande base, curtos e dos extensômetros de haste, longos, dispostos esquematicamente na figura 2.2. Os extensômetros de grande base foram instalados antes da concretagem, e os extensômetros de haste instalados antes do enchimento do reservatório. As leituras iniciais dos extensômetros de grande base foram muito afetadas por efeitos térmicos da cura das primeiras camadas de concreto e não tinham significado físico. Considerou-se a leitura inicial apenas quando os resultados se estabilizaram. Em conseqüência, supõe-se que se perdeu parte dos deslocamentos diferenciais devidos ao carregamento das primeiras camadas de concreto.

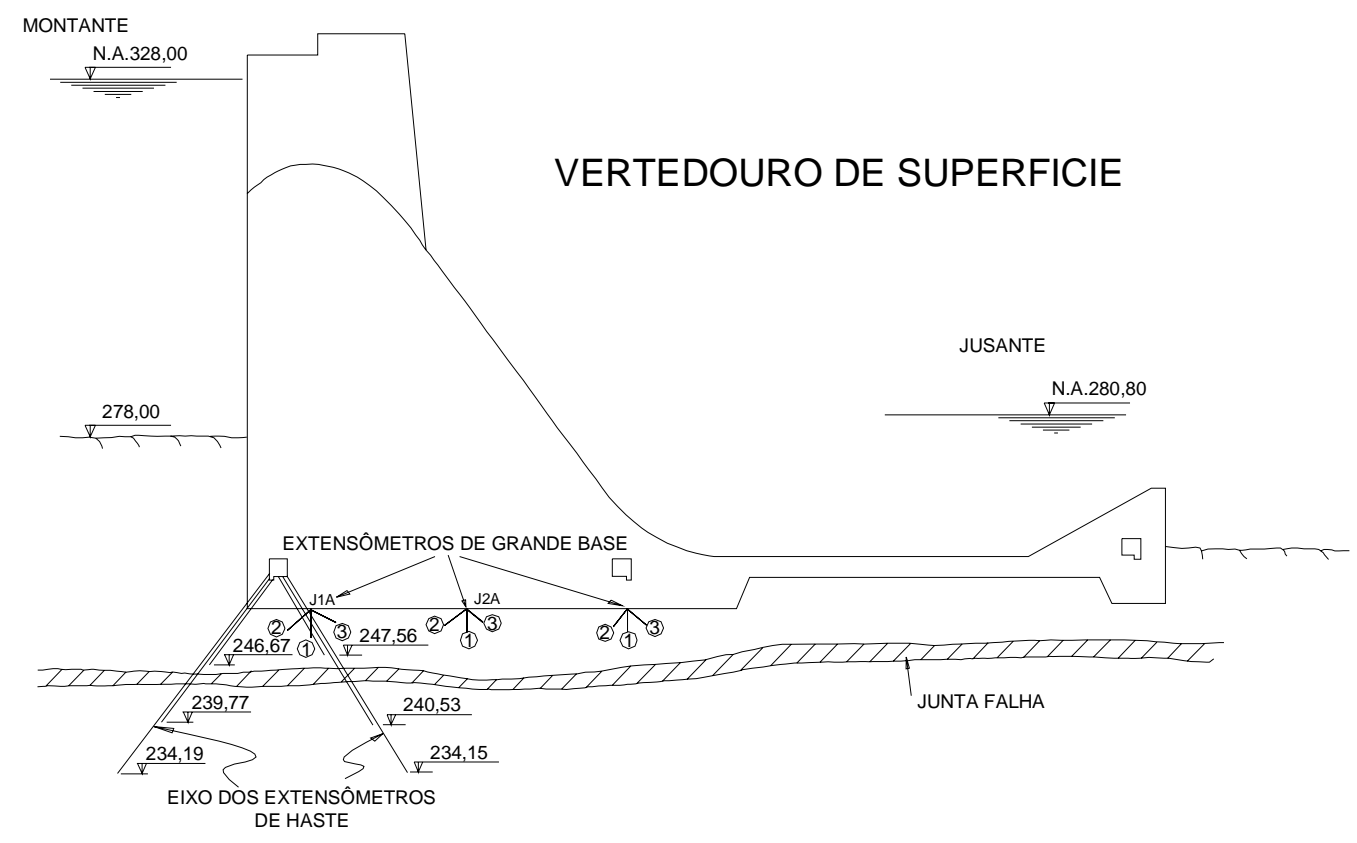

Figura 2.2 Instrumentação do vertedouro da barragem de Ilha Solteira (Celestino, 1983).

Dos resultados obtidos, foi feita uma relação entre as medidas dos extensômetros de grande base, após a conclusão da concretagem e os valores calculados para deslocamentos diferenciais entre pontos extremos dos extensômetros. Dessa relação, podia-se ver que os valores não se situavam ao longo de uma linha reta a $45^{\circ}$ como deveria representar uma total concordância de um modelo perfeito, e ainda não passava pela origem em razão de que a leitura inicial dos extensômetros foi definida depois que parte da construção havia ocorrido. 
O fato de a reta não estar inclinada de $45^{\circ}$ significa que as deformabilidades do modelo e do protótipo são diferentes. No modelo, adotou-se E=200.000 kgf/cm² e pela inclinação obtida da relação poder-se-ia retro-calcular que um valor mais realista estaria em torno de $120.000 \mathrm{kgf} / \mathrm{cm}^{2}$ lembrando-se que esses extensômetros de grande base têm comprimento máximo de 2,0m, atingindo apenas a camada superior do maciço afetado pela escavação. Já nos extensômetros de haste, a correlação entre valores calculados e medidos deu ótima concordância como mostrado na figura 2.3.

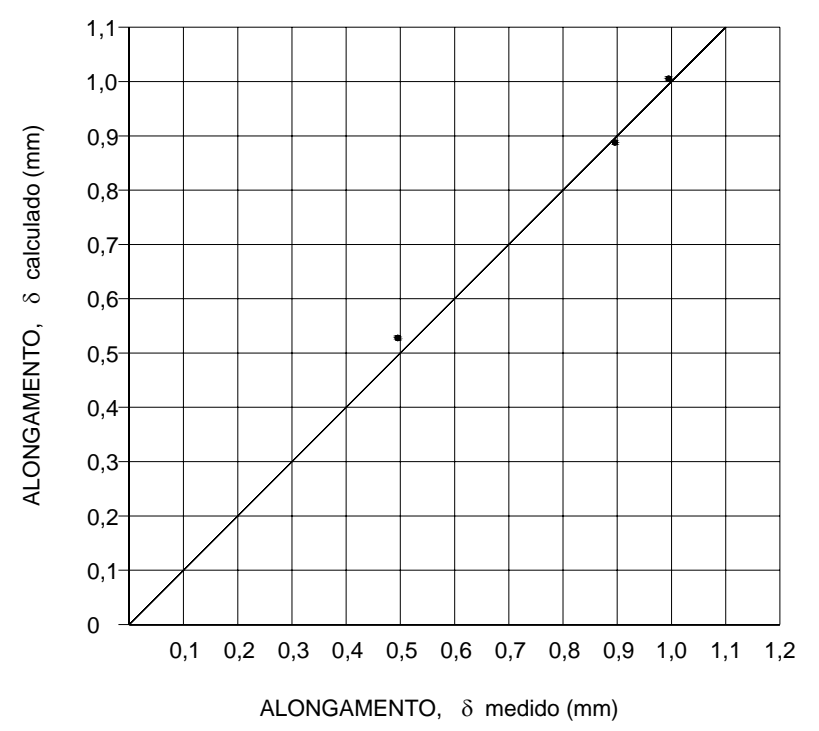

Figura 2.3 Relação entre deslocamentos calculados e medidos (extensômetros longos).

Como resultado do exemplo exposto, poder-se-ia ver que caso se desejasse aferir os valores do módulo de elasticidade e coeficiente de Poisson, uma análise do modelo deve ser realizada adotando-se, como deslocamentos iniciais, não no inicio da construção, mas sim a configuração na data em que as leituras dos instrumentos passam a ser coerentes com carregamentos mecânicos. Assim, a reta de correlação entre deslocamentos medidos e calculados passaria pela origem. O módulo de elasticidade adotado influiria em seu coeficiente angular, que deve ser unitário. O coeficiente de Poisson influiria nas medidas referentes às bases inclinadas, mais afetadas pelo parâmetro.

Silveira et al. (1978) apresentaram um exemplo de aferição de parâmetros sem usar modelos numéricos. Nele, as tensões para cálculo dos módulos de deformabilidade da rocha e de rigidez das descontinuidades foram obtidas a partir de expressões analíticas da teoria da elasticidade, deduzidas para meios contínuos e homogêneos. Essas tensões foram, sem dúvida, obtidas com boa aproximação já que se admitiu um 
estado uniaxial de tensões ao longo da direção das hastes dos extensômetros, ou seja, a medida de um extensômetro foi relacionada apenas com a tensão normal que atua na direção paralela à haste. As outras duas componentes de tensões normais, atuantes em direções perpendiculares à haste, não foram consideradas, ou foram consideradas constantes durante o período de análise.

Paes de Barros e Barbi (1983) apresentam uma experiência interessante, onde foram comparados os resultados das análises de percolação e tensão-deformação acopladas e a linha piezométrica do contato A/B da barragem de Itaipu, obtidas a partir das leituras da instrumentação. O resultado mostrou que as pressões calculadas a montante são significativamente superiores às medidas. Daí, Celestino (1983) explica dois fatos importantes que devem ser levados em conta na aferição deste modelo:

1. O contraste da permeabilidade da cortina de vedação imposta no modelo foi bem grande, o que aumentou a pressão a montante da cortina, reduzindo, por sua vez, as tensões efetivas que originaram o aumento da permeabilidade e, em conseqüência, aumentaram ainda mais a pressão na zona de análise;

2. A ensecadeira de quase $100 \mathrm{~m}$ de altura certamente contribuiu para elevação das tensões efetivas na zona de montante, diminuindo a permeabilidade e as pressões.

Um parâmetro importante a ser levado em conta em eventuais aferições de modelos é o estado de tensões iniciais. Infelizmente, segundo Midea (1983) não existiu um padrão de resultados bem sucedidos de medidas de tensões iniciais nas obras do Alto Paraná. Por este motivo, as medidas de tensões iniciais em rocha devem ser tomadas com reserva. Midea também ressalta a ocorrência de tensões horizontais maiores que as verticais em medidas realizadas em Água Vermelha e Itaipu. A incerteza dos valores de $K$ pode ser uma explicação importante no comportamento hidrogeológico de barragens. Vale a pena lembrar que o acréscimo de pressões de água a montante da vedação não está ligado à ocorrência de tensões de tração. Mesmo com compressão aliviada, haverá um contraste de permeabilidade com a zona de compressão não aliviada, obviamente de menor intensidade, do que se ocorressem tensões de tração.

Celestino (1983) comenta a importância da tendência de renovação dos critérios de projeto. Cruz e Silva (1978) propuseram novos critérios, um deles o de considerar que a pressão a montante da cortina de vedação seja admitida constante com a profundidade. 
Abordar o tema dos critérios de projeto implica também encarar as limitações dos critérios puramente observacionais, limitações devidas a imprecisões das medidas e, pior ainda, à caracterização de propriedades localizadas de enorme dispersão de dados. Obviamente, estabelece-se um critério com base em um número suficiente de dados para que a probabilidade de que se disponha da zona de interesse seja grande. Em rochas, o fluxo preferencial pode-se dar em zonas de limitada extensão, o que diminui a possibilidade de que um piezômetro esteja localizado exatamente na possível zona crítica. Isto é corroborado por estudos feitos por Cruz e Silva (1978) e também Silveira et al.(1981) onde nem sempre pode haver um piezômetro na zona de pressão mais elevada. Celestino (1983) salienta a importância de que, antes de catalogar os valores obtidos, deve-se entender os mecanismos que dão origem a eles e usar as observações para aferir tais mecanismos.

Celestino (1983) cita a experiência de Johandar et al. (1971) que calcularam a vazão da fundação de uma barragem de $10 \mathrm{~m}$ de altura, considerando a variação de permeabilidade devida a tensões efetivas, resultando em $40 \%$ da vazão que seria obtida numa análise que não considerasse este fato. Esses autores descreveram um método iterativo geral para análises acopladas de percolação e tensões.

Em relação ao uso dos modelos matemáticos em projetos do Alto Paraná, Celestino (1983) afirma que estes modelos não têm sido sistematicamente aferidos com dados de instrumentação, o que deveria ser realizado com o intuito de discernimento dos mecanismos de funcionamento de obras concluídas. Para obras em andamento, o uso de fases intermédias de construção permitiria, por meio da comparação de instrumentação com resultados de modelos matemáticos, oferecer úteis subsídios de parâmetros para a análise final da obra. Exemplo disto seria o conhecimento do estado inicial de tensões que é importante para o conhecimento do funcionamento da obra. Com instrumentação simples das escavações e a comparação com modelos matemáticos também simples, seria possível determinar o valor global das tensões iniciais do maciço, determinante do comportamento da obra.

Celestino (1983) discorre sobre estabelecer o modo mais abrangente de tratar as ações da água nas fundações de barragens, levantando a pergunta se sub-pressões, por exemplo, são ações que se devem impor na análise do comportamento da barragem, ou se podem ser tratadas como uma resposta que inclui a intervenção de muitos parâmetros, que podem corresponder à geologia, tipo de estrutura, estado de tensões 
iniciais, tipo de tratamento, etc.

Os modelos com leis fundamentais e universais, quando aferidos e interpretados, contribuirão muito em diferentes condições (Celestino, 1983).

O tema das subpressões em barragens brasileiras, fundadas em formações basálticas, é abordado por Cruz (1978) que mostra, com ajuda de diagramas, as subpressões observadas, tanto para o contato concreto-rocha como para descontinuidades no maciço de fundação. Fazendo uma descrição do tipo de tratamento realizado na fundação, observa que as cortinas de injeção realizadas desde as galerias foram orientadas para montante, enquanto que as executadas a partir da superfície da rocha foram verticais sob a barragem ou orientadas a jusante, quando executadas da superfície da rocha no pé de montante da estrutura. Contudo, os drenos em sua grande maioria foram executados no sentido vertical a partir das galerias paralelas ao eixo ou, às vezes desde galerias dispostas transversalmente ao eixo. Em alguns casos, os drenos foram inclinados para jusante a partir da galeria a montante.

Na análise das subpressões, Cruz (1978) estabelece a relação entre o trecho da fundação injetado e/ou drenado (medido pela diferença entre cotas do nível da rocha de montante e a cota do final do tratamento) e a carga de água a montante (medida pela diferença de cotas entre o nível de água normal e a cota da rocha de fundação a montante da estrutura), fazendo o mesmo para jusante, considerando os níveis de água normais de operação. As diferenças nos valores dessa relação encontradas entre projetos não refletem diferentes critérios e, pelo contrário, provavelmente reflete a natureza da formação basáltica da fundação e as descontinuidades de fluxo preferencial (Cruz, 1978).

Os diagramas de subpressões de várias barragens foram representados pelas envoltórias máximas e mínimas, registradas por piezômetros. Nesses diagramas, foram apresentadas as leituras feitas em seções paralelas, representadas numa única seção. Como só se contou com informação das subpressões a montante devido à presença dos piezômetros instalados nesta zona, Cruz (1978) fez, no trecho de jusante, uma interpretação apoiada na hipótese de que o nível de água a jusante controla as subpressões nesta zona.

A seguir, alguns índices que Cruz (1978) utilizou nas análises, definidos a partir de variáveis mostradas na figura 2.4: 
$\frac{H p}{H_{M}}=D M$, Coeficiente de perda de carga de montante;

$\frac{H p}{H_{J}}=D J$, Coeficiente de perda de carga de jusante;

$1-\frac{H_{D-M}}{H_{M-D}}=E M$, Eficiência de drenagem a montante;

$1-\frac{H_{D-J}}{H_{J-D}}=E J$, Eficiência de drenagem a jusante;

Upiez = Subpressão total medida pelos piezômetros;

Umáx. = Subpressão total teórica para drenos e injeção inoperantes;

Ucat = Subpressão total "catastrófica” para o sistema de bombeamento inoperante;

U67\% = Subpressão total para eficiência de drenagem (a montante) de 67\%.

$\frac{U p i e z}{U m a ́ x .}=$ Relação da pressão total medida em relação à máxima teórica;

$\frac{U p i e z}{U c a t}=$ Relação da pressão total medida em relação à pressão catastrófica;

$\frac{U p i e z}{U 67 \%}=$ Relação da pressão total medida em relação à pressão total calculada para $67 \%$ de EM.

Os valores de DM variaram muito, mas em vários casos foram iguais a 1,0 o que poderia significar que a perda de carga que ocorre a montante das injeções pode ser pequena, seja por fraturamento superficial da rocha devido a escavações ou à separação no contato vertical concreto-rocha ou, seja pela eficiência da injeção que reduz a permeabilidade do maciço, concentrando a maior perda de carga na sua área. Contrariamente, os valores baixos de DM inferiores a 0,5 em $25 \%$ dos casos poderiam ser devidos a um melhor contato concreto-rocha no encaixe sub-vertical, a uma maior eficiência de injeção de colagem, a um maciço escavado cuidadosamente ou a um piezômetro influenciado pela injeção ou pela drenagem. Já os valores de DJ que registraram o valor de 1,0 podem indicar o controle das subpressões pelo nível de água a jusante. 


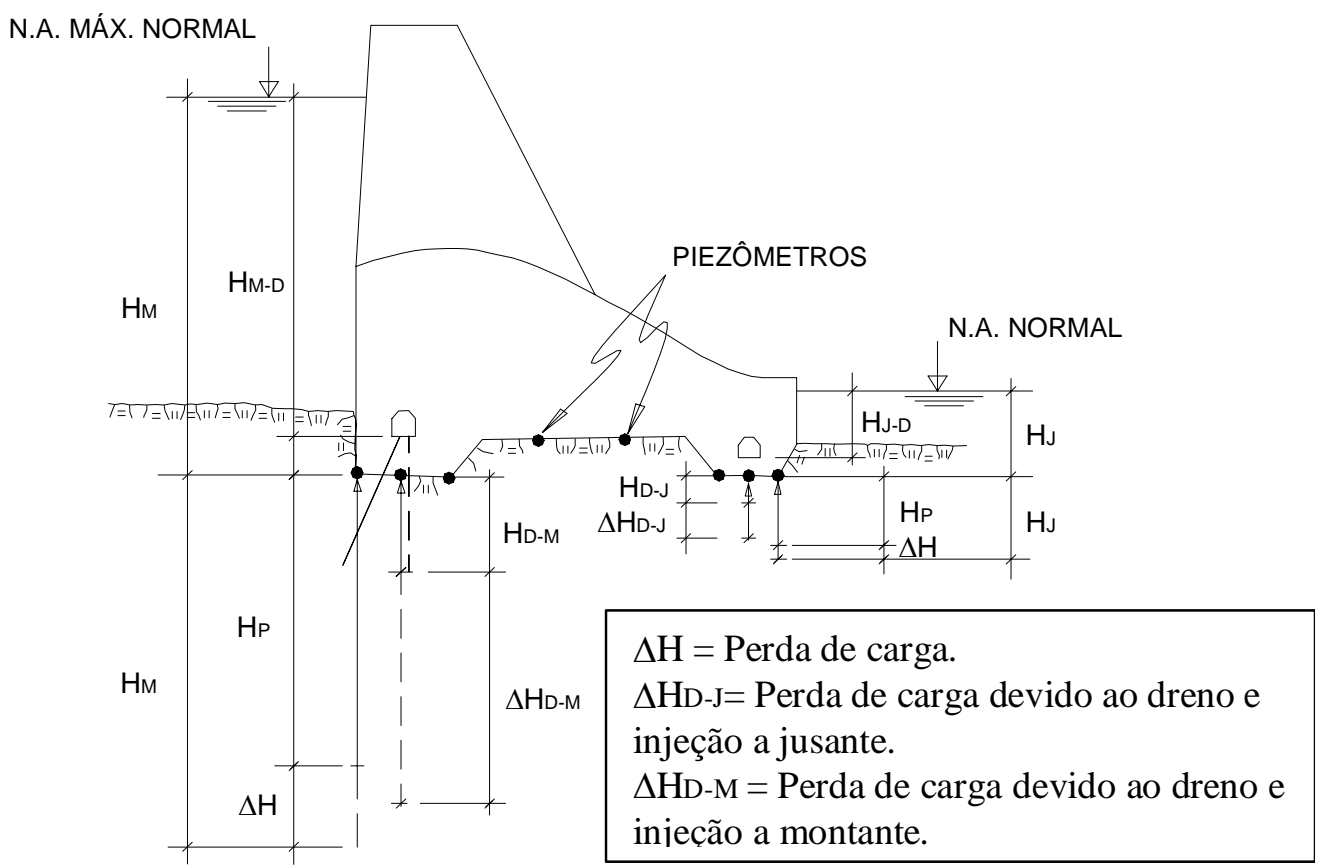

Figura 2.4 Esquema dos índices usados na análise de Cruz (1978).

Os valores de EM indicaram a eficácia dos tratamentos de fundação. É verdade que os efeitos de injeção e drenagem são de difícil diferenciação, mas a queda marcante de subpressões entre piezômetros colocados a montante e jusante da cortina de injeção sugere que as injeções conseguem reduzir as subpressões. Por outro lado, os valores elevados de EJ mostraram também a eficácia do tratamento.

As relações $\frac{U p i e z}{U m a ́ x .}, \frac{U p i e z}{U c a t}$ e $\frac{U p i e z}{U 67 \%}$ foram usadas como parte adicional de segurança dos projetos quanto à análise de estabilidade por escorregamento.

Cruz (1978) salienta que a condição crítica de estabilidade ao escorregamento só pode ser verificada no contato concreto-rocha, ou no subcontato quando o maciço rochoso de fundação até uma profundidade razoável apresenta-se homogêneo e sem descontinuidades que possam representar fraquezas estruturais do maciço. As subpressões nessas descontinuidades seriam as de especial cuidado, portanto, a instrumentação deve estar nesses “planos”.

Para os casos das descontinuidades, Cruz (1978) definiu parâmetros similares a DM, DJ, etc. para as subpressões de três projetos, assumindo planos horizontais para as descontinuidades subhorizontais, em razão da sua formação e origem. Como resultado das análises, chegou a algumas conclusões importantes para os cálculos de estabilidade e para o estabelecimento de critérios de projeto. A figura 2.5 mostra o esquema das 
subpressões no contato e a figura 2.6 as subpressões em descontinuidades do maciço.

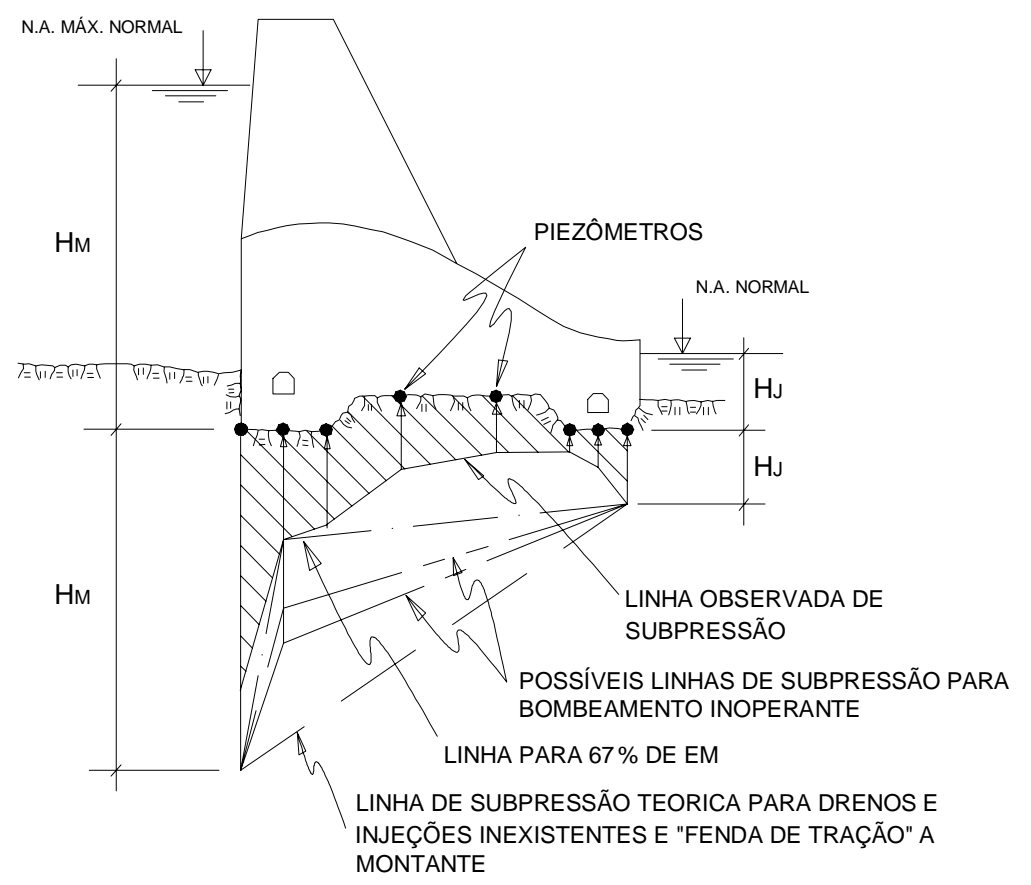

Figura 2.5 Esquema de subpressão no contato concreto-rocha (Cruz, 1978).

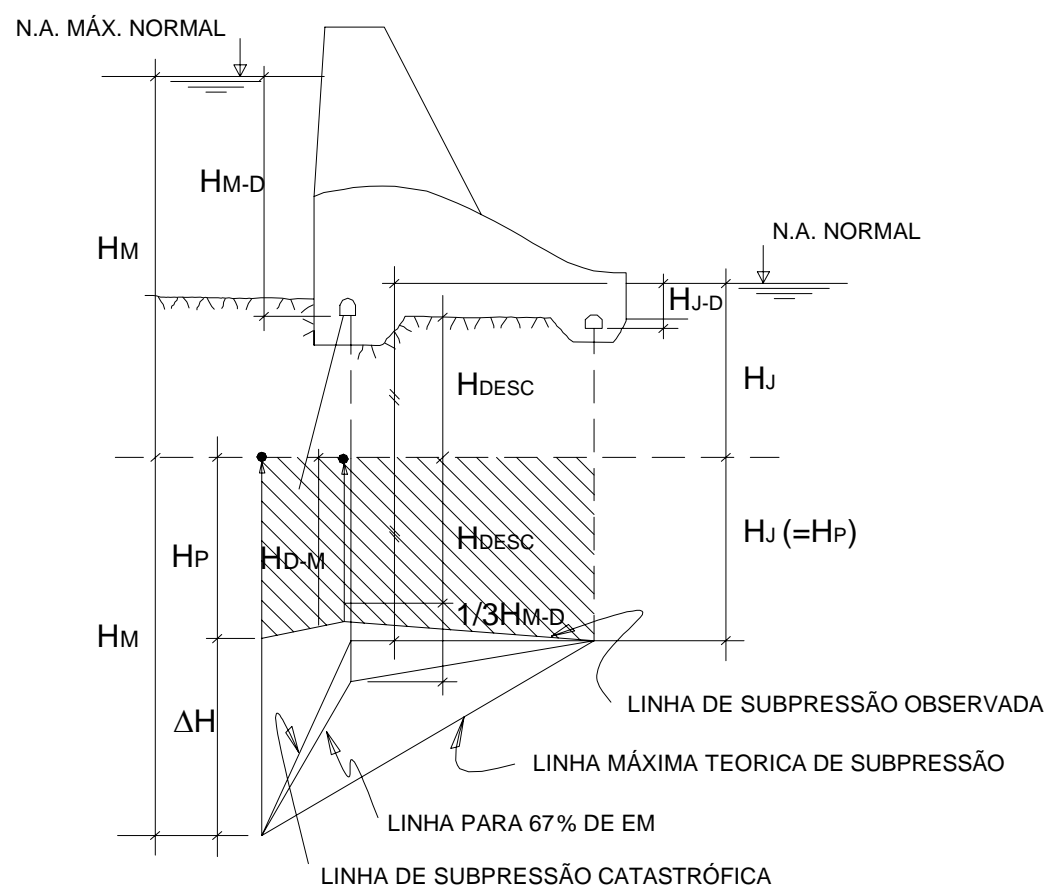

Figura 2.6 Esquema de subpressões na fundação com descontinuidade (Cruz, 1978).

Uma primeira observação importante foi em relação à perda de carga a montante, onde a consideração de colagem no contato concreto-rocha daria como conseqüência uma redução de subpressão nessa zona e uma redução na vazão dos drenos. Mas, se 
uma fenda de tração fosse considerada na zona, essa fenda poderia dar acesso livre de água a alguma descontinuidade existente, o que daria como resultado um valor de $\mathrm{DM}=1,0$.

Uma segunda observação trata das subpressões a jusante, onde quase sempre são controladas pelo nível de água de jusante. Não obstante, nem sempre é assim, pela presença de descontinuidades permitindo o fluxo, resultando em valores de DJ maiores de 1,0 .

Uma terceira observação se relaciona aos valores de EM que mostraram uma eficiência do tratamento das fundações com valores maiores do que os 67\% convencionais, de alguns critérios de projeto. No entanto, o cálculo de EM considera implicitamente a presença da fenda de tração, dando um valor da eficiência da drenagem menor do que o real. Considerando-se o cálculo de um fator de eficiência da drenagem, $E_{d}$, mediante a eq. (1), chega-se a valores de eficiência de 80 a 100\%, concluindo-se que a drenagem tem sido efetiva.

$$
E_{d}=\frac{H_{M}-H_{D-M}}{H_{M}-H_{\text {Desc. }}}
$$

Uma quarta observação trata dos valores de EJ que resultaram nulos, o que foi interpretado como eficiência nula de drenagem para descontinuidades a uma certa profundidade, o que significa que não há bombeamento para reduzir as subpressões. Porém, é recomendável uma drenagem a jusante para se evitar subpressões maiores do que as correspondentes ao nível de água a jusante que poderiam instabilizar o maciço rochoso a jusante das estruturas.

Uma última observação se baseia na análise dos valores de $\frac{\text { Upiez }}{\text { Umáx. }}, \frac{\text { Upiez }}{\text { Ucat }}$ e $\frac{U p i e z}{U 67 \%}$ em função da profundidade das descontinuidades, o que demonstra a influência da profundidade, onde os tratamentos, a partir de galerias de concreto, são inoperantes. Estas análises permitem estabelecer critérios de projeto relativos à profundidade de tratamento de fundação, como injeção e drenos. A figura 2.7 mostra a seção da barragem Jupiá e a seção da barragem Promissão.

Mais tarde, Cruz e Silva (1978) analisaram sete barragens brasileiras (Ilha Solteira, Jurumirim, Jupiá, Capivara, Ibitinga, Promissão e Barra Bonita) assentadas em 
maciço basáltico, usando para esse fim os dados de subpressão recolhidos da instrumentação dessas barragens.

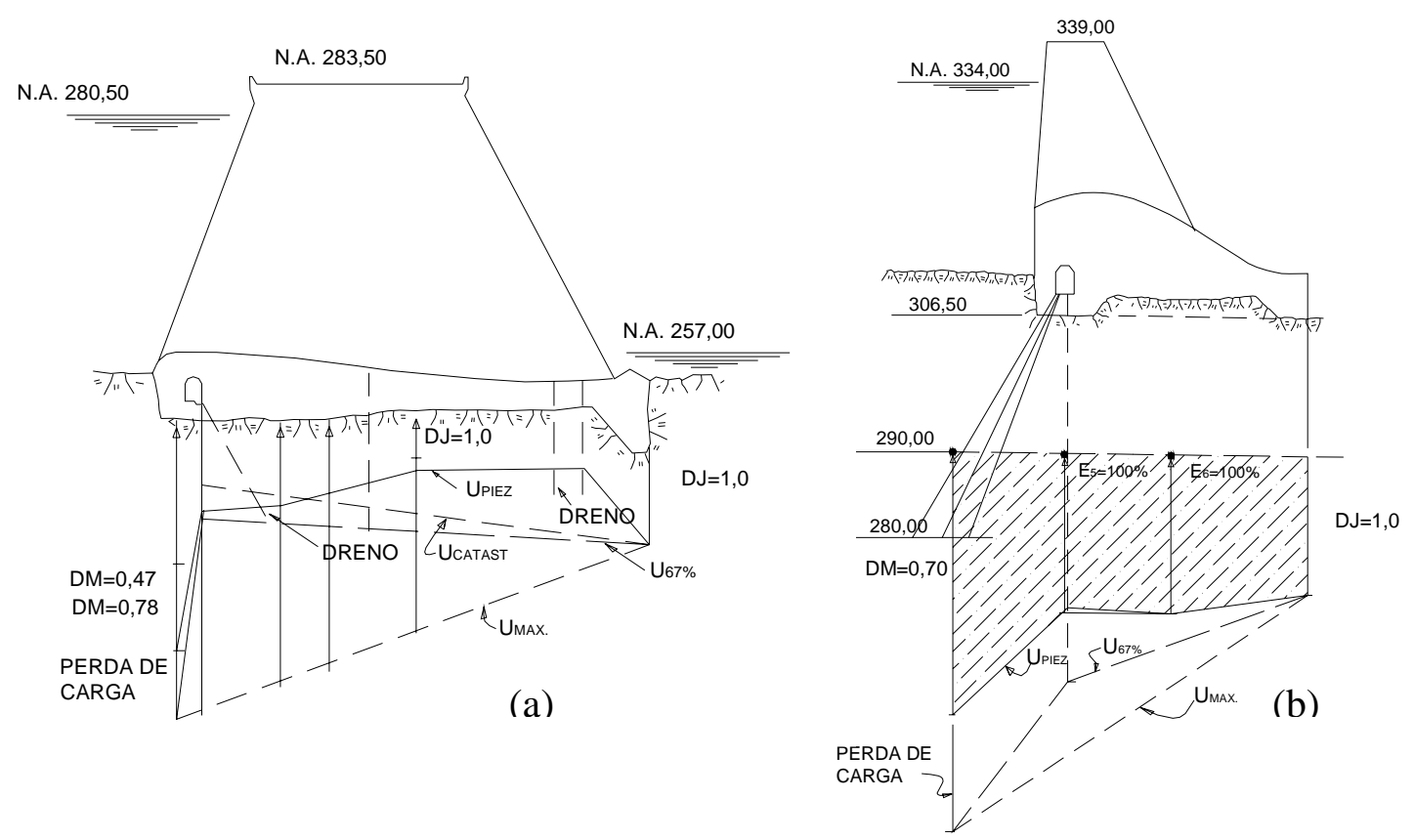

Figura 2.7 (a) Subpressão na fundação do vertedouro de fundo da barragem Jupiá. (b) Na fundação da barragem de Capivara (Cruz,1978).

Para facilitar a análise, as estruturas foram divididas em 4 grupos, considerando-se sua forma, expressa pela relação da largura da base (B) e a altura (H), e o tratamento da fundação que inclui a cortina de injeção e a drenagem. Os grupos I e II consideraram uma cortina de injeção a montante e uma galeria de drenagem, diferenciando-se pela taxa B/H. O grupo III considera duas ou três galerias de drenagem e cortinas de injeção a montante e jusante. Já no grupo IV foram consideradas as estruturas da tomada de água e a casa de força com diferentes níveis de escavação devido a processos construtivos. Adotou-se um perfil médio para as 4 estruturas, considerando-se também drenagem superficial no contato concreto-rocha. Por meio de figuras, Cruz e Silva (1978) dividiram os dados das subpressões como aqueles que correspondem à base da barragem, ou seja, no contato concreto-rocha, e a aqueles das descontinuidades na fundação. Todos os dados são dos piezômetros tipo Casagrande, os quais são considerados confiáveis. Nas figuras 2.8 e 2.9 apresentam-se as leituras piezométricas das pressões na base das barragens e nas descontinuidades. 


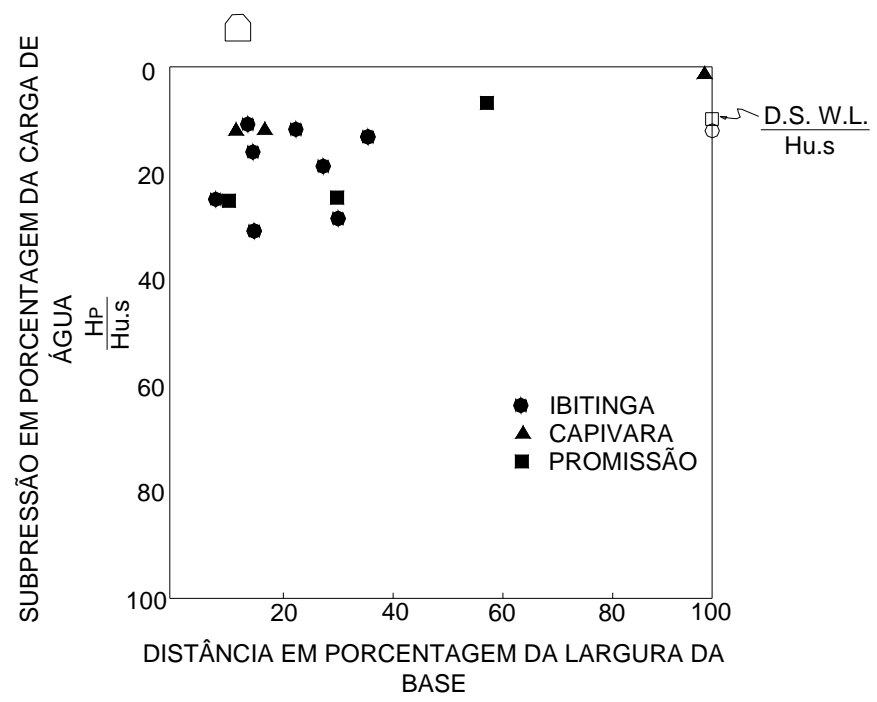

Figura 2.8 Leituras piezométricas da subpressão na base das barragens com B=0,7 a $1,0 \mathrm{H}$.

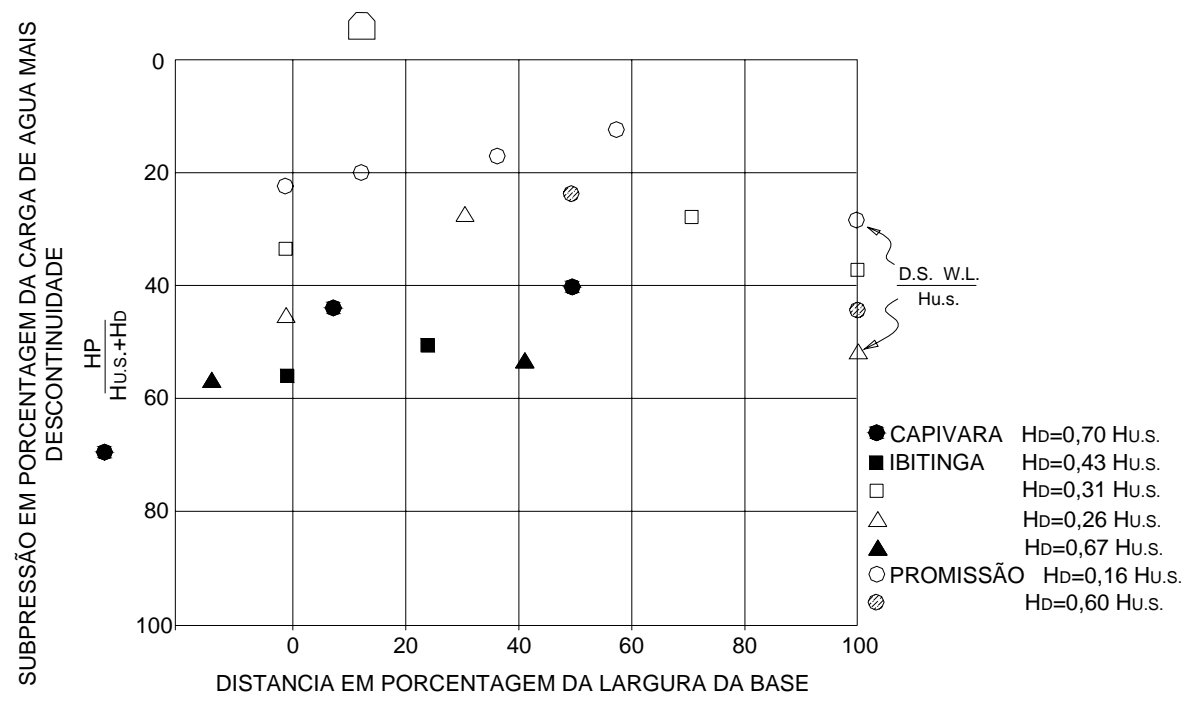

Figura 2.9 Leituras piezométricas da subpressão nas descontinuidades da fundação de barragens com $\mathrm{B}=0,7$ a $1,0 \mathrm{H}$.

Na base dos dados de piezômetros, Cruz e Silva (1978) destacaram a eficiência do sistema de drenagem em relação ao "excesso" da pressão piezométrica acima do nível de drenagem, o que não excedeu a 20\%. Recomendam também que, para fundações de níveis inferiores, deve-se considerar a profundidade da descontinuidade. Valores maiores de subpressões correspondem ao fato de que o dreno não drena em níveis inferiores do que o nível do seu topo. Os valores negativos do "excesso” das pressões piezométricas medidas podem significar que a água flui através de feições mais favoráveis de drenagem, principalmente representados pelas descontinuidades na 
fundação ou em combinação com outros drenos a jusante. Com ajuda das figuras 2.10 e 2.11, Cruz e Silva (1978) apresentam a sua interpretação dos diagramas típicos de subpressões que, segundo eles, poderiam ser usados nos projetos de estruturas similares e assentes em rocha basáltica sob condições normais de operação, sendo que o critério de eficiência de $67 \%$ é o limite maior, caso que não foi considerado nas estruturas analisadas.

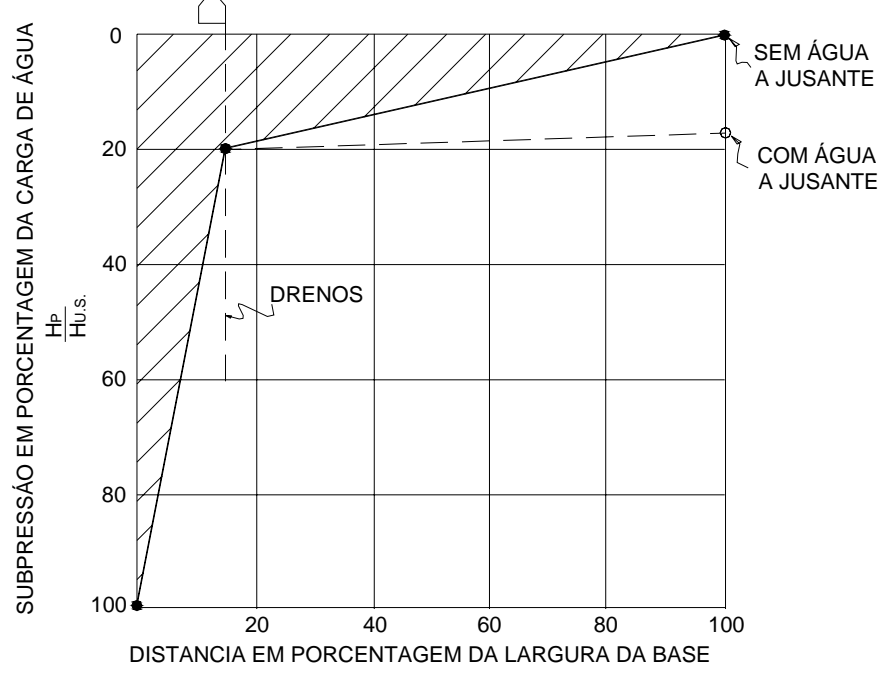

Figura 2.10 Diagrama de subpressão proposto na base da barragem sob condições normais.

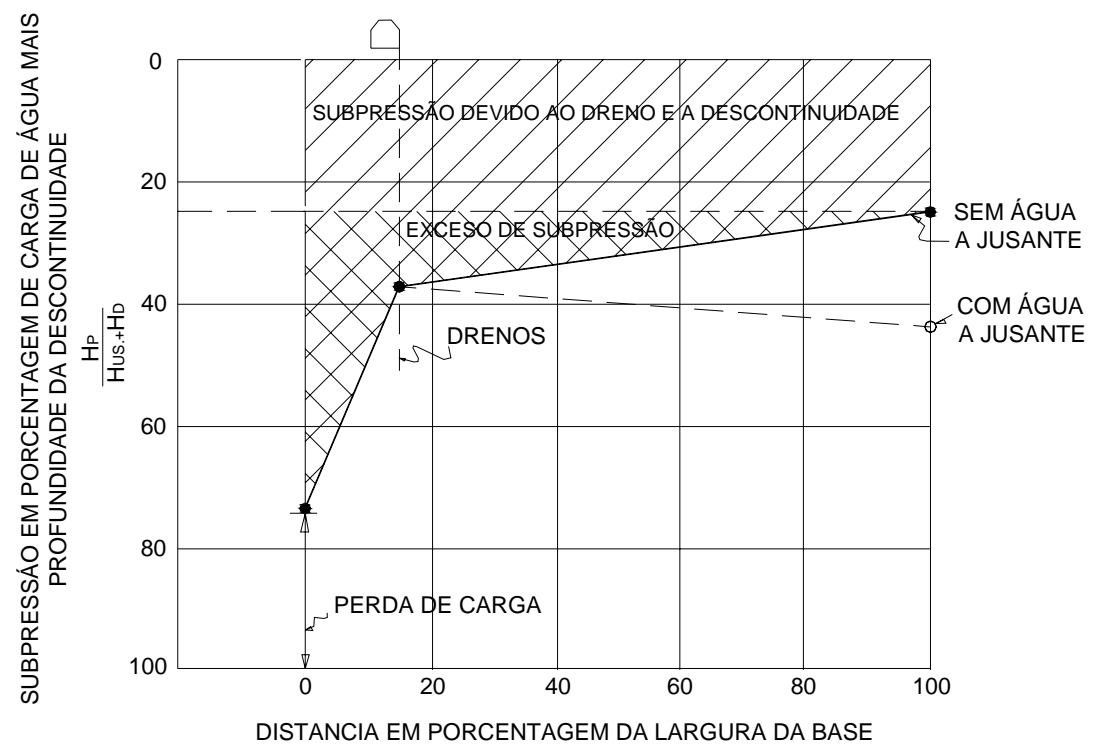

Figura 2.11 Diagrama de subpressão proposto em descontinuidades sob condições normais

Cruz e Silva (1978) definem o maciço basáltico como uma formação anisotrópica 
em relação à permeabilidade. Mediante um modelo, o qual apresenta-se na figura 2.12, são mostrados os valores localizados de condutividade correspondendo aos contatos ou juntas. No contraste, o basalto maciço é bastante impermeável. A camada mais superficial que está em contato com a estrutura pode ter uma condutividade maior aumentada pelas escavações. A partir de uma análise do fluxo simples, este se orienta vertical a montante da barragem, logo sub-horizontal pela descontinuidade, seguida a um fluxo novamente vertical a sub-vertical pelo dreno.

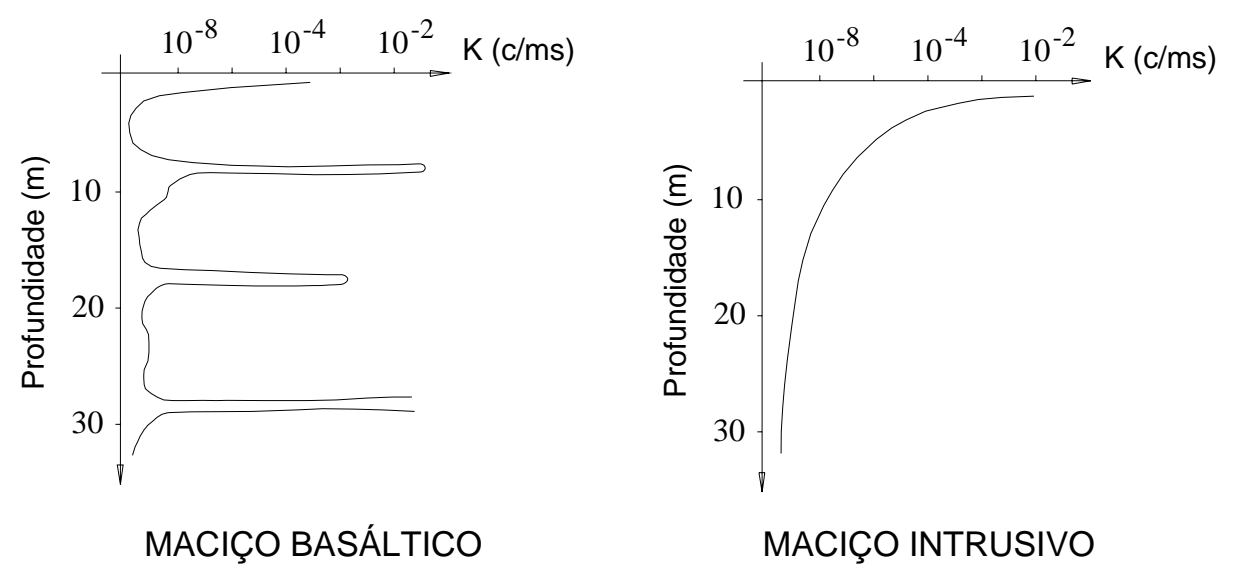

Figura 2.12 Variações na permeabilidade com a profundidade (Apud Cruz e Silva, 1978).

As condutividades localizadas nos contatos ou juntas não representam um papel importante porque são isoladas por camadas impermeáveis de basalto. Só podem merecer cuidado quando existe fluxo livre de água de formações anômalas.

Outro ponto mencionado por Cruz e Silva (1978) trata sobre a consideração nos critérios de projeto de uma fratura vertical originada pela presença de esforços de tração. Estudos teóricos com ajuda de elementos finitos foram desenvolvidos para a barragem de Itaipu, dando resultados que indicaram que se desenvolveria uma zona de tração a montante até uma profundidade de $0,6 \mathrm{H}$ na fundação com uma fratura de tração de $0,3 \mathrm{H}$ no maciço rochoso.

Uma especial observação foi feita em relação à perda de carga na zona a montante. Os dados dos piezômetros localizados a montante da cortina de injeção e da drenagem para diferentes níveis de descontinuidades foram analisados, obtendo-se valores de DM menores de um; se existisse uma fratura, os valores de DM seriam próximos a 1,0, caso que não está acontecendo nas barragens de análise. Como 
resultado disto, Cruz e Silva (1978) propuseram um critério modificado de projeto. Este novo critério de projeto tem como objetivo a redução do empuxo de água a montante na zona da possível fratura e a redução da subpressão. O diagrama do empuxo de água proposto é apresentado na figura 2.13 .

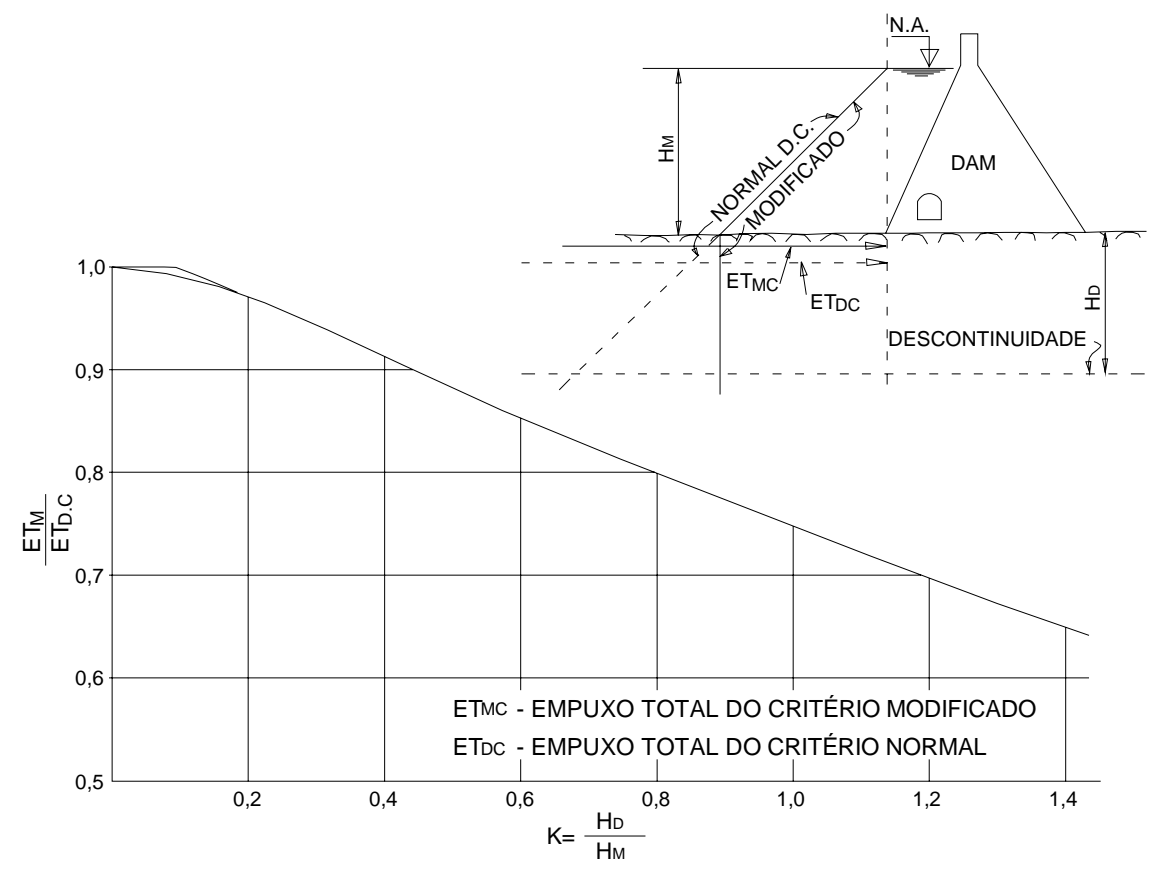

Figura 2.13 Critério proposto para a redução do empuxo de água (Cruz e Silva, 1978).

A partir dos dados e figuras, Cruz e Silva (1978) concluíram que uma grande porcentagem do fluxo vai entre o nível de montante da rocha para os drenos de montante, e um fluxo bem menor vai sob a barragem. Contudo, o fluxo vai desde jusante até os drenos de jusante, se estes existem. No final, o fluxo principal é limitado pelos extremos da estrutura, porém o fluxo independente pode ir pelas descontinuidades, mas isto não influirá na estabilidade da barragem.

No final, Cruz e Silva (1978) concluíram que as subpressões medidas para as sete barragens da CESP são similares na base aos valores observados nas barragens segundo o Bureau of Reclamation e a Tennessee Valley Administration um tanto menores, sendo a comparação válida para estruturas similares, com galeria a montante somente.

\subsection{Antecedente de estudos de barragens no exterior}

No exterior, inúmeros estudos de fundação de barragens têm sido realizados especialmente usando modelos matemáticos. Esses modelos, com ajuda de métodos numéricos como os elementos finitos, têm permitido localizar os setores danificados na 
estrutura e na fundação de barragens. No presente estudo, apresentam-se dois casos que foram executados depois de acontecido o fraturamento, o primeiro no corpo da barragem, enquanto que o segundo, na fundação.

\subsubsection{Barragem Kölbrein}

A barragem de Kölbrein na Áustria, cujo estudo foi realizado por Linsbauer et al. (1989), é um caso típico de fraturamento no corpo da estrutura. Neste caso, as forças devidas ao peso próprio e às injeções originaram o fraturamento do concreto da barragem, duas no paramento a jusante e duas no paramento a montante (uma em 1978 e outra em 1983). As figuras 2.14 e 2.15 mostram as fraturas no pé da estrutura.

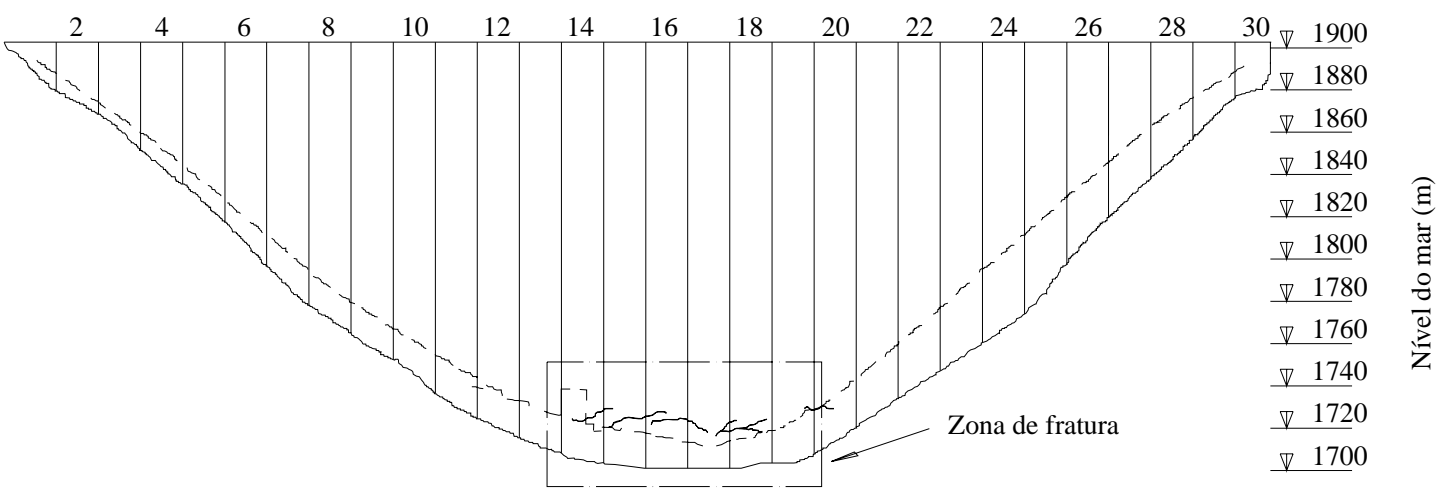

Figura 2.14 Fraturas no pé de montante da barragem Kölbrein (Linsbauer et al., 1989).

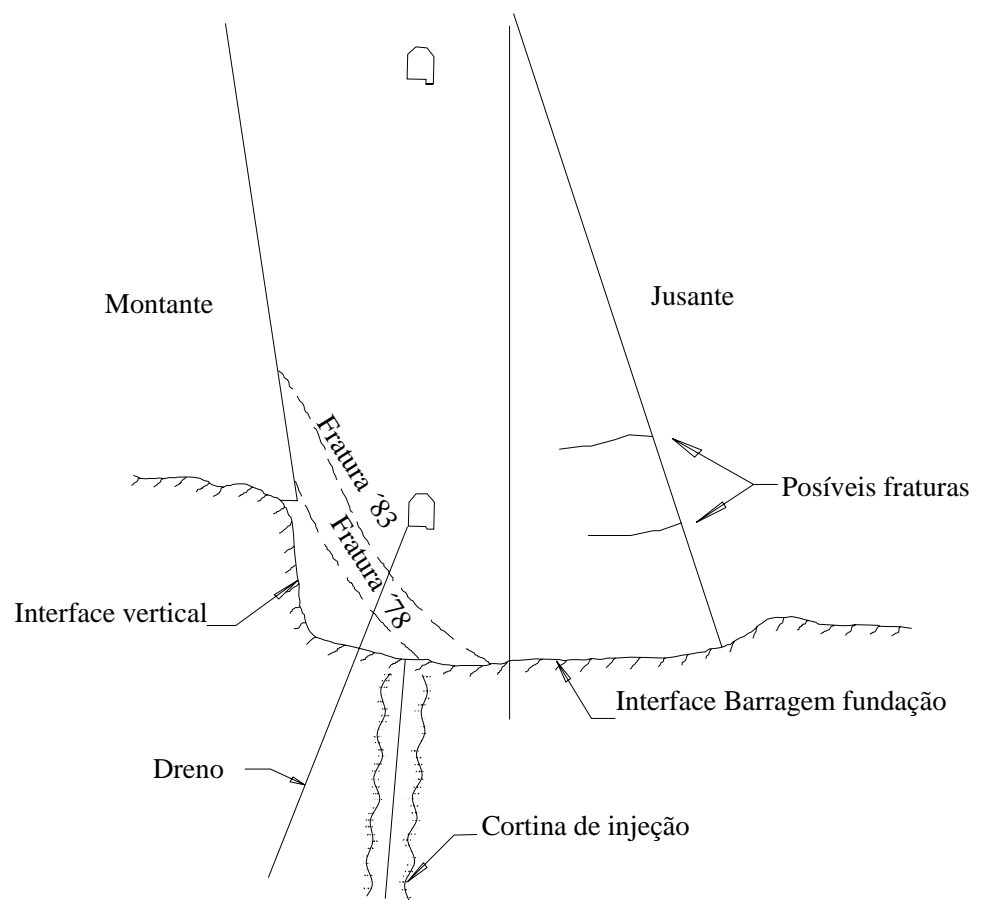

Figura 2.15 Fraturas no pé da barragem (Linsbauer et al., 1989). 
Com o objetivo de analisar a orientação das fraturas, Linsbauer et al. (1989) estudaram seu desenvolvimento no corpo da barragem aplicando os conceitos da Mecânica de Fratura com a ajuda de modelos matemáticos baseados em elementos finitos. Para simular as fraturas e a sua tendência de propagação; primeiro modelaram o estado sem fratura onde se localizou a zona de tração e o campo das deformações para a seção completa da barragem. Uma segunda análise foi realizada da zona de localização das fraturas a jusante, onde foram determinadas as tensões máximas que originaram as fraturas. Os resultados deste processamento, que localizou a posição das fraturas e a abertura delas, concordaram com a informação obtida dos micrômetros deslizantes que indicavam picos das deformações próximas ao local.

As fraturas no paramento a montante foram estudadas em quatro modelos bidimensionais (ver figura 2.16), os quais consistiram de:

a. Modelo de fratura em ângulo;

b. Modelo sem interligação barragem-maciço;

c. Modelo de rigidez variável da base;

d. Modelo de junta de fundação.

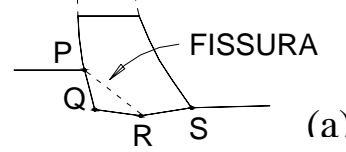

(a)

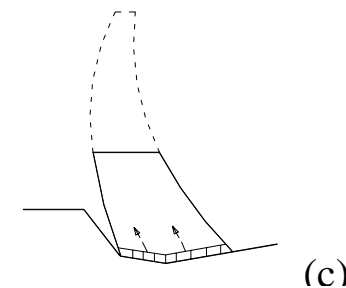

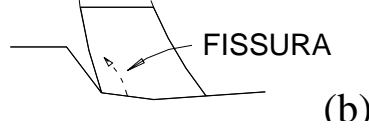

(b)

(d)

Figura 2.16 Esquemas dos quatro modelos para fraturamentos ao lado da montante: (a)

Modelo de fratura em ângulo; (b) Modelo sem interligação barragem-maciço; (c)

Modelo de rigidez variável da base e (d) Modelo de junta de fundação.

O esquema de carregamento considerou as cargas de peso próprio, de água quando o reservatório está cheio e as cargas adicionais devidas a processos construtivos. A figura 2.17 apresenta o esquema de carregamento. As malhas de análise foram de 
elementos quadráticos isoparamétricos e o contato barragem-fundação foi representado por elementos de junta compatíveis, sendo que a propagação da fratura dos modelos era controlada pelos princípios da mecânica da fratura elástica linear do modo misto. Foi assumido também que a formação das fraturas a montante não era influenciada pelas fraturas de jusante.

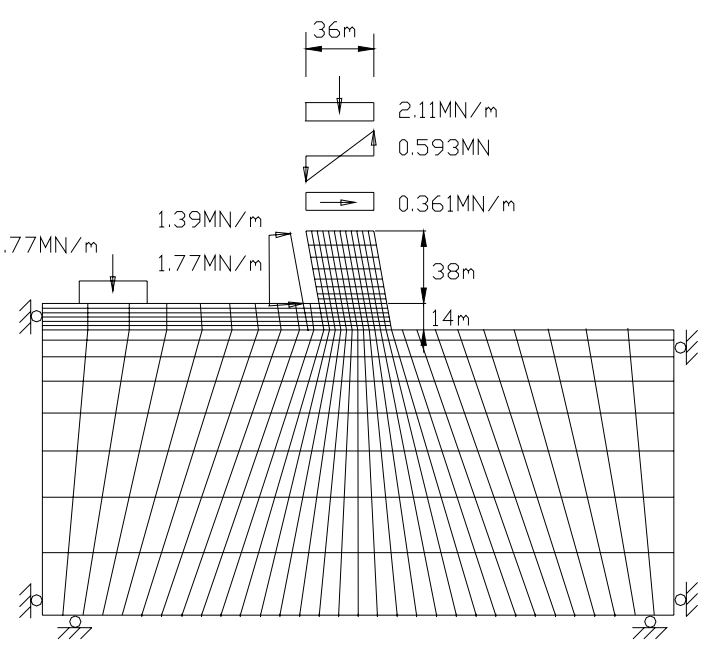

Figura 2.17 Esquema de carregamento (Linsbauer et al. 1989)

O Modelo de fratura em ângulo, para o qual assumiu-se a ligação perfeita entre o concreto e a rocha, considerou um ponto da zona de interface como a região onde existem grandes tensões. Esse ponto P foi escolhido como o inicio da fratura (ver figura 2.18), dando-se o avanço da fratura num ângulo normal às tensões da região. Por meio da figura, pode-se ver o percurso da fratura semelhante com a fratura real em estudo.
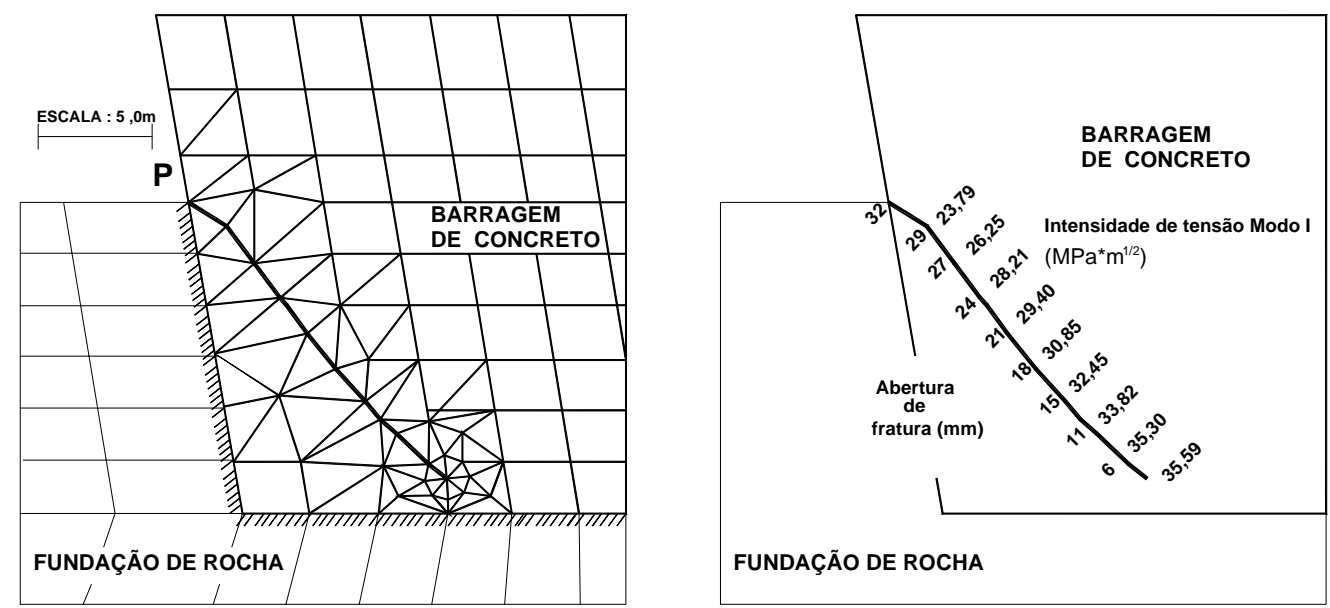

Figura 2.18 Detalhe da zona de propagação da fratura (modelo de fratura em ângulo).

Esta simulação foi satisfatoriamente feita, embora não se conhecessem todas as 
condições de interface, das quais depende sensivelmente a mecânica de fratura.

O Modelo sem interligação barragem-maciço não considera a ligação na interface entre concreto e rocha com o objetivo de observar o efeito dessa abertura no estado de tensões que se dá na região do pé da estrutura. Em relação às grandes tensões principais na região, deu-se início a uma fratura na interface, a alguns metros a jusante do ponto Q. Em dois passos, o fator de intensidade de tensão excedeu a tenacidade da fratura do concreto e se viu mais incrementada com a inclusão da pressão de água. Ainda que avance em linha reta, a fratura ainda se orienta para a interseção com a interface PQ, ao invés de orientar-se para o ponto $\mathrm{P}$ ou acima deste como se pode ver na figura 2.19.

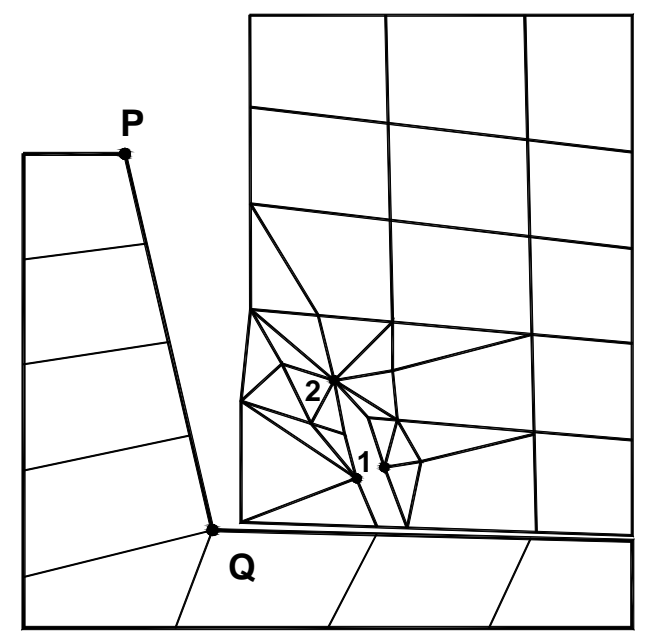

Figura 2.19 Detalhe da malha após dois intervalos de avanço da fratura (modelo sem interligação barragem-maciço).

O modelo de rigidez variável da base consistiu na variação da rigidez ao cisalhamento nos nós dos elementos, resultando no primeiro caso que a zona de alta tensão tem sido alargada para o centro da base da barragem. Estas tensões paralelas à interface justificariam o início da fratura em qualquer lugar dessa zona. No segundo caso de análise, a distribuição de tensões produzida sofreu um alargamento maior ainda da zona de grandes tensões na interface. Ao final, não foi possível realizar análises de propagação porque os autores não tiveram informação concernente às propriedades dos materiais da interface. Salienta-se, contudo, que estes puderam distinguir o tipo de redistribuição de tensão que poderia existir nas fraturas de 1978, no ponto de interface superficial ou ponto P, e na fratura de 1983, no ponto ao longo da interface estrutura fundação, depois que a fratura de 1978 tinha se propagado próximo ao ponto Q, e houvesse causado degradação da interface. 
O modelo da junta de fundação assumiu um deslizamento ao longo da fundação, diretamente abaixo da barragem (ver figura 2.16d). Foi também assumido que o reservatório cheio provocava um movimento de $1 \mathrm{~cm}$ ao longo da junta vertical e que a interface barragem-fundação tinha uma resistência suficiente que provocaria o início de uma fratura, na base da barragem, de maneira que o confinamento da zona de interface se desligava, ficando somente uma região de poucos metros, de um ou outro lado da fratura.

Em conclusão, Linsbauer et al. admitem que o uso dos mecanismos de análise ou modelos investigados pode, em forma combinada, produzir a fratura de 1978. Por não terem informação suficiente para simular o progresso da fratura, o desempenho dos registros da barragem de fontes potenciais, tais como movimentos da ombreira e da fundação, eles não puderam determinar com exatidão a origem das fraturas de 1978 e de 1983. Uma segunda observação foi que diferentes mecanismos podem induzir fraturas em direção oposta. Mesmo assim, eles reconhecem que a zona de início das fraturas na barragem e o comprimento da fratura variam de uma estrutura a outra e consideram que o perfil do deslocamento da abertura da fratura deve ser variável ao longo do comprimento da barragem.

\subsubsection{Barragem Albigna}

A barragem Albigna na Suíça, construída em 1959, é um estudo que está relacionado com a presente pesquisa. Desenvolvido por Kovári e Bergamin (1994), estes aplicaram modelos numéricos na análise da fundação da barragem. A estrutura de concreto encontra-se fundada em granito, caracterizando-se esta pela presença de duas grandes juntas no pé de montante. A determinação das características de deformação da rocha de fundação como resultado das variações dos níveis de água foi o objetivo do estudo de Albigna, cuja seção apresenta-se na figura 2.20. Na figura, também se pode ver a localização da instrumentação instalada. A instrumentação consistia de piezômetros (intervalo de medida $0,5 \mathrm{~m}$ ) e de micrômetros deslizantes para a medição da deformação (intervalo de medida de 1,0m). A estrutura, que se encontra no nível 2000m sobre o nível do mar, possui uma crista de 759m de comprimento com blocos de 20m de largura. A profundidade do bloco maior no vale é de 115m de altura. Entre blocos, existe separação de $5 \mathrm{~m}$ que serve como alivio da subpressão, sendo a capacidade do reservatório de 70 milhões de $\mathrm{m}^{3}$ de água. A estrutura está fundada sobre uma rocha sã de um granito de granulação grossa de boa resistência, mas existem nesta fundação três 
famílias de juntas preenchidas com material cristalino de grande resistência.

No ano 1960, devido ao primeiro enchimento, constatou-se o aparecimento de uma fratura num dos blocos, mais tarde com o correr dos anos aconteceram eventos inesperados como a perda de água e um ligeiro incremento nas deformações permanentes. Tudo isto motivou a observação das deformações em relação à variação dos níveis de carga de água. Com a ajuda de seis perfurações (total de 440m de comprimento) instrumentadas, revelou-se a existência de algumas fissuras ativas que se abriam e se fechavam devido à variação do nível de água. Logo foram descobertas duas juntas (S e L) no pé de montante que eram as responsáveis pela infiltração ocorrida sob a parcela central da barragem. Para evitar a perda de água na zona da junta L imediata ao pé da estrutura, esta foi coberta com neoprene (ver figura 2.20). Em 1987, cinco novas perfurações foram feitas. Nesta época, a maior ênfase foi dada ao programa de observação das leituras de subpressão e deformação durante o enchimento do reservatório.

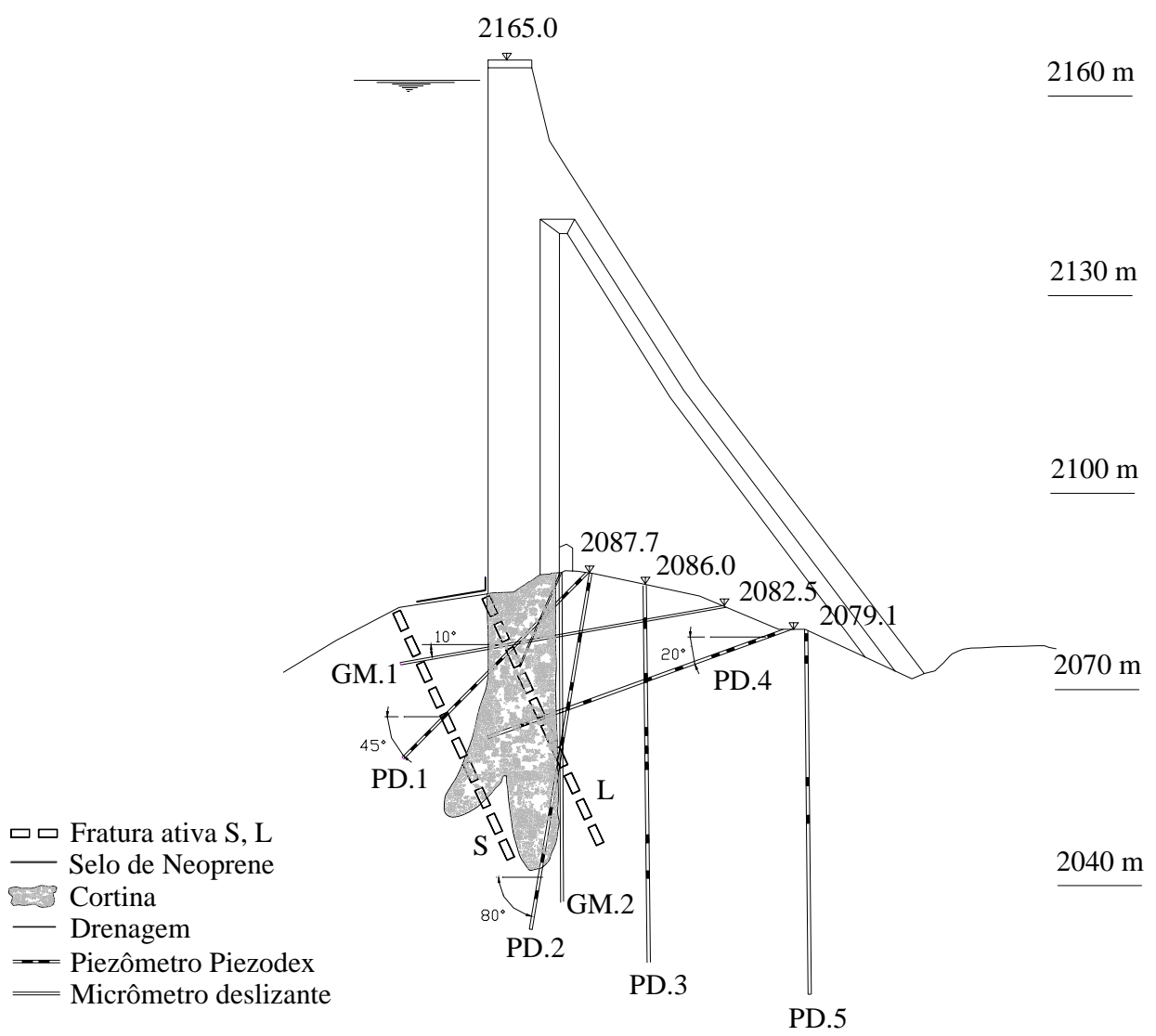

Figura 2.20 Seção transversal da barragem com a instrumentação de Piezômetros e Micrômetros deslizantes, as juntas S, L e o selo de neoprene. 
Todas as leituras foram definidas com relação a sua localização, tempo e exato nível de água, considerando-se principalmente as leituras correspondentes aos níveis máximo e mínimo. As leituras dos piezômetros, quando relacionadas com os níveis de água, deram como resultado que, para o nível 2135m, a pressão de água aumenta bruscamente, o que poderia ser explicado como a mudança abrupta da permeabilidade no maciço rochoso devido à abertura das juntas, além de mostrar que, ante o carregamento cíclico (variação do nível), as pressões medidas se tornavam maiores quando descia o nível do que quando subia.

Os micrômeros deslizantes localizados abaixo da base da estrutura, na zona do pé de montante, demonstraram com suas leituras (picos) a presença das duas juntas interceptadas pelas perfurações instrumentadas (ver figura 2.21). Não obstante, a interpretação das leituras possui alguma incerteza em relação à existência de mais juntas interceptadas e à largura inicial das juntas no momento da calibração do micrômetro que não é conhecida. Em relação às medidas, por exemplo, do desenvolvimento da deformação na junta $S$, estas demonstraram um aumento abrupto das deformações a partir do nível 2130m, mas eram maiores na descida do nível do que na subida (ver figura 2.22).

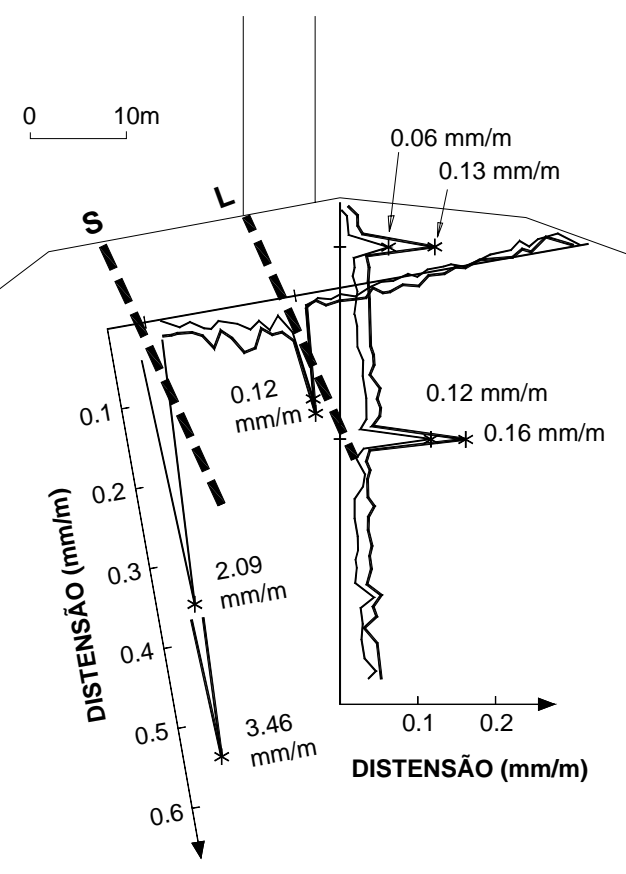

Figura 2.21 Perfis da deformação ao longo das duas perfurações (Kovári e Bergamin, 1994).

Mais tarde, com o intuito de observar o acontecido no marco teórico, foi realizada 
uma análise do modelo numérico de elementos finitos. No modelo, as dimensões foram bastante extensas para não assumir condições de fronteira do fluxo e seja desprezível a influência nos potenciais na faixa dos furos dos piezômetros. O fluxo que flui através do maciço rochoso a montante foi definido em relação ao nível de água, considerando-se a zona protegida com neoprene como impermeável.

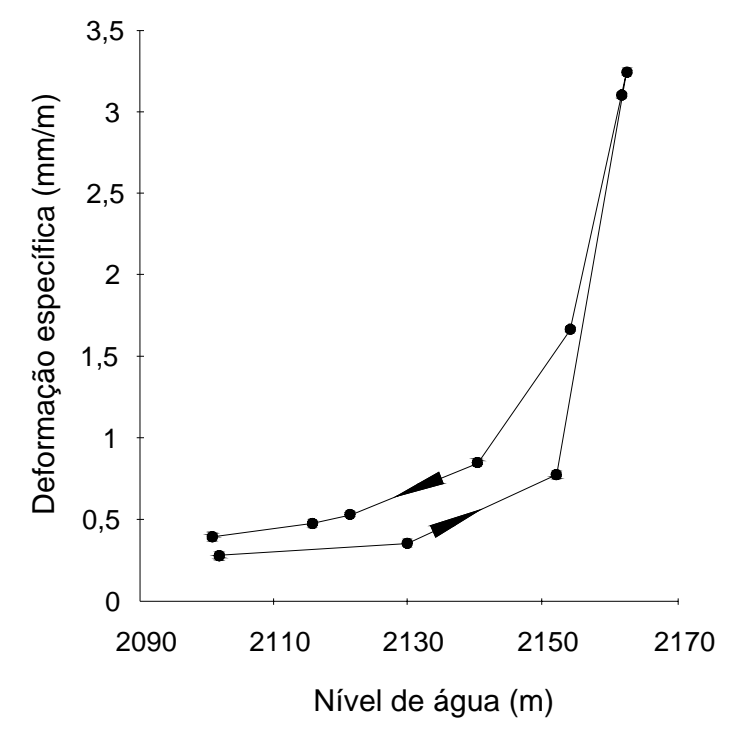

Figura 2.22 Desenvolvimento da deformação na junta ativa S (medida da posição GM.1.46) devido à variação do nível de água.

Os modelos de análise foram três, em função das características do maciço rochoso. O primeiro, homogêneo isotrópico e contínuo. O segundo, com duas zonas maiores de fraturas estendendo-se ao infinito, representando as juntas S e L com uma série de fraturas perpendiculares a elas, com permeabilidade muito menor. $\mathrm{O}$ acréscimo da abertura da fratura para níveis maiores é simulado com o incremento do coeficiente de condutividade nas zonas maiores de fratura. Um terceiro modelo corresponde a um meio homogêneo isotrópico, com duas juntas e a drenagem, considerando-se a permeabilidade variável, em função do nível de água para três níveis: 2162m, 2135m e 2101m. O resultado do modelo 1 se mostra na figura 2.23. Nele se faz a comparação entre os valores das leituras dos piezômetros e os calculados.

No final, nenhum dos modelos descreve uma distribuição semelhante das pressões medidas pelos piezômetros para todos os níveis de análise, talvez devido à falta de leis constitutivas confiáveis que considerassem a variação da permeabilidade. Porém, as pressões observadas puderam ser simuladas com ajuda de fatores físicos, como as juntas de maior dimensão e acréscimos da permeabilidade para níveis altos. A simples 
extensão do meio homogêneo e isotrópico do modelo deu resultados satisfatórios.

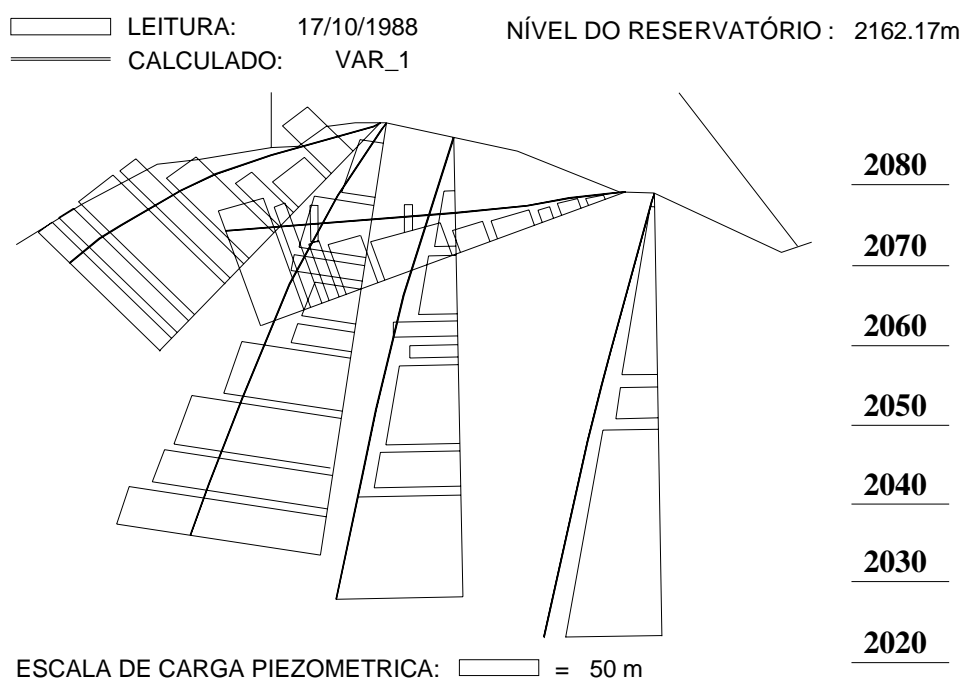

Figura 2.23 Comparação dos valores de pressão calculados com as leituras no nível 2162m (Kovári e Bergamin, 1994).

\subsection{Mecânica de Fratura}

Durante muito tempo, o aparecimento de fraturas em estruturas que foram projetadas sob os conceitos clássicos de tensão limite representava um problema que, às vezes, terminava em tragédia. O desenvolvimento da fratura e a sua relação com o tipo do material, o carregamento e o tempo teriam uma dependência inerente que seria desvendada no início do século XX.

Os princípios da Mecânica da Fratura trouxeram a explicação da propagação da fratura dentro da perspectiva da Mecânica das Rochas, de modo que logo foi possível explicar fenômenos muito importantes, tais como a fluência, a fadiga, o efeito escala e aspectos da relação tensão-deformação, no comportamento das rochas (Bortolucci, 1993).

\subsubsection{Balanço Energético de Griffith}

A necessidade de se explicar como se transmitiam as tensões nos corpos descontínuos, e qual era o mecanismo responsável pela propagação da fratura motivou a Griffith (1920) a estudar este fenômeno, desenvolvendo o conceito do balanço de energia no processo de fraturamento. Segundo este conceito, o balanço de energia considera a transferência da energia de deformação armazenada num corpo fraturado para a energia necessária que cria superfícies fraturadas. Isso explica o fato de que, quando uma fratura se propaga num corpo, haverá liberação de energia de deformação 
armazenada, mas também haverá uma energia de superfície sendo absorvida pelo acréscimo no comprimento da fratura. Assim, um corpo atingirá a ruptura quando a propagação da fratura presente ocorre de forma instável, o que quer dizer que a taxa de energia de deformação liberada é maior do que a taxa de energia de superfície necessária para provocar o processo de fraturamento (Bortolucci, 1993).

Griffith determinou a perda da energia de deformação a partir da análise de Inglis (1913), que foi realizada num corpo infinito com fratura em forma de elipse e submetida a uma tensão remota. Assim a perda de energia de deformação foi expressa pela eq.(2):

$$
U_{e}=\frac{\pi a^{2} \sigma^{2}}{2 E}
$$

onde $E$ é o módulo de elasticidade do material e $a$ o semi comprimento da fratura. A energia de superfície $U_{\mathrm{s}}$ foi determinada pela eq. (3) abaixo:

$$
U_{S}=2 a \gamma
$$

onde $\gamma$ é a energia específica de superfície livre, considerada propriedade do material.

Finalmente, o balanço energético foi definido com a eq. (4):

$$
U_{T}=-\frac{\pi a^{2} \sigma^{2}}{2 E}+2 a \gamma
$$

onde a condição de ruptura se dá quando a energia total, $U_{\mathrm{T}}$, atingir o máximo valor ou quando $\delta U_{T} / \delta a=0$, a partir do qual a tensão crítica para a ruptura expressa-se com a eq. (5):

$$
\sigma_{c r}=\sqrt{\frac{2 E \gamma}{\pi a}}
$$

Da eq. (5), conclui-se que a tensão crítica depende do tamanho da fratura e explica por que, para fraturas maiores, se precisará de menores valores de tensão de ruptura (Bortolucci, 1993). A figura 2.24 apresenta a interpretação gráfica do conceito.

A partir dos anos 50 do século passado, o estudo da propagação da fratura se viu ampliada quando Irwin, Orowan e outros postularam uma teoria modificada à teoria de Griffith. A teoria modificada propunha que, no lugar de se analisar a energia específica de superfície, deve-se considerar a variação da liberação de energia de deformação. Esta teoria propõe que um corpo atinge a ruptura quando a variação da liberação de 
energia (G) atingir o valor crítico, (Gc) que seria uma propriedade do material. Este valor Gc pode ser facilmente obtido em ensaios de materiais em processo de fraturamento. Então, determinando-se o G de um corpo fraturado em função da rigidez e da geometria do corpo, das tensões aplicadas e do tamanho da fratura, e comparando-se com o Gc do material, se a condição é G>Gc, conseqüentemente, a fratura se propaga instavelmente. A ruptura começará quando $\mathrm{G}=\mathrm{Gc}$.

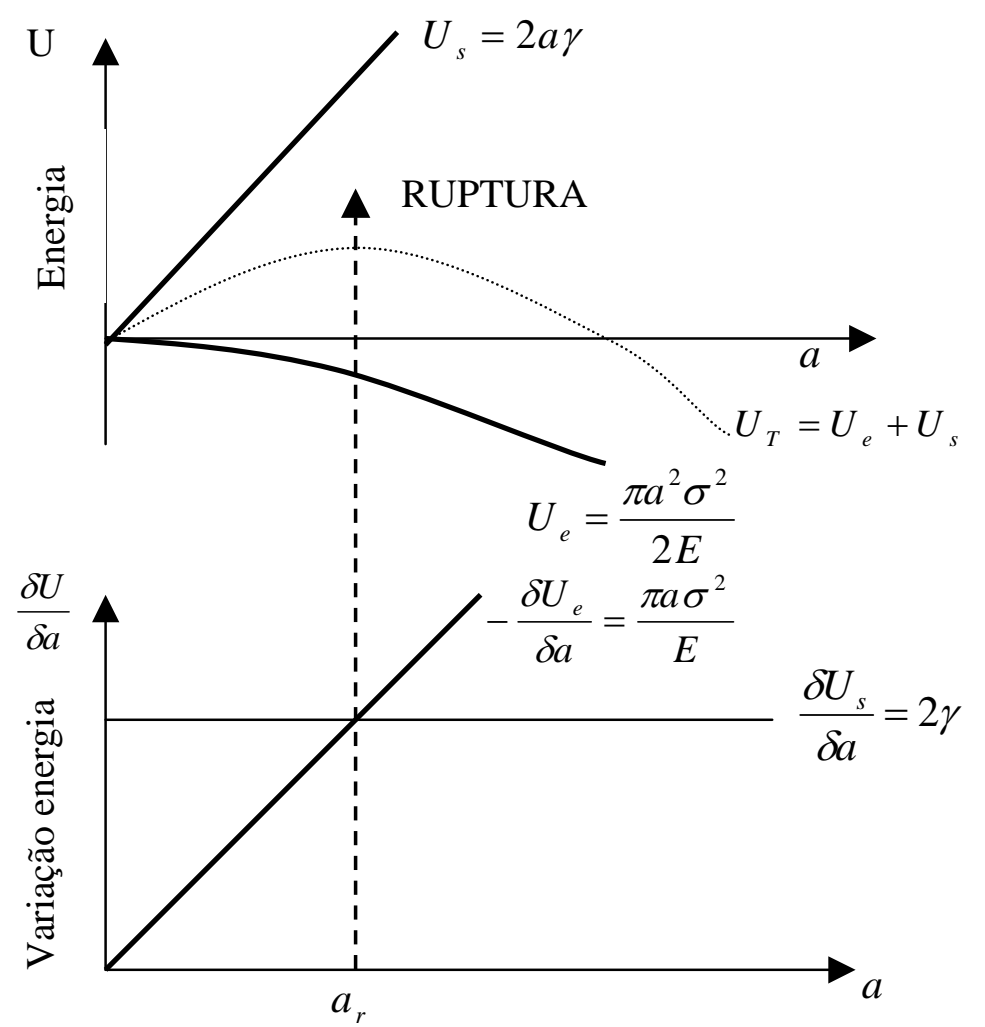

Figura 2.24 Energia e variação da energia em função do tamanho da fratura (Knott, 1973)

Irwin (1957) definiu como "fator de intensidade de tensão" uma constante K que depende da geometria do corpo, das tensões aplicadas e do tamanho da fratura. O aumento do fator de intensidade de tensão pode dar-se se a tensão aplicada for aumentada ou se o tamanho da fratura aumentar. Assim como existe uma variação de liberação de energia crítica (Gc), existe também um valor crítico de intensidade de tensão que determina se a propagação da fratura será instável.

Esse valor crítico de intensidade de tensão, considerado propriedade do material, é chamado de tenacidade à fratura do material (Kc) e é determinado em ensaios de laboratório. O valor de intensidade de tensão $(\mathrm{K})$ pode ser relacionado com a variação 
da liberação de energia (G) da eq. (6) para o estado plano de tensões e eq. (7) para o estado plano de deformações (Knott, 1973).

$$
\begin{gathered}
G=\frac{K^{2}}{E} \\
G=\frac{K^{2}\left(1-v^{2}\right)}{E}
\end{gathered}
$$

Com o intuito de compreender melhor o mecanismo da propagação da fratura, teorias têm sido derivadas como o Modelo Coesivo e a Mecânica do Dano que são empregadas na simulação de modelos matemáticos aplicados à engenharia. No trabalho presente, faz-se uso dos princípios da Mecânica do Dano, aplicados ao modelo de análise da zona fraturada.

\subsubsection{Modos de propagação da fratura}

A propagação da fratura num corpo ocorre de três modos, classificados segundo o tipo de movimento cinemático observado nos lados da fratura. Tal propagação pode ser do Modo I, o qual se dá devido a esforços de tração e se caracteriza pela separação das faces da fratura. O Modo II se dá pelo esforço de cisalhamento, caracterizando-se pelo escorregamento de uma face sobre a outra. Por fim, o Modo III ocorre pela ação de esforços de torção, separando-se as faces de modo a provocar o rasgamento como se pode ver na figura 2.25 .

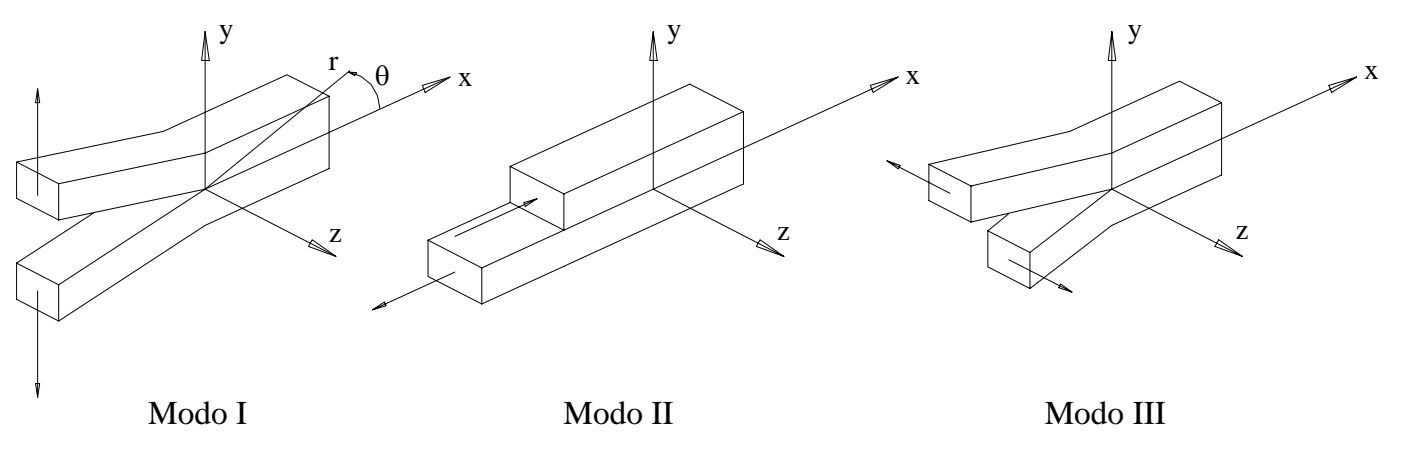

Figura 2.25 Modos de propagação da fratura.

Na realidade, a propagação de uma fratura pode acontecer tanto de um modo, como pela combinação deles, chamando-se, neste ultimo caso, de modo misto. Os Modos I e II ou a combinação deles são os mais freqüentes nos problemas de Mecânica 
das Rochas.

Em situações como a fundação de uma barragem na zona do pé de montante, o desenvolvimento de uma fratura tende a ser por cisalhamento (Pedroso, 1996). Esta zona da fundação da barragem de Porto Primavera, por exemplo, experimenta esforços de cisalhamento devido ao carregamento do peso próprio da estrutura. Estes esforços desenvolvem a fratura e sua propagação, primeiro do modo misto e logo depois do Modo I devido a esforços de tração, ocasionados pelo carregamento de água no reservatório. Mas, vale dizer que a trajetória da propagação da fratura segue um estado de tensões, o que já foi observado por Ingraffea (1983), para quem cada incremento no comprimento da fratura implica em um novo estado de tensões na estrutura.

\subsection{Modelo de Propagação de Fratura}

O Modelo constitutivo que é usado na simulação numérica do desenvolvimento da fratura baseia-se na Teoria da Mecânica do Dano, que visa a quantificação da degradação das propriedades mecânicas do material. Tal degradação resulta do início e crescimento de micro-defeitos, tais como micro-fissuras e cavidades. Essa quantificação é uma variável escalar, chamada variável de dano, representada por $d$. O valor desta variável nos fornece a medida da perda de rigidez secante e varia desde zero, para o material não danificado, até 1, para o material totalmente degradado (ver figura 2.26). Lemaitre (1996) define a variável $d$ conforme se apresenta na eq. (8), a qual se pode interpretar fisicamente como a relação local entre a superfície danificada e a superfície total (nominal) do material.

$$
d=\frac{S_{D}}{S}
$$

onde:

$S_{\mathrm{D}}$ : área das micro-fissuras e cavidades;

S: área total.

Conseqüentemente, o módulo de elasticidade do material danificado se define pela relação da eq.(9):

$$
\bar{E}=E(1-d)
$$

onde E é o módulo de elasticidade do material não danificado. 
A Teoria da Mecânica do Dano está baseada na definição do conceito de tensões efetivas e na hipótese de equivalência de deformações (Lemaitre e Chaboche, 1978): “A deformação associada ao estado degradado submetido a uma determinada tensão $\sigma$ é equivalente à deformação associada ao estado intacto (não degradado) submetido à tensão efetiva $\bar{\sigma}$ ”.

Assim, em termos de tensões, estabelece-se a seguinte equação:

$$
\bar{\sigma}=\frac{\sigma}{(1-d)}=E \varepsilon
$$

onde $\varepsilon$ é a deformação uniaxial.

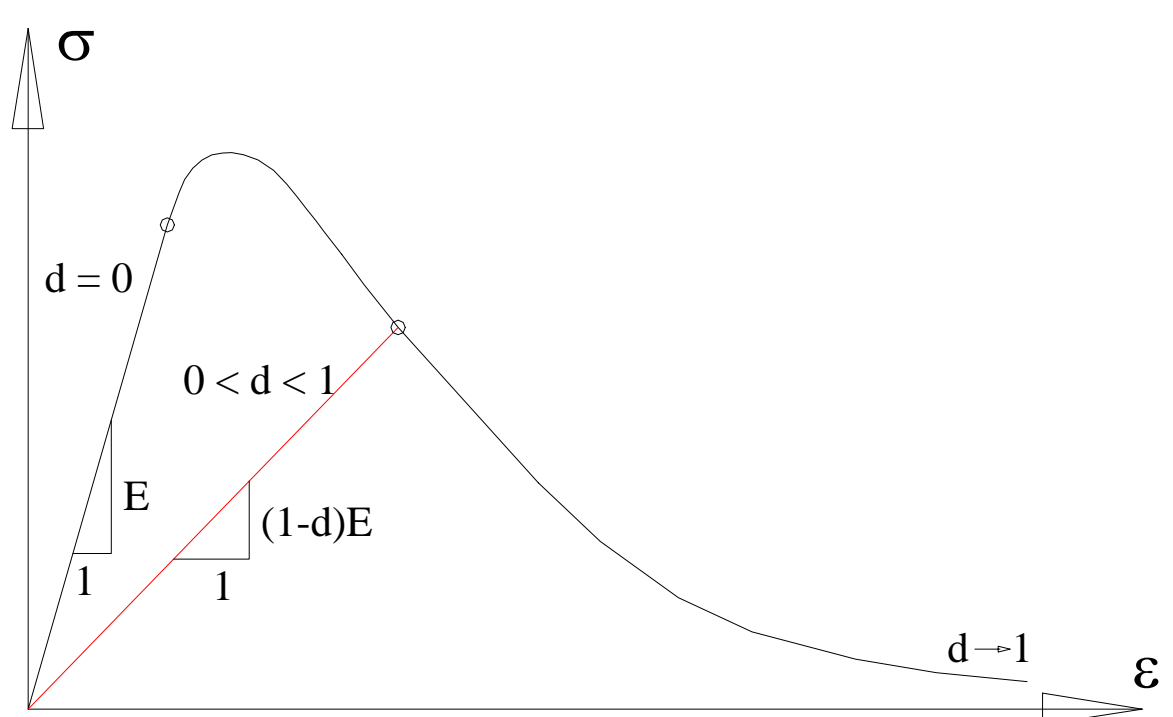

Figura 2.26. Curva uniaxial tensão-deformação para o modelo de degradação (Olivier et al., 1990).

Em problemas multiaxiais, o tensor de tensões efetivas de segunda ordem, $\bar{\sigma}$ é expresso pela eq. (11):

$$
\bar{\sigma}=D_{o}: \varepsilon
$$

onde $\boldsymbol{D}_{\boldsymbol{o}}$ é o tensor constitutivo elástico linear de quarta ordem, $\boldsymbol{\varepsilon}$ é tensor de deformações de segunda ordem e (:) representa o produto tensorial contraído em dois índices. O tensor de tensões efetivas pode ser decomposto em duas componentes $\bar{\sigma}^{+} \mathrm{e}$ $\bar{\sigma}^{-}$, correspondentes à tração e compressão, contendo, respectivamente, as componentes positivas e negativas das tensões principais de $\bar{\sigma}$. A partir da divisão das tensões, podese definir, explicitamente, a lei constitutiva, através do tensor de tensões de Cauchy: 


$$
\sigma=\left(1-d^{+}\right) \bar{\sigma}^{+}+\left(1-d^{-}\right) \bar{\sigma}^{-}
$$

com

$$
0 \leq d^{+} \leq 1 \text { e } 0 \leq d^{-} \leq 1
$$

onde $d^{+}$e $d^{-}$são as variáveis internas de dano de tração e compressão, respectivamente. Em conseqüência o modelo fica definido pelas leis de evolução das variáveis internas de dano.

Os critérios de dano de tração e de compressão são dados pelas eq. (14) e (15), respectivamente.

$$
\begin{aligned}
& g^{+}\left(\bar{\tau}^{+}, r^{+}\right)=\bar{\tau}^{+}-r^{+} \leq 0 \\
& g^{-}\left(\bar{\tau}^{-}, r^{-}\right)=\bar{\tau}^{-}-r^{-} \leq 0
\end{aligned}
$$

onde $\bar{\tau}^{+}$e $\bar{\tau}^{-}$são as normas das tensões efetivas de tração e compressão, e as variáveis $r^{+}$e $r^{-}$são os limites correntes de dano. As expressões das normas $\bar{\tau}^{+}$e $\bar{\tau}^{-}$definem a forma enquanto que os valores dos limites de dano controlam o tamanho da superfície limite do dano, que se expande no espaço das tensões efetivas. Essas variáveis, antes da aplicação de cargas assumem valores iniciais, $r_{o}^{+}$e $r_{o}^{-}$que são atribuídas com base nas tensões uniaxiais correspondentes aos limites de proporcionalidade, $f_{o}^{+}$e $f_{o}^{-}$, de onde:

$$
\begin{aligned}
& r_{o}^{+}=\frac{f_{o}^{+}}{\sqrt{E}} \\
& r_{o}^{-}=\frac{f_{o}^{-}}{\sqrt{E}}
\end{aligned}
$$

onde $E$ é o módulo de elasticidade do material. Devido à fragilidade do material à tração (caso rocha) a tensão limite de proporcionalidade, $f_{o}^{+}$, em geral, coincide com a tensão de resistência à tração, $f_{t}$, a partir da qual ocorre abrandamento da tensão com acréscimo da deformação. A figura 2.27 ilustra os contornos da superfície limite inicial do dano no espaço das tensões principais efetivas que se pode obter com as expressões das normas das tensões efetivas propostas por Cervera et al. (1996).

As variáveis do dano são expressas em função das variáveis limites de dano. Para o caso específico de tração (objetivo do estudo) a evolução do dano é expressa pela eq. 
(18).

$$
d^{+}=1-\frac{r_{o}^{+}}{r^{+}} e^{A^{+}\left(1-\frac{r^{+}}{r_{o}^{+}}\right)}
$$

onde $A^{+}$é o parâmetro de abrandamento da lei de evolução do dano.

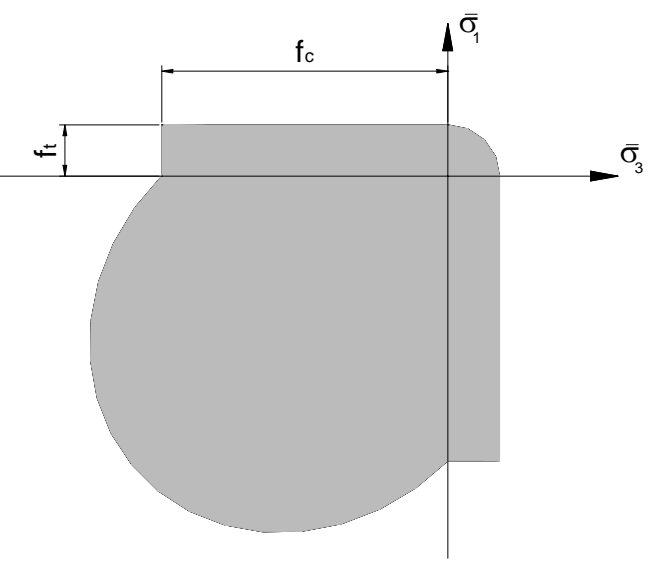

Figura 2.27 Superfície limite inicial do dano no espaço das tensões principais efetivas biaxial.

Como é bem sabido, o emprego de modelo de dano para representar fratura de maneira difusa (smeared crack approach) pode conduzir a uma forte dependência da resposta com respeito ao tamanho e à orientação da malha de elementos finitos. Para minimizar essa falta de objetividade com respeito à malha de elementos finitos sem prejuízo de simplicidade e robustez do método, utilizam-se as seguintes estratégias:

1. A energia dissipada localmente pelo modelo de dano em um processo completo de degradação (estabelecida pelo parâmetro de abrandamento $A^{+}$) é função da energia de fratura do material $\left(G_{\mathrm{F}}\right)$ e do tamanho característico do elemento finito (Cervera et al. 1996);

2. A trajetória da fratura ao longo do processo de carregamento é estabelecida por um algoritmo de traçado progressivo que assegura continuidade da fratura entre elementos finitos. A orientação da linha de fratura no interior de cada elemento é fixada ortogonalmente à direção de máxima tensão no instante em que as tensões alcançam o critério de dano. Somente os elementos atravessados pela linha de fratura podem apresentar comportamento nãolinear, permanecendo os demais em regime elástico linear.

Note que o emprego de tais estratégias conduz a uma forma de representar a 
fratura muito similar à do modelo coesivo (Hillerborg et al. 1976). Nesse caso, a zona de formação da fratura corresponde ao domínio dos elementos atravessados pela trajetória da fratura. A lei de redução das tensões fica estabelecida pela lei de abrandamento do modelo de dano e a abertura da fissura corresponde ao deslocamento relativo entre os lados do elemento, que é resultante da parte inelástica das deformações.

No presente estudo, considera-se o dano progressivo da zona de fundação ao pé da montante da barragem sob a ação da carga de água na frente e no pé de montante da mesma, produzindo o avanço da fratura para cada acréscimo do nível de água. Nesse trabalho, emprega-se um modelo de dano isotrópico com degradação somente por solicitações de tração, no qual somente intervêm as componentes positivas das tensões principais.

\subsection{Determinação da Subpressão}

A ação da água nas fundações mal e pouco foi considerada no começo das construções de barragens. Depois de muitos desastres de estruturas construídas em séculos passados, um comitê de investigação liderado por Maurice Levy no ano de 1895 indicou que as causas do acidente da barragem de Bouzey corresponderam às pressões de água na rocha e à força de subpressão atuante sob a fundação da barragem. A subpressão poderia ter reduzido o peso efetivo da estrutura e, conseqüentemente, a resistência ao cisalhamento (Birindelli, 1987).

O conceito de subpressão e sua atuação passaram por várias etapas onde inicialmente, por falta de dados e precariedades dos ensaios de permeabilidade, a barragem de concreto e o maciço de fundação foram considerados impermeáveis, levando-se em conta que a subpressão só se exercia através das juntas ou fissuras. Mais tarde, como resultados de evidências, foi mostrada a existência de pressões de água tanto na fundação como no corpo da estrutura. Uma das maiores controvérsias que logo surgiu foi em relação à área efetiva de atuação destas pressões. A idéia de que não haveria subpressão entre as partículas do contato que não tinham água era o principal argumento contra a idéia de que a área de atuação das pressões de água era de 100\%.

Contudo, Serafim (1954) cita Castigliano de 1884 como sendo o primeiro que indicou a fissuração e as tensões de tração como as causas da penetração de água na base das estruturas. Outros, como Francis em 1888, sugeriram a existência de pressões na base de barragens de gravidade devido à fissuração da rocha, propondo a execução 
dos drenos na base da estrutura, próximo ao paramento de montante. Afirmava, também, que as subpressões variavam desde a pressão do reservatório a montante até zero a jusante. Com exceção de Levy, todos consideravam a existência de fendas através das quais as pressões de água eram exercidas no interior e na base das barragens. Ainda não se admitia que a pressão hidrostática pudesse ser exercida em toda área das seções horizontais.

Segundo Serafim, foi Pelletrau em 1897 que indicou que sempre ocorreria a subpressão no contato com a estrutura em virtude da permeabilidade da fundação, ainda que esta fosse rocha sã.

Mais tarde, após discussões, dois fatores importantes se consolidaram como sendo relevantes: a área efetiva de atuação da pressão de água sob a base da estrutura e a intensidade com que ela se manifesta. O fator “A” e o fator intensidade "I” constituíamse nos elementos determinantes da subpressão. O fator de área A, segundo Birindelli (1987), foi definido como a porcentagem da área da seção horizontal da base da barragem que deveria ser admitida como sendo a área efetiva de aplicação da solicitação, com valores que poderiam chegar a 100\% ou 1,0 em função da porosidade do meio ou conforme a experiência do projetista. Mas o valor para o fator de área A tinha como base algumas evidências de investigação. Uma muito importante foi a de Terzaghi (1936) que argumentou, com base em sua investigação, que, semelhantemente ao concreto, as mesmas condições poderiam ser encontradas nas rochas, que eram materiais porosos e, em função de sua própria estrutura, estariam submetidas a um alto fator de área, independente da influência de aberturas ou cavidades na rocha, da presença de juntas ou de fraturas. A existência destas facilita o acesso de água, promovendo a saturação da rocha, resultando em um valor alto do fator de área A.

O fator intensidade "I”, segundo Birindelli (1987), foi definido como um coeficiente de minoração do valor de subpressão de montante. Este era expresso como um gradiente que se estendia desde uma pressão correspondente ao nível de jusante até um valor variável da face de montante. Este valor variaria até um máximo correspondendo à pressão total do reservatório, sendo em conseqüência igual a 100\% ou 1,0. Ante a presença de drenagem, esta reduziria a subpressão.

Além das condições geológicas da fundação que influenciam diretamente a intensidade da subpressão atuante na base das estruturas, dedicou-se especial atenção 
aos sistemas de redução desta solicitação, como as cortinas de injeção e drenagem amplamente utilizadas no Estados Unidos. A eficácia da drenagem e das cortinas de injeção foi muito discutida em relação às cortinas de injeção que eram consideradas como proteção permanente, embora existissem algumas dúvidas a esse respeito. Entretanto, Rienius (1948) argumentava que estas cortinas de injeção poderiam ser acessíveis e passíveis de reforço através das galerias próximas à fundação ou desde o reservatório. O sistema de drenagem também tinha algumas observações contrarias, pois se alertava sobre a possibilidade de ineficácia dos drenos devido à colmatação. Em conseqüência disto, foi recomendado um acompanhamento sistemático do funcionamento dos dispositivos de controle, seja através de medidas de pressão ou de vazões para assegurar a eficiência.

São vários os critérios ou normas importantes que foram levadas em conta em relação à determinação da subpressão. Tanto os critérios europeus, americanos e as normas da USBR mostram que as observações do comportamento dos maciços de fundação das estruturas constituem dados de entrada importantes na aferição e ajuste dos critérios. Destacam-se, especialmente, os aspectos pertinentes à geologia local, às características dos tratamentos, etc. Os organismos passaram a não indicar valores a serem assumidos, mas sim a indicar a necessidade de calculá-los em função das condições específicas de cada caso analisado.

No Brasil, tendo como especial marco a existência de grandes barragens, vários estudos têm sido realizados. O mais ilustrativo foi apresentado anteriormente, onde Cruz e Silva (1978) estabelecem critérios para a determinação da subpressão no contato ou interface concreto-rocha e nas descontinuidades.

\subsubsection{Determinação da subpressão média}

A partir do modelo idealizado de Muskat (1937), Andrade (1980) procura estabelecer a subpressão média, $S_{d}$, na linha de drenos. Embora o modelo seja bidimensional (como o de Muskat), Andrade considera um fluxo transversal, paralelo à linha de drenagem, que ocorreria entre drenos em função da diferença de pressão que se estabelece entre a meia distância dos drenos e suas vizinhanças. Andrade amplia a validade de suas equações, fazendo considerações importantes tais como a anisotropia de maciços, a utilização de esquemas de tratamentos diferenciados mais complexos que uma simples linha de drenagem e a imposição de um nível de drenagem inferior ao 
nível de jusante através do uso de bombeamento. Assim, as premissas do método sugerido por ele constituem uma extensão ao método de Casagrande. Cabe esclarecer que, para Casagrande, $S_{\mathrm{d}}$ representa o excesso de subpressão em relação ao nível de jusante. Entende-se este excesso de subpressão como sendo a diferença de potencial existente com relação ao nível de jusante.

Com base na equação de Darcy e da continuidade, sem considerar as perdas de carga que ocorrem ao longo dos drenos, Andrade estabelece o valor da subpressão média na linha de drenos, supondo que estes funcionem com uma eficiência de 100\% dentro de uma camada permeável.

No cálculo da subpressão média na zona dos drenos, Andrade (1980) utiliza um modelo unidimensional como mostrado na figura 2.28(a), onde considera uma linha de drenos paralela à face de montante da barragem a uma distancia $s$, sendo os furos de diâmetro $\phi$ espaçados a uma distância $a_{d}$.

O contato barragem-fundação (AC) é considerado uma descontinuidade principal, onde a vazão que penetra a montante é igual à vazão que sai pelo dreno mais a vazão que vai para jusante, sendo expressa pela eq. (19) e esquematizada na figura 2.28(b).

$$
q_{m}=q_{d}+q_{j}
$$

De acordo com a vazão do meio que está representada pela eq.(20), supõe-se que o fator de escoamento $f$ é constante não só no sentido AC como também no BD, ou seja, ao longo da linha de drenos, de modo que $S_{\mathrm{d}}$ seria constante para qualquer valor de $l(l$ distância de um ponto qualquer até o dreno), inclusive $l=1$, sendo $S_{\mathrm{d}}$ o valor da pressão média no ponto B de acordo com a figura 2.28, e o fator de escoamento no plano BD representado pela eq. (21):

$$
\begin{gathered}
Q=f \cdot i \\
f^{\prime}=f \cdot \lambda^{\prime}
\end{gathered}
$$

onde $\lambda$ ’ é um fator que leva em conta o espaçamento de drenos e o diâmetro dos mesmos. 


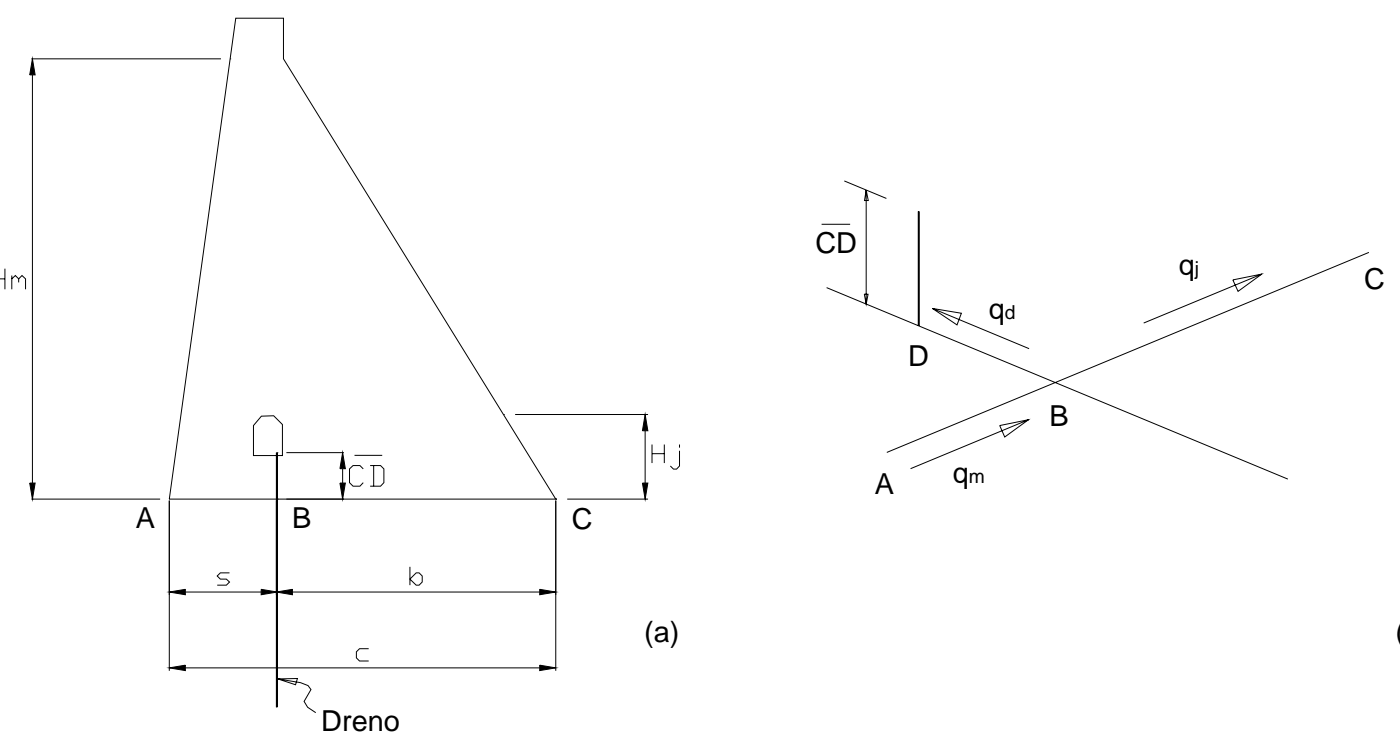

(b)

Figura 2.28 Esquema de Cálculo de Andrade (1988).

Portanto, $\lambda$ ', denominado por Andrade de fator de forma da linha de drenos, representa a modificação que a drenagem provoca no escoamento no plano da linha de drenos. O valor de $\overline{C D}$, de acordo com as figuras 2.28 e 2.29 , é a coluna de água no dreno até a base AC, ou seja, é a distancia da boca do dreno até o plano da descontinuidade em estudo.

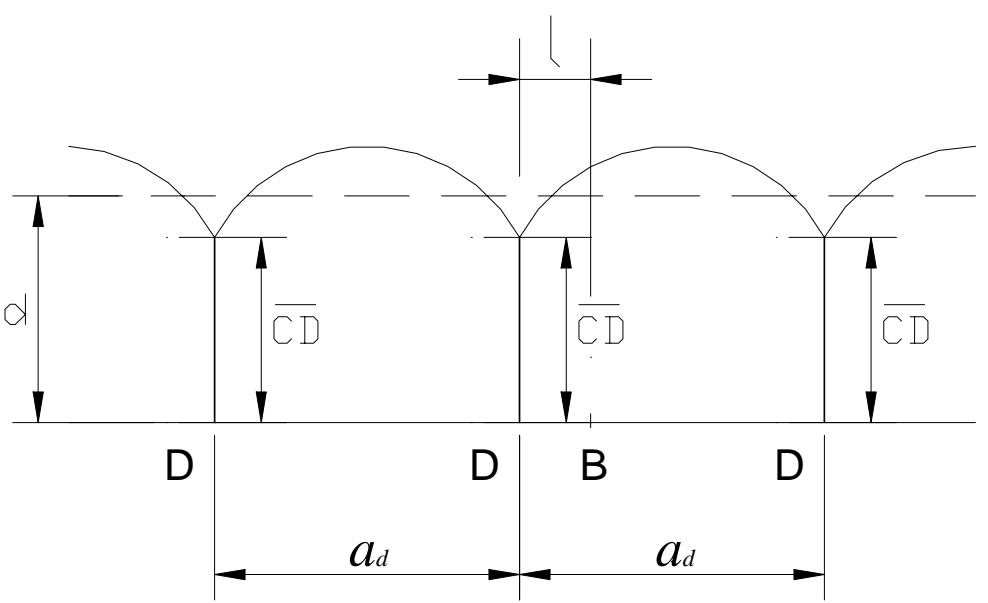

Figura 2.29 Definição da subpressão média (Sd) segundo Andrade (1988).

Com base nas equações (19) e (20), Andrade deduz as seguintes equações (22), (23), (24) e (25):

$$
q_{m}=f \frac{H_{m}-S_{d}}{s}
$$




$$
\begin{gathered}
q_{d}=f \lambda^{\prime}\left[\frac{S_{d}-\overline{C D}}{l}\right] \\
\lambda^{\prime}=l \lambda
\end{gathered}
$$

resultando em:

$$
\begin{gathered}
q_{d}=f \lambda\left(S_{d}-\overline{C D}\right) \\
q_{j}=f \frac{S_{d}-H_{j}}{b}
\end{gathered}
$$

a partir das quais se obteve a seguinte expressão para $S_{\mathrm{d}}$ :

$$
S_{d}=\frac{H_{m} b+H_{j} s+b s \lambda \overline{C D}}{s b \lambda+b+s}
$$

onde $b$ a distância do dreno até a face de jusante e $s$, distância do dreno até a face de montante.

Nesta expressão da eq. 26, o valor do fator de forma da linha de drenos, $\lambda$, é dado por:

$$
\lambda=\frac{2 \pi}{a_{d} \ell n\left[\frac{a_{d}}{2 \pi r_{d}}\right]}
$$

onde $r_{\mathrm{d}}$, é o raio do dreno.

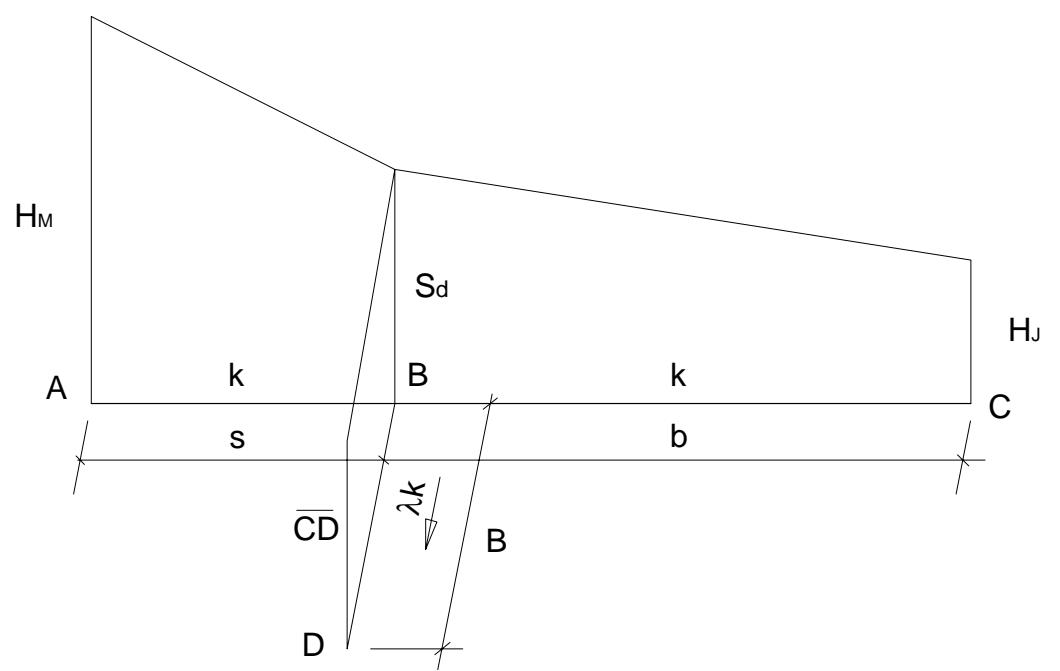

Figura 2.30 Consideração do fator de forma, $\lambda$ (Andrade, 1988). 


\subsubsection{Escoamento do fluxo}

O escoamento do fluxo no maciço rochoso é considerado bem complexo. Para entender como flui a água no meio fraturado, é preciso entender o comportamento do fluxo através de uma simples fratura. Como se sabe, as vazões são maiores onde a quantidade de vazios é maior. Segundo Andrade (1988), nos maciços rochosos existem caminhos que as águas escolherão para percorrer preferencialmente. É como considerar a existência de um gradiente hidráulico que na maioria das vezes não é de grande intensidade. As forças de impulsão geradas pelos gradientes, evidentemente, encaminham as águas subterrâneas para descontinuidades que favorecem sua passagem. Mas, será preciso explicar que existem outros fatores que influenciam o escoamento das águas, como a temperatura, por exemplo, a qual depende da profundidade, assim como o grau geotérmico em geral do meio e a temperatura das águas do reservatório. Sabe-se que as águas represadas sofrem variações sazonais de temperatura e, com isto, influenciam o escoamento das águas subterrâneas. Outro fator pode ser a composição química das substâncias dissolvidas que alteram as rochas de fundação, e, finalmente, o índice mineralógico de solubilidade, a radioatividade, etc.

Existem vários tipos de descontinuidades ou superfícies abertas ou de fraturas que são vias de escoamento como se apresenta na figura 2.31. As de tipo A, que não têm material de preenchimento, as de tipo B com preenchimento de material poroso, as de tipo C, superfícies abertas com preenchimento de material qualquer que poderia ter até sub-fraturas, e aquelas de tipo D, superfícies irregulares compostas por rochas fraturadas que se interligam, mas que funcionam como se fossem uma só descontinuidade.

Aquela de tipo A é a mais representativa porque permite assumir que o escoamento se dá entre duas superfícies paralelas próximas, substituindo-se o modelo real por um modelo teórico como se mostra na figura 2.32. Este modelo teórico serve como apoio para estabelecer um valor nominal da abertura $e$ da descontinuidade. Este valor chama-se abertura nominal, o qual teoricamente representa o espaço onde acontece o escoamento em uma fratura real. Cabe esclarecer que as superfícies paralelas representam os limites impermeáveis para o fluxo. 
A

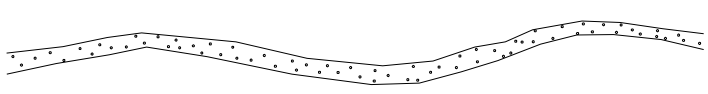

B

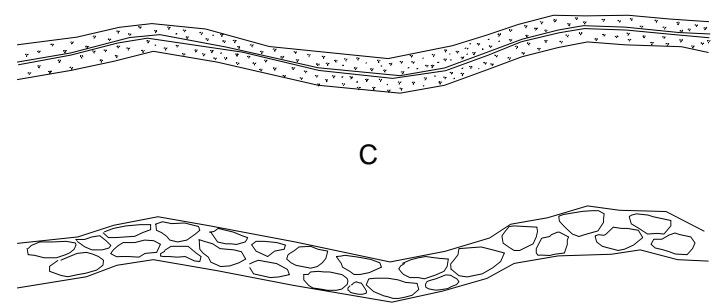

D

Figura 2.31 Tipos de abertura ou descontinuidade (Andrade, 1988).

Como o escoamento tem velocidades em geral baixas, ele pode ser considerado no regime laminar, ou seja, um escoamento onde as partículas de água escoam paralelas à superfície da descontinuidade com uma velocidade média $v_{m}$.

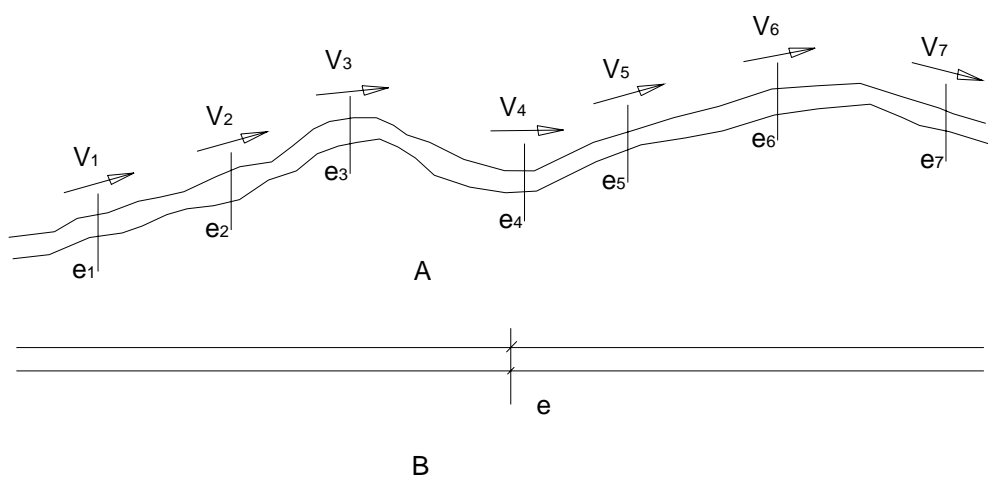

Figura 2.32 Substituição do modelo real (A) pelo modelo teórico (B) (Andrade, 1988).

Devido ao fato de que a abertura nominal de uma fratura é bem pequena, considera-se que o fluxo pode se basear na lei cúbica, a partir da qual deduz-se o valor da permeabilidade ou condutividade da fratura por meio da eq. (28):

$$
q=-f \cdot i
$$

de onde $f$ é o fator de escoamento que se apresenta pela eq. (29):

$$
f=\frac{\gamma_{w} e^{3}}{12 \mu}=\frac{g e^{3}}{12 v}
$$

onde $\gamma_{\mathrm{w}}$ é o peso específico da água, $v$ a viscosidade cinemática e $g$ a aceleração da 
gravidade.

$$
\frac{\gamma_{w}}{\mu}=\frac{g}{v}
$$

onde $\mu$ é a viscosidade dinâmica. A partir das expressões acima, pode-se calcular o valor da condutividade da fratura por meio das eq. (31) e eq. (32):

$$
\begin{gathered}
f=k_{f} A \\
k_{f}=\frac{g e^{2}}{12 v}
\end{gathered}
$$

Onde $k_{f}$ é a condutividade hidráulica da descontinuidade ou fratura e $A$ é a área onde se dá o escoamento na unidade de largura. A eq. (28) da vazão é utilizada num meio descontínuo, onde o escoamento se realiza por descontinuidades principais persistentes de abertura nominal $e$ num regime laminar. Já a eq. (32) foi utilizada nos cálculos do presente estudo. 


\section{METODOLOGIA}

A fundação da barragem da Usina de Porto Primavera, situada entre os Estados de São Paulo e Mato Grosso do Sul, é o objeto do presente trabalho de pesquisa. A metodologia seguida está baseada, inicialmente, na seleção das seções da barragem a serem analisadas. Tomou-se uma seção representativa da zona do vertedouro que foi a seção BV-6, a que possui instrumentação instalada de extensômetros e piezômetros na fundação, assim como uma seção da zona da casa de força, a unidade U-10, que também possui instrumentação instalada na fundação. Seguidamente, deram-se os seguintes passos:

1. A compilação dos parâmetros característicos do material do maciço rochoso, (a saber, a densidade, a condutividade hidráulica, os módulos de deformabilidade nas duas direções e o coeficiente de Poisson) e da estrutura de concreto da barragem usados no projeto original,

2. A compilação dos registros das leituras realizadas pela instrumentação existente na fundação da estrutura (a saber, extensômetros, piezômetros e drenos),

3. A quantificação das cargas de água nos níveis de análise, para a aplicação das pressões correspondentes nas superfícies do paramento a montante e jusante, na fundação assim como na zona de contato concreto-rocha a montante. Determinou-se também o módulo de deformabilidade do maciço (E) e a densidade equivalente para as seções assumidas de análise,

4. O cálculo de parâmetros como a energia de fratura (G), a carga hidráulica média na zona do dreno na fundação, a condutividade do dreno e da zona de fratura para a análise de fluxo.

De acordo com os objetivos de estudo do aparecimento e propagação da fratura, considerou-se a aplicação da Mecânica de Fratura mediante a análise não linear da zona 
de fratura. A análise é realizada sob o Modelo do Dano na zona onde se desenvolve a fratura. No estudo, considerou-se o dano progressivo sob a ação da carga de água na frente e no pé de montante da barragem, originando uma fratura na fundação ao pé do paramento a montante, considerando-se a análise do avanço da fratura para cada acréscimo de nível de água. Nesse trabalho, emprega-se um modelo de dano isótropo com degradação somente por solicitações de tração, no qual somente intervêm as componentes positivas das tensões principais (Oliver et al.1990).

Devido ao carregamento progressivo de água na face da estrutura a montante, propôs-se a análise iterativa de tensão-deformação e pressão hidráulica na parede da fratura baseada no avanço da fratura e na aplicação de forças nodais na parede da fratura, finalizando-se esta análise quando a fratura deixa de progredir. Para o desenvolvimento da análise, realizou-se a construção de um modelo de tensãodeformação, além de um segundo modelo para realizar o cálculo de subpressão para cada avanço da fratura.

Considerou-se realizar a análise para seis níveis de carregamento de água, os quais foram: 242m, 244m, 247m, 250m, 253m e 257m (máximo nível atual de água). As análises tanto de tensão-deformação e pressão de água como de fluxo e subpressão se deram de forma iterativa.

Inicia-se a análise com o processamento do modelo tensão-deformação, considerando todas as cargas hidráulicas correspondentes ao primeiro nível de água. Este primeiro carregamento origina uma fenda ou fratura, a qual será considerada num novo processamento de fluxo e subpressão. Os resultados deste último processamento deram um novo diagrama de subpressão na base que é considerado no seguinte processamento. Ao mesmo tempo, a fratura que se produz será afetada pela pressão hidrostática nas suas paredes correspondentes ao mesmo primeiro nível. Essa pressão hidráulica é considerada constante a partir da superfície da fundação na zona de contato concreto-rocha. A partir dessa pressão, calcularam-se forças nodais que foram aplicadas nos nós dos elementos para um novo processamento de tensão-deformação. Após este último processamento, produziu-se um novo avanço da fratura, o que foi afetado pelas cargas do seguinte nível de água. Assim, deram-se os processamentos com todos os níveis de água até que a fratura deixou de progredir.

Depois de realizados os processamentos de análise, procedeu-se a tomar os 
deslocamentos dos pontos que identificam a posição das hastes dos extensômetros. Estes deslocamentos produzidos sob cada carregamento de água são relacionados com os pontos que representam a posição dos aparelhos de leitura instalados nas galerias de montante. O afastamento ou acercamento dos pontos indicaram o alongamento ou encurtamento das hastes dos extensômetros, o que mostra a possível deformação desenvolvida no maciço rochoso da zona. Das deformações calculadas, foi feita uma aferição com as leituras compiladas dos extensômetros existentes na fundação das seções selecionadas.

\subsection{Parâmetros de análise}

A estrutura de concreto da barragem de Porto Primavera está fundada sobre um maciço basáltico na região de micro-derrames que são simplificados no modelo de análise, mas que influem nos valores das características geomecânicas utilizadas no projeto original. O nível de água máximo considerado para a análise foi $257 \mathrm{~m}$, dado tomado do projeto original. As seções de análise apresentam-se na figura 3.1 para o vertedouro e na figura 3.2 para a casa de força.

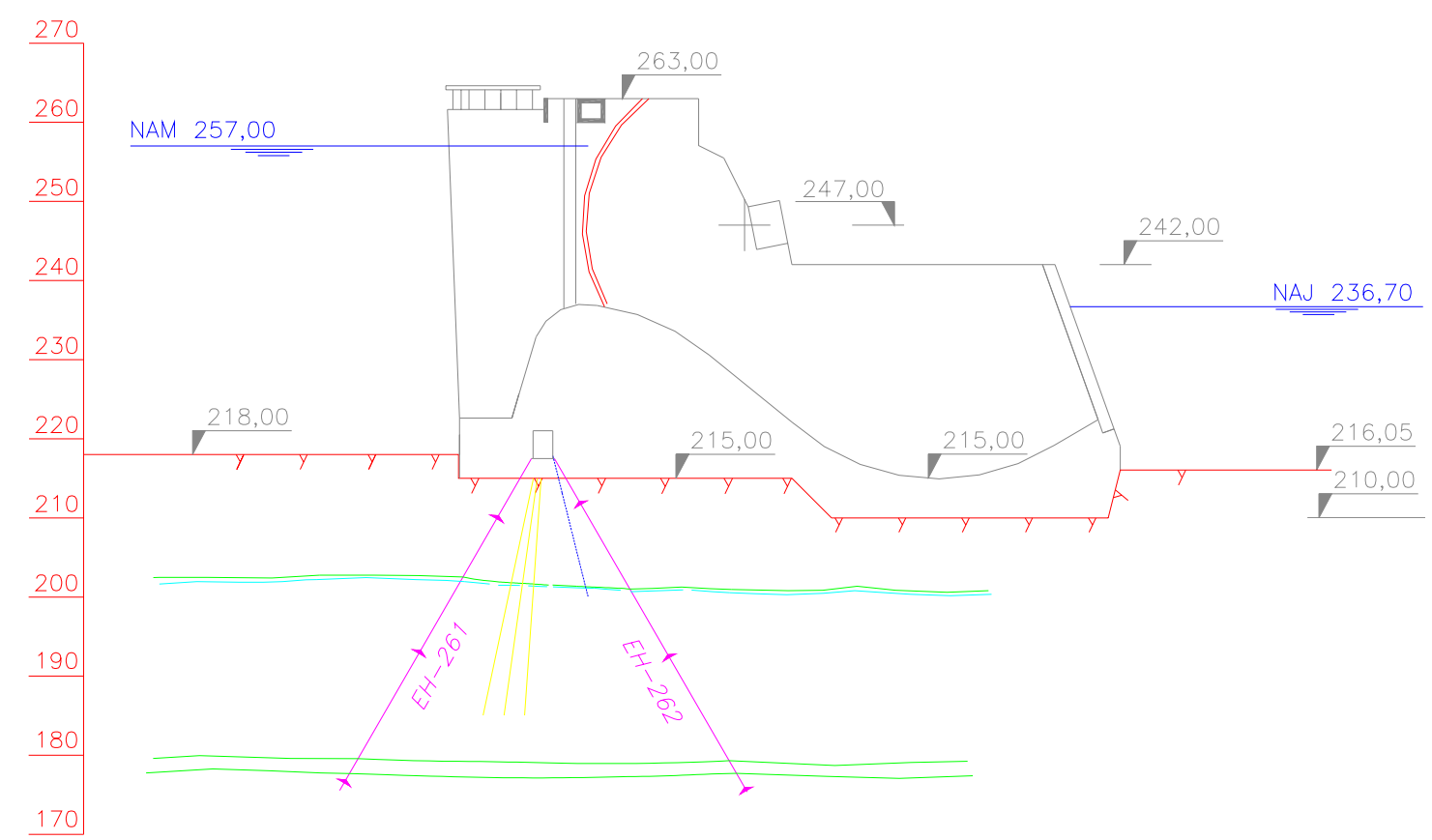

Figura 3.1 Seção de análise do vertedouro sob carga máxima atual de água.

As características geométricas dos blocos do vertedouro e da casa de força são as seguintes: o bloco do vertedouro tem uma largura de $20 \mathrm{~m}$, a qual inclui a zona da 
comporta de $15 \mathrm{~m}$ e os pilares de $5 \mathrm{~m}$, sendo que a casa de força tem uma largura de $31 \mathrm{~m}$ na qual se inclui a zona da tomada de água para as turbinas. A seção de análise assumiuse em 1m. A figura 3.3 apresenta a planta do vertedouro e a figura 3.4 a planta da casa de força.

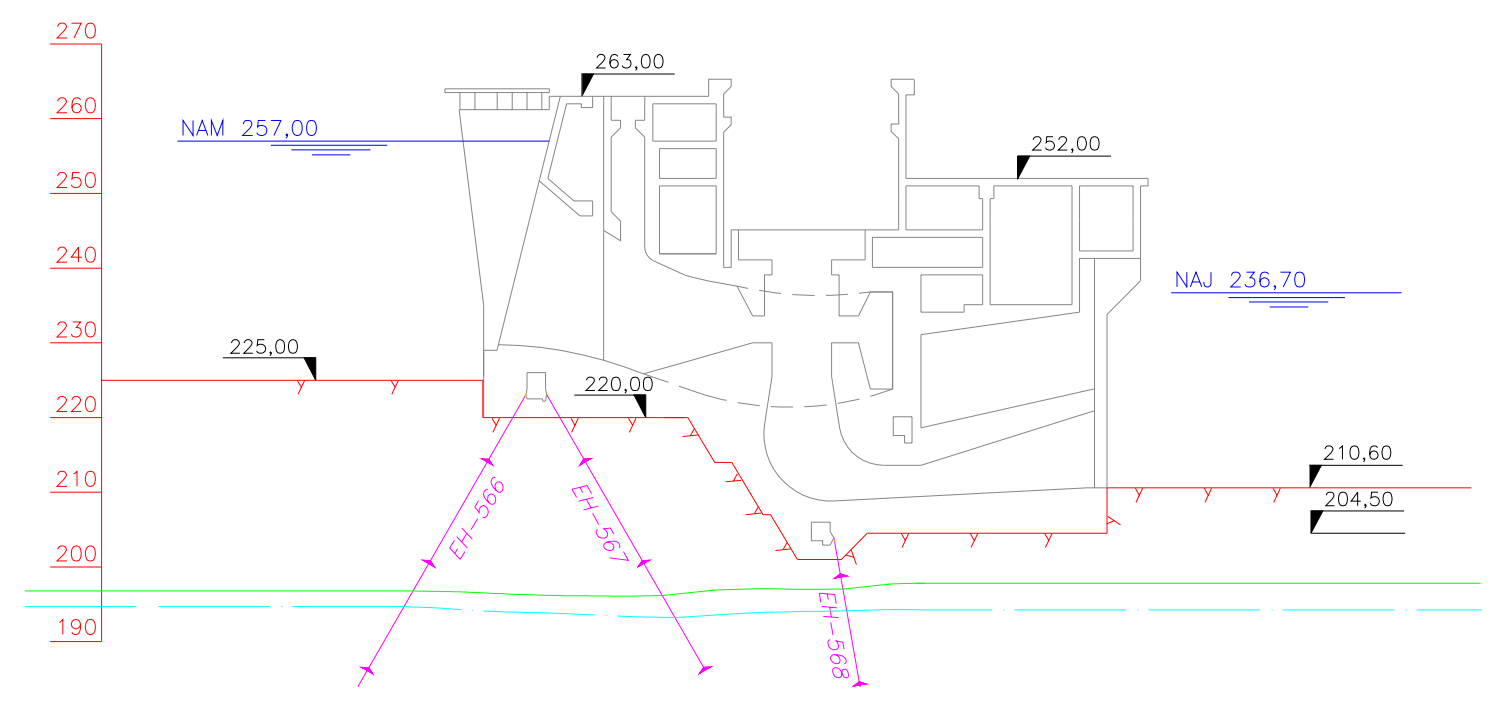

Figura 3.2 Seção de análise da casa de força sob a carga máxima de água.

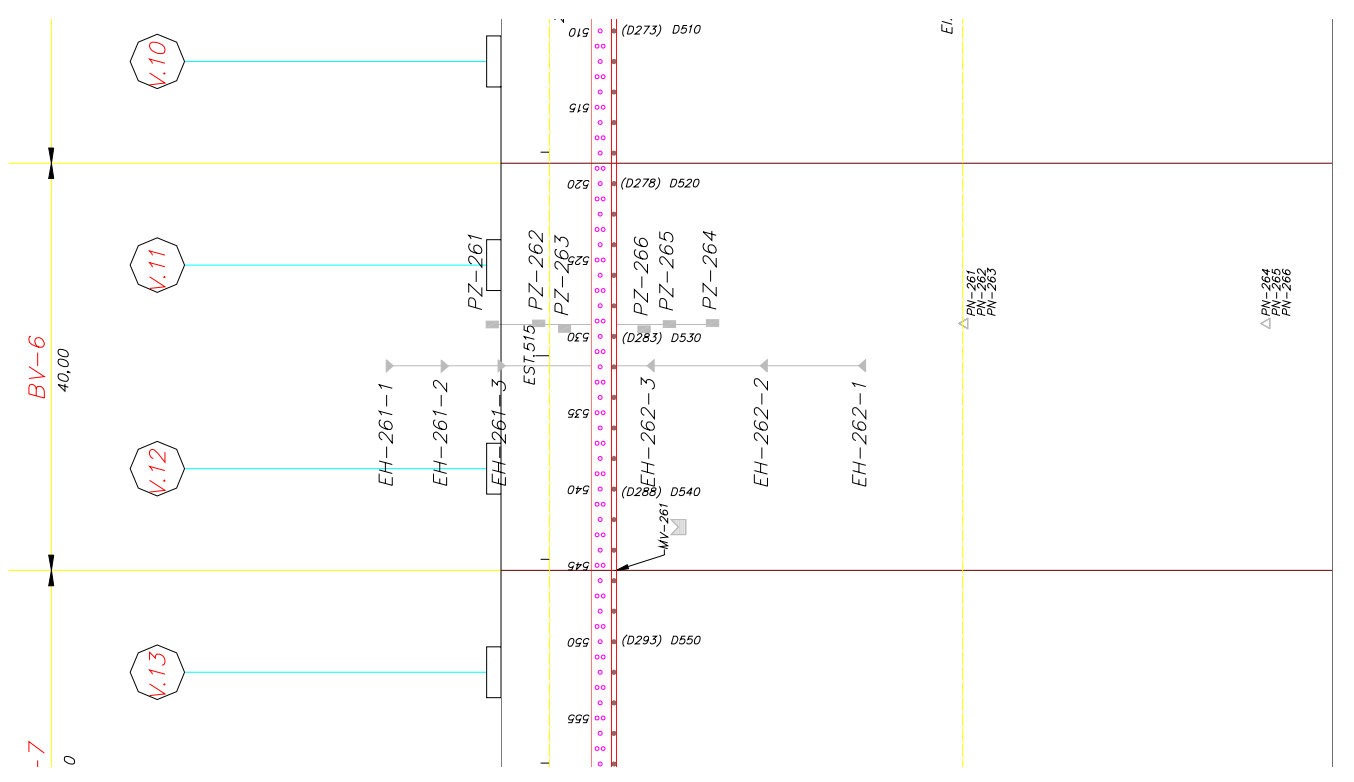

Figura 3.3 Localização em planta do vertedouro BV-6.

Os parâmetros geomecânicos adotados para a análise foram tomados do projeto original, os quais foram:

1. Peso específico do concreto, $\gamma_{\mathrm{c}}=24 \mathrm{kN} / \mathrm{m}^{3}$; 
2. Peso específico do maciço (saturado), $\gamma_{\mathrm{m}}=21 \mathrm{kN} / \mathrm{m}^{3}$;

3. Peso específico do maciço em sua condição natural, $\gamma_{\mathrm{n}}=20 \mathrm{kN} / \mathrm{m}^{3}$;

4. Peso específico da água, $\gamma_{\mathrm{w}}=9,8 \mathrm{kN} / \mathrm{m}^{3}$;

5. Módulo de elasticidade do concreto, E=21 GPa;

6. Módulo de deformabilidade em $x$ (horizontal) do maciço na fundação do vertedouro, $\mathrm{Ex}=25 \mathrm{GPa}$;

7. Módulo de deformabilidade em y (vertical) do maciço na fundação do vertedouro, Ey=10 GPa;

8. Módulo de deformabilidade em $x$ (horizontal) do maciço na fundação da casa de força, $\mathrm{Ex}=25 \mathrm{GPa}$;

9. Módulo de deformabilidade em y (vertical) do maciço na fundação da casa de força, Ey=15 GPa;

10. Coeficiente de Poisson para o concreto de 0,18 , sendo que para o maciço foi de 0,25 .

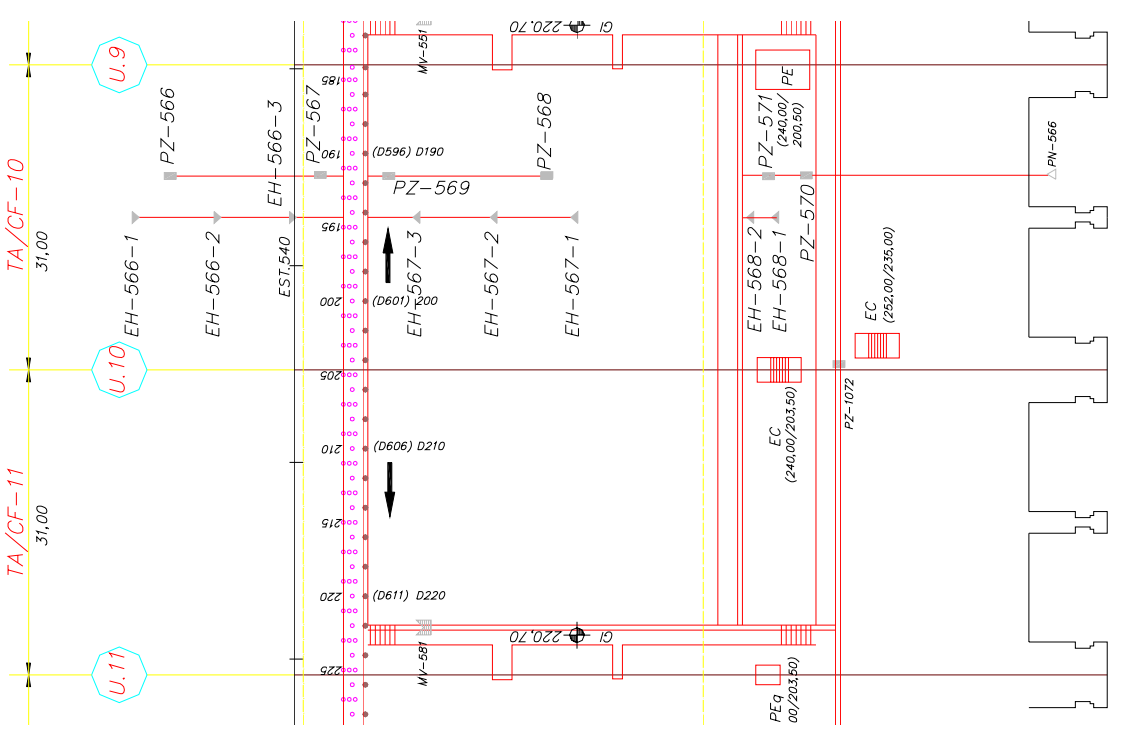

Figura 3.4 Localização em planta da zona da tomada de água e da casa de força U-10.

O módulo de elasticidade para a estrutura, tanto para o vertedouro como para a casa de força, foi adotado do projeto; já o módulo de deformabilidade do maciço foi calculado a partir dos valores nas direções $x$ e $y$, adotando-se a média geométrica dos valores apresentados, que foi de 15,8 GPa para o vertedouro. Todos os parâmetros para 
o concreto foram ponderados em relação às seções adotadas para o vertedouro. Os valores utilizados na análise para o vertedouro apresentam-se na tabela 1.

Tabela 1. Parâmetros característicos dos materiais para a simulação do vertedouro.

\begin{tabular}{|ccccccc|}
\hline Estrutura & Material & $\begin{array}{c}\text { Largura } \\
\mathrm{m}\end{array}$ & $\begin{array}{c}\text { Módulo } \\
\text { Deformabilidade } \\
\mathrm{GPa}\end{array}$ & $\begin{array}{c}\text { Peso } \\
\text { Específico } \\
\mathrm{kN} / \mathrm{m}^{3}\end{array}$ & $\begin{array}{c}\text { Coeficente } \\
\text { Poisson }\end{array}$ & $\begin{array}{c}\mathrm{F}_{\mathrm{t}} \\
\mathrm{MPa}\end{array}$ \\
\hline Pilar & Concreto & 5,00 & 5,25 & 6 & 0,18 & \\
Vertedouro & Concreto & 15,00 & 21,00 & 24 & 0,18 & \\
Maciço & Basalto & & 15,80 & 21 & 0,25 & 0,12 \\
Contato & Basalto & & 10,00 & 7 & 0,30 & 0,06 \\
\hline
\end{tabular}

Na análise da casa de força foi utilizado o módulo de deformabilidade do maciço calculado como a média geométrica dos valores acima citados obtendo-se 19,4 GPa. Os valores adotados da densidade e o módulo de elasticidade do concreto foram os mesmos acima mencionados e ponderados em relação às seções adotadas.

Tabela 2. Parâmetros característicos dos materiais para a simulação da casa de força.

\begin{tabular}{|ccccccc|}
\hline Estrutura & Material & $\begin{array}{c}\text { Largura } \\
\mathrm{m}\end{array}$ & $\begin{array}{c}\text { Módulo de } \\
\text { deformabilidade } \\
\mathrm{GPa}\end{array}$ & $\begin{array}{c}\text { Peso } \\
\text { Específico } \\
\mathrm{kN} / \mathrm{m}^{3}\end{array}$ & $\begin{array}{c}\text { Coeficiente } \\
\text { de Poisson }\end{array}$ & $\begin{array}{c}\mathrm{F}_{\mathrm{t}} \\
\mathrm{MPa}\end{array}$ \\
\hline Pilar & Concreto & 4,50 & 3,05 & 3,48 & 0,18 & \\
Bloco & Concreto & 31,00 & 12,30 & 14,10 & 0,18 & \\
Maciço & Basalto & & 19,40 & 21,00 & 0,25 & 0,12 \\
Contato & Basalto & & 10,00 & 19,00 & 0,30 & 0,06 \\
\hline
\end{tabular}

Outras características consideradas são:

1. As tensões horizontais iniciais existentes no maciço, e que no caso estão na relação $\sigma_{\mathrm{h}}=0,7 \sigma_{\mathrm{v}}$,

2. A energia de fratura $(G)$ em função da tenacidade de fratura $\left(K_{c}\right)$ do material que foi tomado dos resultados de ensaios realizados em basaltos por Pehovaz (2004) na Escola de Engenharia de São Carlos, e

3. A resistência à tração $\left(\mathrm{F}_{\mathrm{t}}\right)$ do maciço, adotada como $0,12 \mathrm{MPa}$, entanto que para o contato 0,06 MPa.

Os valores da energia de fratura com base na tenacidade do material foram calculados com ajuda da eq.(33) para o caso de uma análise plana de deformações. Os valores apresentam-se na tabela 3 :

$$
G_{F}=\frac{K_{c}^{2}\left(1-v^{2}\right)}{E}
$$


Tabela 3 Valores calculados da Energia de fratura para o basalto.

\begin{tabular}{|ccccc|}
\hline \multirow{2}{*}{ Estrutura } & $\begin{array}{c}\text { Tenacidade } \\
\text { de fratura }\end{array}$ & $\begin{array}{c}\text { Coeficiente } \\
\text { de Poisson }\end{array}$ & $\begin{array}{c}\text { Módulo de } \\
\text { Deformabilidade }\end{array}$ & $\begin{array}{c}\text { Energia de } \\
\text { fratura }\end{array}$ \\
\cline { 2 - 5 } & $\mathrm{K}_{\mathrm{c}}$ & $v$ & $\mathrm{E}$ & $\mathrm{G}_{\mathrm{F}}$ \\
\cline { 2 - 5 } & $\mathrm{MPa} \cdot \mathrm{m}^{1 / 2}$ & & $\mathrm{MPa}$ & $\mathrm{N} / \mathrm{m}$ \\
\hline \multirow{2}{*}{ Vertedouro } & 2,31 & 0,25 & 15800 & $\begin{array}{c}316,62 \\
\end{array}$ \\
\cline { 2 - 5 } Casa de & 2,40 & & & 416,77 \\
força & 2,65 & 0,25 & 19365 & 258,33 \\
\hline
\end{tabular}

A condutividade hidráulica do maciço foi determinada com base nos valores de condutividade, achados por Tressoldi et al. (1990), que realizaram ensaios de intercomunicação tridimensionais na fundação da barragem de Porto Primavera. Esses ensaios permitiram a caracterização hidrogeológica e hidrogeotécnica completa do maciço. Para a zona de contato, o valor da condutividade foi tomado do estudo de Tressoldi (1987). Já a condutividade da cortina de injeção foi tomada do projeto original, entanto que para o dreno a condutividade foi calculada. Os valores utilizados são apresentados na tabela 4:

Tabela 4. Valores da condutividade hidráulica.

\begin{tabular}{|ccc|}
\hline Zona & $\mathbf{k}_{\mathbf{x}}, \mathbf{m} / \mathbf{s}$ & $\mathbf{k}_{\mathbf{y}}, \mathbf{m} / \mathbf{s}$ \\
\hline Maciço & $1 \mathrm{e}-05$ & $1 \mathrm{e}-07$ \\
\hline Contato & $3 \mathrm{e}-02$ & $3 \mathrm{e}-03$ \\
\hline Injeção & $2 \mathrm{e}-07$ & $1 \mathrm{e}-07$ \\
\hline Drenagem & $1 \mathrm{e}-04$ & $1 \mathrm{e}-04$ \\
\hline
\end{tabular}

\subsubsection{Cálculo das forças atuantes}

O cálculo das forças atuantes, resultado do carregamento hidráulico nas estruturas do vertedouro e da casa de força, baseia-se nos esquemas de carregamento mostrados nas figuras 3.5 e 3.6 . 


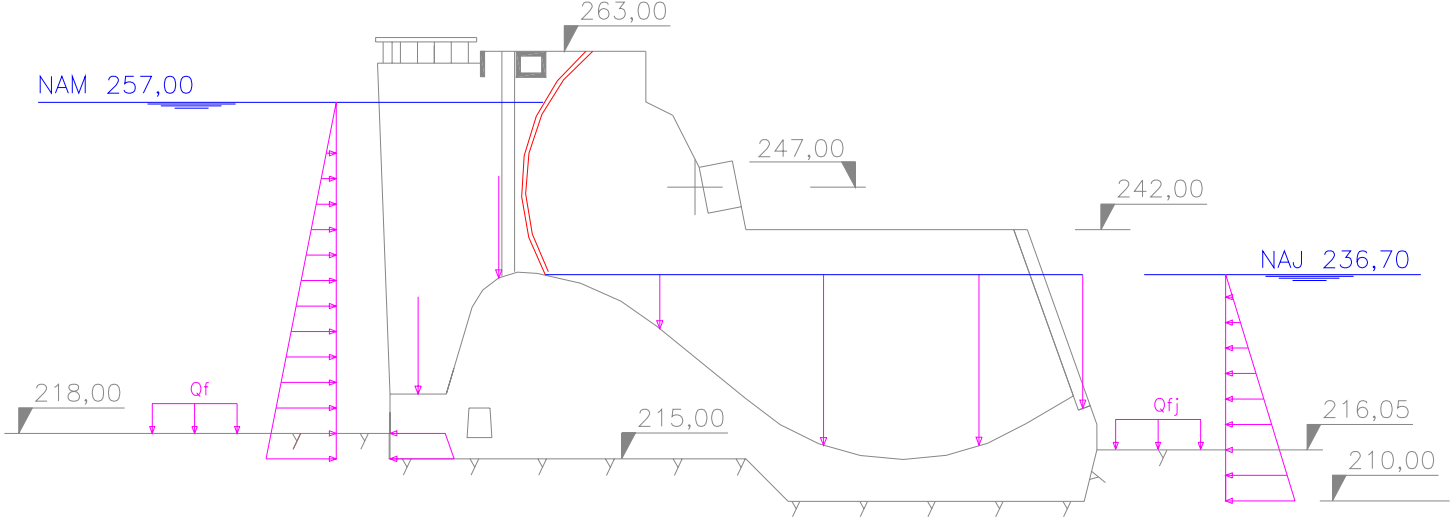

Figura 3.5 Esquema de carregamento hidráulico do vertedouro.

As tensões horizontais iniciais, no maciço, foram calculadas em dependência da relação $\sigma_{\mathrm{h}}=0,7 \sigma_{\mathrm{v}}$. Essas tensões foram consideradas na análise da fundação do vertedouro e da estrutura tomada de água-casa de força.

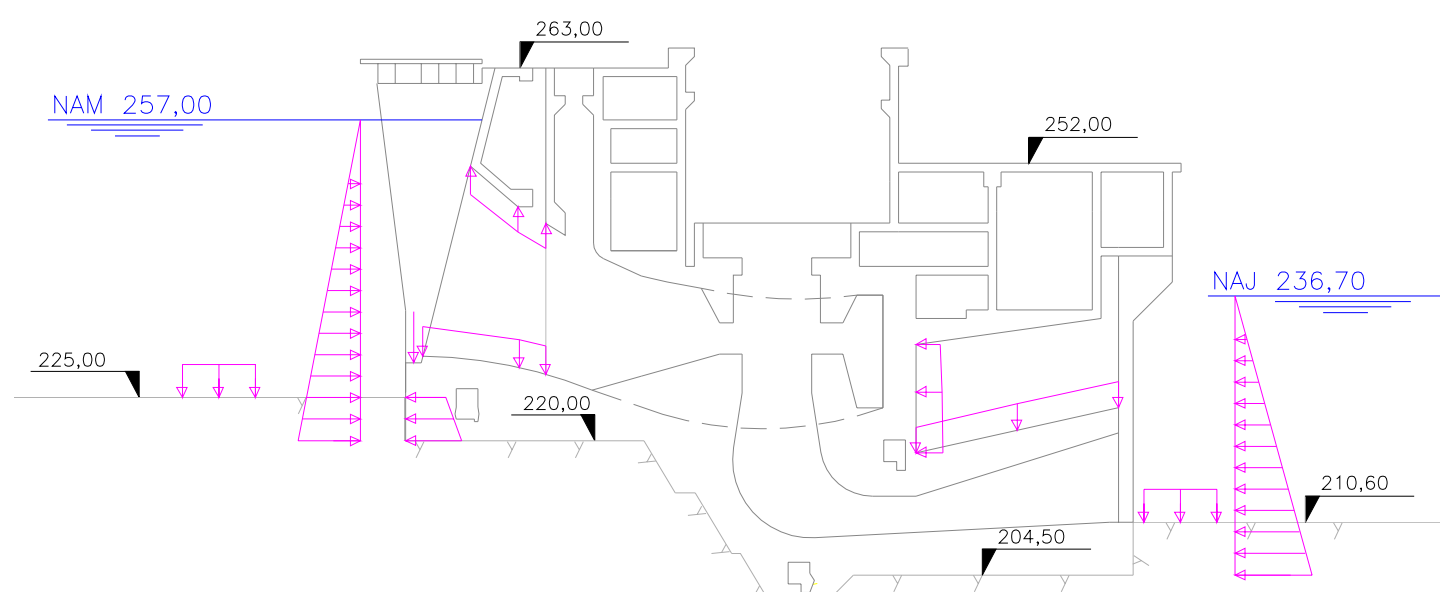

Figura 3.6 Esquema do carregamento hidráulico na tomada e casa de força.

A carga de água na face de montante, tanto para o vertedouro como para a casa de força, foi calculada usando o esquema como se mostra na figura 3.7, sendo que, para efeito de cálculo do vertedouro, considerou-se o nível de superfície da fundação $218 \mathrm{~m}$ e para a casa de força o nível 225m.

Considerando o nível máximo de água na barragem, tomaram-se seis níveis de água que foram representados por cargas nodais equivalentes, calculadas com as eq.(34) 
a eq.(36). As eq.(37) a eq.(40) foram utilizadas para obter a posição das forças nodais equivalentes.

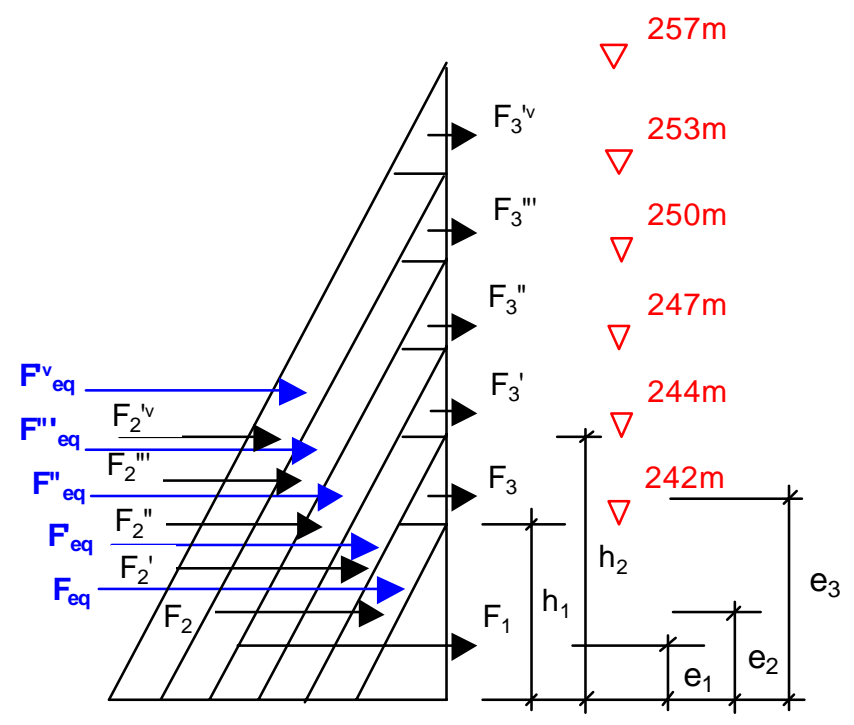

Figura 3.7 Esquema de cálculo das forças nodais equivalentes.

$$
\begin{gathered}
F_{1}=\frac{h_{1}^{2}}{2} \gamma_{w} \\
F_{2}=\left(h_{2}-h_{1}\right) h_{1} \gamma_{w} \\
F_{3}=\frac{\left(h_{2}-h_{1}\right)^{2}}{2} \gamma_{w} \\
e_{1}=\frac{h_{1}}{3} \\
e_{2}=\frac{h_{1}}{2} \\
e_{3}=h_{1}+\frac{\left(h_{2}-h_{1}\right)}{3} \\
e_{e q}=\frac{F_{3} e_{3}+F_{2} e_{2}}{F_{e q}}
\end{gathered}
$$

onde:

$h_{1}$, altura do primeiro nível até a superfície da fundação, ou seja, $h_{1}=(242-218) \mathrm{m}=24 \mathrm{~m}$. 
$h_{2}$, altura do segundo nível até a superfície da fundação, ou seja,

$h_{2}=(244-218) \mathrm{m}=26 \mathrm{~m}$. Estes valores são definidos para o primeiro e segundo nível de carregamento; em seguida, para o terceiro nível de carregamento, $h_{1}=(244-$ 218) $\mathrm{m}=26 \mathrm{~m}$ e $h_{2}=(247-218) \mathrm{m}=29 \mathrm{~m}$; para o quarto nível, $h_{1}=(247-218) \mathrm{m}=29 \mathrm{~m}$ e $h_{2}=(250-218) \mathrm{m}=32 \mathrm{~m}$; para o quinto nível, $h_{1}=(250-218) \mathrm{m}=32 \mathrm{~m}$ e $h_{2}=(253-218) \mathrm{m}=35 \mathrm{~m}$; por fim, para o sexto nível de carregamento, $h_{1}=(253-218) \mathrm{m}=35 \mathrm{~m}$ e $h_{2}=(257$ 218) $\mathrm{m}=39 \mathrm{~m}$.

De igual forma, foram calculadas as forças equivalentes para a casa de força, onde, para o primeiro nível de carregamento, $h_{1}=(242-225) \mathrm{m}=17 \mathrm{~m}$, e para o segundo nível, $h_{2}=(244-225) \mathrm{m}=19 \mathrm{~m}$. Para o terceiro nível, $h_{1}=(244-225) \mathrm{m}=19 \mathrm{~m}$ e $h_{2}=(247$ 225)m=22m. Para o quarto nível, $h_{1}=(247-225) \mathrm{m}=22 \mathrm{~m}$ e $h_{2}=(250-225) \mathrm{m}=25 \mathrm{~m}$. Para o quinto nível, $h_{1}=(250-225) \mathrm{m}=25 \mathrm{~m}$ e $h_{2}=(253-225) \mathrm{m}=28 \mathrm{~m}$. E finalmente, para o sexto nível, $h_{1}=(253-225) \mathrm{m}=28 \mathrm{~m}$ e $h_{2}=(257-225) \mathrm{m}=32 \mathrm{~m}$.

O nível de água a jusante foi fixado devido a sua permanência constante, daí que as forças no vertedouro foram calculadas segundo o esquema da figura 3.8.

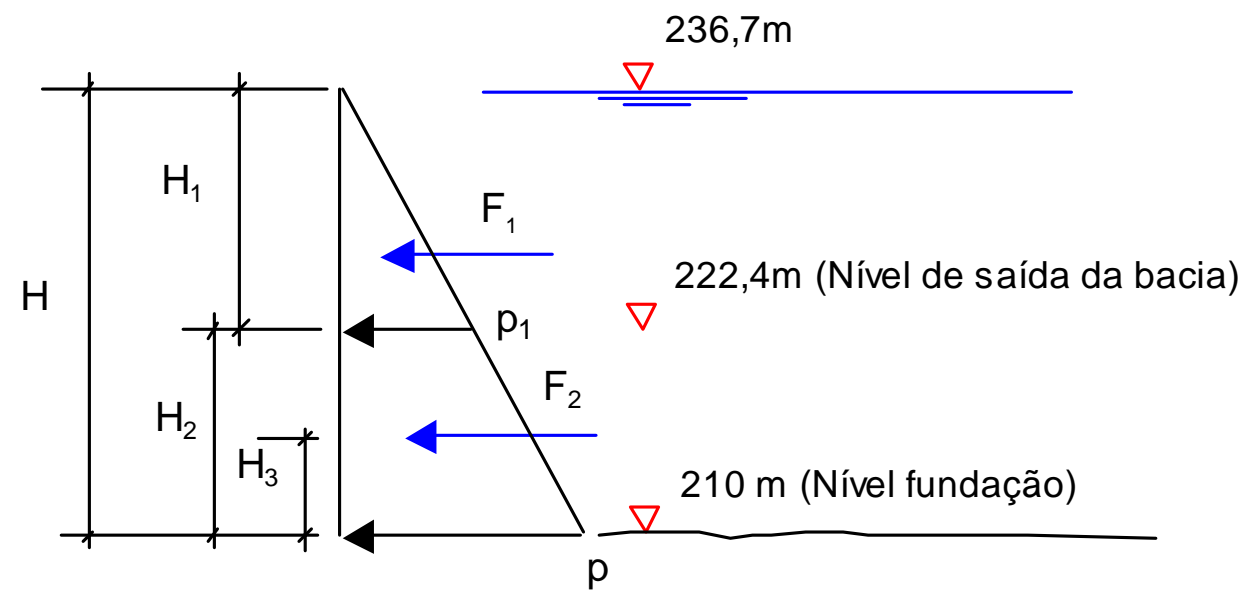

Figura 3.8 Esquema de cálculo da carga de água a jusante do vertedouro.

Consideraram-se dois níveis de aplicação das forças equivalentes, uma primeira $F_{1}$ aplicada nos muros e uma segunda no nível da estrutura de saída de água, $F_{2}$. O procedimento de cálculo foi o seguinte:

Determinação de $\mathrm{H}_{1}, \mathrm{H}_{2}$ e $\mathrm{H}$, assim como das pressões $p_{1}$, para o pilar e, $p$ para o nível de saída do vertedouro.

$\mathrm{H}=(236,7-210,0) \mathrm{m}=26,7 \mathrm{~m}, \mathrm{H}_{1}=(236,7-222,4) \mathrm{m}=14,3 \mathrm{~m}$ e $\mathrm{H}_{2}=\mathrm{H}-\mathrm{H}_{1}=12,4 \mathrm{~m}$. 


$$
\begin{aligned}
& p_{1}=\mathrm{H}_{1} * \gamma_{\mathrm{w}}=140,24 \mathrm{\kappa N} / \mathrm{cm}^{2}, \\
& p=\mathrm{H} * \gamma_{\mathrm{w}}=261,85 \mathrm{\kappa N} / \mathrm{cm}^{2}
\end{aligned}
$$

de onde, $F_{1}=\mathrm{H}_{1}^{2} * 0,5 * \gamma_{\mathrm{w}}=1002,72 \mathrm{KN} / \mathrm{m} *(5 / 20)=250,68 \mathrm{KN} / \mathrm{m}$ ou $F_{1}=25068 \mathrm{kgf} / \mathrm{m}$, $F_{2}=\left(p_{1}+p\right) * 0,5 * \mathrm{H}_{2}=2492,94 \mathrm{KN} / \mathrm{m}$ ou $F_{2}=249294 \mathrm{kgf} / \mathrm{m}$.

Os níveis de aplicação foram: para $F_{1}, 227,2 \mathrm{~m}$ e para $F_{2,} 215,6 \mathrm{~m}$.

De forma similar ao calculo para o vertedouro, as forças a jusante da casa de força foram calculadas segundo o esquema da figura 3.9.

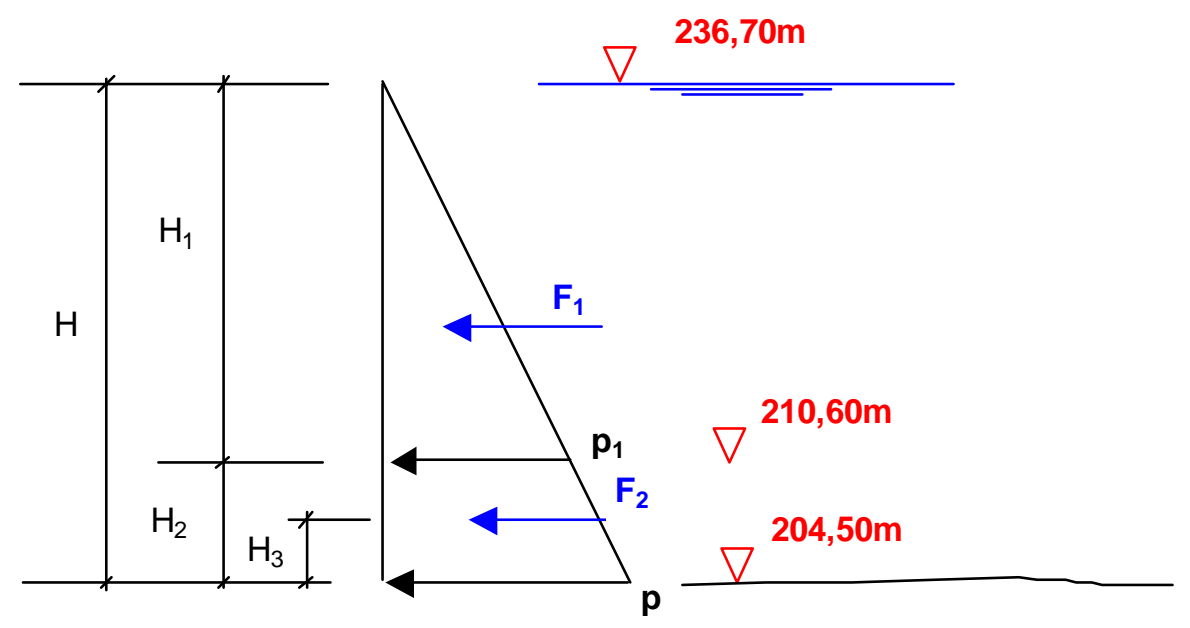

Figura 3.9 Esquema de cálculo das forças a jusante da casa de força.

As forças equivalentes a considerar a jusante, $F_{1}$ para os muros laterais e $F_{2}$ para a saída das turbinas, foram determinadas da mesma forma que para o vertedouro, obtendo-se os seguintes valores:

$F_{1}=75426 \mathrm{kgf} / \mathrm{m}$,

$F_{2}=174383 \mathrm{kgf} / \mathrm{m} \mathrm{e}$,

Nível de aplicação de $F_{1}, 219,3 \mathrm{~m}$,

Nível de aplicação de $F_{2}$, 207,4m.

Foram calculadas, também, as forças pontuais e as pressões de água na superfície da fundação a montante para o vertedouro e para a casa de força. Os valores são apresentados na tabela 5 e 6 respectivamente.

Na casa de força também foram calculadas as forças pontuais em função da pressão de água no conduto, na zona de entrada da tomada e na zona de saída do 
conduto. A figura 3.10 apresenta o esquema de aplicação das forças consideradas para a análise.

Tabela 5. Pressões a montante e a jusante, e cargas pontuais no vertedouro.

\begin{tabular}{|c|c|c|c|c|c|c|}
\hline \multirow{2}{*}{ Carga } & \multicolumn{6}{|c|}{ Níveis de carga } \\
\hline & Nível 1 & Nível 2 & Nível 3 & Nível 4 & Nível 5 & Nível 6 \\
\hline \multicolumn{7}{|l|}{ Pressão, kgf/cm ${ }^{2}$} \\
\hline Na fundação a montante & 2,35 & 2,55 & 2,84 & 3,14 & 3,43 & 3,82 \\
\hline Na fundação a jusante & 2,03 & 2,03 & 2,03 & 2,03 & 2,03 & 2,03 \\
\hline \multicolumn{7}{|l|}{ Força Pontual, kgf } \\
\hline Na crista do vertedouro & 31753 & 40947 & 54032 & 66859 & 79701 & 96810 \\
\hline No pê do vertedouro & 94080 & 103788 & 118352 & 132915 & 147479 & 166897 \\
\hline & \multicolumn{6}{|c|}{114735} \\
\hline Agua no vertedouro & \multicolumn{6}{|c|}{287024} \\
\hline (nivel constante. & \multicolumn{6}{|c|}{282280} \\
\hline & \multicolumn{6}{|c|}{39299} \\
\hline
\end{tabular}

Tabela 6. Pressões de água a montante e a jusante da casa de força.

\begin{tabular}{|c|c|c|c|c|c|c|}
\hline \multirow{2}{*}{ Carga } & \multicolumn{6}{|c|}{ Níveis de carga } \\
\hline & Nível 1 & Nível 2 & Nível 3 & Nível 4 & Nível 5 & Nível 6 \\
\hline \multicolumn{7}{|c|}{ Pressão, kgf/cm ${ }^{2}$} \\
\hline A montante & 1,67 & 1,86 & 2,16 & 2,45 & 2,75 & 3,14 \\
\hline A jusante & \multicolumn{6}{|c|}{2,56} \\
\hline
\end{tabular}

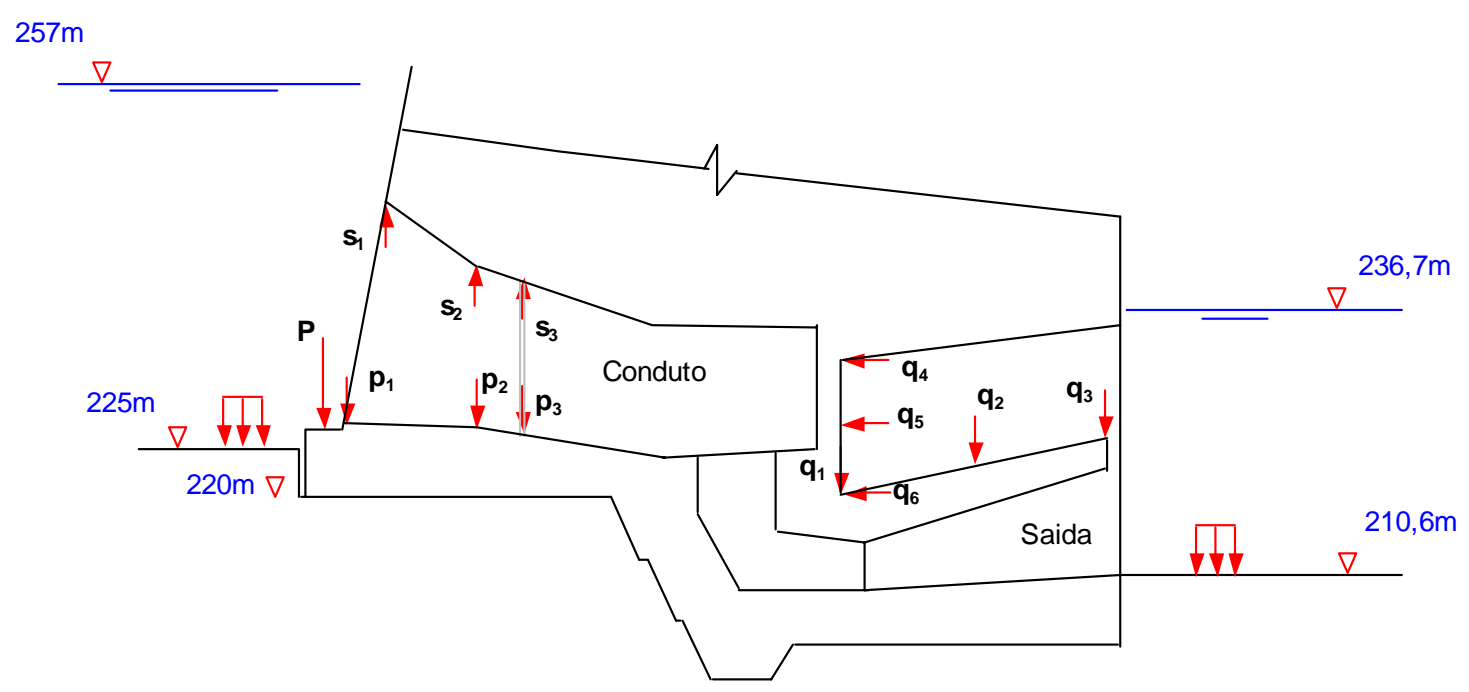

Figura 3.10 Esquema de aplicação da carga na entrada do conduto e na zona de saída.

Ao ter sido considerada uma fenda na zona de contato concreto-rocha a montante, calcularam-se as forças equivalentes à pressão que exerceria a carga hidráulica na zona para simplificar o ingresso de dados. Para o vertedouro, escolheram-se três níveis de aplicação das forças, as quais se apresentam na figura 3.11. 


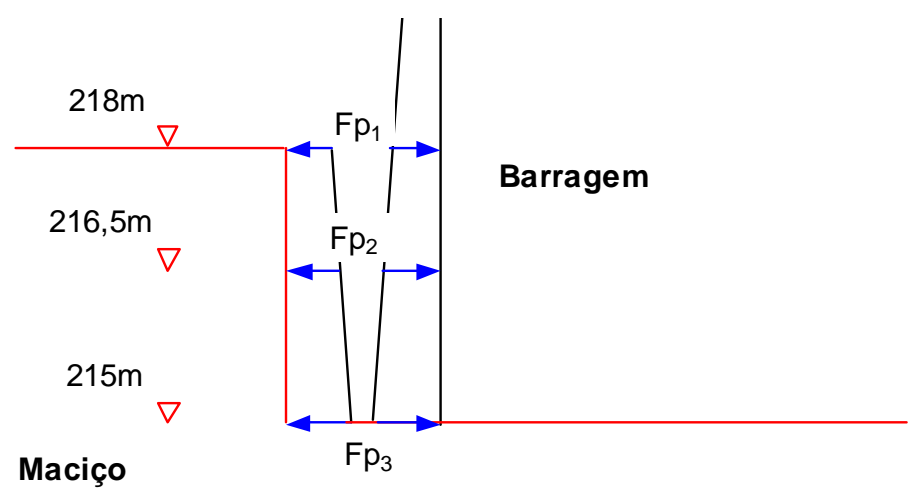

Figura 3.11 Esquema para o cálculo das forças equivalentes na fenda do vertedouro.

Para o caso da casa de força, foram considerados vários pontos de aplicação das forças na fenda do contato entre o maciço de fundação e o pé de montante da estrutura. A figura 3.12 mostra o esquema da aplicação das forças.

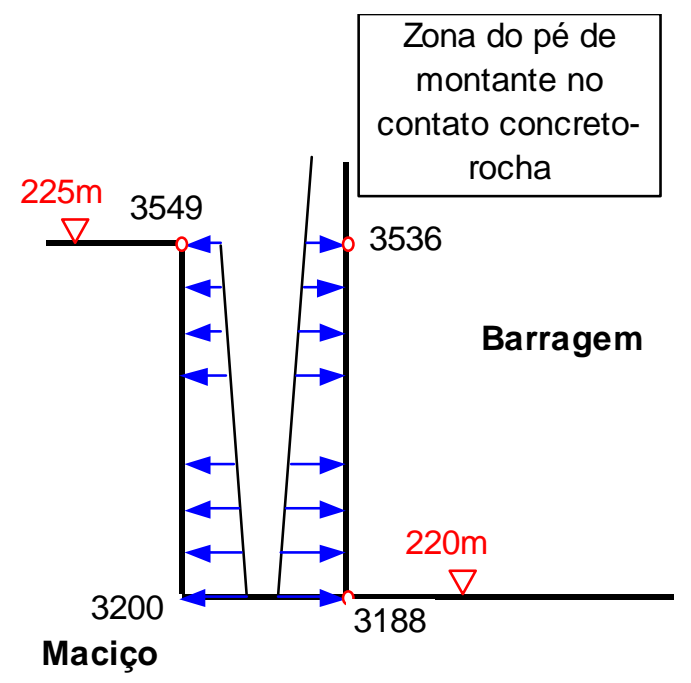

Figura 3.12 Esquema para o cálculo das forças nodais na fenda.

\subsubsection{Subpressão e Pressão Média}

Ao definir a subpressão na base da estrutura, considerou-se o critério de Andrade (1988) assumindo-se a pressão a montante igual à carga hidráulica atuante a montante, enquanto que a pressão a jusante foi considerada igual à carga hidráulica atuante a jusante. Já na zona da boca do dreno, chamada de pressão média, $S_{\mathrm{d}}$ foi determinada a partir do critério proposto por Andrade (1980), onde se considera uma pressão média na linha dos drenos, como descrito na referência bibliográfica exposta anteriormente. Essa pressão média foi calculada tanto para o vertedouro como para a casa de força, tomando-se os seguintes dados:

Carga hidráulica a montante, $H_{\mathrm{m}}=27 \mathrm{~m}$, 
Carga hidráulica a jusante, $H_{\mathrm{j}}=26,7 \mathrm{~m}$,

Comprimento da base da estrutura, $B=81,94 \mathrm{~m}$

Comprimento da base a montante do dreno, $s=12,5 \mathrm{~m}$

Comprimento da base depois do dreno, $b=B$-s=69,44m

Distância entre drenos, $a_{d}=3 \mathrm{~m}$

Raio do dreno, $r_{d}=0,038 \mathrm{~m}$

Nível da boca do dreno, $H_{d}=7,5 \mathrm{~m}$.

Segundo Andrade (1980), para o caso da posição da boca do dreno abaixo do nível de água de jusante, consideram-se as seguintes equações:

$$
\overline{C D}=\Delta H_{w}=-\left(H_{j}-H_{d}\right)
$$

e consideraram-se, também, as eq. (18) e eq. (19). No caso correspondente ao primeiro nível de carga hidráulica, obteve-se:

$$
\Delta H_{\mathrm{w}}=-(26,7-7,5)=-19,2 \mathrm{~m} .
$$

Usando as eq. (27) e eq. (26):

$$
\begin{aligned}
& \lambda=\frac{2 * \pi}{3 * \ln \left(\frac{3}{2 * \pi * 0,038}\right)}=0,828 m^{-1} \\
& S_{\mathrm{d}}=\frac{69,44 * 12,5 * 0,828 *(-19,2)+69,44 * 27+12,5 * 26,7}{12,5 * 69,44 * 0,828+69,44+12,5}=-14,474 \mathrm{~m}
\end{aligned}
$$

O resultado de $S_{\mathrm{d}}$ mostra o sentido do fluxo de jusante a montante. Do mesmo modo, foram calculados todos os valores da pressão média para cada um dos níveis de carregamento hidráulico.

No caso da casa de força, os dados considerados no cálculo foram os seguintes:

Carga hidráulica a montante, $H_{\mathrm{m}}=22,0 \mathrm{~m}$,

Carga hidráulica a jusante, $H_{\mathrm{j}}=32,2 \mathrm{~m}$,

Comprimento da base da estrutura, $B=83,73 \mathrm{~m}$

Comprimento da base a montante do dreno, $s=9,04 \mathrm{~m}$

Comprimento da base a jusante do dreno, $b=B-s=74,69 \mathrm{~m}$ 
Distância entre drenos, $a_{d}=3 \mathrm{~m}$

Raio do dreno, $r_{d}=0,038 \mathrm{~m}$

Nível da boca do dreno, $H_{d}=18 \mathrm{~m}$

Calculando-se, $\Delta H_{\mathrm{w}}=-(32,2-18)=-14,2 \mathrm{~m}$, e logo por meio da eq. (27), calculou-se $\lambda$,

$$
\lambda=\frac{2 * \pi}{3 * \ln \left(\frac{3}{2 * \pi * 0,038}\right)}=0,828 m^{-1},
$$

e seguidamente $S_{\mathrm{d}}$ pela eq. (26),

$$
S_{\mathrm{d}}=\frac{74,69 * 9,04 * 0,828 *(-14,2)+74,69 * 22+9,04 * 32,2}{9,04 * 74,69 * 0,828+74,69+9,04}=-9,339 \mathrm{~m}
$$

\subsubsection{Condutividade hidráulica do dreno}

Para efeito da análise de fluxo, calculou-se a condutividade hidráulica a adotar-se no dreno da fundação tanto do vertedouro como da casa de força. Os dados considerados foram: a condutividade hidráulica do maciço na direção $x, k_{\mathrm{x}}$, a carga hidráulica a montante $H_{\mathrm{m}}$, a jusante $H_{\mathrm{j}}$ e a carga média $\left(S_{\mathrm{d}}\right)$ na boca do dreno. Também fizeram parte dos dados: a profundidade do dreno, $H_{\mathrm{dr}}=20 \mathrm{~m}$ (dado do projeto), a distância entre drenos, $a_{d}=3 \mathrm{~m}$ (dado do projeto), o comprimento desde a face de montante ao dreno $s$ (dado do projeto), e o comprimento do dreno a jusante $b$ (também dado do projeto).

Para o vertedouro, tomaram-se os dados de $H_{\mathrm{m}}, H_{\mathrm{j}}$ e $S_{\mathrm{d}}$. O valor de $k_{\mathrm{x}}=1 \mathrm{e}-05 \mathrm{~m} / \mathrm{s}$ para o maciço foi tomado da tabela 4 e os valores de $s$ e $b$ como antes apresentados. A partir dessa informação, calculou-se o gradiente para o primeiro nível de carregamento com a eq.(42).

$$
i=\left(\frac{H_{m}-S_{d}}{\mathrm{~s}}-\frac{S_{d}-H_{j}}{b}\right)
$$

$i=\left(\frac{242-222,23}{12,5}-\frac{222,23-236,7}{69,44}\right)=1,79$

Assumiu-se que a quantidade de vazão que passa pela área de influência do dreno seja aquele que saia pelo dreno para o qual calculou-se a vazão da área de influência, ou seja, na área de $3 \mathrm{~m}$, que é a distância entre drenos e a profundidade do dreno, $H_{\mathrm{dr}}=20 \mathrm{~m}$. 


$$
A=H_{\mathrm{dr}} * a_{d}=20 * 3=60 \mathrm{~m}^{2}
$$

Pela equação de Darcy, eq. (43):

$$
Q=k_{x} \cdot i \cdot A
$$

$$
Q=1,074 e-03 m^{3} / \mathrm{seg}
$$

Seguidamente, assumiu-se um comprimento da circunferência do dreno na análise de $L=0,3 \mathrm{~m}$, e calculou-se a superfície da circunferência do dreno:

$$
A_{\mathrm{d}}=L * H_{\mathrm{dr}}=0,3 * 20=6 \mathrm{~m}^{2} \text {, que vazará } Q_{\mathrm{d}} \text {. }
$$

Para que o dreno consiga conduzir a água que passaria na área de influência do dreno, precisa-se que $Q=Q_{\mathrm{d}}$; em razão desta igualdade, calculou-se a condutividade hidráulica do dreno, $k_{\mathrm{d}}$, a qual foi realizada da seguinte forma:

$$
Q_{d}=k_{d} \cdot i \cdot A_{d}
$$

$$
\text { e, } \quad k_{d}=\frac{Q_{d}}{i \cdot A_{d}}
$$

Considerando-se a igualdade de $Q=Q_{\mathrm{d}}$, determinou-se $k_{\mathrm{d}}$ :

$$
k_{d}=\frac{1,074 e-03}{1,79 * 6}=1 e-04 \mathrm{~m} / \mathrm{seg}
$$

Assim foi calculado o valor $k_{\mathrm{d}}$ para todos os níveis de carga, dando como resultado valores muito próximos de $1 \mathrm{e}-04 \mathrm{~m} / \mathrm{seg}$, tomando-se esse valor constante.

De igual modo, foi calculado para o dreno da casa de força. Mas, embora esta seja outra estrutura, os valores de $k_{\mathrm{d}}$ foram similares. Na continuação, apresenta-se o cálculo realizado de $k_{\mathrm{d}}$ para o nível máximo $257 \mathrm{~m}$.

$$
\begin{aligned}
& i=\left(\frac{257-229,11}{9,04}-\frac{229,11-236,7}{74,69}\right)=3,187 \\
& Q=1,9122 e-03 m^{3} / \mathrm{seg} \\
& k_{d}=\frac{1,9122 e-03}{3,187 * 6}=1 e-04 \mathrm{~m} / \mathrm{seg}
\end{aligned}
$$

\subsubsection{Cálculo da condutividade hidráulica na fratura}

Como resultado da abertura da fratura e do avanço da mesma devido à pressão 
hidráulica, considerou-se uma condutividade dependendo da dimensão da abertura. A análise tensão-deformação, que se apresenta mais adiante tem como resultado de saída a abertura dos elementos da malha de análise. Segundo o modelo matemático, o cálculo da abertura dos elementos foi realizado com os deslocamentos dos nós. Assim, no presente trabalho, calcularam-se os valores da condutividade hidráulica para cada elemento danificado na zona de fratura tanto do vertedouro como da casa de força.

Para efeitos de cálculo da condutividade hidráulica da fratura, por ser tão pequena, aplicou-se o critério da lei cúbica. Na continuação, apresentam-se os dados principais de cálculo.

A condutividade do maciço, $k_{\mathrm{x}}=1,0 \mathrm{e}-03 \mathrm{~cm} / \mathrm{s}, k_{\mathrm{y}}=1,0 \mathrm{e}-05 \mathrm{~cm} / \mathrm{s}, k_{\mathrm{xy}}=1,0 \mathrm{e}-03 \mathrm{~cm} / \mathrm{s}$ Gravidade, $g=981 \mathrm{~cm} / \mathrm{s}^{2}$,

Viscosidade cinemática da água $\left(20^{\circ}\right), v=0,01 \mathrm{~cm}^{2} / \mathrm{s}$,

A abertura, e, foi dada pelos dados de saída do modelo analisado.

Como os valores da condutividade da abertura da fratura foram pequenos, considerou-se incluí-los no elemento danificado e calcular a condutividade ponderada para cada um deles, dependendo da largura de cada elemento danificado. Assim, foi assumido que,

$$
Q_{t}=Q_{f}+Q_{m}
$$

Onde, $Q_{t}$, é a vazão do elemento;

$Q_{f}$, a vazão que passa pela abertura;

$Q_{m}$, a vazão que passa pela zona sem abertura.

Em conseqüência, com o uso da eq. (46) e a eq. (32) da lei cúbica, foi deduzida a eq. (47).

$$
k_{t}=\frac{k_{f} e+k_{x y}\left(l_{e}-e\right)}{l_{e}}
$$

onde $k_{t}$ é a condutividade total ou ponderada do elemento danificado no sentido vertical, $l_{e}$ a largura do elemento danificado, $k_{f}$ a condutividade da abertura que foi calculada com a eq. (32) e $k_{x y}$ a condutividade da parte do elemento sem fratura. Salienta-se que, $k_{x y}$,foi calculada como a média geométrica dos valores da condutividade de um 
elemento sem fratura, assumindo-se que esta zona estaria já afetada. No processo de análise de fluxo e subpressão, as condutividades utilizadas para o elemento danificado foram $k_{t}$ no sentido vertical e $k_{x}$ no sentido horizontal, considerando-se, em conseqüência, os elementos danificados anisotrópicos. O mesmo procedimento de cálculo foi seguido tanto para o vertedouro como para a casa de força.

O cálculo das forças equivalentes da pressão hidráulica exercida pela água na fratura foi realizado em função do dano que experimentou cada elemento atravessado pela fratura. No capítulo dos modelos, será relatado o procedimento de cálculo daquelas forças.

\subsection{MODELOS DE ANÁLISE}

Todas as estruturas hidráulicas de barragens estão sujeitas a forças de empuxo de água, as quais exercem pressão no paramento a montante da estrutura, originando esforços de tração tanto na estrutura como na fundação do pé da estrutura. Estes esforços de tração podem ser aumentados pelos acréscimos de água ou pela ação dinâmica da mesma.

Outro aspecto que deve ser levado em consideração quanto à zona de fundação é a ação do peso próprio que produz esforços de cisalhamento na zona de contato rochaparamento de montante, o que levará ao fraturamento devido à ação combinada de esforços que originam a propagação de fraturas dos tipos I e II. Pedroso et al. (1996) realizaram uma análise numérica de uma barragem concluindo na existência desta condição de cisalhamento na zona de fundação.

Em face da variação progressiva da carga hidrostática e do efeito que esta tem nas primeiras fraturas formadas na zona de fundação no pé de montante, propôs-se a análise iterativa tensão-deformação e pressão de água na fratura, juntamente a uma análise de fluxo e subpressão. Para este fim, propôs-se um modelo para tensão-deformação e um segundo para o cálculo do efeito da subpressão na base da estrutura.

\subsubsection{Modelo Tensão-Deformação e Pressão de água}

O modelo de análise proposto baseia-se nos seguintes princípios:

1. Análise bidimensional não linear;

2. Mecânica do Dano;

3. Deformação plana; 
4. Forças de superfície nas paredes da fratura;

5. Meio saturado;

6. Lei constitutiva baseada na degradação do material pela solicitação de esforços de tração.

Na elaboração do modelo, preparou-se uma malha da estrutura e da fundação com a ajuda do programa GID (Interactive Graphical User Interface, 1999) que trabalha com elementos finitos. Este programa permite a definição, preparação e visualização da geometria, dos materiais e das condições de carga e de contorno do modelo, considerando as características dos materiais. Permite também a visualização dos resultados da simulação numérica após o processamento do programa Omega (Organized Module for Engineering General Analysis, 1996).

No modelo, fez-se uso de elementos finitos triangulares com interpolação linear dos deslocamentos. Realizou-se o arranjo da malha considerando uma profundidade de duas vezes a altura da estrutura, o comprimento da lateral a montante de uma vez e meia $(1,5)$ da altura, sendo que a lateral a jusante é igual a uma altura e a base da estrutura corresponde a 1,8 da altura. A figura 3.13 mostra a malha antes da análise. Salienta-se que, a montante, não existe contato (chamada fenda) entre o concreto da estrutura e o maciço até a base da estrutura como se mostra na figura 3.13, no extremo superior direito. Ressalta-se também que na malha foram considerados como nós os pontos de localização das hastes dos extensômetros existentes nos blocos tanto do vertedouro como da casa de força. A figura 3.14 apresenta a malha para a casa de força.

O Modelo Tensão-Deformação é processado com ajuda do programa Omega adaptado por Manzoli (1998) para realizar a análise não linear da fratura sob o Modelo de propagação da Fratura. O processo de cálculo tensão-deformação inicia-se com o ingresso de todas as características geomecânicas da fundação, as características elásticas do material da estrutura, a densidade da estrutura e do maciço, a carga hidráulica a montante e a jusante, assim como também a subpressão no estado sem fratura. A primeira carga hidráulica a ser aplicada corresponde ao nível 242m, a qual origina esforços de tração na rocha, no pé de montante, produzindo uma fenda a qual por sua vez suportará esforços de tração até que tais esforços atinjam a resistência a tração da rocha, produzindo-se o dano no material e, conseqüentemente, a propagação da fratura. A figura 3.15 mostra o processo de fraturamento sob pressão hidráulica. 


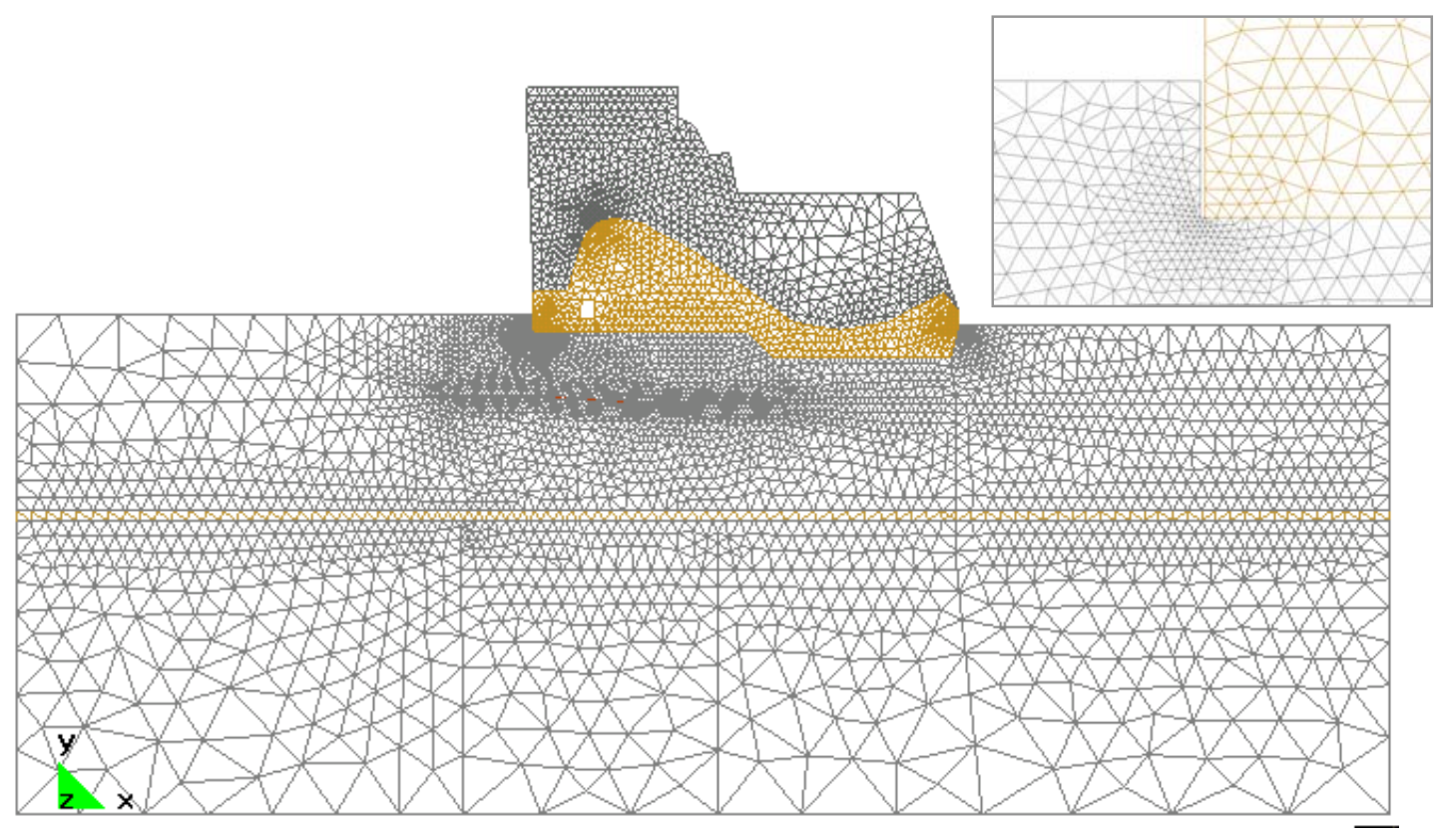

Figura 3.13 Malha de análise do vertedouro (Programa GID).

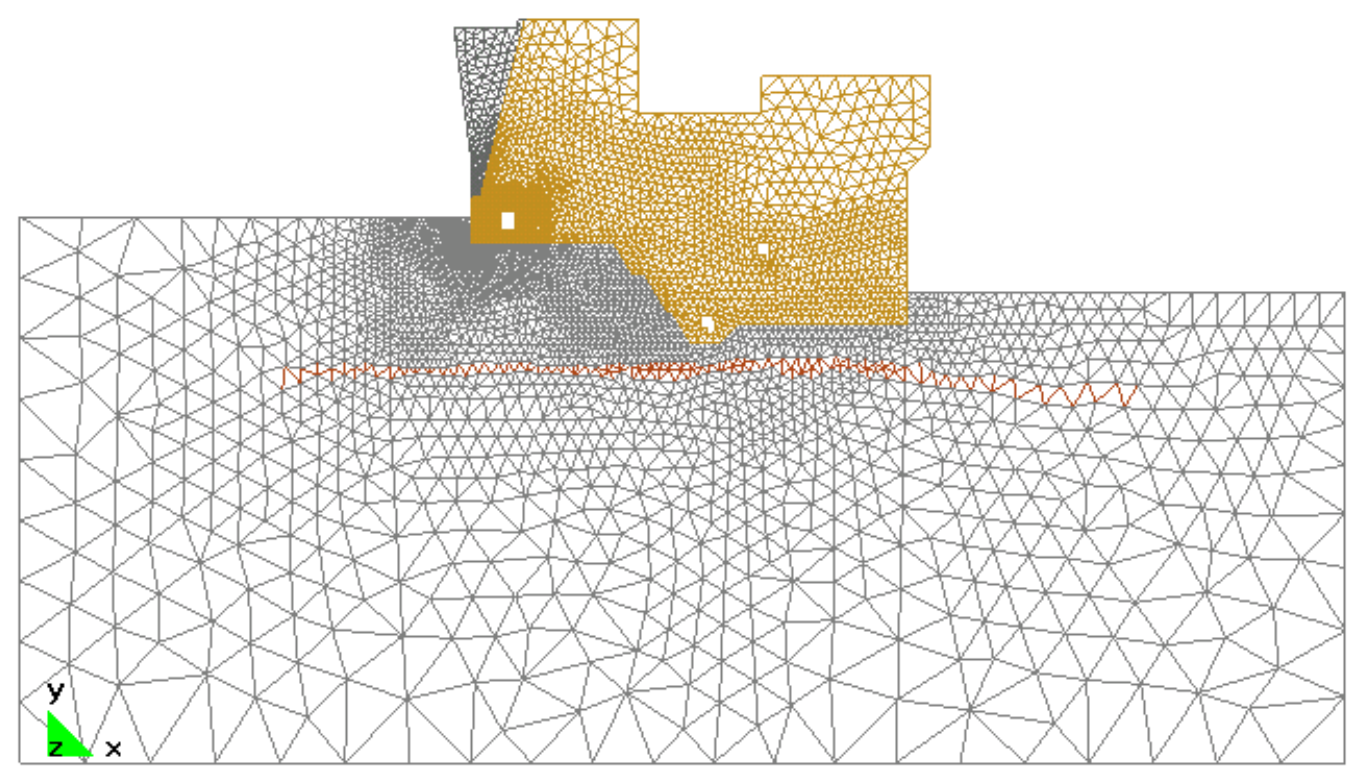

Figura 3.14 Malha de análise da casa de força.

A zona de fratura na malha está representada pelos elementos danificados que o programa fornece como resultado da aplicação das forças do peso próprio, da carga de água e da subpressão. Após o aparecimento da primeira fratura sob o nível 242m, os elementos danificados são considerados na análise do Modelo de fluxo para a determinação da subpressão influenciada pela presença da fratura. O processo de carregamento hidráulico se deu com incrementos do nível de 2m para o segundo nível, 3m para os níveis terceiro, quarto e quinto, e 4m para o nível máximo de trabalho $(257 \mathrm{~m})$. 


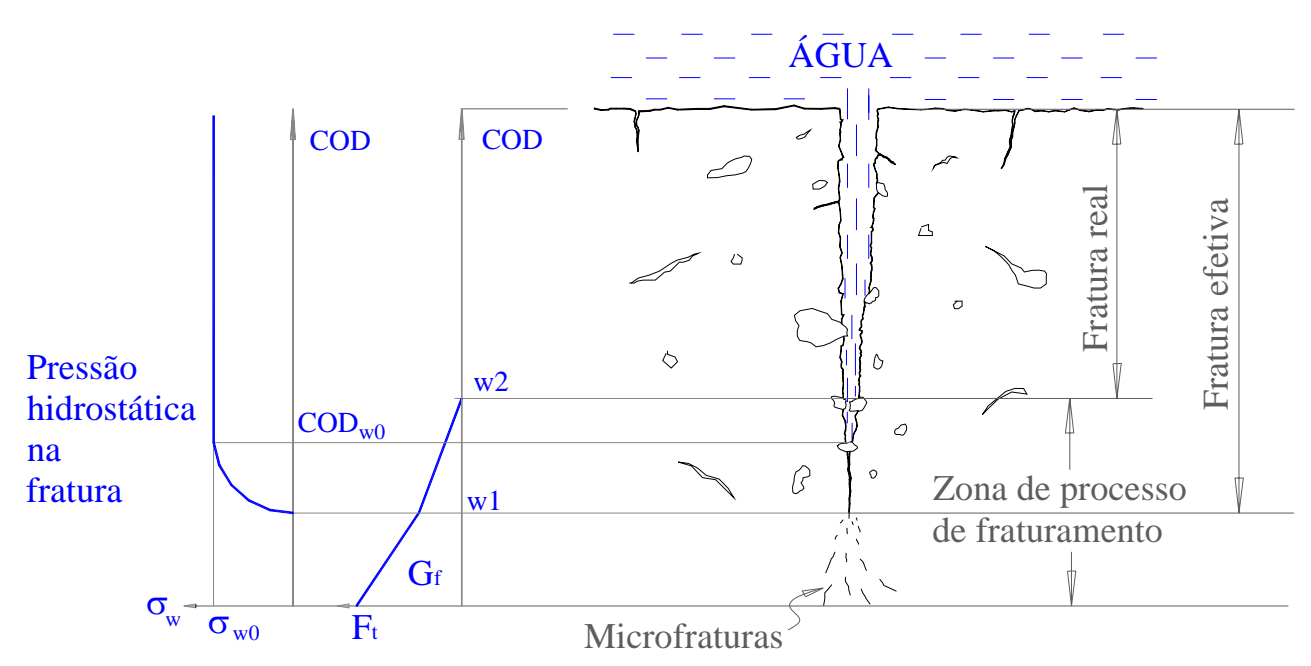

Figura 3.15 Pressão de água na fratura (Reich et al., 1994).

Uma vez obtidos os novos valores de subpressão com a presença da primeira fratura, realizou-se o segundo processamento do Modelo tensão-deformação onde foi considerado o efeito da pressão hidráulica na primeira fratura originada pela pressão do primeiro nível (242m); neste caso, a pressão foi transformada em forças nodais que, conjuntamente com as forças de subpressão, foram aplicadas como forças nodais nos elementos danificados pela primeira carga hidráulica. Após o segundo processamento, a fratura teve um novo avanço. Seguidamente, foi incrementada a carga hidráulica para o nível de água $244 \mathrm{~m}$, exercendo-se uma pressão maior no paramento, na fundação e na fratura aberta, produzindo-se um segundo avanço da fratura em profundidade. Aplicouse, logo, a pressão correspondente ao atual nível de água na nova fratura. Assim, repetiu-se o processo de carregamento progressivo da carga hidráulica para os níveis 247m, 250m, 253m e 257m. A pressão de água atuante na superfície da fratura foi considerada constante a partir da superfície de montante.

Nota-se que as forças nodais equivalentes à pressão hidráulica na fratura foram calculadas considerando a direção da fratura e o grau do dano por cada elemento, sendo aplicadas perpendicular à face da fratura. Os cálculos foram feitos para todos os níveis de carga hidráulica. A figura 3.16 mostra o eixo da fratura nos elementos afetados.

Os cálculos dos valores das forças nodais consideradas no avanço da fratura foram identificados como PPv30pC para o vertedouro e PPcf12p para a casa de força, sendo apresentados nas tabelas A-10 a A-15 do anexo A para o vertedouro e nas tabelas A-16 a A-21 para a casa de força. 
Um esquema da aplicação das forças nodais perpendiculares ao eixo da fratura se apresenta na figura 3.17 .

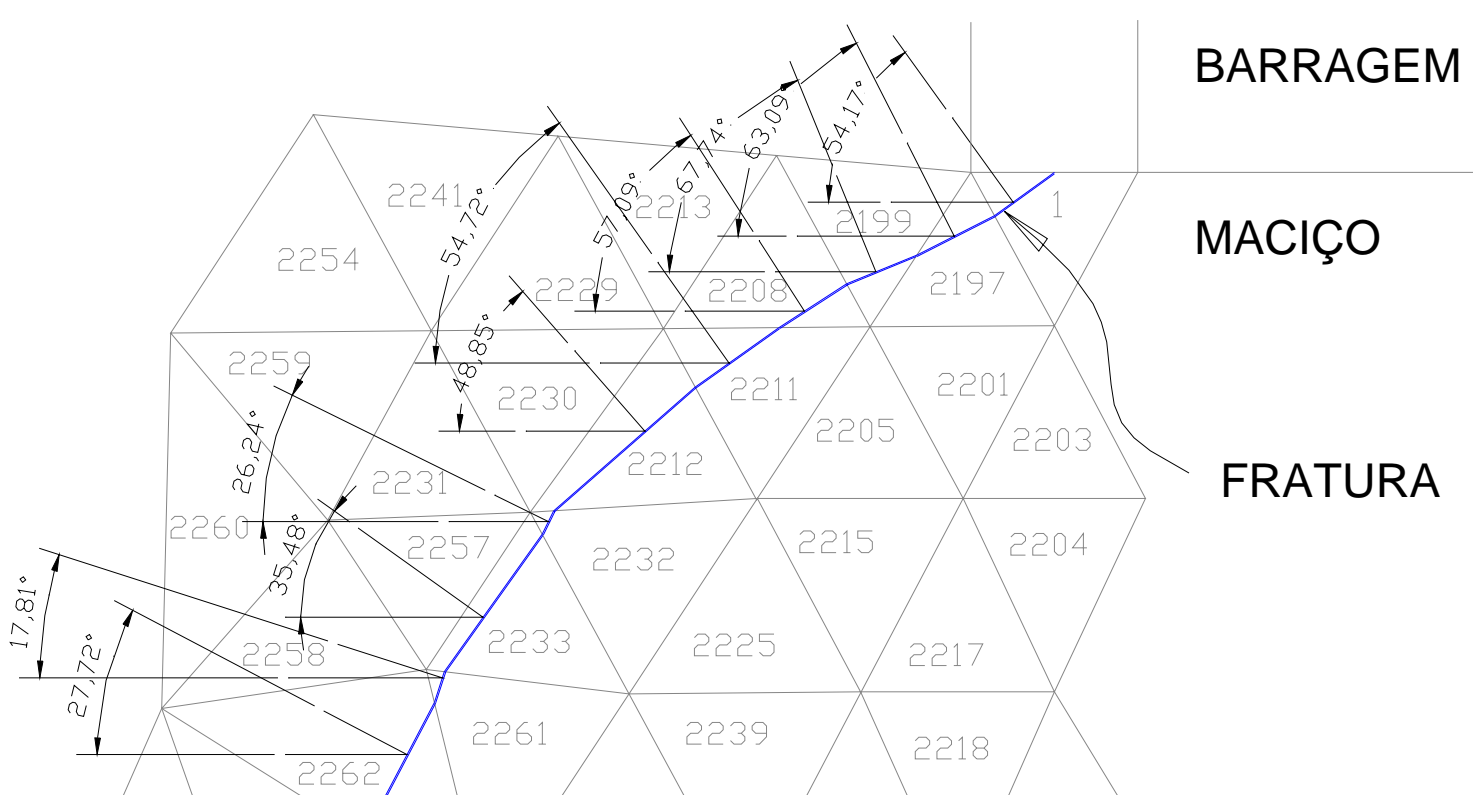

Figura 3.16 Orientação da fratura e ângulos de inclinação das forças.

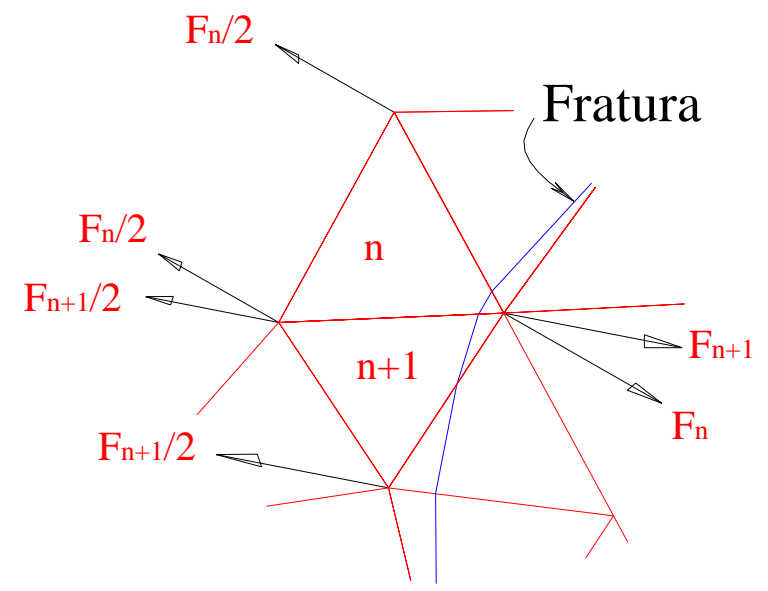

Figura 3.17 Esquema da aplicação das forças nodais nos elementos danificados.

\subsubsection{Modelo de Análise de fluxo e subpressão}

O modelo de análise da subpressão considerou as características anisotrópicas do maciço da fundação tanto do vertedouro como da casa de força, tomando-se os valores da condutividade hidráulica do maciço apresentados na tabela 4. Para a análise, preparou-se uma malha de elementos finitos considerando uma extensão a montante correspondente ao dobro da altura da estrutura, uma profundidade correspondente ao dobro da altura e, a jusante, uma extensão que corresponde a um e meio $(1,5)$ da altura. Realizou-se o processamento do modelo de análise da subpressão com ajuda do 
programa SEEP/W (GEO-SLOPE).

Para representar a zona do pé de montante no contato concreto-maciço onde ocorre a fratura, acrescentou-se a quantidade de elementos de dimensões bem menores do que o resto do maciço, repetindo-se os elementos da malha da simulação de tensãodeformação. Nos elementos desta zona danificada, adotaram-se os valores da condutividade hidráulica calculados para cada elemento danificado como foi explicado no item 3.1.4 e são apresentados no anexo B. A figura 3.18 mostra o modelo de análise para subpressão no nível $257 \mathrm{~m}$ do vertedouro e a figura 3.19 mostra a zona de fratura onde as cores dos elementos indicam a diferença de condutividade entre os elementos.

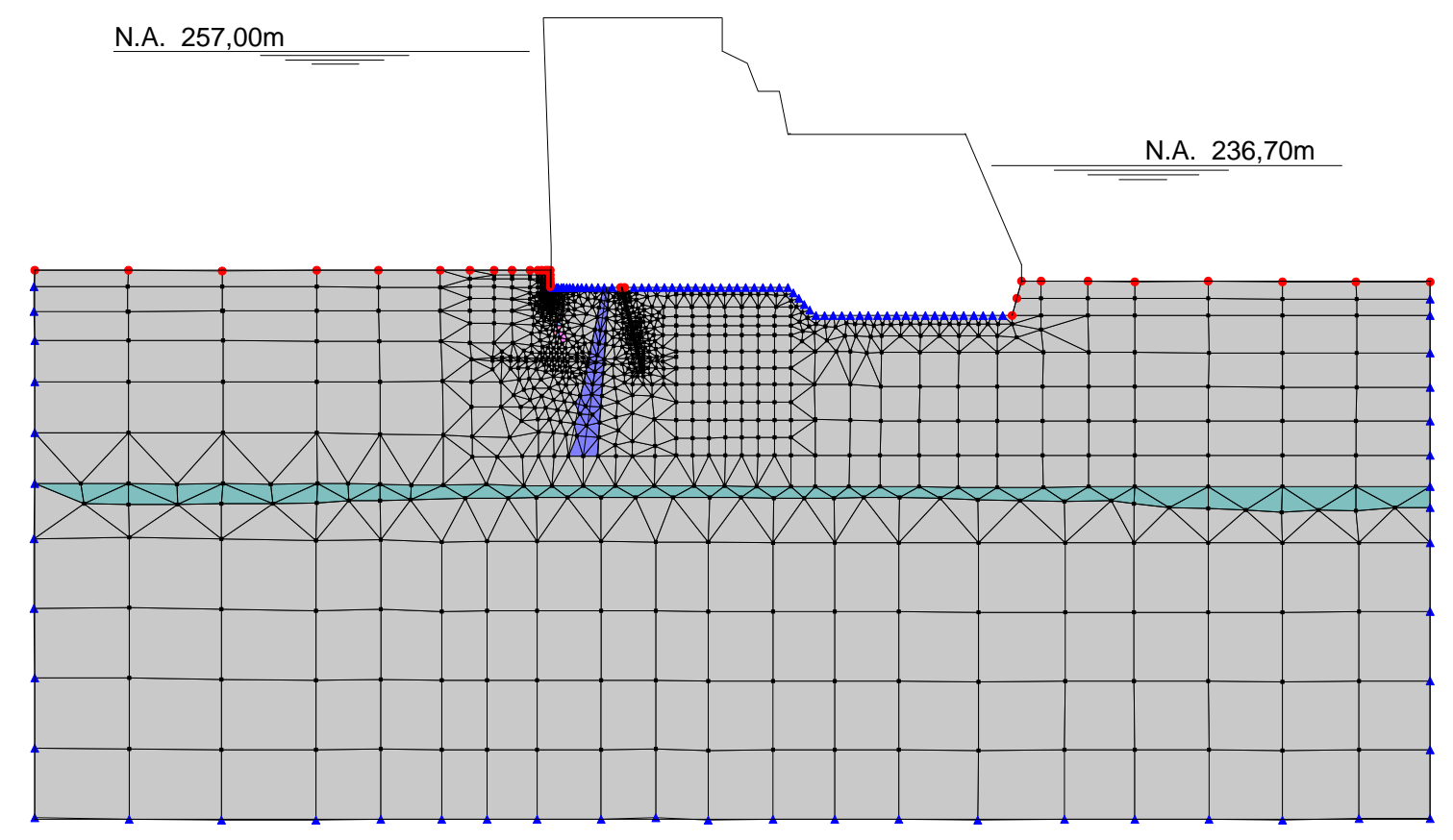

Figura 3.18 Modelo de análise para calcular as forças equivalentes da subpressão no vertedouro (Programa SEEP/W).

Depois de obtida a primeira fratura, esta é considerada no cálculo da subpressão afetada, agora, pela presença das fraturas. A nova subpressão foi transformada em forças nodais equivalentes, as quais foram aplicadas na base da estrutura de análise tensão-deformação para ser processada novamente e dar o seguinte avanço da fratura. O cálculo da variação da subpressão para cada nível de carregamento hidráulico é apresentado no anexo B. 


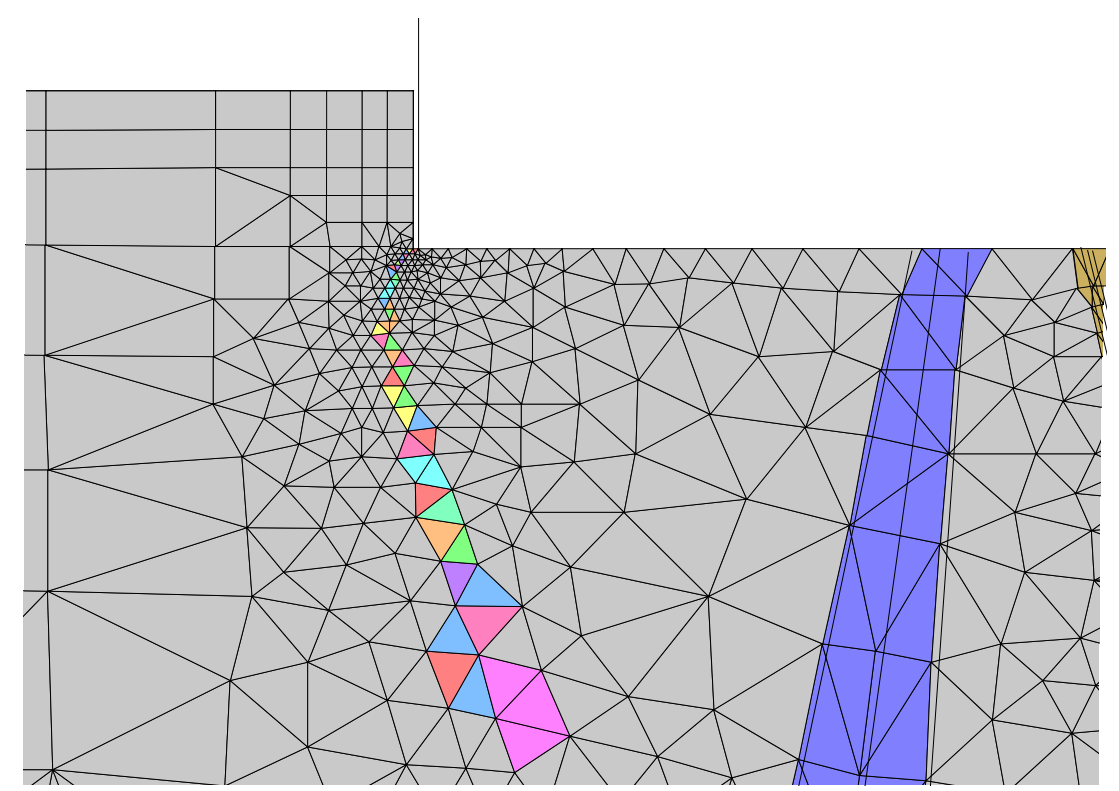

Figura 3.19 Discretização da zona de fratura para o cálculo da subpressão.

Na figura 3.20, mostra-se a malha para o modelo de análise da subpressão da casa de força e na figura 3.21, a zona de discretização da fratura no modelo.

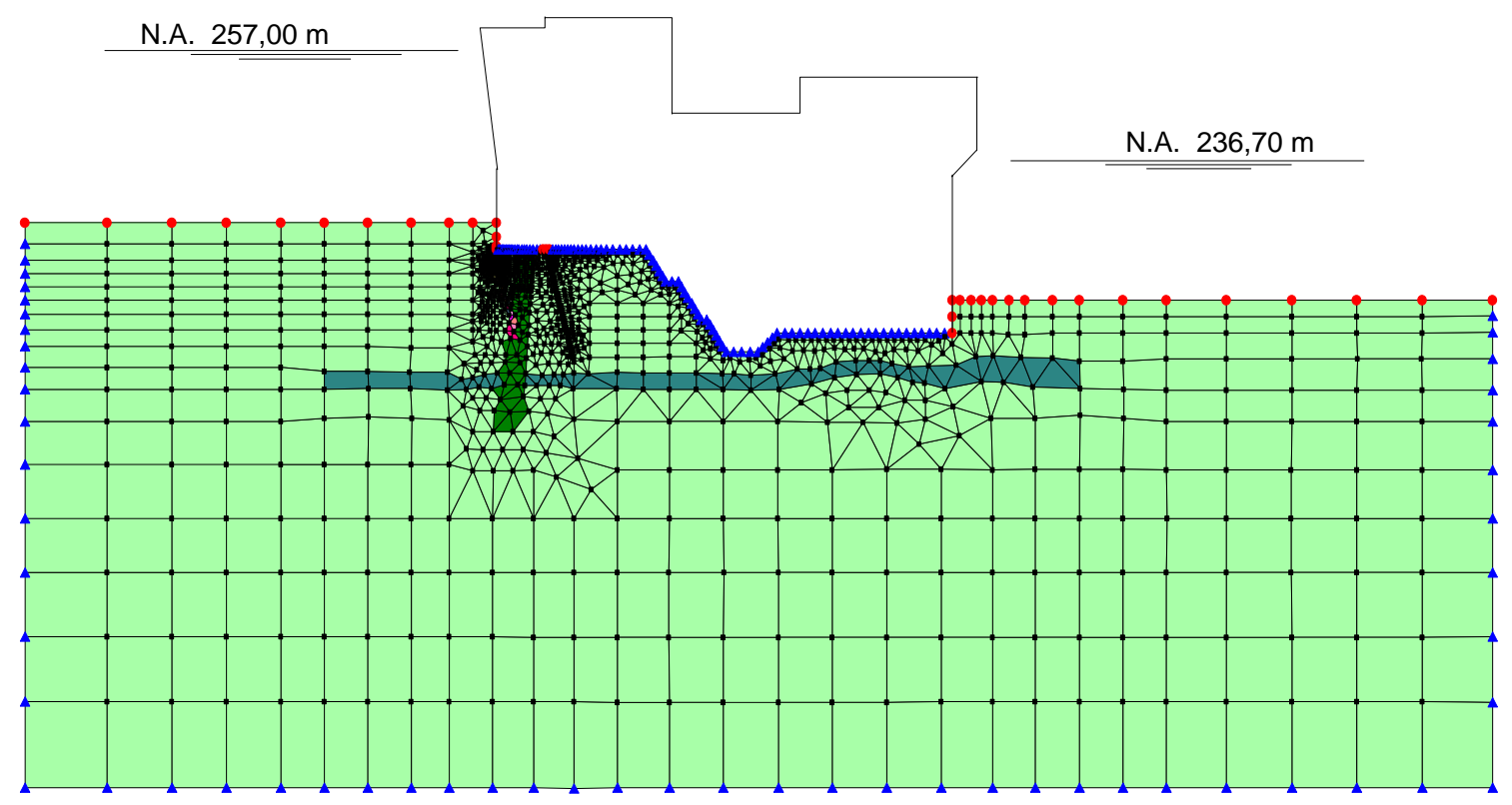

Figura 3.20 Modelo de análise para calcular as forças equivalentes da subpressão na casa de força. 


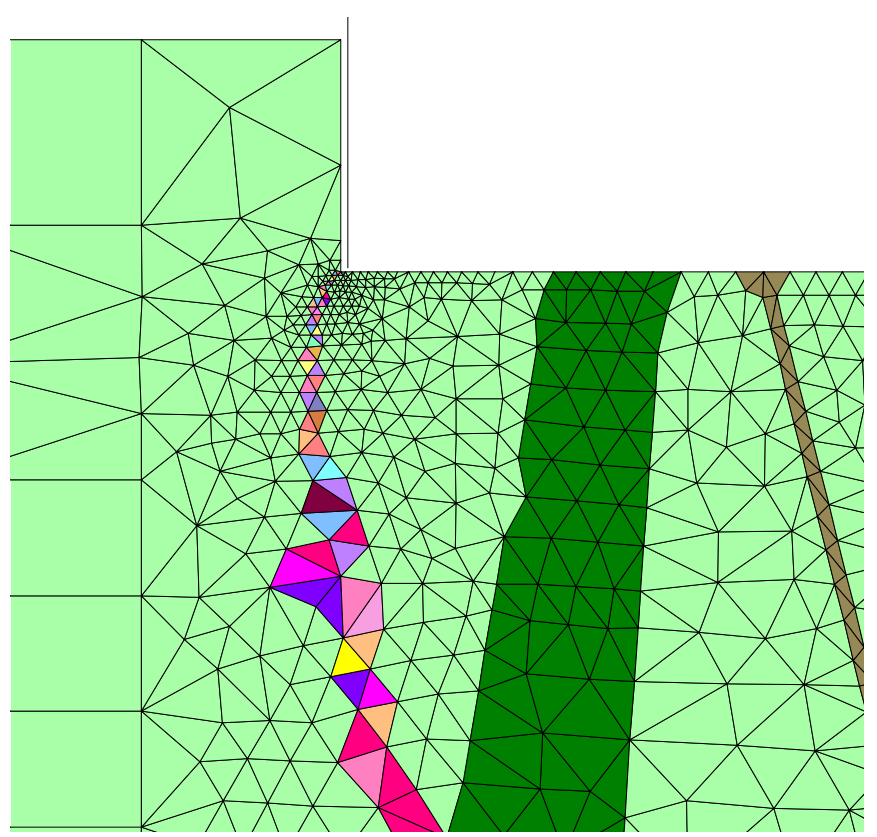

Figura 3.21 Discretização da zona de fratura para o cálculo da subpressão. 


\section{RESULTADOS}

Para cada nível de água e após a aplicação do carregamento na fratura, obteve-se o avanço da mesma, indicado pelo dano sofrido pelos elementos da malha de análise, tanto para o vertedouro como para a casa de força. As figuras 4.1 a 4.6 mostram o desenvolvimento da fratura no maciço mediante os elementos danificados em função do parâmetro do dano (D), parâmetro cujo valor é representado pela intensidade de cores.
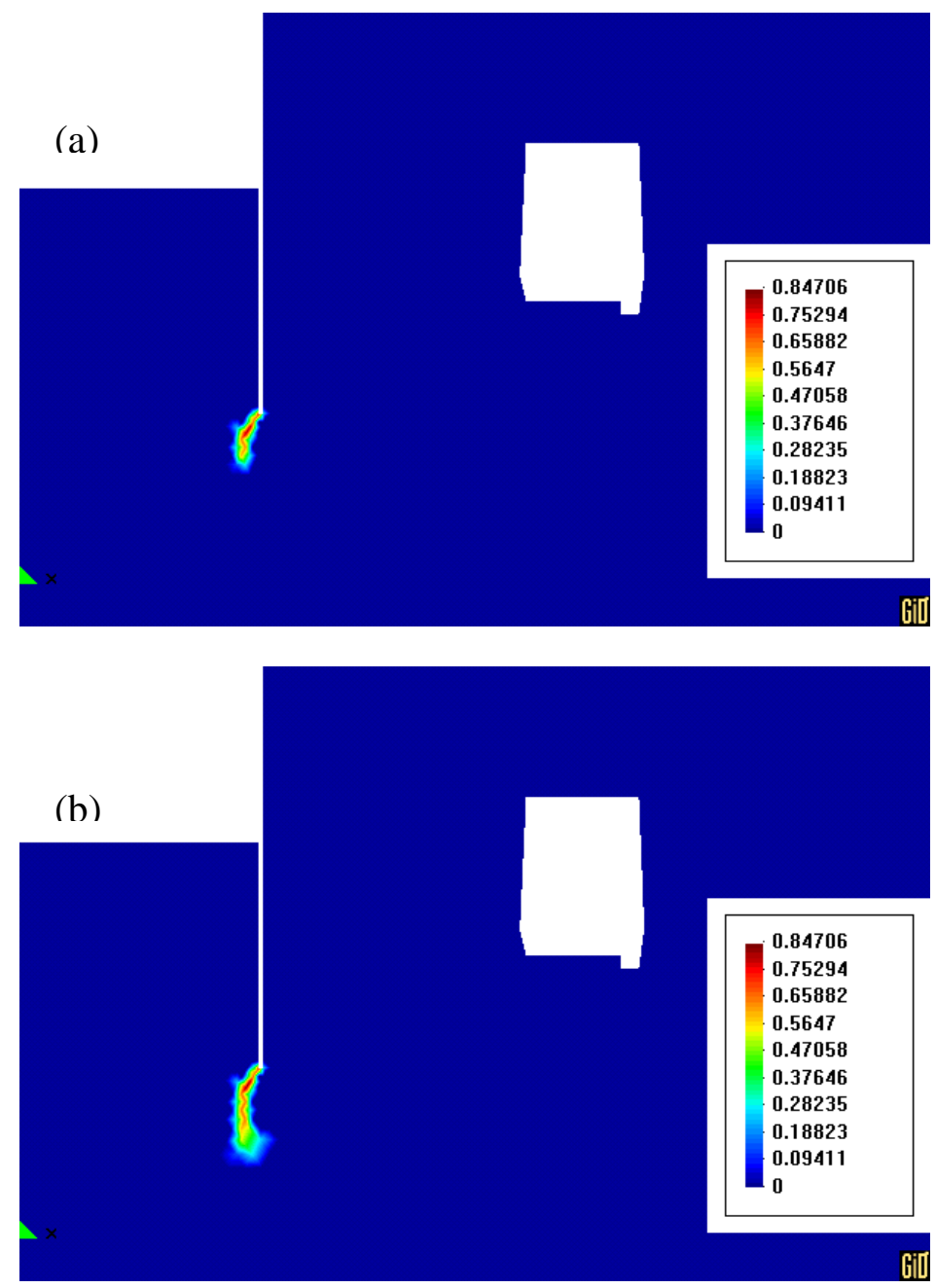

Figura 4.1 Desenvolvimento da fratura na fundação da casa de força: (a) sob carga do nível 242m e (b) sob a aplicação da carga do mesmo nível na fratura. 


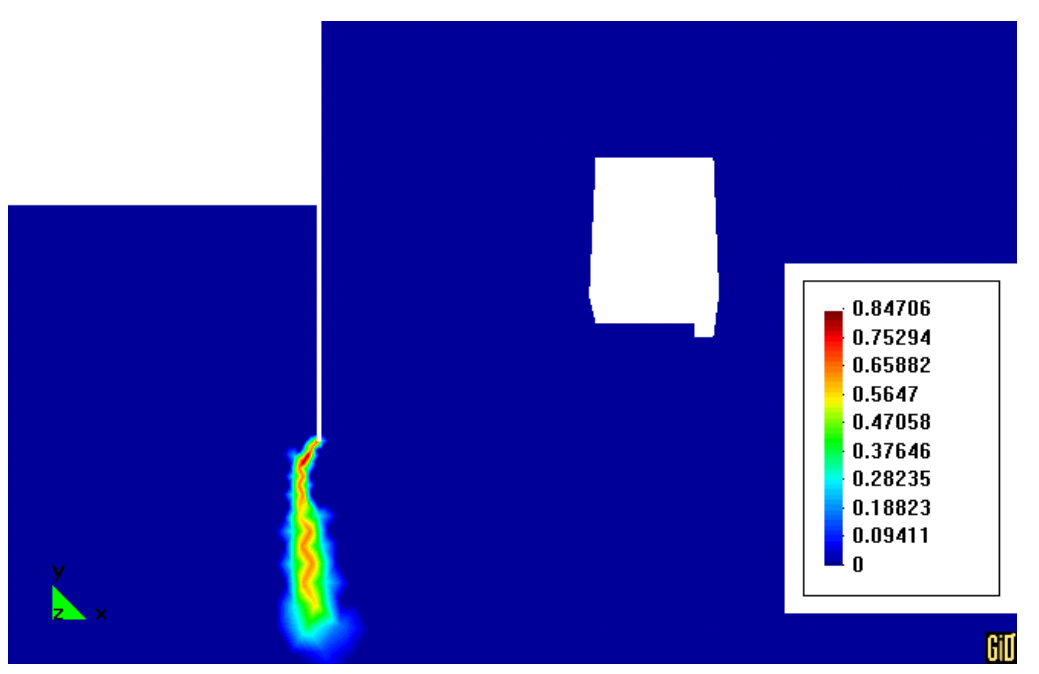

Figura 4.2 Avanço da fratura sob carga do nível de água 244m.

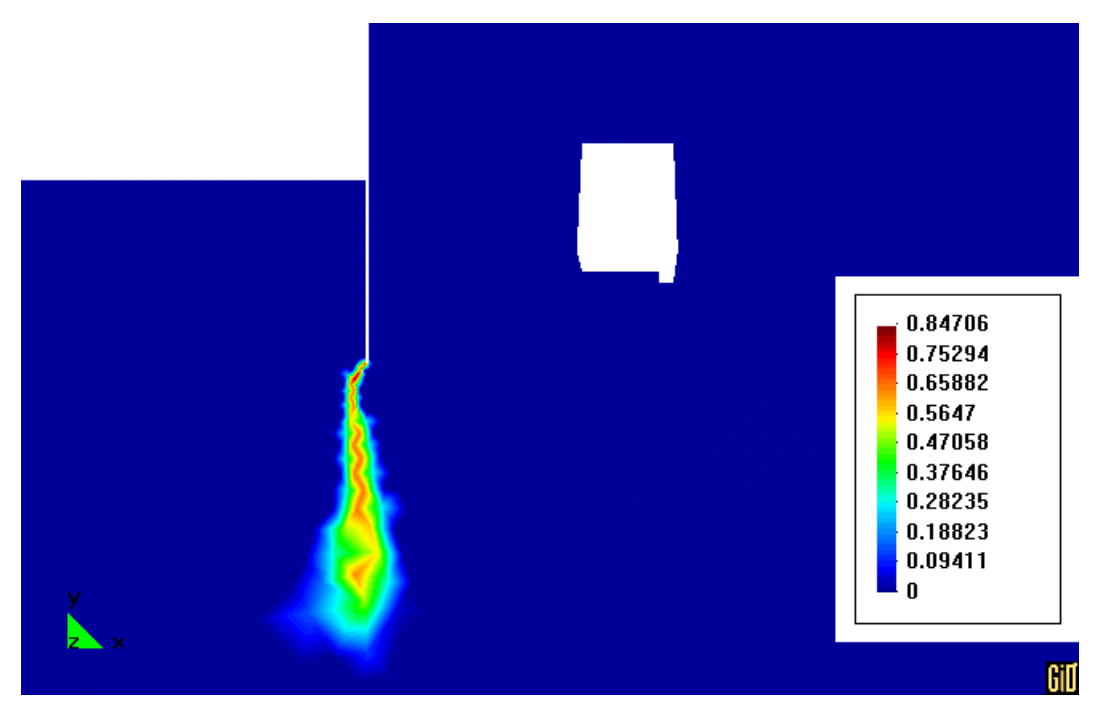

Figura 4.3 Avanço da fratura sob carga do nível de água 247m.

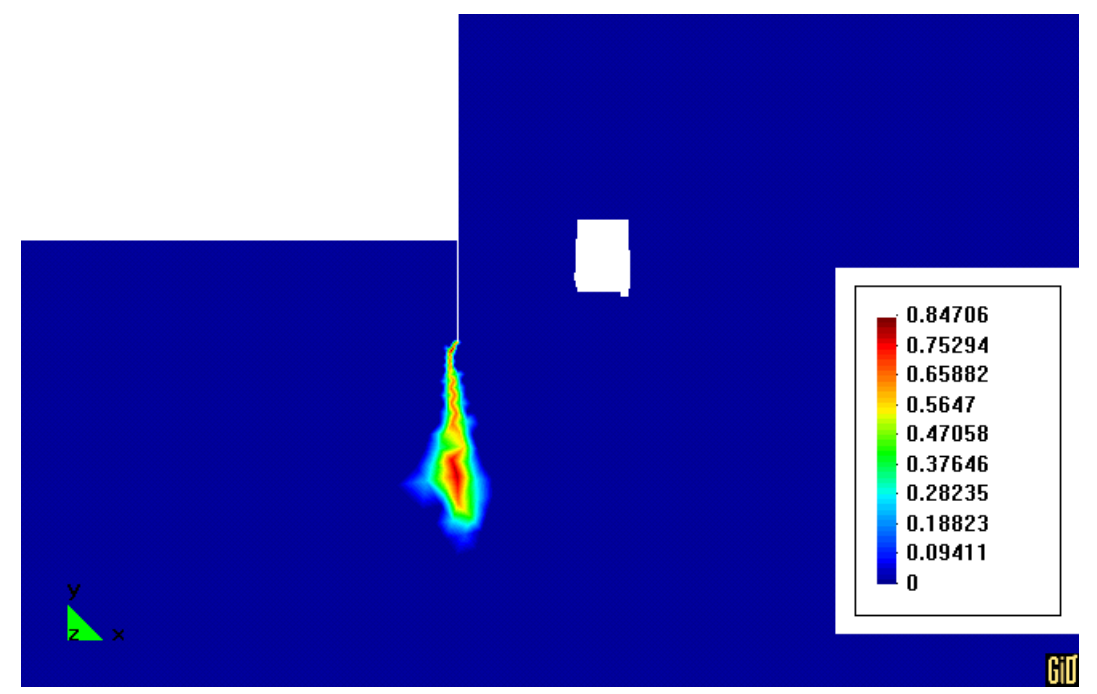

Figura 4.4 Avanço da fratura sob carga do nível de água 250m. 
A partir dos resultados do processamento de cada nível de água, foram tomados os deslocamentos dos nós selecionados para as hastes dos extensômetros e para os pontos de controle na galeria de drenagem. Estes deslocamentos permitem determinar as deformações que se produzem no maciço.

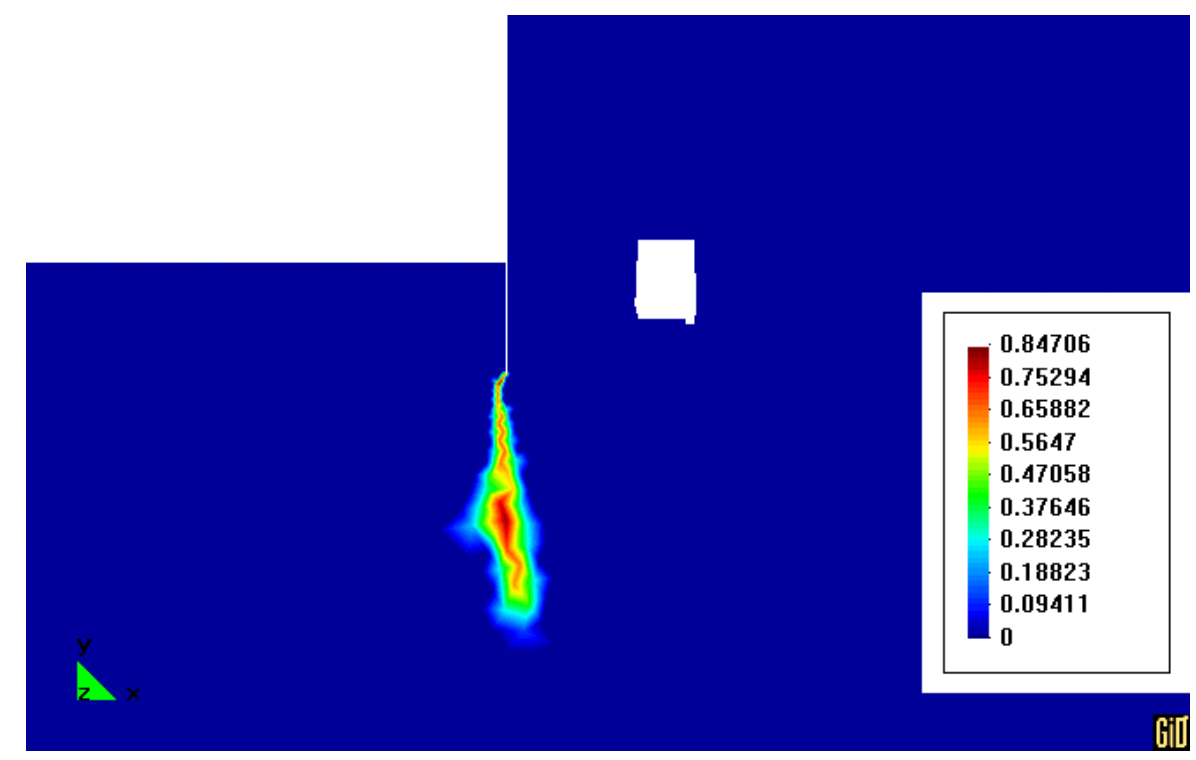

Figura 4.5 Avanço da fratura sob carga do nível de água 253m.

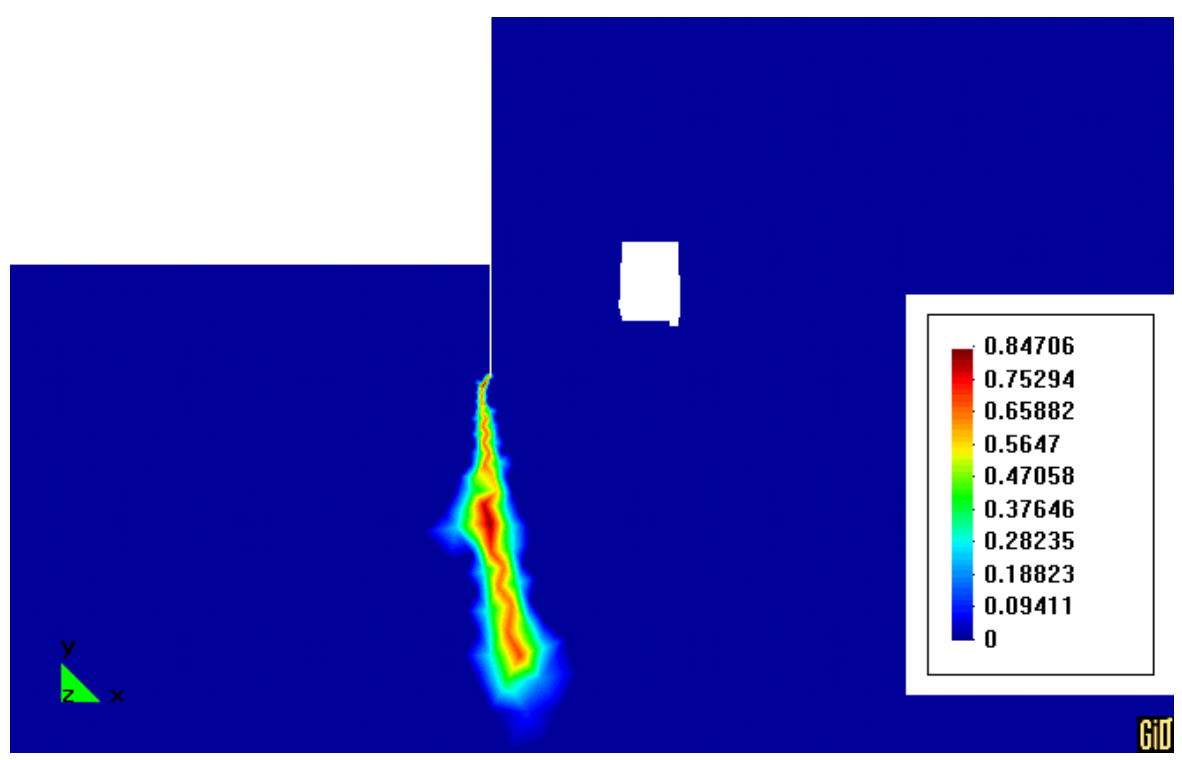

Figura 4.6 Avanço da fratura sob carga do nível de água 257m.

O procedimento seguido para o cálculo dos deslocamentos das hastes foi, inicialmente, o de relacionar a posição inicial dos nós (extensômetros) com os pontos de controle, obtendo-se os comprimentos inicias. Em seguida, após a aplicação do carregamento de cada nível, foram relacionadas as posições dos nós deslocados com os pontos de controle, também deslocados, o que forneceu a variação da distância entre as 
hastes e os pontos de controle. A diminuição ou o aumento das distâncias entre os pontos das hastes permitiu considerá-las como os deslocamentos sofridos pelo maciço. Esses deslocamentos calculados para o vertedouro foram comparados com os registros dos extensômetros EH-261 e EH-262 existentes no vertedouro, e os deslocamentos calculados para a casa de força foram comparados com as leituras dos extensômetros EH-566, EH-567 e EH-568. As tabelas 7 e 8 apresentam os deslocamentos calculados para o vertedouro, enquanto que as tabelas 9 e 11 apresentam os deslocamentos calculados para a casa de força.

Tabela 7. Deslocamentos das hastes do extensômetro EH-261 no vertedouro.

\begin{tabular}{|cccccccc|}
\hline \multirow{2}{*}{ Nível } & \multicolumn{4}{c}{ Comprimento Hastes } & \multicolumn{3}{c|}{ Deslocamento, mm } \\
& L1, cm & L2, cm & L3, cm & Haste 1 & Haste 2 & Haste 3 \\
\hline (inicial) & 4729,64 & 2840,423 & 875,4473 & & & \\
242 & 4729,484 & 2840,349 & 875,4302 & $-1,56$ & $-0,73$ & $-0,17$ \\
244 & 4729,486 & 2840,351 & 875,4307 & $-1,54$ & $-0,72$ & $-0,17$ \\
247 & 4729,489 & 2840,353 & 875,4314 & $-1,51$ & $-0,69$ & $-0,16$ \\
250 & 4729,493 & 2840,357 & 875,4323 & $-1,47$ & $-0,66$ & $-0,15$ \\
253 & 4729,498 & 2840,36 & 875,4333 & $-1,42$ & $-0,62$ & $-0,14$ \\
257 & 4729,508 & 2840,369 & 875,4364 & $-1,32$ & $-0,54$ & $-0,11$ \\
\hline
\end{tabular}

Tabela 8. Deslocamentos das hastes do extensômetro EH-262 no vertedouro.

\begin{tabular}{|cccccccc|}
\hline \multirow{2}{*}{ Nível } & \multicolumn{3}{c}{ Comprimento Hastes } & \multicolumn{3}{c|}{ Deslocamento, mm } \\
& $\mathbf{L 1}, \mathbf{c m}$ & $\mathbf{L 2}, \mathbf{c m}$ & $\mathbf{L 3}, \mathbf{c m}$ & Haste 1 & Haste 2 & Haste 3 \\
\hline (inicial) & 4843,9766 & 2902,6879 & 668,42875 & & & \\
242 & 4843,8108 & 2902,6104 & 668,4164 & $-1,66$ & $-\mathbf{0 , 7 8}$ & $-\mathbf{0 , 1 2}$ \\
244 & 4843,8096 & 2902,6096 & 668,4162 & $-1,67$ & $-\mathbf{0 , 7 8}$ & $-\mathbf{0 , 1 3}$ \\
247 & 4843,808 & 2902,6086 & 668,41594 & $-1,69$ & $-\mathbf{0 , 7 9}$ & $-\mathbf{0 , 1 3}$ \\
250 & 4843,8066 & 2902,6077 & 668,41573 & $-1,70$ & $-\mathbf{0 , 8 0}$ & $-\mathbf{0 , 1 3}$ \\
253 & 4843,8053 & 2902,607 & 668,41559 & $-\mathbf{1 , 7 1}$ & $-\mathbf{0 , 8 1}$ & $-\mathbf{0 , 1 3}$ \\
257 & 4843,804 & 2902,6062 & 668,41537 & $-\mathbf{1 , 7 3}$ & $-\mathbf{0 , 8 2}$ & $-\mathbf{0 , 1 3}$ \\
\hline
\end{tabular}


Tabela 9. Deslocamentos das hastes do extensômetro EH-566 na casa de força.

\begin{tabular}{|cccccccc|}
\hline \multirow{2}{*}{ Nível } & \multicolumn{4}{c}{ Comprimento Hastes } & \multicolumn{3}{c|}{ Deslocamento, mm } \\
& L1, cm & L2, cm & L3, cm & Haste 1 & Haste 2 & Haste 3 \\
\hline (inicial) & 4260,369 & 2606,722 & 1037,428 & & & \\
242 & 4260,271 & 2606,672 & 1037,408 & $-0,98$ & $-0,50$ & $-0,20$ \\
244 & 4260,276 & 2606,677 & 1037,410 & $-0,92$ & $-0,45$ & $-0,17$ \\
247 & 4260,285 & 2606,685 & 1037,411 & $-0,84$ & $-0,38$ & $-0,17$ \\
250 & 4260,295 & 2606,694 & 1037,411 & $-0,74$ & $-0,28$ & $-0,16$ \\
253 & 4260,309 & 2606,707 & 1037,412 & $-0,59$ & $-0,15$ & $-0,15$ \\
257 & 4260,332 & 2606,730 & 1037,414 & $-0,36$ & 0,08 & $-0,14$ \\
\hline
\end{tabular}

Tabela 10. Deslocamentos das hastes do extensômetro EH-567 na casa de força.

\begin{tabular}{|cccccccc|}
\hline \multirow{2}{*}{ Nível } & \multicolumn{3}{c}{ Comprimento Hastes } & \multicolumn{3}{c|}{ Deslocamento, $\mathbf{m m}$} \\
& L1, cm & L2, cm & L3, cm & Haste 1 Haste 2 Haste 3 \\
\hline (inicial) & 4255,773 & 2607,959 & 1037,677 & & & \\
242 & 4255,664 & 2607,900 & 1037,654 & $-\mathbf{1 , 0 9}$ & $-\mathbf{0 , 5 8}$ & $-\mathbf{0 , 2 2}$ \\
244 & 4255,661 & 2607,898 & 1037,653 & $-\mathbf{1 , 1 2}$ & $-\mathbf{0 , 6 0}$ & $-\mathbf{0 , 2 3}$ \\
247 & 4255,658 & 2607,896 & 1037,653 & $-\mathbf{1 , 1 5}$ & $-\mathbf{0 , 6 3}$ & $-\mathbf{0 , 2 4}$ \\
250 & 4255,656 & 2607,894 & 1037,652 & $-\mathbf{1 , 1 7}$ & $-\mathbf{0 , 6 4}$ & $-\mathbf{0 , 2 5}$ \\
253 & 4255,654 & 2607,893 & 1037,652 & $-\mathbf{1 , 1 9}$ & $-\mathbf{0 , 6 6}$ & $-\mathbf{0 , 2 5}$ \\
257 & 4255,653 & 2607,891 & 1037,653 & $-\mathbf{1 , 2 1}$ & $-\mathbf{0 , 6 7}$ & $-\mathbf{0 , 2 4}$ \\
\hline
\end{tabular}

Tabela 11. Deslocamentos das hastes do extensômetro EH-568 na casa de força.

\begin{tabular}{|ccccc|}
\hline \multirow{2}{*}{ Nível } & \multicolumn{2}{c}{ Comprimento Hastes } & \multicolumn{2}{c|}{ Deslocamento, mm } \\
& L1, cm & L2, cm & Haste 1 & Haste 2 \\
\hline (inicial) & 1991,085 & 526,100 & & \\
242 & 1991,026 & 526,081 & $-\mathbf{0 , 5 9 2}$ & $-\mathbf{0 , 1 9 2}$ \\
244 & 1991,026 & 526,081 & $-\mathbf{0 , 5 9 2}$ & $-\mathbf{0 , 1 9 2}$ \\
247 & 1991,026 & 526,081 & $-\mathbf{0 , 5 9 2}$ & $-\mathbf{0 , 1 9 1}$ \\
250 & 1991,026 & 526,081 & $-\mathbf{0 , 5 9 3}$ & $-\mathbf{0 , 1 9 1}$ \\
253 & 1991,026 & 526,081 & $-\mathbf{0 , 5 9 3}$ & $-\mathbf{0 , 1 9 0}$ \\
257 & 1991,026 & 526,081 & $-\mathbf{0 , 5 9 4}$ & $-\mathbf{0 , 1 8 8}$ \\
\hline
\end{tabular}


Outro parâmetro de interesse obtido foi a abertura da fratura desenvolvida na rocha sob cada nível de água. Esta abertura foi utilizada no cálculo de fluxo e da subpressão. A partir da análise de fluxo, realizou-se, também, o cálculo da vazão no dreno e comparou-se com os registros dos drenos existentes na fundação das seções selecionadas, o qual se apresenta no item 4.1.

\subsection{Aferição dos resultados}

Nos modelos matemáticos de análise de fraturas, adotam-se parâmetros e hipóteses que devem ser verificados com medições da instrumentação existente na fundação. Celestino (1983) propõe que, na aferição dos resultados de modelos com aqueles medidos pela instrumentação, deve-se procurar a correspondência das medições dos extensômetros com os deslocamentos calculados no modelo. A partir desta correspondência, pode-se retro-analisar o modelo e encontrar os parâmetros correspondentes às leituras feitas nas datas definidas para as mesmas condições.

Um ponto importante a se considerar na aferição dos dados é a variação do parâmetro de condutividade hidráulica do maciço, o qual se vê afetado pelas variações das tensões efetivas produzidas pelo carregamento da estrutura. Este problema foi inicialmente estudado por Johandar et al. (1971). Outro aspecto a ser considerado corresponde às condições de contorno do modelo que nem sempre corresponderão à situação real do problema.

No presente trabalho, na aferição dos resultados, consideraram-se os registros dos deslocamentos dos extensômetros de haste EH-261 e EH-262 do vertedouro, os quais estão localizados embaixo da galeria de montante como é mostrado na figura 4.7. Cada extensômetro possui três hastes numeradas ascendentemente (de baixo para acima). Já a informação dos piezômetros foi considerada para correlacionar os possíveis efeitos da presença do fraturamento. Os piezômetros desta seção do vertedouro foram identificados como PZ-261, PZ-262 e PZ-263 inclinados a montante, enquanto que PZ264, PZ-265 e PZ-266 estão orientados a jusante. A tabela 12 apresenta a informação de localização da instrumentação supramencionada indicando a cota da base de cada aparelho. 
Tabela 12. Cota de instalação dos extensômetros e dos piezômetros do vertedouro.

\begin{tabular}{|ccc|}
\hline \multicolumn{2}{|c|}{ Instrumentação } & Cota (m) \\
\hline Extensômetro & Haste 1 & 176,54 \\
EH-261 & Haste 2 & 192,90 \\
& Haste 3 & 209,92 \\
\hline Ponto de controle & 261 & 218,09 \\
\hline Extensômetro & Haste 1 & 175,55 \\
EH-262 & Haste 2 & 192,36 \\
& Haste 3 & 211,71 \\
\hline Ponto de controle & 262 & 217,97 \\
\hline & PZ - 261 & 201,38 \\
& PZ - 262 & 209,32 \\
Piezômetros & PZ - 263 & 213,74 \\
& PZ - 264 & 201,74 \\
& PZ - 265 & 209,13 \\
& PZ - 266 & 213,48 \\
\hline
\end{tabular}

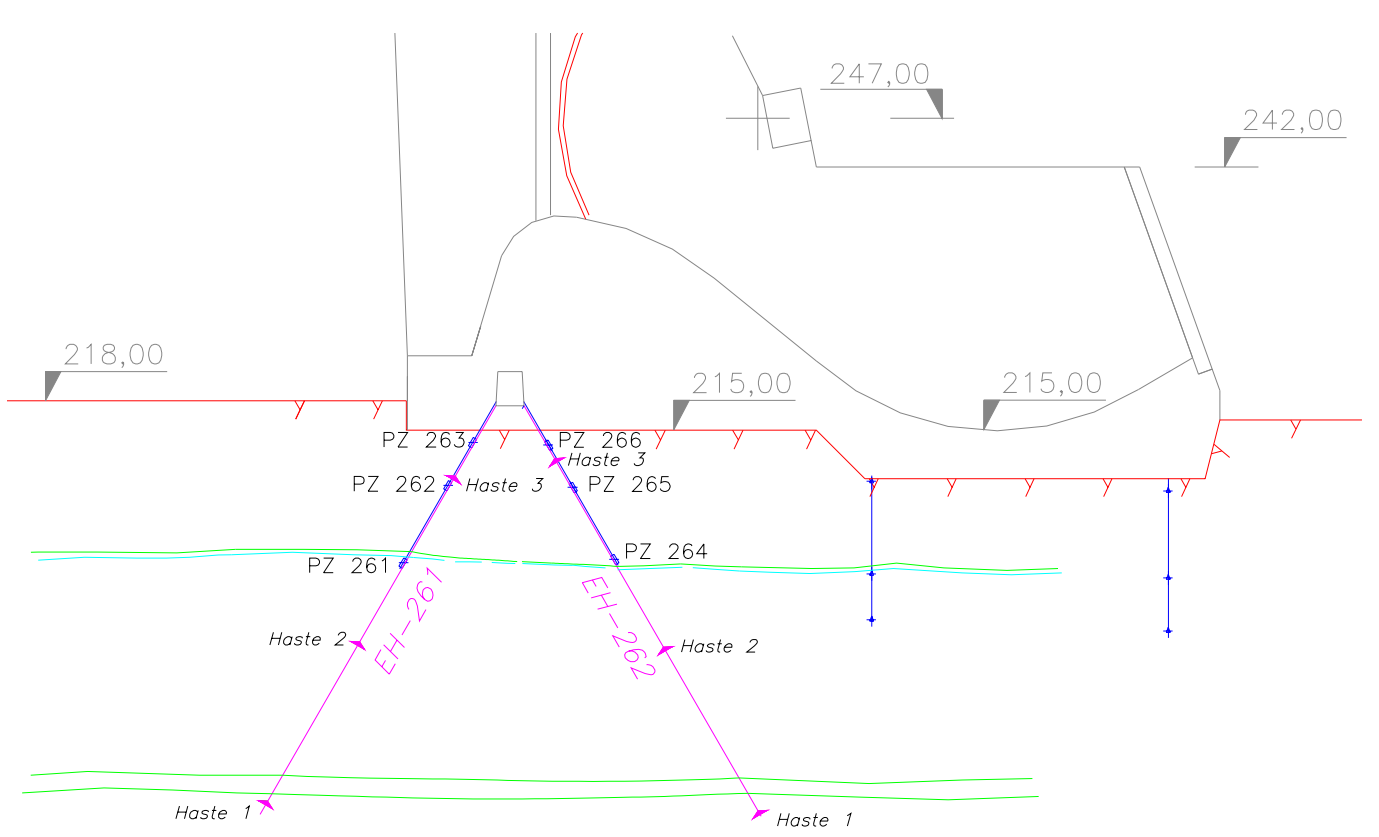

Figura 4.7 Extensômetros e Piezômetros existentes na seção de análise do vertedouro.

De igual modo, foram utilizados os registros dos extensômetros de haste EH-566, EH-567 e EH-568 para a casa de força. Os piezômetros desta seção foram identificados como PZ-566 e PZ-567 inclinados a montante, ao passo que, orientados a jusante, estão PZ-568 e PZ-569, na seção de análise. A figura 4.8 apresenta a localização da instrumentação e a tabela 13 as cotas da base de cada aparelho. 


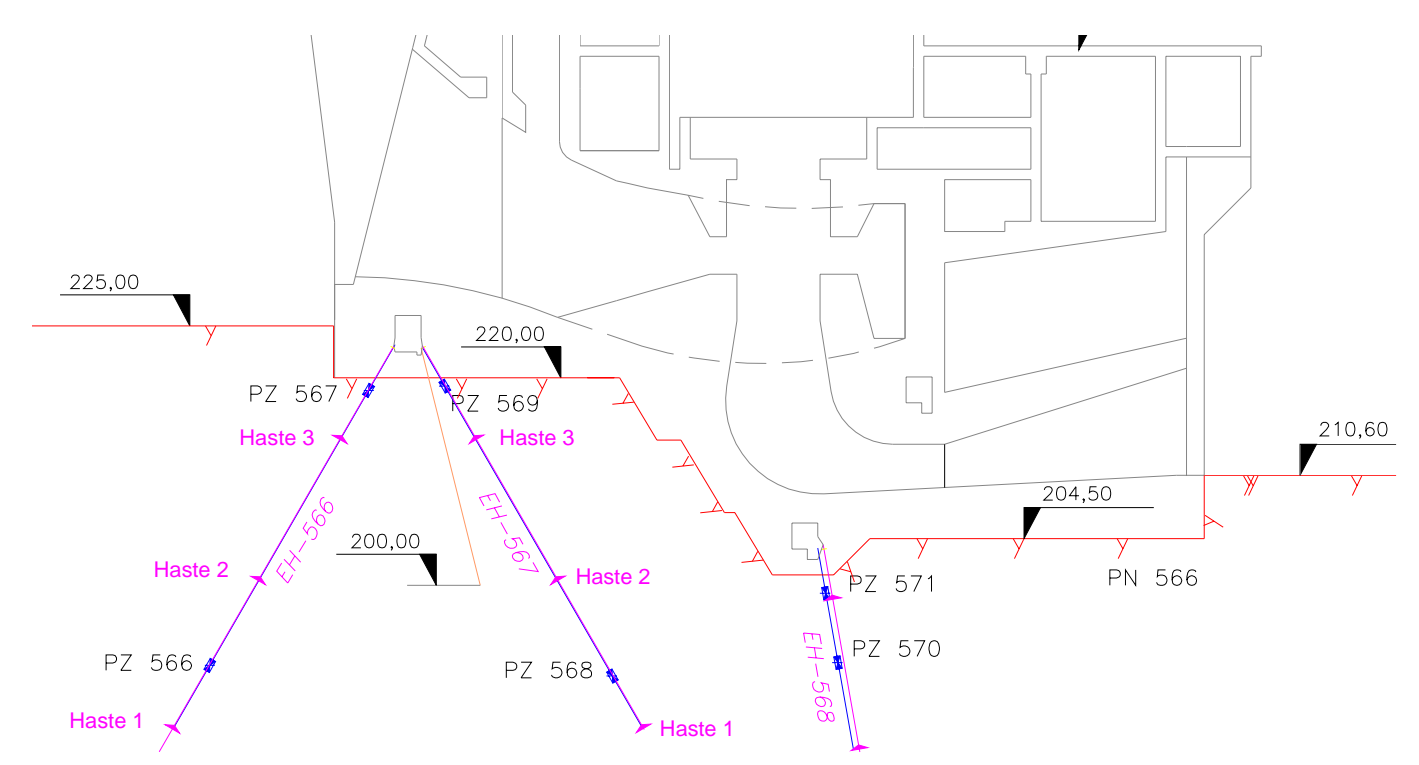

Figura 4.8 Extensômetros e Piezômetros existentes na seção de análise da casa de força.

Tabela 13. Cota de instalação dos extensômetros e dos piezômetros da casa de força.

\begin{tabular}{|ccc|}
\hline \multicolumn{2}{|c|}{ Instrumentação } & Cota (m) \\
\hline Extensômetro & Haste 1 & 186,14 \\
EH-566 & Haste 2 & 200,46 \\
& Haste 3 & 214,06 \\
\hline Ponto de controle & 566 & 223,06 \\
\hline \multirow{2}{*}{ Extensômetro } & Haste 1 & 186,20 \\
EH-567 & Haste 2 & 200,47 \\
& Haste 3 & 214,07 \\
\hline Ponto de controle & 567 & 223,09 \\
\hline \multirow{2}{*}{ Extensômetro } & Haste 1 & 184,21 \\
EH-568 & Haste 2 & 198,66 \\
\hline Ponto de controle & 568 & 203,91 \\
\hline & $\mathrm{PZ} \mathrm{-} \mathrm{566}$ & 192,28 \\
& $\mathrm{PZ}-567$ & 218,79 \\
Piezômetros & $\mathrm{PZ}-568$ & 191,25 \\
& $\mathrm{PZ}-569$ & 219,20 \\
& $\mathrm{PZ} \mathrm{-} \mathrm{570}$ & 192,55 \\
$\mathrm{PZ}-571$ & 199,24 \\
\hline
\end{tabular}

$\mathrm{Na}$ aferição dos dados calculados com aqueles das leituras tanto do vertedouro como da casa de força, procurou-se achar a correspondência entre os deslocamentos calculados e os das leituras. Para esse fim, prepararam-se gráficos relacionando os valores obtidos para cada nível de carga e os valores das leituras para cada haste dos extensômetros. Na seqüência, as figuras 4.9 a 4.11 apresentam os deslocamentos para o extensômetro EH-261, e as figuras 4.12 a 4.14 apresentam os deslocamentos para o extensômetro EH-262. 


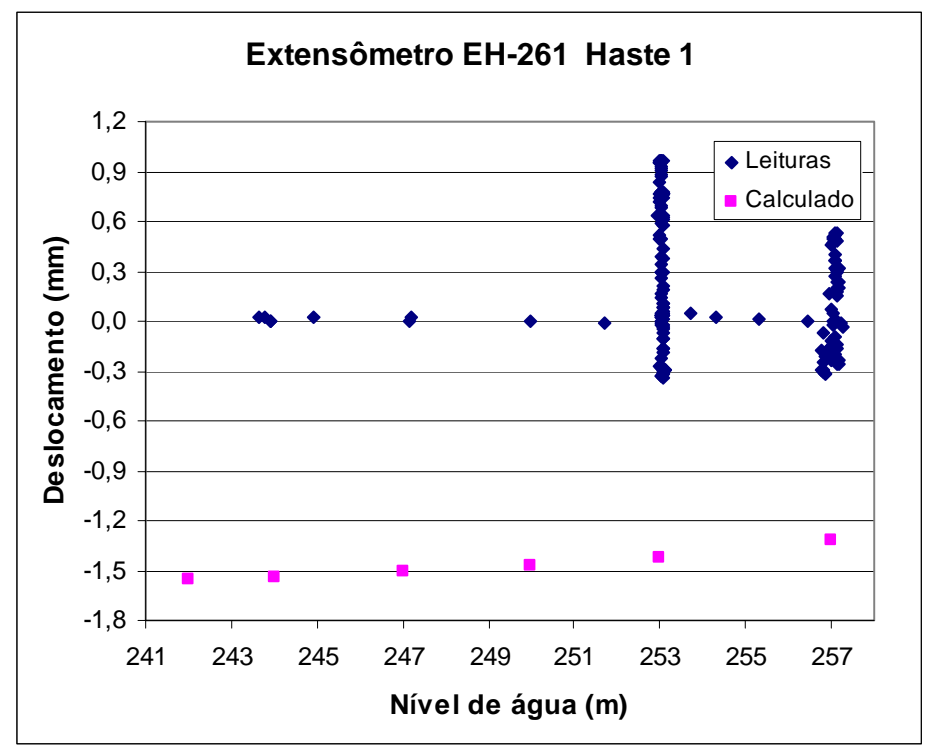

Figura 4.9 Comparação dos deslocamentos calculados e medidos da haste 1 do EH-261.

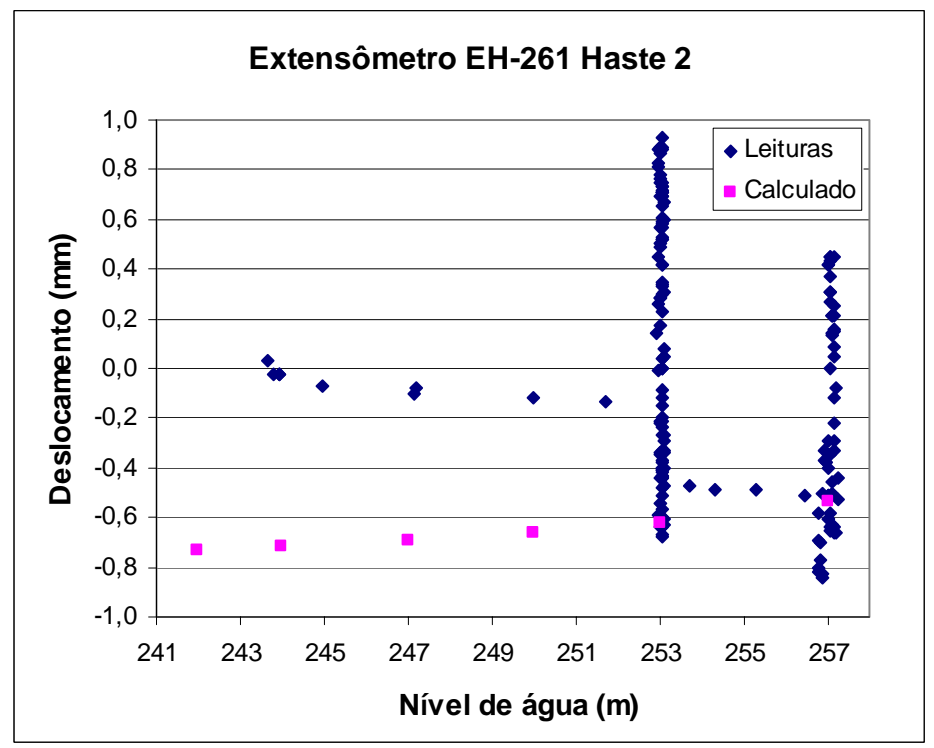

Figura 4.10 Comparação dos deslocamentos calculados e medidos da haste 2 do EH261.

Não se deve buscar semelhança entre os valores iniciais de cálculo e instrumentação. Muitos efeitos decorrentes da concretagem não foram simulados. Portanto a comparação deve ser feita apenas com as variações em função do nível d'água. 


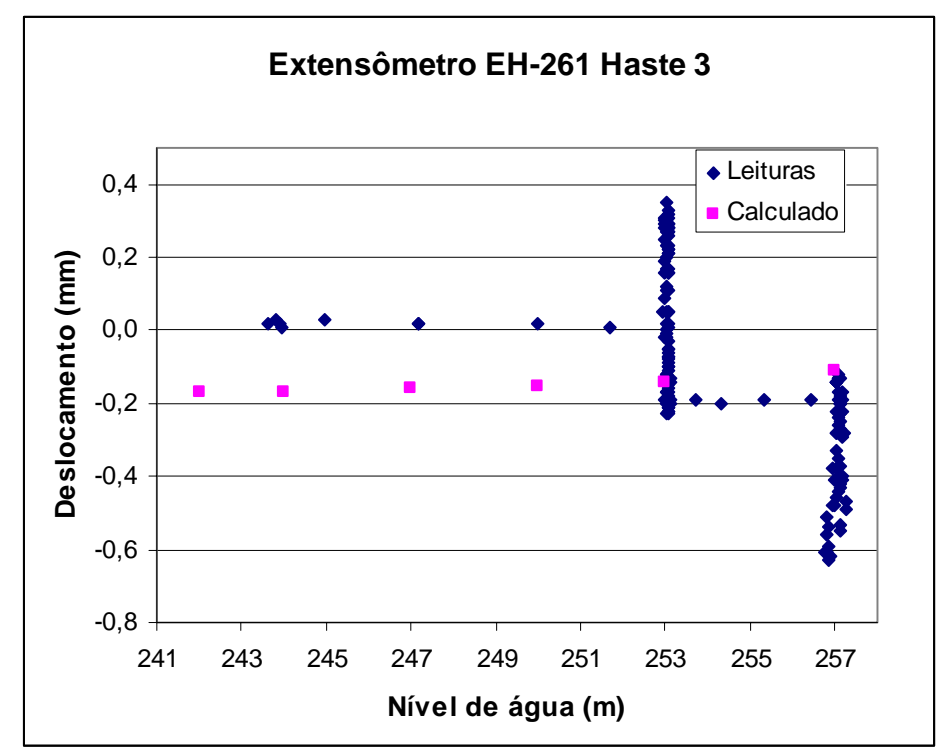

Figura 4.11 Comparação dos deslocamentos calculados e medidos da haste 3 do EH261.

Neste primeiro extensômetro EH-261, os valores calculados mostraram-se próximos daqueles das leituras na haste 3 , a qual se encontra próxima à superfície do contato estrutura-fundação. Porém, foi necessário analisar o comportamento das hastes do extensômetro EH-262 para se ter uma idéia geral desta zona do maciço. As figuras 4.12 a 4.14 apresentam a comparação dos valores calculados com os medidos.

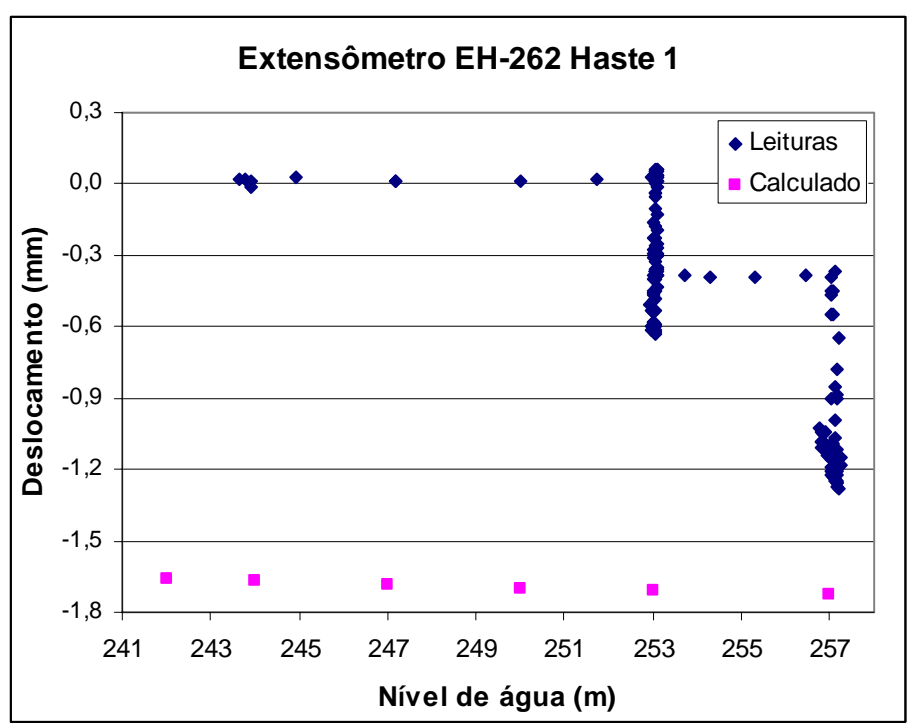

Figura 4.12 Comparação dos deslocamentos calculados e medidos da haste 1 do EH262. 


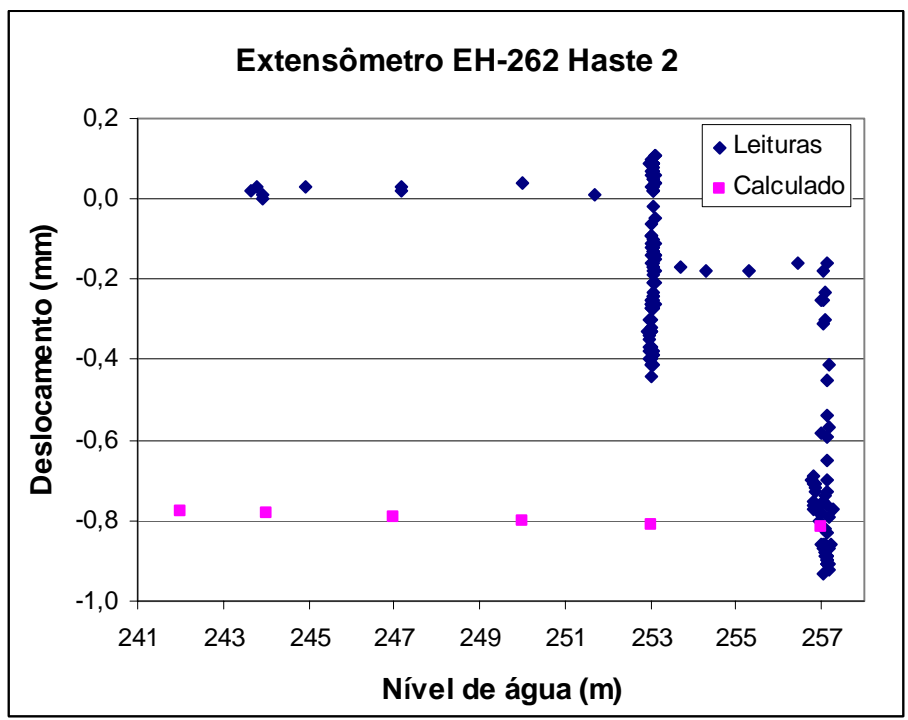

Figura 4.13 Comparação dos deslocamentos calculados e medidos da haste 2 do EH262.

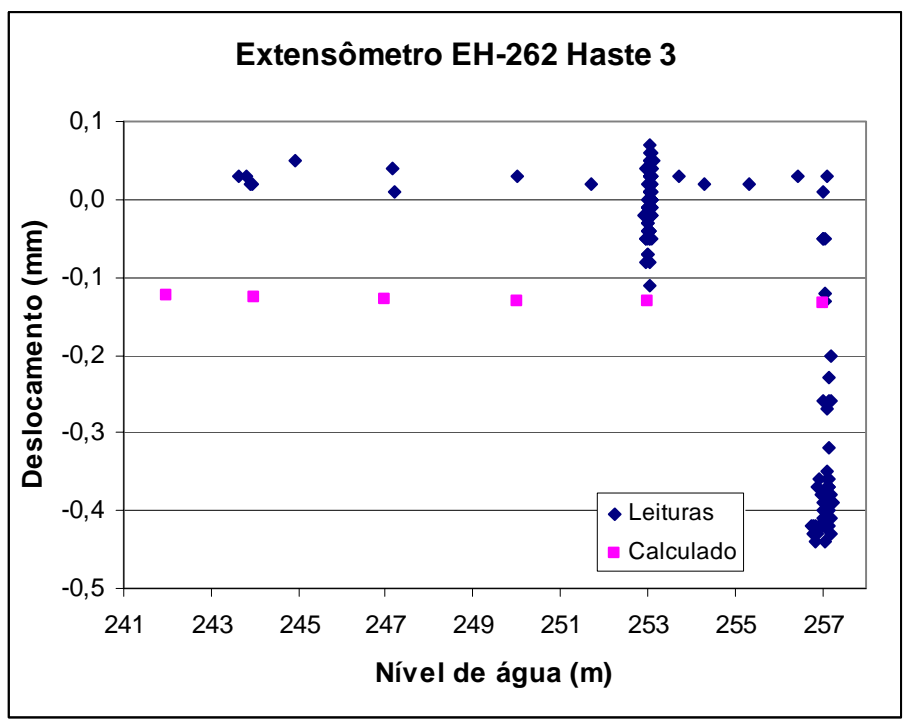

Figura 4.14 Comparação dos deslocamentos calculados e medidos da haste 3 do EH262.

Como mostrado pelas figuras, os valores dos deslocamentos calculados são mais próximos dos medidos nas hastes superficiais do que aqueles correspondentes às hastes inferiores, e se mostram mais afastados nas hastes mais profundas. Por outro lado, observou-se, também, que a variação dos deslocamentos, mostrados pelas leituras, são bem pequenos e quase semelhantes aos calculados, enquanto que os carregamentos hidráulicos não são constantes. Contudo, quando o carregamento hidráulico, nos níveis altos, permanece constante por um longo período de tempo, como foram nos níveis 253m e 257m, verifica-se que as leituras mostraram oscilação dos deslocamentos 
(compressão e distensão), o que é bem diferente da tendência dos valores calculados. As possíveis causas que justificam este comportamento e as discussões correspondentes são apresentadas no item 4.2 .

Para o caso da estrutura da tomada de água-casa de força a comparação dos dados calculados e as leituras esta apresentada nas figuras 4.15 a 4.17 correspondente ao extensômetro EH-566.

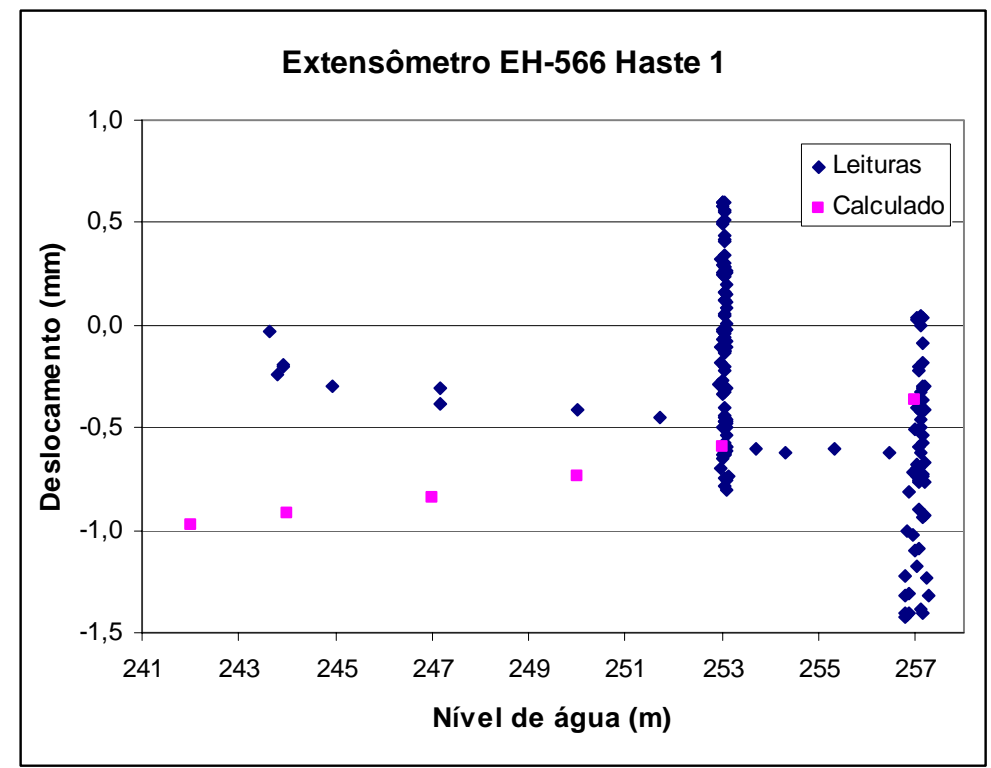

Figura 4.15 Comparação dos deslocamentos calculados e medidos da haste 1 do EH566.

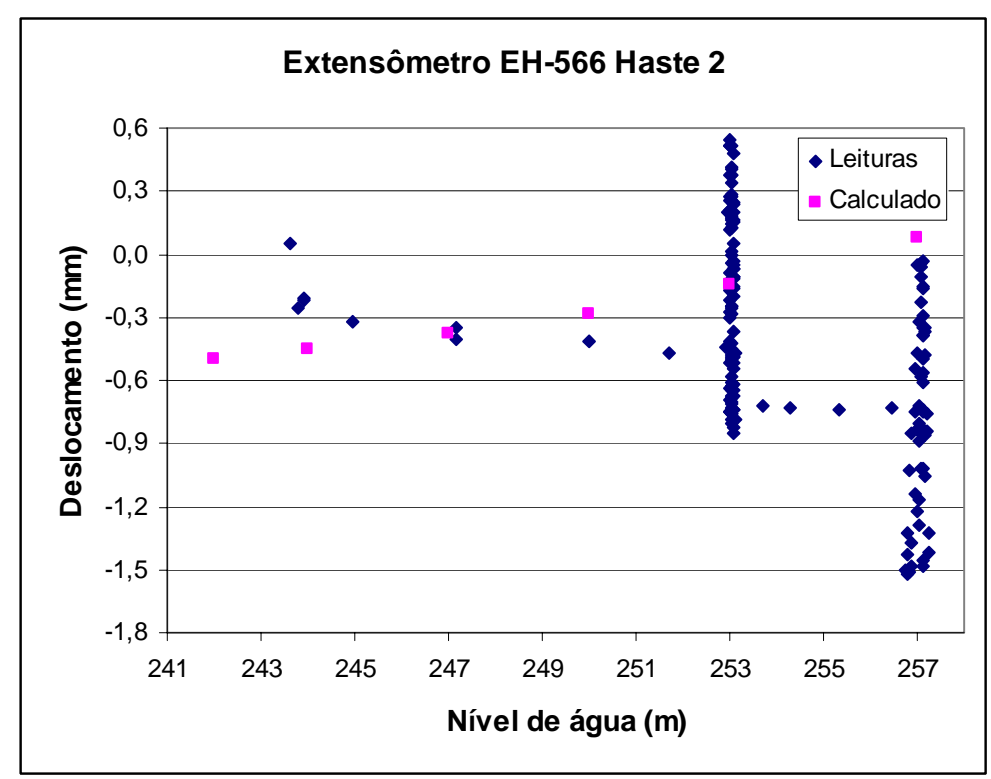

Figura 4.16 Comparação dos deslocamentos calculados e medidos da haste 2 do EH566. 


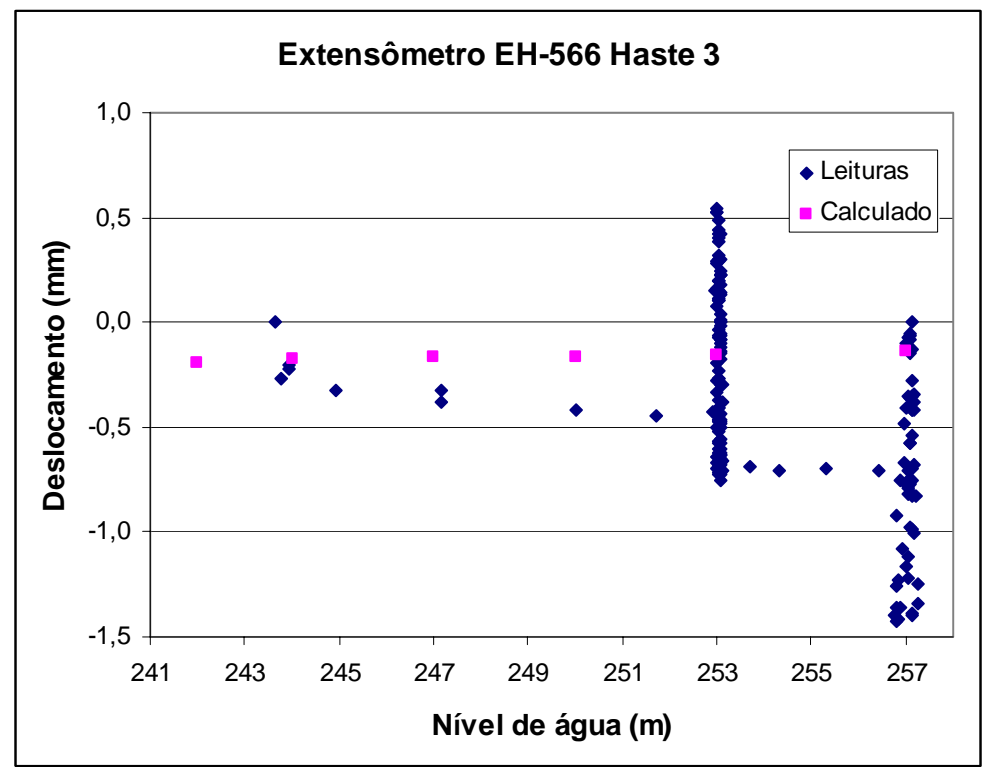

Figura 4.17 Comparação dos deslocamentos calculados e medidos da haste 3 do EH566.

Pelas figuras mostradas do EH-566, observa-se proximidade dos valores calculados com as leituras como no caso de montante do vertedouro, porém, se mostraram com tendência à distensão. Não obstante, é preciso ver as figuras do EH-567 a jusante do tratamento de fundação por meio das figuras 4.18 a 4.20, assim como as figuras 4.21 e 4.22 do extensômetro 568.

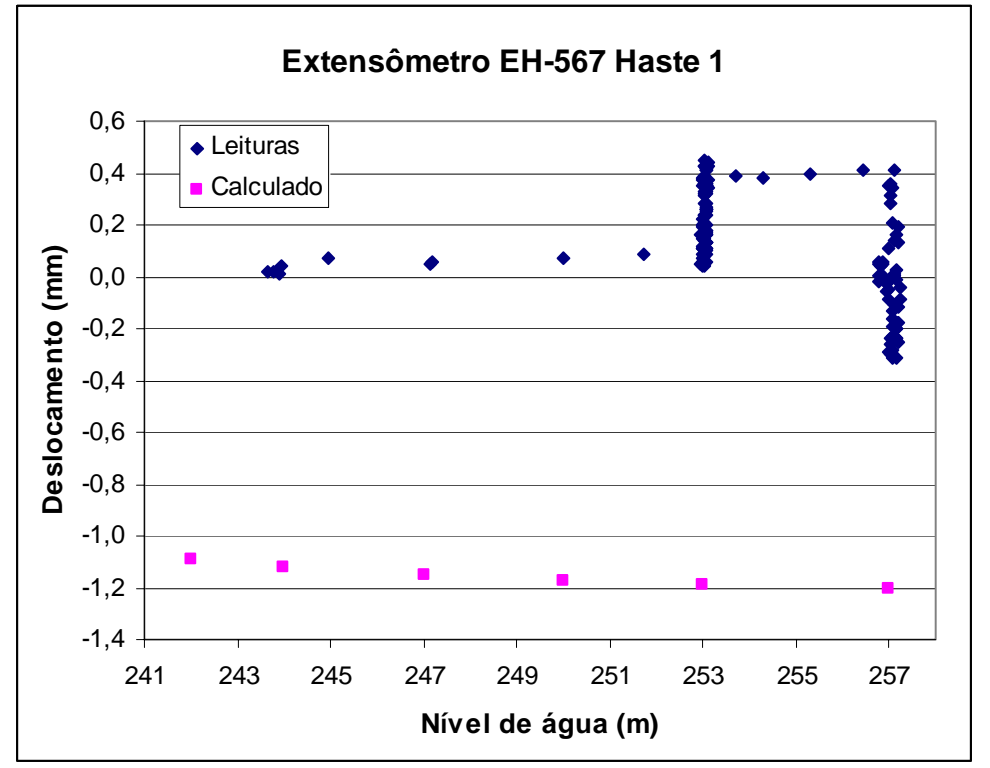

Figura 4.18 Comparação dos deslocamentos calculados e medidos da haste 1 do EH567. 


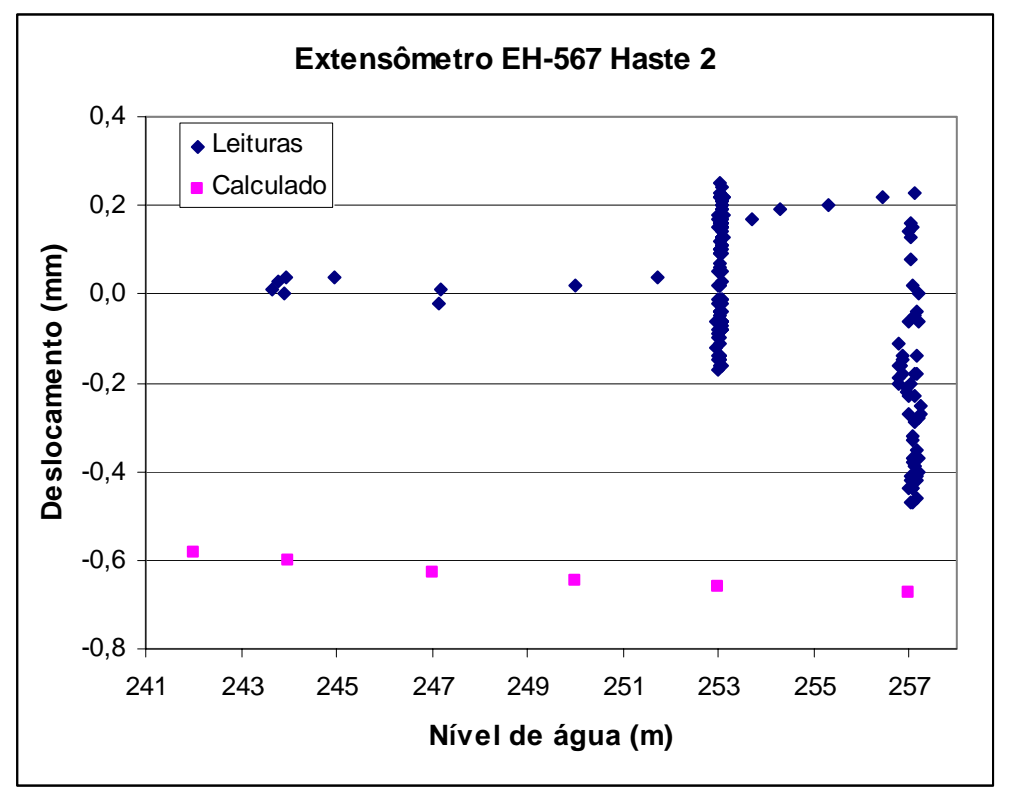

Figura 4.19 Comparação dos deslocamentos calculados e medidos da haste 2 do EH567.

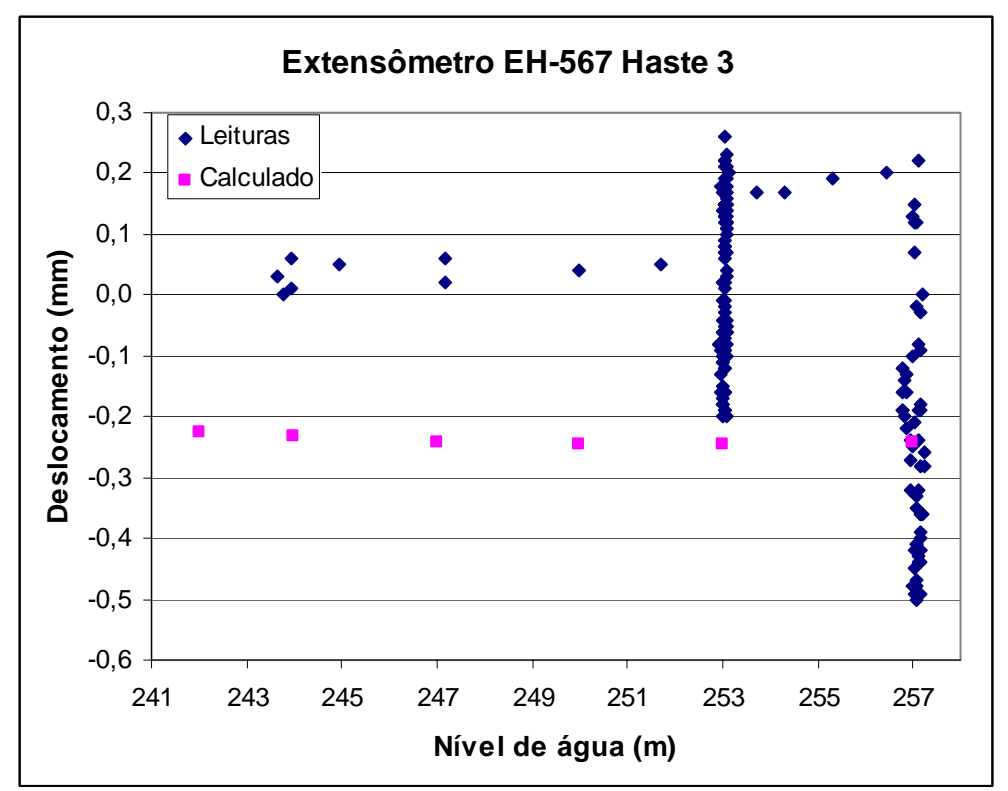

Figura 4.20 Comparação dos deslocamentos calculados e medidos da haste 3 do EH567. 


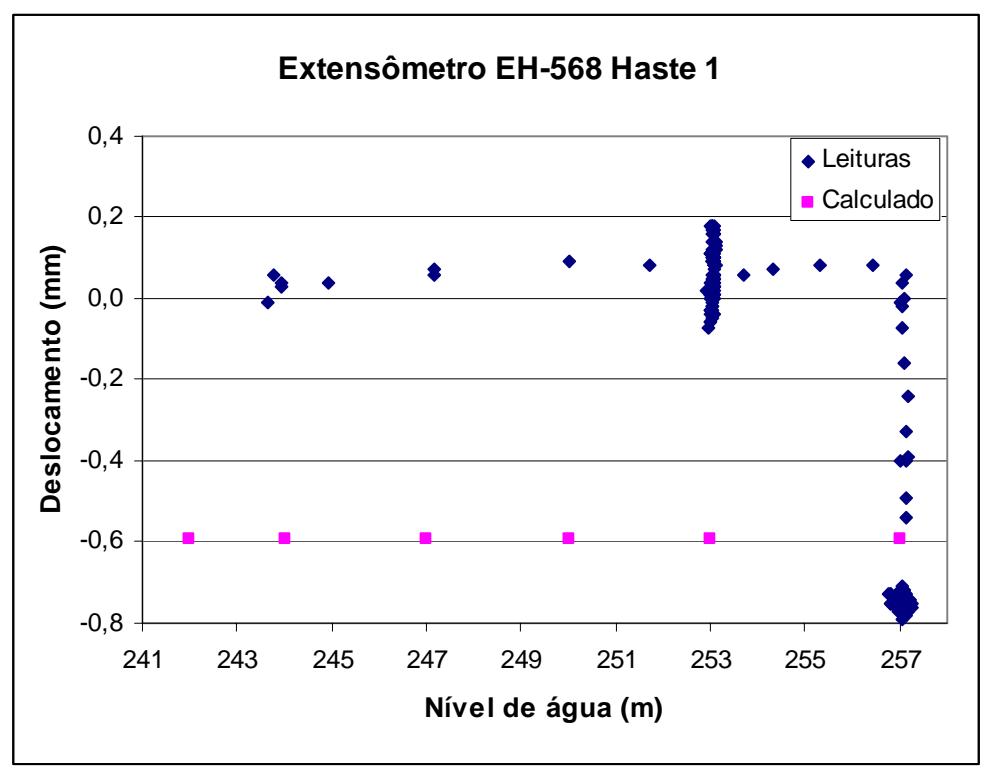

Figura 4.21 Comparação dos deslocamentos calculados e medidos da haste 1 do EH568.

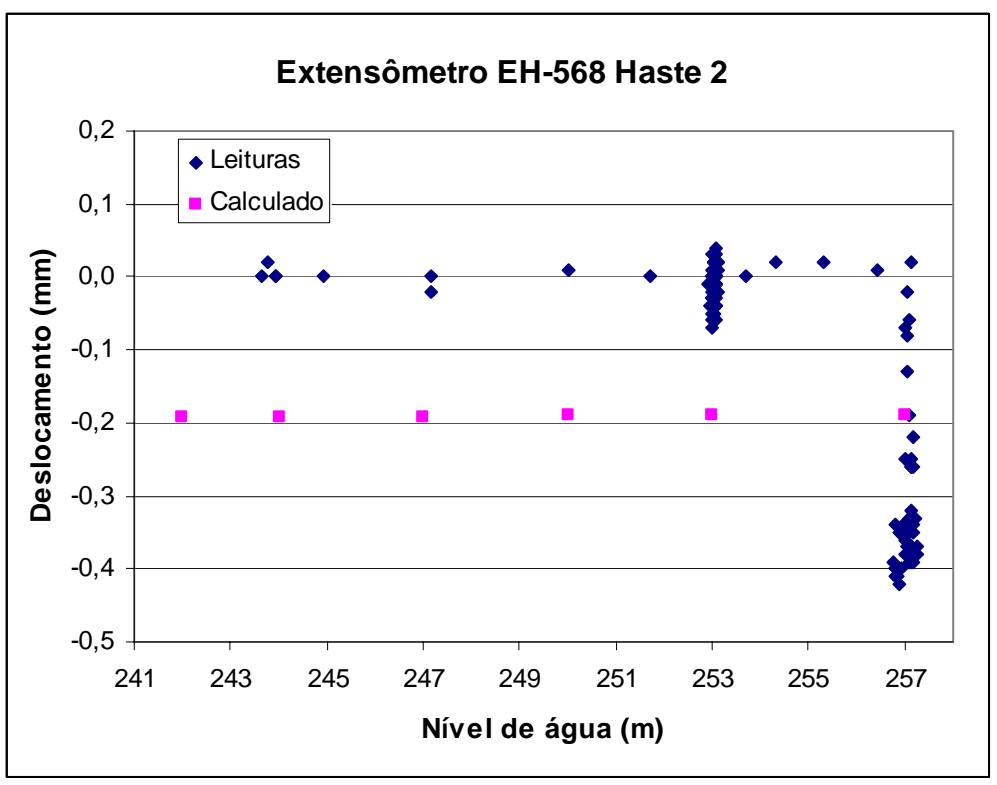

Figura 4.22 Comparação dos deslocamentos calculados e medidos da haste 2 do EH568.

De acordo com as figuras correspondentes à estrutura da tomada de água-casa de força, observa-se o mesmo comportamento da zona do vertedouro onde os valores calculados das hastes 3 próximas ao contato estrutura-fundação mostram-se mais próximos aos valores fornecidos pela instrumentação. Contudo, é importante analisar o porquê da tendência contrária das leituras em relação aos valores calculados, o que se expõe no item 4.2 .

Também, foi realizada a comparação das vazões calculadas e os registros de Rossana Herrera López 
vazões dos drenos nas seções de análise. A figura 4.23 mostra a comparação das vazões no vertedouro, enquanto que a figura 4.24 mostra a comparação para a estrutura tomada de água-casa de força.

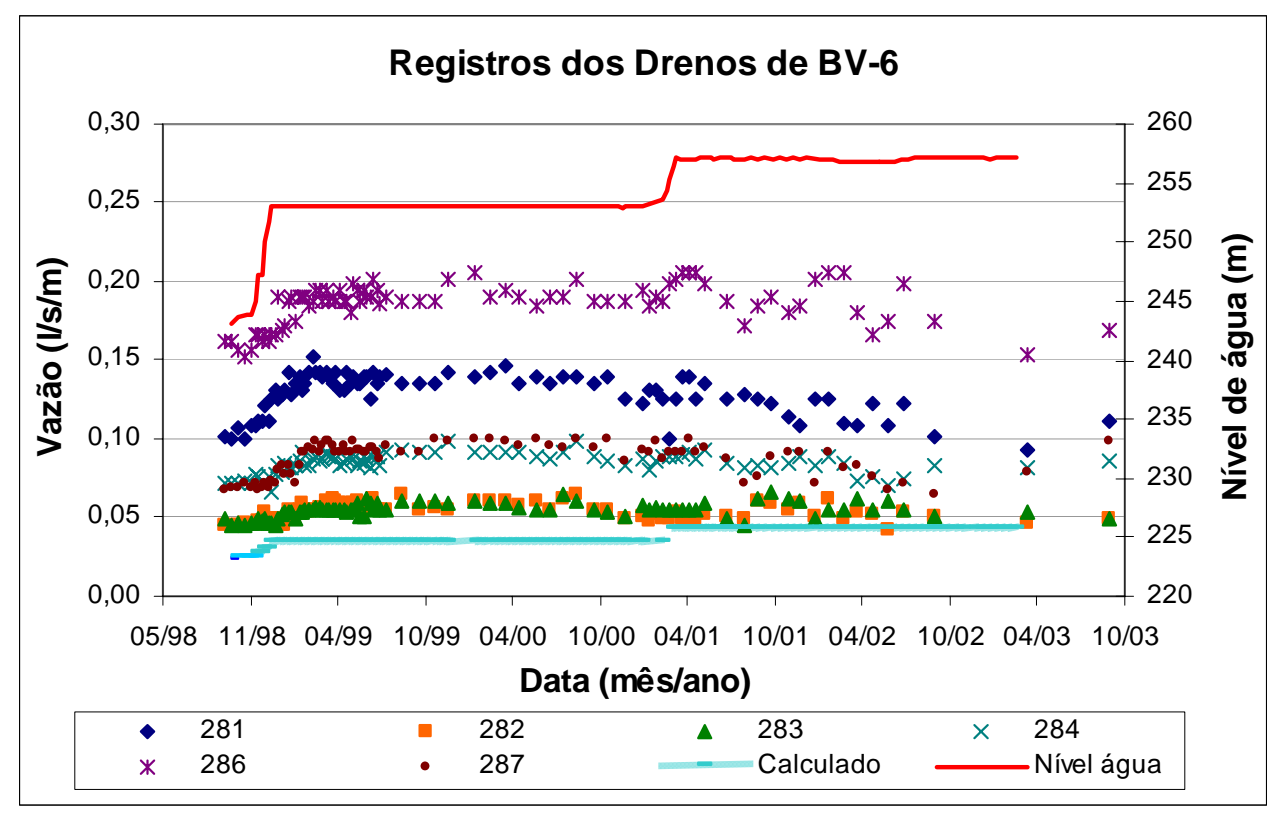

Figura 4.23 Comparação das vazões dos drenos do bloco BV-6 e as respectivas vazões calculadas.

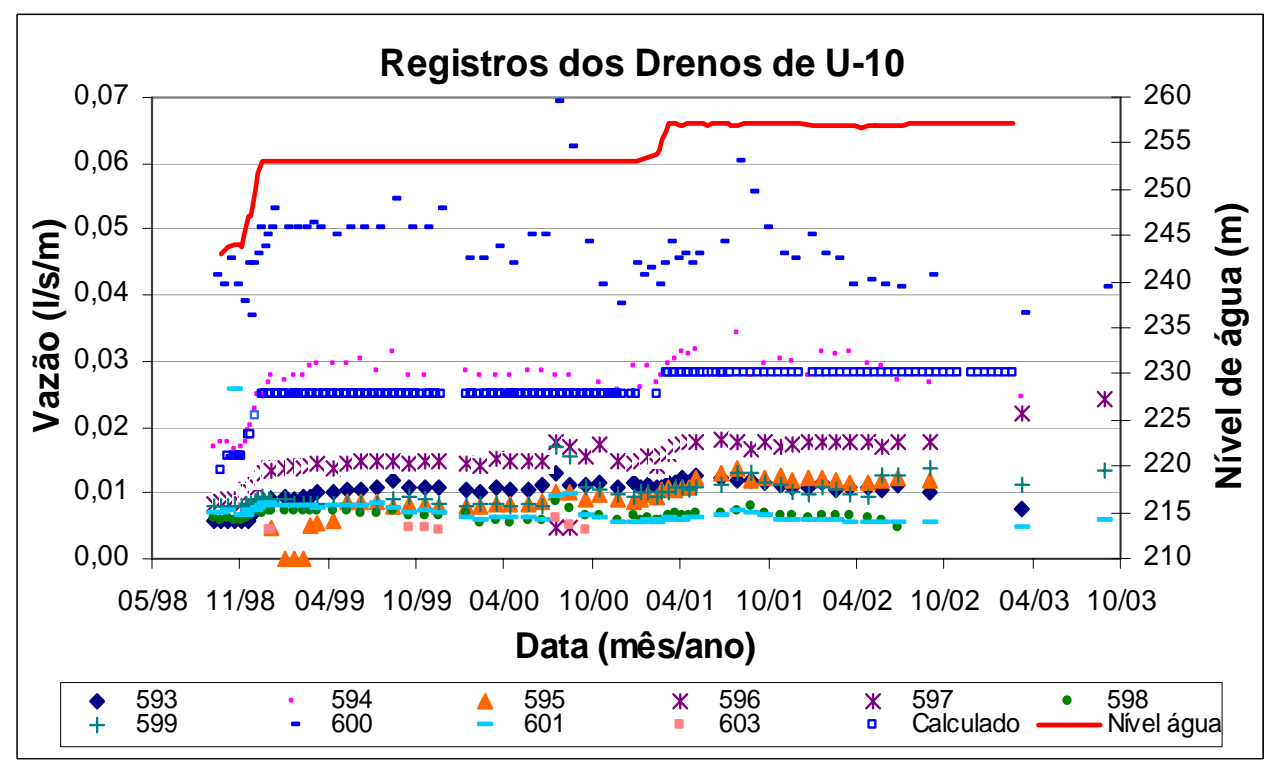

Figura 4.24 Comparação das vazões dos drenos da U-10 e as respectivas vazões calculadas.

\subsection{Discussão}

A partir da aferição dos deslocamentos da fundação do vertedouro e da casa de força, observaram-se os seguintes aspectos que merecem discussão para tentar explicar 
o comportamento do maciço basáltico da fundação da Usina de Porto Primavera.

Como se sabe, o maciço de fundação da barragem está conformado por derrames basálticos da Formação Serra Geral (Tressoldi, 1990). Estes derrames espessos de elevada continuidade lateral, denominados macroderrames, encontram-se mais constantes na fundação da estrutura tomada de água-casa de força, com presença de contatos à profundidade, preenchidos de brecha basáltica calcária e basalto amigdaloidal. Contudo, sob o vertedouro, os derrames não apresentam continuidade lateral e têm variação do material com contatos subverticais. Estas características brevemente citadas podem nos ajudar a explicar o comportamento do maciço.

Deve-se considerar, segundo Kovári e Bergamin (1994) que ante a presença de uma fenda ou fratura a montante, as hastes do extensômetro a montante sofrem contração sob a carga do peso próprio da estrutura e vai sofrendo distensão à medida que sobe o nível da água do reservatório sendo isto mais marcante nas hastes próximas à abertura. Ressalta-se que esta foi a tendência demonstrada pelos cálculos obtidos. Os deslocamentos do extensômetro a montante da cortina de vedação, segundo os cálculos, mostraram distensão à medida que se aumenta o nível de água, enquanto que o extensômetro orientado para jusante experimenta compressão sob o aumento da carga hidráulica. Esta tendência se reflete tanto no vertedouro como na casa de força.

A partir dessa tendência lógica do comportamento do maciço de fundação, quando comparados os deslocamentos calculados com os registros dos extensômetros existentes, observa-se um comportamento mais concordante no caso do vertedouro, não sendo assim para a casa de força que se mostra bem diferente, o que fica demonstrado com as figuras que mostram a relação entre os deslocamentos calculados e os medidos.

Segundo as figuras correspondentes ao extensômetro EH-261, observa-se que as três hastes mostram grande oscilação desde compressão no início do enchimento, para logo mostrar distensão, sendo que este comportamento se repete durante o tempo que o nível de água permanece constante. Esta variação continua se repetindo até nível de água mais elevado onde acontece de novo uma compressão maior para logo continuar com a mesma oscilação descrita acima, durante a segunda etapa de enchimento. Contudo, nem todas as hastes reagiram da mesma forma, visto que a segunda haste se mostrou mais marcante. A primeira haste mostrou uma oscilação intermédia, enquanto que a terceira oscilou menos. Aparentemente, isto poderia ser explicado pela 
variabilidade do material do maciço à profundidade visto que, como foi mencionado acima, o vertedouro encontra-se sobre derrames pouco constantes e existem descontinuidades, especialmente uma que passa próxima à segunda haste. O fenômeno de oscilação de compressão e distensão mostrada pelas hastes poderia ser entendido como uma resposta do maciço primeiramente a um aumento de carregamento (primeiro enchimento), e posteriormente à permanência de um carregamento hidráulico por um longo período de tempo, o que poderia ter provocado a abertura de fendas, levando o maciço a experimentar deformações oscilantes também provocadas pela influência da variação sazonal da temperatura (Guidicini e Andrade 1987). O processo de abertura de trincas no maciço é na realidade dependente do tempo, devido a componentes viscosas do comportamento do material intacto. Esta dependência não é levada em conta no modelo matemático. As figuras 4.25 e 4.26 nos fornecem uma visão deste fenômeno.

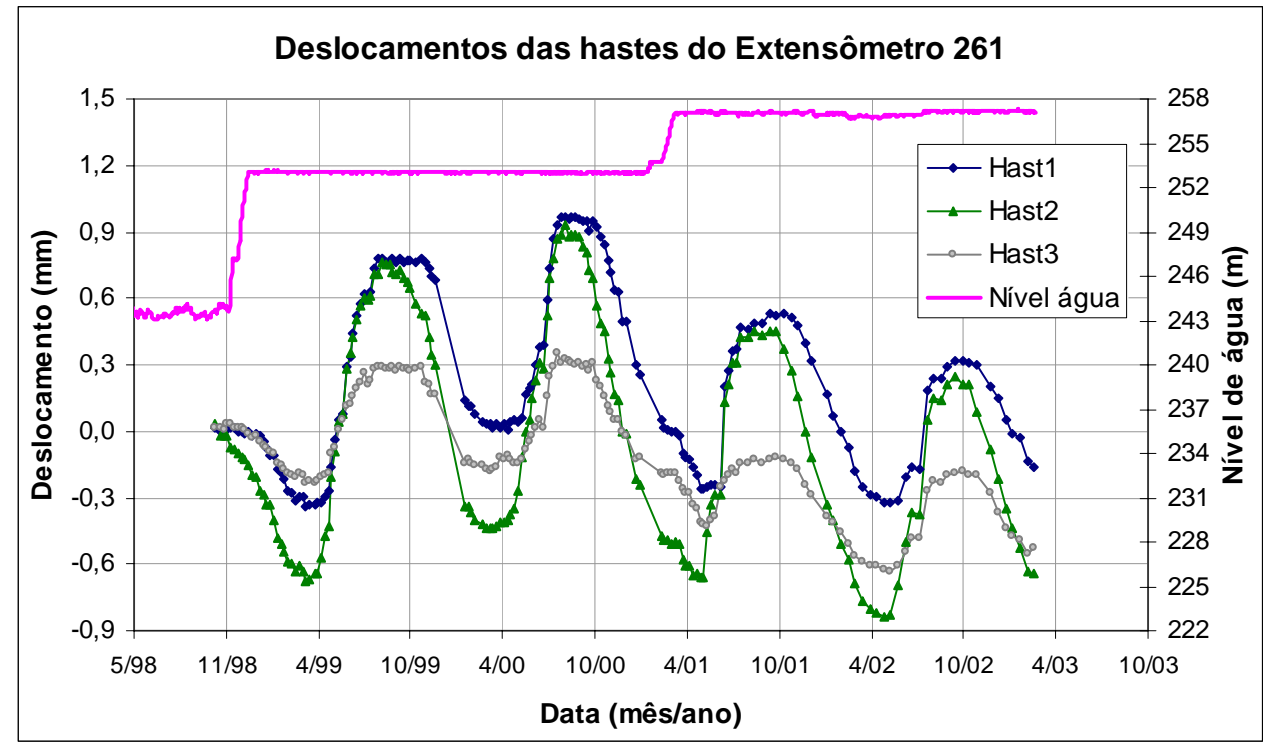

Figura 4.25 Deslocamentos das hastes no tempo do enchimento em relação ao nível de água do reservatório.

No vertedouro, um aspecto importante a ressaltar é a diferença de tendências na comparação de resultados medidos e calculados para as hastes correspondentes à região superficial. Isto somente pode ser explicado por heterogeneidades presentes na fundação, na escala da estrutura, não detectadas na caracterização do maciço.

Outro aspecto que deve ser comentado está relacionado com a possibilidade da influência da variação sazonal de temperatura como mostra a figura 4.26, onde a oscilação dos deslocamentos foi cíclica, produzindo-se compressão quase um mês depois de acabado o inverno, e distensão a quase dois meses de ter acabado o verão. Isto 
poderia ser devido ao resfriamento ou ao aumento de temperatura do meio rochoso (Guidicini e Andrade, 1987).

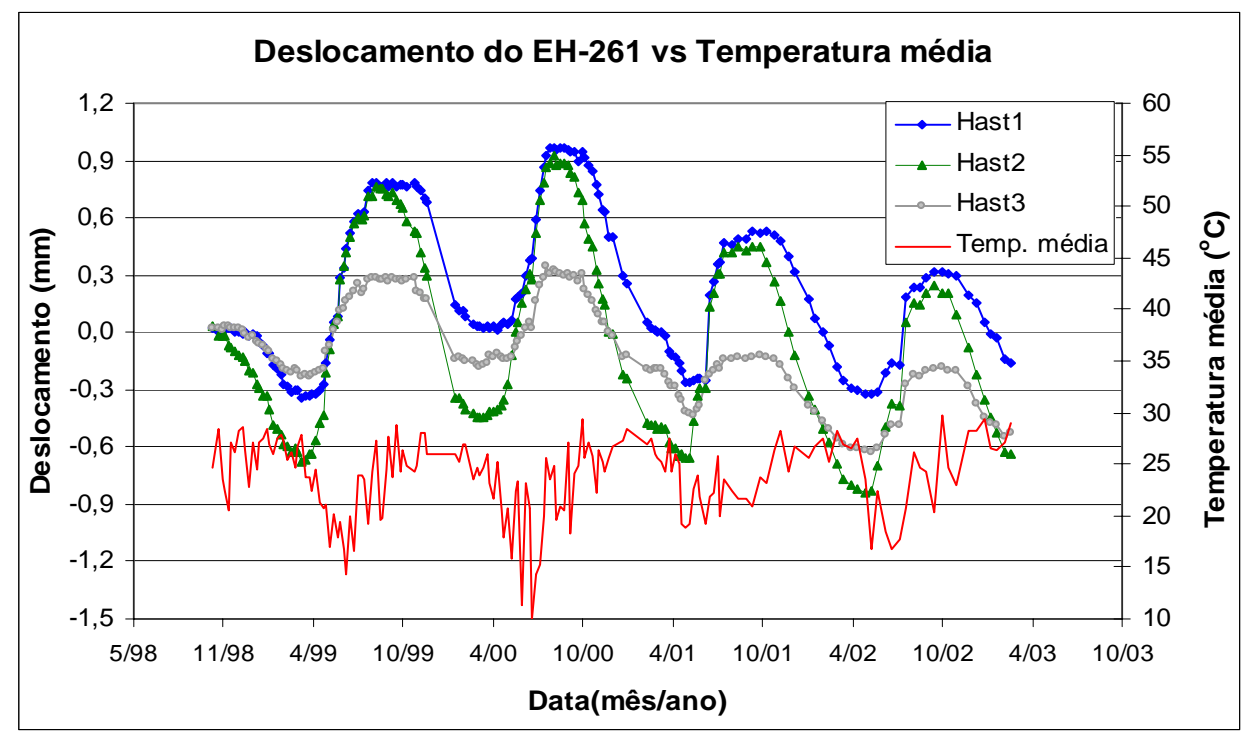

Figura 4.26 Deslocamentos das hastes em relação à temperatura média.

O extensômetro EH-262 experimenta uma situação similar ao EH-261 com a diferença de que a haste 3 quase não mostra distensão do maciço, enquanto que as hastes 1 e 2 mostram uma oscilação menor entre compressão e distensão. Isto poderia ser explicado devido à sua posição visto que esta se encontra a jusante do tratamento de impermeabilização e dreno, de modo que as descontinuidades e fraturas não se veriam tão afetadas pelo carregamento hidráulico. As figuras 4.27 e 4.28 apresentam os deslocamentos das hastes do extensômetro EH-262 no tempo.

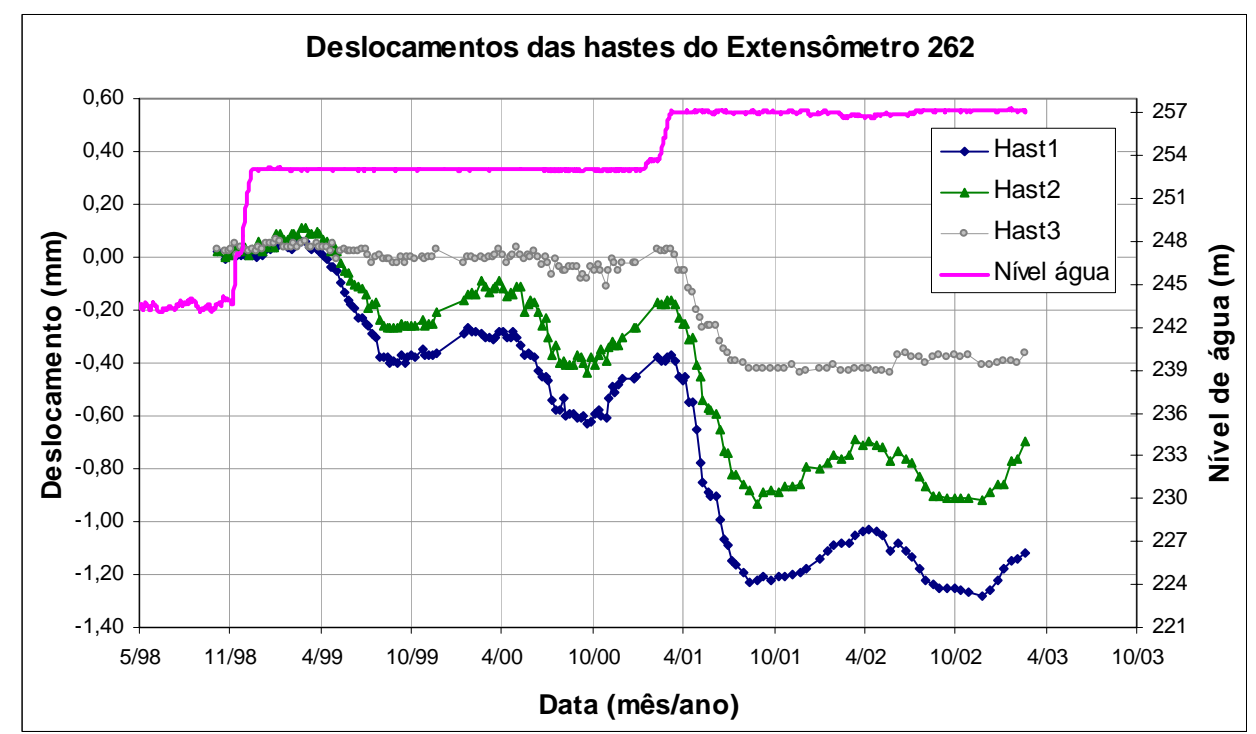

Figura 4.27 Deslocamentos das hastes em relação ao nível de água do reservatório. 
Em relação aos cálculos para o EH-262, estes mostram uma tendência de compressão similar às leituras. Quanto à oscilação mostrada pelas leituras das hastes sob os carregamentos dos níveis $253 \mathrm{~m}$ e $257 \mathrm{~m}$, não se conseguiu simulá-la por não se dispor de um programa que considere o carregamento e a degradação do material no tempo.

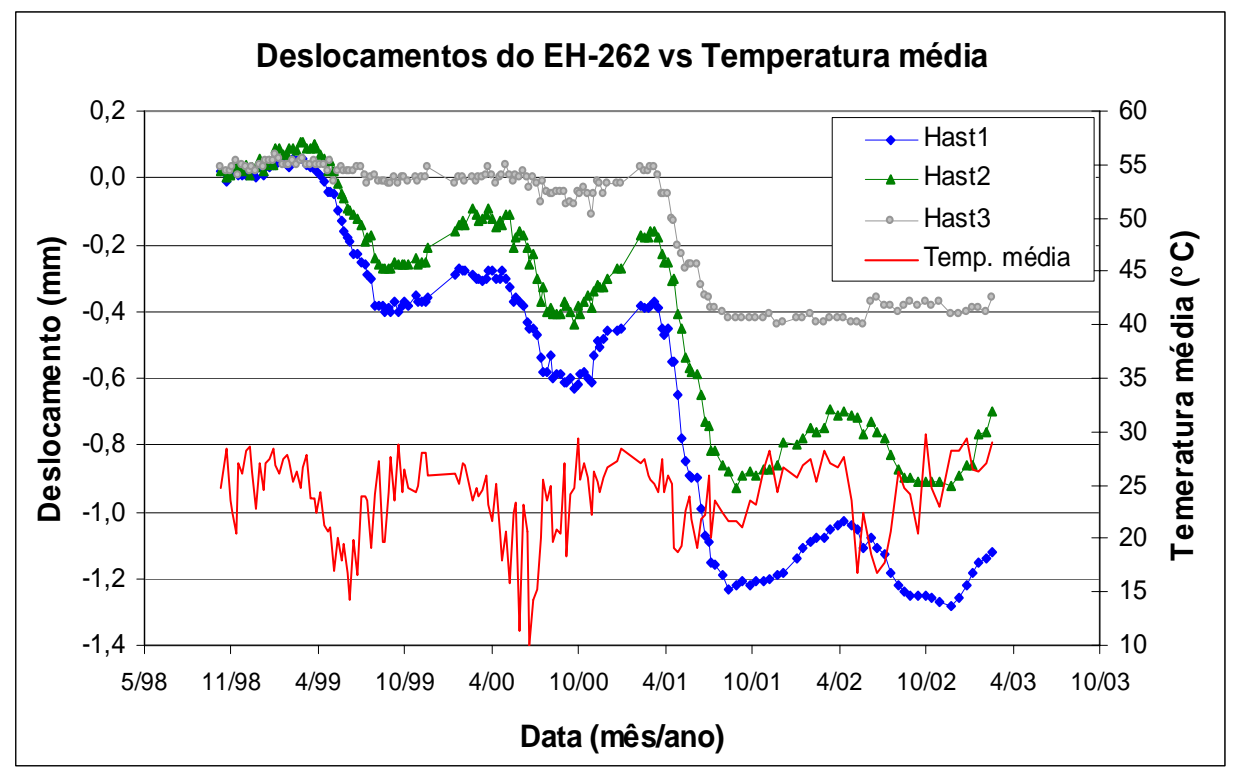

Figura 4.28 Deslocamentos das hastes em relação à temperatura média.

No caso da casa de força, é necessário dizer que devido à não concordância dos deslocamentos calculados e os deslocamentos das leituras, principalmente dos extensômetros EH-566 e EH-567 se torna difícil afirmar o que motivou esta contradição. Uma possível causa poderia ser a geologia local. Contudo a oscilação de compressão e distensão cíclica se mostra muito similar entre as hastes do EH-566 como o ilustra a figura 4.29. Com os primeiros carregamentos de níveis inferiores a 253m, as leituras registraram compressão, mas quando este carregamento permanece no nível do primeiro enchimento (ou seja, 253m) e logo no segundo enchimento no nível 257m, verificou-se a ocorrência de grande oscilação.

Conforme a figura 4.29, parece que a zona do extensômetro EH-566 (de montante) reage de acordo a determinados períodos do ano, sendo possível relacionar o comportamento oscilante à variação das temperaturas. A figura 4.30 mostra os deslocamentos ocorridos em relação à temperatura média. 


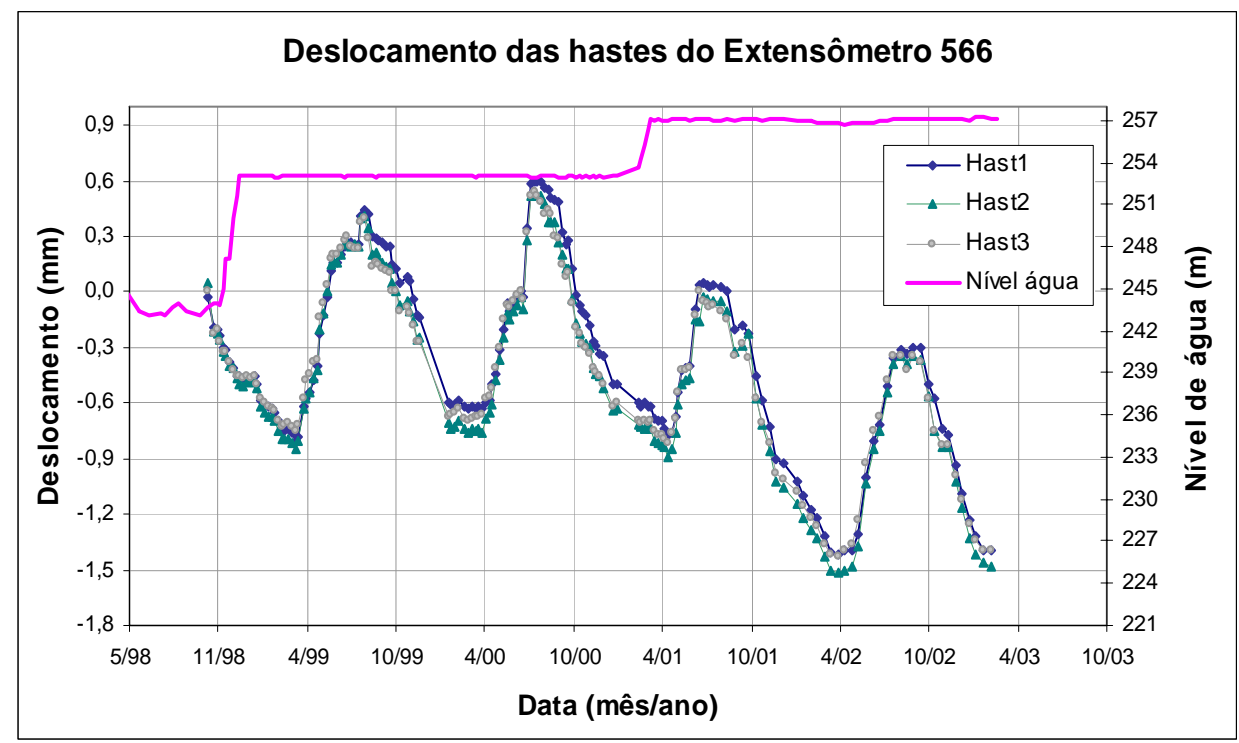

Figura 4.29 Deslocamentos das hastes no tempo em relação ao nível de água.

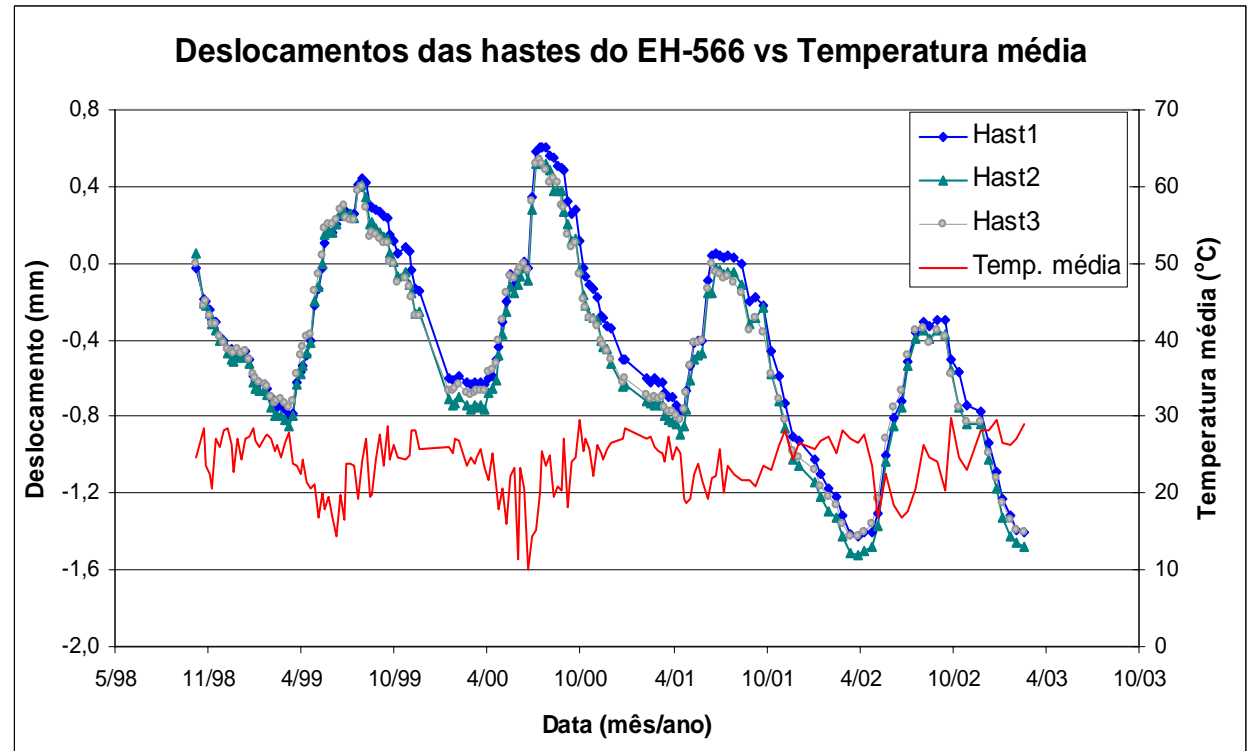

Figura 4.30 Deslocamentos das hastes do EH-566 em relação à temperatura média.

A figura 4.31 apresenta os deslocamentos das hastes do EH-567 com uma oscilação menor, mas semelhante às hastes do EH-566. Já no caso do EH-568 a oscilação foi irregular e, sob o carregamento máximo, mostra uma tendência à estabilização como apresenta a figura 4.32. A figura 4.33 mostra os deslocamentos em relação à temperatura média. 


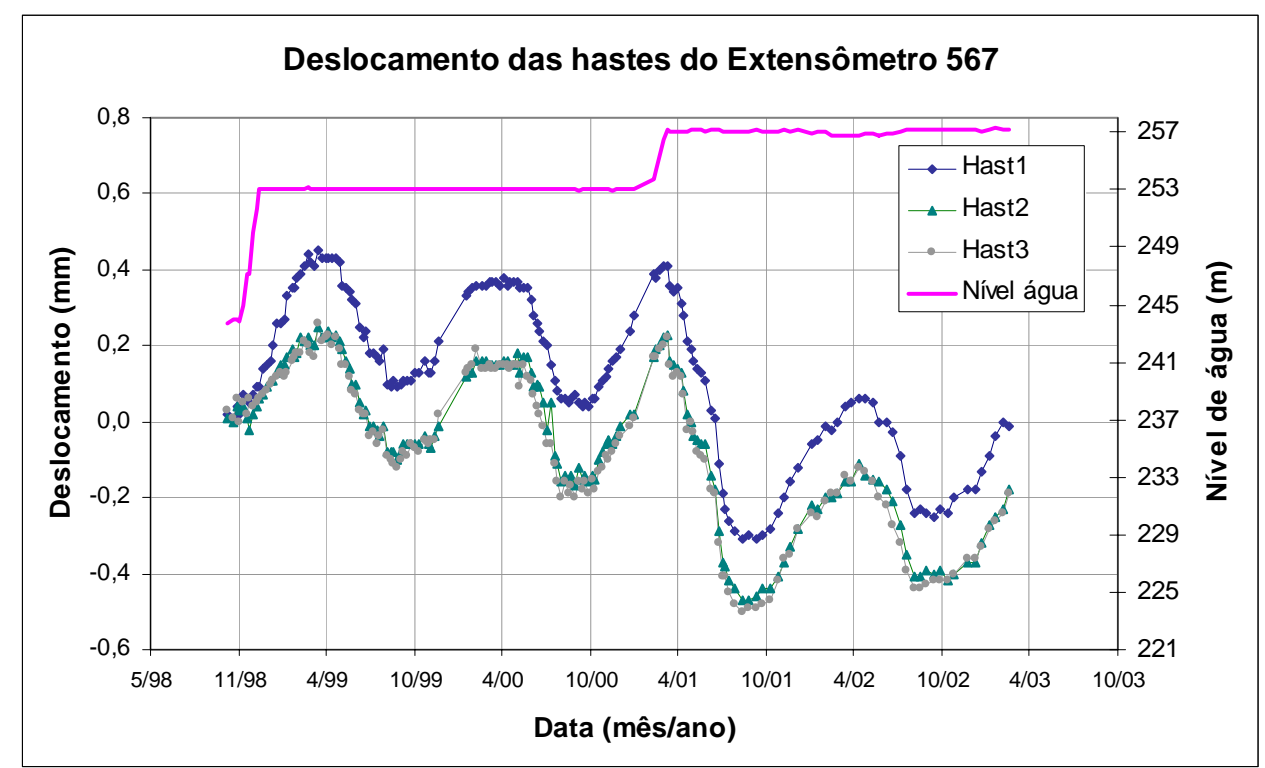

Figura 4.31 Deslocamentos das hastes no tempo em relação ao nível de água.

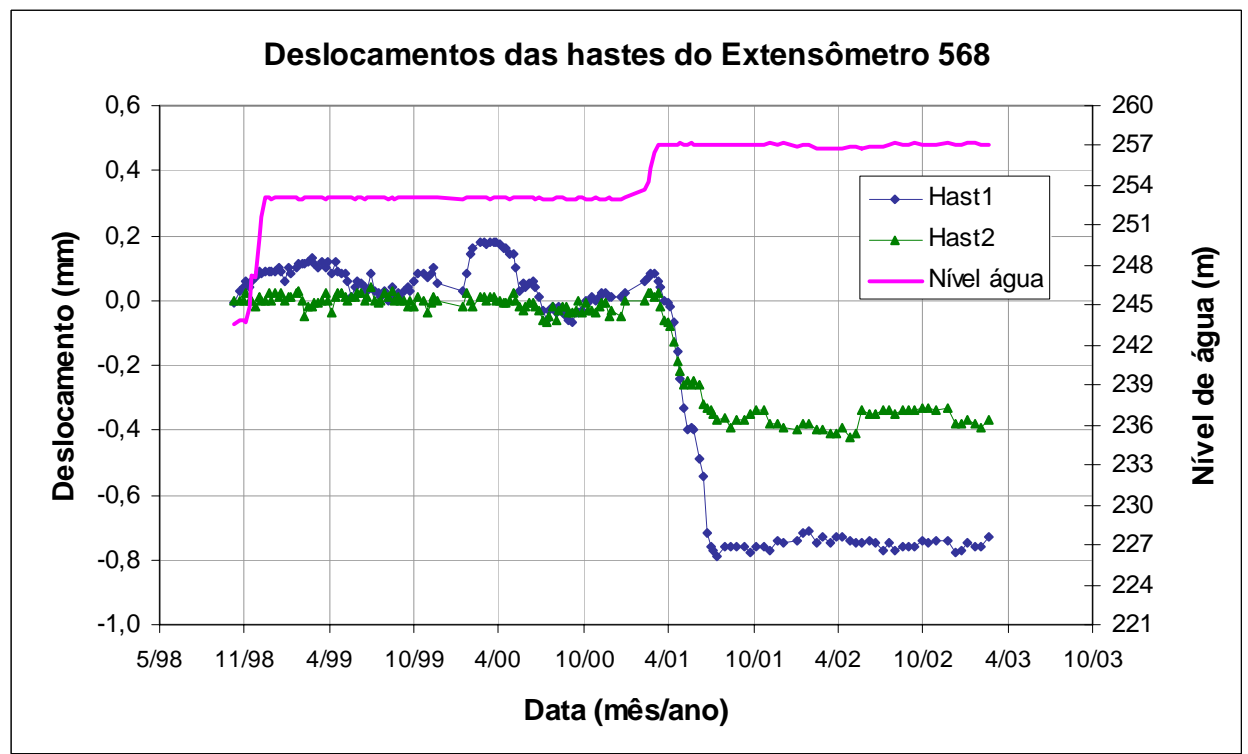

Figura 4.32 Deslocamentos das hastes do EH-568 no tempo em relação ao nível de água. 


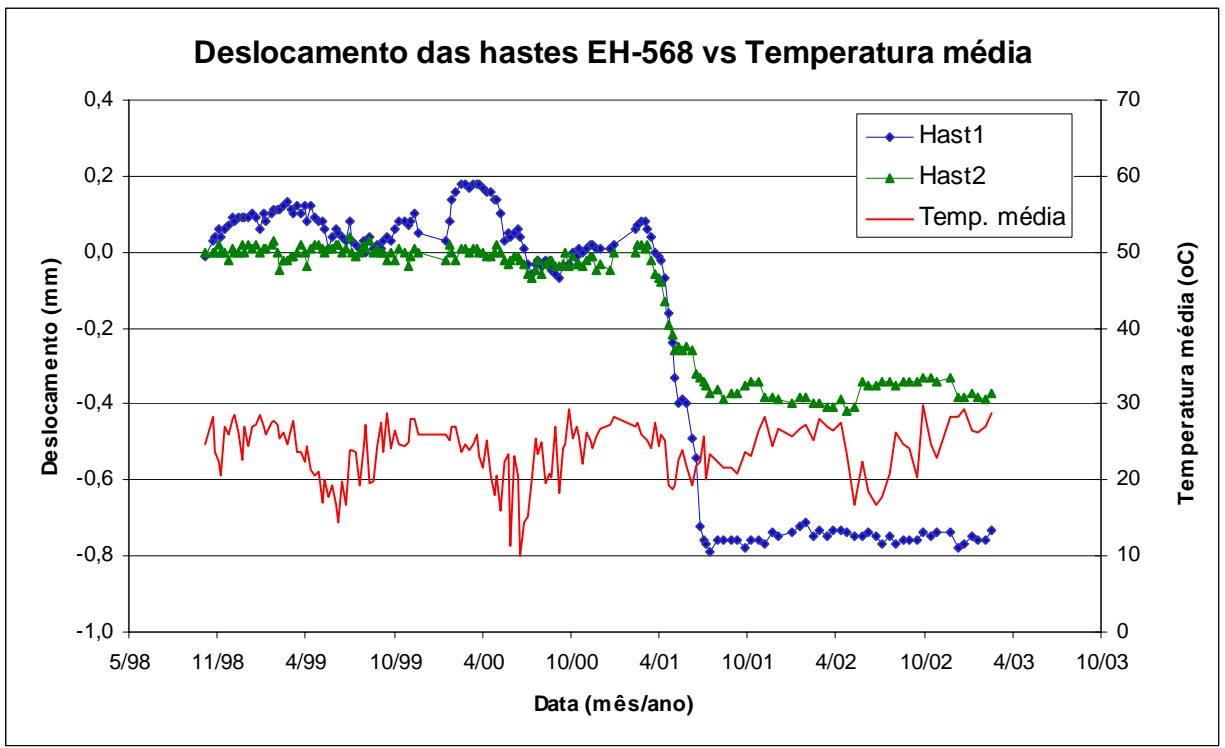

Figura 4.33 Deslocamentos das hastes do EH-568 em relação à temperatura média.

Como foi visto nas figuras apresentadas, a influência da temperatura se torna um fator a mais a considerar nas análises. Por esta razão, as hastes dos extensômetros foram relacionadas entre si a fim de se verificar o que acontecia quando, simultaneamente, uma experimentava distensão e a outra compressão sob uma mesma temperatura. Por meio das figuras 4.34 a 4.36, mostram-se essas relações para o caso do vertedouro.

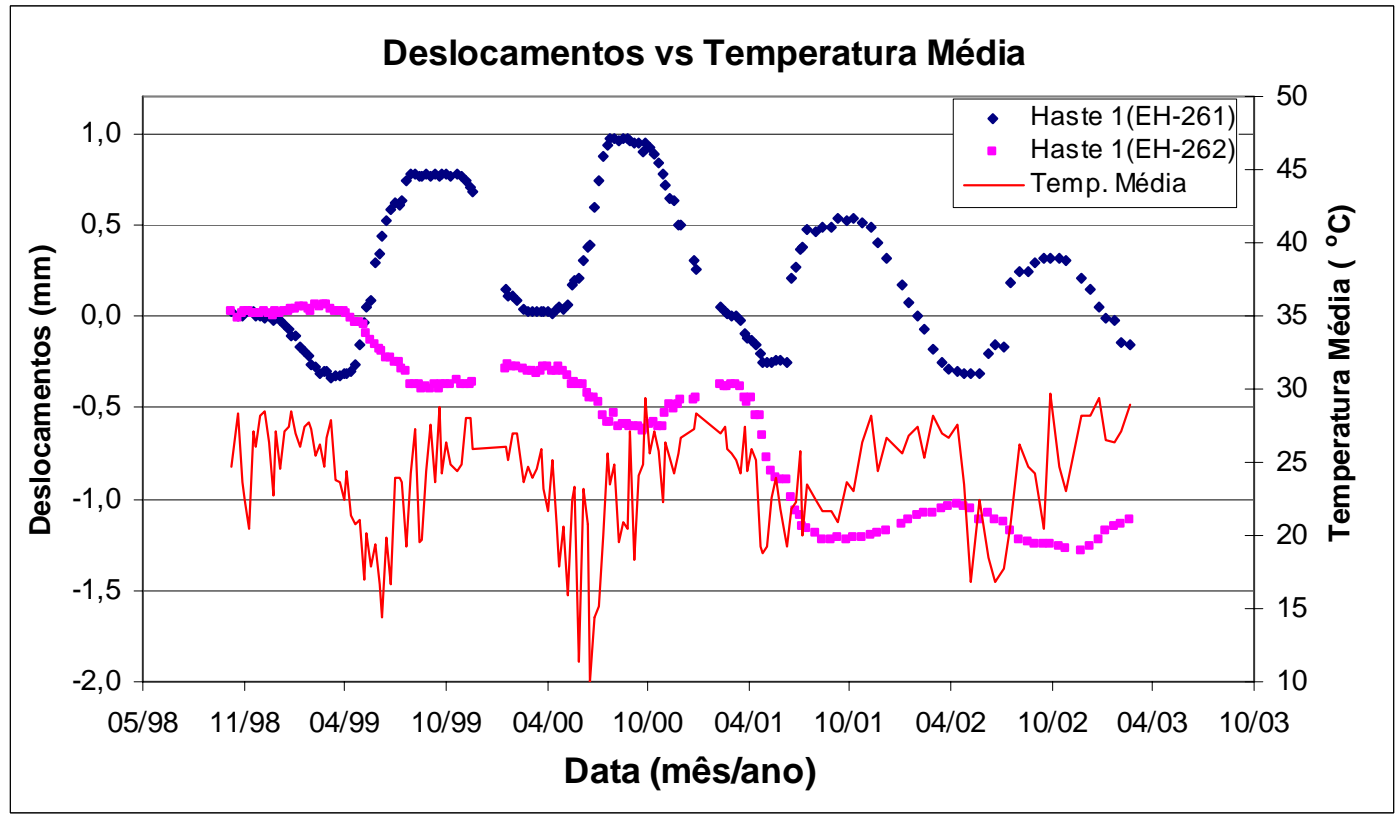

Figura 4.34 Comparação das hastes 1 dos extensômetros 261 e 262. 


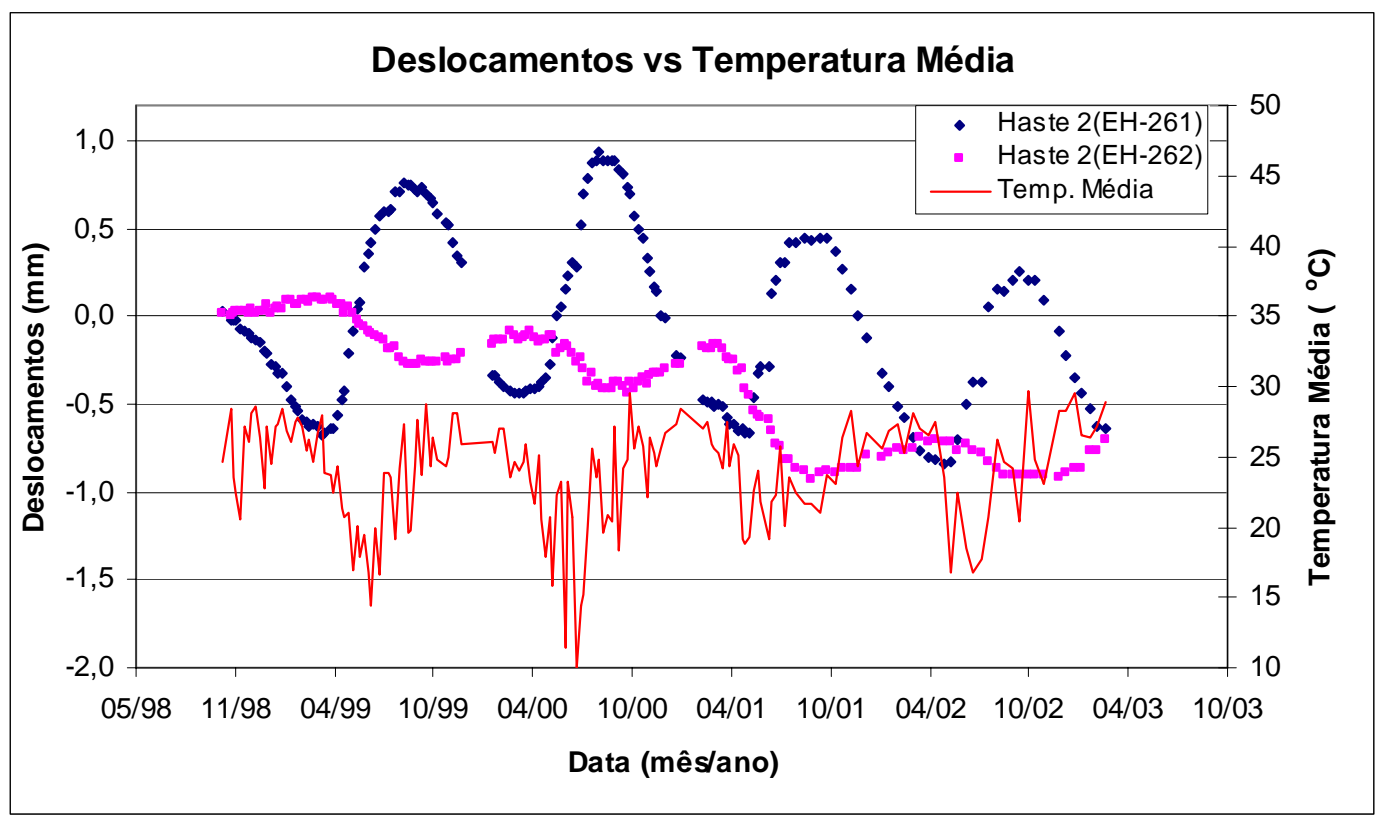

Figura 4.35 Comparação das hastes 2 dos extensômetros 261 e 262.

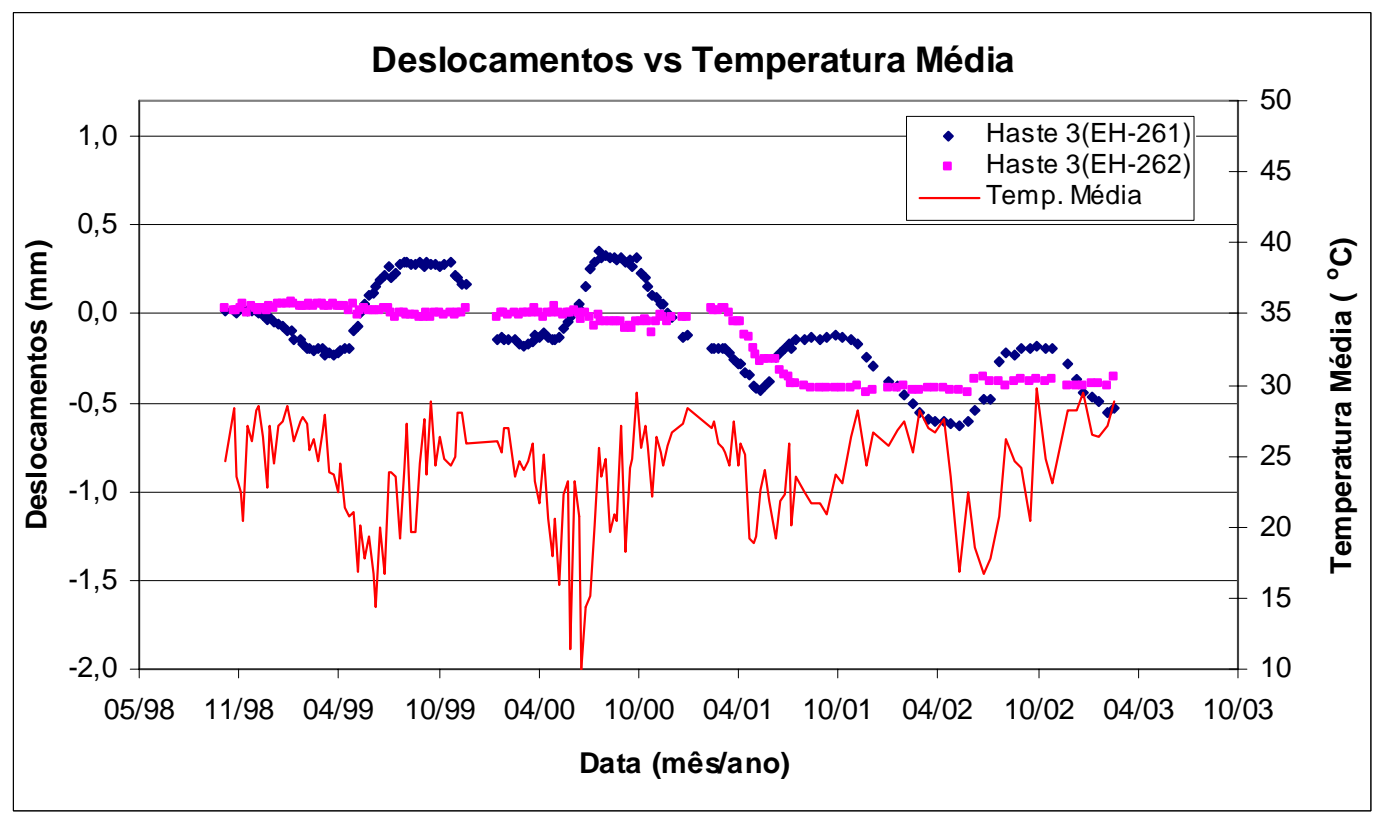

Figura 4.36 Comparação das hastes 3 dos extensômetros 261 e 262.

Para o caso da casa de força, a comparação dos deslocamentos das hastes dos extensômetros EH-566 e 567 mostra também uma relação dependente da presença da fratura, só que a oscilação das hastes a montante se mostra mais constante, o que poderia ser atribuído à influência da fratura. As figuras 4.37 a 4.39 mostram a comparação dos extensômetros. 


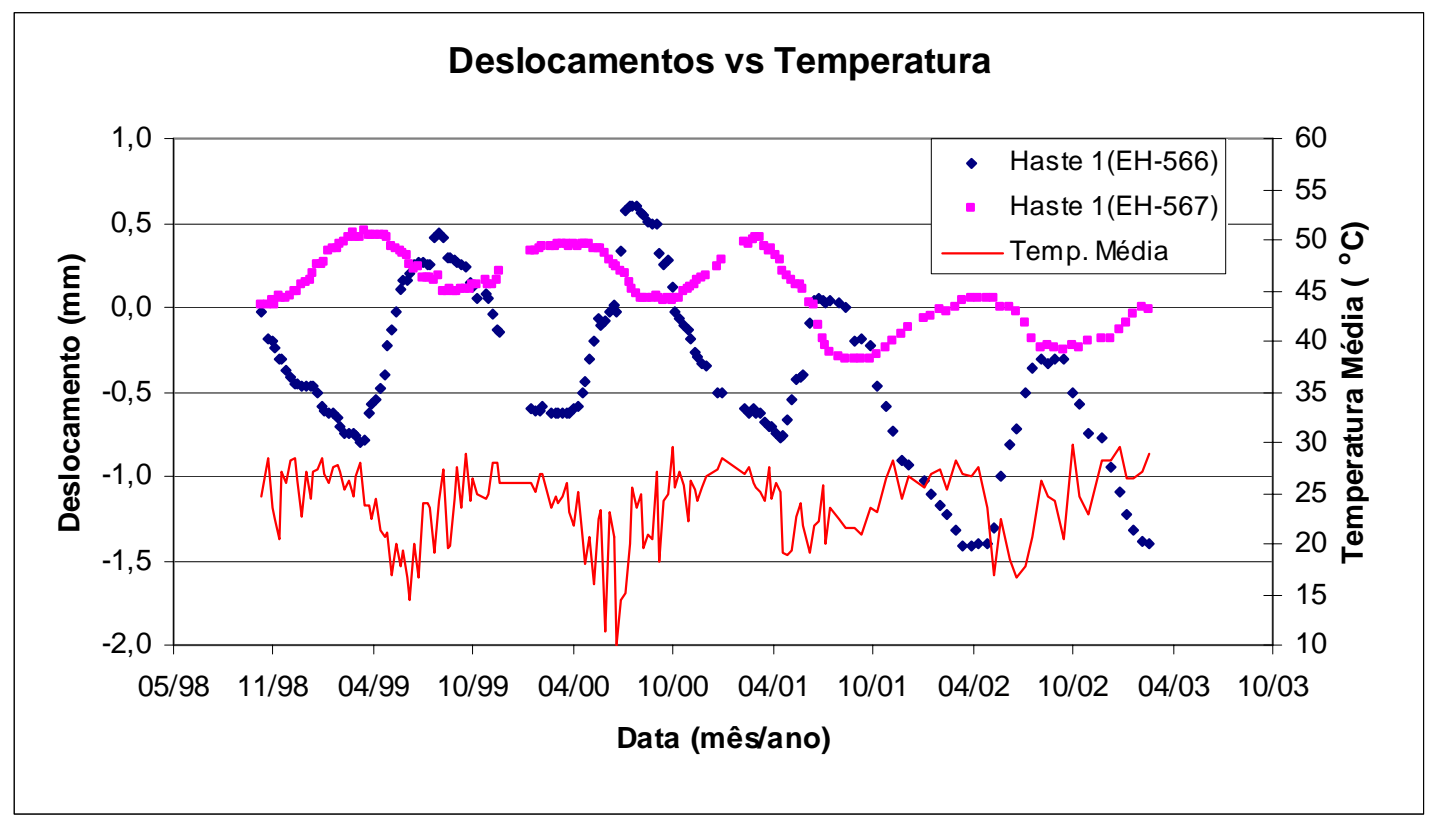

Figura 4.37 Comparação das hastes 1 dos extensômetros 566 e 567.

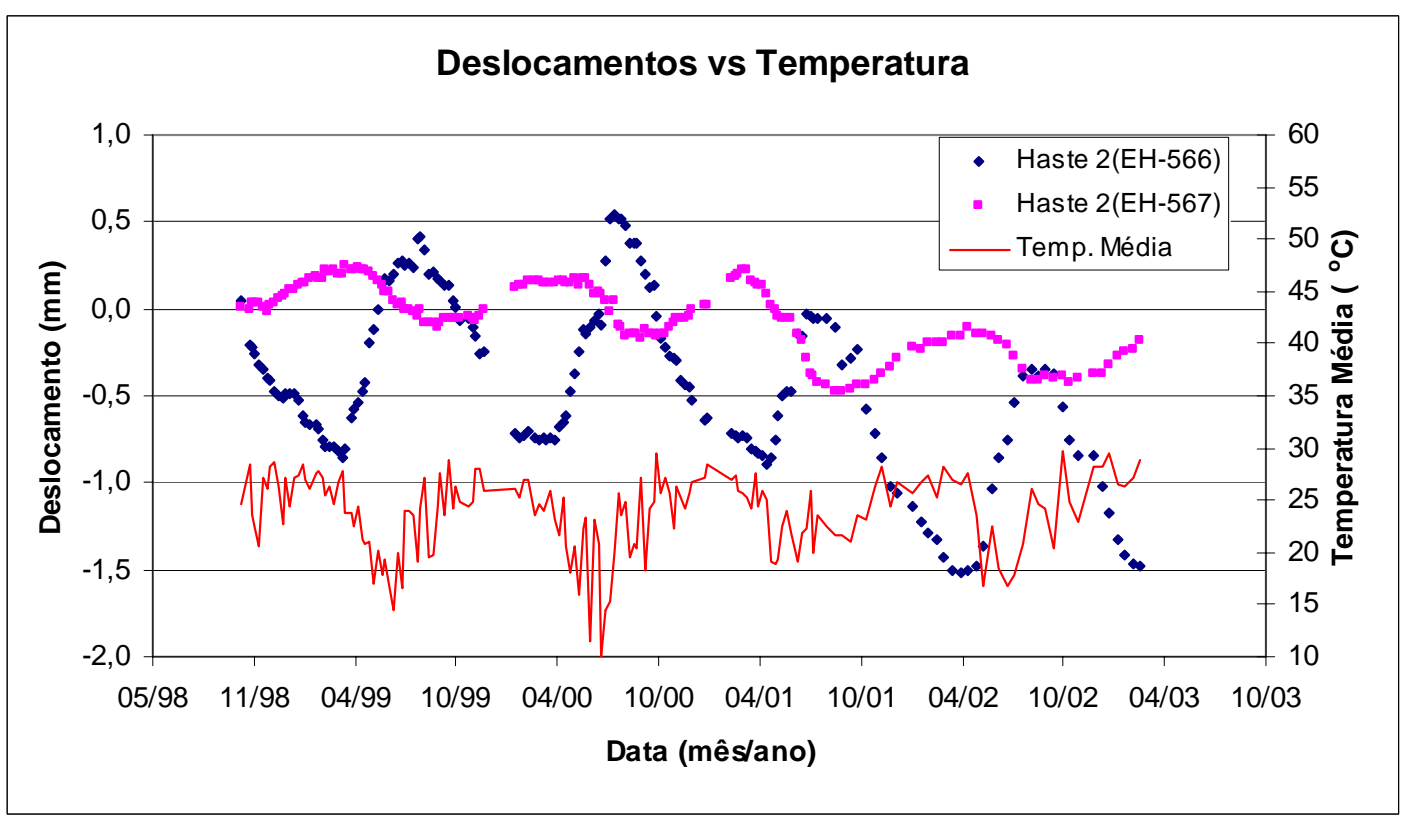

Figura 4.38 Comparação das hastes 2 dos extensômetros 566 e 567.

No que concerne às relações das hastes a montante, observa-se que as oscilações são maiores, o que evidencia a sensibilidade da zona aos efeitos térmicos que não poderia ser só atribuída ao concreto da galeria visto que os deslocamentos dos extensômetros da mesma galeria mostram diferentes oscilações.

Será preciso também, deixar em claro que as hastes dos extensômetros estão sujeitas a deformações por variações de temperatura. E a pesar que não há medidas de 
temperatura conhecidas no interior de maciços de barragens brasileiras, conhecem-se dados de variação de temperatura de água de reservatórios, que revelam uma amplitude sazonal a pequena profundidade bem menor que a da temperatura ambiente. A amplitude para a água em profundidade é ainda menor que a da água a pequena profundidade. Em conseqüência, no interior do maciço, a amplitude deve ser ainda menor que a da água em profundidade. Por esta razão não tem sido comum considerar a influência da variação de temperatura nas leituras.

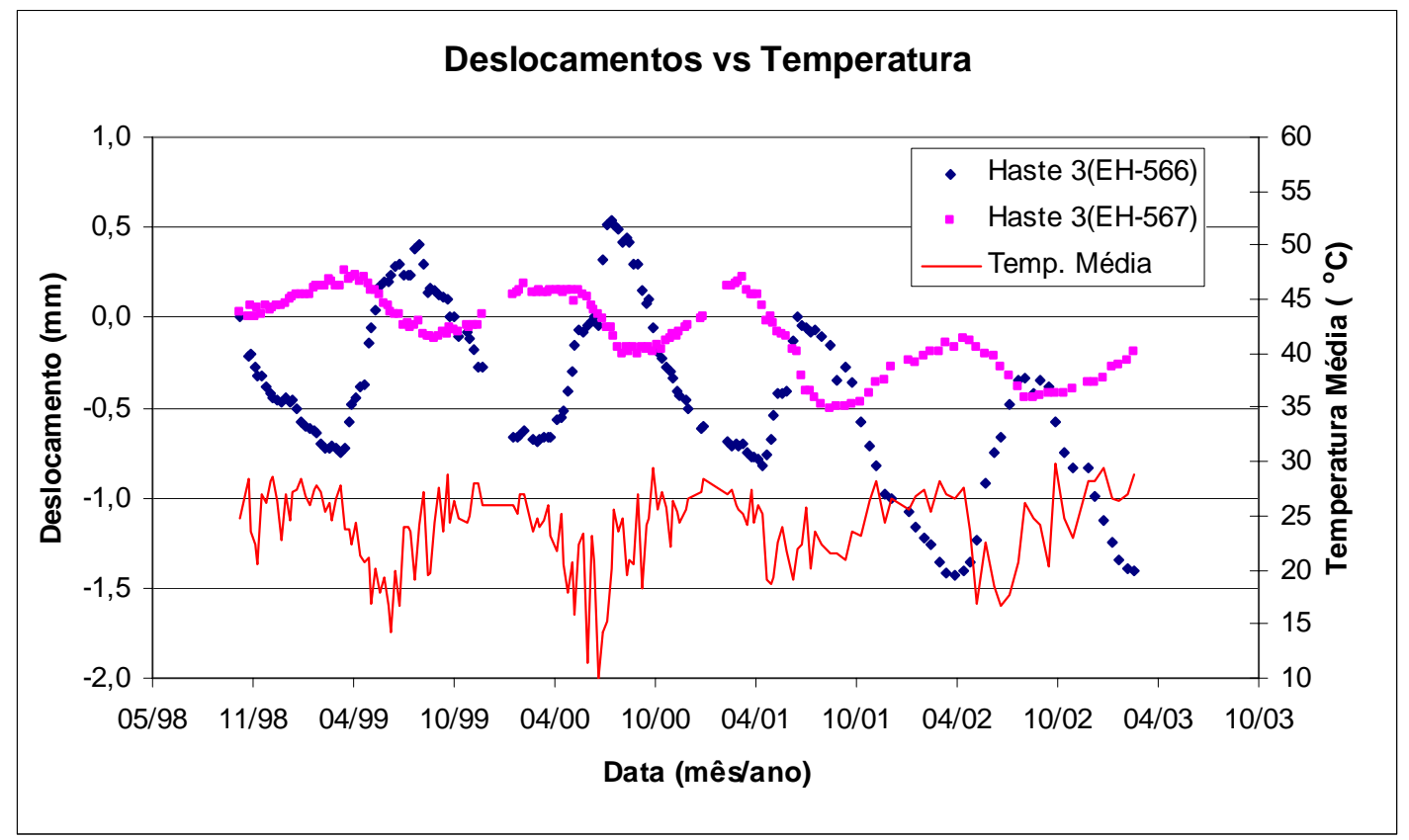

Figura 4.39 Comparação das hastes 3 dos extensômetros 566 e 567.

Outro aspecto importante e que deve ser submetido à discussão é o efeito da presença da fratura na zona de montante das estruturas do vertedouro e da casa de força. Segundo os cálculos, desenvolveu-se uma fratura no pé de montante do vertedouro que avançou à profundidade de $10 \mathrm{~m}$. A fratura passou pelas hastes 2 e 3 e devido a isto poderia se dizer que o efeito se vê refletido nos deslocamentos que mostram certa tendência com as leituras dessas hastes. A figura 4.40 apresenta a fratura desenvolvida em relação à instrumentação no vertedouro. 
Figura 4.40 Desenvolvimento da fratura a montante do vertedouro.

Na casa de força, desenvolveu-se uma fratura de aproximadamente 12,4m de comprimento, a qual passou, também, pelas hastes 1 e 2 do EH-566 como apresenta a figura 4.41. Esta fratura parece que influiu no piezômetro PZ-567 como se pode apreciar na figura 4.42 .

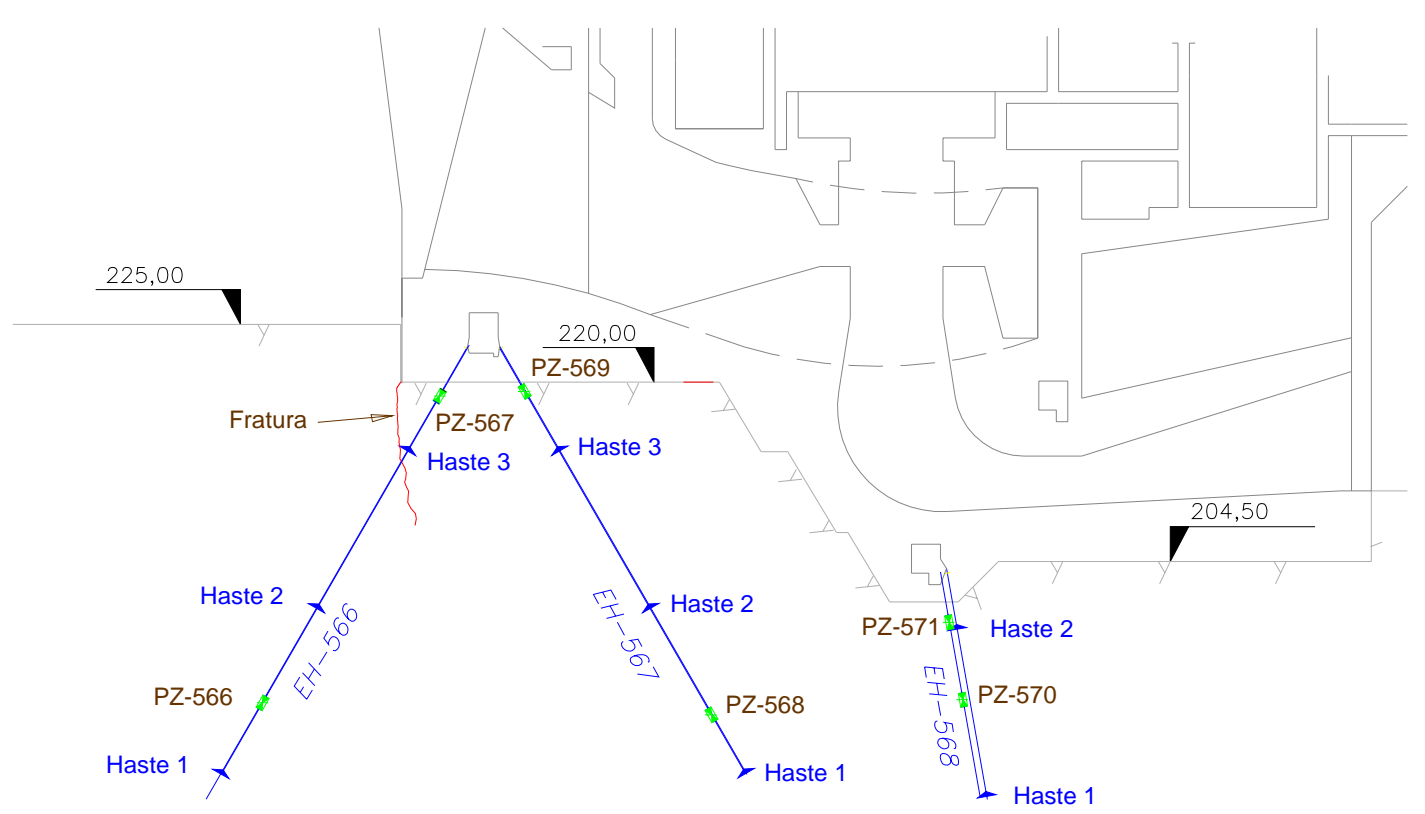

Figura 4.41 Desenvolvimento da fratura a montante da estrutura tomada de água-casa de força.

Em relação aos registros dos piezômetros e do nível de água, verifica-se que o piezômetro PZ-567 mostra algumas alterações ao se elevar a carga hidráulica para o nível $257 \mathrm{~m}$, dando motivo a se suspeitar quanto a alguma influência da fratura nessa 
zona do piezômetro, sendo isto uma prova a mais da presença do fraturamento.

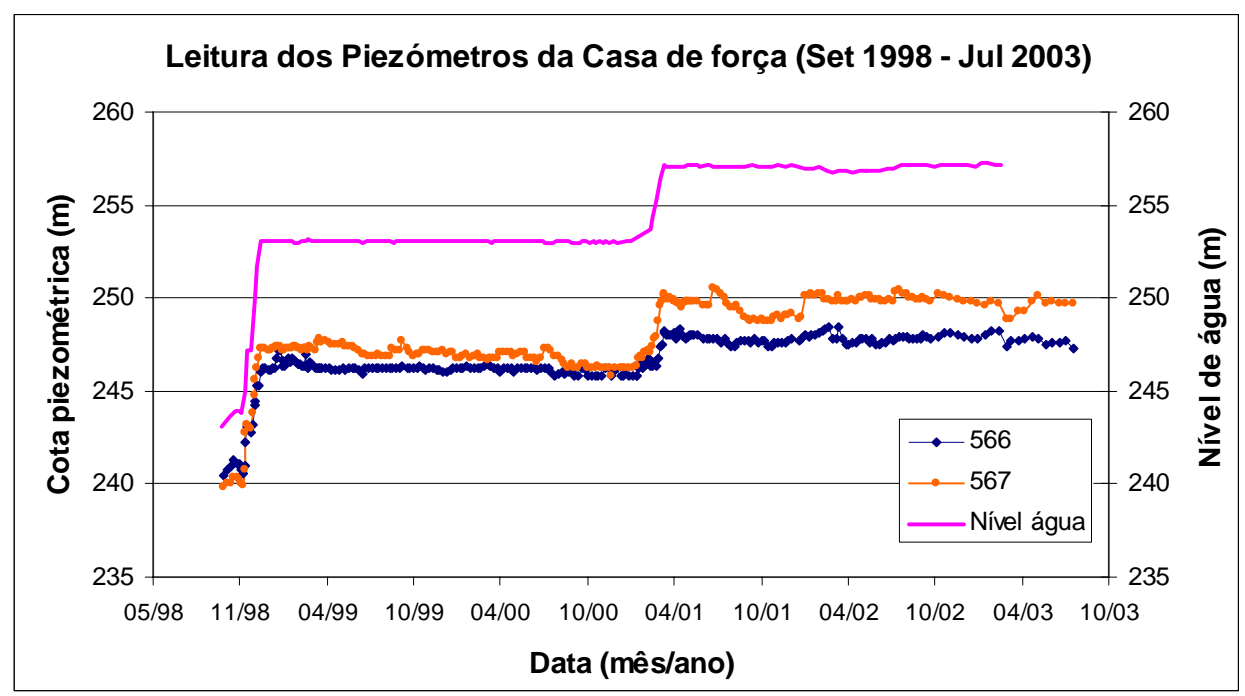

Figura 4.42 Leituras dos piezômetros a montante em relação ao nível de água.

Esta situação da influência da fratura nos registros dos piezômetros a montante se vê refletida, também, numa análise inicial que foi feita na seção do vertedouro BV-2 (ver figura 4.43), onde a fratura, obtida da simulação, passou próxima ao piezômetro PZ-222, e este tinha registrado, nas leituras, alterações marcantes no período de enchimento como mostra a figura 4.44 .

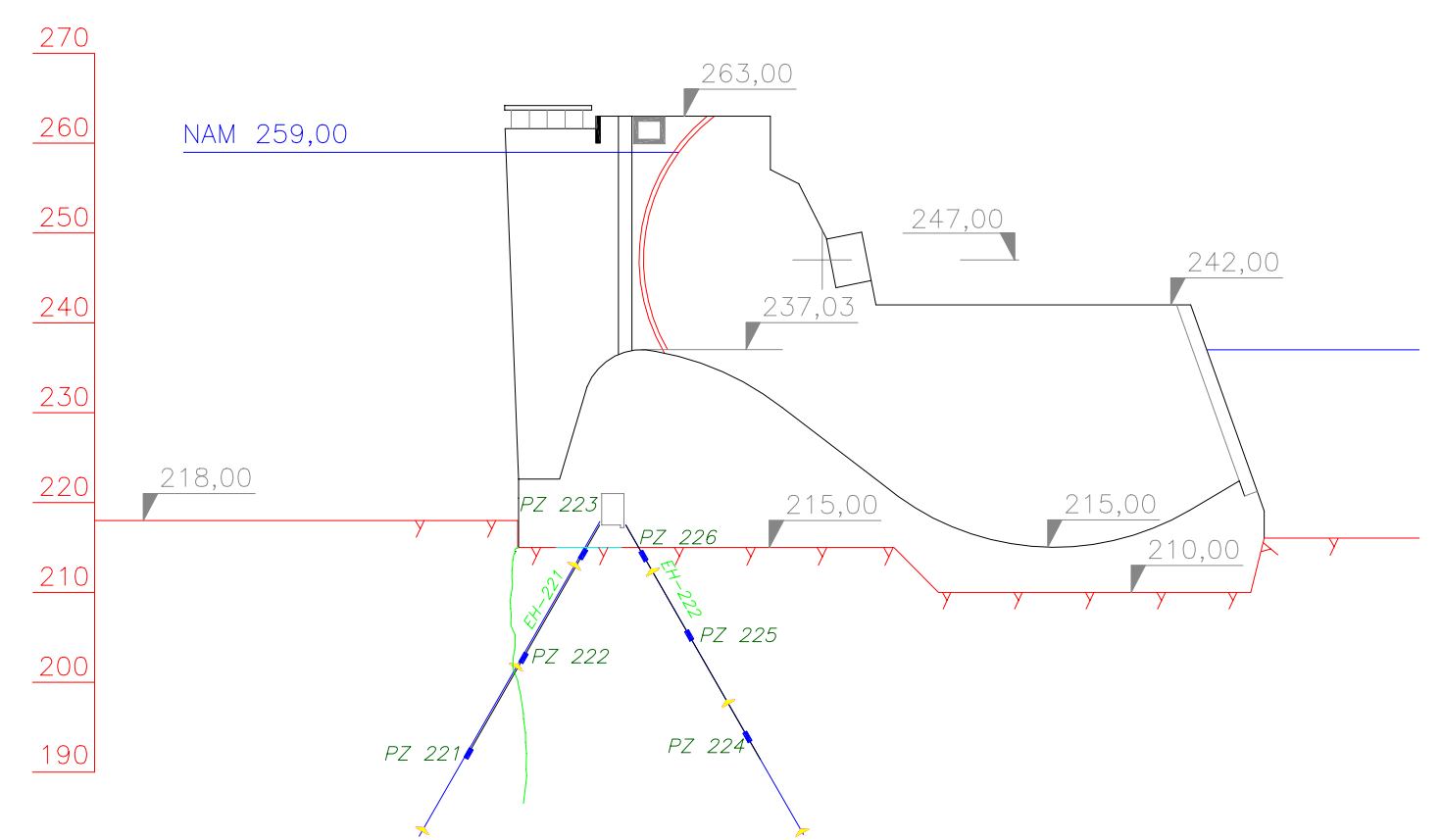

Figura 4.43 Localização da fratura em relação aos piezômetros na seção BV-2.

Com base na análise realizada, pode-se dar por aceita a presença do fraturamento e os efeitos que este tem na fundação, determinando-se que é necessário o ajuste dos 
parâmetros do módulo de deformabilidade do maciço para os distintos derrames.

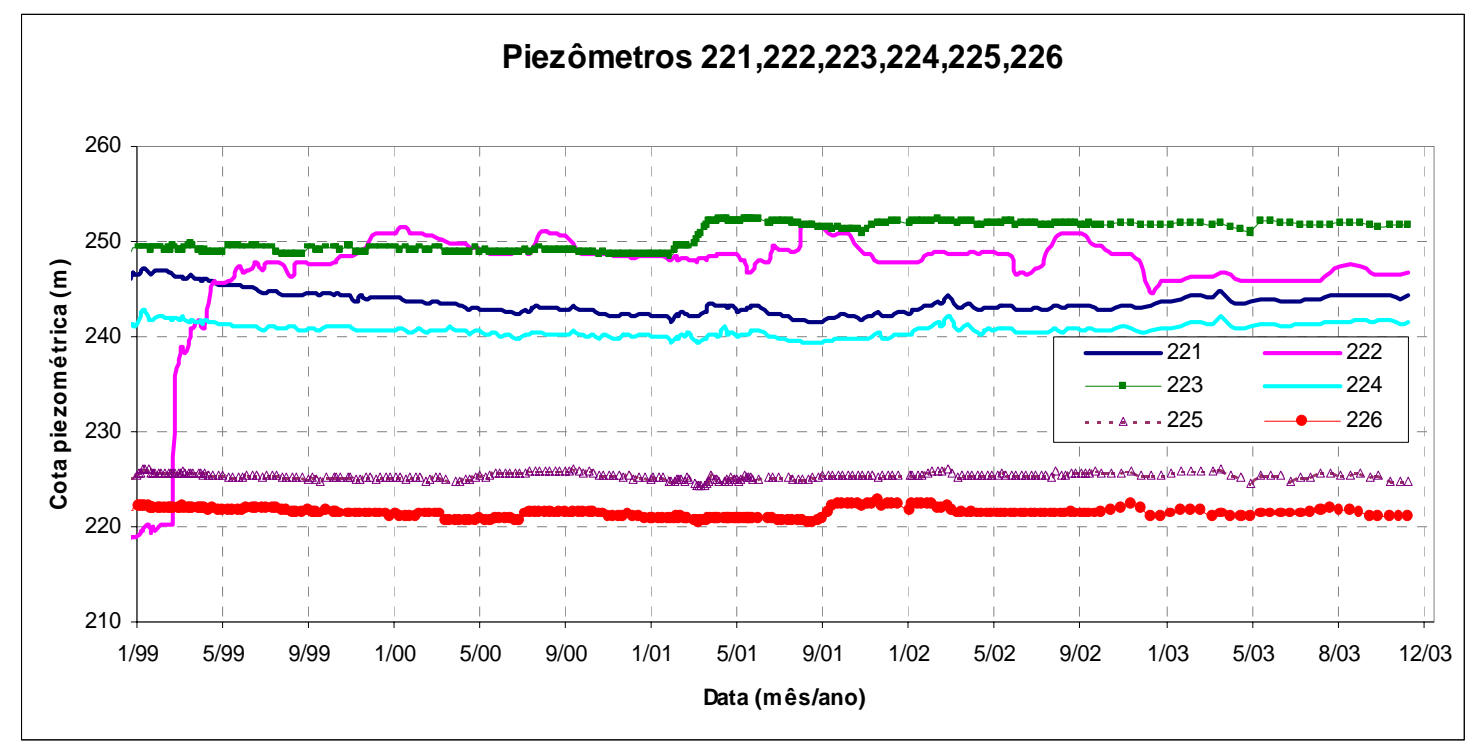

Figura 4.44 Leituras dos piezômetros PZ-221, PZ-222, PZ-223, PZ-224, PZ-225 e PZ226 no vertedouro BV-2.

Com base nos resultados da análise de fluxo e subpressão foi feita uma avaliação da variação da subpressão para o caso sem fratura e com a presença da fratura sob o nível de água de 257m. Verifica-se, a partir disto, que a fratura origina o aumento da subpressão a montante, situação que se dá em menor grau a jusante. Este efeito apresenta-se na figura 4.45

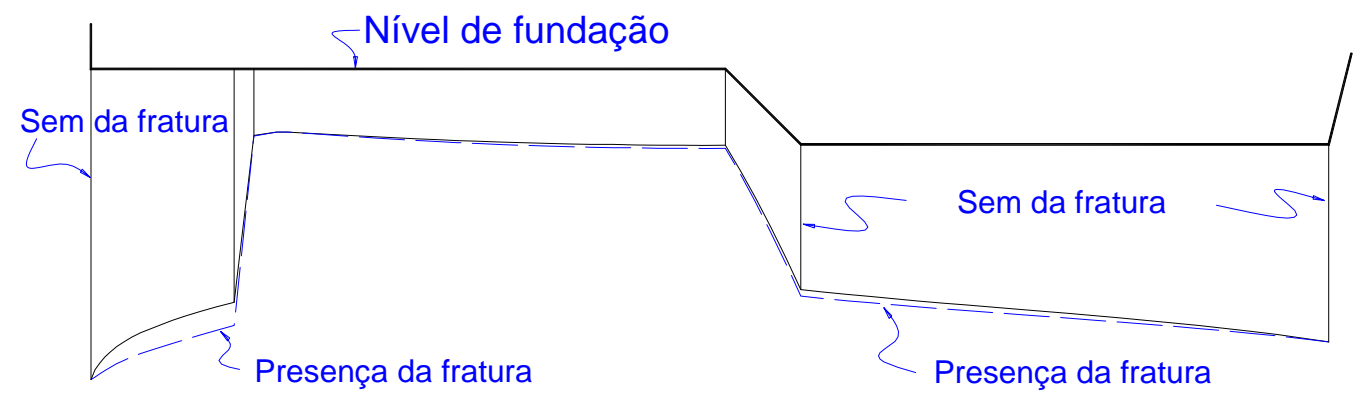

Figura 4.45 Subpressão calculada sem fratura e com fratura na fundação do vertedouro.

Por fim, em relação às pressões na fratura, considerou-se fazer uma comparação dos critérios de Rocha e Cruz, adotadas na prática comum, e os resultados da análise, tomando-se as pressões para o nível máximo de água de 257m no vertedouro. A figura 4.46 mostra a comparação. 


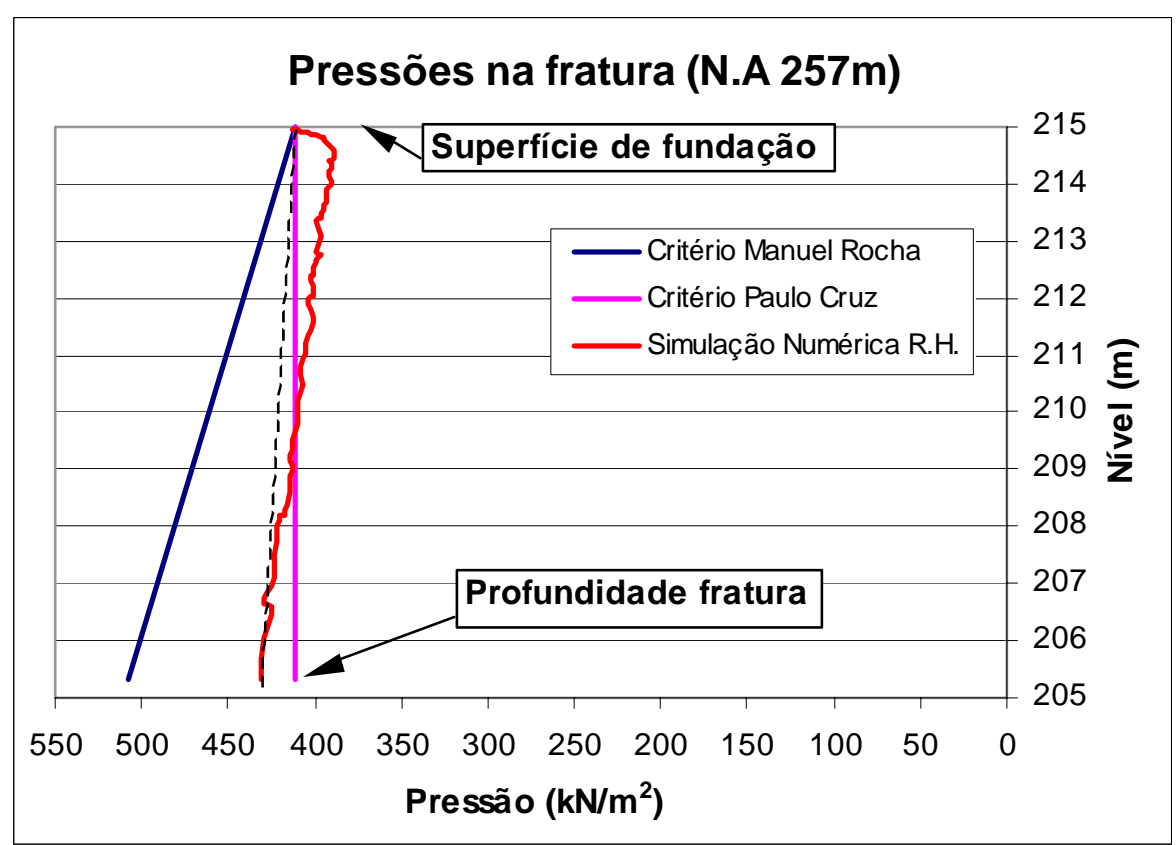

Figura 4.46 Comparação dos critérios de projeto e o resultado da simulação numérica.

Ao fazer a comparação das pressões na fratura em relação às pressões calculadas, esta última se apresenta um tanto menor nas proximidades da superfície da fundação para logo, a profundidade, se situar entre os outros dois critérios e mais próxima ao critério de Cruz (1978). Isto poderia ser explicado pelo tamanho da abertura na superfície da fundação. A tendência de aumento das pressões calculadas poderia ser considerada pela linha tracejada. Essa tendência mostrada pela simulação numérica demonstra a clara vantagem da aplicação da Mecânica da fratura em análises de fundações de barragens, vantagem esta que acabará se refletindo em termos econômicos. 


\section{CONCLUSÕES}

O trabalho de pesquisa teve a finalidade de discernir problemas relacionados à presença de fratura e os efeitos que esta provocaria na fundação, especialmente a montante da cortina de vedação. A principal preocupação foi a de determinar as variáveis que devem ser consideradas ao se assumir parâmetros que caracterizam os materiais e os critérios adotados na elaboração de modelos matemáticos que possam representar fielmente o estado de tensões do sistema barragem-fundação-água. É importante mencionar que, mais que uma comparação numérica, procurou-se chegar a determinar os parâmetros que permitam avaliar a segurança e a estabilidade da estrutura, assim como ajudar no controle da instrumentação e, conseqüentemente, a segurança das estruturas hidráulicas.

O uso de modelos numéricos baseados nos princípios da Mecânica da Fratura tornou possível simular o comportamento do maciço de fundação. Mediante a simulação do avanço de uma fratura na fundação a montante, foram determinados os deslocamentos da instrumentação. A aferição dos resultados da análise com as leituras da instrumentação permitiu não somente a compreensão da influência do fraturamento no comportamento do maciço rochoso, assim como a necessidade da elaboração de um modelo que possua condições de contorno que se assemelhem às condições reais. Outro fator que foi visto como sendo importante corresponde à consideração da degradação do material no tempo.

Embora tenham sido efetuadas simplificações nos modelos de análise, os resultados obtidos do processamento mostraram-se satisfatórios em relação aos dados da instrumentação. Como foi apresentado acima, os gráficos mostraram a influência do fraturamento no comportamento do maciço tanto nos deslocamentos, como nas vazões e nos registros da piezometria.

Finalmente, a análise realizada da modelagem das seções do vertedouro e da 
estrutura da tomada de água-casa de força tornou possível o estabelecimento das seguintes conclusões:

1. Em face da existência de vários derrames rochosos e descontinuidades que fazem o maciço heterogêneo e anisotrópico, é essencial preparar um modelo de análise mais detalhado das feições do maciço e suas características geomecânicas, como o módulo de deformabilidade e o coeficiente de Poisson, que têm uma grande influência no comportamento do mesmo;

2. O fraturamento do maciço rochoso de fundação a montante exerce uma influência direta na subpressão, especialmente a montante da cortina de vedação, sendo necessário o controle de piezômetros que se localizam próximos a possíveis fraturas determinadas com base em uma análise de fraturamento do maciço;

3. É possível o estabelecimento de parâmetros de controle tais como as vazões que dão conta do estado da fundação em relação às forças de subpressão;

4. Ao se considerar as feições do maciço, é necessária a análise do comportamento tensão-deformação e das forças de percolação a fim de se avaliar o efeito destas últimas no fraturamento e nas feições;

5. É necessário avaliar a influência da temperatura sazonal no comportamento do maciço rochoso fraturado;

6. Deve-se considerar a importância e a vantagem do uso dos métodos computacionais e da aplicação da Mecânica da Fratura na modelagem numérica de fraturamentos de maciços rochosos e sua influência em termos econômicos.

Os items apresentados representam os principais aspectos que a autora deste trabalho considera como sendo necessários para se chegar a um melhor controle de parâmetros que permitem a segurança das estruturas hidráulicas. 


\section{REFERÊNCIAS BIBLIOGRÁFICAS}

ANDRADE, R.M. (1980). Cálculo da subpressão em estruturas de concreto assentes em maciços permeáveis anisotrópicos. Engevix, Rio de Janeiro, p. 70.

ANDRADE, R.M. (1988). Mecânica do escoamento em maciços fraturados aplicada a barragens. Engevix, Rio de Janeiro, p.139-142.

BIRINDELLI, M.C.A.G. (1987). Análise de métodos de avaliação de subpressão em estruturas tipo gravidade. Dissertação de Mestrado, Escola Politécnica de São Paulo.

BORTOLUCCI, A A. (1993). Modelo de ruptura em compressão de materiais frágeis baseado na mecânica da fratura e aplicado ao efeito escala. Tese de doutorado EESC/USP. Capítulo. 2, p.21-27.

CELESTINO, T.B. (1983). Emprego de modelos matemáticos no projeto de fundações de barragens de concreto. Simpósio sobre a Geotecnia da Bacia do Alto Paraná, São Paulo. p.299-318.

CERVERA, M.; OLIVIER, J. e MANZOLI, O. (1996). A rate dependent isotropic damage model for the seismic analysis of concrete dams. Earthquake Engineering and Structural Dynamics. Vol. 25, p. 987-1010.

Companhia Energética do estado de São Paulo (CESP). Dados da Usina Hidroelétrica de Porto Primavera. (2003).

CRUZ, P. T. (1978). Análise de subpressões em barragens de concreto fundadas em formações basálticas. Notas de Aula, Escola Politécnica da USP. Vol.VI, parte 1.

CRUZ, P. T. e SILVA, R. F. (1978). Uplift pressures at the base and in the rock basaltic foundations of gravity concrete dams. Proc. Int. Symposium of Rock Mechanic related to dam foundation, ISRM, pp. III, p. 1-25, Rio de Janeiro.

GEOSLOPE International Ltd. (SEEP/W). Versão 4.22, (1991-1999). Alberta, Canadá.

GID (Interactive Graphical User Interface, 1999). International Center for Numerical methods in Engineering (CIMNE). Barcelona, Spain 
GRIFFITH, A.A. (1920). The phenomena of rupture and flow in solids. Philosophical Transactions Royal Society, London. Vol. A221, p.163-198.

GUIDICINI, G. (1983). Uma avaliação de conceitos sobre injeção e drenagem na fundação de barragens. Simpósio sobre a Geotecnia da Bacia do Alto Paraná, São Paulo.

GUIDICIN, G. e ANDRADE R.M. (1987). Oscilação sazonal de subpressões na fundação de estruturas hidráulicas por variações térmicas ambientais. V Congresso Brasileiro de Geologia e Engenharia, São Paulo. Vol. 1, p. 21-40.

HILLERBORG, A; MODEER, M. e PETERSSON, P-E. (1976). Analysis of crack formation and crack growth in concrete by means of fracture mechanics and finite elements. Cement and Concrete research. Vol. 6, p. 773-782. Pergamon Press, Inc.

INGLIS, G.R. (1913). Stresses in a Plate due to the presence of cracks and sharp corners. Trans. Royal Institute Naval Architects. Vol. 60, p.219-230.

INGRAFFEA, A.R. (1983). Numerical modeling of Fracture propagation. In: Rossmanith, H.P., ed. Rock Fracture Mechanics. Wien:Springer, p. 484 (International Centre for Mechanical Sciences: Courses and Lectures).

IRWIN, G.R. (1957). Analysis of stresses and strain near the end of a crack transversing a plate. Journal Applied Mechanics. Vol. 24, p. 361-364.

JOHANDAR, N.; WITHERSPOON, P. e BREKKE, T.L. (1971). A method for coupled stress and flow analysis of fractured rock masses. Dept. Civil Eng., University of California, Berkeley.

KNOTT, J.F. (1973). Fundamentals of Fracture Mechanics. Butterworth Publishers. $2^{\text {nd }}$. Edition, p. 108.

KÓVARI, K. e BERGAMIN, St. (1994). Joint opening and head distribution in the foundation rock of the Albigna gravity dam. Seveth Int. IAEG Congress. Balkema, Rotterdam, p. 3797-3806.

LEMAITRE, J. (1996). A course on damage mechanics. Springer-Verlag, Berlin, 228p.

LEMAITRE, J. e CHABOCHE, J.L. (1978). Aspects phénoménologiques de la rupture par endommagement. J. Mec. Appl. Vol.2, p. 317-365.

LINSBAUER, H.N.; INGRAFFEA, A.R.; ROSSMANITH, H.P.e WAWRZYNEK, P.A. (1989). Simulation of cracking in large Arch Dam: Part I and Part II. Journal of Structural Engineering, Vol. 115-7, p.1599-1630. 
MANZOLI, O.L. (1998). Localización de deformaciones: Análisis y simulación numérica de Discontinuidades en Mecánica de Sólidos. Tesis doctoral, Universidad Técnica de Cataluña.

MIDEA, N. F. (1983). Resenha e análise crítica dos métodos e técnicas de ensaios geomecânicos efetuados para escavação em rocha. Simpósio sobre a Geotecnia da Bacia do Alto Paraná, São Paulo.

MUSKAT, M. (1937). The flow of homogeneous fluids through porous media. New York, Mc Graw-Hill. P. 763.

OLIVIER, J.; CERVERA, M.; OLLER, S.; LUBLINER, J. (1990) Isotropic damage models and smeared crack analysis of concrete. Computer Aided Analysis and Design of Concrete Structures, Swansea. Pineridge Press, p.945-957.

OMEGA (Organized Module for Engineering General Analysis, 1996).

PAES DE BARROS, F. e BARBI, A. L. (1983). Análise do comportamento das fundações das estruturas de concreto de Itaipu. XV Seminário Nacional de Grandes barragens, Rio de Janeiro.

PEDROSO, E.O.; LINS, P.G.C.; CELESTINO, T.B. e BORTOLUCCI, A.A. (1996). Um estudo do comportamento de fundações de barragens pela Mecânica da Fratura. In. VIII Congresso Brasileiro de Geologia e Engenharia, ABGE, Rio de Janeiro.

PEHOVAZ, H.I.A.; BORTOLUCCI, A.A. e CELESTINO, T.B. (2004). Ensaios não convencionais para a determinação da tenacidade à fratura em rochas: análise e comparação (Ensaios em basalto e granito). Escola de Engenharia de São Carlos.

REICH, R.W.; BRÜHWILER, E.; SLOWIK, V. e SAOUMA, V.E. (1994). Experimental and computational aspects of a water/fracture interaction. In: Proceedings of the International workshop on dam fracture and damage. Dam Fracture and Damage, Bourdarot, Mazars \& Saouma eds. Balkema, Rotterdam 1994.

RIENIUS, E. (1948). Effect of hydrostatic uplift on stresses in concrete and on the stability of dams. In: III Congress on Large Dams, Estocolmo, Transactions. Paris, C.I.B. Vol. 1, Rep. 57.

ROSSO, J. A.; FLORINI, A.S.; PORTO, E.C. e SILVEIRA, J. F. (1997). Barragem de Itaipu - Lições aprendidas com o comportamento térmico das estruturas tipo gravidade - aliviada e contraforte. In: XXII Seminário Nacional de Grandes Barragens, Vol. 1, p.161-176. 
SERAFIM, J.L. (1954). A subpressão nas barragens. Lisboa, LNEC, p. 243 (LNEC Publicação n.55).

SILVEIRA, J.F.A.; MIYA, S. e YENDO, M. (1978). Geomechanical parameters computed from instrumentation measurements at Água Vermelha dam foundation. Proc. Int. Symposium of Rock Mechanic related to dam foundation, ISRM, Vol. 1, pp. II, p. 103-120.

SUZUKI, H. (1995). Behaviors of Kaore Arch Dam and its foundation rock during test filling. Rock Foundation. Yoshinaka \& Kikuchi eds. Balkema, Rotterdam, p. 367374.

TERZAGHI, K. (1936). Simple tests determine hydrostatic uplift. Engineering News Record, New York.

TRESSOLDI, M. (1987). Aspectos hidrogeológicos dos derrames basálticos das fundações das estruturas de concreto da Usina de Porto Primavera. Anais do V. Congresso Brasileiro de Geologia de Engenharia, São Paulo. ABGE, p. 357-363.

TRESSOLDI, M.; CELESTINO, T.B.; COSTA, S.M.K.M. e VICENZO JR., M.C. (1990). Caracterização hidrogeologica e hidrogeotécnica de basaltos fraturados através de ensaios tridimensionais-o exemplo de Porto Primavera. VI Congresso Brasileiro de Geologia de Engenharia, Salvador.

ZIENKIEWICZ, O. C.; VALLIAPPAN, S. e KING, I.P. (1968). Stress analysis of rock as a no-tension material. Geotechnique, Vol. 18, p. 56-66. 
ANEXO A - Cálculo de forças. 
Tabela A-1 Tensões horizontais no maciço de fundação do Vertedouro.

Tabela A-2 Tensões horizontais no maciço de fundação da Casa de Força.

Tabela A-3 Forças nodais equivalentes de água no paramento de montante do Vertedouro.

Tabela A-4 Forças nodais equivalentes de água no paramento de montante da Casa de Força.

Tabela A-5 Força pontuais no conduto da estrutura Tomada de água-Casa de Força,

Tabela A-6 Força pontuais na zona de saída da estrutura Tomada de água-Casa de Força.

Tabela A-7 Força nodais na fenda do Vertedouro.

Tabela A-8 Força nodais na fenda da estrutura Tomada de água-Casa de Força, níveis 1 a 3.

Tabela A-9 Força nodais na fenda da estrutura Tomada de água-Casa de Força, níveis 4 a 6.

Tabela A-10 Forças nodais equivalentes à pressão hidráulica na fratura. PPv30pC Vertedouro, nível 1.

Tabela A-11 Forças nodais equivalentes à pressão hidráulica na fratura. PPv30pC Vertedouro, nível 2.

Tabela A-12 Forças nodais equivalentes à pressão hidráulica na fratura. PPv30pC Vertedouro, nível 3.

Tabela A-13 Forças nodais equivalentes à pressão hidráulica na fratura. PPv30pC Vertedouro, nível 4.

Tabela A-14 Forças nodais equivalentes à pressão hidráulica na fratura. PPv30pC Vertedouro, nível 5.

Tabela A-15 Forças nodais equivalentes à pressão hidráulica na fratura. PPv30pC Vertedouro, nível 6.

Tabela A-16 Forças nodais equivalentes à pressão hidráulica na fratura. PPcf12p Casa de força, nível 1.

Tabela A-17 Forças nodais equivalentes à pressão hidráulica na fratura. PPcf12p Casa de força, nível 2.

Tabela A-18 Forças nodais equivalentes à pressão hidráulica na fratura. PPcf12p Casa de força, nível 3.

Tabela A-19 Forças nodais equivalentes à pressão hidráulica na fratura. PPcf12p Casa de força, nível 4. 
Tabela A-20 Forças nodais equivalentes à pressão hidráulica na fratura. PPcf12p Casa de força, nível 5.

Tabela A-21 Forças nodais equivalentes à pressão hidráulica na fratura. PPcf12p Casa de força, nível 6. 
$\underline{\text { Tabela A-1 }}$

Vertedouro

Tenssões horizontais

Peso específico, $\gamma$

$$
\mathrm{k}=\quad 0,7
$$

$0,002 \mathrm{kgf} / \mathrm{cm}^{3}$

$$
\sigma_{h}=k \sigma_{v}
$$

\begin{tabular}{|c|c|c|c|c|c|c|c|c|c|}
\hline \multicolumn{5}{|c|}{ Montante } & \multicolumn{5}{|c|}{ Jusante } \\
\hline Elemento & Nós & Nível & $\begin{array}{c}\sigma_{\mathrm{v}} \\
\mathrm{kgf} / \mathrm{cm}^{2}\end{array}$ & $\begin{array}{c}\sigma_{\mathrm{h},} \\
\mathrm{kgf} / \mathrm{cm}^{2}\end{array}$ & Elementos & Nós & Nível & $\begin{array}{c}\sigma_{\mathrm{v}} \\
\mathrm{kgf} / \mathrm{cm}^{2}\end{array}$ & $\begin{array}{c}\sigma_{\mathrm{h},} \\
\mathrm{kgf} / \mathrm{cm}^{2}\end{array}$ \\
\hline & 6958 & 218,00 & 0,00 & 0 & & 909 & 216,05 & 0,00 & 0 \\
\hline 5189 & 6057 & 21362 & ० 88 & 061 & 12189 & 788 & 21222 & (77 & 051 \\
\hline 5095 & & & & & 12141 & & & & \\
\hline & 6955 & 210,37 & 1,53 & 1,07 & & 689 & 209,37 & 1,34 & 0,94 \\
\hline 4923 & & & & & 12122 & & & & \\
\hline 4828 & 6954 & 207,72 & 2,06 & 1,44 & 11881 & 609 & 207,01 & 1,81 & 1,27 \\
\hline 4746 & 6953 & 205,56 & 2,49 & 1,74 & 11817 & 536 & 205,08 & 2,19 & 1,54 \\
\hline 4744 & 6949 & 203,80 & 2,84 & 1,99 & 11688 & 473 & 203,51 & 2,51 & 1,75 \\
\hline 4336 & 6947 & 202,36 & 3,13 & 2,19 & 11301 & 420 & 202,24 & 2,76 & 1,93 \\
\hline 7092 & 6945 & 201,20 & 3,36 & 2,35 & 13198 & 380 & 201,20 & 2,97 & 2,08 \\
\hline 6117 & 6943 & 200,50 & 3,50 & 2,45 & 9735 & 355 & 200,50 & 3,11 & 2,18 \\
\hline 6415 & 6940 & 199,25 & 3,75 & 2,63 & 10112 & 317 & 199,25 & 3,36 & 2,35 \\
\hline 6527 & 6937 & 197,69 & 4,06 & 2,84 & 10227 & 283 & 197,69 & 3,67 & 2,57 \\
\hline 6621 & 6931 & 195,78 & 4,44 & 3,11 & 10394 & 248 & 195,78 & 4,05 & 2,84 \\
\hline 7007 & 6924 & 193,45 & 4,91 & 3,44 & 10581 & 218 & 193,45 & 4,52 & 3,16 \\
\hline 7058 & 6916 & 190,60 & 5,48 & 3,84 & 10555 & 182 & 190,60 & 5,09 & 3,56 \\
\hline 7086 & 6903 & 187,11 & 6,18 & 4,32 & 10727 & 154 & 187,11 & 5,79 & 4,05 \\
\hline 7010 & 6891 & 182,84 & 7,03 & 4,92 & 10652 & 121 & 184,84 & 6,24 & 4,37 \\
\hline 8764 & 6881 & 179,57 & 7,69 & 5,38 & 10732 & 100 & 179,57 & 7,30 & 5,11 \\
\hline 10860 & 6874 & 177,68 & 8,06 & 5,64 & 8868 & 85 & 177,68 & 7,67 & 5,37 \\
\hline 11010 & 6864 & 174,47 & 8,71 & 6,09 & 9036 & 72 & 174,65 & 8,28 & 5,80 \\
\hline 11019 & 6855 & 170,50 & 9,50 & 6,65 & 9042 & 54 & 170,89 & 9,03 & 6,32 \\
\hline 11058 & 6840 & 165,62 & 10,48 & 7,33 & 9061 & 41 & 166,28 & 9,95 & 6,97 \\
\hline 11097 & 6825 & 159,65 & 11,67 & 8,17 & 9096 & 27 & 160,64 & 11,08 & 7,76 \\
\hline 11130 & 6810 & 152,37 & 13,13 & 9,19 & 9165 & 17 & 153,75 & 12,46 & 8,72 \\
\hline 11178 & 6796 & 143,47 & 14,91 & 10,43 & 9221 & 10 & 145,34 & 14,14 & 9,90 \\
\hline 11188 & 6782 & 132,58 & 17,08 & 11,96 & 9227 & 4 & 135,04 & 16,20 & 11,34 \\
\hline & 6778 & 120,00 & 19,60 & 13,72 & & 1 & 120,00 & 19,21 & 13,45 \\
\hline
\end{tabular}


Tabela A-2

\section{Casa de Força}

Tenssões horizontais

Peso específico, $\gamma$

$$
\begin{array}{ll}
\mathrm{k}= & 0,7
\end{array}
$$

$$
\sigma_{h}=k \sigma_{v}
$$

\begin{tabular}{|c|c|c|c|c|c|c|c|c|c|}
\hline \multicolumn{5}{|c|}{ Montante } & \multicolumn{5}{|c|}{ Jusante } \\
\hline Elementos & Nós & Nível & $\begin{array}{c}\sigma_{\mathrm{v}} \\
\mathrm{kgf/ \textrm {cm } ^ { 2 }}\end{array}$ & $\begin{array}{c}\sigma_{\mathrm{h}} \\
\mathrm{kgf/ \textrm {cm } ^ { 2 }}\end{array}$ & Elementos & Nós & Nível & $\begin{array}{c}\sigma_{\mathrm{v}} \\
\mathrm{kgf/} / \mathrm{cm}^{2}\end{array}$ & $\begin{array}{c}\sigma_{\mathrm{h}} \\
\mathrm{kgf} / \mathrm{cm}^{2}\end{array}$ \\
\hline 2946 & 4362 & 225,00 & 0,00 & 0 & 4474 & 126 & 210,60 & 0,00 & 0 \\
\hline 2949 & 4361 & 213,33 & 2,33 & 1,63 & 8071 & 95 & 204,00 & 1,32 & 0,92 \\
\hline 2948 & 4360 & 201,67 & 4,67 & 3,27 & 8151 & 76 & 198,55 & 2,41 & 1,69 \\
\hline 2939 & 4358 & 190,00 & 7,00 & 4,90 & 8175 & 57 & 192,34 & 3,65 & 2,56 \\
\hline 2940 & 4356 & 178,33 & 9,33 & 6,53 & 8218 & 43 & 185,26 & 5,07 & 3,55 \\
\hline 2950 & 4354 & 166,67 & 11,67 & 8,17 & 8245 & 30 & 177,20 & 6,68 & 4,68 \\
\hline 2938 & 4353 & 155,00 & 14,00 & 9,80 & 8262 & 18 & 167,99 & 8,52 & 5,97 \\
\hline 2945 & 4351 & 143,33 & 16,33 & 11,43 & 8263 & 12 & 157,49 & 10,62 & 7,44 \\
\hline 2947 & 4350 & 131,67 & 18,67 & 13,07 & 8285 & 7 & 145,46 & 13,03 & 9,12 \\
\hline & 4348 & 120,00 & 21,00 & 14,70 & 8277 & $\begin{array}{l}3 \\
1\end{array}$ & $\begin{array}{l}132,73 \\
120,00\end{array}$ & $\begin{array}{l}15,57 \\
18,12\end{array}$ & $\begin{array}{l}10,90 \\
12,68\end{array}$ \\
\hline
\end{tabular}

$0,002 \mathrm{kgf} / \mathrm{cm} 3$ 
Tabela A-3

\begin{tabular}{|c|c|c|c|c|c|c|}
\hline Nível & & $\begin{array}{c}\mathbf{F}_{\mathbf{n}} \\
\mathbf{k N}^{*}\end{array}$ & $\begin{array}{l}e_{n} \\
m\end{array}$ & $\begin{array}{l}e_{\text {eq }} \\
\mathbf{m}\end{array}$ & $\begin{array}{c}\text { Nível Apli. } \\
F_{\text {eq }}, \mathbf{m}\end{array}$ & $\begin{array}{c}\text { Forças } F_{\text {eq }} \\
\text { kgf }\end{array}$ \\
\hline Nível 1, 242m & $F_{1}$ & 2824 & 8,00 & & 226,00 & 282442 \\
\hline \multirow{2}{*}{ Nível 2, 244m } & $F_{2}$ & 471 & 12,00 & 12,51 & 230,51 & \multirow{2}{*}{49035} \\
\hline & $F_{3}$ & 20 & 24,67 & & & \\
\hline \multirow{2}{*}{ Nível 3, 247m } & $\mathrm{F}_{2}^{\prime}$ & 765 & 13,00 & 13,76 & 231,76 & \multirow{2}{*}{80908} \\
\hline & $\mathrm{F}_{3}^{\prime}$ & 44 & 27,00 & & & \\
\hline \multirow{2}{*}{ Nível $4,250 \mathrm{~m}$} & $\mathrm{~F}_{2}$ & 853 & 14,50 & 15,26 & 233,26 & \multirow{2}{*}{89734} \\
\hline & $\mathrm{F}_{3}$ & 44 & 30,00 & & & \\
\hline \multirow{2}{*}{ Nível 5, 253m } & F'"2 & 941 & 16,00 & 16,76 & 234,76 & \multirow{2}{*}{98560} \\
\hline & F"'3 & 44 & 33,00 & & & \\
\hline \multirow{2}{*}{ Nível 6, 257m } & $\mathrm{F}_{2}^{\mathrm{iv}}$ & 1373 & 17,50 & 18,52 & 236,52 & \multirow{2}{*}{145144} \\
\hline & $\mathrm{F}_{3}^{\mathrm{iv}}$ & 78 & 36,33 & & & \\
\hline
\end{tabular}

Tabela A-4

\begin{tabular}{|c|c|c|c|c|c|c|}
\hline Nível & & $\begin{array}{c}F_{n} \\
k N^{*}\end{array}$ & $\begin{array}{l}e_{n} \\
m\end{array}$ & $\begin{array}{l}\mathbf{e}_{\text {eq }} \\
\mathbf{m}\end{array}$ & $\begin{array}{c}\text { Nível Apli. } \\
F_{\text {eq }}, m\end{array}$ & $\begin{array}{c}\text { Força Eq } \\
\text { kqf }\end{array}$ \\
\hline Nível 1, 242m & $F_{1}$ & 1417 & 5,67 & & \begin{tabular}{|l|}
230,67 \\
\end{tabular} & 141711 \\
\hline \multirow[t]{2}{*}{ Nível 2, 244m } & $F_{2}$ & 333 & 8,50 & 9,01 & 234,01 & \multirow{2}{*}{35305} \\
\hline & $F_{3}$ & 20 & 17,67 & & & \\
\hline \multirow{2}{*}{ Nível 3, 247m } & $\mathrm{F}_{2}^{\prime}$ & 559 & 9,50 & 10,27 & 235,27 & \multirow{2}{*}{60313} \\
\hline & $\mathrm{F}_{3}$ & 44 & 20,00 & & & \\
\hline \multirow[t]{2}{*}{ Nível 4, 250m } & $\mathrm{F}_{2}$ & 647 & 11,00 & 11,77 & 236,77 & \multirow{2}{*}{69139} \\
\hline & $\mathrm{F}_{3}$ & 44 & 23,00 & & & \\
\hline Nível $5,253 \mathrm{~m}$ & $\mathrm{~F}^{\prime \prime 2}$ & 736 & 12,50 & 13,26 & 238,26 & 77966 \\
\hline \multirow[b]{2}{*}{ Nível $6,257 \mathrm{~m}$} & & & & 1502 & 2102 & \multirow[b]{2}{*}{117684} \\
\hline & $\mathrm{F}^{\mathrm{V}^{2}}$ & 78 & 29,33 & $\perp v, V L$ & $\angle 4 U, 0 \angle$ & \\
\hline
\end{tabular}


Tabela A-5

\begin{tabular}{|c|c|c|c|c|c|c|c|}
\hline $\begin{array}{l}\text { Pressões } \\
\text { Conduto }\end{array}$ & $\begin{array}{l}\text { Cotas } \\
(\mathrm{m})\end{array}$ & $\begin{array}{l}\mathrm{H} \\
(\mathrm{m})\end{array}$ & $\begin{array}{l}\text { Pressão } \\
\text { kgf/cm2 }\end{array}$ & $\begin{array}{l}\text { Comprimentc } \\
\text { (m) }\end{array}$ & $\begin{array}{l}\text { Largura } \\
\text { (m) }\end{array}$ & $\begin{array}{c}\text { Força tot. } \\
\text { kgf }\end{array}$ & $\begin{array}{c}\text { Força Pontual } \\
\mathrm{kgf} / \mathrm{m}\end{array}$ \\
\hline \multicolumn{8}{|c|}{ Nível 6, 257m } \\
\hline \multirow[t]{2}{*}{ p1 } & 229,76 & 27,24 & 2,67 & & & & 105434 \\
\hline & & & & 11,16 & 21,5 & 6536888 & \\
\hline \multirow[t]{2}{*}{ p2 } & 228,68 & 28,32 & 2,78 & \multirow{3}{*}{3,2} & \multirow{3}{*}{21,5} & & \multirow[t]{2}{*}{136803} \\
\hline & & & & & & 1944885 & \\
\hline p3 & 227,67 & 29,33 & 2,88 & & & & 31369 \\
\hline \multirow[t]{2}{*}{ s1 } & 251,68 & 5,32 & 0,61 & \multirow{2}{*}{7,19} & \multirow[b]{2}{*}{21,5} & & \multirow[t]{2}{*}{21853} \\
\hline & & & & & & 1354874 & \\
\hline \multirow[t]{2}{*}{ s2 } & 247 & 10 & 1,14 & \multirow{3}{*}{3,75} & \multirow{3}{*}{21,5} & & \multirow[t]{2}{*}{44873} \\
\hline & & & 1,61 & & & 1427250 & \\
\hline s3 & 245,05 & 11,95 & 1,93 & & & & 23020 \\
\hline \multicolumn{8}{|c|}{ Nível 5, 253m } \\
\hline \multirow[t]{2}{*}{ p1 } & 229,76 & 23,24 & 2,28 & \multirow[b]{2}{*}{11,16} & \multirow{3}{*}{21,5} & & 90252 \\
\hline & & & & & & 5595652 & \\
\hline p2 & 228,68 & 24,32 & 2,39 & & & & 117269 \\
\hline & & & & 3,2 & 21,5 & 1674996 & \\
\hline p3 & 227,67 & 25,33 & 2,48 & & & & 27016 \\
\hline s1 & 251,68 & 1,32 & 0,15 & & & & 10441 \\
\hline & & & & 7,19 & 21,5 & 647368 & \\
\hline s2 & 247 & 6 & 0,69 & & & & 25072 \\
\hline & & & 0,97 & 3,75 & 21,5 & 907068 & \\
\hline s3 & 245,05 & 7,95 & 1,28 & & & & 14630 \\
\hline Nível 4, 250 & & & & & & & \\
\hline p1 & 229,76 & 20,24 & 1,98 & & & & 78867 \\
\hline & & & & 11,16 & 21,5 & 4889724 & \\
\hline p2 & 228,68 & 21,32 & 2,09 & & & & 102618 \\
\hline & & & & 3,2 & 21,5 & 1472580 & \\
\hline p3 & 227,67 & 22,33 & 2,19 & & & & 23751 \\
\hline s1 & 251,68 & - & 0,00 & & & & 2744 \\
\hline & & & & 4,61 & 21,5 & 170111 & \\
\hline s2 & 247 & 3 & 0,34 & & & & 11081 \\
\hline & & & 0,48 & 3,75 & 21,5 & 516931 & \\
\hline s3 & 245,05 & 4,95 & 0,80 & & & & 8338 \\
\hline Nível 3, 247 & & & & & & & \\
\hline p1 & 229,76 & 17,24 & 1,69 & & & & 67481 \\
\hline & & & & 11,16 & 21,5 & 4183797 & \\
\hline p2 & 228,68 & 18,32 & 1,80 & & & & 87967 \\
\hline & & & & 3,2 & 21,5 & 1270163 & \\
\hline p3 & 227,67 & 19,33 & 1,90 & & & & 20487 \\
\hline s2 & 247 & 0 & 0,00 & & & & 2045 \\
\hline & & & & 3,75 & 21,5 & 126794 & \\
\hline s3 & 245,05 & 1,95 & 0,31 & & & & 2045 \\
\hline Nível 2, 24 & & & & & & & \\
\hline p1 & 229,76 & 14,24 & 1,40 & & & & 56095 \\
\hline & & & & 11,16 & 21,5 & 3477869 & \\
\hline p2 & 228,68 & 15,32 & 1,50 & & & & 73316 \\
\hline & & & & 3,2 & 21,5 & 1067747 & \\
\hline p3 & 227,67 & 16,33 & 1,60 & & & & 17222 \\
\hline Nível 1, 242 & & & & & & & \\
\hline p1 & 229,76 & 12,24 & 1,20 & & & & 48504 \\
\hline & & & & 11,16 & 21,5 & 3007251 & \\
\hline p2 & 228,68 & 13,32 & 1,31 & & & & 63549 \\
\hline p3 & 227,67 & 14,33 & 1,41 & 3,2 & 21,5 & 932803 & 15045 \\
\hline
\end{tabular}


Tabela A-6

\begin{tabular}{|c|c|c|c|c|c|c|c|}
\hline $\begin{array}{l}\text { Pressões } \\
\text { Saida }\end{array}$ & $\begin{array}{c}\text { Cotas } \\
(\mathrm{m})\end{array}$ & $\begin{array}{c}\mathbf{H} \\
(\mathrm{m})\end{array}$ & $\begin{array}{l}\text { Pressão } \\
\text { kgf/cm2 }\end{array}$ & $\begin{array}{c}\text { Comprimel } \\
(\mathrm{m})\end{array}$ & $\begin{array}{l}\text { Largura } \\
(\mathrm{m})\end{array}$ & $\begin{array}{c}\text { Força } \\
\text { kgf }\end{array}$ & $\begin{array}{c}\text { Força Pontual } \\
\text { kgf } / \mathrm{m}\end{array}$ \\
\hline \multirow[t]{2}{*}{$q 1$} & 218,61 & 18,09 & 1,77 & & & & 72912 \\
\hline & & & & 11,94 & 23,0 & 4520533 & \\
\hline \multirow[t]{2}{*}{ q2 } & 221,22 & 15,48 & 1,52 & & & & 134486 \\
\hline & & & & 11,94 & 23,0 & 3817609 & \\
\hline q3 & 223,83 & 12,87 & 1,26 & & & & 61574 \\
\hline \multirow[t]{2}{*}{ q4 } & 231,1 & 5,60 & 0,55 & & & & 16708 \\
\hline & & & & 5,5 & 23,0 & 1035889 & \\
\hline \multirow[t]{2}{*}{ q5 } & 225,6 & 11,10 & 1,09 & & & & 53823 \\
\hline & & & & 6,99 & 23,0 & 2301152 & \\
\hline q6 & 218,61 & 18,09 & 1,77 & & & & 37115 \\
\hline
\end{tabular}

Tabela A-7

\begin{tabular}{|c|c|c|c|c|c|c|c|}
\hline \multirow{2}{*}{$\begin{array}{c}\text { Nível de } \\
\text { aplicação } \\
\text { das forças }\end{array}$} & \multirow{2}{*}{$\begin{array}{l}\text { Carga } \\
\text { Força }\end{array}$} & \multicolumn{6}{|c|}{ Níveis de carga } \\
\hline & & Nível 1 & Nível 2 & Nível 3 & $\begin{array}{l}\text { Nível } 4 \\
\text { ff }\end{array}$ & Nível 5 & Nível 6 \\
\hline $218 m$ & $\mathrm{Fp}_{1}$ & 17928 & 19399 & 21606 & 23813 & 26019 & 28961 \\
\hline $216,5 \mathrm{~m}$ & $\mathrm{Fp}_{2}$ & 37512 & 40454 & 44867 & 49280 & 53693 & 59578 \\
\hline $215 \mathrm{~m}$ & $\mathrm{Fp}_{3}$ & 19583 & 21054 & 23261 & 25468 & 27674 & 30616 \\
\hline
\end{tabular}


Tabela A-8

\begin{tabular}{|cccccccc|}
\hline Nível 1 & \multicolumn{2}{c}{$\mathbf{2 4 2} \mathbf{~ m}$} \\
\hline Nós & $\begin{array}{c}\text { Coord. Y } \\
\text { cm }\end{array}$ & $\begin{array}{c}\text { Distância } \\
\mathbf{~} \mathbf{c m}\end{array}$ & $\mathbf{k g f / \mathbf { c m } ^ { 2 }}$ & $\mathbf{k g f}$ & $\mathbf{k g f}(-)$ & Nós & kgf (+) \\
\hline $\mathbf{3 5 4 9}$ & 22500,00 & & 1,67 & 10587 & $\mathbf{5 2 9 3}$ & $\mathbf{3 5 3 6}$ & $\mathbf{5 2 9 3}$ \\
$\mathbf{3 5 1 3}$ & 22437,64 & 62,36 & 1,73 & 10968 & $\mathbf{1 0 7 7 8}$ & $\mathbf{3 5 0 3}$ & $\mathbf{1 0 7 7 8}$ \\
$\mathbf{3 4 8 1}$ & 22375,28 & 62,36 & 1,79 & 10720 & $\mathbf{1 0 8 4 4}$ & $\mathbf{3 4 7 0}$ & $\mathbf{1 0 8 4 4}$ \\
$\mathbf{3 4 4 2}$ & 22316,33 & 58,95 & 1,85 & 9732 & $\mathbf{1 0 2 2 6}$ & $\mathbf{3 4 3 3}$ & $\mathbf{1 0 2 2 6}$ \\
$\mathbf{3 4 1 2}$ & 22264,36 & 51,97 & 1,90 & 8813 & $\mathbf{9 2 7 2}$ & $\mathbf{3 3 9 6}$ & $\mathbf{9 2 7 2}$ \\
$\mathbf{3 3 8 0}$ & 22218,48 & 45,88 & 1,94 & 7961 & $\mathbf{8 3 8 7}$ & $\mathbf{3 3 6 7}$ & $\mathbf{8 3 8 7}$ \\
$\mathbf{3 3 5 2}$ & 22177,93 & 40,55 & 1,98 & 7174 & $\mathbf{7 5 6 8}$ & $\mathbf{3 3 3 5}$ & $\mathbf{7 5 6 8}$ \\
$\mathbf{3 3 2 2}$ & 22142,07 & 35,86 & 2,02 & 6449 & $\mathbf{6 8 1 2}$ & $\mathbf{3 3 0 7}$ & $\mathbf{6 8 1 2}$ \\
$\mathbf{3 3 0 0}$ & 22110,36 & 31,71 & 2,05 & 5781 & $\mathbf{6 1 1 5}$ & $\mathbf{3 2 8 4}$ & $\mathbf{6 1 1 5}$ \\
$\mathbf{3 2 7 5}$ & 22082,34 & 28,02 & 2,08 & 5165 & $\mathbf{5 4 7 3}$ & $\mathbf{3 2 6 6}$ & $\mathbf{5 4 7 3}$ \\
$\mathbf{3 2 5 2}$ & 22057,61 & 24,73 & 2,10 & 4598 & $\mathbf{4 8 8 1}$ & $\mathbf{3 2 3 5}$ & $\mathbf{4 8 8 1}$ \\
$\mathbf{3 2 3 3}$ & 22035,84 & 21,77 & 2,12 & 4075 & $\mathbf{4 3 3 7}$ & $\mathbf{3 2 1 8}$ & $\mathbf{4 3 3 7}$ \\
$\mathbf{3 2 1 6}$ & 22016,72 & 19,12 & 2,14 & 3594 & $\mathbf{3 8 3 5}$ & $\mathbf{3 1 9 9}$ & $\mathbf{3 8 3 5}$ \\
$\mathbf{3 2 0 0}$ & 22000,00 & 16,72 & 2,16 & & $\mathbf{1 7 9 7}$ & $\mathbf{3 1 8 8}$ & $\mathbf{1 7 9 7}$ \\
\hline
\end{tabular}

\begin{tabular}{|cccccccc|}
\hline Nível 2 & \multicolumn{2}{c}{$\mathbf{2 4 4} \mathbf{~ m}$} & \multicolumn{3}{c|}{ Forças equivalentes } \\
\hline Nós & $\begin{array}{c}\text { Coord. Y } \\
\text { cm }\end{array}$ & $\begin{array}{c}\text { Distância } \\
\text { cm }\end{array}$ & $\mathbf{k g f / \mathbf { c m } ^ { 2 }}$ & $\mathbf{k g f}$ & $\mathbf{k g f}(-)$ & Nós & kgf (+) \\
\hline $\mathbf{3 5 4 9}$ & 22500,00 & & 1,86 & 11810 & $\mathbf{5 9 0 5}$ & $\mathbf{3 5 3 6}$ & $\mathbf{5 9 0 5}$ \\
$\mathbf{3 5 1 3}$ & 22437,64 & 62,36 & 1,92 & 12191 & $\mathbf{1 2 0 0 1}$ & $\mathbf{3 5 0 3}$ & $\mathbf{1 2 0 0 1}$ \\
$\mathbf{3 4 8 1}$ & 22375,28 & 62,36 & 1,99 & 11877 & $\mathbf{1 2 0 3 4}$ & $\mathbf{3 4 7 0}$ & $\mathbf{1 2 0 3 4}$ \\
$\mathbf{3 4 4 2}$ & 22316,33 & 58,95 & 2,04 & 10751 & $\mathbf{1 1 3 1 4}$ & $\mathbf{3 4 3 3}$ & $\mathbf{1 1 3 1 4}$ \\
$\mathbf{3 4 1 2}$ & 22264,36 & 51,97 & 2,09 & 9713 & $\mathbf{1 0 2 3 2}$ & $\mathbf{3 3 9 6}$ & $\mathbf{1 0 2 3 2}$ \\
$\mathbf{3 3 8 0}$ & 22218,48 & 45,88 & 2,14 & 8757 & $\mathbf{9 2 3 5}$ & $\mathbf{3 3 6 7}$ & $\mathbf{9 2 3 5}$ \\
$\mathbf{3 3 5 2}$ & 22177,93 & 40,55 & 2,18 & 7878 & $\mathbf{8 3 1 7}$ & $\mathbf{3 3 3 5}$ & $\mathbf{8 3 1 7}$ \\
$\mathbf{3 3 2 2}$ & 22142,07 & 35,86 & 2,21 & 7071 & $\mathbf{7 4 7 4}$ & $\mathbf{3 3 0 7}$ & $\mathbf{7 4 7 4}$ \\
$\mathbf{3 3 0 0}$ & 22110,36 & 31,71 & 2,25 & 6330 & $\mathbf{6 7 0 1}$ & $\mathbf{3 2 8 4}$ & $\mathbf{6 7 0 1}$ \\
$\mathbf{3 2 7 5}$ & 22082,34 & 28,02 & 2,27 & 5650 & $\mathbf{5 9 9 0}$ & $\mathbf{3 2 6 6}$ & $\mathbf{5 9 9 0}$ \\
$\mathbf{3 2 5 2}$ & 22057,61 & 24,73 & 2,30 & 5025 & $\mathbf{5 3 3 8}$ & $\mathbf{3 2 3 5}$ & $\mathbf{5 3 3 8}$ \\
$\mathbf{3 2 3 3}$ & 22035,84 & 21,77 & 2,32 & 4450 & $\mathbf{4 7 3 8}$ & $\mathbf{3 2 1 8}$ & $\mathbf{4 7 3 8}$ \\
$\mathbf{3 2 1 6}$ & 22016,72 & 19,12 & 2,34 & 3922 & $\mathbf{4 1 8 6}$ & $\mathbf{3 1 9 9}$ & $\mathbf{4 1 8 6}$ \\
$\mathbf{3 2 0 0}$ & 22000,00 & 16,72 & 2,35 & & $\mathbf{1 9 6 1}$ & $\mathbf{3 1 8 8}$ & $\mathbf{1 9 6 1}$ \\
\hline
\end{tabular}

\begin{tabular}{|cccccccc|}
\hline Nível 3 & \multicolumn{2}{c}{$\mathbf{2 4 7} \mathbf{~ m}$} & \multicolumn{3}{c|}{ Forças equivalentes } \\
\hline Nós & $\begin{array}{c}\text { Coord. Y } \\
\text { cm }\end{array}$ & $\begin{array}{c}\text { Distância } \\
\mathbf{~} \mathbf{c m}\end{array}$ & $\mathbf{k g f / \mathbf { c m } ^ { 2 }}$ & $\mathbf{k g f}$ & $\mathbf{k g f}(-)$ & Nós & kgf (+) \\
\hline $\mathbf{3 5 4 9}$ & 22500,00 & & 2,16 & 13645 & $\mathbf{6 8 2 2}$ & $\mathbf{3 5 3 6}$ & $\mathbf{6 8 2 2}$ \\
$\mathbf{3 5 1 3}$ & 22437,64 & 62,36 & 2,22 & 14026 & $\mathbf{1 3 8 3 5}$ & $\mathbf{3 5 0 3}$ & $\mathbf{1 3 8 3 5}$ \\
$\mathbf{3 4 8 1}$ & 22375,28 & 62,36 & 2,28 & 13611 & $\mathbf{1 3 8 1 9}$ & $\mathbf{3 4 7 0}$ & $\mathbf{1 3 8 1 9}$ \\
$\mathbf{3 4 4 2}$ & 22316,33 & 58,95 & 2,34 & 12280 & $\mathbf{1 2 9 4 6}$ & $\mathbf{3 4 3 3}$ & $\mathbf{1 2 9 4 6}$ \\
$\mathbf{3 4 1 2}$ & 22264,36 & 51,97 & 2,39 & 11063 & $\mathbf{1 1 6 7 1}$ & $\mathbf{3 3 9 6}$ & $\mathbf{1 1 6 7 1}$ \\
$\mathbf{3 3 8 0}$ & 22218,48 & 45,88 & 2,43 & 9950 & $\mathbf{1 0 5 0 6}$ & $\mathbf{3 3 6 7}$ & $\mathbf{1 0 5 0 6}$ \\
$\mathbf{3 3 5 2}$ & 22177,93 & 40,55 & 2,47 & 8933 & $\mathbf{9 4 4 1}$ & $\mathbf{3 3 3 5}$ & $\mathbf{9 4 4 1}$ \\
$\mathbf{3 3 2 2}$ & 22142,07 & 35,86 & 2,51 & 8004 & $\mathbf{8 4 6 8}$ & $\mathbf{3 3 0 7}$ & $\mathbf{8 4 6 8}$ \\
$\mathbf{3 3 0 0}$ & 22110,36 & 31,71 & 2,54 & 7155 & $\mathbf{7 5 7 9}$ & $\mathbf{3 2 8 4}$ & $\mathbf{7 5 7 9}$ \\
$\mathbf{3 2 7 5}$ & 22082,34 & 28,02 & 2,57 & 6377 & $\mathbf{6 7 6 6}$ & $\mathbf{3 2 6 6}$ & $\mathbf{6 7 6 6}$ \\
$\mathbf{3 2 5 2}$ & 22057,61 & 24,73 & 2,59 & 5666 & $\mathbf{6 0 2 2}$ & $\mathbf{3 2 3 5}$ & $\mathbf{6 0 2 2}$ \\
$\mathbf{3 2 3 3}$ & 22035,84 & 21,77 & 2,61 & 5013 & $\mathbf{5 3 3 9}$ & $\mathbf{3 2 1 8}$ & $\mathbf{5 3 3 9}$ \\
$\mathbf{3 2 1 6}$ & 22016,72 & 19,12 & 2,63 & 4414 & $\mathbf{4 7 1 3}$ & $\mathbf{3 1 9 9}$ & $\mathbf{4 7 1 3}$ \\
$\mathbf{3 2 0 0}$ & 22000,00 & 16,72 & 2,65 & & $\mathbf{2 2 0 7}$ & $\mathbf{3 1 8 8}$ & $\mathbf{2 2 0 7}$ \\
\hline
\end{tabular}


Tabela A-9

\begin{tabular}{|cccccccc|}
\hline Nível 4 & \multicolumn{2}{c}{$\mathbf{2 5 0} \mathbf{~ m}$} & \multicolumn{4}{c|}{ Forças equivalentes } \\
\hline Nós & $\begin{array}{c}\text { Coord. Y } \\
\text { cm }\end{array}$ & $\begin{array}{c}\text { Distância } \\
\text { cm }\end{array}$ & $\mathbf{k g f / \mathbf { c m } ^ { 2 }}$ & $\mathbf{k g f}$ & $\mathbf{k g f}(-)$ & Nós & kgf (+) \\
\hline $\mathbf{3 5 4 9}$ & 22500,00 & & 2,45 & 15479 & $\mathbf{7 7 4 0}$ & $\mathbf{3 5 3 6}$ & $\mathbf{7 7 4 0}$ \\
$\mathbf{3 5 1 3}$ & 22437,64 & 62,36 & 2,51 & 15861 & $\mathbf{1 5 6 7 0}$ & $\mathbf{3 5 0 3}$ & $\mathbf{1 5 6 7 0}$ \\
$\mathbf{3 4 8 1}$ & 22375,28 & 62,36 & 2,57 & 15346 & $\mathbf{1 5 6 0 3}$ & $\mathbf{3 4 7 0}$ & $\mathbf{1 5 6 0 3}$ \\
$\mathbf{3 4 4 2}$ & 22316,33 & 58,95 & 2,63 & 13809 & $\mathbf{1 4 5 7 7}$ & $\mathbf{3 4 3 3}$ & $\mathbf{1 4 5 7 7}$ \\
$\mathbf{3 4 1 2}$ & 22264,36 & 51,97 & 2,68 & 12412 & $\mathbf{1 3 1 1 1}$ & $\mathbf{3 3 9 6}$ & $\mathbf{1 3 1 1 1}$ \\
$\mathbf{3 3 8 0}$ & 22218,48 & 45,88 & 2,73 & 11143 & $\mathbf{1 1 7 7 8}$ & $\mathbf{3 3 6 7}$ & $\mathbf{1 1 7 7 8}$ \\
$\mathbf{3 3 5 2}$ & 22177,93 & 40,55 & 2,77 & 9988 & $\mathbf{1 0 5 6 5}$ & $\mathbf{3 3 3 5}$ & $\mathbf{1 0 5 6 5}$ \\
$\mathbf{3 3 2 2}$ & 22142,07 & 35,86 & 2,80 & 8937 & $\mathbf{9 4 6 2}$ & $\mathbf{3 3 0 7}$ & $\mathbf{9 4 6 2}$ \\
$\mathbf{3 3 0 0}$ & 22110,36 & 31,71 & 2,83 & 7979 & $\mathbf{8 4 5 8}$ & $\mathbf{3 2 8 4}$ & $\mathbf{8 4 5 8}$ \\
$\mathbf{3 2 7 5}$ & 22082,34 & 28,02 & 2,86 & 7105 & $\mathbf{7 5 4 2}$ & $\mathbf{3 2 6 6}$ & $\mathbf{7 5 4 2}$ \\
$\mathbf{3 2 5 2}$ & 22057,61 & 24,73 & 2,89 & 6306 & $\mathbf{6 7 0 6}$ & $\mathbf{3 2 3 5}$ & $\mathbf{6 7 0 6}$ \\
$\mathbf{3 2 3 3}$ & 22035,84 & 21,77 & 2,91 & 5575 & $\mathbf{5 9 4 1}$ & $\mathbf{3 2 1 8}$ & $\mathbf{5 9 4 1}$ \\
$\mathbf{3 2 1 6}$ & 22016,72 & 19,12 & 2,93 & 4906 & $\mathbf{5 2 4 0}$ & $\mathbf{3 1 9 9}$ & $\mathbf{5 2 4 0}$ \\
$\mathbf{3 2 0 0}$ & 22000,00 & 16,72 & 2,94 & & $\mathbf{2 4 5 3}$ & $\mathbf{3 1 8 8}$ & $\mathbf{2 4 5 3}$ \\
\hline
\end{tabular}

\begin{tabular}{|cccccccc|}
\hline Nível 5 & \multicolumn{2}{c}{$\mathbf{2 5 3} \mathbf{~ m}$} & \multicolumn{3}{c|}{ Forças equivalentes } \\
\hline Nós & $\begin{array}{c}\text { Coord. Y } \\
\mathbf{c m}\end{array}$ & $\begin{array}{c}\text { Distância } \\
\mathbf{c m}\end{array}$ & $\mathbf{k g f / \mathbf { c m } ^ { 2 }}$ & $\mathbf{k g f}$ & $\mathbf{k g f}(\mathbf{- )}$ & Nós & kgf (+) \\
\hline $\mathbf{3 5 4 9}$ & 22500,00 & & 2,75 & 17314 & $\mathbf{8 6 5 7}$ & $\mathbf{3 5 3 6}$ & $\mathbf{8 6 5 7}$ \\
$\mathbf{3 5 1 3}$ & 22437,64 & 62,36 & 2,81 & 17695 & $\mathbf{1 7 5 0 5}$ & $\mathbf{3 5 0 3}$ & $\mathbf{1 7 5 0 5}$ \\
$\mathbf{3 4 8 1}$ & 22375,28 & 62,36 & 2,87 & 17080 & $\mathbf{1 7 3 8 8}$ & $\mathbf{3 4 7 0}$ & $\mathbf{1 7 3 8 8}$ \\
$\mathbf{3 4 4 2}$ & 22316,33 & 58,95 & 2,93 & 15338 & $\mathbf{1 6 2 0 9}$ & $\mathbf{3 4 3 3}$ & $\mathbf{1 6 2 0 9}$ \\
$\mathbf{3 4 1 2}$ & 22264,36 & 51,97 & 2,98 & 13762 & $\mathbf{1 4 5 5 0}$ & $\mathbf{3 3 9 6}$ & $\mathbf{1 4 5 5 0}$ \\
$\mathbf{3 3 8 0}$ & 22218,48 & 45,88 & 3,02 & 12336 & $\mathbf{1 3 0 4 9}$ & $\mathbf{3 3 6 7}$ & $\mathbf{1 3 0 4 9}$ \\
$\mathbf{3 3 5 2}$ & 22177,93 & 40,55 & 3,06 & 11043 & $\mathbf{1 1 6 8 9}$ & $\mathbf{3 3 3 5}$ & $\mathbf{1 1 6 8 9}$ \\
$\mathbf{3 3 2 2}$ & 22142,07 & 35,86 & 3,10 & 9870 & $\mathbf{1 0 4 5 6}$ & $\mathbf{3 3 0 7}$ & $\mathbf{1 0 4 5 6}$ \\
$\mathbf{3 3 0 0}$ & 22110,36 & 31,71 & 3,13 & 8803 & $\mathbf{9 3 3 7}$ & $\mathbf{3 2 8 4}$ & $\mathbf{9 3 3 7}$ \\
$\mathbf{3 2 7 5}$ & 22082,34 & 28,02 & 3,16 & 7832 & $\mathbf{8 3 1 8}$ & $\mathbf{3 2 6 6}$ & $\mathbf{8 3 1 8}$ \\
$\mathbf{3 2 5 2}$ & 22057,61 & 24,73 & 3,18 & 6947 & $\mathbf{7 3 9 0}$ & $\mathbf{3 2 3 5}$ & $\mathbf{7 3 9 0}$ \\
$\mathbf{3 2 3 3}$ & 22035,84 & 21,77 & 3,20 & 6138 & $\mathbf{6 5 4 2}$ & $\mathbf{3 2 1 8}$ & $\mathbf{6 5 4 2}$ \\
$\mathbf{3 2 1 6}$ & 22016,72 & 19,12 & 3,22 & 5398 & $\mathbf{5 7 6 8}$ & $\mathbf{3 1 9 9}$ & $\mathbf{5 7 6 8}$ \\
$\mathbf{3 2 0 0}$ & 22000,00 & 16,72 & 3,24 & & $\mathbf{2 6 9 9}$ & $\mathbf{3 1 8 8}$ & $\mathbf{2 6 9 9}$ \\
\hline
\end{tabular}

\begin{tabular}{|cccccccc|}
\hline Nível 6 & \multicolumn{2}{c}{ 257 m } & \multicolumn{3}{c|}{ Forças equivalentes } \\
\hline Nós & $\begin{array}{c}\text { Coord. Y } \\
\text { cm }\end{array}$ & $\begin{array}{c}\text { Distância } \\
\text { cm }\end{array}$ & kgf/cm & kgf & kgf (-) & Nós & kgf (+) \\
\hline $\mathbf{3 5 4 9}$ & 22500,00 & & 3,14 & 19760 & $\mathbf{9 8 8 0}$ & $\mathbf{3 5 3 6}$ & $\mathbf{9 8 8 0}$ \\
$\mathbf{3 5 1 3}$ & 22437,64 & 62,36 & 3,20 & 20142 & $\mathbf{1 9 9 5 1}$ & $\mathbf{3 5 0 3}$ & $\mathbf{1 9 9 5 1}$ \\
$\mathbf{3 4 8 1}$ & 22375,28 & 62,36 & 3,26 & 19393 & $\mathbf{1 9 7 6 7}$ & $\mathbf{3 4 7 0}$ & $\mathbf{1 9 7 6 7}$ \\
$\mathbf{3 4 4 2}$ & 22316,33 & 58,95 & 3,32 & 17377 & $\mathbf{1 8 3 8 5}$ & $\mathbf{3 4 3 3}$ & $\mathbf{1 8 3 8 5}$ \\
$\mathbf{3 4 1 2}$ & 22264,36 & 51,97 & 3,37 & 15562 & $\mathbf{1 6 4 6 9}$ & $\mathbf{3 3 9 6}$ & $\mathbf{1 6 4 6 9}$ \\
$\mathbf{3 3 8 0}$ & 22218,48 & 45,88 & 3,41 & 13927 & $\mathbf{1 4 7 4 4}$ & $\mathbf{3 3 6 7}$ & $\mathbf{1 4 7 4 4}$ \\
$\mathbf{3 3 5 2}$ & 22177,93 & 40,55 & 3,45 & 12450 & $\mathbf{1 3 1 8 8}$ & $\mathbf{3 3 3 5}$ & $\mathbf{1 3 1 8 8}$ \\
$\mathbf{3 3 2 2}$ & 22142,07 & 35,86 & 3,49 & 11114 & $\mathbf{1 1 7 8 2}$ & $\mathbf{3 3 0 7}$ & $\mathbf{1 1 7 8 2}$ \\
$\mathbf{3 3 0 0}$ & 22110,36 & 31,71 & 3,52 & 9903 & $\mathbf{1 0 5 0 8}$ & $\mathbf{3 2 8 4}$ & $\mathbf{1 0 5 0 8}$ \\
$\mathbf{3 2 7 5}$ & 22082,34 & 28,02 & 3,55 & 8802 & $\mathbf{9 3 5 2}$ & $\mathbf{3 2 6 6}$ & $\mathbf{9 3 5 2}$ \\
$\mathbf{3 2 5 2}$ & 22057,61 & 24,73 & 3,57 & 7801 & $\mathbf{8 3 0 2}$ & $\mathbf{3 2 3 5}$ & $\mathbf{8 3 0 2}$ \\
$\mathbf{3 2 3 3}$ & 22035,84 & 21,77 & 3,59 & 6888 & $\mathbf{7 3 4 4}$ & $\mathbf{3 2 1 8}$ & $\mathbf{7 3 4 4}$ \\
$\mathbf{3 2 1 6}$ & 22016,72 & 19,12 & 3,61 & 6053 & $\mathbf{6 4 7 1}$ & $\mathbf{3 1 9 9}$ & $\mathbf{6 4 7 1}$ \\
$\mathbf{3 2 0 0}$ & 22000,00 & 16,72 & 3,63 & & $\mathbf{3 0 2 7}$ & $\mathbf{3 1 8 8}$ & $\mathbf{3 0 2 7}$ \\
\hline
\end{tabular}


Tabela A-10

\section{Forças nodais equivalentes à pressão hidráulica na fratura - PPv30pC- Vertedouro}

\begin{tabular}{|l|l|l|l|l|l|l|}
\cline { 2 - 7 } \multicolumn{1}{c|}{} & h1 & h2 & h3 & h4 & h5 & h6 \\
\hline Nível 218 & 2,354 & 2,550 & 2,844 & 3,138 & 3,432 & 3,825 \\
\hline Nível 215 & 2,648 & 2,844 & 3,138 & 3,432 & 3,727 & 4,119 \\
\hline
\end{tabular}

\section{Pressão na fratura}

Nível $242 \mathrm{~m}$, pressão 2,648

\begin{tabular}{|c|c|c|c|c|c|c|c|c|c|c|c|c|c|c|c|c|c|c|}
\hline \multirow{3}{*}{$\#$} & \multirow{3}{*}{$\begin{array}{l}\text { Area } \\
\mathbf{c m}^{2}\end{array}$} & \multirow{3}{*}{$\begin{array}{l}\text { Pressão } \\
\mathrm{kgf} / \mathrm{cm}^{2}\end{array}$} & \multirow{3}{*}{$\begin{array}{c}\text { Força } \\
\text { kgf }\end{array}$} & & & & & & & & & & & & & & & \\
\hline & & & & \multirow{2}{*}{\begin{tabular}{|c} 
Ângulo \\
rad
\end{tabular}} & \multicolumn{2}{|c|}{ Força nos eixos } & \multirow[t]{2}{*}{ Elemen } & \multirow[t]{2}{*}{ Nó } & \multirow{2}{*}{\multicolumn{4}{|c|}{$\mathrm{x}$}} & \multirow{3}{*}{$\begin{array}{l}\begin{array}{l}\text { Fx } \\
\text { kgf }\end{array} \\
-1538\end{array}$} & \multirow{2}{*}{\multicolumn{4}{|c|}{$\mathbf{Y}$}} & \multirow{2}{*}{$\begin{array}{l}\text { Fy } \\
\text { kgf }\end{array}$} \\
\hline & & & & & $\mathrm{x}$ & $y$ & & & & & & & & & & & & \\
\hline & 443 & 2,648 & 1171,9 & 0,945 & $-686,0$ & 950,2 & \multirow{3}{*}{1} & 3330 & -686 & & & & & 950,2 & & & & 2737 \\
\hline \multirow[t]{2}{*}{1} & & & & & 343,0 & $-475,1$ & & 3323 & 343,0 & & & & 655 & $-475,1$ & & & & -1090 \\
\hline & & & & & 343,0 & $-475,1$ & & 3324 & 343,0 & & & & 343 & $-475,1$ & & & & -475 \\
\hline \multirow{3}{*}{2} & 521 & 2,648 & 1379,3 & 1,101 & $-624,3$ & 1230,0 & \multirow{3}{*}{2197} & 3330 & & $-624,3$ & & & & & 1230,0 & & & \\
\hline & & & & & 312,1 & $-615,0$ & & 3331 & 312,1 & & & & 1932 & -615 & & & & -3466 \\
\hline & & & & & 312,1 & $-615,0$ & & 3323 & & 312,1 & & & & & \begin{tabular}{|c|}
-615 \\
\end{tabular} & & & \\
\hline \multirow{3}{*}{3} & 455 & 2,648 & 1204,2 & 1,182 & 456,2 & $-1114,5$ & \multirow{3}{*}{2199} & 3331 & & 456,2 & & & & & \begin{tabular}{|c|}
-1114 \\
\end{tabular} & & & \\
\hline & & & & & $-228,1$ & 557,2 & & 3330 & & & $-228,1$ & & & & & 557,2 & & \\
\hline & & & & & $-228,1$ & 557,2 & & 3346 & $-228,1$ & & & & -575 & 557,2 & & & & 1093 \\
\hline \multirow{3}{*}{4} & 482 & 2,648 & 1275,4 & 0,996 & 692,9 & $-1070,7$ & \multirow{3}{*}{2208} & 3331 & & & 692,9 & & & & & $-1070,7$ & & \\
\hline & & & & & $-346,5$ & 535,4 & & 3346 & & $-346,5$ & & & & & 535,4 & & & \\
\hline & & & & & $-346,5$ & 535,4 & & 3348 & $-346,5$ & & & & -886 & 535,4 & & & & 1787 \\
\hline \multirow{3}{*}{5} & 616 & 2,648 & 1631,1 & 0,955 & $-942,1$ & 1331,5 & \multirow{3}{*}{2211} & 3348 & & -942 & & & & & 1331,5 & & & \\
\hline & & & & & 471,0 & $-665,8$ & & 3333 & 471,0 & & & & -334 & -666 & & & & -506 \\
\hline & & & & & 471,0 & $-665,8$ & & 3331 & & & & 471,0 & & & & & -666 & \\
\hline \multirow{3}{*}{6} & 310 & 2,648 & 820,4 & 0,197 & $-804,7$ & 160,2 & \multirow{3}{*}{2212} & 3333 & & $-804,7$ & & & & & 160 & & & \\
\hline & & & & & 402,3 & $-80,1$ & & 3348 & & & 402,3 & & & & & $-80,1$ & & \\
\hline & & & & & 402,3 & $-80,1$ & & 3353 & 402,3 & & & & 402 & $-80,1$ & & & & -80 \\
\hline
\end{tabular}

Forças nodais

equivalentes, $\mathrm{kgf}$

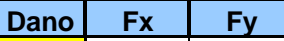

\begin{tabular}{|r|r|r|}
\hline \multirow{2}{*}{0,977} & -1503 & 2674 \\
\cline { 2 - 3 } & 640 & -1065 \\
\hline
\end{tabular}

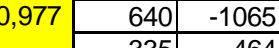

\begin{tabular}{|l|l|l|}
\hline \multirow{2}{*}{0,949} & & \\
\cline { 2 - 3 } & 1833 & -3288 \\
\cline { 2 - 2 } & & \\
\hline
\end{tabular}$$
\begin{array}{|l|l|l|}
\hline \multirow{2}{*}{0,949} & 1833 & -3288 \\
\cline { 2 - 3 } & & \\
\hline & & \\
\hline
\end{array}
$$

0,709

\begin{tabular}{|l|r|r|}
\cline { 2 - 3 } 0,889 & -408 & 775 \\
\cline { 2 - 3 } & & \\
\cline { 2 - 3 } 0,647 & -788 & 1588 \\
\hline \multirow{2}{*}{0,647} & -216 & -327 \\
\cline { 2 - 3 } & & \\
\hline \multirow{2}{*}{0,435} & & \\
\cline { 2 - 3 } & & \\
\cline { 2 - 3 } & 175 & -35 \\
\hline
\end{tabular} 
Tabela A-11
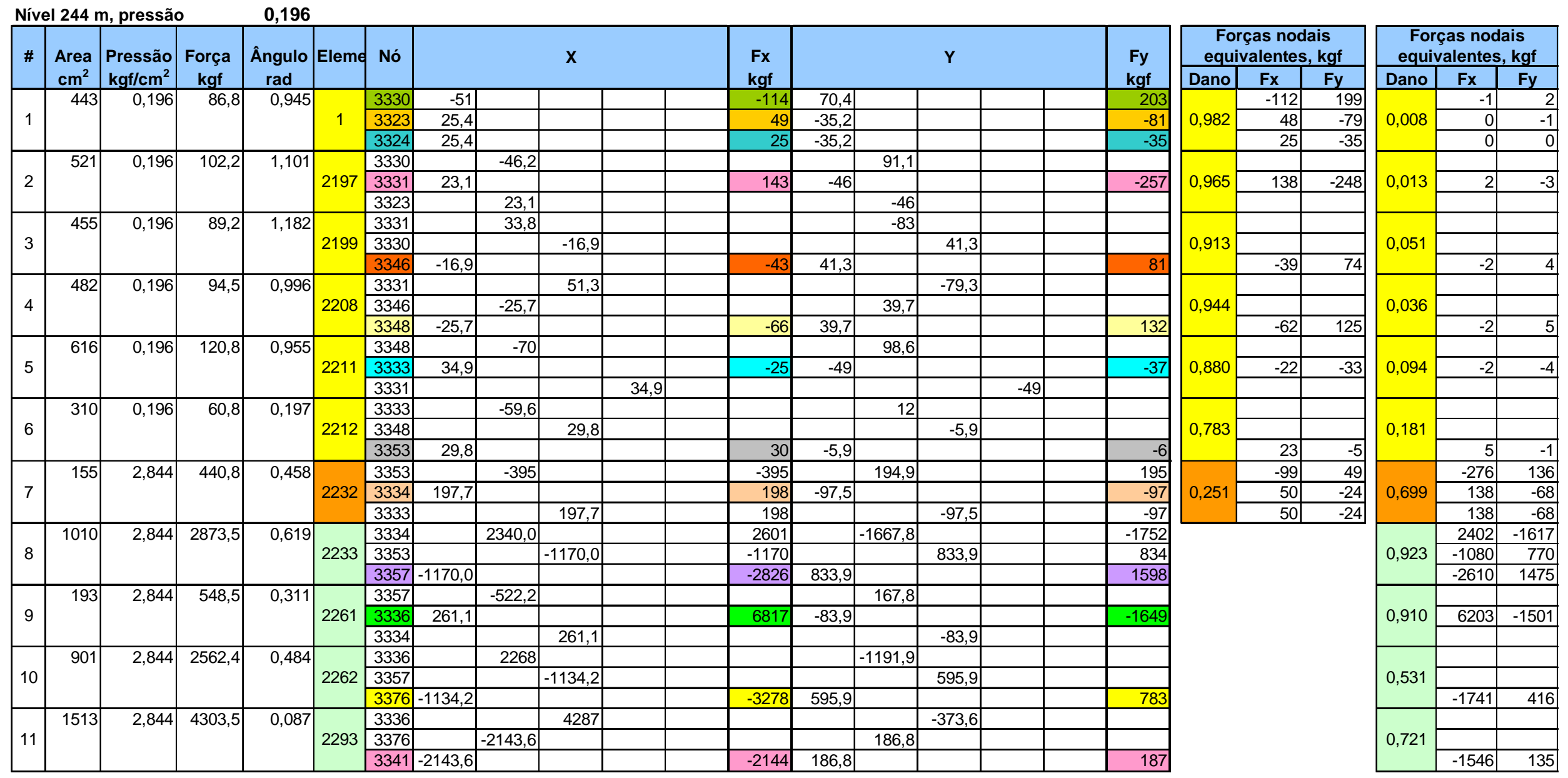


\section{Tabela A-12 (1)}

\section{Nível 247 m, pressão}

0,294

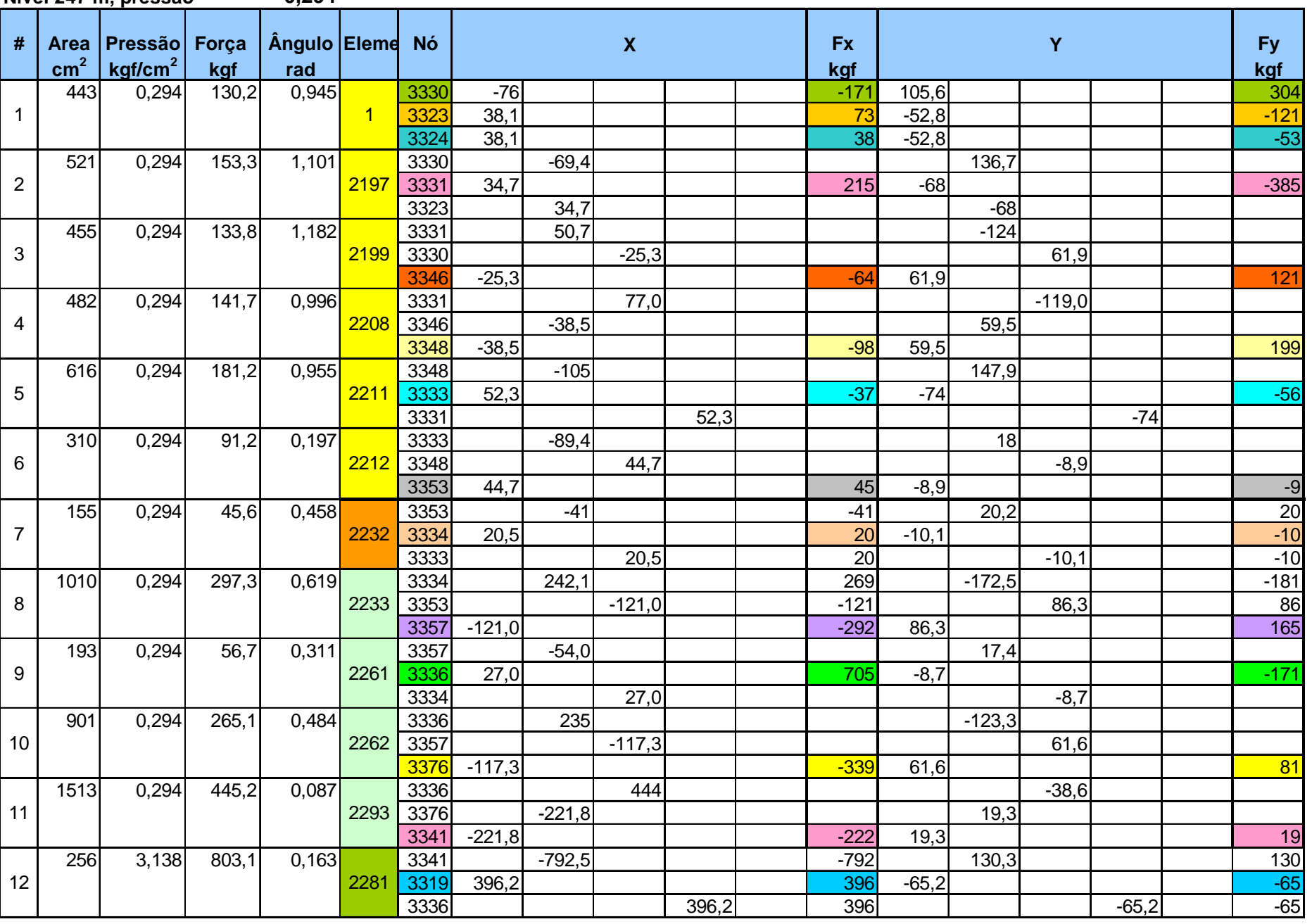

Forças nodais

equivalentes, kgf

\begin{tabular}{|l|l|l|} 
Dano & Fx & Fy \\
\hline
\end{tabular}

Forças nodais

equivalentes, kgf

\begin{tabular}{|r|r|r|}
\hline \multirow{2}{*}{0,990} & -169 & 32 \\
\cline { 2 - 3 } & 72 & -120 \\
\cline { 2 - 3 } & 38 & -52 \\
\hline
\end{tabular} \begin{tabular}{l|l|l} 
Dano & $\mathrm{Fx}$ & $\mathrm{Fy}$
\end{tabular}

1

\begin{tabular}{|l|l|l|}
\hline \multirow{2}{*}{0,979} & & \\
\cline { 2 - 3 } & 210 & -377 \\
\cline { 2 - 3 } & &
\end{tabular}

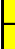

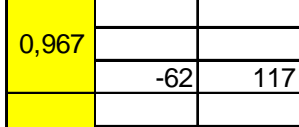

\begin{tabular}{|l|r|r|}
\hline \multirow{2}{*}{0,981} & & \\
\cline { 2 - 3 } & & \\
\cline { 2 - 3 } & -97 & 195 \\
\hline
\end{tabular}

\begin{tabular}{|l|l|l|}
\cline { 2 - 3 } 0,977 & -36 & -55 \\
\hline
\end{tabular}

\begin{tabular}{|l|l|l|}
\hline & & \\
\hline & & \\
\hline
\end{tabular}

0,971

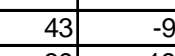

\begin{tabular}{|l|r|r|}
\hline \multirow{2}{*}{0,964} & -39 & 19 \\
\cline { 2 - 3 } & 20 & -10 \\
\hline
\end{tabular}

\begin{tabular}{|l|r|r|}
\hline \multirow{2}{*}{0,964} & 20 & -10 \\
\cline { 2 - 3 } & 20 & -10 \\
\hline
\end{tabular}

\begin{tabular}{|r|r|r|}
\hline \multirow{2}{*}{0,955} & 257 & -173 \\
\cline { 2 - 3 } & -116 & 82 \\
\hline
\end{tabular}

\begin{tabular}{|r|r|}
\hline & -116 \\
\hline-279 & 158 \\
\hline
\end{tabular}

\begin{tabular}{|l|l|l|}
\cline { 2 - 3 } 0,949 & 669 & -162 \\
\hline
\end{tabular}

\begin{tabular}{|l|r|r|}
\hline \multirow{2}{*}{0,012} & 0 & -1 \\
\cline { 2 - 3 } & &
\end{tabular}

0,017

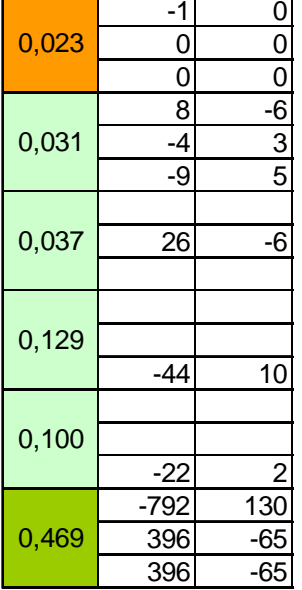


Tabela A-12 (2)

\begin{tabular}{|c|c|c|c|c|c|c|c|c|c|c|c|c|c|c|c|c|}
\hline \multirow{3}{*}{13} & \multirow[t]{3}{*}{181} & \multirow[t]{3}{*}{3,138} & \multirow[t]{3}{*}{566,5} & \multirow[t]{3}{*}{0,296} & \multirow{3}{*}{2294} & 3341 & & & $-541,8$ & & -3099 & & & 165,3 & & 1507 \\
\hline & & & & & & 3318 & 270,9 & & & & 6104 & \begin{tabular}{|l|}
$-82,7$ \\
\end{tabular} & & & & -2748 \\
\hline & & & & & & 3319 & & 270,9 & & & \begin{tabular}{|l|}
271 \\
\end{tabular} & & \begin{tabular}{|l|}
$-82,7$ \\
\end{tabular} & & & -83 \\
\hline \multirow{3}{*}{14} & \multirow[t]{3}{*}{1840} & \multirow[t]{3}{*}{3,138} & \multirow[t]{3}{*}{5774,3} & \multirow[t]{3}{*}{0,483} & \multirow{3}{*}{2308} & 3318 & & 5113,5 & & & & & $-2682,4$ & & & \\
\hline & & & & & & 3341 & & & & $-2556,7$ & & & & & 1341,2 & \\
\hline & & & & & & 3340 & $-2556,7$ & & & & -6161 & 1341,2 & & & & 1332 \\
\hline \multirow{3}{*}{15} & \multirow[t]{3}{*}{459} & \multirow[t]{3}{*}{3,138} & \multirow[t]{3}{*}{1440,1} & \multirow[t]{3}{*}{\begin{tabular}{|c|}
$-0,023$ \\
\end{tabular}} & \multirow{3}{*}{2327} & 3340 & & \begin{tabular}{|l|}
-1440 \\
\end{tabular} & & & & & \begin{tabular}{|c|}
$-33,7$ \\
\end{tabular} & & & \\
\hline & & & & & & 3317 & 719,9 & & & & 9802 & 16,8 & & & & 1456 \\
\hline & & & & & & 3318 & & & 719,9 & & & & & 16,8 & & \\
\hline \multirow{3}{*}{16} & \multirow[t]{3}{*}{1380} & \multirow[t]{3}{*}{3,138} & \multirow[t]{3}{*}{4329,2} & \multirow[t]{3}{*}{0,011} & \multirow{3}{*}{2349} & 3317 & & 4329 & & & & & $-49,1$ & & & \\
\hline & & & & & & 3340 & & & $-2164,5$ & & & & & 24,6 & & \\
\hline & & & & & & 3342 & $-2164,5$ & & & & \begin{tabular}{|c|}
-3686 \\
\end{tabular} & 24,6 & & & & -365 \\
\hline \multirow{3}{*}{17} & \multirow[t]{3}{*}{1001} & \multirow[t]{3}{*}{3,138} & \multirow[t]{3}{*}{3140,5} & \multirow[t]{3}{*}{$-0,251$} & \multirow{3}{*}{2375} & 3317 & & & 3042,1 & & & & & 779,9 & & \\
\hline & & & & & & 3342 & & $-1521,1$ & & & & & $-390,0$ & & & \\
\hline & & & & & & 3316 & $-1521,1$ & & & & \begin{tabular}{|c|}
-7838 \\
\end{tabular} & $-390,0$ & & & & -2088 \\
\hline & 1180 & 3,138 & 3702,8 & \begin{tabular}{|c|}
$-0,393$ \\
\end{tabular} & & 3316 & & $-3421,2$ & & & & & $-1416,4$ & & & \\
\hline 18 & & & & & 2376 & 3271 & 1710,6 & & & & 7502 & 708,2 & & & & 1272 \\
\hline & & & & & & 3317 & & & & 1710,6 & & & & & 708,2 & \\
\hline & 1854 & 3,138 & 5819,1 & $-0,097$ & & 3271 & & 5791,7 & & & & & 563,8 & & & \\
\hline 19 & & & & & 2377 & 3316 & & & $-2895,8$ & & & & & $-281,9$ & & \\
\hline & & & & & & 3264 & $-2895,8$ & & & & -2896 & $-281,9$ & & & & -282 \\
\hline
\end{tabular}

\begin{tabular}{|l|r|r|}
\hline \multirow{2}{*}{0,962} & -2981 & 1449 \\
\cline { 2 - 3 } & 5872 & -2643 \\
\cline { 2 - 3 } 0,935 & 261 & -80 \\
\cline { 2 - 3 } & & \\
\cline { 2 - 3 } & -5761 & 1246 \\
\hline \multirow{2}{*}{0,927} & & \\
\cline { 2 - 3 } & 9086 & 1350 \\
\hline \multirow{2}{*}{0,841} & & \\
\cline { 2 - 3 } & & \\
\cline { 2 - 3 } 0,852 & -3100 & -307 \\
\cline { 2 - 3 } & & \\
\cline { 2 - 3 } & -6681 & -1780 \\
\hline \multirow{3}{*}{0,629} & & \\
\cline { 2 - 3 } & 4721 & 800 \\
\cline { 2 - 3 } 0 & & \\
\hline \multirow{2}{*}{0,420} & & \\
\cline { 2 - 3 } & & \\
\cline { 2 - 3 } & -1215 & -118 \\
\hline
\end{tabular}


Tabela A-13 (1)
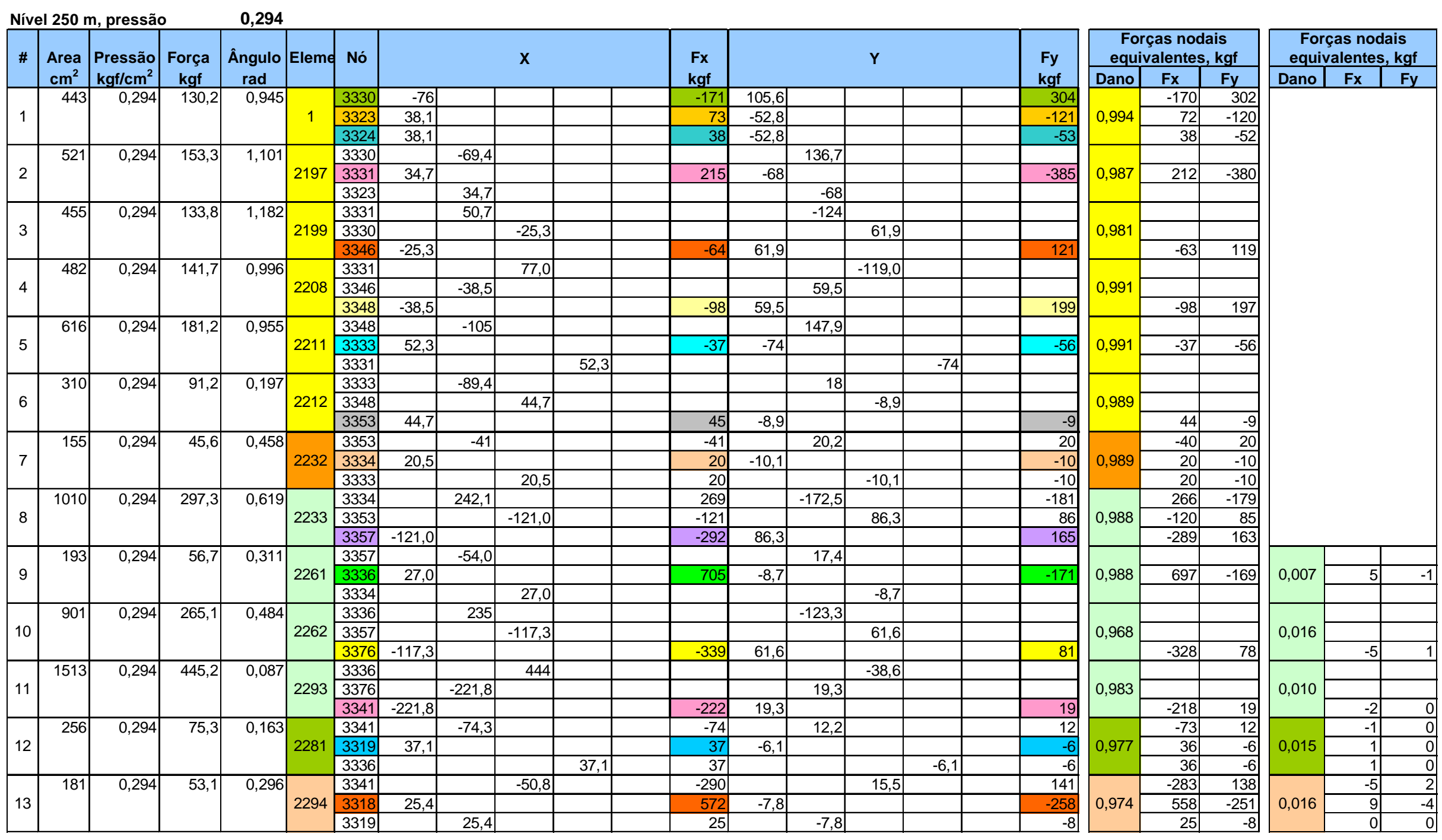
Tabela A-13 (2)
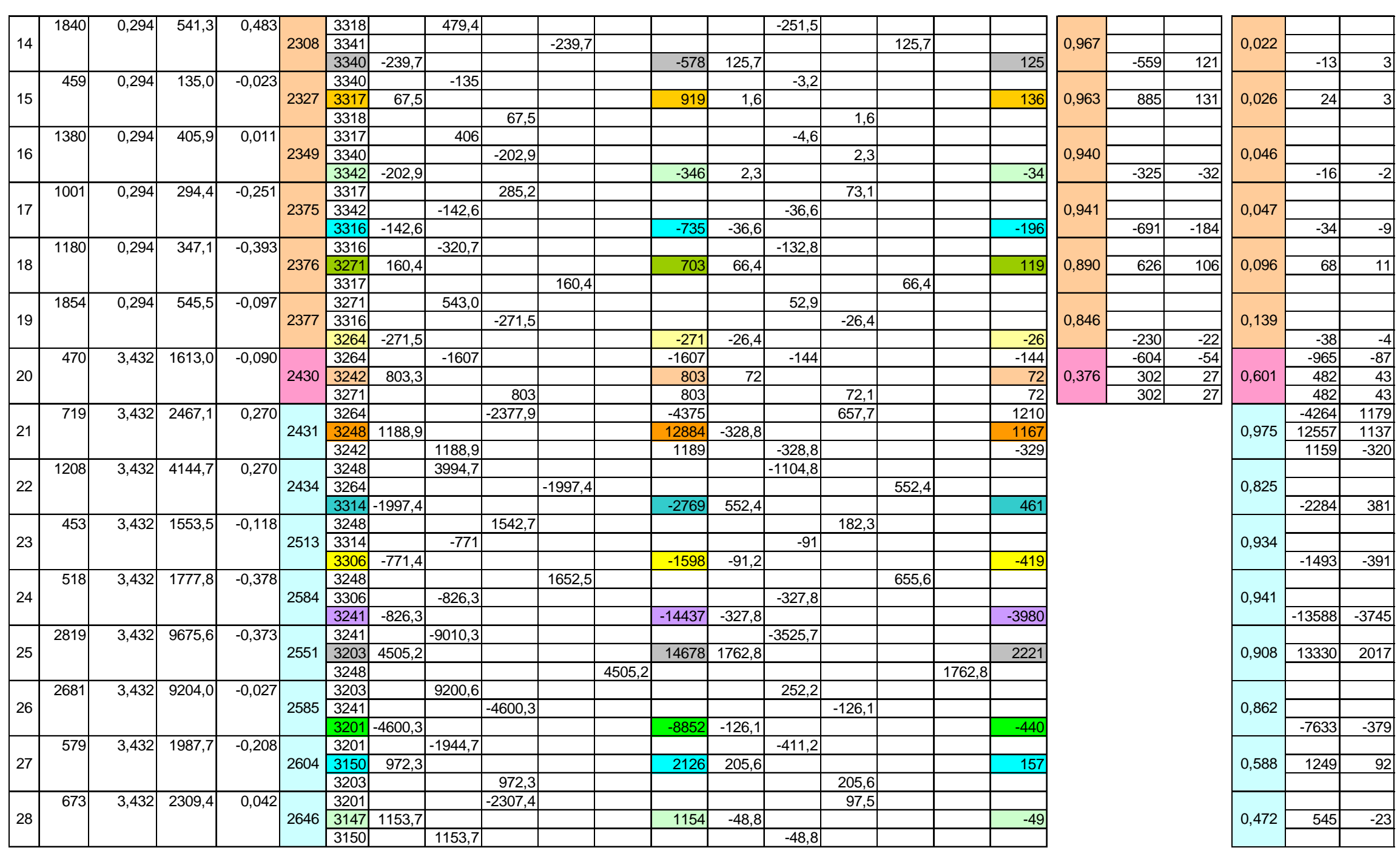
Tabela A-14 (1)

Nível 253 m, pressão

0,294
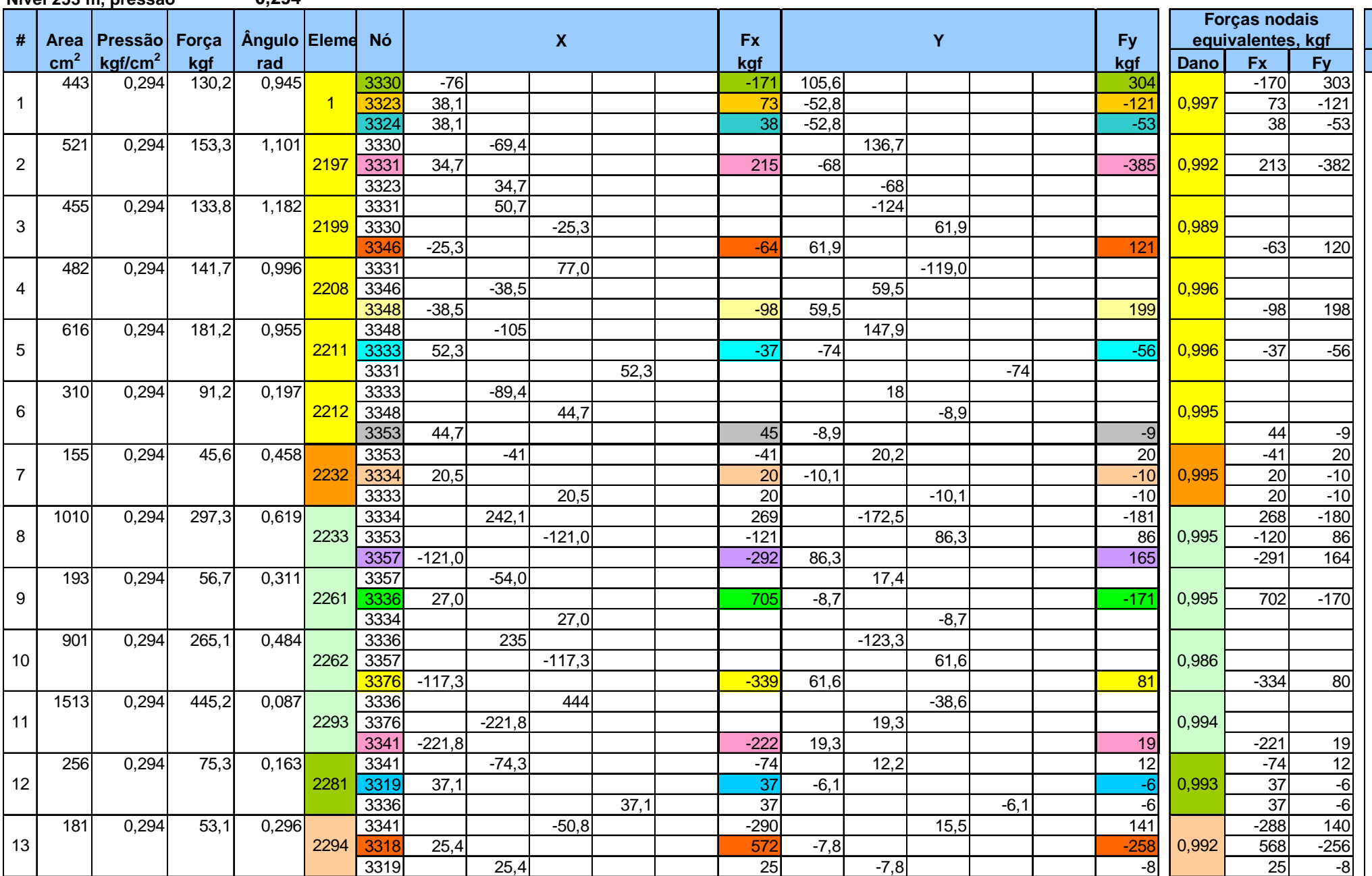

Forças nodais

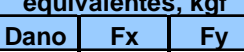

\begin{tabular}{|r|r|r|}
\hline \multirow{2}{*}{0,992} & 568 & -256 \\
\cline { 2 - 3 } & 25 & -8 \\
\hline
\end{tabular} 
Tabela A-14 (2)
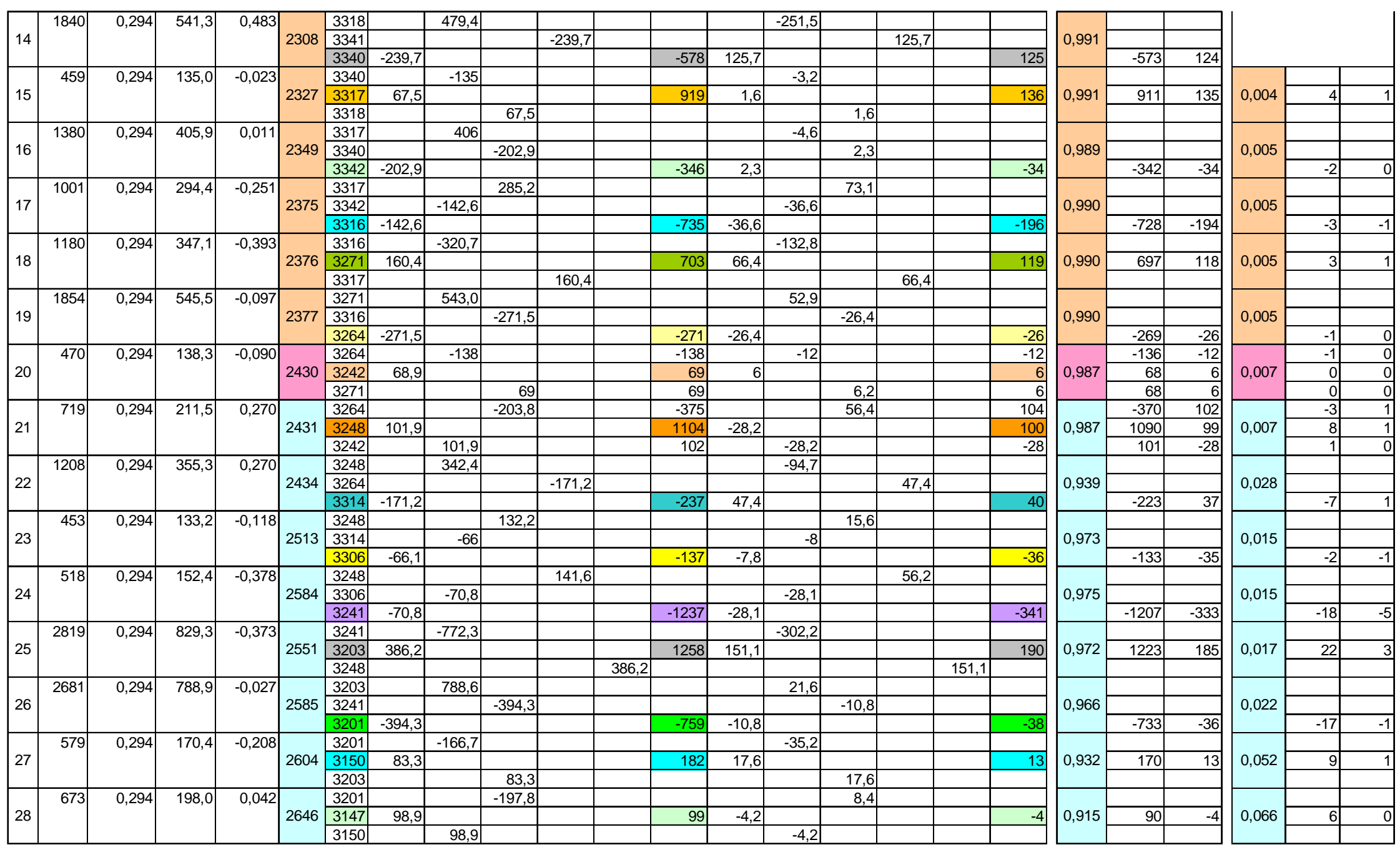


\section{Tabela A-14 (3)}

\begin{tabular}{|c|c|c|c|c|c|c|c|c|c|c|c|c|c|c|c|c|c|c|c|c|c|c|}
\hline \multirow{3}{*}{29} & \multirow[t]{3}{*}{3301} & \multirow[t]{3}{*}{3,727} & \multirow[t]{3}{*}{12301,0} & \multirow[t]{3}{*}{$\mid-0,502$} & \multirow{3}{*}{2668} & 3147 & & \#\#\#\#\# & & & 11872 & & 5924,2 & & & 6327 & \multirow{3}{*}{0,634} & 7528 & 4012 & \multirow{3}{*}{0,337} & 3996 & 2130 \\
\hline & & & & & & 3201 & & & & $-5390,2$ & -5390 & & & & $-2962,1$ & -2962 & & \begin{tabular}{|l|l|}
-3418 \\
\end{tabular} & -1878 & & \begin{tabular}{|l|}
-1814 \\
\end{tabular} & $\begin{array}{l}-997 \\
\end{array}$ \\
\hline & & & & & & 3200 & $-5390,2$ & & & & -5936 & $-2962,1$ & & & & -3164 & & \begin{tabular}{|c|}
-3764 \\
\end{tabular} & -2006 & & \begin{tabular}{|c|}
-1998 \\
\end{tabular} & -1065 \\
\hline \multirow{3}{*}{30} & \multirow[t]{3}{*}{312} & \multirow[t]{3}{*}{3,727} & \multirow{3}{*}{1163,7} & \multirow{3}{*}{$-0,354$} & \multirow{3}{*}{2677} & 3147 & & & \begin{tabular}{|l|}
1091,7 \\
\end{tabular} & & & & & 403,0 & & & \multirow{3}{*}{0,57} & & & \multirow{3}{*}{0,404} & & \\
\hline & & & & & & 3200 & & $-545,8$ & & & & & $-201,5$ & & & & & & & & & \\
\hline & & & & & & 3145 & $-545,8$ & & & & -546 & \begin{tabular}{|l|}
$-201,5$ \\
\end{tabular} & & & & -201 & & \begin{tabular}{|c|}
-311 \\
\end{tabular} & -115 & & $\begin{array}{l}-220 \\
\end{array}$ & -81 \\
\hline \multirow{3}{*}{31} & \multirow[t]{3}{*}{4347} & \multirow[t]{3}{*}{3,727} & \multirow[t]{3}{*}{\begin{tabular}{|l|}
16199,8 \\
\end{tabular}} & \multirow{3}{*}{\begin{tabular}{|c|}
$-0,601$ \\
\end{tabular}} & \multirow{3}{*}{2715} & 3145 & & -13359 & & & -14290 & & $-9164,0$ & & & -9239 & & & & \multirow{3}{*}{0,960} & -13723 & $\begin{array}{l}-8872 \\
\end{array}$ \\
\hline & & & & & & 3147 & & & & 6679,3 & 6679 & & & & 4582,0 & 4582 & & & & & 6414 & 4400 \\
\hline & & & & & & 3106 & 6679,3 & & & & 16098 & 4582,0 & & & & 5551 & & & & & 15459 & 5331 \\
\hline \multirow{3}{*}{32} & \multirow[t]{3}{*}{502} & \multirow[t]{3}{*}{3,727} & 1868,9 & $-0,080$ & & 3106 & & 1862,9 & & & & & 149,6 & & & & & & & & & \\
\hline & & & & & 2716 & 3145 & & & $-931,5$ & & & & & \begin{tabular}{|c|}
$-74,8$ \\
\end{tabular} & & & & & & 0,947 & & \\
\hline & & & & & & 3100 & \begin{tabular}{|l|}
$-931,5$ \\
\end{tabular} & & & & -29573 & \begin{tabular}{|l|l|}
$-74,8$ \\
\end{tabular} & & & & -1824 & & & & & -27992 & -1727 \\
\hline & 4079 & 3,727 & \begin{tabular}{|l|}
15200,7 \\
\end{tabular} & \begin{tabular}{|c|c|}
$-0,108$ \\
\end{tabular} & & 3100 & & -15112 & & & & & $-1639,0$ & & & & & & & & & \\
\hline 33 & & & & & 2778 & 3051 & 7556,0 & & & & 11644 & 819,5 & & & & 910 & & & & 0,885 & 10302 & 805 \\
\hline & & & & & & 3106 & & & 7556 & & & & & 819,5 & & & & & & & & \\
\hline & 2194 & 3,727 & 8177,3 & \begin{tabular}{|c|}
$-0,022$ \\
\end{tabular} & & 3100 & & & $-8175,3$ & & & & & \begin{tabular}{|l|}
$-181,2$ \\
\end{tabular} & & & & & & & & \\
\hline 34 & & & & & 2809 & 3036 & 4087,7 & & & & 25020 & 90,6 & & & & 3391 & & & & 0,842 & 21064 & 2855 \\
\hline & & & & & & 3051 & & 4087,7 & & & & & \begin{tabular}{|c|}
90,6 \\
\end{tabular} & & & & & & & & & \\
\hline & 2874 & 3,727 & 10708,6 & 0,013 & & 3036 & & 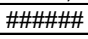 & & & & & $-142,0$ & & & & & & & & & \\
\hline 35 & & & & & 2825 & 3100 & & & & $-5353,8$ & & & & & 71,0 & & & & & 0,243 & & \\
\hline & & & & & & 3095 & $-5353,8$ & & & & -10466 & 71,0 & & & & -1650 & & & & & -2540 & -400 \\
\hline & 2895 & 3,727 & 10788,3 & $-0,325$ & & 3036 & & & \#\#\#\#" & & & & & 3442,8 & & & & & & & & \\
\hline 36 & & & & & 2935 & 3095 & & $-5112,1$ & & & & & $-1721,4$ & & & & & & & 0,123 & & \\
\hline & & & & & & 3039 & $-5112,1$ & & & & \begin{tabular}{|c|}
-5112 \\
\end{tabular} & $-1721,4$ & & & & -1721 & & & & & -631 & -212 \\
\hline
\end{tabular}


Tabela A-15 (1)

\begin{tabular}{|c|c|c|c|c|c|c|c|c|c|c|c|c|c|c|c|c|}
\hline \multicolumn{17}{|c|}{ Nível 257 m, pressão } \\
\hline \# & Area & Pressão & Força & Ângulo & Eleme & Nó & \multicolumn{4}{|c|}{$\mathrm{x}$} & $F x$ & \multicolumn{4}{|c|}{$\mathbf{Y}$} & $\mathrm{Fy}$ \\
\hline & 443 & 0392 & 1736 & 0945 & \multirow{4}{*}{1} & & & & & & & & & & & \\
\hline \multirow{3}{*}{1} & & 0,394 & 173,6 & 0,945 & & 3330 & -102 & & & & -228 & 140,8 & & & & 406 \\
\hline & & & & & & 3323 & 50,8 & & & & 97 & $-70,4$ & & & & -161 \\
\hline & & & & & & 3324 & 50,8 & & & & 51 & $-70,4$ & & & & -70 \\
\hline \multirow{3}{*}{2} & 521 & 0,392 & 204,3 & 1,101 & \multirow{3}{*}{2197} & 3330 & & $-92,5$ & & & & & 182,2 & & & \\
\hline & & & & & & 3331 & 46,2 & & & & 286 & -91 & & & & -513 \\
\hline & & & & & & 3323 & & 46,2 & & & & & \begin{tabular}{l|l|}
-91 \\
\end{tabular} & & & \\
\hline \multirow{4}{*}{3} & 455 & 0,392 & 178,4 & 1,182 & \multirow{3}{*}{2199} & 3331 & & 67,6 & & & & & -165 & & & \\
\hline & & & & & & 3330 & & & $-33,8$ & & & & & 82,6 & & \\
\hline & & & & & & 3346 & $-33,8$ & & & & -85 & 82,6 & & & & 162 \\
\hline & 482 & 0,392 & 188,9 & 0,996 & \multirow{3}{*}{2208} & 3331 & & & 102,7 & & & & & $-158,6$ & & \\
\hline \multirow[t]{3}{*}{4} & & & & & & 3346 & & $-51,3$ & & & & & 79,3 & & & \\
\hline & & & & & & 3348 & $-51,3$ & & & & -131 & 79,3 & & & & 265 \\
\hline & 616 & 0,392 & 241,6 & 0,955 & \multirow{3}{*}{2211} & 3348 & & -140 & & & & & 197,3 & & & \\
\hline \multirow[t]{3}{*}{5} & & & & & & 3333 & 69,8 & & & & -49 & \begin{tabular}{l|l|}
-99 \\
\end{tabular} & & & & -75 \\
\hline & & & & & & 3331 & & & & 69,8 & & & & & -99 & \\
\hline & 310 & 0,392 & 121,5 & 0,197 & \multirow{3}{*}{2212} & 3333 & & $-119,2$ & & & & & 24 & & & \\
\hline \multirow[t]{3}{*}{6} & & & & & & 3348 & & & 59,6 & & & & & $-11,9$ & & \\
\hline & & & & & & 3353 & 59,6 & & & & 60 & $-11,9$ & & & & -12 \\
\hline & 155 & 0,392 & 60,8 & 0,458 & \multirow{3}{*}{2232} & 3353 & & -55 & & & -55 & & 26,9 & & & 27 \\
\hline \multirow[t]{2}{*}{7} & & & & & & 3334 & 27,3 & & & & 27 & $-13,4$ & & & & -13 \\
\hline & & & & & & 3333 & & & 27,3 & & 27 & & & $-13,4$ & & -13 \\
\hline \multirow{3}{*}{8} & 1010 & 0,392 & 396,3 & 0,619 & \multirow{3}{*}{2233} & 3334 & & 322,8 & & & 359 & & $-230,0$ & & & -242 \\
\hline & & & & & & 3353 & & & $-161,4$ & & -161 & & & 115,0 & & 115 \\
\hline & & & & & & 3357 & $-161,4$ & & & & -390 & 115,0 & & & & 220 \\
\hline \multirow{4}{*}{9} & 193 & 0,392 & 75,7 & 0,311 & & 3357 & & $-72,0$ & & & & & 23,1 & & & \\
\hline & & & & & 2261 & 3336 & 36,0 & & & & 940 & $-11,6$ & & & & -227 \\
\hline & & & & & & 3334 & & & 36,0 & & & & & $-11,6$ & & \\
\hline & 901 & 0,392 & 353,4 & 0,484 & & 3336 & & 313 & & & & & $-164,4$ & & & \\
\hline 10 & & & & & 2262 & 3357 & & & $-156,4$ & & & & & 82,2 & & \\
\hline & & & & & & 3376 & $-156,4$ & & & & -452 & 82,2 & & & & 108 \\
\hline & 1513 & 0,392 & 593,6 & 0,087 & & 3336 & & & 591 & & & & & $-51,5$ & & \\
\hline 11 & & & & & 2293 & 3376 & & $-295,7$ & & & & & 25,8 & & & \\
\hline & & & & & & 3341 & $-295,7$ & & & & -296 & 25,8 & & & & 26 \\
\hline & 256 & 0,392 & 100,4 & 0,163 & & 3341 & & $-99,1$ & & & -99 & & \begin{tabular}{|l|}
16,3 \\
\end{tabular} & & & 16 \\
\hline 12 & & & & & 2281 & 3319 & 49,5 & & & & 50 & $-8,1$ & & & & -8 \\
\hline & & & & & & 3336 & & & & 49,5 & 50 & & & & $-8,1$ & -8 \\
\hline & 181 & 0,392 & \begin{tabular}{|c|}
70,8 \\
\end{tabular} & 0,296 & & 3341 & & & $-67,7$ & & -387 & & & 20,7 & & 188 \\
\hline 13 & & & & & 2294 & 3318 & 33,9 & & & & 763 & \begin{tabular}{|c|} 
\\
\end{tabular} & & & & -344 \\
\hline & & & & & & 3319 & & 33,9 & & & 34 & & \begin{tabular}{|c|}
$-10,3$ \\
\end{tabular} & & & -10 \\
\hline
\end{tabular}

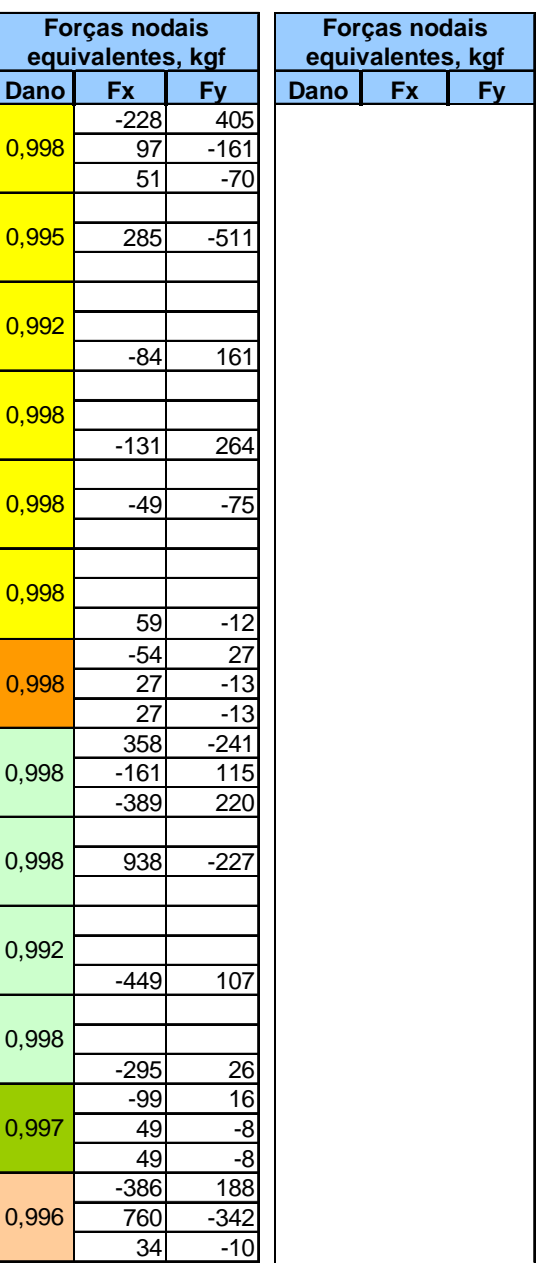




\section{Tabela A-15 (2)}

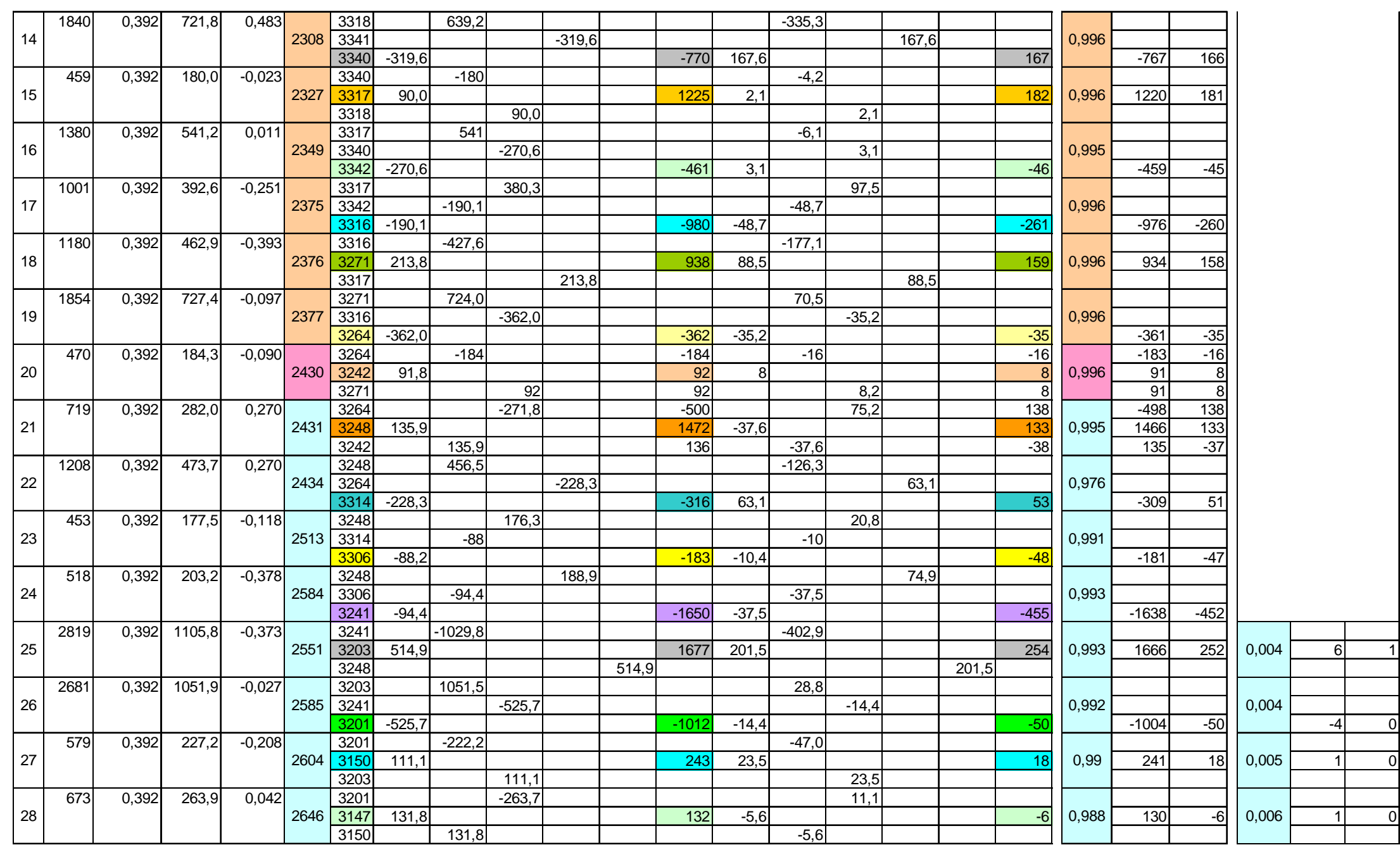




\section{Tabela A-15 (3)}
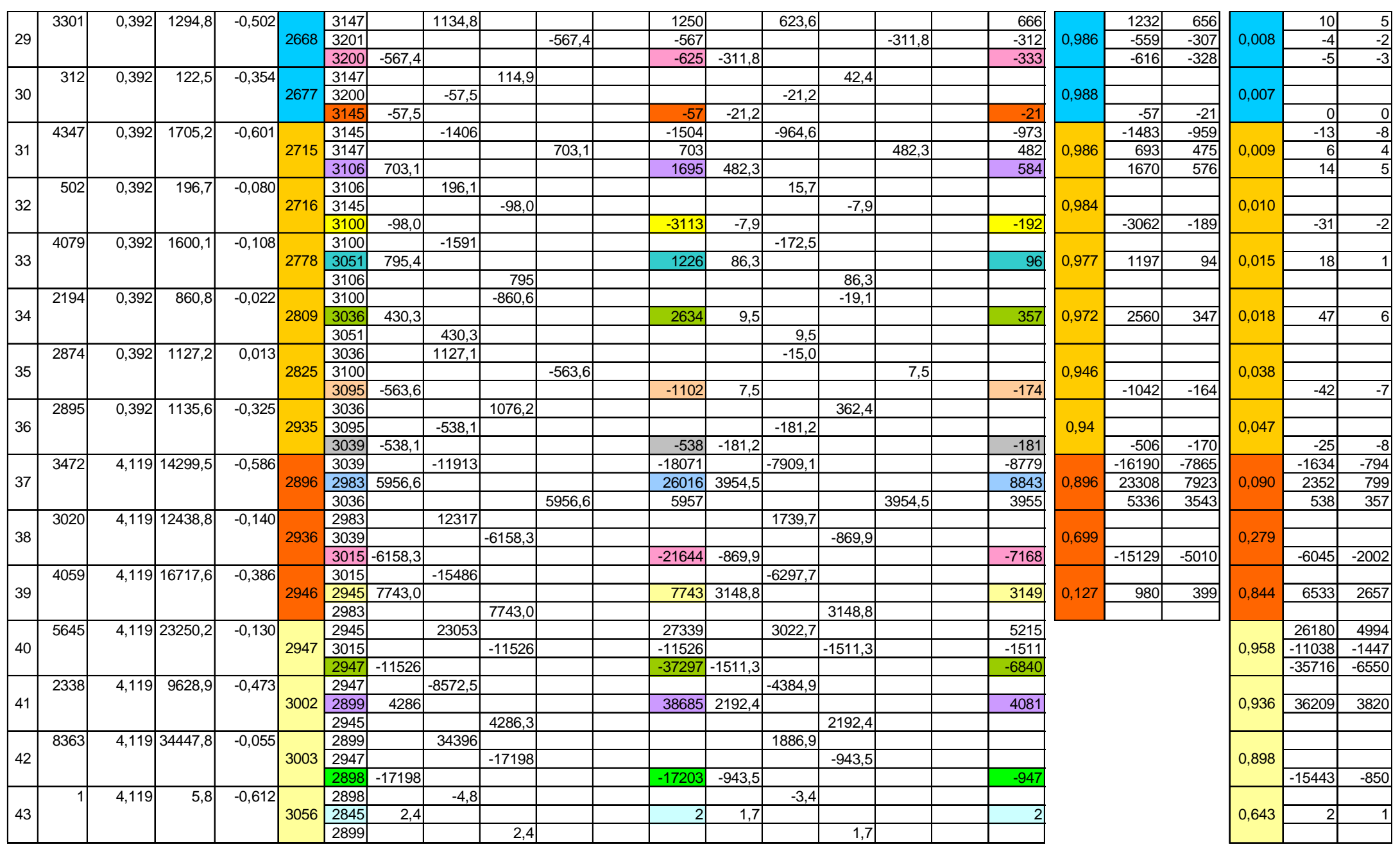
Tabela A-15 (4)

\begin{tabular}{|c|c|c|c|c|c|c|c|c|c|c|c|c|}
\hline \multirow{3}{*}{29} & 3301 & 0,392 & 1294,8 & $-0,502$ & \multirow{3}{*}{2668} & 3147 & \multirow{3}{*}{0,002} & 2 & 1 & & & \\
\hline & & & & & & \begin{tabular}{|l|}
3201 \\
\end{tabular} & & -1 & 0 & & & \\
\hline & & & & & & 3200 & & \begin{tabular}{l|}
-1 \\
\end{tabular} & -1 & & & \\
\hline \multirow{3}{*}{30} & 312 & 0,392 & 122,5 & $-0,354$ & \multirow{3}{*}{2677} & \begin{tabular}{|l|}
3147 \\
\end{tabular} & \multirow{3}{*}{0,001} & & & & & \\
\hline & & & & & & \begin{tabular}{|l|}
3200 \\
\end{tabular} & & & & & & \\
\hline & & & & & & 3145 & & 0 & 0 & & & \\
\hline \multirow{3}{*}{31} & 4347 & 0,392 & 1705,2 & $-0,601$ & \multirow{3}{*}{2715} & \begin{tabular}{|l|}
3145 \\
\end{tabular} & \multirow{3}{*}{0,001} & -2 & -1 & & & \\
\hline & & & & & & \begin{tabular}{|l|}
3147 \\
\end{tabular} & & 1 & 1 & & & \\
\hline & & & & & & 3106 & & 2 & 1 & & & \\
\hline \multirow{3}{*}{32} & 502 & 0,392 & $\begin{array}{l}196,7 \\
\end{array}$ & $-0,080$ & \multirow{3}{*}{2716} & \begin{tabular}{|l|}
3106 \\
\end{tabular} & \multirow{3}{*}{0,002} & & & & & \\
\hline & & & & & & \begin{tabular}{|l|}
3145 \\
\end{tabular} & & & & & & \\
\hline & & & & & & 3100 & & -5 & 0 & & & \\
\hline \multirow{2}{*}{33} & 4079 & o,392 & 1600,1 & \begin{tabular}{|c|}
$-0,108$ \\
\end{tabular} & & 3100 & \multirow[b]{2}{*}{0,002} & & & & & \\
\hline & & & & & 2778 & \begin{tabular}{|l|}
3051 \\
3106
\end{tabular} & & 3 & 0 & & & \\
\hline \multirow[b]{2}{*}{34} & 2194 & 0,392 & \begin{tabular}{|l|}
860,8 \\
\end{tabular} & \begin{tabular}{|c|}
$-0,022$ \\
\end{tabular} & & \begin{tabular}{|l|}
3100 \\
\end{tabular} & \multirow[b]{2}{*}{0,003} & & & \multirow[b]{2}{*}{0,001} & & \\
\hline & & & & & 2809 & \begin{tabular}{|l|}
3036 \\
3051 \\
\end{tabular} & & 8 & 1 & & 3 & \\
\hline \multirow{3}{*}{35} & 2874 & 0,392 & 1127,2 & \begin{tabular}{|l|}
0,013 \\
\end{tabular} & & 3036 & \multirow{3}{*}{0,005} & & & \multirow{3}{*}{0,002} & & \\
\hline & & & & & 2825 & \begin{tabular}{|l|}
3100 \\
\end{tabular} & & & & & & \\
\hline & & & & & & 3095 & & -6 & -1 & & -2 & \\
\hline \multirow{3}{*}{36} & 2895 & 0,392 & 1135,6 & $-0,325$ & & 3036 & \multirow{3}{*}{0,004} & & & & & \\
\hline & & & & & 2935 & \begin{tabular}{|l|}
3095 \\
\end{tabular} & & & & 0,001 & & \\
\hline & & & & & & \begin{tabular}{|l|}
3039 \\
\end{tabular} & & -2 & -1 & & \begin{tabular}{l|} 
\\
\end{tabular} & \\
\hline & 3472 & 4,119 & 14299,5 & \begin{tabular}{|c|}
$-0,586$ \\
\end{tabular} & & \begin{tabular}{|l|}
3039 \\
\end{tabular} & & -94 & -46 & & -25 & -12 \\
\hline 37 & & & & & 2896 & 2983 & 0,005 & 136 & 46 & 0,001 & 36 & 12 \\
\hline & & & & & & 3036 & & 31 & 21 & & 8 & \\
\hline & 3020 & 4,119 & 12438,8 & $-0,140$ & & \begin{tabular}{|l|}
2983 \\
\end{tabular} & & & & & & \\
\hline 38 & & & & & 2936 & \begin{tabular}{|l|}
3039 \\
\end{tabular} & 0,010 & & & 0,002 & & \\
\hline & & & & & & 3015 & & -206 & -68 & & -48 & -16 \\
\hline & 4059 & 4,119 & 16717,6 & \begin{tabular}{|c|}
$-0,386$ \\
\end{tabular} & & 3015 & & & & & & \\
\hline 39 & & & & & 2946 & 2945 & 0,015 & 113 & 46 & 0,003 & 22 & \\
\hline & & & & & & 2983 & & & & & & \\
\hline & 5645 & 4,119 & 23250,2 & $-0,130$ & & \begin{tabular}{|l|}
2945 \\
\end{tabular} & & 737 & 141 & & 94 & 18 \\
\hline 40 & & & & & 2947 & 3015 & 0,027 & -311 & -41 & 0,003 & -40 & -5 \\
\hline & & & & & & 2947 & & -1006 & -184 & & -128 & -23 \\
\hline & 2338 & 4,119 & $\begin{array}{l}9628,9 \\
\end{array}$ & $-0,473$ & & \begin{tabular}{|l|}
2947 \\
\end{tabular} & & & & & & \\
\hline 41 & & & & & 3002 & \begin{tabular}{|l|}
2899 \\
\end{tabular} & 0,0479 & 1855 & 196 & 0,004 & 173 & 18 \\
\hline & $\begin{array}{l}8363 \\
\end{array}$ & $\mid 4,119$ & & 0055 & & $\frac{2945}{2899}$ & & & & & & \\
\hline 42 & & & $34+4+1,0$ & $-0,000$ & 3003 & \begin{tabular}{|l|}
2947 \\
\end{tabular} & 0,084 & & & 0,006 & & \\
\hline & & & & & & 2898 & & -1441 & $-79,29$ & & $\begin{array}{l}-102 \\
\end{array}$ & -6 \\
\hline & & 4,119 & 5,8 & $-0,612$ & & \begin{tabular}{|l|}
2898 \\
\end{tabular} & & & & & & \\
\hline 43 & & & & & 3056 & \begin{tabular}{|l|}
2845 \\
2899
\end{tabular} & 0,318 & 1 & 1 & 0,018 & 0 & 0 \\
\hline
\end{tabular}


Tabela A-15 (5)

\begin{tabular}{|c|c|c|c|c|c|c|c|c|c|c|c|c|}
\hline \multirow{3}{*}{44} & 4 & 4,119 & 16,6 & $-0,122$ & \multirow{3}{*}{3057} & 2898 & \multirow{3}{*}{0,94} & -17636 & -2156 & \multirow{3}{*}{0,031} & -589 & -72 \\
\hline & & & & & & 2843 & & 59318 & 23435 & & 1981 & 783 \\
\hline & & & & & & 2845 & & 8 & 1 & & 0 & 0 \\
\hline \multirow{3}{*}{45} & 9170 & 4,119 & 37770,6 & $-0,122$ & \multirow{3}{*}{3161} & 2843 & & & & \multirow{3}{*}{0,330} & & \\
\hline & & & & & & 2898 & 0,620 & & & & & \\
\hline & & & & & & 2904 & & -15857 & -3442 & & -8451 & -1835 \\
\hline \multirow{3}{*}{46} & 3682 & 4,119 & 15164,9 & $-0,445$ & \multirow{3}{*}{3162} & 2843 & & & & \multirow{3}{*}{0,212} & & \\
\hline & & & & & & 2904 & 0,750 & & & & & \\
\hline & & & & & & 2846 & & -9597 & -7626 & & -2718 & -2160 \\
\hline \multirow{3}{*}{47} & 4430 & 4,119 & 18247,8 & $-0,859$ & \multirow{3}{*}{3223} & 2843 & & & & \multirow{3}{*}{0,652} & & \\
\hline & & & & & & 2846 & 0,278 & & & & & \\
\hline & & & & & & 2796 & & -1659 & -1924 & & -3887 & -4508 \\
\hline \multirow{3}{*}{48} & 4456 & 4,119 & 18355,6 & $-1,310$ & \multirow{3}{*}{3170} & 2796 & & & & \multirow{3}{*}{0,186} & -10566 & -3330 \\
\hline & & & & & & 2795 & & & & & \begin{tabular}{|l|}
2479 \\
\end{tabular} & 2512 \\
\hline & & & & & & 2843 & & & & & 439 & 1645 \\
\hline \multirow[b]{2}{*}{49} & 5802 & 4,119 & 23897,8 & $-0,402$ & \multirow[b]{2}{*}{3213} & 2796 & & & & \multirow[b]{2}{*}{0,684} & & \\
\hline & & & & & & 2759 & & & & & 17852 & 72 \\
\hline \multirow[b]{2}{*}{50} & 7664 & 4,119 & 31568,8 & 0,294 & \multirow[b]{2}{*}{3212} & 2796 & & & & \multirow[b]{2}{*}{0,334} & & \\
\hline & & & & & & $\frac{2760}{2759}$ & & & & & 5051 & -1527 \\
\hline
\end{tabular}


Tabela A-16 (1)

Forças nodais equivalentes à pressão hidráulica na fratura - PPcf12p - Casa de Força

\begin{tabular}{|l|l|l|l|l|l|l|}
\cline { 2 - 7 } \multicolumn{1}{c|}{} & h1 & h2 & h3 & h4 & h5 & h6 \\
\hline Nível 225 & 1,667 & 1,863 & 2,158 & 2,452 & 2,746 & 3,138 \\
\hline Nível 220 & 2,158 & 2,354 & 2,648 & 2,942 & 3,236 & 3,629 \\
\hline
\end{tabular}

Pressão na fratura

Nível $242 \mathrm{~m}$ (h1=22m), pressão

2,158

\begin{tabular}{|c|c|c|c|c|c|c|c|c|c|c|c|c|c|c|c|c|c|c|}
\hline \multirow{3}{*}{ \# } & & \multirow{3}{*}{$\begin{array}{l}\text { Pressão } \\
\mathbf{k g f f} / \mathrm{cm}^{2}\end{array}$} & \multirow{3}{*}{$\begin{array}{c}\text { Força } \\
\mathrm{kgf}\end{array}$} & & & & & & & & & & & & & & & \\
\hline & \multirow{2}{*}{$\begin{array}{l}\text { Area } \\
\mathrm{cm}^{2}\end{array}$} & & & \multirow{2}{*}{$\begin{array}{c}\text { Ângulo } \\
\text { rad }\end{array}$} & \multicolumn{2}{|c|}{ Força nos eixos } & \multirow[t]{2}{*}{ Elemen } & \multirow[t]{2}{*}{ Nó } & \multirow{2}{*}{\multicolumn{4}{|c|}{$x$}} & \multirow{3}{*}{$\begin{array}{l}\begin{array}{l}\text { Fx } \\
\text { kgf }\end{array} \\
-1593\end{array}$} & \multirow{2}{*}{\multicolumn{4}{|c|}{$\mathbf{Y}$}} & \multirow{3}{*}{$\begin{array}{l}\text { Fy } \\
\text { kgf } \\
2210\end{array}$} \\
\hline & & & & & $x$ & $\mathrm{y}$ & & & & & & & & & & & & \\
\hline & 467 & 2,158 & \begin{tabular}{|c|}
1008,4 \\
\end{tabular} & 0,722 & $-756,9$ & 666,3 & \multirow{3}{*}{1} & 3200 & $-756,9$ & & & & & 666,3 & & & & \\
\hline \multirow[t]{2}{*}{1} & & & & & 378,4 & $-333,2$ & & 3187 & 378,4 & & & & 687 & $-333,2$ & & & & -988 \\
\hline & & & & & 378,4 & $-333,2$ & & 3188 & 378,4 & & & & 378 & $-333,2$ & & & & -333 \\
\hline \multirow{3}{*}{2} & \multirow[t]{3}{*}{671} & \multirow[t]{3}{*}{2,158} & \multirow[t]{3}{*}{1447,3} & \multirow[t]{3}{*}{1,131} & $-616,2$ & 1309,5 & \multirow{3}{*}{1137} & 3200 & & $-616,2$ & & & & & 1309,5 & & & \\
\hline & & & & & 308,1 & $-654,8$ & & 3201 & 308,1 & & & & 1997 & $-654,8$ & & & & -1958 \\
\hline & & & & & 308,1 & $-654,8$ & & 3187 & & 308,1 & & & & & $\begin{array}{l}-654,8 \\
\end{array}$ & & & \\
\hline \multirow{3}{*}{3} & \multirow[t]{3}{*}{304} & \multirow[t]{3}{*}{2,158} & \multirow[t]{3}{*}{656,0} & \multirow[t]{3}{*}{0,836} & \begin{tabular}{|l|}
439,6 \\
\end{tabular} & $-486,9$ & \multirow{3}{*}{1139} & 3201 & & 439,6 & & & & & $-486,9$ & & & \\
\hline & & & & & $-219,8$ & 243,5 & & 3200 & & & $-219,8$ & & & & & 243,5 & & \\
\hline & & & & & $-219,8$ & 243,5 & & 3221 & $-219,8$ & & & & -307 & 243,5 & & & & 340 \\
\hline & 121 & 2,158 & 261,2 & 0,836 & 175,1 & $-193,9$ & & 3201 & & & 175,1 & & & & & \begin{tabular}{|c|}
$-193,9$ \\
\end{tabular} & & \\
\hline 4 & & & & & $-87,5$ & 96,9 & 1148 & 3221 & & $-87,5$ & & & & & \begin{tabular}{|c|}
96,9 \\
\end{tabular} & & & \\
\hline & & & & & $-87,5$ & 96,9 & & 3222 & $\begin{array}{l}-87,5 \\
\end{array}$ & & & & -2281 & 96,9 & & & & 1387 \\
\hline & 1151 & 2,158 & 2483,2 & 0,525 & $-2148,8$ & 1244,6 & & 3222 & & -2149 & & & & & 1244,6 & & & \\
\hline 5 & & & & & 1074,4 & $-622,3$ & 1150 & 3202 & 1074,4 & & & & 3318 & $-622,3$ & & & & -1975 \\
\hline & & & & & 1074,4 & $-622,3$ & & 3201 & & & & 1074,4 & & & & & $-622,3$ & \\
\hline & 59 & 2,158 & 127,3 & 0,801 & 88,6 & $-91,4$ & & 3202 & & 88,6 & & & & & \begin{tabular}{|c|}
$-91,4$ \\
\end{tabular} & & & \\
\hline 6 & & & & & \begin{tabular}{|l|} 
\\
\end{tabular} & 45,7 & 1151 & 3222 & & & \begin{tabular}{|c|}
$-44,3$ \\
\end{tabular} & & & & & \begin{tabular}{|c|}
45,7 \\
\end{tabular} & & \\
\hline & & & & & $-44,3$ & 45,7 & & 3225 & \begin{tabular}{|l|l|}
$-44,3$ \\
\end{tabular} & & & & -950 & 45,7 & & & & 576 \\
\hline & 973 & 2,158 & 2098,6 & 0,530 & 1811,0 & $-1060,4$ & & 3202 & & & 1811 & & & & & -1060 & & \\
\hline 7 & & & & & $-905,5$ & 530,2 & 1165 & 3225 & & $-905,5$ & & & & & 530,2 & & & \\
\hline & & & & & $-905,5$ & 530,2 & & 3203 & $-905,5$ & & & & -3172 & 530,2 & & & & 2121 \\
\hline & 369 & 2,158 & 796,4 & 0,530 & $-687,2$ & 402,4 & & 3203 & & $-687,2$ & & & & & 402,4 & & & \\
\hline 8 & & & & & 343,6 & $-201,2$ & 1160 & 3184 & 343,6 & & & & 365 & $-201,2$ & & & & -214 \\
\hline & & & & & 343,6 & $\begin{array}{l}-201,2 \\
\end{array}$ & & 3202 & & & & 343,6 & & & & & $\begin{array}{l}-201,2 \\
\end{array}$ & \\
\hline
\end{tabular}

Forças nodais

equivalentes, kgf

\begin{tabular}{l|l|l|} 
Dano & Fx & Fy \\
\hline
\end{tabular}

\begin{tabular}{|l|r|r|}
\hline \multirow{2}{*}{0,995} & -1586 & 2209 \\
\cline { 2 - 3 } & 683 & -983 \\
\hline
\end{tabular}

\begin{tabular}{ll|l|}
\cline { 2 - 3 } 0 & 377 & -332 \\
\hline
\end{tabular}

\begin{tabular}{l|l|l|}
0,090 & 1977 & -1938 \\
\cline { 2 - 2 } & & \\
\hline
\end{tabular}

\begin{tabular}{|l|l|l|}
\multirow{2}{*}{0,982} & & \\
\cline { 2 - 3 } & & \\
\cline { 2 - 3 } & -302 & 334 \\
\hline
\end{tabular}

\begin{tabular}{|l|r|r|}
\multirow{2}{*}{0,994} & & \\
\cline { 2 - 3 } & & \\
\cline { 2 - 3 } & -2266 & 1378 \\
\hline
\end{tabular}

\begin{tabular}{|l|r|r|}
\hline 0,993 & 3295 & -1962 \\
\cline { 2 - 3 }
\end{tabular}

\begin{tabular}{|l|r|r|}
\hline \multirow{2}{*}{0,992} & & \\
\cline { 2 - 3 } & & \\
\cline { 2 - 3 } & -943 & 572 \\
\hline
\end{tabular}

0,991

\begin{tabular}{l|l|l|} 
& -3144 & 2102 \\
\hline & & \\
\hline
\end{tabular}

\begin{tabular}{|l|l|l|}
\cline { 2 - 3 } 0,989 & 361 & -212 \\
\cline { 2 - 3 }
\end{tabular} 


\section{Tabela A-16 (2)}

\begin{tabular}{|c|c|c|c|c|c|c|c|c|c|c|c|c|c|c|c|c|c|c|c|c|c|c|c|}
\hline \multirow{3}{*}{9} & \multirow[t]{3}{*}{23} & \multirow[t]{3}{*}{2,158} & \multirow[t]{3}{*}{50,7} & \multirow[t]{3}{*}{0,551} & $-43,2$ & 26,5 & \multirow{3}{*}{1170} & 3203 & & & $-43,2$ & & & & & & 26,5 & & & \multirow[b]{2}{*}{-211} & \multirow{3}{*}{0,989} & \multirow[b]{2}{*}{280} & \multirow[b]{2}{*}{-209} \\
\hline & & & & & 21,6 & $\begin{array}{l}-13,3 \\
\end{array}$ & & 3181 & 21,6 & & & & & 283 & $-13,3$ & & & & & & & & \\
\hline & & & & & 21,6 & $-13,3$ & & 3184 & & 21,6 & & & & & & \begin{tabular}{l|}
$-13,3$ \\
\end{tabular} & & & & & & & \\
\hline \multirow{3}{*}{10} & \multirow[t]{3}{*}{304} & \multirow[t]{3}{*}{2,158} & \multirow[t]{3}{*}{655,7} & \multirow[t]{3}{*}{0,648} & $-523,0$ & $\begin{array}{l}395,5 \\
\end{array}$ & \multirow{3}{*}{1179} & 3203 & & & & $-523,0$ & & & & & & 395,5 & & & \multirow{3}{*}{0,975} & & \\
\hline & & & & & 261,5 & \begin{tabular}{|l|}
$-197,8$ \\
\end{tabular} & & 3205 & 261,5 & & & & & 4058 & $-197,8$ & & & & & -2235 & & 3957 & -2179 \\
\hline & & & & & 261,5 & \begin{tabular}{|l|}
$-197,8$ \\
\end{tabular} & & 3181 & & 261,5 & & & & & & $-197,8$ & & & & & & & \\
\hline \multirow{3}{*}{11} & \multirow[t]{3}{*}{1178} & 2,158 & 2540,7 & 0,648 & 2026,4 & $-1532,6$ & & 3205 & & 2026,4 & & & & & & -1533 & & & & & & & \\
\hline & & & & & $-1013,2$ & 766,3 & 1191 & 3203 & & & & & -1013 & & & & & & 766,3 & & 0,956 & & \\
\hline & & & & & $-1013,2$ & 766,3 & & 3226 & -1013 & & & & & -1085 & 766,3 & & & & & 802 & & -1037 & 766 \\
\hline & 74 & 2,158 & 160,2 & 0,456 & 143,8 & \begin{tabular}{|l|}
$-70,5$ \\
\end{tabular} & & 3205 & & & 143,8 & & & & & & $-70,5$ & & & & & & \\
\hline 12 & & & & & $-71,9$ & 35,2 & 1192 & 3226 & & $-71,9$ & & & & & & 35,2 & & & & & 0,970 & & \\
\hline & & & & & $-71,9$ & 35,2 & & 3246 & \begin{tabular}{|l|}
$-71,9$ \\
\end{tabular} & & & & & -209 & 35,2 & & & & & 53 & & \begin{tabular}{|l|}
-203 \\
\end{tabular} & 52 \\
\hline & 128 & 2,158 & 276,9 & 0,132 & 274,5 & $-36,4$ & & 3205 & & & & 274,5 & & & & & & $-36,4$ & & & & & \\
\hline 13 & & & & & $-137,2$ & \begin{tabular}{ll|}
18,2 \\
\end{tabular} & 1223 & 3246 & & $-137,2$ & & & & & & 18,2 & & & & & 0,985 & & \\
\hline & & & & & $-137,2$ & 18,2 & & 3209 & $-137,2$ & & & & & -5901 & 18,2 & & & & & 896 & & -5815 & 883 \\
\hline & 1306 & 2,158 & 2818,1 & 0,286 & $-2703,7$ & 794,7 & & 3209 & & -2704 & & & & & & 794,7 & & & & & & & \\
\hline 14 & & & & & 1351,9 & \begin{tabular}{|l|}
$-397,4$ \\
\end{tabular} & 1210 & 3179 & 1351,9 & & & & & 2520 & $-397,4$ & & & & & -392 & 0,982 & 2474 & -385 \\
\hline & & & & & 1351,9 & $-397,4$ & & 3205 & & & & & 1351,9 & & & & & & $-397,4$ & & & & \\
\hline & 1083 & 2,158 & 2336,5 & $-0,004$ & $-2336,5$ & $\begin{array}{l}-10,2 \\
\end{array}$ & & 3209 & & & -2336 & & & & & & $-10,2$ & & & & & & \\
\hline 15 & & & & & 1168,2 & $\begin{array}{r}5,1 \\
\end{array}$ & 1227 & 3177 & 1168,2 & & & & & 5300 & 5,1 & & & & & 280 & 0,979 & 5188 & 274 \\
\hline & & & & & 1168,2 & 5,1 & & 3179 & & 1168,2 & & & & & & 5,1 & & & & & & & \\
\hline & 677 & 2,158 & 1459,8 & 0,128 & 1447,9 & \begin{tabular}{l|l|}
$-186,5$ \\
\end{tabular} & & 3177 & & 1447,9 & & & & & & $-186,5$ & & & & & & & \\
\hline 16 & & & & & \begin{tabular}{|l|}
$-723,9$ \\
\end{tabular} & \begin{tabular}{|l|}
93,3 \\
\end{tabular} & 1246 & 3209 & & & & $-723,9$ & & & & & & 93,3 & & & 0,970 & & \\
\hline & & & & & $\begin{array}{l}-723,9 \\
\end{array}$ & 93,3 & & 3208 & $-723,9$ & & & & & -1427 & 93,3 & & & & & -18 & & -1384 & -17 \\
\hline & 659 & 2,158 & 1422,6 & $-0,157$ & 1405,2 & 221,8 & & 3177 & & & 1405,2 & & & & & & 221,8 & & & & & & \\
\hline 17 & & & & & $\begin{array}{l}-702,6 \\
\end{array}$ & \begin{tabular}{l|l|}
$-110,9$ \\
\end{tabular} & 1264 & 3208 & & $-702,6$ & & & & & & $-110,9$ & & & & & 0,971 & & \\
\hline & & & & & $-702,6$ & $-110,9$ & & 3175 & $-702,6$ & & & & & -7595 & $-110,9$ & & & & & -614 & & -7376 & -597 \\
\hline & 1206 & 2,158 & 2601,1 & $-0,185$ & $-2556,7$ & $-478,5$ & & 3175 & & -2557 & & & & & & $-478,5$ & & & & & & & \\
\hline 18 & & & & & 1278,4 & 239,2 & 1273 & 3142 & 1278,4 & & & & & 3388 & 239,2 & & & & & 242 & 0,957 & 3243 & 232 \\
\hline & & & & & 1278,4 & 239,2 & & 3177 & & & & 1278,4 & & & & & & 239,2 & & & & & \\
\hline & 1955 & 2,158 & 4218,7 & $-0,001$ & $-4218,7$ & \begin{tabular}{|l|}
$-5,9$ \\
\end{tabular} & & 3175 & & & -4219 & & & & & & $-5,9$ & & & & & & \\
\hline 19 & & & & & 2109,3 & 2,9 & 1274 & 3135 & 2109,3 & & & & & 2343 & 2,9 & & & & & 41 & 0,948 & 2222 & 39 \\
\hline & & & & & 2109,3 & 2,9 & & 3142 & & 2109,3 & & & & & & 2,9 & & & & & & & \\
\hline & 110 & 2,158 & 236,9 & $-0,163$ & 233,8 & 38,4 & & 3135 & & 233,8 & & & & & & 38,4 & & & & & & & \\
\hline 20 & & & & & $-116,9$ & \begin{tabular}{|l|}
$-19,2$ \\
\end{tabular} & 1314 & 3175 & & & & $-116,9$ & & & & & & $-19,2$ & & & 0,783 & & \\
\hline & & & & & $-116,9$ & $-19,2$ & & 3174 & $-116,9$ & & & & & -117 & $-19,2$ & & & & & -19 & & -92 & -15 \\
\hline
\end{tabular}


Tabela A-17 (1)
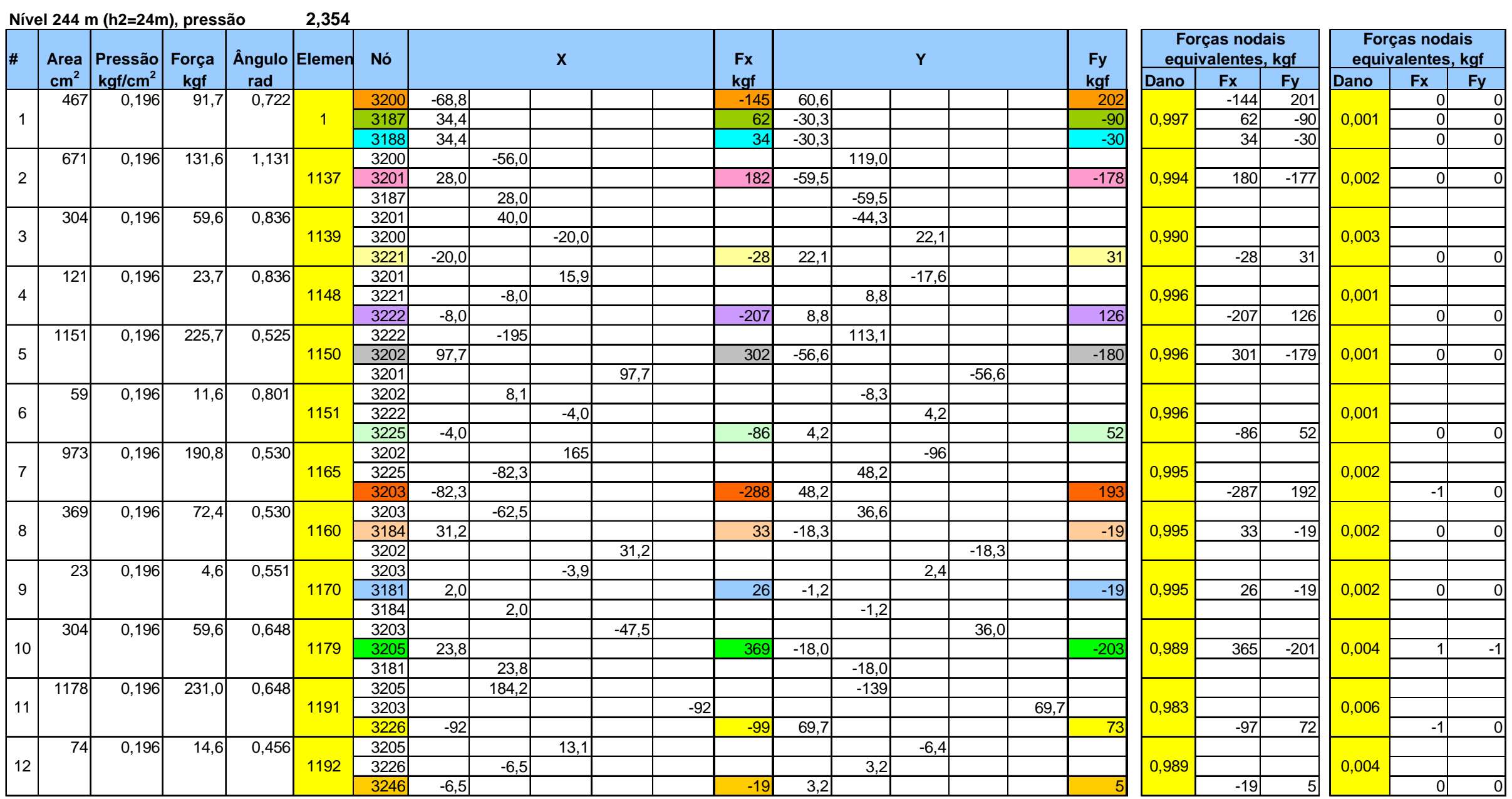
Tabela A-17 (2)
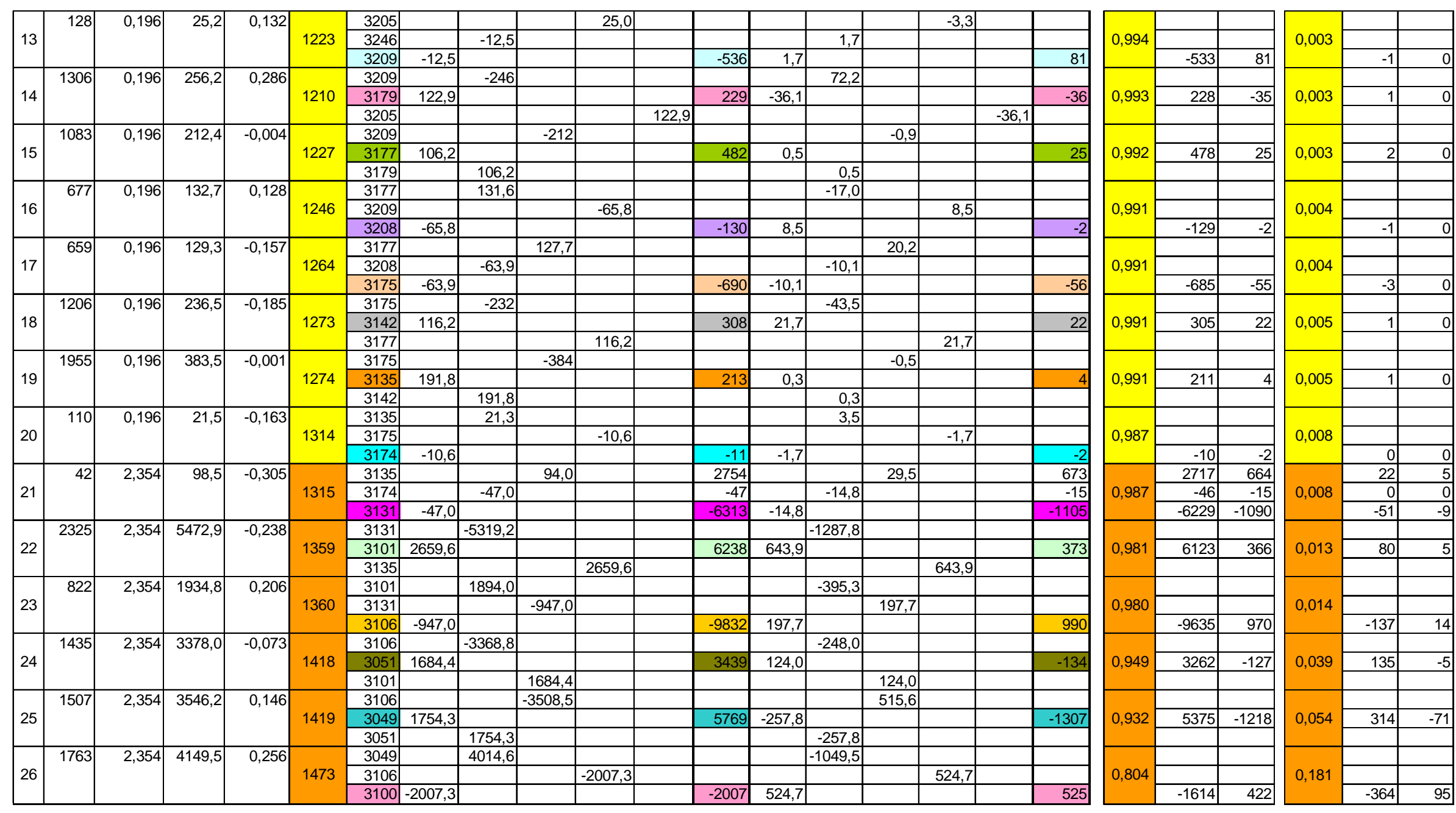


\section{Tabela A-17 (3)}

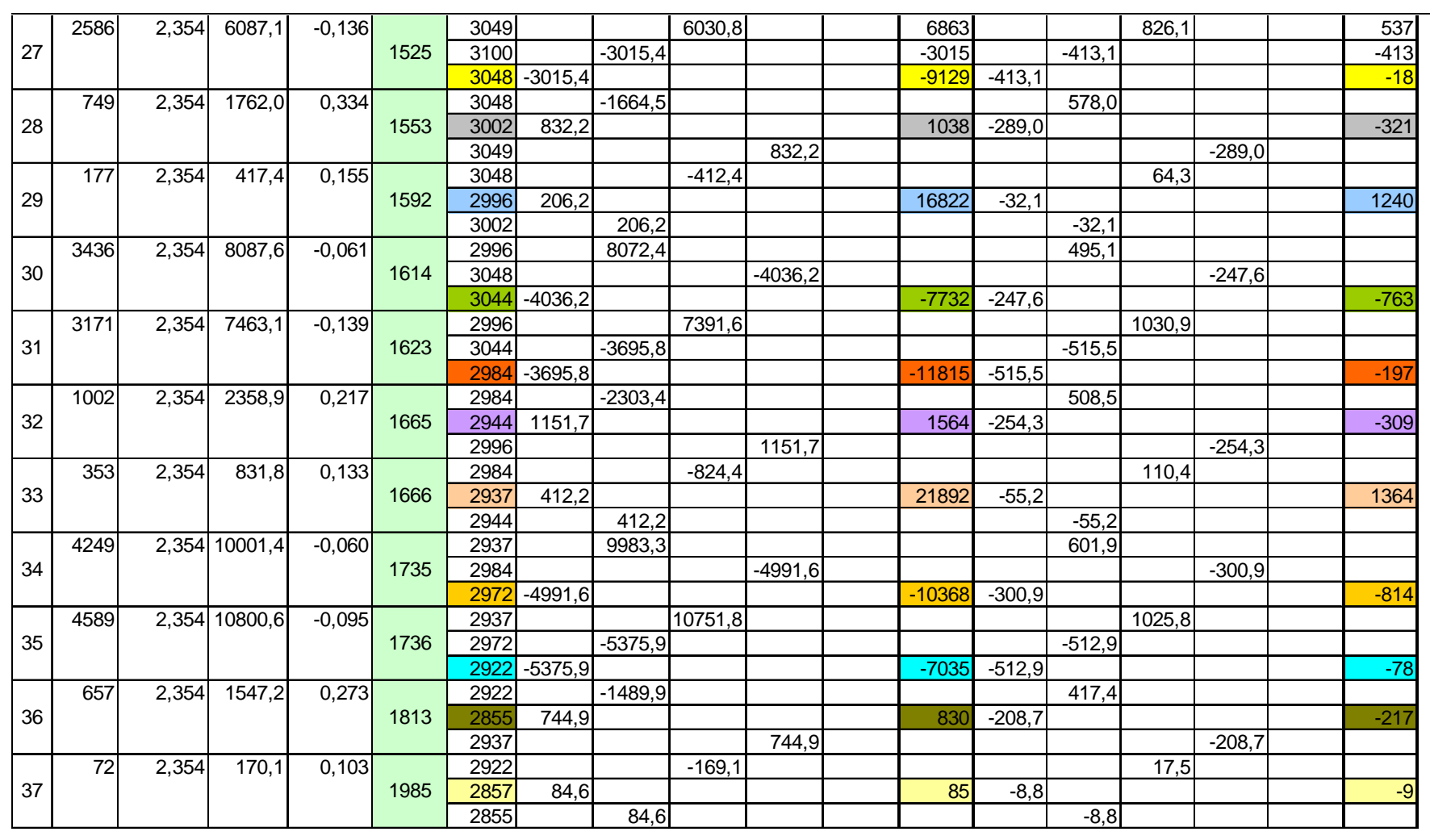

\begin{tabular}{|l|r|r|}
\hline \multirow{2}{*}{0,985} & 6763 & 529 \\
\cline { 2 - 3 } & -2972 & -407 \\
\cline { 2 - 3 } 0,979 & -8996 & -18 \\
\cline { 2 - 3 } & 1017 & -314 \\
\hline \multirow{2}{*}{0,978} & & \\
\cline { 2 - 3 } & 16457 & 1213 \\
\hline \multirow{2}{*}{0,970} & & \\
\cline { 2 - 3 } & & \\
\hline \multirow{2}{*}{0,968} & & -7500 \\
\cline { 2 - 3 } & & \\
\hline \multirow{2}{*}{0,950} & -11433 & -191 \\
\cline { 2 - 3 } & 1486 & -294 \\
\hline \multirow{2}{*}{0,947} & & \\
\cline { 2 - 3 } & 20736 & 1292 \\
\hline \multirow{2}{*}{0,910} & & \\
\cline { 2 - 3 } & & \\
\hline \multirow{2}{*}{0,898} & -9434 & -741 \\
\cline { 2 - 3 } & & \\
\cline { 2 - 3 } & -6317 & -70 \\
\hline \multirow{2}{*}{0,633} & & \\
\cline { 2 - 3 } & 525 & -138 \\
\hline \multirow{2}{*}{0,612} & & \\
\cline { 2 - 3 } & 52 & -5 \\
\hline & & \\
\hline
\end{tabular}


Tabela A-18 (1)

Nível $247 \mathrm{~m}(\mathrm{~h} 3=27 \mathrm{~m})$, pressão $\quad 2,648$

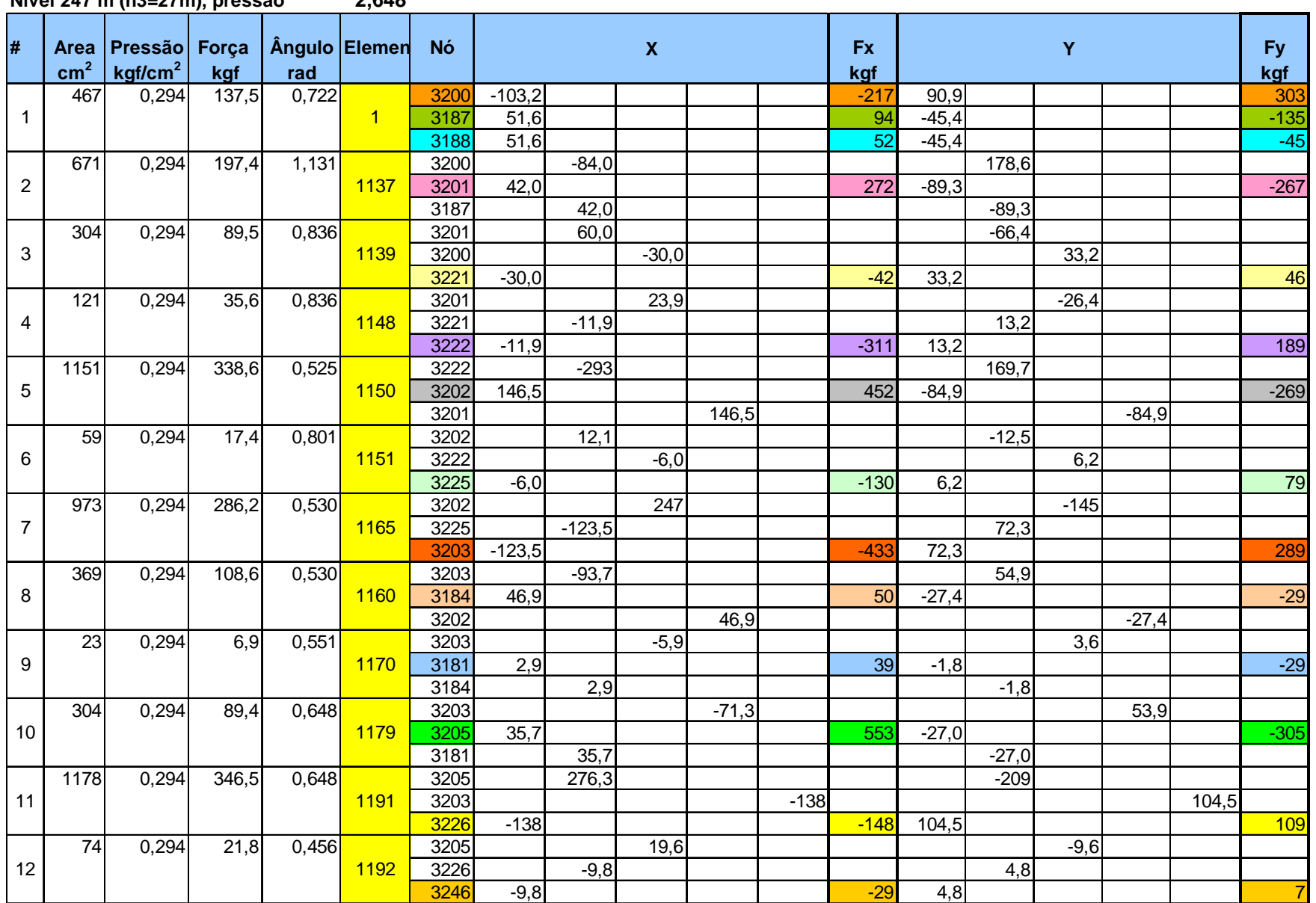

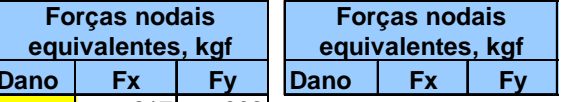

\begin{tabular}{|c|c|c|}
\hline Dano & $\mathrm{FX}$ & $\mathrm{Fy}$ \\
\hline & -217 & 302 \\
\hline
\end{tabular}

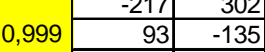

\begin{tabular}{rr|r|} 
& 52 & -45 \\
\hline \multirow{2}{*}{0,996} & & \\
\cline { 2 - 3 } & 271 & -266 \\
\hline
\end{tabular}$$
\text { (0, }
$$

\begin{tabular}{|l|r|r|}
\hline \multirow{2}{*}{0,994} & & \\
\cline { 2 - 3 } & -42 & 46 \\
\hline
\end{tabular}

\begin{tabular}{|l|r|r|}
\hline \multirow{2}{*}{0,998} & & \\
\cline { 2 - 3 } & -310 & 189 \\
\hline
\end{tabular}

\begin{tabular}{|l|r|r|}
\multirow{2}{*}{0,998} & 452 & -269 \\
\cline { 2 - 3 } & & \\
\hline
\end{tabular}

\begin{tabular}{|l|r|r|}
\hline \multirow{2}{*}{0,998} & & \\
\cline { 2 - 3 } & & \\
\hline & -129 & 78 \\
\hline
\end{tabular}

\begin{tabular}{|l|l|r|}
\hline \multirow{2}{*}{0,998} & & \\
\cline { 2 - 3 } & & \\
\cline { 2 - 3 } & -432 & 289 \\
\hline & & \\
\hline
\end{tabular}

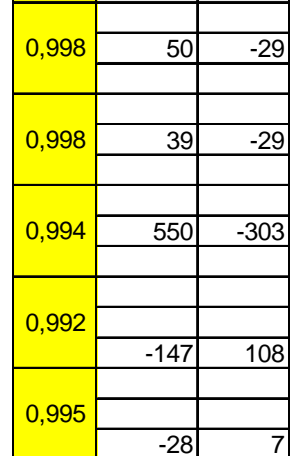




\section{Tabela A-18 (2)}

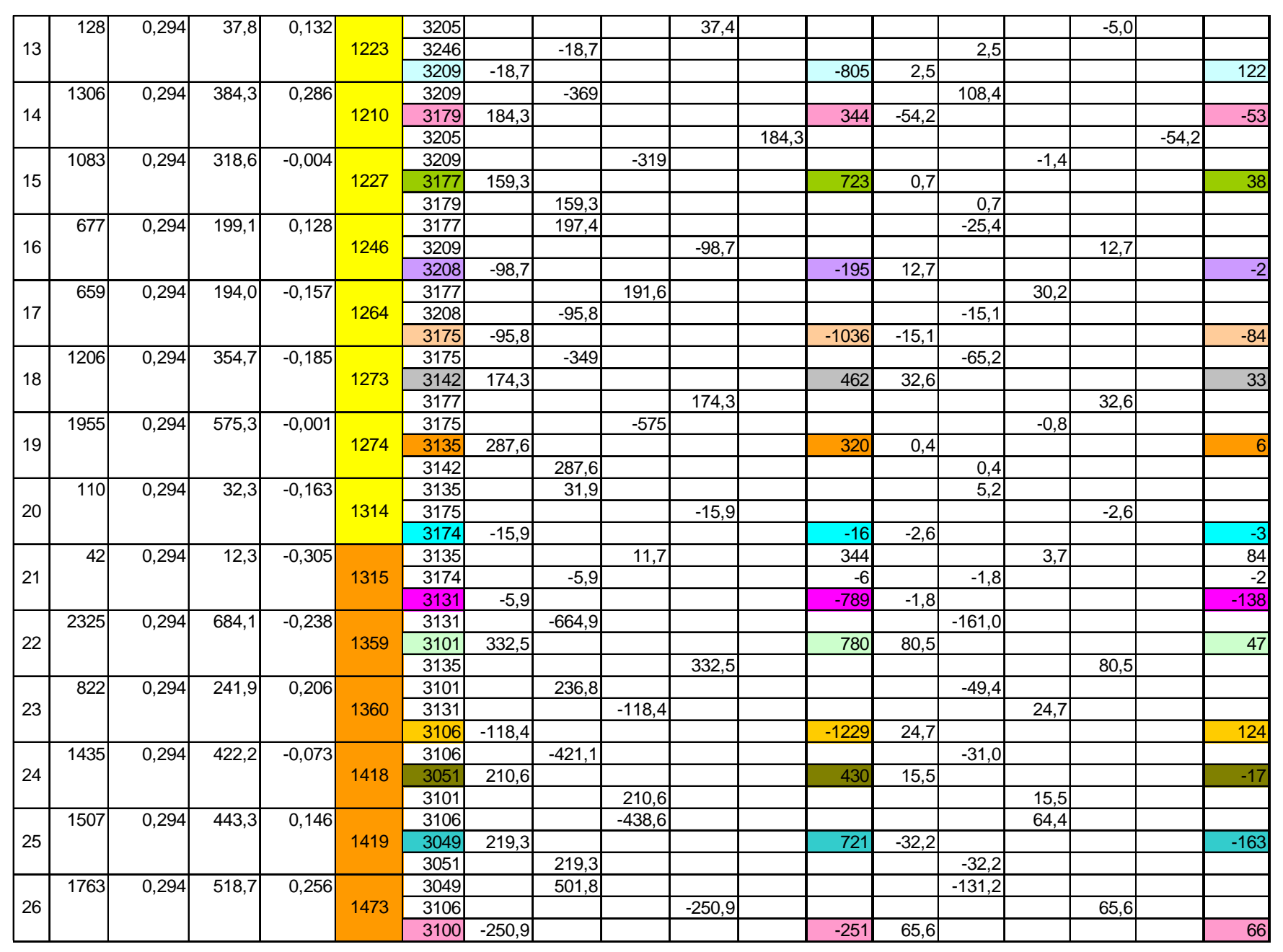

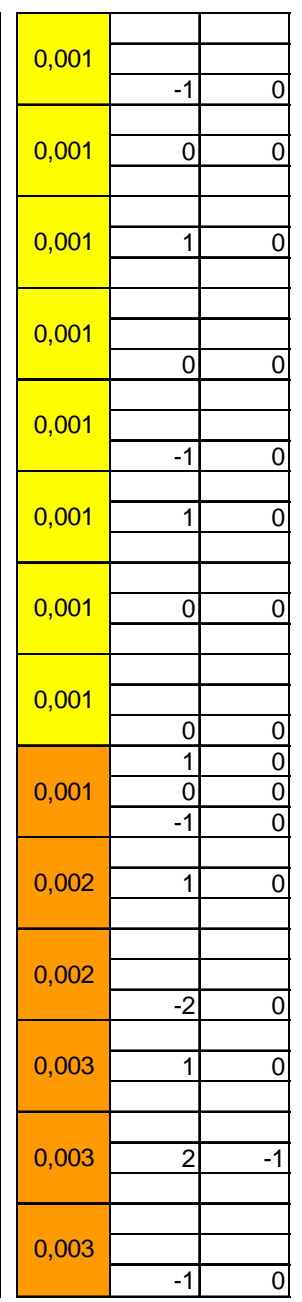


Tabela A-18 (3)

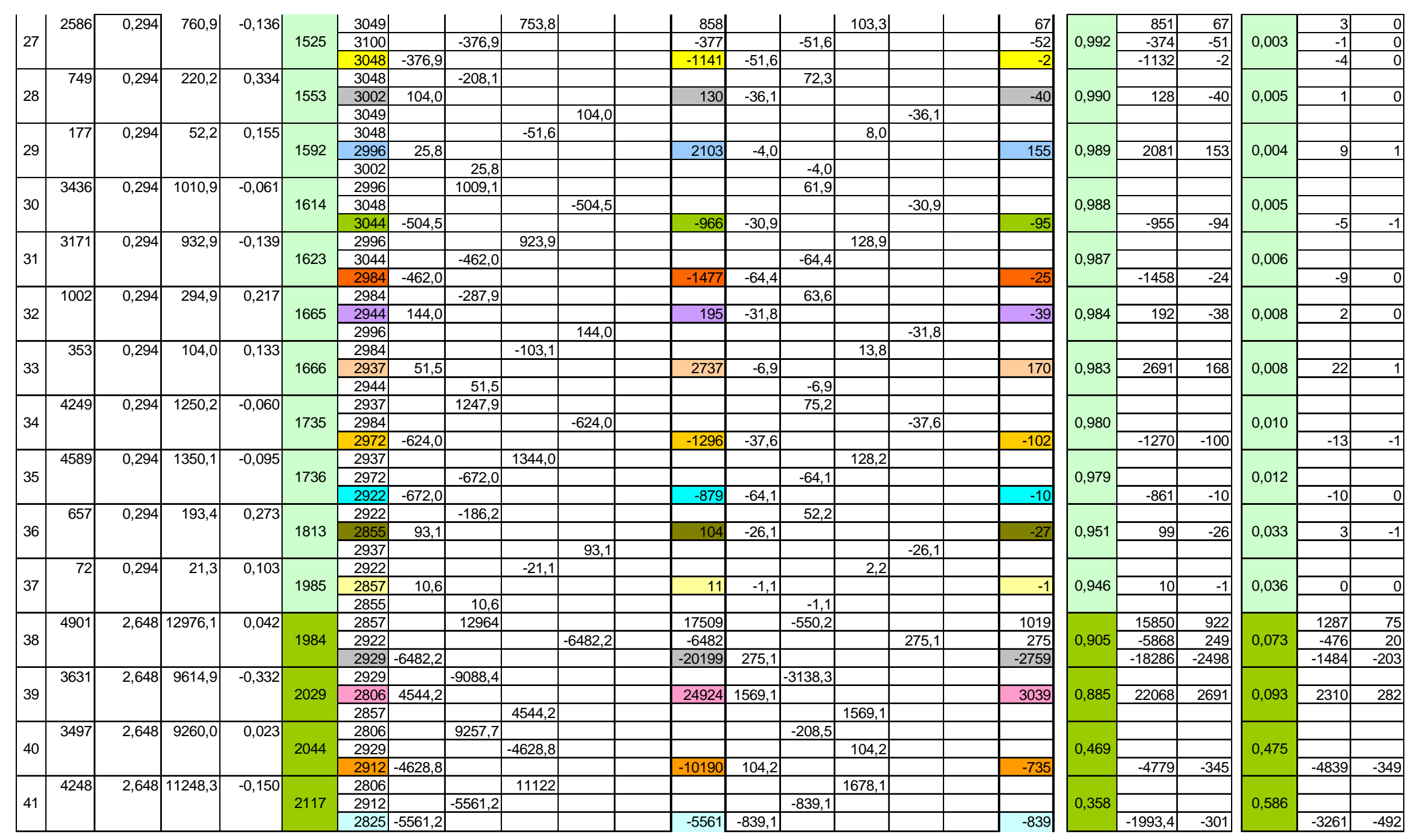


Tabela A-18 (4)

\begin{tabular}{|c|c|c|c|c|c|c|c|c|c|c|c|c|c|c|c|c|c|c|}
\hline \multirow{3}{*}{42} & \multirow[t]{3}{*}{$\begin{array}{ll}2362 \\
\end{array}$} & \multirow[t]{3}{*}{2,648} & \multirow[t]{3}{*}{6253,5} & \multirow[t]{3}{*}{$\mid-0,283$} & \multirow{3}{*}{2109} & 2825 & & -6005 & & & & -22833 & & \begin{tabular}{|l|}
-1745 \\
\end{tabular} & & & & -332 \\
\hline & & & & & & 2743 & 3003 & & & & & 10341 & 872 & & & & & 256 \\
\hline & & & & & & 2806 & & & & 3002,6 & & 3003 & & & & 872 & & 872 \\
\hline \multirow{3}{*}{43} & \multirow[t]{3}{*}{$\begin{array}{l}5562 \\
\end{array}$} & \multirow[t]{3}{*}{2,648} & \multirow[t]{3}{*}{14727,6} & \multirow[t]{3}{*}{ o,084 } & \multirow{3}{*}{2169} & 2825 & & & -14676 & & & & & & 1232,4 & & & \\
\hline & & & & & & 2769 & 7338,0 & & & & & 26674 & $-616,2$ & & & & & 6122 \\
\hline & & & & & & 2743 & & 7338,0 & & & & & & $\begin{array}{l}-616,2 \\
\end{array}$ & & & & \\
\hline \multirow{3}{*}{44} & \multirow[t]{3}{*}{1631} & \multirow[t]{3}{*}{2,648} & \multirow[t]{3}{*}{4318,4} & \multirow[t]{3}{*}{ o,084 } & \multirow{3}{*}{2170} & 2769 & & 4303 & & & & & & $\begin{array}{l}-361,4 \\
\end{array}$ & & & & \\
\hline & & & & & & 2825 & & & & $-2151,6$ & & & & & & 180,7 & & \\
\hline & & & & & & 2904 & $-2151,6$ & & & & & -2847 & 180,7 & & & & & 113 \\
\hline \multirow{3}{*}{45} & \multirow[t]{3}{*}{528} & \multirow[t]{3}{*}{2,648} & \multirow[t]{3}{*}{\begin{tabular}{|l|l|}
1397,4 \\
\end{tabular}} & \multirow[t]{3}{*}{\begin{tabular}{|c|c|}
$-0,066$ \\
\end{tabular}} & \multirow{3}{*}{2256} & 2769 & & & 1390,9 & & & & & & 134,4 & & & \\
\hline & & & & & & 2904 & & \begin{tabular}{|l|}
$-695,5$ \\
\end{tabular} & & & & & & $-67,2$ & & & & \\
\hline & & & & & & 2893 & $-695,5$ & & & & & -1425 & $-67,2$ & & & & & -334 \\
\hline \multirow{3}{*}{46} & \multirow[t]{3}{*}{587} & \multirow[t]{3}{*}{2,648} & \multirow[t]{3}{*}{1553,9} & \multirow[t]{3}{*}{ |-0,351 } & & 2769 & & & & 1459,2 & & & & & & 534,3 & & \\
\hline & & & & & 2299 & 2893 & & $\begin{array}{l}-729,6 \\
\end{array}$ & & & & & & $-267,1$ & & & & \\
\hline & & & & & & 2782 & $-729,6$ & & & & & -2299 & $-267,1$ & & & & & -1096 \\
\hline & 1341 & 2,648 & 3549,6 & $\begin{array}{l}-0,486 \\
\end{array}$ & & 2769 & & & & & 3139,1 & & & & & & 1657,1 & \\
\hline 47 & & & & & 2298 & 2782 & & $-1569,5$ & & & & & & \begin{tabular}{|l|}
$-828,6$ \\
\end{tabular} & & & & \\
\hline & & & & & & 2697 & $-1569,5$ & & & & & -19657 & $-828,6$ & & & & & -10377 \\
\hline & 7724 & 2,648 & 20452,6 & $-0,486$ & & 2697 & & -18087 & & & & & & \begin{tabular}{|l|}
-9548 \\
\end{tabular} & & & & \\
\hline 48 & & & & & 2221 & 2686 & 9043,5 & & & & & 9044 & \begin{tabular}{|l|l|}
4774,2 \\
\end{tabular} & & & & & 4774 \\
\hline & & & & & & 2769 & & & & & 9043,5 & & & & & & 4774,2 & \\
\hline
\end{tabular}

\begin{tabular}{|l|r|r|}
\hline \multirow{2}{*}{0,935} & -21355 & -310 \\
\cline { 2 - 3 } & 9672 & 240 \\
\cline { 2 - 3 } & 2808 & 816 \\
\hline \multirow{2}{*}{0,898} & & \\
\cline { 2 - 3 } & 23940 & 5495 \\
\cline { 2 - 3 } & & \\
\hline \multirow{2}{*}{0,455} & & \\
\cline { 2 - 3 } & & \\
\hline \multirow{2}{*}{0,564} & -1295 & 52 \\
\cline { 2 - 3 } & & \\
\cline { 2 - 3 } 0,609 & -803 & -188 \\
\cline { 2 - 3 } & & \\
\cline { 2 - 3 } & -1399 & -667 \\
\hline \multirow{2}{*}{0,540} & & \\
\cline { 2 - 3 } & -10613 & -5602 \\
\hline \multirow{2}{*}{0,276} & & \\
\cline { 2 - 3 } & 2500 & 1320 \\
\cline { 2 - 3 } & & \\
\hline
\end{tabular}


Tabela A-19 (1)

Nível 250 m (h4=30m), pressão

2,942
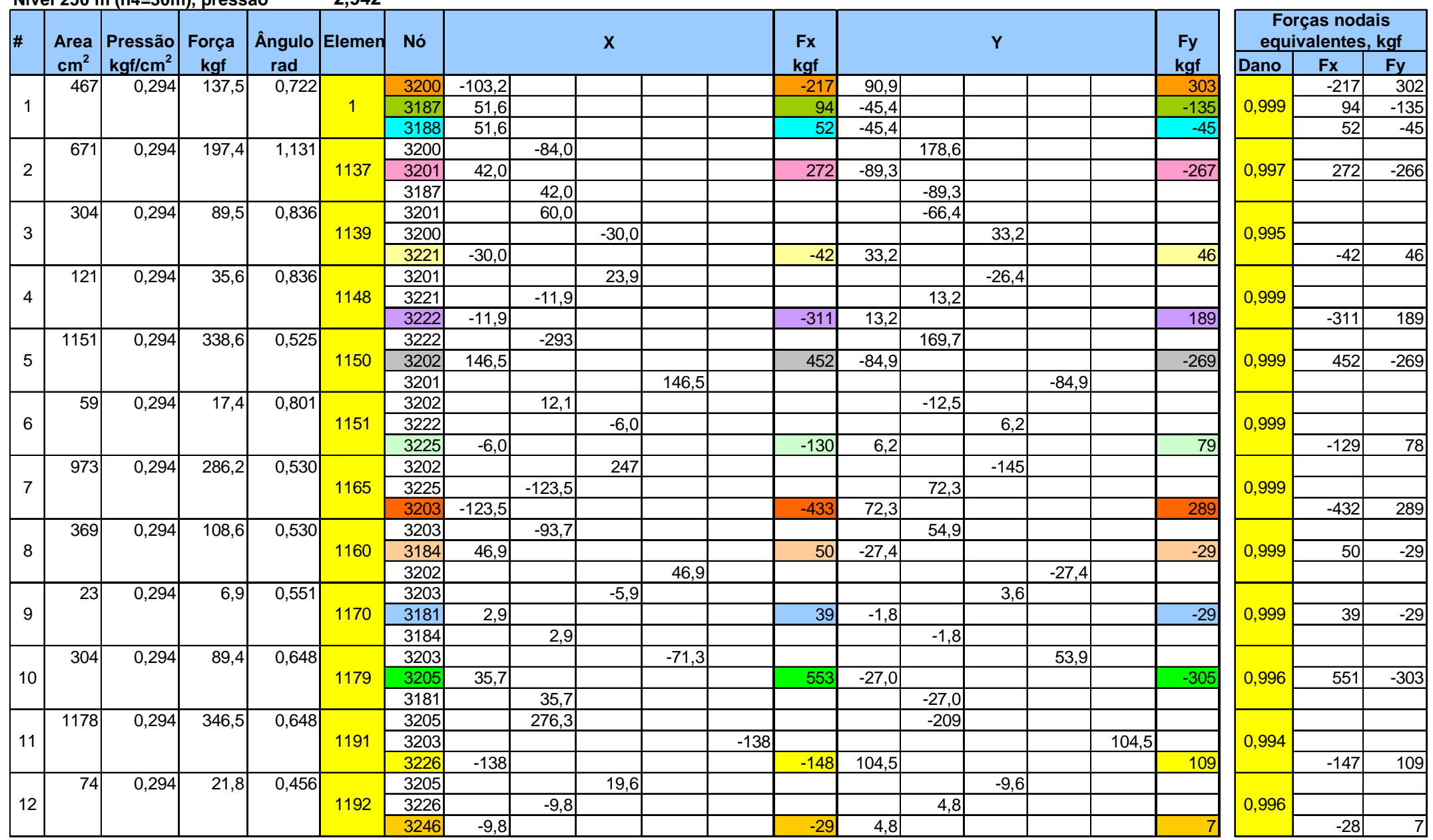

Forças nodais

equivalentes, kgf

\begin{tabular}{|l|l|l|}
\hline Dano & Fx & Fy \\
\hline
\end{tabular}

\begin{tabular}{|l|l|}
\hline-28 & 7 \\
\hline
\end{tabular} 


\section{Tabela A-19 (2)}
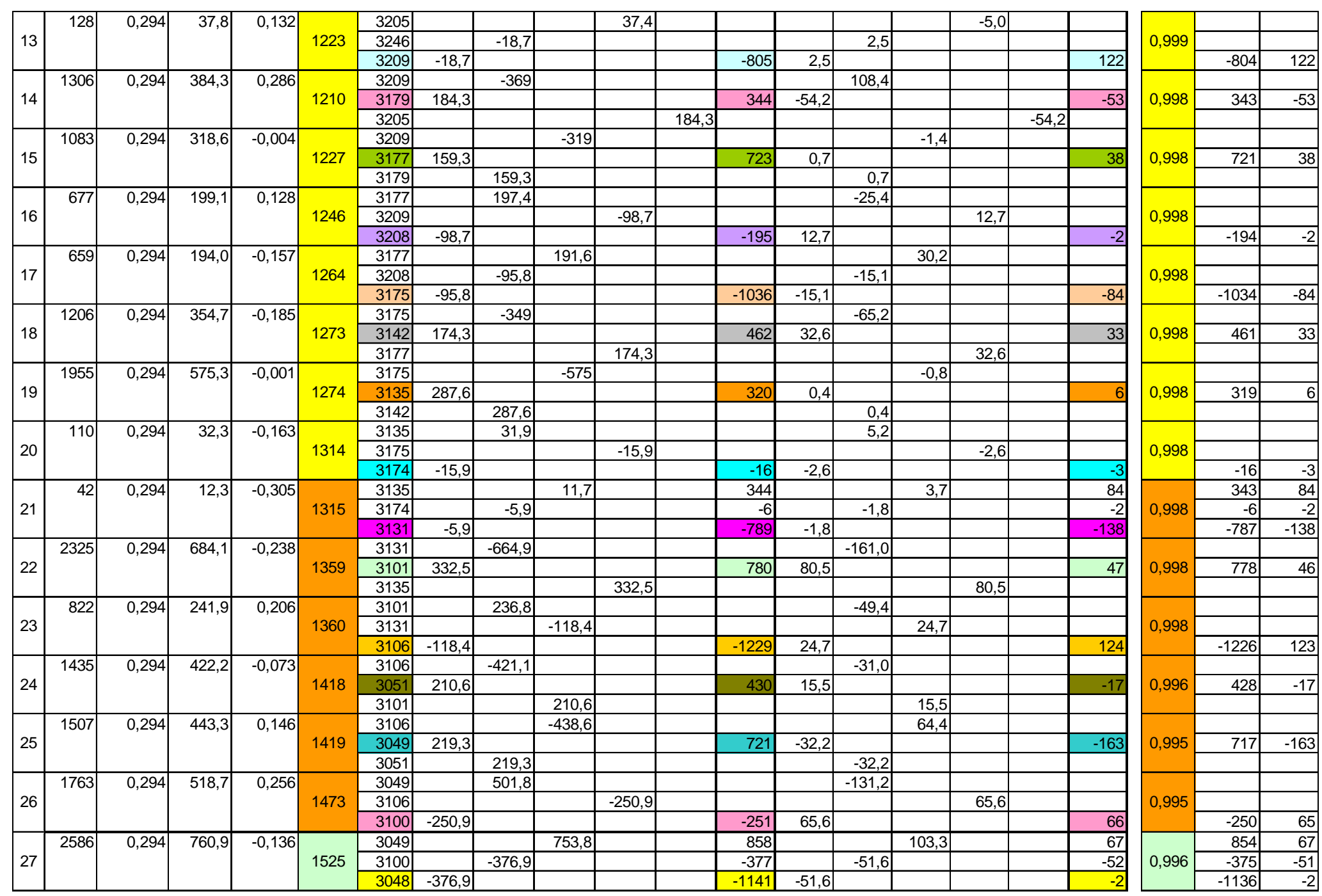
Tabela A-19 (3)
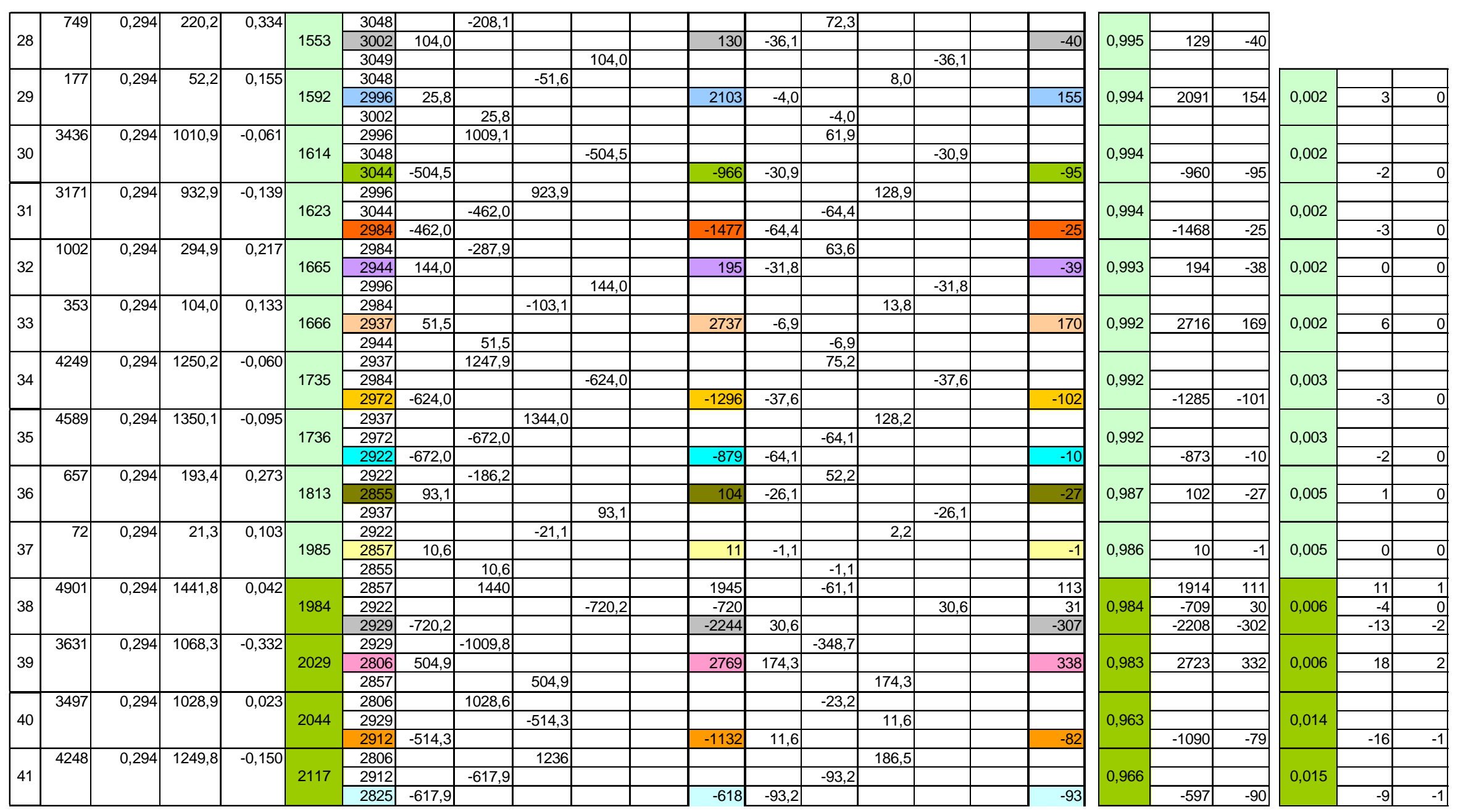
Tabela A-19 (4)

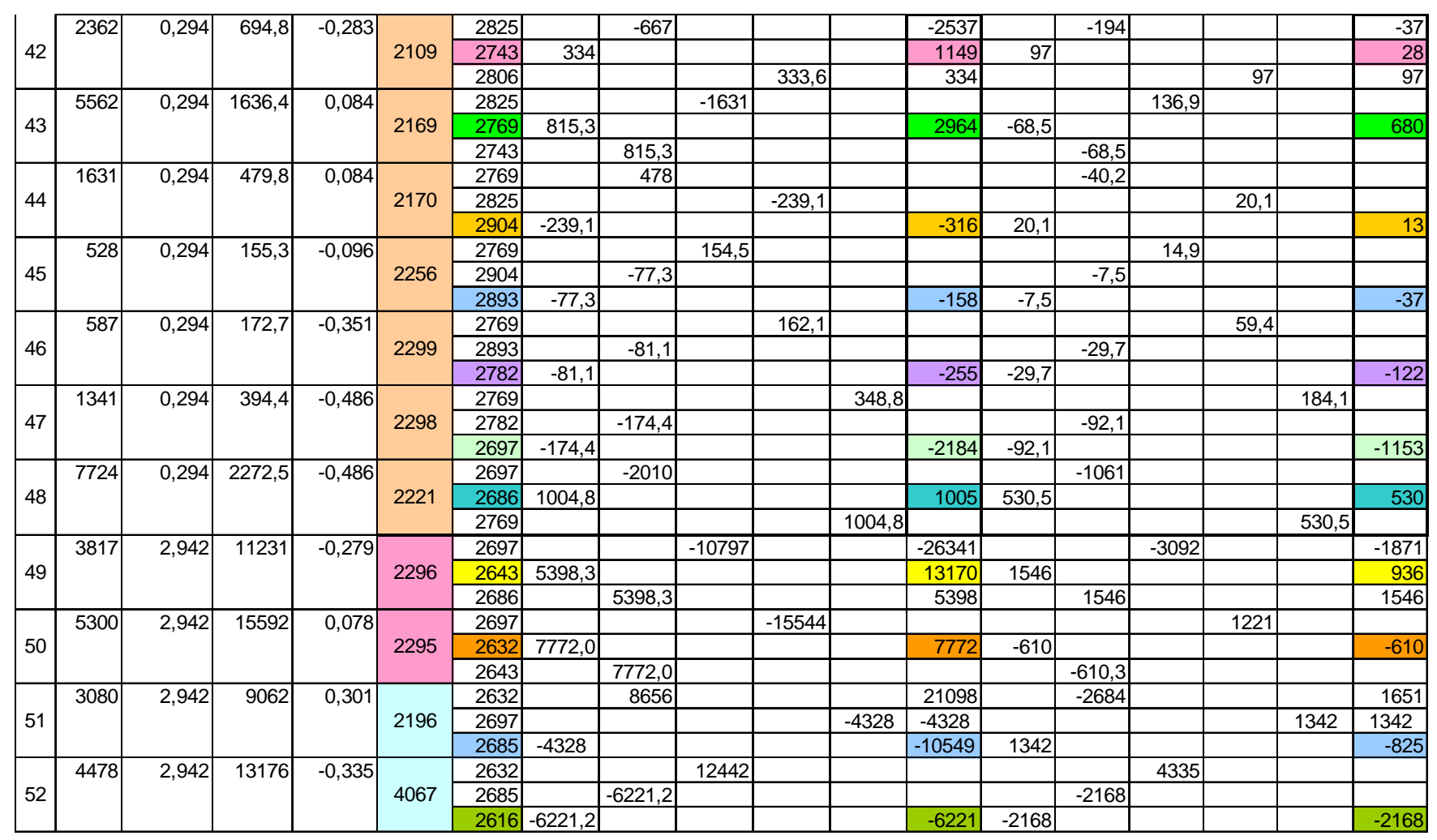

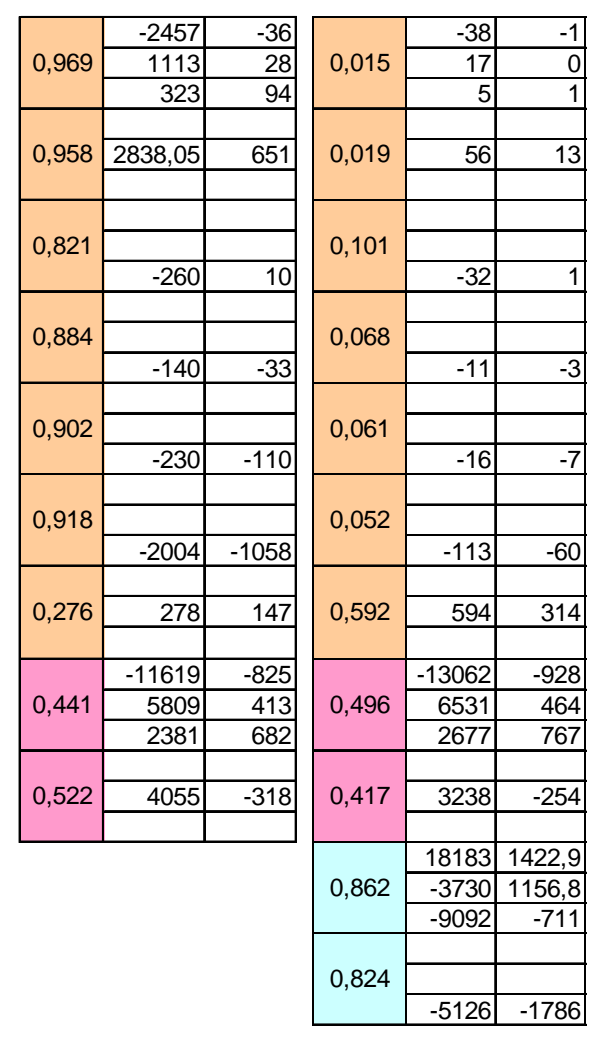


Tabela A-20 (1)
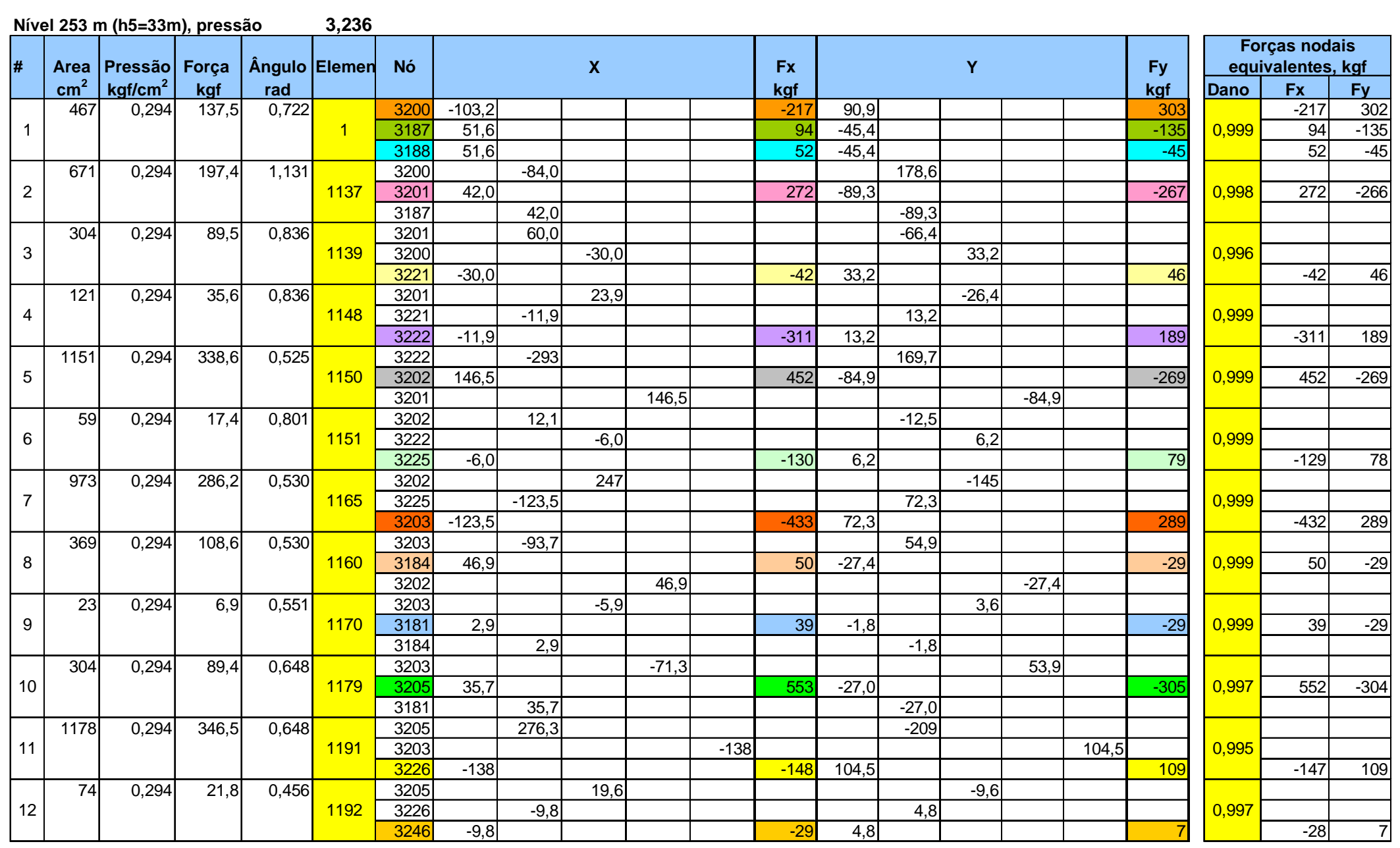

Forças nodais \begin{tabular}{|l|c|c|}
\hline \multicolumn{3}{|c|}{ equivalentes, kgf } \\
\hline Dano & Fx & Fy \\
\hline
\end{tabular}

\begin{tabular}{|c|r|r|}
\hline Dano & $F x$ & $F y$ \\
\cline { 2 - 3 } & -217 & 302 \\
\cline { 2 - 3 } & & -135 \\
\hline
\end{tabular}

$$
0,996
$$$$
0,990
$$ 


\section{Tabela A-20 (2)}

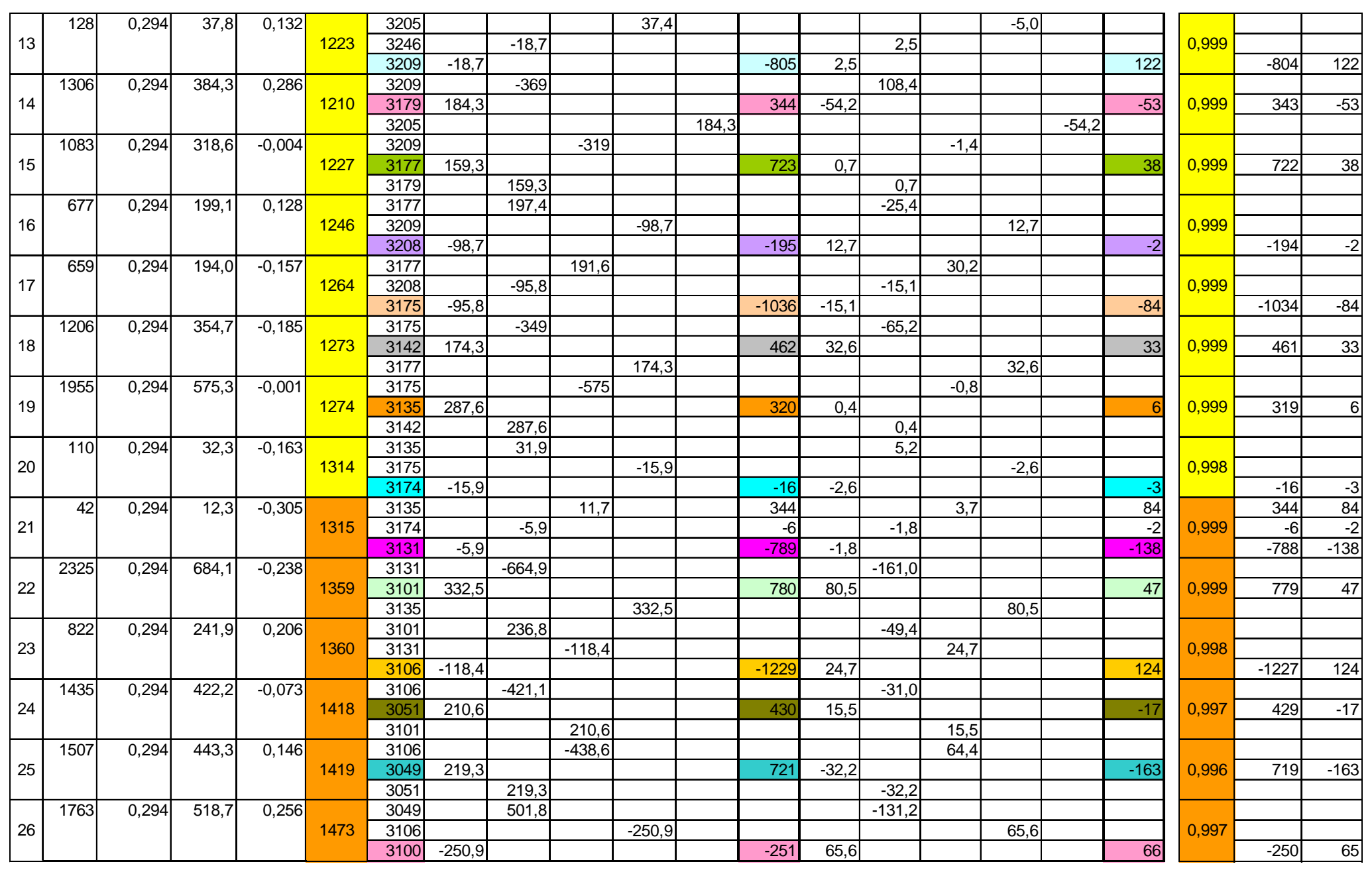


Tabela A-20 (3)

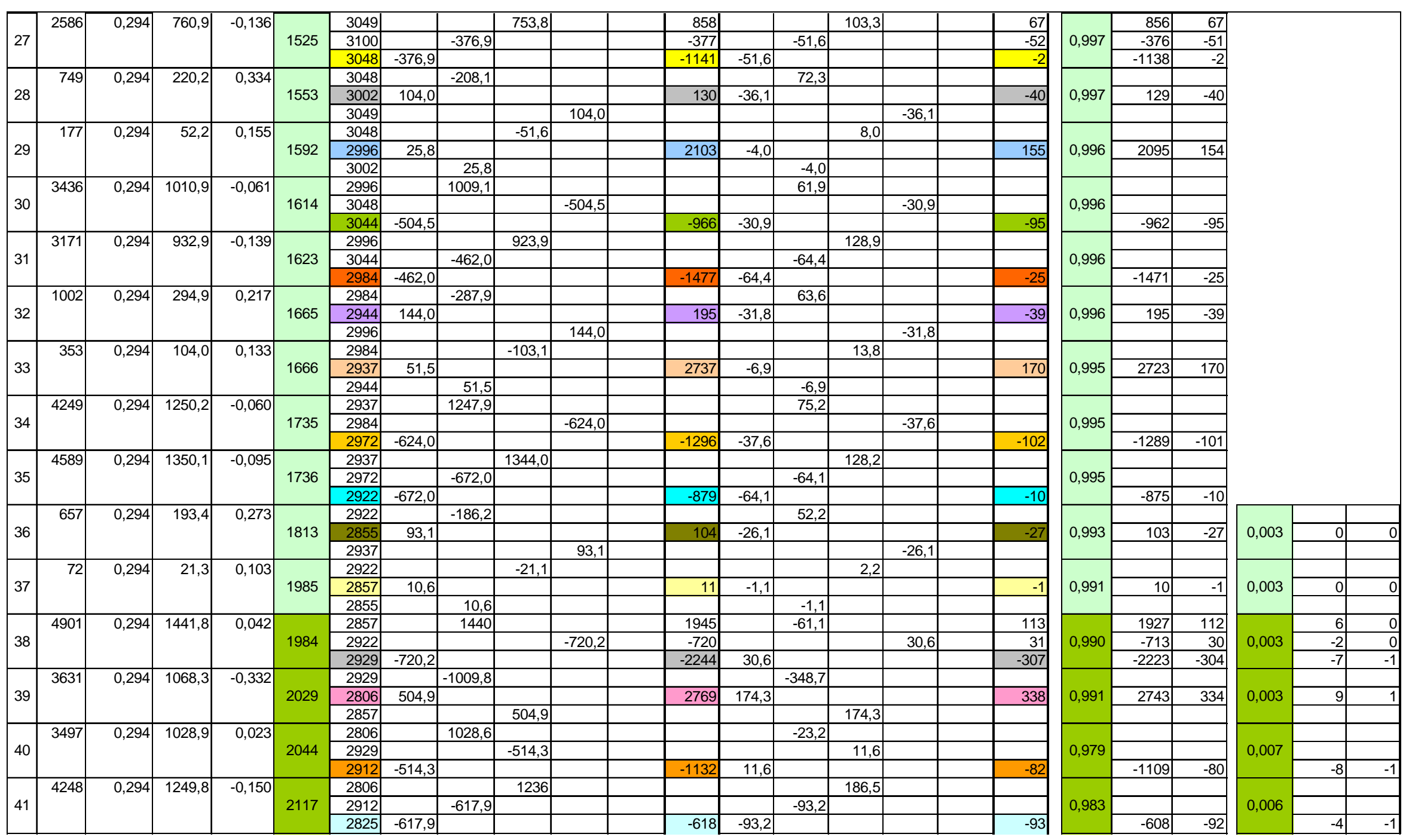


Tabela A-20 (4)

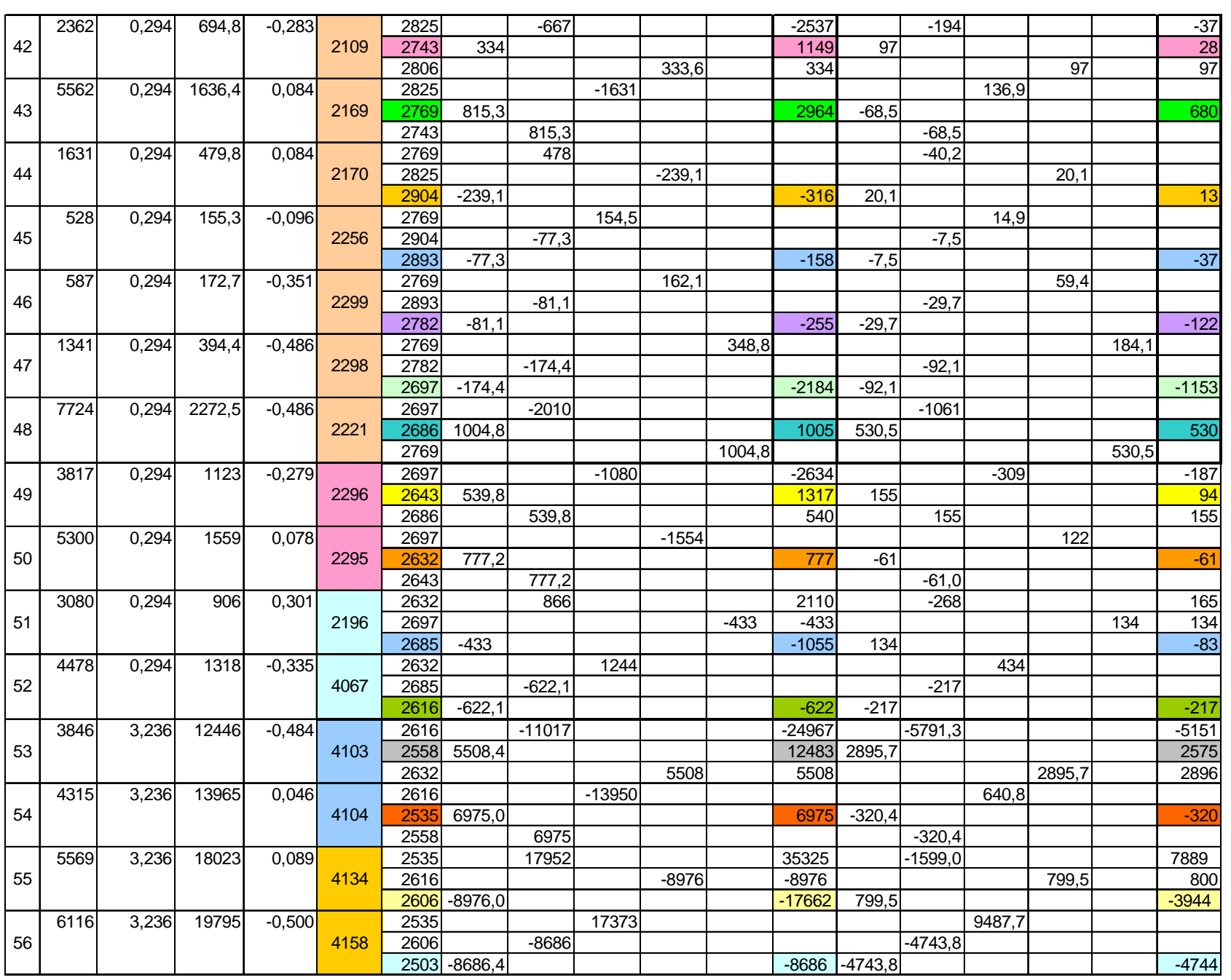

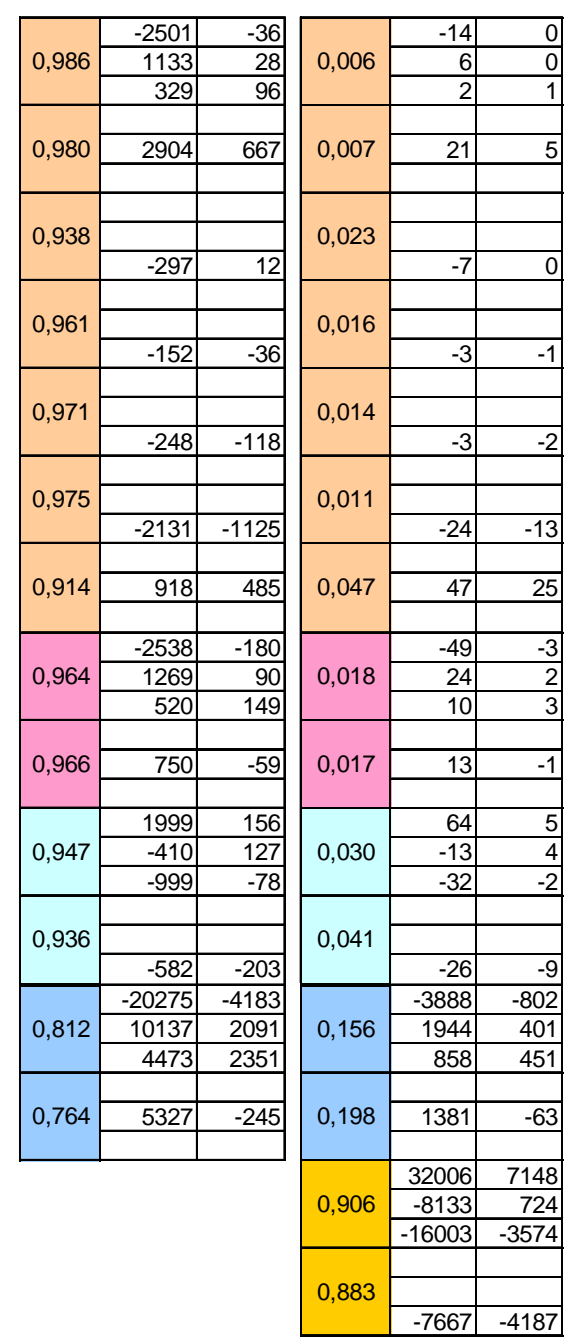


Tabela A-21 (1)

Nível $257 \mathrm{~m}(\mathrm{~h} 6=37 \mathrm{~m})$, pressão

3,629
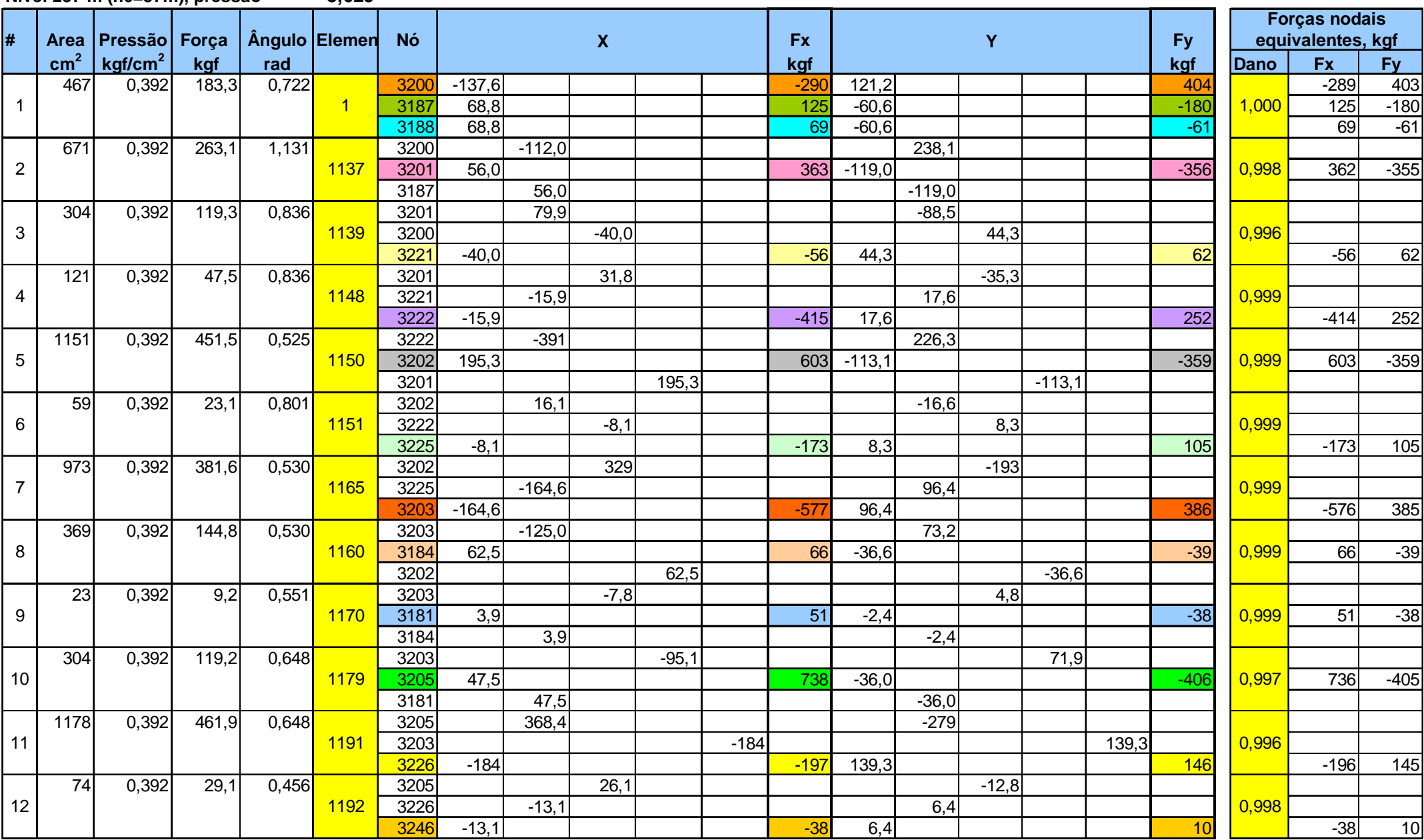


\section{Tabela A-21 (2)}
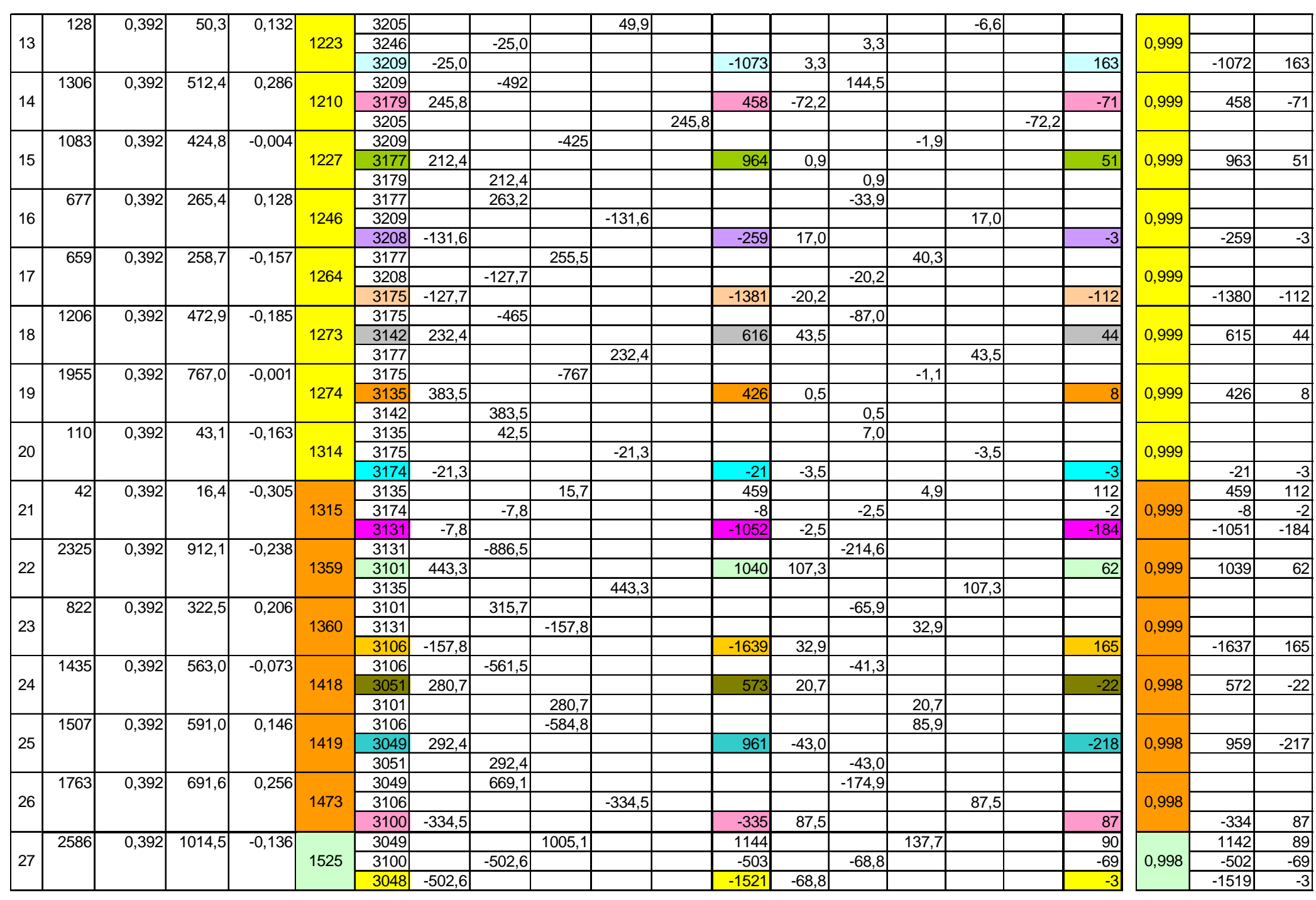
Tabela A-21 (3)

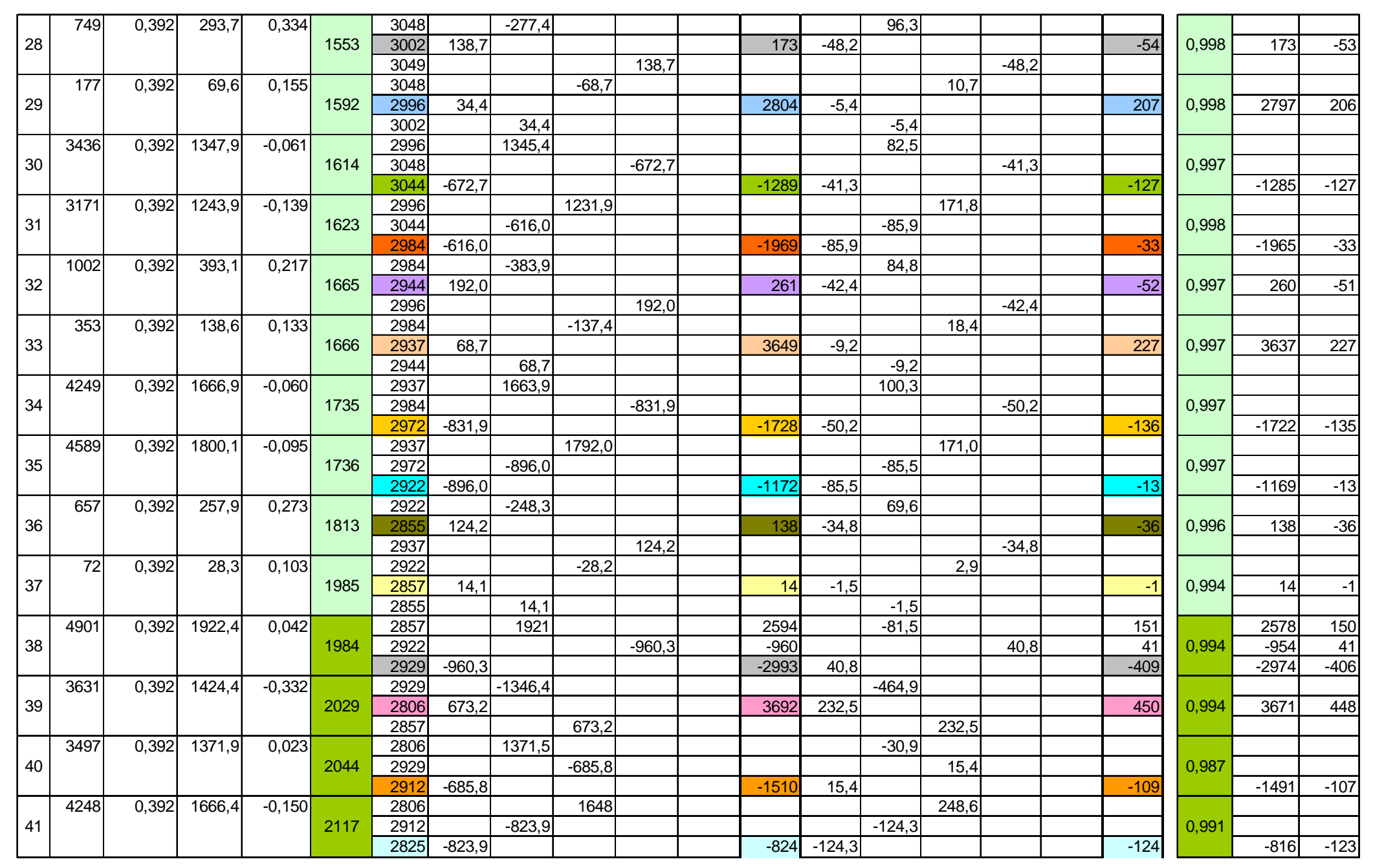


Tabela A-21 (4)
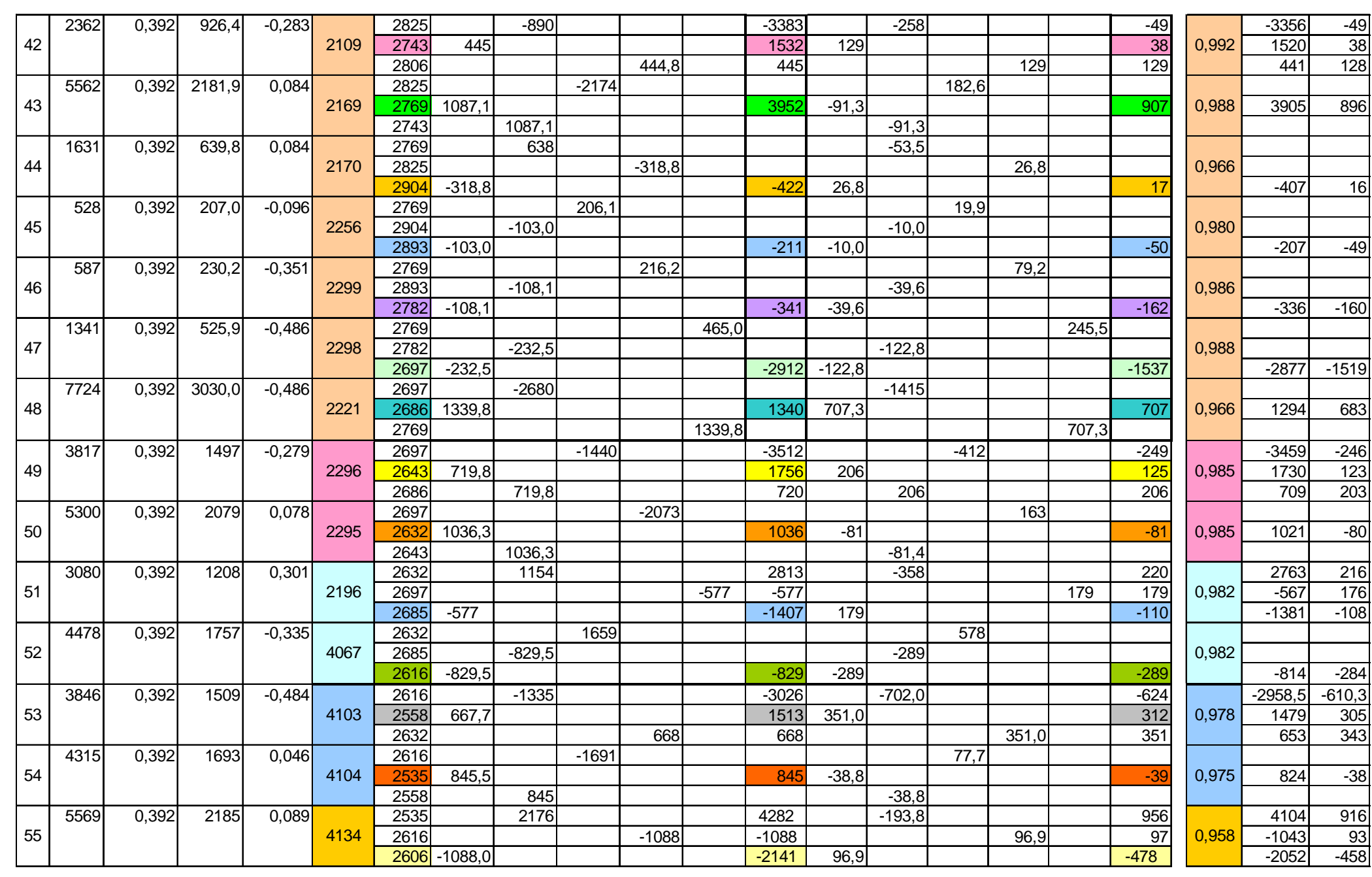
Tabela A-21 (5)

\begin{tabular}{|c|c|c|c|c|c|c|c|c|c|c|c|c|c|c|c|c|c|c|c|}
\hline \multirow{3}{*}{56} & \multirow[t]{3}{*}{6116} & \multirow[t]{3}{*}{0,392} & \multirow[t]{3}{*}{2399} & \multirow[t]{3}{*}{$-0,500$} & \multirow{3}{*}{4158} & 2535 & & & 2106 & & & & & 1150,0 & & & \multirow{3}{*}{0,95} & & \\
\hline & & & & & & 2606 & & -1053 & & & & & $-575,0$ & & & & & & \\
\hline & & & & & & 2503 & $-1052,9$ & & & & -1053 & $-575,0$ & & & & $\begin{array}{r}-575 \\
\end{array}$ & & -1000 & -546 \\
\hline \multirow{3}{*}{57} & \multirow[t]{3}{*}{5668} & \multirow[t]{3}{*}{3,629} & \multirow[t]{3}{*}{20567} & \multirow[t]{3}{*}{$-0,713$} & \multirow{3}{*}{4161} & 2503 & & -15555 & & & -52773 & & -13455 & & & -12667 & \multirow{3}{*}{0,795} & -41947 & -10069 \\
\hline & & & & & & 2453 & 7778 & & & & 16004 & 6728 & & & & 8153 & & 12721 & $\begin{array}{r}6481 \\
\end{array}$ \\
\hline & & & & & & 2535 & & & & 7778 & 7778 & & & & 6728 & 6728 & & 6182 & 5348 \\
\hline \multirow{3}{*}{58} & \multirow[t]{3}{*}{4602} & \multirow[t]{3}{*}{3,629} & \multirow[t]{3}{*}{16699} & \multirow[t]{3}{*}{$-0,172$} & \multirow{3}{*}{4191} & 2503 & & & -16453 & & & & & -2851 & & & \multirow{3}{*}{ 0,769 } & & \\
\hline & & & & & & 2376 & 8227 & & & & 18609 & 1425 & & & & -394 & & 14301 & -303 \\
\hline & & & & & & 2453 & & 8227 & & & & & 1425 & & & & & & \\
\hline \multirow{3}{*}{59} & \multirow[t]{3}{*}{5810} & \multirow[t]{3}{*}{3,629} & \multirow[t]{3}{*}{21081} & \multirow[t]{3}{*}{0,173} & \multirow{3}{*}{4246} & 2503 & & & & -20764 & & & & & 3639 & & \multirow{3}{*}{0,297} & & \\
\hline & & & & & & 2429 & 10382 & & & & 10382 & -1819 & & & & -1819 & & 3081 & -540 \\
\hline & & & & & & 2376 & & 10382 & & & & & -1819 & & & & & & \\
\hline
\end{tabular}


ANEXO B - Cálculo da Condutividade Hidráulica e Subpressão. 
Tabela B-1 Condutividade hidráulica calculada para os elementos danificados do vertedouro sob o primeiro a sexto nível de água.

Tabela B-2 Condutividade hidráulica calculada para os elementos danificados da casa de força sob o primeiro a quarto nível de água.

Tabela B-3 Cálculo de subpressão para o vertedouro sob o primeiro a sexto nível.

Tabela B-4 Cálculo de subpressão para a casa de força sob o primeiro a sexto nível. 
Tabela B-1 (1)

\begin{tabular}{|c|c|c|c|c|c|}
\hline \multirow[t]{2}{*}{ \# } & \multirow{2}{*}{ Elemento } & $e_{\text {frat }}$ & $K_{f}$ & I & $\mathrm{K}_{\mathrm{t}}$ \\
\hline & & $\mathrm{cm}$ & $\mathrm{cm} / \mathrm{s}$ & $\mathrm{cm}$ & $\mathrm{cm} / \mathrm{s}$ \\
\hline \multicolumn{6}{|c|}{ Nível 1} \\
\hline 1 & 1 & 0,00169 & 0,02338 & 8,78 & $1,0 \mathrm{E}-03$ \\
\hline 2 & 2197 & 0,00156 & 0,01978 & 9,21 & $1,0 \mathrm{E}-03$ \\
\hline 3 & 2199 & 0,00065 & 0,00341 & 9,73 & $1,0 \mathrm{E}-03$ \\
\hline 4 & 2208 & 0,00082 & 0,00546 & 10,30 & $1,0 \mathrm{E}-03$ \\
\hline 5 & 2211 & 0,00015 & 0,00018 & 10,29 & $1,0 \mathrm{E}-03$ \\
\hline 6 & 2212 & 0,00010 & 0,00009 & 10,46 & $1,0 \mathrm{E}-03$ \\
\hline \multicolumn{6}{|c|}{ Nível, 2 pressão fratura 1} \\
\hline 1 & 1 & 0,00251 & 0,05135 & 8,78 & $1,0 \mathrm{E}-03$ \\
\hline 2 & 2197 & 0,00229 & 0,04290 & 9,21 & $1,0 \mathrm{E}-03$ \\
\hline 3 & 2199 & 0,00133 & 0,01448 & 9,73 & $1,0 \mathrm{E}-03$ \\
\hline 4 & 2208 & 0,00152 & 0,01898 & 10,30 & $1,0 \mathrm{E}-03$ \\
\hline 5 & 2211 & 0,00049 & 0,00199 & 10,29 & $1,0 \mathrm{E}-03$ \\
\hline 6 & 2212 & 0,00040 & 0,00128 & 10,46 & $1,0 \mathrm{E}-03$ \\
\hline 7 & 2232 & 0,00004 & 0,00001 & 10,91 & $1,0 \mathrm{E}-03$ \\
\hline \multicolumn{6}{|c|}{ Nível, 2 pressão fratura 2} \\
\hline 1 & 1 & 0,00396 & 0,12799 & 8,78 & 1,1E-03 \\
\hline 2 & 2197 & 0,00392 & 0,12543 & 9,21 & $1,1 \mathrm{E}-03$ \\
\hline 3 & 2199 & 0,00306 & 0,07653 & 9,73 & 1,0E-03 \\
\hline 4 & 2208 & 0,00344 & 0,09688 & 10,30 & 1,0E-03 \\
\hline 5 & 2211 & 0,00214 & 0,03728 & 10,29 & 1,0E-03 \\
\hline 6 & 2212 & 0,00229 & 0,04300 & 10,46 & $1,0 \mathrm{E}-03$ \\
\hline 7 & 2232 & 0,00142 & 0,01645 & 10,91 & $1,0 \mathrm{E}-03$ \\
\hline 8 & 2233 & 0,00098 & 0,00780 & 10,93 & 1,0E-03 \\
\hline 9 & 2261 & 0,00073 & 0,00437 & 10,94 & 1,0E-03 \\
\hline 10 & 2262 & 0,00017 & 0,00024 & 14,86 & 1,0E-03 \\
\hline 11 & 2293 & 0,00027 & 0,00061 & 14,23 & $1,0 \mathrm{E}-03$ \\
\hline \multicolumn{6}{|c|}{ Nível, 3 pressão fratura 2} \\
\hline 1 & 1 & 0,00423 & 0,14628 & 8,78 & 1,1E-03 \\
\hline 2 & 2197 & 0,00417 & 0,14223 & 9,21 & 1,1E-03 \\
\hline 3 & 2199 & 0,00331 & 0,08964 & 9,73 & 1,0E-03 \\
\hline 4 & 2208 & 0,00374 & 0,11444 & 10,30 & $1,0 \mathrm{E}-03$ \\
\hline 5 & 2211 & 0,00252 & 0,05198 & 10,29 & 1,0E-03 \\
\hline 6 & 2212 & 0,00276 & 0,06230 & 10,46 & $1,0 \mathrm{E}-03$ \\
\hline 7 & 2232 & 0,00210 & 0,03591 & 10,91 & $1,0 \mathrm{E}-03$ \\
\hline 8 & 2233 & 0,00168 & 0,02305 & 10,93 & $1,0 \mathrm{E}-03$ \\
\hline 9 & 2261 & 0,00146 & 0,01739 & 10,94 & $1,0 \mathrm{E}-03$ \\
\hline 10 & 2262 & 0,00064 & 0,00334 & 14,86 & 1,0E-03 \\
\hline 11 & 2293 & 0,00074 & 0,00451 & 14,23 & 1,0E-03 \\
\hline 12 & 2281 & 0,00005 & 0,00002 & 15,41 & $1,0 \mathrm{E}-03$ \\
\hline \multicolumn{6}{|c|}{ Nível, 3 pressão fratura 3} \\
\hline 1 & 1 & 0,00620 & 0,31397 & 8,78 & $1,2 \mathrm{E}-03$ \\
\hline 2 & 2197 & 0,00644 & 0,33955 & 9,21 & 1,2E-03 \\
\hline 3 & 2199 & 0,00526 & 0,22658 & 9,73 & $1,1 \mathrm{E}-03$ \\
\hline 4 & 2208 & 0,00582 & 0,27731 & 10,30 & $1,2 \mathrm{E}-03$ \\
\hline 5 & 2211 & 0,00475 & 0,18460 & 10,29 & 1,1E-03 \\
\hline 6 & 2212 & 0,00551 & 0,24844 & 10,46 & 1,1E-03 \\
\hline 7 & 2232 & 0,00554 & 0,25120 & 10,91 & $1,1 \mathrm{E}-03$ \\
\hline 8 & 2233 & 0,00468 & 0,17904 & 10,93 & 1,1E-03 \\
\hline 9 & 2261 & 0,00520 & 0,22117 & 10,94 & $1,1 \mathrm{E}-03$ \\
\hline 10 & 2262 & 0,00345 & 0,09711 & 14,86 & $1,0 \mathrm{E}-03$ \\
\hline 11 & 2293 & 0,00415 & 0,14047 & 14,23 & $1,0 \mathrm{E}-03$ \\
\hline 12 & 2281 & 0,00160 & 0,02084 & 15,41 & 1,0E-03 \\
\hline 13 & 2294 & 0,00238 & 0,04642 & 17,05 & $1,0 \mathrm{E}-03$ \\
\hline 14 & 2308 & 0,00163 & 0,02161 & 17,21 & $1,0 \mathrm{E}-03$ \\
\hline 15 & 2327 & 0,00124 & 0,01262 & 17,35 & 1,0E-03 \\
\hline 16 & 2349 & 0,00056 & 0,00253 & 18,38 & $1,0 \mathrm{E}-03$ \\
\hline 17 & 2375 & 0,00073 & 0,00440 & 19,48 & $1,0 \mathrm{E}-03$ \\
\hline 18 & 2376 & 0,00023 & 0,00043 & 18,30 & 1,0E-03 \\
\hline 19 & 2377 & 0,00009 & 0,00006 & 18,30 & $1,0 \mathrm{E}-03$ \\
\hline
\end{tabular}


Tabela B-1 (2)

\begin{tabular}{|c|c|c|c|c|c|}
\hline \# & Elemento & $\begin{array}{l}\mathbf{e}_{\text {frat }} \\
\mathrm{cm}\end{array}$ & $\begin{array}{c}\mathbf{K}_{\mathbf{f}} \\
\mathrm{cm} / \mathrm{s}\end{array}$ & $\begin{array}{c}\text { I } \\
\mathrm{cm}\end{array}$ & $\begin{array}{c}\mathbf{K}_{\mathbf{t}} \\
\mathrm{cm} / \mathrm{s}\end{array}$ \\
\hline \multicolumn{6}{|c|}{ Nível, 4 pressão fratura 3} \\
\hline 1 & 1 & 0,00668 & 0,36496 & 8,78 & $1,3 \mathrm{E}-03$ \\
\hline 2 & 2197 & 0,00695 & 0,39468 & 9,21 & $1,3 \mathrm{E}-03$ \\
\hline 3 & 2199 & 0,00571 & 0,26650 & 9,73 & $1,2 \mathrm{E}-03$ \\
\hline 4 & 2208 & 0,00632 & 0,32604 & 10,30 & $1,2 \mathrm{E}-03$ \\
\hline 5 & 2211 & 0,00532 & 0,23108 & 10,29 & $1,1 \mathrm{E}-03$ \\
\hline 6 & 2212 & 0,00619 & 0,31339 & 10,46 & $1,2 \mathrm{E}-03$ \\
\hline 7 & 2232 & 0,00638 & 0,33305 & 10,91 & $1,2 \mathrm{E}-03$ \\
\hline 8 & 2233 & 0,00546 & 0,24343 & 10,93 & $1,1 \mathrm{E}-03$ \\
\hline 9 & 2261 & 0,00613 & 0,30756 & 10,94 & $1,2 \mathrm{E}-03$ \\
\hline 10 & 2262 & 0,00425 & 0,14741 & 14,86 & $1,0 \mathrm{E}-03$ \\
\hline 11 & 2293 & 0,00519 & 0,21997 & 14,23 & $1,1 \mathrm{E}-03$ \\
\hline 12 & 2281 & 0,00243 & 0,04831 & 15,41 & $1,0 \mathrm{E}-03$ \\
\hline 13 & 2294 & 0,00376 & 0,11588 & 17,05 & $1,0 \mathrm{E}-03$ \\
\hline 14 & 2308 & 0,00331 & 0,08953 & 17,21 & $1,0 \mathrm{E}-03$ \\
\hline 15 & 2327 & 0,00247 & 0,04983 & 17,35 & $1,0 \mathrm{E}-03$ \\
\hline 16 & 2349 & 0,00154 & 0,01931 & 18,38 & $1,0 \mathrm{E}-03$ \\
\hline 17 & 2375 & 0,00194 & 0,03082 & 19,48 & $1,0 \mathrm{E}-03$ \\
\hline 18 & 2376 & 0,00 & 974 & 18,30 & $1,0 \mathrm{E}-03$ \\
\hline 19 & 2377 & 0,00061 & 0,00306 & 18,30 & $1,0 \mathrm{E}-03$ \\
\hline 20 & 2430 & 0,00007 & 0,00004 & 18,35 & $1,0 \mathrm{E}-03$ \\
\hline \multicolumn{6}{|c|}{ Nível, 4 pressão fratura 4} \\
\hline 1 & 1 & 0,00981 & 0,78691 & 8,78 & $1,9 \mathrm{E}-03$ \\
\hline 2 & 2197 & 0,01085 & 0,96315 & 9,21 & $2,1 \mathrm{E}-03$ \\
\hline 3 & 2199 & 0,00888 & 0,64529 & 9,73 & $1,6 \mathrm{E}-03$ \\
\hline 4 & 2208 & 0,00944 & 2787 & 10,30 & $1,7 \mathrm{E}-03$ \\
\hline 5 & 2211 & 0,00873 & 0,62313 & 10,29 & $1,5 \mathrm{E}-03$ \\
\hline 6 & 2212 & 0,01059 & 0,91651 & 10,46 & $1,9 \mathrm{E}-03$ \\
\hline 7 & 2232 & 0,01238 & 1,25378 & 10,91 & $2,4 \mathrm{E}-03$ \\
\hline 8 & 2233 & 0,01042 & 0,88834 & 10,93 & $1,8 \mathrm{E}-03$ \\
\hline 9 & 2261 & 0,01267 & 1,31139 & 10,94 & $2,5 \mathrm{E}-03$ \\
\hline 10 & 2262 & 0,00930 & 0,70649 & 14,86 & $1,4 \mathrm{E}-03$ \\
\hline 11 & 2293 & 0,01182 & 1,14193 & 14,23 & $1,9 \mathrm{E}-03$ \\
\hline 12 & 2281 & 0,00628 & 0,32214 & 15,41 & $1,1 \mathrm{E}-03$ \\
\hline 13 & 2294 & 0,00953 & 0,74321 & 17,05 & $1,4 \mathrm{E}-03$ \\
\hline 14 & 2308 & 0,00901 & 0,66371 & 17,21 & $1,3 \mathrm{E}-03$ \\
\hline 15 & 2327 & 0,00809 & 0,53503 & 17,35 & $1,2 \mathrm{E}-03$ \\
\hline 16 & 2349 & 0,00694 & 0,39353 & 18,38 & $1,1 \mathrm{E}-03$ \\
\hline 17 & 2375 & 0,00950 & 0,73720 & 19,48 & $1,4 \mathrm{E}-03$ \\
\hline 18 & 2376 & 0,00886 & 0,64216 & 18,30 & $1,3 \mathrm{E}-03$ \\
\hline 19 & 2377 & 0,00702 & 0,40277 & 18,30 & $1,2 \mathrm{E}-03$ \\
\hline 20 & 2430 & 0,00431 & 0,15180 & 18,35 & $1,0 \mathrm{E}-03$ \\
\hline 21 & 2431 & 0,00462 & 0,17479 & 15,38 & $1,1 \mathrm{E}-03$ \\
\hline 22 & 2434 & 0,00084 & 0,00580 & 22,62 & $1,0 \mathrm{E}-03$ \\
\hline 23 & 2513 & 0,00210 & 0,03593 & 30,83 & $1,0 \mathrm{E}-03$ \\
\hline 24 & 2584 & 0,00340 & 0,09463 & 29,19 & $1,0 \mathrm{E}-03$ \\
\hline 25 & 2551 & 0,00204 & 0,03405 & 28,01 & $1,0 \mathrm{E}-03$ \\
\hline 26 & 2585 & 0,00108 & 0,00955 & 30,72 & $1,0 \mathrm{E}-03$ \\
\hline 27 & 2604 & 0,00029 & 0,00070 & 33,43 & $1,0 \mathrm{E}-03$ \\
\hline 28 & 2646 & 0,00019 & 0,00028 & 34,79 & $1,0 \mathrm{E}-03$ \\
\hline
\end{tabular}


Tabela B-1 (3)

\begin{tabular}{|c|c|c|c|c|c|}
\hline \# & Elemento & $\begin{array}{l}\boldsymbol{e}_{\text {frat }} \\
\mathrm{cm}\end{array}$ & $\begin{array}{c}\mathbf{K}_{\mathbf{f}} \\
\mathrm{cm} / \mathrm{s}\end{array}$ & $\begin{array}{c}\text { I } \\
\mathrm{cm}\end{array}$ & $\begin{array}{c}\mathbf{K}_{\mathbf{t}} \\
\mathrm{cm} / \mathrm{s}\end{array}$ \\
\hline \multicolumn{6}{|c|}{ Nível, 5 pressão fratura 4} \\
\hline 1 & 1 & 0,01076 & 0,94714 & 8,78 & $2,2 \mathrm{E}-03$ \\
\hline 2 & 2197 & 0,01201 & 1,17940 & 9,21 & $2,5 \mathrm{E}-03$ \\
\hline 3 & 2199 & 0,00985 & 0,79257 & 9,73 & $1,8 \mathrm{E}-03$ \\
\hline 4 & 2208 & 0,01039 & 0,88254 & 10,30 & $1,9 \mathrm{E}-03$ \\
\hline 5 & 2211 & 0,00982 & 0,78766 & 10,29 & $1,8 \mathrm{E}-03$ \\
\hline 6 & 2212 & 0,01197 & 1,17220 & 10,46 & $2,3 \mathrm{E}-03$ \\
\hline 7 & 2232 & 0,01426 & 1,66132 & 10,91 & $3,2 \mathrm{E}-03$ \\
\hline 8 & 2233 & 0,01201 & 1,18000 & 10,93 & $2,3 \mathrm{E}-03$ \\
\hline 9 & 2261 & 0,01470 & 1,76768 & 10,94 & $3,4 \mathrm{E}-03$ \\
\hline 10 & 2262 & 0,01090 & 0,97061 & 14,86 & $1,7 \mathrm{E}-03$ \\
\hline 11 & 2293 & 0,01390 & 1,57875 & 14,23 & $2,5 \mathrm{E}-03$ \\
\hline 12 & 2281 & 0,00756 & 0,46770 & 15,41 & $1,2 \mathrm{E}-03$ \\
\hline 13 & 2294 & 0,01148 & 1,07727 & 17,05 & $1,7 \mathrm{E}-03$ \\
\hline 14 & 2308 & 0,01108 & 1,00396 & 17,21 & $1,6 \mathrm{E}-03$ \\
\hline 15 & 2327 & 0,00998 & 0,81445 & 17,35 & $1,5 \mathrm{E}-03$ \\
\hline 16 & 2349 & 0,00897 & 0,65791 & 18,38 & $1,3 \mathrm{E}-03$ \\
\hline 17 & 2375 & 0,01219 & 1,21525 & 19,48 & $1,8 \mathrm{E}-03$ \\
\hline 18 & 2376 & 0,01192 & 1,16172 & 18,30 & $1,8 \mathrm{E}-03$ \\
\hline 19 & 2377 & 0,01007 & 0,82958 & 18,30 & $1,5 \mathrm{E}-03$ \\
\hline 20 & 2430 & 0,00804 & 0,52881 & 18,35 & $1,2 \mathrm{E}-03$ \\
\hline 21 & 2431 & 0,0 & 0918 & 15,38 & $1,4 \mathrm{E}-03$ \\
\hline 22 & 2434 & 0,00264 & 0,05696 & 22,62 & $1,0 \mathrm{E}-03$ \\
\hline 23 & 2513 & 0,00497 & 0,20195 & 30,83 & $1,0 \mathrm{E}-03$ \\
\hline 24 & 2584 & 0,00829 & 0,56165 & 29,19 & $1,2 \mathrm{E}-03$ \\
\hline 25 & 2551 & 0,00734 & 0,44101 & 28,01 & $1,1 \mathrm{E}-03$ \\
\hline 26 & 2585 & 0,00473 & 0,18257 & 30,72 & $1,0 \mathrm{E}-03$ \\
\hline 27 & 2604 & 0,00276 & 0,06222 & 33,43 & $1,0 \mathrm{E}-03$ \\
\hline 28 & 2646 & 0,00209 & 0,03556 & 34,79 & $1,0 \mathrm{E}-03$ \\
\hline 29 & 2668 & 0.00001 & 0.00000 & 36,44 & $1.0 \mathrm{E}-03$ \\
\hline 30 & 2677 & 0,00040 & 0,00132 & 37,60 & $1,0 \mathrm{E}-03$ \\
\hline
\end{tabular}


Tabela B-1 (4)

\begin{tabular}{|c|c|c|c|c|c|}
\hline \# & Elemento & $\begin{array}{l}\mathbf{e}_{\text {frat }} \\
\mathrm{cm}\end{array}$ & $\begin{array}{c}\mathbf{K}_{\mathbf{f}} \\
\mathrm{cm} / \mathrm{s}\end{array}$ & $\begin{array}{c}\text { I } \\
\mathrm{cm}\end{array}$ & $\begin{array}{c}\mathbf{K}_{\mathbf{t}} \\
\mathrm{cm} / \mathrm{s}\end{array}$ \\
\hline \multicolumn{6}{|c|}{ Nível, 5 pressão fratura 5} \\
\hline 1 & 1 & 0,01409 & 1,62200 & 8,78 & $3,6 \mathrm{E}-03$ \\
\hline 2 & 2197 & 0,01682 & 2,31313 & 9,21 & $5,2 \mathrm{E}-03$ \\
\hline 3 & 2199 & 0,01358 & 1,50692 & 9,73 & $3,1 \mathrm{E}-03$ \\
\hline 4 & 2208 & 0,01364 & 1,52203 & 10,30 & $3,0 \mathrm{E}-03$ \\
\hline 5 & 2211 & 0,01347 & 1,48427 & 10,29 & $2,9 \mathrm{E}-03$ \\
\hline 6 & 2212 & 0,01703 & 2,37225 & 10,46 & $4,9 \mathrm{E}-03$ \\
\hline 7 & 2232 & 0,02200 & 3,95788 & 10,91 & $9,0 \mathrm{E}-03$ \\
\hline 8 & 2233 & 0,01813 & 2,68819 & 10,93 & $5,5 \mathrm{E}-03$ \\
\hline 9 & 2261 & 0,02336 & 4,46119 & 10,94 & 1,1E-02 \\
\hline 10 & 2262 & 0,01769 & 2,55949 & 14,86 & $4,0 \mathrm{E}-03$ \\
\hline 11 & 2293 & 0,02303 & 4,33510 & 14,23 & $8,0 \mathrm{E}-03$ \\
\hline 12 & 2281 & 0,01263 & 1,30504 & 15,41 & $2,1 \mathrm{E}-03$ \\
\hline 13 & 2294 & 0,01889 & 2,91681 & 17,05 & $4,2 \mathrm{E}-03$ \\
\hline 14 & 2308 & 0,01800 & 2,64794 & 17,21 & $3,8 \mathrm{E}-03$ \\
\hline 15 & 2327 & 0,01770 & 2,56213 & 17,35 & $3,6 \mathrm{E}-03$ \\
\hline 16 & 2349 & 0,01632 & 2,17775 & 18,38 & $2,9 \mathrm{E}-03$ \\
\hline 17 & 2375 & 0,02290 & 4,28695 & 19,48 & $6,0 \mathrm{E}-03$ \\
\hline 18 & 2376 & 0,02358 & 4,54635 & 18,30 & 6,9E-03 \\
\hline 19 & 2377 & 0,01982 & 3,21113 & 18,30 & $4,5 \mathrm{E}-03$ \\
\hline 20 & 2430 & 0,01745 & 2,48788 & 18,35 & $3,4 \mathrm{E}-03$ \\
\hline 21 & 2431 & 0,01882 & 2,89613 & 15,38 & $4,5 \mathrm{E}-03$ \\
\hline 22 & 2434 & 0,00626 & 0,31988 & 22,62 & $1,1 \mathrm{E}-03$ \\
\hline 23 & 2513 & 0,01157 & 1,09450 & 30,83 & $1,4 \mathrm{E}-03$ \\
\hline 24 & 2584 & 0,01976 & 3,19061 & 29,19 & $3,2 \mathrm{E}-03$ \\
\hline 25 & 2551 & 0,01936 & 3,06396 & 28,01 & $3,1 \mathrm{E}-03$ \\
\hline 26 & 2585 & 0,01244 & 1,26585 & 30,72 & $1,5 \mathrm{E}-03$ \\
\hline 27 & 2604 & 0,01172 & 1,12253 & 33,43 & $1,4 \mathrm{E}-03$ \\
\hline 28 & 2646 & 0,00950 & 0,73703 & 34,79 & $1,2 \mathrm{E}-03$ \\
\hline 29 & 2668 & 0,00313 & 0,08002 & 36,44 & $1,0 \mathrm{E}-03$ \\
\hline 30 & 2677 & 0,00948 & 0,73411 & 37,60 & $1,2 \mathrm{E}-03$ \\
\hline 31 & 2715 & 0,00728 & 0,43344 & 39,56 & $1,1 \mathrm{E}-03$ \\
\hline 32 & 2716 & 0,00404 & 0,13311 & 40,73 & $1,0 \mathrm{E}-03$ \\
\hline 33 & 2778 & 0,00165 & 0,02226 & 45,73 & $1,0 \mathrm{E}-03$ \\
\hline 34 & 2809 & 0,00139 & 0,01575 & 54,40 & $1,0 \mathrm{E}-03$ \\
\hline 35 & 2825 & 0,00010 & 0,00007 & 62,66 & $1,0 \mathrm{E}-03$ \\
\hline \begin{tabular}{l|l}
36 \\
\end{tabular} & 2935 & 0,00007 & 0,00004 & 60,07 & $1,0 \mathrm{E}-03$ \\
\hline
\end{tabular}


Tabela B-1 (5)

\begin{tabular}{|c|c|c|c|c|c|}
\hline \# & Elemento & $\begin{array}{l}\boldsymbol{e}_{\text {frat }} \\
\mathrm{cm}\end{array}$ & $\begin{array}{c}\mathbf{K}_{\mathbf{f}} \\
\mathrm{cm} / \mathrm{s}\end{array}$ & $\begin{array}{c}\text { I } \\
\mathrm{cm}\end{array}$ & $\begin{array}{c}\mathbf{K}_{\mathbf{t}} \\
\mathrm{cm} / \mathrm{s}\end{array}$ \\
\hline \multicolumn{6}{|c|}{ Nível, 6 pressão fratura 5} \\
\hline 1 & 1 & 0,01565 & 2,00194 & 8,78 & $4,6 \mathrm{E}-03$ \\
\hline 2 & 2197 & 0,01907 & 2,97167 & 9,21 & $7,2 \mathrm{E}-03$ \\
\hline 3 & 2199 & 0,01535 & 1,92568 & 9,73 & $4,0 \mathrm{E}-03$ \\
\hline 4 & 2208 & 0,01519 & 1,88705 & 10,30 & $3,8 \mathrm{E}-03$ \\
\hline 5 & 2211 & 0,01528 & 1,90815 & 10,29 & $3,8 \mathrm{E}-03$ \\
\hline 6 & 2212 & 0,01951 & 3,11332 & 10,46 & $6,8 \mathrm{E}-03$ \\
\hline 7 & 2232 & 0,02578 & 5,43165 & 10,91 & $1,4 \mathrm{E}-02$ \\
\hline 8 & 2233 & 0,02117 & 3,66302 & 10,93 & $8,1 \mathrm{E}-03$ \\
\hline 9 & 2261 & 0,02759 & 6,22207 & 10,94 & $1,7 \mathrm{E}-02$ \\
\hline 10 & 2262 & 0,02105 & 3,62172 & 14,86 & $6,1 \mathrm{E}-03$ \\
\hline 11 & 2293 & 0,02749 & 6,17811 & 14,23 & $1,3 \mathrm{E}-02$ \\
\hline 12 & 2281 & 0,01522 & 1,89360 & 15,41 & $2,9 \mathrm{E}-03$ \\
\hline 13 & 2294 & 0,02270 & 4,21111 & 17,05 & $6,6 \mathrm{E}-03$ \\
\hline 14 & 2308 & 0,02172 & 3,85629 & 17,21 & $5,9 \mathrm{E}-03$ \\
\hline 15 & 2327 & 0,02163 & 3,82450 & 17,35 & $5,8 \mathrm{E}-03$ \\
\hline 16 & 2349 & 0,0 & 3,33574 & 18,38 & $4,7 \mathrm{E}-03$ \\
\hline 17 & 2375 & 0,0 & 6,58580 & 19,48 & $1,1 \mathrm{E}-02$ \\
\hline 18 & 2376 & 0,02965 & 7,18883 & 18,30 & $1,3 \mathrm{E}-02$ \\
\hline 19 & 2377 & 0,02512 & 5,16048 & 18,30 & $8,1 \mathrm{E}-03$ \\
\hline 20 & 2430 & 0,02283 & 4,26254 & 18,35 & $6,3 \mathrm{E}-03$ \\
\hline 21 & 2431 & 0,02456 & 4,93247 & 15,38 & $8,9 \mathrm{E}-03$ \\
\hline 22 & 2434 & 0,00858 & 0,60144 & 22,62 & $1,2 \mathrm{E}-03$ \\
\hline 23 & 2513 & 556 & 1,97921 & 30,83 & $2,0 \mathrm{E}-03$ \\
\hline 24 & 2584 & 0,02654 & 5,75674 & 29,19 & $6,2 \mathrm{E}-03$ \\
\hline 25 & 2551 & 0,02704 & 5,97729 & 28,01 & $6,8 \mathrm{E}-03$ \\
\hline 26 & 2585 & 0,01769 & 2,55863 & 30,72 & $2,5 \mathrm{E}-03$ \\
\hline 27 & 2604 & 0,01866 & 2,84531 & 33,43 & $2,6 \mathrm{E}-03$ \\
\hline 28 & 2646 & 0,01554 & 1,97438 & 34,79 & $1,9 \mathrm{E}-03$ \\
\hline 29 & 2668 & 0,00693 & 0,39236 & 36,44 & $1,1 \mathrm{E}-03$ \\
\hline 30 & 2677 & 0,02000 & 3,27001 & 37,60 & $2,7 \mathrm{E}-03$ \\
\hline 31 & 2715 & 0,01900 & 2,95079 & 39,56 & $2,4 \mathrm{E}-03$ \\
\hline 32 & 2716 & 0,01291 & 1,36346 & 40,73 & $1,4 \mathrm{E}-03$ \\
\hline 33 & 2778 & & 0,75035 & 45,73 & $1,2 \mathrm{E}-03$ \\
\hline 34 & 2809 & 0,00884 & 0,63898 & 54,40 & $1,1 \mathrm{E}-03$ \\
\hline 35 & 2825 & 0,00502 & 0,20575 & 62,66 & $1,0 \mathrm{E}-03$ \\
\hline 36 & 2935 & 0,00559 & 0,25577 & 60,07 & $1,0 \mathrm{E}-03$ \\
\hline 37 & 2896 & 0,00437 & 0,15585 & 55,42 & $1,0 \mathrm{E}-03$ \\
\hline 38 & 2936 & 0,00072 & 0,00420 & 68,84 & $1,0 \mathrm{E}-03$ \\
\hline 39 & 2946 & 0,00010 & 0,00008 & 82,42 & $1,0 \mathrm{E}-03$ \\
\hline
\end{tabular}


Tabela B-1 (6)

\begin{tabular}{|c|c|c|c|c|c|}
\hline \# & Elemento & $\begin{array}{l}\mathbf{e}_{\text {frat }} \\
\mathrm{cm}\end{array}$ & $\begin{array}{c}\mathbf{K}_{\mathbf{f}} \\
\mathrm{cm} / \mathrm{s}\end{array}$ & $\begin{array}{c}\text { I } \\
\mathrm{cm}\end{array}$ & $\begin{array}{c}\mathbf{K}_{\mathbf{t}} \\
\mathrm{cm} / \mathrm{s}\end{array}$ \\
\hline \multicolumn{6}{|c|}{ Nível, 6 pressão fratura 6} \\
\hline 1 & 1 & 0,01998 & 3,26230 & 8,78 & $8,4 \mathrm{E}-03$ \\
\hline 2 & 2197 & 0,02711 & 6,00969 & 9,21 & $1,9 \mathrm{E}-02$ \\
\hline 3 & 2199 & 0,02122 & 3,67939 & 9,73 & $9,0 \mathrm{E}-03$ \\
\hline 4 & 2208 & 0,01934 & 3,05641 & 10,30 & $6,7 \mathrm{E}-03$ \\
\hline 5 & 2211 & 0,02025 & 3,35341 & 10,29 & $7,6 \mathrm{E}-03$ \\
\hline 6 & 2212 & 0,02729 & 6,08865 & 10,46 & $1,7 \mathrm{E}-02$ \\
\hline 7 & 2232 & 0,03980 & 12,94769 & 10,91 & $4,8 \mathrm{E}-02$ \\
\hline 8 & 2233 & 0,03167 & 8,19718 & 10,93 & $2,5 \mathrm{E}-02$ \\
\hline 9 & 2261 & 0,04387 & 15,73464 & 10,94 & $6,4 \mathrm{E}-02$ \\
\hline 10 & 2262 & 0,03417 & 9,54368 & 14,86 & $2,3 \mathrm{E}-02$ \\
\hline 11 & 2293 & 0,04553 & 16,94775 & 14,23 & $5,5 \mathrm{E}-02$ \\
\hline 12 & 2281 & 0,02499 & 5,10482 & 15,41 & 9,3E-03 \\
\hline 13 & 2294 & 0,03669 & 11,00297 & 17,05 & $2,5 \mathrm{E}-02$ \\
\hline 14 & 2308 & 0,03411 & 9,51058 & 17,21 & $2,0 \mathrm{E}-02$ \\
\hline 15 & 2327 & 0,03739 & 11,42656 & 17,35 & $2,6 \mathrm{E}-02$ \\
\hline 16 & 2349 & 0,03511 & 10,07754 & 18,38 & $2,0 \mathrm{E}-02$ \\
\hline 17 & 2375 & 100 & 21,26701 & 19,48 & $5,7 \mathrm{E}-02$ \\
\hline 18 & 2376 & 0,05476 & 24,51413 & 18,30 & $7,4 \mathrm{E}-02$ \\
\hline 19 & 2377 & 0,04533 & 16,79490 & 18,30 & $4,3 \mathrm{E}-02$ \\
\hline 20 & 2430 & 0,04225 & 14,59614 & 18,35 & $3,5 \mathrm{E}-02$ \\
\hline 21 & 2431 & 0,04271 & 14,91057 & 15,38 & $4,2 \mathrm{E}-02$ \\
\hline 22 & 2434 & 0,01589 & 2,06351 & 22,62 & $2,4 \mathrm{E}-03$ \\
\hline 23 & 2513 & 942 & 7,073 & 30,83 & 7,7E-03 \\
\hline 24 & 2584 & 0,05109 & 21,33453 & 29,19 & $3,8 \mathrm{E}-02$ \\
\hline 25 & 2551 & 0,05300 & 22,96386 & 28,01 & $4,4 \mathrm{E}-02$ \\
\hline 26 & 2585 & 0,03357 & 9,21195 & 30,72 & $1,1 \mathrm{E}-02$ \\
\hline 27 & 2604 & 0,03772 & 11,63255 & 33,43 & $1,4 \mathrm{E}-02$ \\
\hline 28 & 2646 & 0,03062 & 7,66416 & 34,79 & $7,7 \mathrm{E}-03$ \\
\hline 29 & 2668 & 0,01645 & 2,21246 & 36,44 & $2,0 \mathrm{E}-03$ \\
\hline 30 & 2677 & 0,04330 & 15,32640 & 37,60 & $1,9 \mathrm{E}-02$ \\
\hline 31 & 2715 & 0,04403 & 15,84740 & 39,56 & 1,9E-02 \\
\hline 32 & 2716 & 0,02950 & 7,11356 & 40,73 & $6,2 \mathrm{E}-03$ \\
\hline 33 & 2778 & 0,02497 & 5,09690 & 45,73 & $3,8 \mathrm{E}-03$ \\
\hline 34 & 2809 & 0,02288 & 4,28114 & 54,40 & $2,8 \mathrm{E}-03$ \\
\hline 35 & 2825 & 0,01763 & 2,53963 & 62,66 & 1,7E-03 \\
\hline 36 & 2935 & 0,02465 & 4,96768 & 60,07 & $3,0 \mathrm{E}-03$ \\
\hline 37. & 2896 & 0,02937 & 7,05274 & 55,42 & $4,7 \mathrm{E}-03$ \\
\hline 38 & 2936 & 0,01488 & 1,81085 & 68,84 & 1,4E-03 \\
\hline 39 & 2946 & 0,01566 & 2,00573 & 82,42 & $1,4 \mathrm{E}-03$ \\
\hline 40 & 2947 & 0,00964 & 0,76018 & 72,30 & 1,1E-03 \\
\hline 41 & 3002 & 0,00711 & 0,41290 & 63,06 & $1,0 \mathrm{E}-03$ \\
\hline 42 & 3003 & 0,00337 & 0,09294 & 63,52 & 1,0E-03 \\
\hline 43 & 3056 & 0,00127 & 0,01315 & 76,59 & 1,0E-03 \\
\hline
\end{tabular}


Tabela B-2 (1)

\begin{tabular}{|c|c|c|c|c|c|}
\hline \# & Elemento & $\begin{array}{l}\mathbf{e}_{\text {frat }} \\
\mathrm{cm}\end{array}$ & $\begin{array}{c}\mathbf{K}_{\mathbf{f}} \\
\mathrm{cm} / \mathrm{s}\end{array}$ & $\mathrm{cm}$ & $\begin{array}{c}\mathrm{K}_{\mathrm{t}} \\
\mathrm{cm} / \mathrm{s}\end{array}$ \\
\hline \multicolumn{6}{|c|}{ 1ro Nível } \\
\hline 1 & 1 & 0,00874 & 0,62503 & 8,78 & $1,6 \mathrm{E}-03$ \\
\hline 2 & 1137 & 0,00685 & 0,38376 & 9,20 & $1,3 \mathrm{E}-03$ \\
\hline 3 & 1139 & 0,00641 & 0,33546 & 10,19 & $1,2 \mathrm{E}-03$ \\
\hline 4 & 1148 & 0,00785 & 0,50350 & 10,38 & $1,4 \mathrm{E}-03$ \\
\hline 5 & 1150 & 0,00775 & 0,49071 & 10,29 & $1,4 \mathrm{E}-03$ \\
\hline 6 & 1151 & 0,00678 & 0,37544 & 10,53 & $1,2 \mathrm{E}-03$ \\
\hline 7 & 1165 & 0,00188 & 0,02875 & 12,26 & $1,0 \mathrm{E}-03$ \\
\hline 8 & 1160 & 0,00117 & 0,01125 & 12,26 & $1,0 \mathrm{E}-03$ \\
\hline 9 & 1170 & 0,00540 & 0,23875 & 12,26 & 1,1E-03 \\
\hline 10 & 1179 & 0,00445 & 0,16213 & 12,99 & $1,1 \mathrm{E}-03$ \\
\hline 11 & 1191 & 0,00273 & 0,06098 & 13,95 & $1,0 \mathrm{E}-03$ \\
\hline 12 & 1192 & 0,00367 & 0,11035 & 14,83 & $1,0 \mathrm{E}-03$ \\
\hline 13 & 1223 & 0,00455 & 0,16924 & 14,22 & $1,1 \mathrm{E}-03$ \\
\hline 14 & 1210 & 0,00193 & 0,03031 & 15,41 & $1,0 \mathrm{E}-03$ \\
\hline 15 & 1227 & 0,00333 & 0,09059 & 17,05 & $1,0 \mathrm{E}-03$ \\
\hline 16 & 1246 & 0,00266 & 0,05795 & 17,21 & $1,0 \mathrm{E}-03$ \\
\hline 17 & 1264 & 0,00275 & 0,06182 & 17,35 & $1,0 \mathrm{E}-03$ \\
\hline 18 & 1273 & 0,00172 & 0,02418 & 16,30 & $1,0 \mathrm{E}-03$ \\
\hline 19 & 1274 & 0,00141 & 0,01617 & 16,30 & $1,0 \mathrm{E}-03$ \\
\hline 20 & 1314 & 0,00022 & 0,00039 & 17,56 & $1,0 \mathrm{E}-03$ \\
\hline \multicolumn{6}{|c|}{ Nível 2, fratura 1} \\
\hline 1 & 1 & 0,01483 & 1,79868 & 8,78 & $4,0 \mathrm{E}-03$ \\
\hline 2 & 1137 & 0,01 & 1,11701 & 9,20 & $2,4 \mathrm{E}-03$ \\
\hline 3 & 1139 & 0,01157 & 1,09429 & 10,19 & $2,2 \mathrm{E}-03$ \\
\hline 4 & 1148 & 0,01436 & 1,68677 & 10,38 & $3,3 \mathrm{E}-03$ \\
\hline 5 & 1150 & 0,01496 & 1,82939 & 10,29 & $3,7 \mathrm{E}-03$ \\
\hline 6 & 1151 & 0,01376 & 1,54886 & 10,53 & $3,0 \mathrm{E}-03$ \\
\hline 7 & 1165 & 0,00338 & 0,09346 & 12,26 & $1,0 \mathrm{E}-03$ \\
\hline 8 & 1160 & 0,00292 & 0,06958 & 12,26 & $1,0 \mathrm{E}-03$ \\
\hline 9 & 1170 & 0,01280 & 1,34037 & 12,26 & 2,4E-03 \\
\hline 10 & 1179 & 0,01087 & 0,96647 & 12,99 & $1,8 \mathrm{E}-03$ \\
\hline 11 & 1191 & 0,00758 & 0,46990 & 13,95 & $1,3 \mathrm{E}-03$ \\
\hline 12 & 1192 & 0,00929 & 0,70620 & 14,83 & $1,4 \mathrm{E}-03$ \\
\hline 13 & 1223 & 0,01138 & 1,05860 & 14,22 & $1,8 \mathrm{E}-03$ \\
\hline 14 & 1210 & 0,00524 & 0,22484 & 15,41 & $1,1 \mathrm{E}-03$ \\
\hline 15 & 1227 & 0,00869 & 0,61664 & 17,05 & $1,3 \mathrm{E}-03$ \\
\hline 16 & 1246 & 0,00900 & 0,66146 & 17,21 & $1,3 \mathrm{E}-03$ \\
\hline 17 & 1264 & 0,00926 & 0,70141 & 17,35 & $1,4 \mathrm{E}-03$ \\
\hline 18 & 1273 & 0,00858 & 0,60132 & 16,30 & $1,3 \mathrm{E}-03$ \\
\hline 19 & 1274 & 0,00783 & 0,50085 & 16,30 & $1,2 \mathrm{E}-03$ \\
\hline 20 & 1314 & 0,00453 & 0,16762 & 17,56 & $1,0 \mathrm{E}-03$ \\
\hline 21 & 1315 & 0,00692 & 0,39175 & 18,30 & $1,1 \mathrm{E}-03$ \\
\hline 22 & 1359 & 0,00506 & 0,20939 & 18,35 & $1,1 \mathrm{E}-03$ \\
\hline 23 & 1360 & 0,00405 & 0,13433 & 19,89 & $1,0 \mathrm{E}-03$ \\
\hline 24 & 1418 & 0,00197 & 0,03185 & 29,23 & $1,0 \mathrm{E}-03$ \\
\hline 25 & 1419 & 0,00203 & 0,03375 & 35,49 & $1,0 \mathrm{E}-03$ \\
\hline 26 & 1473 & 0,00065 & 0,00342 & 32,63 & $1,0 \mathrm{E}-03$ \\
\hline
\end{tabular}


Tabela B-2 (2)

\begin{tabular}{|c|c|c|c|c|c|}
\hline \# & Elemento & $\begin{array}{l}\mathbf{e}_{\text {frat }} \\
\mathrm{cm}\end{array}$ & $\begin{array}{c}\mathbf{K}_{\mathbf{f}} \\
\mathrm{cm} / \mathrm{s}\end{array}$ & $\begin{array}{c}\text { I } \\
\mathrm{cm}\end{array}$ & $\begin{array}{c}K_{\mathbf{t}} \\
\mathrm{cm} / \mathrm{s}\end{array}$ \\
\hline \multicolumn{6}{|c|}{ Nível 2, fratura 2} \\
\hline 1 & 1 & 0,02121 & 3,67832 & 8,78 & 9,9E-03 \\
\hline 2 & 1137 & 0,01681 & 2,30887 & 9,20 & $5,2 \mathrm{E}-03$ \\
\hline 3 & 1139 & 0,01774 & 2,57247 & 10,19 & $5,5 \mathrm{E}-03$ \\
\hline 4 & 1148 & 0,02094 & 3,58553 & 10,38 & $8,2 \mathrm{E}-03$ \\
\hline 5 & 1150 & 0,02265 & 4,19358 & 10,29 & $1,0 \mathrm{E}-02$ \\
\hline 6 & 1151 & 0,02059 & 3,46540 & 10,53 & $7,8 \mathrm{E}-03$ \\
\hline 7 & 1165 & 0,00460 & 0,17293 & 12,26 & 1,1E-03 \\
\hline 8 & 1160 & 0,00419 & 0,14355 & 12,26 & $1,0 \mathrm{E}-03$ \\
\hline 9 & 1170 & 0,02020 & 3,33593 & 12,26 & $6,5 \mathrm{E}-03$ \\
\hline 10 & 1179 & 0,01786 & 2,60905 & 12,99 & $4,6 \mathrm{E}-03$ \\
\hline 11 & 1191 & 0,01310 & 1,40192 & 13,95 & $2,3 \mathrm{E}-03$ \\
\hline 12 & 1192 & 0,01564 & 1,99877 & 14,83 & $3,1 \mathrm{E}-03$ \\
\hline 13 & 1223 & 0,01918 & 3,00759 & 14,22 & $5,1 \mathrm{E}-03$ \\
\hline 14 & 1210 & 0,00902 & 0,66535 & 15,41 & $1,4 \mathrm{E}-03$ \\
\hline 15 & 1227 & 0,01522 & 1,89350 & 17,05 & $2,7 \mathrm{E}-03$ \\
\hline 16 & 1246 & 0,01664 & 2,26485 & 17,21 & $3,2 \mathrm{E}-03$ \\
\hline 17 & 1264 & 0,01747 & 2,49524 & 17,35 & $3,5 \mathrm{E}-03$ \\
\hline 18 & 1273 & 0,01732 & 2,45342 & 16,30 & $3,6 \mathrm{E}-03$ \\
\hline 19 & 1274 & 0,01588 & 2,06242 & 16,30 & $3,0 \mathrm{E}-03$ \\
\hline 20 & 1314 & 0,01121 & 1,02701 & 17,56 & 1,7E-03 \\
\hline 21 & 1315 & 0,01731 & 2,44989 & 18,30 & $3,3 \mathrm{E}-03$ \\
\hline 22 & 1359 & 0,01569 & 2,01332 & 18,35 & $2,7 \mathrm{E}-03$ \\
\hline 23 & 1360 & 0,01217 & 1,21126 & 19,89 & $1,7 \mathrm{E}-03$ \\
\hline 24 & 1418 & 0,00907 & 0,67240 & 29,23 & $1,2 \mathrm{E}-03$ \\
\hline 25 & 1419 & 0,01090 & 0,97102 & 35,49 & $1,3 \mathrm{E}-03$ \\
\hline 26 & 1473 & 0,00960 & 0,75290 & 32,63 & $1,2 \mathrm{E}-03$ \\
\hline 27 & 1525 & 0,00950 & 0,73796 & 30,72 & $1,2 \mathrm{E}-03$ \\
\hline 28 & 1553 & 0,00199 & 0,03243 & 33,43 & $1,0 \mathrm{E}-03$ \\
\hline 29 & 1592 & 0,00716 & 0,41937 & 34,79 & $1,1 \mathrm{E}-03$ \\
\hline 30 & 1614 & 0,00431 & 0,15215 & 36,44 & $1,0 \mathrm{E}-03$ \\
\hline 31 & 1623 & 0,00531 & 0,23082 & 37,60 & $1,0 \mathrm{E}-03$ \\
\hline 32 & 1665 & 0,00175 & 0,02513 & 39,56 & $1,0 \mathrm{E}-03$ \\
\hline 33 & 1666 & 0,00342 & 0,09566 & 40,73 & $1,0 \mathrm{E}-03$ \\
\hline 34 & 1735 & 0,00161 & 0,02116 & 40,73 & $1,0 \mathrm{E}-03$ \\
\hline 35 & 1736 & 0,00182 & 0,02698 & 41,20 & $1,0 \mathrm{E}-03$ \\
\hline 36 & 1813 & 0,00019 & 0,00031 & 52,71 & $1,0 \mathrm{E}-03$ \\
\hline 37 & 1985 & 0,00043 & 0,00152 & 54,68 & $1,0 \mathrm{E}-03$ \\
\hline
\end{tabular}


Tabela B-2 (3)

\begin{tabular}{|c|c|c|c|c|c|}
\hline \# & Elemento & $\begin{array}{l}e_{\text {frat }} \\
\mathrm{cm}\end{array}$ & $\begin{array}{c}\mathbf{K}_{\mathbf{f}} \\
\mathrm{cm} / \mathrm{s}\end{array}$ & $\mathrm{cm}$ & $\begin{array}{c}\mathrm{K}_{\mathbf{t}} \\
\mathrm{cm} / \mathrm{s}\end{array}$ \\
\hline \multicolumn{6}{|c|}{ Nível 3, fratura 2} \\
\hline 1 & 1 & 0,02541 & 5,27731 & 8,78 & $1,6 \mathrm{E}-02$ \\
\hline 2 & 1137 & 0,02016 & 3,32325 & 9,20 & $8,3 \mathrm{E}-03$ \\
\hline 3 & 1139 & 0,02167 & 3,83997 & 10,19 & $9,2 \mathrm{E}-03$ \\
\hline 4 & 1148 & 0,02530 & 5,23274 & 10,38 & $1,4 \mathrm{E}-02$ \\
\hline 5 & 1150 & 0,02764 & 6,24640 & 10,29 & $1,8 \mathrm{E}-02$ \\
\hline 6 & 1151 & 0,02512 & 5,15695 & 10,53 & $1,3 \mathrm{E}-02$ \\
\hline 7 & 1165 & 0,00549 & 0,24637 & 12,26 & $1,1 \mathrm{E}-03$ \\
\hline 8 & 1160 & 0,00514 & 0,21607 & 12,26 & $1,1 \mathrm{E}-03$ \\
\hline 9 & 1170 & 0,02508 & 5,14172 & 12,26 & $1,2 \mathrm{E}-02$ \\
\hline 10 & 1179 & 0,02241 & 4,10409 & 12,99 & $8,1 \mathrm{E}-03$ \\
\hline 11 & 1191 & 0,01670 & 2,27873 & 13,95 & $3,7 \mathrm{E}-03$ \\
\hline 12 & 1192 & 0,01974 & 3,18408 & 14,83 & $5,2 \mathrm{E}-03$ \\
\hline 13 & 1223 & 0,02419 & 4,78561 & 14,22 & $9,1 \mathrm{E}-03$ \\
\hline 14 & 1210 & 0,01153 & 1,08593 & 15,41 & $1,8 \mathrm{E}-03$ \\
\hline 15 & 1227 & 0,01936 & 3,06437 & 17,05 & 4,5E-03 \\
\hline 16 & 1246 & 0,02158 & 3,80668 & 17,21 & $5,8 \mathrm{E}-03$ \\
\hline 17 & 1264 & 0,02262 & 4,18322 & 17,35 & $6,5 \mathrm{E}-03$ \\
\hline 18 & 1273 & 0,02280 & 4,24972 & 16,30 & $6,9 \mathrm{E}-03$ \\
\hline 19 & 1274 & 0,02101 & 3,60866 & 16,30 & $5,6 \mathrm{E}-03$ \\
\hline 20 & 1314 & 0,01532 & 1,91832 & 17,56 & $2,7 \mathrm{E}-03$ \\
\hline 21 & 1315 & 0,02361 & 4,55793 & 18,30 & $6,9 \mathrm{E}-03$ \\
\hline 22 & 1359 & 0,02210 & 3,99396 & 18,35 & $5,8 \mathrm{E}-03$ \\
\hline 23 & 1360 & 0,01713 & 2,39974 & 19,89 & $3,1 \mathrm{E}-03$ \\
\hline 24 & 1418 & 0,01354 & 1,49874 & 29,23 & $1,7 \mathrm{E}-03$ \\
\hline 25 & 1419 & 0,01658 & 2,24645 & 35,49 & $2,0 \mathrm{E}-03$ \\
\hline 26 & 1473 & 0,01597 & 2,08503 & 32,63 & $2,0 \mathrm{E}-03$ \\
\hline 27 & 1525 & 0,01653 & 2,23439 & 30,72 & $2,2 \mathrm{E}-03$ \\
\hline 28 & 1553 & 0,00417 & 0,14198 & \begin{tabular}{|l|}
33,43 \\
\end{tabular} & $1,0 \mathrm{E}-03$ \\
\hline 29 & 1592 & 0,01465 & 1,75435 & 34,79 & 1,7E-03 \\
\hline 30 & 1614 & 0,01065 & 0,92659 & 36,44 & $1,3 \mathrm{E}-03$ \\
\hline 31 & 1623 & 0,01330 & 1,44568 & 37,60 & $1,5 \mathrm{E}-03$ \\
\hline 32 & 1665 & 0,00540 & 0,23831 & 39,56 & $1,0 \mathrm{E}-03$ \\
\hline 33 & 1666 & 0,01104 & 0,99597 & 40,73 & $1,3 \mathrm{E}-03$ \\
\hline 34 & 1735 & 0,00791 & 0,51214 & 40,73 & 1,1E-03 \\
\hline 35 & 1736 & 0,00912 & 0,67997 & 41,20 & $1,2 \mathrm{E}-03$ \\
\hline 36 & 1813 & 0,00045 & 0,00164 & 52,71 & $1,0 \mathrm{E}-03$ \\
\hline 37 & 1985 & 0,00437 & 0,15633 & 54,68 & $1,0 \mathrm{E}-03$ \\
\hline 38 & 1984 & 0,00209 & 0,03570 & 55,37 & $1,0 \mathrm{E}-03$ \\
\hline 39 & 2029 & 0,00289 & 0,06844 & 70,57 & $1,0 \mathrm{E}-03$ \\
\hline 40 & 2044 & 0,00035 & 0,00098 & 111,88 & $1,0 \mathrm{E}-03$ \\
\hline 41 & 2117 & 0,00025 & 0,00052 & 87,92 & $1,0 \mathrm{E}-03$ \\
\hline
\end{tabular}


Tabela B-2 (4)

\begin{tabular}{|c|c|c|c|c|c|}
\hline \# & Elemento & $\begin{array}{l}\mathbf{e}_{\text {frat }} \\
\mathrm{cm}\end{array}$ & $\begin{array}{c}\mathbf{K}_{\mathbf{f}} \\
\mathrm{cm} / \mathrm{s}\end{array}$ & $\mathrm{cm}$ & $\begin{array}{c}\mathbf{K}_{\mathbf{t}} \\
\mathrm{cm} / \mathrm{s}\end{array}$ \\
\hline \multicolumn{6}{|c|}{ Nível 3, fratura 3} \\
\hline 1 & 1 & 0,03282 & 8,80561 & 8,78 & $3,4 \mathrm{E}-02$ \\
\hline 2 & 1137 & 0,02618 & 5,60225 & 9,20 & $1,7 \mathrm{E}-02$ \\
\hline 3 & 1139 & 0,02984 & 7,27949 & 10,19 & $2,2 \mathrm{E}-02$ \\
\hline 4 & 1148 & 0,03279 & 8,79078 & 10,38 & $2,9 \mathrm{E}-02$ \\
\hline 5 & 1150 & 0,03711 & 11,25577 & 10,29 & $4,2 \mathrm{E}-02$ \\
\hline 6 & 1151 & 0,03287 & 8,83002 & 10,53 & $2,9 \mathrm{E}-02$ \\
\hline 7 & 1165 & 0,00628 & 0,32195 & 12,26 & $1,2 \mathrm{E}-03$ \\
\hline 8 & 1160 & 0,00591 & 0,28590 & 12,26 & $1,1 \mathrm{E}-03$ \\
\hline 9 & 1170 & 0,03384 & 9,36206 & 12,26 & $2,7 \mathrm{E}-02$ \\
\hline 10 & 1179 & 0,03150 & 8,11187 & 12,99 & 2,1E-02 \\
\hline 11 & 1191 & 0,02388 & 4,66275 & 13,95 & $9,0 \mathrm{E}-03$ \\
\hline 12 & 1192 & 0,02792 & 6,37244 & 14,83 & 1,3E-02 \\
\hline 13 & 1223 & 0,03437 & 9,65947 & 14,22 & $2,4 \mathrm{E}-02$ \\
\hline 14 & 1210 & 0,01587 & 2,05970 & 15,41 & $3,1 \mathrm{E}-03$ \\
\hline 15 & 1227 & 0,02822 & 6,51158 & 17,05 & $1,2 \mathrm{E}-02$ \\
\hline 16 & 1246 & 0,03125 & 7,98485 & 17,21 & $1,5 \mathrm{E}-02$ \\
\hline 17 & 1264 & 0,03395 & 9,42078 & 17,35 & $1,9 \mathrm{E}-02$ \\
\hline 18 & 1273 & 0,03464 & 9,81084 & 16,30 & $2,2 \mathrm{E}-02$ \\
\hline 19 & 1274 & 0,03127 & 7,99375 & 16,30 & $1,6 \mathrm{E}-02$ \\
\hline 20 & 1314 & 0,02382 & 4,63853 & 17,56 & 7,3E-03 \\
\hline 21 & 1315 & 0,03703 & 11,20744 & 18,30 & $2,4 \mathrm{E}-02$ \\
\hline 22 & 1359 & 0,03485 & 9,92917 & 18,35 & $2,0 \mathrm{E}-02$ \\
\hline 23 & 1360 & 0,02528 & 5,22495 & 19,89 & $7,6 \mathrm{E}-03$ \\
\hline 24 & 1418 & 0,02129 & 3,70431 & 29,23 & $3,7 \mathrm{E}-03$ \\
\hline 25 & 1419 & 0,02532 & 5,24260 & 35,49 & $4,7 \mathrm{E}-03$ \\
\hline 26 & 1473 & 0,02444 & 4,88398 & 32,63 & 4,7E-03 \\
\hline 27 & 1525 & 0,02709 & 5,99876 & 30,72 & $6,3 \mathrm{E}-03$ \\
\hline 28 & 1553 & 0,00627 & 0,32135 & 33,43 & 1,1E-03 \\
\hline 29 & 1592 & 0,02381 & 4,63617 & 34,79 & $4,2 \mathrm{E}-03$ \\
\hline 30 & 1614 & 0,01866 & 2,84691 & 36,44 & $2,5 \mathrm{E}-03$ \\
\hline 31 & 1623 & 0,02366 & 4,57463 & 37,60 & $3,9 \mathrm{E}-03$ \\
\hline 32 & 1665 & 0,00978 & 8201 & 39,56 & $1,2 \mathrm{E}-03$ \\
\hline 33 & 1666 & 0,02031 & 7266 & 40,73 & $2,7 \mathrm{E}-03$ \\
\hline 34 & 1735 & 0,01679 & 2,30543 & 40,73 & $2,0 \mathrm{E}-03$ \\
\hline 35 & 1736 & 0,01962 & 3,14737 & 41,20 & $2,5 \mathrm{E}-03$ \\
\hline 36 & 1813 & 0,00000 & 0,00000 & 52,71 & $1,0 \mathrm{E}-03$ \\
\hline 37 & 1985 & 0,01334 & 1,45511 & 54,68 & $1,4 \mathrm{E}-03$ \\
\hline 38 & 1984 & 0,01079 & 0,95213 & 55,37 & $1,2 \mathrm{E}-03$ \\
\hline 39 & 2029 & 0,01494 & 1,82569 & 70,57 & $1,4 \mathrm{E}-03$ \\
\hline 40 & 2044 & 0,00617 & 0,31131 & 111,88 & $1,0 \mathrm{E}-03$ \\
\hline 41 & 2117 & 0,00653 & 0,34867 & 87,92 & $1,0 \mathrm{E}-03$ \\
\hline 42 & 2109 & 0,00573 & 0,26835 & 78,23 & $1,0 \mathrm{E}-03$ \\
\hline 43 & 2169 & 0,00304 & 0,07575 & 74,25 & $1,0 \mathrm{E}-03$ \\
\hline 44 & 2170 & 0,00033 & 0,00087 & 83,98 & $1,0 \mathrm{E}-03$ \\
\hline 45 & 2256 & 0,00075 & 0,00457 & 131,62 & $1,0 \mathrm{E}-03$ \\
\hline 46 & 2299 & 0,00108 & 0,00945 & 80,75 & $1,0 \mathrm{E}-03$ \\
\hline 47 & 2298 & 0,00069 & 0,00391 & 83,61 & $1,0 \mathrm{E}-03$ \\
\hline 48 & 2221 & 0,00002 & 0,00000 & 129,54 & $1,0 \mathrm{E}-03$ \\
\hline
\end{tabular}


Tabela B-2 (5)

\begin{tabular}{|c|c|c|c|c|c|}
\hline \# & Elemento & $\begin{array}{l}\mathbf{e}_{\text {frat }} \\
\mathrm{cm}\end{array}$ & $\begin{array}{c}\mathbf{K}_{\mathbf{f}} \\
\mathrm{cm} / \mathrm{s}\end{array}$ & $\begin{array}{c}\text { I } \\
\mathrm{cm}\end{array}$ & $\begin{array}{c}\mathbf{K}_{\mathbf{t}} \\
\mathrm{cm} / \mathrm{s}\end{array}$ \\
\hline \multicolumn{6}{|c|}{ Nível 4, fratura 3} \\
\hline 1 & 1 & 0,03462 & 9,79949 & 8,78 & $4,0 \mathrm{E}-02$ \\
\hline 2 & 1137 & 0,02764 & 6,24370 & 9,20 & $2,0 \mathrm{E}-02$ \\
\hline 3 & 1139 & 0,03178 & 8,25881 & 10,19 & $2,7 \mathrm{E}-02$ \\
\hline 4 & 1148 & 0,03464 & 9,80783 & 10,38 & $3,4 \mathrm{E}-02$ \\
\hline 5 & 1150 & 0,03940 & 12,69051 & 10,29 & $5,0 \mathrm{E}-02$ \\
\hline 6 & 1151 & 0,03479 & 9,89531 & 10,53 & $3,4 \mathrm{E}-02$ \\
\hline 7 & 1165 & 0,00651 & 0,34639 & 12,26 & $1,2 \mathrm{E}-03$ \\
\hline 8 & 1160 & 0,00616 & 0,31063 & 12,26 & $1,2 \mathrm{E}-03$ \\
\hline 9 & 1170 & 0,03603 & 10,60978 & 12,26 & $3,2 \mathrm{E}-02$ \\
\hline 10 & 1179 & 0,03373 & 9,30121 & 12,99 & $2,5 \mathrm{E}-02$ \\
\hline 11 & 1191 & 0,02566 & 5,38457 & 13,95 & $1,1 \mathrm{E}-02$ \\
\hline 12 & 1192 & 0,02993 & 7,32235 & 14,83 & $1,6 \mathrm{E}-02$ \\
\hline 13 & 1223 & 0,03686 & 11,10751 & 14,22 & $3,0 \mathrm{E}-02$ \\
\hline 14 & 1210 & 0,01698 & 2,35823 & 15,41 & $3,6 \mathrm{E}-03$ \\
\hline 15 & 1227 & 0,03037 & 7,54042 & 17,05 & $1,4 \mathrm{E}-02$ \\
\hline 16 & 1246 & 0,03367 & 9,26885 & 17,21 & $1,9 \mathrm{E}-02$ \\
\hline 17 & 1264 & 0,03670 & 11,01158 & 17,35 & $2,4 \mathrm{E}-02$ \\
\hline 18 & 1273 & 0,03756 & 11,53158 & 16,30 & $2,8 \mathrm{E}-02$ \\
\hline 19 & 1274 & 0,03385 & 9,36605 & 16,30 & $2,0 \mathrm{E}-02$ \\
\hline 20 & 1314 & 0,02597 & 5,51248 & 17,56 & $9,2 \mathrm{E}-03$ \\
\hline 21 & 1315 & 0,04039 & 13,33413 & 18,30 & $3,0 \mathrm{E}-02$ \\
\hline 22 & & 0,03813 & 11,88297 & 18,35 & $2,6 \mathrm{E}-02$ \\
\hline 23 & 1360 & 0,02747 & 6,17042 & 19,89 & $9,5 \mathrm{E}-03$ \\
\hline 24 & 1418 & 0,02337 & 4,46302 & 29,23 & $4,6 \mathrm{E}-03$ \\
\hline 25 & 1419 & 0,02773 & 6,28714 & 35,49 & $5,9 \mathrm{E}-03$ \\
\hline 26 & 1473 & 0,02686 & 5,89631 & 32,63 & $5,9 \mathrm{E}-03$ \\
\hline 27 & 1525 & 0,03002 & 7,36835 & 30,72 & $8,2 \mathrm{E}-03$ \\
\hline 28 & 1553 & 0,00696 & 0,39615 & 33,43 & $1,1 \mathrm{E}-03$ \\
\hline 29 & 1592 & 0,02654 & 5,75722 & 34,79 & $5,4 \mathrm{E}-03$ \\
\hline 30 & & 109 & 3,63655 & 36,44 & $3,1 \mathrm{E}-03$ \\
\hline 31 & 1623 & 0,02679 & 5,86622 & 37,60 & $5,2 \mathrm{E}-03$ \\
\hline 32 & 1665 & 0,01125 & 1,03447 & 39,56 & $1,3 \mathrm{E}-03$ \\
\hline 33 & 1666 & 0,02333 & 4,45024 & 40,73 & $3,5 \mathrm{E}-03$ \\
\hline 34 & 1735 & 0,01980 & 3,20430 & 40,73 & $2,6 \mathrm{E}-03$ \\
\hline 35 & 1736 & 0,02317 & 4,38871 & 41,20 & $3,5 \mathrm{E}-03$ \\
\hline 36 & 1813 & 0,00254 & 0,05294 & 52,71 & $1,0 \mathrm{E}-03$ \\
\hline 37 & 1985 & 0,01656 & 2,24254 & 54,68 & $1,7 \mathrm{E}-03$ \\
\hline 38 & 1984 & 1410 & 1,62519 & 55,37 & $1,4 \mathrm{E}-03$ \\
\hline 39 & 2029 & & 3,00164 & 70,57 & $1,8 \mathrm{E}-03$ \\
\hline 40 & 2044 & 0,00941 & 0,72419 & 111,88 & $1,1 \mathrm{E}-03$ \\
\hline 41 & 2117 & 0,01061 & 0,91945 & 87,92 & $1,1 \mathrm{E}-03$ \\
\hline 42 & 2109 & 0,01139 & 1,06087 & 78,23 & $1,2 \mathrm{E}-03$ \\
\hline 43 & 2169 & 0,00772 & 0,48697 & 74,25 & $1,1 \mathrm{E}-03$ \\
\hline 44 & 2170 & 0,00154 & 0,01943 & 83,98 & $1,0 \mathrm{E}-03$ \\
\hline 45 & 2256 & 0,00354 & 0,10249 & 131,62 & $1,0 \mathrm{E}-03$ \\
\hline 46 & 2299 & 0,00531 & 0,23093 & 80,75 & $1,0 \mathrm{E}-03$ \\
\hline 47 & 2298 & 0,00511 & 0,21365 & 83,61 & $1,0 \mathrm{E}-03$ \\
\hline 48 & 2221 & 0,00019 & 0,00030 & 129,54 & $1,0 \mathrm{E}-03$ \\
\hline 49 & 2296 & 0,00049 & 0,00199 & 87,44 & $1,0 \mathrm{E}-03$ \\
\hline 50 & 2295 & 0,00044 & 0,00158 & 77,03 & $1,0 \mathrm{E}-03$ \\
\hline
\end{tabular}


Tabela B-3 (1)

Subpressão do vertedouro - PPv30pC

\begin{tabular}{|l|r|r|r|l|}
\hline \multirow{2}{*}{ Nível de água } & $\mathbf{H m}$ & \multicolumn{1}{|c|}{ Sd } & \multicolumn{1}{|c|}{$\mathbf{H j}$} & \multirow{2}{*}{ Observ. } \\
\cline { 2 - 4 } & \multicolumn{3}{|c|}{$\mathrm{kgf} / \mathrm{cm}^{2}$} \\
h1: $242 \mathrm{~m}$ & 2,65 & & 2,62 & \\
h2: $244 \mathrm{~m}$ & 2,84 & & 2,62 & Fratura \\
h3: $247 \mathrm{~m}$ & 3,14 & & 2,62 & Fratura \\
h4: $250 \mathrm{~m}$ & 3,43 & & 2,62 & Fratura \\
h5: $253 \mathrm{~m}$ & 3,73 & & 2,62 & Fratura \\
h6: $257 \mathrm{~m}$ & 4,12 & & 2,62 & Fratura \\
\hline
\end{tabular}

Nível 1

Nível 1, fratura 1

\begin{tabular}{|c|c|c|c|c|c|c|c|c|c|c|c|}
\hline \multirow{3}{*}{ Ptos } & \multirow{3}{*}{ Nós } & \multirow{2}{*}{\multicolumn{2}{|c|}{ Coordenadas }} & \multirow{2}{*}{\multicolumn{2}{|c|}{ Compr. XiSubpressãd }} & \multirow{3}{*}{$\begin{array}{l}\text { Força de } \\
\text { Subp. kgf }\end{array}$} & \multirow{3}{*}{$\begin{array}{c}\text { Força } \\
\text { nodal, kgf }\end{array}$} & \multirow[b]{3}{*}{$\Delta \mathrm{F} 2$} & & \multirow{3}{*}{$\begin{array}{c}\text { Força } \\
\text { nodal, kgf }\end{array}$} \\
\hline & & & & & & & & & & & \\
\hline & & $x$ & $y$ & $\mathrm{~cm}$ & $\mathrm{kgf} / \mathrm{cm} 2$ & & & & $\mathrm{kgf} / \mathrm{cm} 2$ & Subp. kgf & \\
\hline 1 & 3324 & 180 & 21500 & & 2,65 & & 3533 & 31 & 2,65 & & 3563 \\
\hline 2 & 3263 & 207,1 & 21500 & 27,07 & 2,57 & 7066 & 7409 & 111 & 2,62 & 7127 & 7521 \\
\hline 3 & 3227 & 237,5 & 21500 & 30,41 & 2,53 & 7753 & 8132 & 199 & 2,59 & 7914 & 8331 \\
\hline 4 & 3191 & 271,5 & 21500 & 34,04 & 2,48 & 8511 & 8921 & 270 & 2,55 & 8748 & 9191 \\
\hline 5 & 3144 & 309,5 & 21500 & 37,98 & 2,44 & 9331 & 9774 & 328 & 2,52 & 9633 & 10102 \\
\hline 6 & 3107 & 351,8 & 21500 & 42,27 & 2,40 & 10217 & 10693 & 376 & 2,48 & 10570 & 11069 \\
\hline 7 & 3060 & 398,7 & 21500 & 46,95 & 2,36 & 11169 & 11685 & 416 & 2,45 & 11568 & 12101 \\
\hline 8 & 3025 & 450,8 & 21500 & 52,08 & 2,32 & 12200 & 12754 & 453 & 2,41 & 12634 & 13207 \\
\hline 9 & 2980 & 508,5 & 21500 & 57,69 & 2,29 & 13308 & 13920 & 490 & 2,37 & 13779 & 14410 \\
\hline 10 & 2942 & 572,4 & 21500 & 63,87 & 2,26 & 14532 & 15199 & 527 & 2,34 & 15040 & 15727 \\
\hline 11 & 2896 & 643,0 & 21500 & 70,69 & 2,23 & 15867 & 16582 & 567 & 2,31 & 16414 & 17148 \\
\hline 12 & 2849 & 721,3 & 21500 & 78,21 & 2,19 & 17296 & 18070 & 608 & 2,27 & 17883 & 18678 \\
\hline 13 & 2812 & 807,8 & 21500 & 86,58 & 2,16 & 18844 & 19691 & 652 & 2,23 & 19473 & 20343 \\
\hline 14 & 2772 & 903,7 & 21500 & 95,89 & 2,12 & 20538 & 21467 & 701 & 2,19 & 21213 & 22168 \\
\hline 15 & 2731 & 1010,0 & 21500 & 106,30 & 2,09 & 22396 & 23415 & 755 & 2,16 & 23123 & 24169 \\
\hline 16 & 2686 & 1128,0 & 21500 & 117,98 & 2,05 & 24433 & 21361 & 610 & 2,12 & 25216 & 21971 \\
\hline 17 & 2643 & 1259,2 & 21500 & 131,15 & 0,74 & 18289 & 14596 & 223 & 0,74 & 18726 & 14819 \\
\hline 18 & 2591 & 1410,0 & 21500 & 150,85 & 0,71 & 10902 & 7933 & 5 & 0,71 & 10912 & 7938 \\
\hline 19 & 2542 & 1480,0 & 21500 & 70,00 & 0,71 & 4963 & 8697 & 1 & 0,71 & 4963 & 8698 \\
\hline 20 & 2497 & 1653,4 & 21500 & 173,41 & 0,72 & 12430 & 10997 & 2 & 0,72 & 12432 & 11000 \\
\hline 21 & 2455 & 1784,3 & 21500 & 130,92 & 0,74 & 9565 & 9702 & 4 & 0,74 & 9568 & 9706 \\
\hline 22 & 2407 & 1916,8 & 21500 & 132,51 & 0,75 & 9840 & 9983 & 5 & 0,75 & 9845 & 9988 \\
\hline 23 & 2366 & 2051,0 & 21500 & 134,17 & 0,76 & 10125 & 10271 & 7 & 0,76 & 10131 & 10278 \\
\hline 24 & 2322 & 2186,9 & 21500 & 135,92 & 0,77 & 10416 & 10561 & 8 & 0,77 & 10424 & 10569 \\
\hline 25 & 2281 & 2324,7 & 21500 & 137,74 & 0,78 & 10706 & 10855 & 10 & 0,78 & 10715 & 10864 \\
\hline 26 & 2234 & 2464,3 & 21500 & 139,65 & 0,79 & 11004 & 11157 & 11 & 0,79 & 11014 & 11168 \\
\hline 27 & 2189 & 2606,0 & 21500 & 141,64 & 0,80 & 11310 & 11463 & 12 & 0,80 & 11321 & 11475 \\
\hline 28 & 2149 & 2749,7 & 21500 & 143,72 & 0,81 & 11616 & 11769 & 13 & 0,81 & 11629 & 11782 \\
\hline 29 & 2103 & 2895,6 & 21500 & 145,89 & 0,82 & 11922 & 12075 & 14 & 0,82 & 11936 & 12089 \\
\hline 30 & 2059 & 3043,7 & 21500 & 148,14 & 0,83 & 12227 & 12295 & 15 & 0,83 & 12242 & 12311 \\
\hline 31 & 2015 & 3192,2 & 21500 & 148,48 & 0,84 & 12363 & 12411 & 16 & 0,84 & 12379 & 12427 \\
\hline 32 & 1968 & 3340,7 & 21500 & 148,47 & 0,84 & 12458 & 12499 & 17 & 0,84 & 12474 & 12516 \\
\hline 33 & 1930 & 3489,1 & 21500 & 148,48 & 0,85 & 12540 & 12574 & 17 & 0,85 & 12557 & 12592 \\
\hline 34 & 1888 & 3637,6 & 21500 & 148,48 & 0,85 & 12609 & 12636 & 17 & 0,85 & 12626 & 12653 \\
\hline 35 & 1851 & 3786,1 & 21500 & 148,48 & 0,85 & 12663 & 12672 & 29 & 0,86 & 12680 & 12701 \\
\hline 36 & 1808 & 3934,6 & 21500 & 148,48 & 0,85 & 12681 & 12693 & 40 & 0,86 & 12721 & 12734 \\
\hline 37 & 1768 & 4083,0 & 21500 & 148,47 & 0,86 & 12706 & 12724 & 29 & 0,86 & 12746 & 12753 \\
\hline 38 & 1733 & 4231,5 & 21500 & 148,48 & 0,86 & 12742 & 12742 & 18 & 0,86 & 12760 & 12761 \\
\hline 39 & 1691 & 4380,0 & 21500 & 148,48 & 0,86 & 12743 & 10989 & 16 & 0,86 & 12761 & 11005 \\
\hline 40 & 1645 & 4480,0 & 21400 & 100,00 & 0,99 & 9235 & 9963 & 14 & 0,99 & 9249 & 9978 \\
\hline 41 & 1604 & 4580,0 & 21300 & 100,00 & 1,15 & 10692 & 11536 & 17 & 1,15 & 10707 & 11553 \\
\hline 42 & 1563 & 4680,0 & 21200 & 100,00 & 1,33 & 12380 & 13352 & 19 & 1,33 & 12398 & 13371 \\
\hline 43 & 1517 & 4780,0 & 21100 & 100,00 & 1,54 & 14325 & 15427 & 21 & 1,54 & 14345 & 15447 \\
\hline 44 & 1480 & 4880,0 & 21000 & 100,00 & 1,77 & 16529 & 21913 & 28 & 1,77 & 16550 & 21941 \\
\hline 45 & 1437 & 5032,7 & 21000 & 152,70 & 1,81 & 27298 & 27714 & 33 & 1,81 & 27332 & 27748 \\
\hline 46 & 1405 & 5186,9 & 21000 & 154,16 & 1,84 & 28130 & 28525 & 33 & 1,84 & 28163 & 28558 \\
\hline 47 & 1369 & 5342,5 & 21000 & 155,68 & 1,87 & 28919 & 29325 & 32 & 1,88 & 28952 & 29358 \\
\hline 48 & 1329 & 5499,8 & 21000 & 157,28 & 1,91 & 29731 & 30155 & 32 & 1,91 & 29764 & 30187 \\
\hline 49 & 1291 & 5658,8 & 21000 & 158,93 & 1,94 & 30578 & 31011 & 32 & 1,94 & 30610 & 31043 \\
\hline 50 & 1252 & 5819,4 & 21000 & 160,67 & 1,97 & 31444 & 31881 & 31 & 1,98 & 31475 & 31912 \\
\hline 51 & 1215 & 5981,9 & 21000 & 162,47 & 2,00 & 32318 & 32767 & 31 & 2,01 & 32349 & 32798 \\
\hline 52 & 1183 & 6146,2 & 21000 & 164,35 & 2,04 & 33216 & 33686 & 30 & 2,04 & 33246 & 33715 \\
\hline 53 & 1151 & 6312,5 & 21000 & 166,31 & 2,07 & 34155 & 34644 & 28 & 2,07 & 34184 & 34672 \\
\hline 54 & 1117 & 6480,9 & 21000 & 168,33 & 2,10 & 35133 & 35648 & 28 & 2,11 & 35161 & 35676 \\
\hline 55 & 1085 & 6651,3 & 21000 & 170,46 & 2,14 & 36164 & 36665 & 27 & 2,14 & 36191 & 36691 \\
\hline 56 & 1055 & 6823,6 & 21000 & 172,27 & 2,18 & 37165 & 37487 & 25 & 2,18 & 37191 & 37511 \\
\hline 57 & 1027 & 6995,9 & 21000 & 172,27 & 2,21 & 37808 & 38140 & 22 & 2,21 & 37831 & 38162 \\
\hline 58 & 999 & 7168,1 & 21000 & 172,26 & 2,25 & 38472 & 38822 & 21 & 2,25 & 38493 & 38842 \\
\hline 59 & 963 & 7340,4 & 21000 & 172,27 & 2,29 & 39172 & 39541 & 19 & 2,30 & 39191 & 39560 \\
\hline 60 & 930 & 7512,7 & 21000 & 172,27 & 2,34 & 39911 & 40303 & 17 & 2,34 & 39929 & 40320 \\
\hline 61 & 897 & 7684,9 & 21000 & 172,26 & 2,39 & 40696 & 41118 & 14 & 2,39 & 40711 & 41132 \\
\hline 62 & 860 & 7857,2 & 21000 & 172,27 & 2,44 & 41539 & 41994 & 11 & 2,44 & 41552 & 42005 \\
\hline 63 & 829 & 8029,5 & 21000 & 172,27 & 2,49 & 42448 & 42945 & 7 & 2,49 & 42458 & 42953 \\
\hline
\end{tabular}


Tabela B-3 (2)

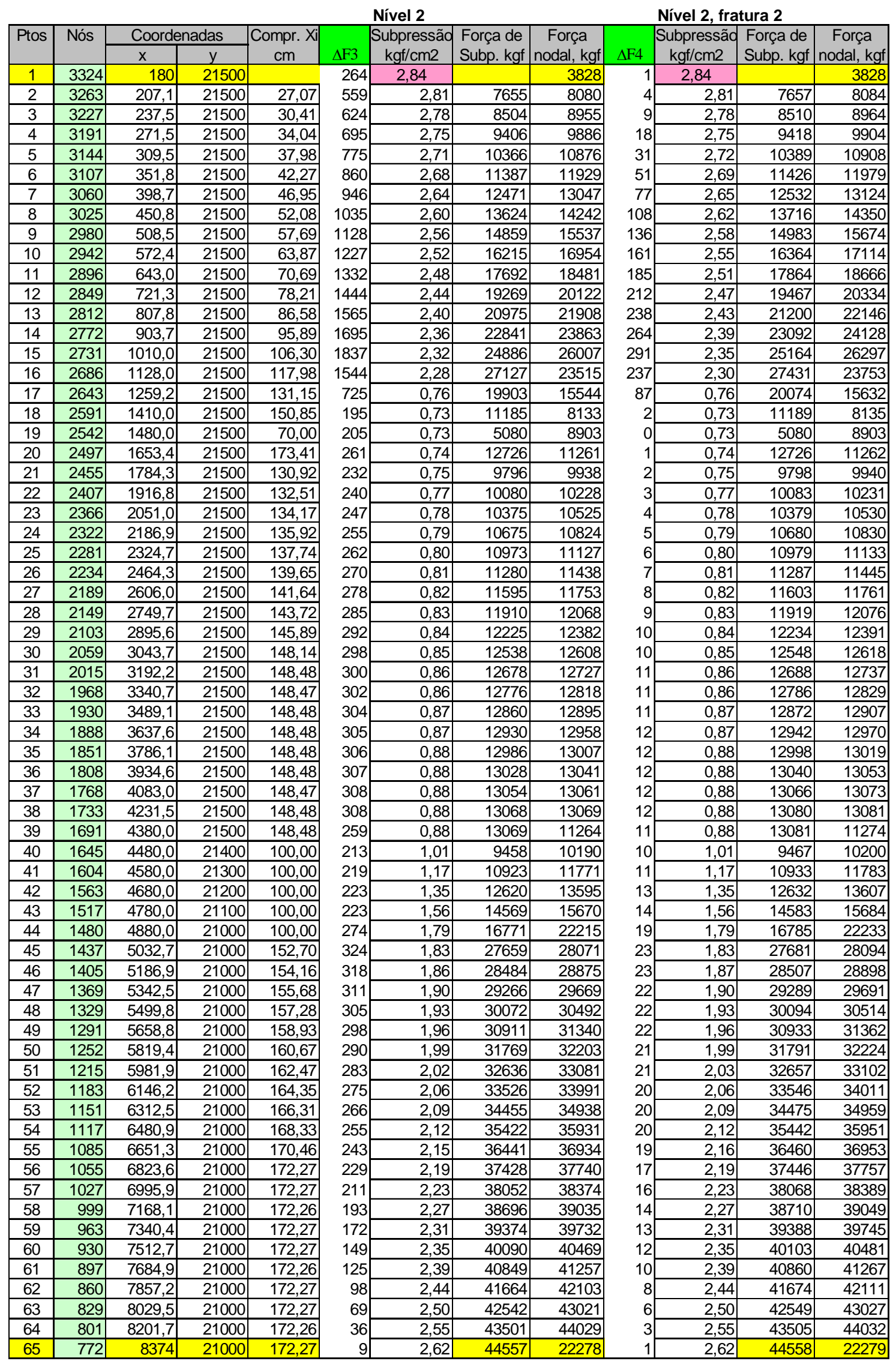


Tabela B-3 (3)

\begin{tabular}{|c|c|c|c|c|c|c|c|c|c|c|c|c|}
\hline \multirow{3}{*}{ Ptos } & & & & & & \multicolumn{4}{|c|}{ Nível 3, fratura 2} & \multicolumn{3}{|c|}{ Nível 3, fratura 3} \\
\hline & \multirow[t]{2}{*}{ Nós } & \multicolumn{2}{|c|}{ Coordenadas } & \multirow{2}{*}{$\begin{array}{c}\text { Compr. Xi } \\
\mathrm{cm}\end{array}$} & \multirow[b]{2}{*}{$\Delta \mathrm{F} 5$} & Subpressão & Força de & Força & & Subpressãd & Força de & Força \\
\hline & & $\mathrm{x}$ & $y$ & & & kgf/cm2 & Subp. kgf & nodal, kgf & $\Delta \mathrm{F} 6$ & $\mathrm{kgf} / \mathrm{cm} 2$ & Subp. kgf & nodal, kgf \\
\hline 1 & 3324 & 180 & 21500 & & 395 & 3,14 & & 4224 & 0 & 3,14 & & 4224 \\
\hline 2 & 3263 & 207,1 & 21500 & 27,07 & 834 & 3,10 & 8448 & 8917 & 1 & 3,10 & 8448 & 8919 \\
\hline 3 & 3227 & 237,5 & 21500 & 30,41 & 922 & 3,07 & 9387 & 9886 & 3 & 3,07 & 9389 & 9889 \\
\hline 4 & 3191 & 271,5 & 21500 & 34,04 & 1016 & 3,03 & 10385 & 10920 & 4 & 3,03 & 10389 & 10924 \\
\hline 5 & 3144 & 309,5 & 21500 & 37,98 & 1116 & 3,00 & 11454 & 12024 & 6 & 3,00 & 11459 & 12030 \\
\hline 6 & 3107 & 351,8 & 21500 & 42,27 & 1223 & 2,96 & 12594 & 13202 & 12 & 2,96 & 12602 & 13214 \\
\hline 7 & 3060 & 398,7 & 21500 & 46,95 & 1338 & 2,92 & 13811 & 14463 & 24 & 2,93 & 13827 & 14486 \\
\hline 8 & 3025 & 450,8 & 21500 & 52,08 & 1462 & 2,88 & 15115 & 15812 & 43 & 2,89 & 15146 & 15854 \\
\hline 9 & 2980 & 508,5 & 21500 & 57,69 & 1594 & 2,84 & 16509 & 17268 & 69 & 2,85 & 16563 & 17337 \\
\hline 10 & 2942 & 572,4 & 21500 & 63,87 & 1736 & 2,80 & 18027 & 18850 & 100 & 2,82 & 18110 & 18950 \\
\hline 11 & 2896 & 643,0 & 21500 & 70,69 & 1887 & 2,76 & 19674 & 20553 & 135 & 2,78 & 19790 & 20688 \\
\hline 12 & 2849 & 721,3 & 21500 & 78,21 & 2048 & 2,72 & 21432 & 22381 & 175 & 2,74 & 21587 & 22557 \\
\hline 13 & 2812 & 807,8 & 21500 & 86,58 & 2221 & 2,67 & 23331 & 24367 & 216 & 2,70 & 23527 & 24583 \\
\hline 14 & 2772 & $\begin{array}{l}903,7 \\
\end{array}$ & 21500 & 95,89 & 2408 & 2,63 & \begin{tabular}{|l|}
25403 \\
\end{tabular} & 26536 & 254 & 2,65 & 25638 & 26790 \\
\hline 15 & 2731 & 1010,0 & 21500 & 106,30 & 2611 & 2,58 & 27669 & 28908 & 289 & 2,61 & 27941 & 29197 \\
\hline 16 & 2686 & 1128,0 & 21500 & 117,98 & 2200 & 2,53 & 30147 & 25953 & 239 & 2,56 & 30452 & 26192 \\
\hline 17 & 2643 & 1259,2 & 21500 & 131,15 & 1050 & 0,79 & 21759 & 16682 & 89 & 0,79 & 21932 & 16770 \\
\hline 18 & 2591 & 1410,0 & 21500 & 150,85 & 297 & 0,75 & 11604 & 8431 & 2 & 0,75 & 11609 & 8434 \\
\hline 19 & 2542 & 1480,0 & 21500 & 70,00 & 314 & 0,75 & 5259 & 9217 & 1 & 0,75 & 5259 & 9218 \\
\hline 20 & 2497 & 1653,4 & 21500 & 173,41 & 398 & 0,77 & 13175 & 11660 & 3 & 0,77 & 13177 & 11664 \\
\hline 21 & 2455 & 1784,3 & 21500 & 130,92 & 353 & \begin{tabular}{l|l}
0,78 \\
\end{tabular} & 10145 & 10294 & 5 & 0,78 & 10150 & 10299 \\
\hline 22 & 2407 & 1916,8 & 21500 & 132,51 & 365 & 0,79 & 10442 & 10596 & 8 & 0,80 & 10449 & 10604 \\
\hline 23 & 2366 & 2051,0 & 21500 & 134,17 & 376 & 0,81 & 10749 & 10906 & 10 & 0,81 & 10758 & 10916 \\
\hline 24 & 2322 & 2186,9 & 21500 & 135,92 & 388 & 0,82 & 11062 & 11217 & 12 & 0,82 & 11074 & 11230 \\
\hline 25 & 2281 & 2324,7 & 21500 & 137,74 & 399 & 0,83 & 11372 & 11532 & 14 & 0,83 & 11386 & 11546 \\
\hline 26 & 2234 & 2464,3 & 21500 & 139,65 & 410 & 0,84 & 11691 & 11855 & 17 & \begin{tabular}{l|l|}
0,84 \\
\end{tabular} & 11707 & 11871 \\
\hline 27 & 2189 & 2606,0 & 21500 & 141,64 & 421 & $\begin{array}{ll}0,85 \\
\end{array}$ & 12018 & 12182 & 19 & $\begin{array}{l}0,86 \\
\end{array}$ & 12036 & 12201 \\
\hline 28 & 2149 & 2749,7 & 21500 & 143,72 & 432 & 0,86 & 12345 & 12509 & 21 & 0,87 & 12365 & 12529 \\
\hline 29 & 2103 & 2895,6 & 21500 & 145,89 & 443 & 0,87 & 12672 & 12834 & 22 & 0,87 & 12693 & 12857 \\
\hline 30 & 2059 & 3043,7 & 21500 & 148,14 & 451 & 0,88 & 12997 & 13069 & 24 & 0,88 & 13020 & 13093 \\
\hline 31 & 2015 & 3192,2 & 21500 & 148,48 & 454 & 0,89 & 13141 & 13192 & 25 & 0,89 & 13166 & 13217 \\
\hline 32 & 1968 & 3340,7 & 21500 & 148,47 & 457 & 0,90 & 13242 & 13286 & 26 & 0,90 & 13268 & 13312 \\
\hline 33 & 1930 & 3489,1 & 21500 & 148,48 & 459 & 0,90 & 13330 & 13366 & 27 & 0,90 & 13356 & 13393 \\
\hline 34 & 1888 & 3637,6 & 21500 & 148,48 & 461 & 0,90 & 13402 & 13431 & 27 & 0,91 & 13429 & 13459 \\
\hline 35 & 1851 & 3786,1 & 21500 & 148,48 & 463 & 0,91 & 13460 & 13482 & 28 & 0,91 & 13488 & 13510 \\
\hline 36 & 1808 & 3934,6 & 21500 & 148,48 & 464 & \begin{tabular}{|l|}
0,91 \\
\end{tabular} & 13503 & 13517 & 28 & 0,91 & 13531 & 13545 \\
\hline 37 & 1768 & 4083,0 & 21500 & 148,47 & 465 & 0,91 & 13530 & 13538 & 29 & \begin{tabular}{|l|l|}
0,91 \\
\end{tabular} & 13559 & 13566 \\
\hline 38 & 1733 & 4231,5 & 21500 & 148,48 & 465 & \begin{tabular}{|l|}
0,91 \\
\end{tabular} & 13546 & 13546 & 29 & \begin{tabular}{l|}
0,91 \\
\end{tabular} & 13574 & 13575 \\
\hline 39 & 1691 & 4380,0 & 21500 & 8,48 & 391 & 0,91 & 13547 & & 25 & \begin{tabular}{|l|}
0,91 \\
\end{tabular} & 13576 & 1690 \\
\hline 40 & 1645 & 4480,0 & 21400 & 100,00 & 321 & 1,04 & 9784 & 10521 & 22 & 1,05 & 9805 & 10543 \\
\hline 41 & 1604 & 4580,0 & 21300 & 00,00 & 330 & 1,21 & 11258 & 12112 & 26 & 1,21 & 11282 & 12138 \\
\hline 42 & 1563 & 4680,0 & 21200 & 100,00 & 335 & 1,39 & 12966 & 13943 & 31 & 1,39 & 12995 & 13973 \\
\hline 43 & 1517 & 4780,0 & 21100 & 100,00 & 333 & 1,60 & 14919 & & 35 & 1,60 & 14952 & 16052 \\
\hline 44 & 1480 & 4880,0 & 21000 & 0,00 & 409 & 1,83 & 17115 & 22643 & 45 & $\begin{array}{ll}1,83 \\
\end{array}$ & 7151 & 22688 \\
\hline 45 & 1437 & 5032,7 & 21000 & 152,70 & 484 & 1,86 & 28170 & 28578 & 54 & 1,87 & 28225 & 28632 \\
\hline 46 & 1405 & 5186,9 & 21000 & 54,16 & 474 & 1,90 & 28986 & 29372 & 54 & 1,90 & 29040 & 29426 \\
\hline 47 & 1369 & 5342,5 & 21000 & 155,68 & 466 & 1,93 & 29759 & 30157 & 53 & 1,93 & 29813 & 30210 \\
\hline 48 & 1329 & 5499,8 & 21000 & 157,28 & 456 & 1,96 & 30556 & 30970 & 53 & 1,96 & 30608 & 31023 \\
\hline 49 & 1291 & 5658,8 & 21000 & 158,93 & 446 & $\begin{array}{l}1,99 \\
\end{array}$ & 31385 & & 52 & 1,99 & 31437 & 31860 \\
\hline 50 & 1252 & 5819,4 & 21000 & 160,67 & 435 & 2,02 & 32232 & 32660 & 51 & 2,02 & 32284 & 32710 \\
\hline 51 & 1215 & 5981,9 & 21000 & 62,47 & 424 & 2,05 & 33087 & 33525 & 50 & 2,05 & 33137 & 33575 \\
\hline 52 & 1183 & 6146,2 & 21000 & 164,35 & 411 & 2,08 & 33964 & 34422 & 48 & 2,08 & 34013 & 34470 \\
\hline 53 & 1151 & 6312,5 & 21000 & 166,31 & 396 & 2,11 & 34879 & 35355 & 47 & \begin{tabular}{|l|}
2,12 \\
\end{tabular} & 34927 & 35402 \\
\hline 54 & 1117 & 6480,9 & 21000 & 168,33 & 381 & 2,14 & 35831 & 36332 & 46 & 2,15 & 35877 & 36377 \\
\hline 55 & 1085 & 6651,3 & 21000 & 170,46 & 363 & 2,18 & 36833 & \begin{tabular}{|l|l|}
37316 \\
\end{tabular} & 44 & \begin{tabular}{|l|}
2,18 \\
\end{tabular} & 36878 & 37361 \\
\hline 56 & 1055 & 6823,6 & 21000 & 172,27 & 342 & 2,21 & 37800 & & 41 & 2,21 & 37843 & 38140 \\
\hline 57 & 1027 & 6995,9 & 21000 & 72,27 & 317 & 2,25 & 38398 & 38706 & 38 & 2,25 & 38438 & 38744 \\
\hline 58 & 999 & 7168,1 & 21000 & 172,26 & 288 & 2,28 & 39013 & 39337 & 35 & \begin{tabular}{|l|}
2,29 \\
\end{tabular} & 39050 & 39372 \\
\hline 59 & 963 & 7340,4 & 21000 & 172,27 & 257 & 2,32 & 39661 & 40002 & 32 & 2,32 & 39694 & 40034 \\
\hline 60 & 930 & 7512,7 & 21000 & 172,27 & 223 & 2,36 & 40343 & 40704 & 28 & 2,36 & 40373 & 40732 \\
\hline 61 & 897 & 7684,9 & 21000 & 172,26 & 187 & 2,41 & 41066 & 41454 & 23 & 2,41 & 41091 & 41477 \\
\hline 62 & 860 & 7857,2 & 21000 & 172,27 & 147 & 2,45 & 41842 & 42259 & 18 & 2,45 & 41862 & 42277 \\
\hline 63 & 829 & 8029,5 & 21000 & 172,27 & 103 & 2,50 & 42676 & 43130 & 12 & 2,50 & 42691 & 43143 \\
\hline 64 & 801 & 8201,7 & 21000 & 172,26 & 54 & 2,56 & 43585 & 44086 & 6 & 2,56 & 43595 & 44092 \\
\hline 65 & 772 & 8374 & 21000 & 172,27 & 14 & 2,62 & 44586 & 22293 & 2 & 2,62 & 44590 & 22295 \\
\hline
\end{tabular}


Tabela B-3 (4)

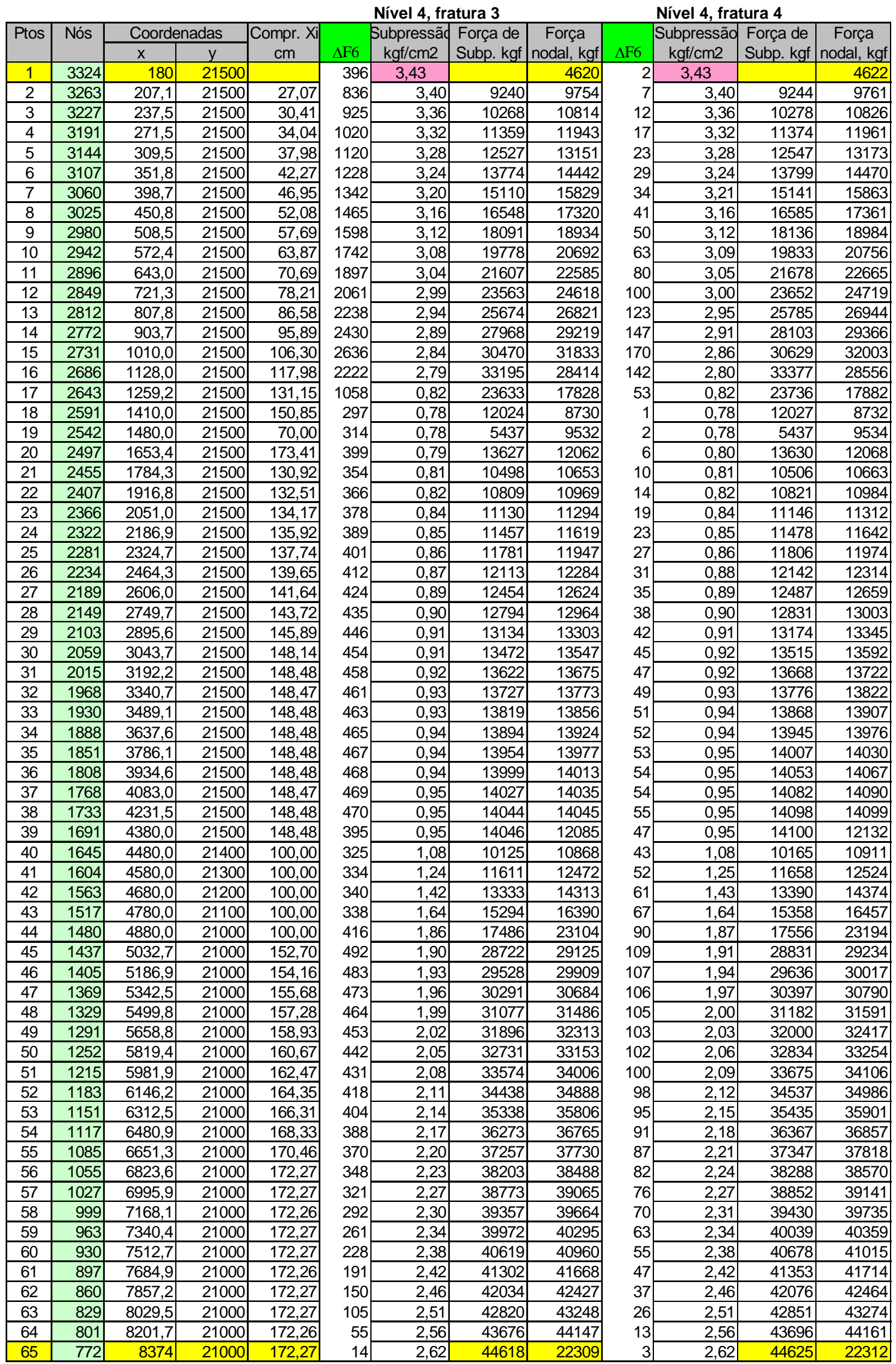


Tabela B-3 (5)

\begin{tabular}{|c|c|c|c|c|c|c|c|c|c|c|c|c|}
\hline \multirow{3}{*}{ Ptos } & \multirow{3}{*}{ Nós } & \multirow{2}{*}{\multicolumn{2}{|c|}{ Coordenadas }} & \multirow{3}{*}{$\begin{array}{c}\text { Compr. Xi } \\
\mathrm{cm}\end{array}$} & \multicolumn{4}{|c|}{ Nível 5, fratura 4} & \multicolumn{4}{|c|}{ Nível 5, fratura 5} \\
\hline & & & & & & Subpressão & Força de & Força & & Subpressãd & Força de & Força \\
\hline & & $\mathrm{x}$ & $\mathrm{y}$ & & $\Delta \mathrm{F} 6$ & $\mathrm{kgf} / \mathrm{cm} 2$ & Subp. kgf & nodal, kgf & $\Delta \mathrm{F} 6$ & $\mathrm{kgf} / \mathrm{cm} 2$ & Subp. kgf & nodal, kgf \\
\hline 1 & 3324 & 180 & 21500 & & 397 & 3,73 & & \begin{tabular}{|r|}
5019 \\
\end{tabular} & 3 & 3,73 & & 5021 \\
\hline 2 & 3263 & 207,1 & 21500 & 27,07 & 838 & 3,69 & 10037 & 10599 & 9 & 3,69 & 10042 & 10608 \\
\hline 3 & 3227 & 237,5 & 21500 & 30,41 & 929 & 3,65 & 11160 & 11755 & 17 & 3,65 & 11174 & 11773 \\
\hline 4 & 3191 & 271,5 & 21500 & 34,04 & 1026 & 3,61 & 12350 & 12987 & 25 & 3,61 & 12371 & 13011 \\
\hline 5 & 3144 & 309,5 & 21500 & 37,98 & 1129 & 3,57 & 13623 & 14302 & 33 & 3,57 & 13652 & 14335 \\
\hline 6 & 3107 & 351,8 & 21500 & 42,27 & 1239 & 3,52 & 14982 & 15709 & 43 & 3,53 & 15019 & 15752 \\
\hline 7 & 3060 & 398,7 & 21500 & 46,95 & 1357 & 3,48 & 16437 & 17220 & 56 & 3,49 & 16486 & 17277 \\
\hline 8 & 3025 & 450,8 & 21500 & 52,08 & 1484 & 3,43 & 18004 & 18844 & 74 & 3,45 & 18068 & 18918 \\
\hline 9 & 2980 & 508,5 & 21500 & 57,69 & 1621 & 3,39 & 19685 & 20605 & 94 & 3,41 & 19768 & 20699 \\
\hline 10 & 2942 & 572,4 & 21500 & 63,87 & 1769 & 3,35 & 21525 & 22525 & 117 & 3,37 & 21630 & 22642 \\
\hline 11 & 2896 & 643,0 & 21500 & 70,69 & 1929 & 3,31 & 23525 & 24594 & 143 & 3,33 & 23654 & 24737 \\
\hline 12 & 2849 & 721,3 & 21500 & 78,21 & 2100 & 3,26 & 25664 & 26819 & 173 & 3,28 & 25821 & 26992 \\
\hline 13 & 2812 & 807,8 & 21500 & 86,58 & 2285 & 3,21 & 27974 & 29229 & 204 & 3,23 & 28162 & 29434 \\
\hline 14 & 2772 & 903,7 & 21500 & 95,89 & 2485 & 3,15 & 30484 & 31851 & 237 & 3,18 & 30705 & 32088 \\
\hline 15 & 2731 & 1010,0 & 21500 & 106,30 & 2699 & 3,10 & 33218 & 34702 & 268 & 3,12 & 33470 & 34970 \\
\hline 16 & 2686 & 1128,0 & 21500 & 117,98 & 2274 & 3,04 & 36187 & 30831 & 222 & 3,06 & 36469 & 31052 \\
\hline 17 & 2643 & 1259,2 & 21500 & 131,15 & 1077 & 0,85 & 25475 & 18959 & 82 & 0,85 & 25635 & 19041 \\
\hline 18 & 2591 & 1410,0 & 21500 & 150,85 & 297 & 0,80 & 12443 & 9029 & 2 & 0,80 & 12448 & 9032 \\
\hline 19 & 2542 & 1480,0 & 21500 & 70,00 & 315 & 0,80 & 5615 & 9848 & 3 & 0,80 & 5615 & 9852 \\
\hline 20 & 2497 & 1653,4 & 21500 & 173,41 & 402 & 0,82 & 14081 & 12470 & 11 & 0,82 & 14088 & 12481 \\
\hline 21 & 2455 & 1784,3 & 21500 & 130,92 & 359 & 0,84 & 10858 & 11023 & 19 & 0,84 & 10873 & 11042 \\
\hline 22 & 2407 & 1916,8 & 21500 & 132,51 & 374 & 0,85 & 11187 & 11357 & 28 & 0,85 & 11211 & 11385 \\
\hline 23 & 2366 & 2051,0 & 21500 & 134,17 & 388 & $\begin{array}{ll}0,87 \\
\end{array}$ & 11527 & 11700 & 37 & 0,87 & 11560 & 11737 \\
\hline 24 & 2322 & 2186,9 & 21500 & 135,92 & 402 & 0,88 & 11874 & 12044 & 46 & 0,88 & 11915 & 12090 \\
\hline 25 & 2281 & 2324,7 & 21500 & 137,74 & 416 & 0,89 & 12215 & 12390 & 54 & 0,90 & 12265 & 12444 \\
\hline 26 & 2234 & 2464,3 & 21500 & 139,65 & 430 & 0,91 & 12565 & 12744 & 62 & 0,91 & 12623 & 12807 \\
\hline 27 & 2189 & 2606,0 & 21500 & 141,64 & 444 & 0,92 & 12924 & 13103 & 70 & 0,92 & 12990 & 13173 \\
\hline 28 & 2149 & 2749,7 & 21500 & 143,72 & 457 & 0,93 & 13281 & 13460 & 78 & 0,94 & 13356 & 13538 \\
\hline 29 & 2103 & 2895,6 & 21500 & 145,89 & 470 & 0,94 & 13638 & 13815 & 85 & 0,95 & 13719 & 13900 \\
\hline 30 & 2059 & 3043,7 & 21500 & 148,14 & 480 & 0,95 & 13992 & 14072 & 91 & 0,96 & 14081 & 14163 \\
\hline 31 & 2015 & 3192,2 & 21500 & 148,48 & 485 & 0,96 & 14151 & 14207 & 96 & 0,96 & 14245 & 14303 \\
\hline 32 & 1968 & 3340,7 & 21500 & 148,47 & 489 & 0,96 & 14263 & 14311 & 100 & 0,97 & 14361 & 14411 \\
\hline 33 & 1930 & 3489,1 & 21500 & 148,48 & 492 & 0,97 & 14359 & 14399 & 103 & 0,98 & 14461 & 14503 \\
\hline 34 & 1888 & 3637,6 & 21500 & 148,48 & 495 & 0,97 & 14439 & 14471 & 106 & 0,98 & 14544 & 14577 \\
\hline 35 & 1851 & 3786,1 & 21500 & 148,48 & 497 & 0,98 & 14503 & 14527 & 108 & 0,99 & 14610 & 14635 \\
\hline 36 & 1808 & 3934,6 & 21500 & 148,48 & 499 & 0,98 & 14551 & 14566 & 110 & 0,99 & 14660 & 14676 \\
\hline 37 & 1768 & 4083,0 & 21500 & 148,47 & 500 & 0,98 & 14581 & 14590 & 111 & 0,99 & 14692 & 14701 \\
\hline 38 & 1733 & 4231,5 & 21500 & 148,48 & 501 & 0,98 & 14599 & 14600 & 112 & 0,99 & 14710 & 14712 \\
\hline 39 & 1691 & 4380,0 & 21500 & 148,48 & 422 & 0,98 & 14601 & 12554 & 96 & 0,99 & 14713 & 12651 \\
\hline 40 & 1645 & 4480,0 & 21400 & 100,00 & 349 & 1,12 & 10507 & 11260 & 89 & 1,13 & 10588 & 11349 \\
\hline 41 & 1604 & 4580,0 & 21300 & 100,00 & 363 & 1,28 & 12014 & 12887 & 107 & 1,30 & 12111 & 12994 \\
\hline 42 & 1563 & 4680,0 & 21200 & 100,00 & 374 & 1,47 & 13760 & 14748 & 127 & 1,48 & 13877 & 14875 \\
\hline 43 & 1517 & 4780,0 & 21100 & 100,00 & 377 & 1,68 & 15737 & 16834 & 142 & 1,69 & 15872 & 16977 \\
\hline 44 & 1480 & 4880,0 & 21000 & 100,00 & 468 & 1,91 & 17932 & 23662 & 192 & 1,92 & 18081 & 23854 \\
\hline 45 & 1437 & 5032,7 & 21000 & 152,70 & 555 & 1,94 & 29392 & 29789 & 234 & 1,96 & 29626 & 30022 \\
\hline 46 & 1405 & 5186,9 & 21000 & 154,16 & 546 & 1,97 & 30186 & 30562 & 232 & 1,99 & 30419 & 30794 \\
\hline 47 & 1369 & 5342,5 & 21000 & 155,68 & 536 & 2,00 & 30938 & 31326 & 230 & 2,02 & 31169 & 31556 \\
\hline 48 & 1329 & 5499,8 & 21000 & 157,28 & 526 & 2,03 & 31714 & 32117 & 227 & 2,05 & 31942 & 32344 \\
\hline 49 & 1291 & 5658,8 & 21000 & 158,93 & 515 & 2,06 & 32520 & 32931 & 224 & 2,07 & 32746 & 33155 \\
\hline 50 & 1252 & 5819,4 & 21000 & 160,67 & 502 & 2,09 & 33342 & 33756 & 221 & 2,10 & 33565 & 33977 \\
\hline 51 & 1215 & 5981,9 & 21000 & 162,47 & 489 & 2,12 & 34171 & 34595 & 217 & 2,13 & 34389 & 34811 \\
\hline 52 & 1183 & 6146,2 & 21000 & 164,35 & 475 & 2,14 & 35019 & 35461 & 212 & 2,16 & 35233 & 35673 \\
\hline 53 & 1151 & 6312,5 & 21000 & 166,31 & 460 & 2,17 & 35903 & 36361 & 205 & 2,19 & 36112 & 36566 \\
\hline 54 & 1117 & 6480,9 & 21000 & 168,33 & 442 & 2,20 & 36819 & 37299 & 199 & 2,21 & 37021 & 37498 \\
\hline 55 & 1085 & 6651,3 & 21000 & 170,46 & 421 & 2,23 & 37780 & 38239 & 191 & 2,24 & 37975 & 38430 \\
\hline 56 & 1055 & 6823,6 & 21000 & 172,27 & 396 & 2,26 & 38698 & 38966 & 181 & 2,27 & 38885 & 39147 \\
\hline 57 & 1027 & 6995,9 & 21000 & 172,27 & 366 & 2,29 & 39234 & 39507 & 168 & 2,30 & 39408 & 39675 \\
\hline 58 & 999 & 7168,1 & 21000 & 172,26 & 333 & 2,33 & 39781 & 40068 & 154 & 2,33 & 39942 & 40222 \\
\hline 59 & 963 & 7340,4 & 21000 & 172,27 & 298 & 2,36 & 40355 & 40656 & 138 & 2,37 & 40502 & 40794 \\
\hline 60 & 930 & 7512,7 & 21000 & 172,27 & 259 & 2,40 & 40957 & 41275 & 121 & 2,40 & 41087 & 41395 \\
\hline 61 & 897 & 7684,9 & 21000 & 172,26 & 217 & 2,43 & 41592 & 41932 & 101 & 2,44 & 41703 & 42033 \\
\hline 62 & 860 & 7857,2 & 21000 & 172,27 & 171 & 2,47 & 42272 & 42635 & 80 & 2,48 & 42363 & 42715 \\
\hline 63 & 829 & 8029,5 & 21000 & 172,27 & 120 & 2,52 & 42999 & 43394 & 56 & 2,52 & 43068 & 43450 \\
\hline 64 & 801 & 8201,7 & 21000 & 172,26 & 62 & 2,57 & 43789 & 44223 & 29 & 2,57 & 43832 & 44252 \\
\hline 65 & 772 & 8374 & 21000 & 172,27 & 16 & 2,62 & 44657 & 22328 & 7 & 2,62 & 44671 & 22336 \\
\hline
\end{tabular}


Tabela B-3 (6)

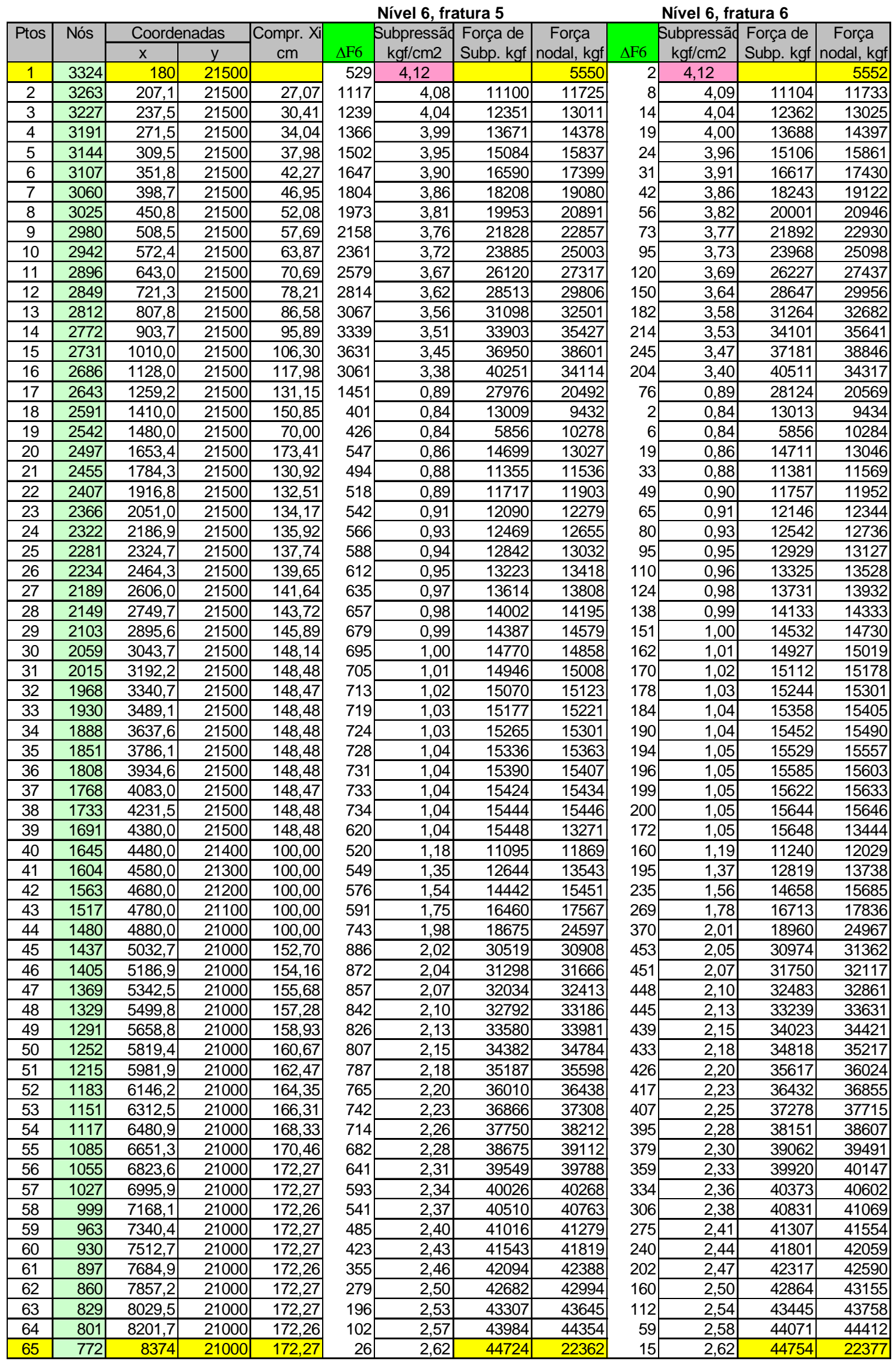


Tabela B-4 (1)

Subpressão da casa de força - PPcf12p

\begin{tabular}{|c|c|c|c|c|}
\hline \multirow{2}{*}{ Nível de água } & $\mathrm{Hm}$ & Sd & $\mathrm{Hj}$ & \multirow{2}{*}{ Observ. } \\
\hline & \multicolumn{3}{|c|}{$\mathrm{kgf} / \mathrm{cm}^{2}$} & \\
\hline h1: $242 \mathrm{~m}$ & 2,16 & & 2,56 & \\
\hline h2: 244 m & 2,35 & & 2,56 & Fratura \\
\hline h3: 247 m & 2,65 & & 2,56 & Fratura \\
\hline h4: $250 \mathrm{~m}$ & 2,94 & & 2,56 & Fratura \\
\hline h5: $253 \mathrm{~m}$ & 3,24 & & 2,56 & Fratura \\
\hline h6: $257 \mathrm{~m}$ & 3,63 & & 2,56 & Fratura \\
\hline
\end{tabular}

Nível 1

\begin{tabular}{|c|c|c|c|c|c|c|c|c|c|c|c|}
\hline \multirow[t]{2}{*}{ Ptos } & \multirow[t]{2}{*}{ Omega } & \multicolumn{2}{|c|}{ Coordenadas } & \multirow{2}{*}{$\begin{array}{c}\text { Compr. Xi } \\
\mathrm{cm}\end{array}$} & \multirow{2}{*}{$\begin{array}{c}\text { Subpressão } \\
\text { kgf/cm2 }\end{array}$} & \multirow{2}{*}{$\begin{array}{l}\text { Força de } \\
\text { Subp. kgf }\end{array}$} & \multirow{2}{*}{$\begin{array}{l}\text { Força } \\
\text { nodal, }\end{array}$} & \multirow[b]{2}{*}{$\Delta \mathrm{F} 1$} & \multirow{2}{*}{$\begin{array}{c}\text { Subpressão } \\
\mathrm{kgf} / \mathrm{cm} 2\end{array}$} & \multirow{2}{*}{\begin{tabular}{|l|} 
Força de \\
Subp. kgf \\
\end{tabular}} & Força \\
\hline & & $\mathrm{x}$ & $\mathrm{y}$ & & & & & & & & nodal, \\
\hline 1 & 3188 & 180 & 22000 & & $\begin{array}{r}2,16 \\
\end{array}$ & & 1664 & 8 & 2,16 & & 1672 \\
\hline 2 & 3153 & 195,5 & 22000 & 15,51 & 2,13 & 3328 & 3445 & 27 & 2,15 & 3344 & 3472 \\
\hline 3 & 3128 & 212,3 & 22000 & 16,75 & 2,12 & 3562 & 3689 & 45 & 2,15 & 3601 & 3735 \\
\hline 4 & 3102 & 230,3 & 22000 & 18,05 & 2,11 & 3816 & 3949 & 60 & 2,14 & 3868 & 4009 \\
\hline 5 & 3078 & 249,7 & 22000 & 19,43 & 2,09 & 4082 & 4221 & 77 & 2,13 & 4150 & 4298 \\
\hline 6 & 3045 & 270,6 & 22000 & 20,89 & 2,08 & 4361 & 4510 & 95 & 2,12 & 4447 & 4604 \\
\hline 7 & 3016 & 293,1 & 22000 & 22,45 & 2,07 & 4658 & 4816 & 113 & 2,12 & 4762 & 4929 \\
\hline 8 & 2985 & 317,2 & 22000 & 24,10 & 2,06 & 4974 & 5141 & 132 & 2,11 & 5096 & 5273 \\
\hline 9 & 2962 & 343,0 & 22000 & 25,86 & 2,05 & 5309 & 5488 & 151 & 2,10 & 5451 & 5638 \\
\hline 10 & 2935 & 370,8 & 22000 & 27,73 & 2,04 & 5667 & 5857 & 169 & 2,10 & 5826 & 6026 \\
\hline 11 & 2903 & 400,5 & 22000 & 29,73 & 2,03 & 6047 & 6250 & 189 & 2,09 & 6226 & 6439 \\
\hline 12 & 2870 & 432,4 & 22000 & 31,87 & 2,02 & 6453 & 6670 & 209 & 2,08 & 6652 & 6880 \\
\hline 13 & 2839 & 466,5 & 22000 & 34,16 & 2,01 & 6887 & 7120 & 230 & 2,08 & 7107 & 7350 \\
\hline 14 & 2807 & 503,1 & 22000 & 36,61 & 2,00 & 7353 & 7603 & 252 & 2,07 & 7594 & 7855 \\
\hline 15 & 2779 & 542,4 & 22000 & 39,24 & 2,00 & 7853 & 8119 & 274 & 2,07 & 8116 & 8393 \\
\hline 16 & 2738 & 584,4 & 22000 & 42,06 & 1,99 & 8386 & 8669 & 296 & 2,06 & 8670 & 8965 \\
\hline 17 & 2703 & 629,5 & 22000 & 45,11 & 1,98 & 8953 & 8895 & 309 & 2,05 & 9260 & 9204 \\
\hline 18 & 2660 & 677,9 & 22000 & 48,39 & 1,67 & 8837 & 8424 & 294 & 1,73 & 9148 & 8718 \\
\hline 19 & 2636 & 729,9 & 22000 & 51,94 & 1,41 & 8010 & 7601 & 247 & 1,46 & 8288 & 7849 \\
\hline 20 & 2600 & 785,7 & 22000 & 55,79 & 1,17 & 7193 & 6730 & 177 & 1,20 & 7410 & 6907 \\
\hline 21 & 2550 & 845,3 & 22000 & 59,67 & 0,93 & 6267 & 5613 & 91 & 0,95 & 6404 & 5705 \\
\hline 22 & 2510 & 905,0 & 22000 & 59,67 & 0,73 & 4960 & 4647 & 24 & 0,73 & 5006 & 4671 \\
\hline 23 & 2471 & 964,7 & 22000 & 59,67 & 0,72 & 4335 & 4325 & 1 & 0,73 & 4337 & 4327 \\
\hline 24 & 2434 & 1024,3 & 22000 & 59,67 & 0,72 & 4316 & 4311 & 0 & 0,72 & 4317 & 4312 \\
\hline 25 & 2391 & 1084,0 & 22000 & 59,67 & 0,72 & 4307 & 4197 & 0 & 0,72 & 4307 & 4197 \\
\hline 26 & 2358 & 1140,6 & 22000 & 56,63 & 0,72 & 4087 & 4091 & 0 & 0,72 & 4087 & 4091 \\
\hline 27 & 2327 & 1197,3 & 22000 & 56,63 & 0,72 & 4094 & 4101 & 0 & 0,72 & 4094 & 4101 \\
\hline 28 & 2292 & 1253,9 & 22000 & 56,63 & 0,73 & 4108 & 4114 & 1 & 0,73 & 4108 & 4115 \\
\hline 29 & 2264 & 1310,5 & 22000 & 56,63 & 0,73 & 4120 & 4126 & 1 & 0,73 & 4121 & 4127 \\
\hline 30 & 2239 & 1367,1 & 22000 & 56,63 & 0,73 & 4132 & 4137 & 2 & 0,73 & 4133 & 4139 \\
\hline 31 & 2208 & 1423,8 & 22000 & 56,63 & 0,73 & 4142 & 4147 & 2 & 0,73 & 4144 & 4149 \\
\hline 32 & 2182 & 1480,4 & 22000 & 56,63 & 0,73 & 4152 & & 2 & 0,73 & 4154 & 4159 \\
\hline 33 & 2159 & 1537,0 & 22000 & 56,63 & 0,74 & 4161 & 4426 & 3 & 0,74 & 4164 & 4429 \\
\hline 34 & 2138 & 1600,7 & 22000 & 63,71 & 0,74 & 4692 & 4864 & 4 & 0,74 & 4695 & 4867 \\
\hline 35 & 2116 & 1668,9 & 22000 & 68,23 & 0,74 & 5036 & 5223 & 4 & 0,74 & 5040 & 5227 \\
\hline 36 & 2092 & 1742,1 & 22000 & 73,13 & 0,74 & 5410 & 5613 & 5 & 0,74 & 5414 & 5618 \\
\hline 37 & 2063 & 1820,5 & 22000 & 78,42 & 0,74 & 5816 & 6036 & 6 & 0,74 & 5821 & 6041 \\
\hline 38 & 2039 & 1904,6 & 22000 & 84,16 & 0,74 & 6255 & & 7 & 0,74 & 6262 & 6501 \\
\hline 39 & 2009 & 1995,0 & 22000 & 90,38 & 0,75 & 6732 & 6991 & 8 & 0,75 & 6739 & 6999 \\
\hline 40 & 1985 & 2092,2 & 22000 & 97,15 & 0,75 & 7250 & 7532 & 9 & 0,75 & 7258 & 7541 \\
\hline 41 & 1950 & 2196,7 & 22000 & 104,51 & 0,75 & 7814 & 8122 & 10 & 0,75 & 7824 & 8132 \\
\hline 42 & 1922 & 2309,2 & 22000 & 112,55 & 0,75 & 8431 & 8767 & 11 & 0,75 & 8441 & 8778 \\
\hline 43 & 1891 & 2430,6 & 22000 & 121,34 & 0,75 & 9104 & 9177 & 12 & 0,75 & 9116 & 9189 \\
\hline 44 & 1854 & 2553,7 & 22000 & 23,10 & 0,75 & 9249 & 9254 & 12 & 0,75 & 9262 & 9267 \\
\hline 45 & 1816 & 2676,8 & 22000 & 23,10 & 0,75 & 9259 & 9263 & 13 & 0,75 & 9272 & 9275 \\
\hline 46 & 1789 & 2799,9 & 22000 & 123,10 & 0,75 & 9266 & 9268 & 13 & 0,75 & 9279 & 9281 \\
\hline 47 & 1753 & 2923,0 & 22000 & 123,10 & 0,75 & 9270 & 7061 & 10 & 0,75 & 9283 & 7071 \\
\hline 48 & 1715 & 2983,2 & 21900 & 60,17 & 0,86 & 4852 & 5191 & 9 & 0,86 & 4860 & 5199 \\
\hline 49 & 1674 & 3043,3 & 21800 & 60,17 & 0,98 & 5529 & 5886 & 11 & 0,98 & 5539 & 5898 \\
\hline 50 & 1635 & 3103,5 & 21700 & 60,17 & 1,10 & 6244 & 6604 & 15 & 1,10 & 6257 & 6619 \\
\hline 51 & 1598 & 3163,7 & 21600 & 60,17 & 1,22 & 6964 & 7324 & 18 & 1,22 & 6980 & 7342 \\
\hline 52 & 1552 & 3223,8 & 21500 & 60,17 & 1,34 & 7684 & 8045 & 21 & 1,34 & 7704 & 8066 \\
\hline 53 & 1521 & 3284,0 & 21400 & 60,17 & 1,46 & 8406 & 12548 & 33 & 1,46 & 8428 & 12581 \\
\hline 54 & 1485 & 3398,5 & 21400 & 114,50 & 1,46 & 16690 & 16693 & 45 & 1,46 & 16734 & 16738 \\
\hline 55 & 1455 & 3513,0 & 21400 & 114,50 & 1,46 & 16696 & 12908 & 35 & 1,46 & 16741 & 12943 \\
\hline 56 & 1418 & 3573,1 & 21300 & 60,14 & 1,57 & 9120 & 9470 & 26 & 1,58 & 9145 & 9496 \\
\hline 57 & 1379 & 3633,3 & 21200 & 60,14 & 1,69 & 9820 & 10169 & 28 & 1,70 & 9847 & 10197 \\
\hline 58 & 1347 & 3693,4 & 21100 & 60,14 & 1,81 & 10519 & 10866 & 29 & 1,81 & 10547 & 10895 \\
\hline 59 & 1313 & 3753,6 & 21000 & 60,14 & 1,92 & 11214 & 11561 & 30 & 1,93 & 11244 & 11591 \\
\hline 60 & 1282 & 3813,7 & 20900 & 60,14 & 2,04 & 11907 & 12253 & 32 & 2,04 & 11938 & 12284 \\
\hline 61 & 1248 & 3873,9 & 20800 & 60,14 & 2,15 & 12598 & 12945 & 32 & 2,16 & 12631 & 12977 \\
\hline 62 & 1218 & 3934,0 & 20700 & 60,14 & 2,27 & 13291 & 17871 & 44 & 2,27 & 13324 & 17915 \\
\hline 63 & 1191 & 4033,0 & 20700 & 99,00 & 2,27 & 22452 & 18222 & 44 & 2,27 & 22506 & 18266 \\
\hline
\end{tabular}


Tabela B-4 (2)

\begin{tabular}{|c|c|c|c|c|c|c|c|c|c|c|c|}
\hline 64 & 1162 & 4093,2 & 20600 & 60,17 & 2,38 & 13991 & 14341 & 34 & 2,39 & 14025 & 14374 \\
\hline 65 & 1131 & 4153,3 & 20500 & 60,17 & 2,50 & 14690 & 15059 & 34 & 2,51 & 14724 & 15093 \\
\hline 66 & 1098 & 4213,5 & 20400 & 60,17 & 2,63 & 15428 & 15815 & 34 & 2,63 & 15462 & 15848 \\
\hline 67 & 1071 & 4273,7 & 20300 & 60,17 & 2,76 & 16201 & 16625 & 33 & 2,76 & 16235 & 16658 \\
\hline 68 & 1045 & 4333,8 & 20200 & 60,16 & 2,91 & 17049 & 17561 & 32 & 2,92 & 17082 & 17593 \\
\hline 69 & 1010 & 4394,0 & 20100 & 60,17 & 3,10 & 18073 & 30246 & 48 & 3,10 & 18104 & 30294 \\
\hline 70 & 984 & 4530,4 & 20100 & 136,39 & 3,12 & 42418 & 43961 & 67 & 3,13 & 42484 & 44028 \\
\hline 71 & 947 & 4675,6 & 20100 & 145,16 & 3,15 & 45504 & 47190 & 69 & 3,15 & 45572 & 47259 \\
\hline 72 & 916 & 4830,3 & 20100 & 154,72 & 3,17 & 48876 & 49084 & 68 & 3,18 & 48946 & 49152 \\
\hline 73 & 878 & 4985,0 & 20100 & 154,72 & 3,20 & 49292 & 38465 & 50 & 3,20 & 49358 & 38514 \\
\hline 74 & 870 & 5072,0 & 20188 & 87,00 & 3,15 & 27637 & 27453 & 31 & 3,16 & 27671 & 27484 \\
\hline 75 & 865 & 5159,0 & 20275 & 87,00 & 3,12 & 27269 & 27074 & 26 & 3,12 & 27298 & 27101 \\
\hline 76 & 861 & 5246,0 & 20363 & 87,00 & 3,06 & 26880 & 26624 & 22 & 3,07 & 26903 & 26646 \\
\hline 77 & 857 & 5333,0 & 20450 & 87,00 & 3,00 & 26368 & 34169 & 27 & 3,00 & 26389 & 34195 \\
\hline 78 & 824 & 5473,0 & 20450 & 140,00 & 3,00 & 41969 & 41972 & 32 & 3,00 & 42001 & 42004 \\
\hline 79 & 794 & 5613,0 & 20450 & 140,00 & 3,00 & 41974 & 41981 & 32 & 3,00 & 42006 & 42014 \\
\hline 80 & 768 & 5753,0 & 20450 & 140,00 & 3,00 & 41989 & 42001 & 32 & 3,00 & 42021 & 42033 \\
\hline 81 & 740 & 5893,0 & 20450 & 140,00 & 3,00 & 42013 & 42029 & 32 & 3,00 & 42045 & 42061 \\
\hline 82 & 706 & 6033,0 & 20450 & 140,00 & 3,00 & 42045 & 42065 & 31 & 3,01 & 42076 & 42096 \\
\hline 83 & 680 & 6173,0 & 20450 & 140,00 & 3,01 & 42085 & 42109 & 30 & 3,01 & 42116 & 42139 \\
\hline 84 & 652 & 6313,0 & 20450 & 140,00 & 3,01 & 42132 & 42160 & 30 & 3,01 & 42162 & 42190 \\
\hline 85 & 626 & 6453,0 & 20450 & 140,00 & 3,02 & 42188 & 42219 & 29 & 3,02 & 42217 & 42248 \\
\hline 86 & 602 & 6593,0 & 20450 & 140,00 & 3,02 & 42250 & 42285 & 28 & 3,02 & 42279 & 42313 \\
\hline 87 & 577 & 6733,0 & 20450 & 140,00 & 3,03 & 42319 & 42357 & 27 & 3,03 & 42347 & 42384 \\
\hline 88 & 553 & 6873,0 & 20450 & 140,00 & 3,03 & 42396 & 42437 & 26 & 3,03 & 42422 & 42463 \\
\hline 89 & 529 & 7013,0 & 20450 & 140,00 & 3,04 & 42479 & 42524 & 25 & 3,04 & 42505 & 42550 \\
\hline 90 & 511 & 7153,0 & 20450 & 140,00 & 3,04 & 42570 & 42619 & 23 & 3,05 & 42594 & 42643 \\
\hline 91 & 490 & 7293,0 & 20450 & 140,00 & 3,05 & 42669 & 42722 & 21 & 3,05 & 42691 & 42743 \\
\hline 92 & 468 & 7433,0 & 20450 & 140,00 & 3,06 & 42775 & 42832 & 20 & 3,06 & 42795 & 42852 \\
\hline 93 & 449 & 7573,0 & 20450 & 140,00 & 3,07 & 42890 & 42952 & 18 & 3,07 & 42909 & 42970 \\
\hline 94 & 432 & 7713,0 & 20450 & 140,00 & 3,08 & 43014 & 43081 & 16 & 3,08 & 43031 & 43097 \\
\hline 95 & 417 & 7853,0 & 20450 & 140,00 & 3,09 & 43148 & 43221 & 14 & 3,09 & 43163 & 43235 \\
\hline 96 & 401 & 7993,0 & 20450 & 140,00 & 3,10 & 43294 & 43372 & 13 & 3,10 & 43307 & 43385 \\
\hline 97 & 384 & 8133,0 & 20450 & 140,00 & 3,11 & 43451 & 43529 & 11 & 3,11 & 43463 & 43540 \\
\hline 98 & 369 & 8273,0 & 20450 & 140,00 & 3,12 & 43607 & 43706 & 8 & 3,12 & 43617 & 43714 \\
\hline 99 & 355 & 8413,0 & 20450 & 140,00 & 3,14 & 43804 & 43936 & 4 & 3,14 & 43810 & 43940 \\
\hline 100 & 340 & 8553 & 20450 & 140,00 & 3,16 & 44069 & 22034 & 1 & 3,16 & 44071 & 22035 \\
\hline
\end{tabular}


Tabela B-4 (3)

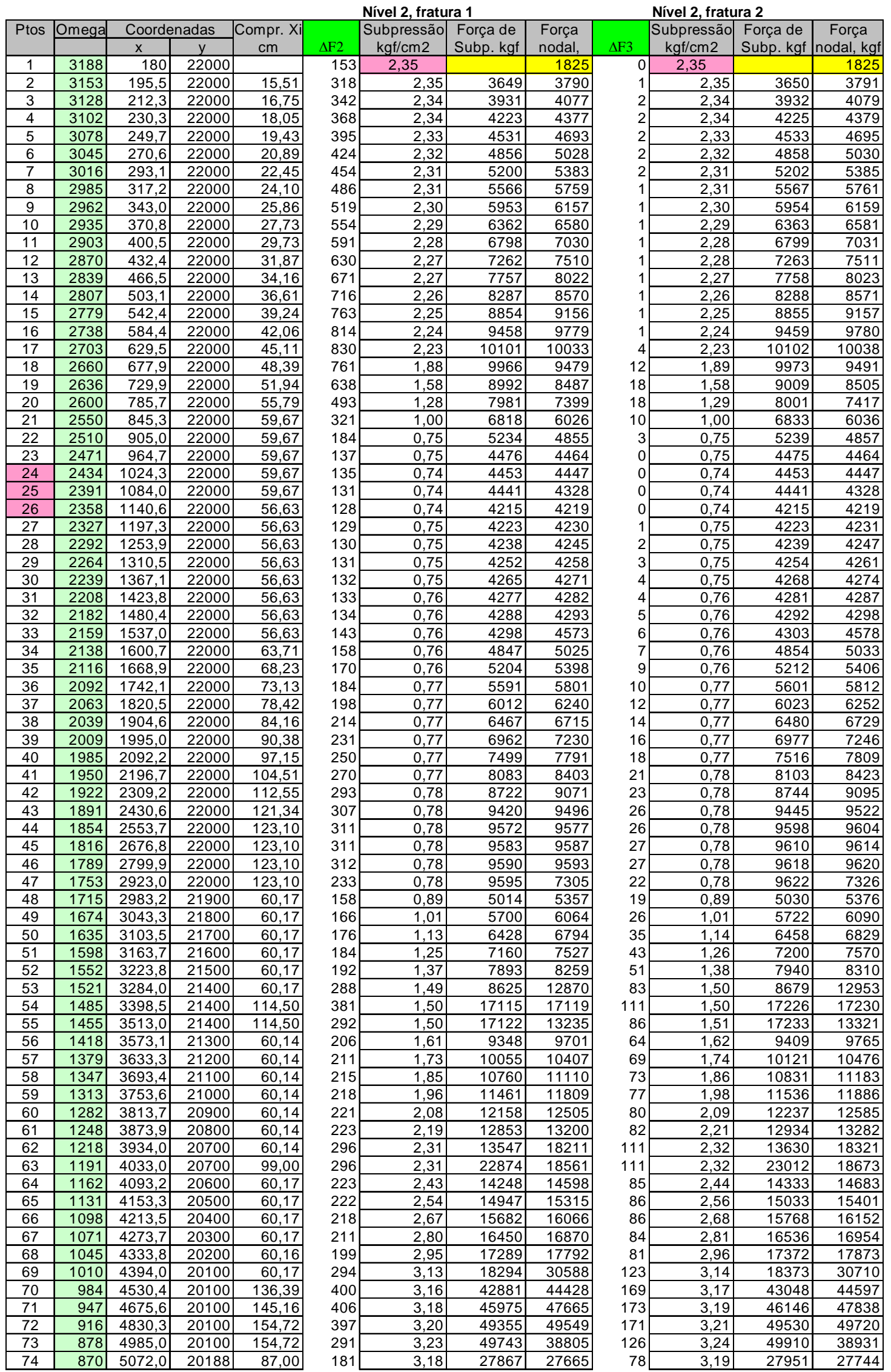


Tabela B-4 (4)

\begin{tabular}{|r|r|r|r|r|}
\hline 75 & 865 & 5159,0 & 20275 & 87,00 \\
\hline 76 & 861 & 5246,0 & 20363 & 87,00 \\
\hline 77 & 857 & 5333,0 & 20450 & 87,00 \\
\hline 78 & 824 & 5473,0 & 20450 & 140,00 \\
\hline 79 & 794 & 5613,0 & 20450 & 140,00 \\
\hline 80 & 768 & 5753,0 & 20450 & 140,00 \\
\hline 81 & 740 & 5893,0 & 20450 & 140,00 \\
\hline 82 & 706 & 6033,0 & 20450 & 140,00 \\
\hline 83 & 680 & 6173,0 & 20450 & 140,00 \\
\hline 84 & 652 & 6313,0 & 20450 & 140,00 \\
\hline 85 & 626 & 6453,0 & 20450 & 140,00 \\
\hline 86 & 602 & 6593,0 & 20450 & 140,00 \\
\hline 87 & 577 & 6733,0 & 20450 & 140,00 \\
\hline 88 & 553 & 6873,0 & 20450 & 140,00 \\
\hline 89 & 529 & 7013,0 & 20450 & 140,00 \\
\hline 90 & 511 & 7153,0 & 20450 & 140,00 \\
\hline 91 & 490 & 7293,0 & 20450 & 140,00 \\
\hline 92 & 468 & 7433,0 & 20450 & 140,00 \\
\hline 93 & 449 & 7573,0 & 20450 & 140,00 \\
\hline 94 & 432 & 7713,0 & 20450 & 140,00 \\
\hline 95 & 417 & 7853,0 & 20450 & 140,00 \\
\hline 96 & 401 & 7993,0 & 20450 & 140,00 \\
\hline 97 & 384 & 8133,0 & 20450 & 140,00 \\
\hline 98 & 369 & 8273,0 & 20450 & 140,00 \\
\hline 99 & 355 & 8413,0 & 20450 & 140,00 \\
\hline 100 & 340 & 8553 & 20450 & 140,00 \\
\hline
\end{tabular}

\begin{tabular}{|c|c|c|c|}
\hline 153 & 3,14 & 27464 & 27254 \\
\hline 131 & 3,08 & 27043 & 26777 \\
\hline 153 & 3,01 & 26510 & 34348 \\
\hline 185 & 3,01 & 42186 & 42189 \\
\hline 184 & 3,01 & 42191 & 42198 \\
\hline 183 & 3,02 & 42205 & 42216 \\
\hline 181 & 3,02 & 42227 & 42242 \\
\hline 179 & 3,02 & 42256 & 42274 \\
\hline 175 & 3,02 & 42293 & 42314 \\
\hline 172 & 3,03 & 42336 & 42361 \\
\hline 167 & 3,03 & 42386 & 42414 \\
\hline 161 & 3,03 & 42442 & 42474 \\
\hline 156 & 3,04 & 42505 & 42540 \\
\hline 149 & 3,04 & 42575 & 42613 \\
\hline 142 & 3,05 & 42650 & 42692 \\
\hline 135 & 3,06 & 42733 & 42777 \\
\hline 127 & 3,06 & 42822 & 42870 \\
\hline 118 & 3,07 & 42918 & 42970 \\
\hline 107 & 3,08 & 43021 & 43077 \\
\hline 97 & 3,09 & 43133 & 43194 \\
\hline 85 & 3,09 & 43254 & 43320 \\
\hline 71 & 3,10 & 43385 & 43456 \\
\hline 57 & 3,11 & 43527 & 43597 \\
\hline 43 & 3,12 & 43667 & 43756 \\
\hline 24 & 3,14 & 43845 & 43964 \\
\hline 6 & 3,16 & 44083 & 22042 \\
\hline
\end{tabular}

\begin{tabular}{|c|c|c|c|}
\hline 66 & 3,14 & 27536 & 27320 \\
\hline 57 & 3,09 & 27104 & 26833 \\
\hline 67 & 3,02 & 26563 & 34415 \\
\hline 81 & 3,02 & 42267 & 42270 \\
\hline 81 & 3,02 & 42272 & 42279 \\
\hline 80 & 3,02 & 42286 & 42296 \\
\hline 79 & 3,02 & 42307 & 42321 \\
\hline 78 & 3,03 & 42335 & 42353 \\
\hline 77 & 3,03 & 42370 & 42391 \\
\hline 75 & 3,03 & 42412 & 42436 \\
\hline 73 & 3,03 & 42460 & 42487 \\
\hline 71 & 3,04 & 42515 & 42545 \\
\hline 69 & 3,04 & 42575 & 42609 \\
\hline 65 & 3,05 & 42642 & 42678 \\
\hline 62 & 3,05 & 42714 & 42754 \\
\hline 59 & 3,06 & 42793 & 42836 \\
\hline 56 & 3,07 & 42879 & 42925 \\
\hline 52 & 3,07 & 42972 & 43021 \\
\hline 47 & 3,08 & 43071 & 43125 \\
\hline 42 & 3,09 & 43178 & 43236 \\
\hline 36 & 3,10 & 43294 & 43356 \\
\hline 31 & 3,11 & 43419 & 43487 \\
\hline 26 & 3,12 & 43555 & 43623 \\
\hline 19 & 3,13 & 43691 & 43775 \\
\hline 10 & 3,14 & 43860 & 43974 \\
\hline 2 & 3,16 & 44088 & 22044 \\
\hline
\end{tabular}


Tabela B-4 (5)

Nível 3, fratura 2

Nível 3, fratura 3

\begin{tabular}{|c|c|c|c|c|c|c|c|c|c|c|c|c|}
\hline \multirow[t]{2}{*}{ Ptos } & \multirow[t]{2}{*}{ Omega } & \multicolumn{2}{|c|}{ Coordenadas } & \multirow{2}{*}{$\begin{array}{c}\text { Compr. Xi } \\
\mathrm{cm}\end{array}$} & \multirow[b]{2}{*}{$\Delta \mathrm{F} 4$} & \multirow{2}{*}{$\begin{array}{c}\text { Subpressão } \\
\mathrm{kgf} / \mathrm{cm} 2\end{array}$} & \multirow{2}{*}{$\begin{array}{l}\text { Força de } \\
\text { Subp. kgf }\end{array}$} & \multirow{2}{*}{\begin{tabular}{c|} 
Força \\
nodal, kgf
\end{tabular}} & \multirow[b]{2}{*}{$\Delta \mathrm{F} 5$} & \multirow{2}{*}{\begin{tabular}{|c|}
$\begin{array}{c}\text { Subpressão } \\
\mathrm{kgf} / \mathrm{cm} 2\end{array}$ \\
\end{tabular}} & \multirow{2}{*}{$\begin{array}{l}\text { Força de } \\
\text { Subp. kgf }\end{array}$} & \multirow{2}{*}{$\begin{array}{c}\text { Força } \\
\text { nodal, kgf }\end{array}$} \\
\hline & & $\mathrm{x}$ & $\mathrm{y}$ & & & & & & & & & \\
\hline 1 & 3188 & 180 & 22000 & & 228 & 2,65 & & 2053 & 0 & 2,65 & & 2053 \\
\hline 2 & 3153 & 195,5 & 22000 & 15,51 & 474 & 2,65 & 4106 & 4265 & 0 & 2,65 & 4107 & 4266 \\
\hline 3 & 3128 & 212,3 & 22000 & 16,75 & 510 & 2,64 & 4424 & 4588 & 0 & 2,64 & 4424 & 4588 \\
\hline 4 & 3102 & 230,3 & 22000 & 18,05 & 546 & 2,63 & 4752 & 4925 & 0 & 2,63 & 4752 & 4925 \\
\hline 5 & 3078 & 249,7 & 22000 & 19,43 & 585 & 2,62 & 5098 & 5280 & -1 & 2,62 & 5097 & 5279 \\
\hline 6 & 3045 & 270,6 & 22000 & 20,89 & 625 & 2,61 & 5462 & 5655 & -2 & 2,61 & 5461 & 5653 \\
\hline 7 & 3016 & 293,1 & 22000 & 22,45 & 668 & 2,60 & 5848 & 6053 & -3 & 2,60 & 5846 & 6051 \\
\hline 8 & 2985 & 317,2 & 22000 & 24,10 & 714 & 2,59 & 6258 & 6475 & -4 & 2,59 & 6255 & 6471 \\
\hline 9 & 2962 & 343,0 & 22000 & 25,86 & 762 & 2,58 & 6691 & 6921 & -4 & 2,58 & 6687 & 6917 \\
\hline 10 & 2935 & 370,8 & 22000 & 27,73 & 813 & 2,57 & 7151 & 7395 & -5 & 2,57 & 7146 & 7390 \\
\hline 11 & 2903 & 400,5 & 22000 & 29,73 & 868 & 2,56 & 7639 & 7899 & -6 & 2,56 & 7633 & 7893 \\
\hline 12 & 2870 & 432,4 & 22000 & 31,87 & 926 & 2,56 & 8159 & 8436 & -7 & 2,55 & 8153 & 8430 \\
\hline 13 & 2839 & 466,5 & 22000 & 34,16 & 987 & 2,55 & 8714 & 9010 & -8 & 2,54 & 8707 & 9003 \\
\hline 14 & 2807 & 503,1 & 22000 & 36,61 & 1053 & 2,54 & 9306 & 9624 & -9 & 2,54 & 9298 & 9615 \\
\hline 15 & 2779 & 542,4 & 22000 & 39,24 & 1124 & 2,53 & 9942 & 10280 & -10 & 2,53 & 9932 & 10270 \\
\hline 16 & 2738 & 584,4 & 22000 & 42,06 & 1199 & 2,52 & 10619 & 10979 & -11 & 2,52 & 10608 & 10969 \\
\hline 17 & 2703 & 629,5 & 22000 & 45,11 & 1216 & 2,51 & 11340 & 11254 & -6 & 2,51 & 11329 & 11248 \\
\hline 18 & 2660 & 677,9 & 22000 & 48,39 & 1105 & 2,11 & 11167 & 10596 & 7 & 2,11 & 11167 & 10603 \\
\hline 19 & 2636 & 729,9 & 22000 & 51,94 & 918 & 1,75 & 10025 & 9423 & 16 & 1,76 & 10039 & 9439 \\
\hline 20 & 2600 & 785,7 & 22000 & 55,79 & 709 & 1,41 & 8822 & 8126 & 17 & 1,41 & 8840 & 8143 \\
\hline 21 & 2550 & 845,3 & 22000 & 59,67 & 467 & 1,08 & 7430 & 6503 & 10 & 1,08 & 7445 & 6513 \\
\hline 22 & 2510 & 905,0 & 22000 & 59,67 & 273 & 0,79 & 5575 & 5131 & 2 & 0,79 & 5580 & 5133 \\
\hline 23 & 2471 & 964,7 & 22000 & 59,67 & 209 & 0,78 & 4686 & 4673 & 0 & 0,78 & 4685 & 4672 \\
\hline 24 & 2434 & 1024,3 & 22000 & 59,67 & 206 & 0,78 & 4659 & 4653 & 0 & 0,78 & 4659 & 4653 \\
\hline 25 & 2391 & 1084,0 & 22000 & 59,67 & 200 & 0,78 & 4646 & 4528 & 0 & 0,78 & 4646 & 4528 \\
\hline 26 & 2358 & 1140,6 & 22000 & 56,63 & 195 & 0,78 & 4409 & 4414 & 0 & 0,78 & 4409 & 4414 \\
\hline 27 & 2327 & 1197,3 & 22000 & 56,63 & 197 & 0,78 & 4419 & 4428 & 1 & 0,78 & 4419 & 4429 \\
\hline 28 & 2292 & 1253,9 & 22000 & 56,63 & 199 & 0,79 & 4437 & 4446 & 2 & 0,79 & 4439 & 4448 \\
\hline 29 & 2264 & 1310,5 & 22000 & 56,63 & 201 & 0,79 & 4454 & 4462 & 3 & 0,79 & 4457 & 4465 \\
\hline 30 & 2239 & 1367,1 & 22000 & 56,63 & 203 & 0,79 & 4470 & 4477 & 4 & 0,79 & 4474 & 4481 \\
\hline 31 & 2208 & 1423,8 & 22000 & 56,63 & 204 & 0,79 & 4484 & 4491 & 5 & 0,79 & 4489 & 4496 \\
\hline 32 & 2182 & 1480,4 & 22000 & 56,63 & 206 & 0,80 & 4498 & 4504 & 6 & 0,80 & 4503 & 4510 \\
\hline 33 & 2159 & 1537,0 & 22000 & 56,63 & 220 & 0,80 & 4510 & 4799 & 7 & 0,80 & 4516 & 4806 \\
\hline 34 & 2138 & 1600,7 & 22000 & 63,71 & 243 & 0,80 & 5088 & 5276 & 9 & 0,80 & 5096 & 5285 \\
\hline 35 & 2116 & 1668,9 & 22000 & 68,23 & 263 & 0,80 & 5465 & 5669 & 10 & 0,80 & 5474 & 5679 \\
\hline 36 & 2092 & 1742,1 & 22000 & 73,13 & 284 & 0,80 & 5874 & 6096 & 12 & 0,81 & 5885 & 6108 \\
\hline 37 & 2063 & 1820,5 & 22000 & 78,42 & 307 & 0,81 & 6318 & 6559 & 15 & 0,81 & 6331 & 6573 \\
\hline 38 & 2039 & 1904,6 & 22000 & 84,16 & 332 & 0,81 & 6799 & 7061 & 17 & 0,81 & 6815 & 7078 \\
\hline 39 & 2009 & 1995,0 & 22000 & 90,38 & 359 & 0,81 & 7322 & 7605 & 19 & 0,81 & 7340 & 7625 \\
\hline 40 & 1985 & 2092,2 & 22000 & 97,15 & 389 & 0,81 & 7889 & 8198 & 22 & 0,82 & 7910 & 8220 \\
\hline 41 & 1950 & 2196,7 & 22000 & 104,51 & 421 & 0,81 & 8507 & 8844 & 25 & 0,82 & 8530 & 8869 \\
\hline 42 & 1922 & 2309,2 & 22000 & 112,55 & 456 & 0,82 & 9182 & 9550 & 28 & 0,82 & 9208 & 9579 \\
\hline 43 & 1891 & 2430,6 & 22000 & 121,34 & 479 & 0,82 & 9919 & 10000 & 31 & 0,82 & 9949 & 10031 \\
\hline 44 & 1854 & 2553,7 & 22000 & 123,10 & 484 & 0,82 & 10081 & 10088 & 32 & 0,82 & 10113 & 10120 \\
\hline 45 & 1816 & 2676,8 & 22000 & 123,10 & 486 & 0,82 & 10095 & 10099 & 33 & 0,82 & 10127 & 10132 \\
\hline 46 & 1789 & 2799,9 & 22000 & 123,10 & 487 & 0,82 & 10104 & 10107 & 33 & 0,82 & 10137 & 10140 \\
\hline 47 & 1753 & 2923,0 & 22000 & 123,10 & 365 & 0,82 & 10109 & 7691 & 26 & 0,82 & 10143 & 7717 \\
\hline 48 & 1715 & 2983,2 & 21900 & 60,17 & 249 & 0,93 & 5272 & 5625 & 23 & 0,93 & 5291 & 5648 \\
\hline 49 & 1674 & 3043,3 & 21800 & 60,17 & 266 & 1,06 & 5978 & 6356 & 32 & 1,06 & 6005 & 6388 \\
\hline 50 & 1635 & 3103,5 & 21700 & 60,17 & 285 & 1,18 & 6734 & 7114 & 44 & 1,19 & 6772 & 7158 \\
\hline 51 & 1598 & 3163,7 & 21600 & 60,17 & 303 & 1,31 & 7494 & 7873 & 57 & 1,32 & 7544 & 7930 \\
\hline 52 & 1552 & 3223,8 & 21500 & 60,17 & 321 & 1,43 & 8252 & 8631 & 69 & 1,45 & 8315 & 8700 \\
\hline 53 & 1521 & 3284,0 & 21400 & 60,17 & 487 & 1,56 & 9009 & 13440 & 115 & 1,57 & 9084 & 13555 \\
\hline 54 & 1485 & 3398,5 & 21400 & 114,50 & 645 & 1,56 & 17870 & 17874 & 155 & 1,57 & 18025 & 18029 \\
\hline 55 & 1455 & 3513,0 & 21400 & 114,50 & 495 & 1,56 & 17879 & 13817 & 121 & 1,58 & 18034 & 13937 \\
\hline 56 & 1418 & 3573,1 & 21300 & 60,14 & 352 & 1,68 & 9755 & 10117 & 91 & 1,70 & 9841 & 10208 \\
\hline 57 & 1379 & 3633,3 & 21200 & 60,14 & 363 & 1,80 & 10479 & 10839 & 100 & 1,82 & 10575 & 10939 \\
\hline 58 & 1347 & 3693,4 & 21100 & 60,14 & 373 & 1,92 & 11200 & 11556 & 108 & 1,94 & 11304 & 11664 \\
\hline 59 & 1313 & 3753,6 & 21000 & 60,14 & 381 & 2,04 & 11913 & 12267 & 115 & 2,06 & 12025 & 12383 \\
\hline 60 & 1282 & 3813,7 & 20900 & 60,14 & 388 & 2,16 & 12622 & 12973 & 121 & 2,18 & 12740 & 13095 \\
\hline
\end{tabular}


Tabela B-4 (6)

\begin{tabular}{|r|r|r|r|r|}
\hline 61 & 1248 & 3873,9 & 20800 & 60,14 \\
\hline 62 & 1218 & 3934,0 & 20700 & 60,14 \\
\hline 63 & 1191 & 4033,0 & 20700 & 99,00 \\
\hline 64 & 1162 & 4093,2 & 20600 & 60,17 \\
\hline 65 & 1131 & 4153,3 & 20500 & 60,17 \\
\hline 66 & 1098 & 4213,5 & 20400 & 60,17 \\
\hline 67 & 1071 & 4273,7 & 20300 & 60,17 \\
\hline 68 & 1045 & 4333,8 & 20200 & 60,16 \\
\hline 69 & 1010 & 4394,0 & 20100 & 60,17 \\
\hline 70 & 984 & 4530,4 & 20100 & 136,39 \\
\hline 71 & 947 & 4675,6 & 20100 & 145,16 \\
\hline 72 & 916 & 4830,3 & 20100 & 154,72 \\
\hline 73 & 878 & 4985,0 & 20100 & 154,72 \\
\hline 74 & 870 & 5072,0 & 20188 & 87,00 \\
\hline 75 & 865 & 5159,0 & 20275 & 87,00 \\
\hline 76 & 861 & 5246,0 & 20363 & 87,00 \\
\hline 77 & 857 & 5333,0 & 20450 & 87,00 \\
\hline 78 & 824 & 5473,0 & 20450 & 140,00 \\
\hline 79 & 794 & 5613,0 & 20450 & 140,00 \\
\hline 80 & 768 & 5753,0 & 20450 & 140,00 \\
\hline 81 & 740 & 5893,0 & 20450 & 140,00 \\
\hline 82 & 706 & 6033,0 & 20450 & 140,00 \\
\hline 83 & 680 & 6173,0 & 20450 & 140,00 \\
\hline 84 & 652 & 6313,0 & 20450 & 140,00 \\
\hline 85 & 626 & 6453,0 & 20450 & 140,00 \\
\hline 86 & 602 & 6593,0 & 20450 & 140,00 \\
\hline 87 & 577 & 6733,0 & 20450 & 140,00 \\
\hline 88 & 553 & 6873,0 & 20450 & 140,00 \\
\hline 89 & 529 & 7013,0 & 20450 & 140,00 \\
\hline 90 & 511 & 7153,0 & 20450 & 140,00 \\
\hline 91 & 490 & 7293,0 & 20450 & 140,00 \\
\hline 92 & 468 & 7433,0 & 20450 & 140,00 \\
\hline 93 & 449 & 7573,0 & 20450 & 140,00 \\
\hline 94 & 432 & 7713,0 & 20450 & 140,00 \\
\hline 95 & 417 & 7853,0 & 20450 & 140,00 \\
\hline 96 & 401 & 7993,0 & 20450 & 140,00 \\
\hline 97 & 384 & 8133,0 & 20450 & 140,00 \\
\hline 98 & 369 & 8273,0 & 20450 & 140,00 \\
\hline 99 & 355 & 8413,0 & 20450 & 140,00 \\
\hline 100 & 340 & 8553 & 20450 & 140,00 \\
\hline & & & & \\
\hline 70
\end{tabular}

\begin{tabular}{|c|c|c|c|}
\hline 392 & 2,27 & 13325 & 13675 \\
\hline 522 & 2,39 & 14024 & 18843 \\
\hline 522 & 2,39 & 23661 & 19195 \\
\hline 395 & 2,51 & 14728 & 15079 \\
\hline 393 & 2,62 & 15429 & 15794 \\
\hline 387 & 2,75 & 16160 & 16539 \\
\hline 376 & 2,88 & 16919 & 17330 \\
\hline 355 & 3,02 & 17742 & 18228 \\
\hline 528 & 3,20 & 18714 & 31238 \\
\hline 721 & 3,22 & 43763 & 45318 \\
\hline 733 & 3,24 & 46873 & 48571 \\
\hline 717 & 3,26 & 50268 & 50437 \\
\hline 525 & 3,28 & 50607 & 39456 \\
\hline 327 & 3,22 & 28305 & 28071 \\
\hline 276 & 3,17 & 27837 & 27596 \\
\hline 236 & 3,11 & 27356 & 27069 \\
\hline 277 & 3,04 & 26783 & 34692 \\
\hline 334 & 3,04 & 42602 & 42604 \\
\hline 333 & 3,04 & 42606 & 42612 \\
\hline 330 & 3,04 & 42617 & 42626 \\
\hline 326 & 3,05 & 42635 & 42647 \\
\hline 322 & 3,05 & 42659 & 42674 \\
\hline 316 & 3,05 & 42690 & 42707 \\
\hline 309 & 3,05 & 42725 & 42745 \\
\hline 301 & 3,06 & 42765 & 42788 \\
\hline 291 & 3,06 & 42811 & 42836 \\
\hline 280 & 3,06 & 42861 & 42889 \\
\hline 269 & 3,07 & 42917 & 42947 \\
\hline 257 & 3,07 & 42978 & 43011 \\
\hline 243 & 3,08 & 43044 & 43079 \\
\hline 228 & 3,08 & 43115 & 43153 \\
\hline 211 & 3,09 & 43191 & 43232 \\
\hline 193 & 3,09 & 43273 & 43318 \\
\hline 174 & 3,10 & 43362 & 43410 \\
\hline 153 & 3,11 & 43458 & 43510 \\
\hline 129 & 3,12 & 43561 & 43616 \\
\hline 104 & 3,12 & 43672 & 43727 \\
\hline 77 & 3,13 & 43782 & 43853 \\
\hline 43 & 3,14 & 43923 & 44017 \\
\hline 11 & 3,16 & 44111 & 22055 \\
\hline
\end{tabular}

\begin{tabular}{|c|c|c|c|}
\hline 126 & 2,29 & 13449 & 13801 \\
\hline 171 & 2,41 & 14153 & 19014 \\
\hline 173 & 2,41 & 23875 & 19367 \\
\hline 132 & 2,53 & 14860 & 15211 \\
\hline 134 & 2,65 & 15562 & 15928 \\
\hline 134 & 2,77 & 16294 & 16674 \\
\hline 133 & 2,90 & 17053 & 17463 \\
\hline 128 & 3,04 & 17874 & 18356 \\
\hline 196 & 3,22 & 18839 & 31435 \\
\hline 270 & 3,24 & 44030 & 45588 \\
\hline 277 & 3,26 & 47147 & 48848 \\
\hline 274 & 3,28 & 50549 & 50711 \\
\hline 202 & 3,30 & 50874 & 39658 \\
\hline 126 & 3,24 & 28441 & 28197 \\
\hline 107 & 3,19 & 27953 & 27703 \\
\hline 91 & 3,12 & 27453 & 27161 \\
\hline 108 & 3,05 & 26868 & 34800 \\
\hline 130 & 3,05 & 42732 & 42734 \\
\hline 129 & 3,05 & 42736 & 42741 \\
\hline 128 & 3,05 & 42746 & 42755 \\
\hline 127 & 3,06 & 42763 & 42774 \\
\hline 125 & 3,06 & 42785 & 42799 \\
\hline 123 & 3,06 & 42813 & 42830 \\
\hline 120 & 3,06 & 42846 & 42865 \\
\hline 118 & 3,06 & 42884 & 42905 \\
\hline 114 & 3,07 & 42927 & 42950 \\
\hline 111 & 3,07 & 42974 & 43000 \\
\hline 106 & 3,08 & 43026 & 43054 \\
\hline 101 & 3,08 & 43082 & 43112 \\
\hline 95 & 3,08 & 43142 & 43175 \\
\hline 90 & 3,09 & 43208 & 43243 \\
\hline 84 & 3,09 & 43278 & 43316 \\
\hline 77 & 3,10 & 43354 & 43394 \\
\hline 69 & 3,11 & 43435 & 43479 \\
\hline 60 & 3,11 & 43523 & 43569 \\
\hline 51 & 3,12 & 43616 & 43667 \\
\hline 42 & 3,13 & 43718 & 43769 \\
\hline 31 & 3,13 & 43819 & 43883 \\
\hline 16 & 3,14 & 43947 & 44033 \\
\hline 4 & 3,16 & 44119 & 22059 \\
\hline
\end{tabular}


Tabela B-4 (7)

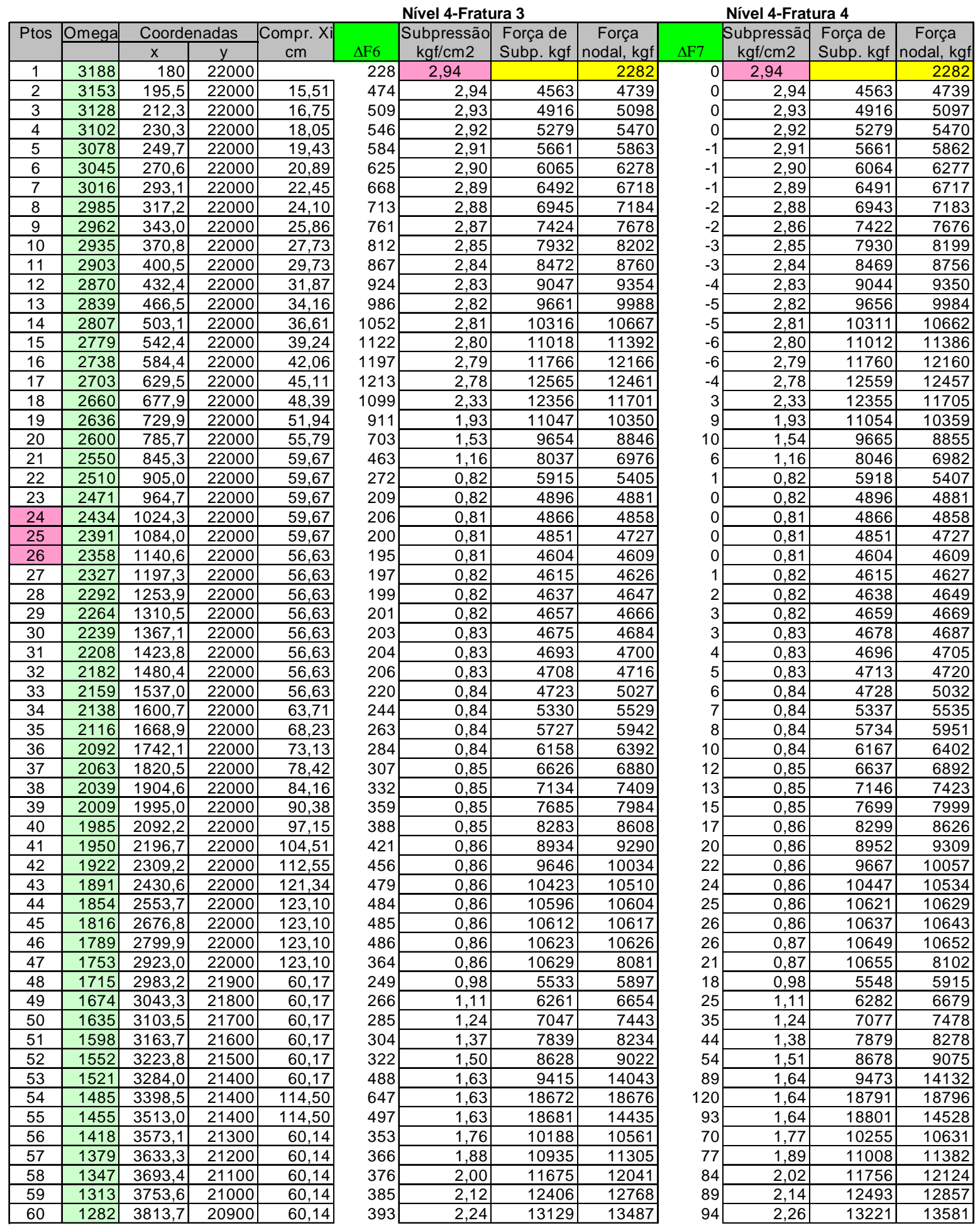


Tabela B-4 (8)

\begin{tabular}{|r|r|r|r|r|}
\hline 61 & 1248 & 3873,9 & 20800 & 60,14 \\
\hline 62 & 1218 & 3934,0 & 20700 & 60,14 \\
\hline 63 & 1191 & 4033,0 & 20700 & 99,00 \\
\hline 64 & 1162 & 4093,2 & 20600 & 60,17 \\
\hline 65 & 1131 & 4153,3 & 20500 & 60,17 \\
\hline 66 & 1098 & 4213,5 & 20400 & 60,17 \\
\hline 67 & 1071 & 4273,7 & 20300 & 60,17 \\
\hline 68 & 1045 & 4333,8 & 20200 & 60,16 \\
\hline 69 & 1010 & 4394,0 & 20100 & 60,17 \\
\hline 70 & 984 & 4530,4 & 20100 & 136,39 \\
\hline 71 & 947 & 4675,6 & 20100 & 145,16 \\
\hline 72 & 916 & 4830,3 & 20100 & 154,72 \\
\hline 73 & 878 & 4985,0 & 20100 & 154,72 \\
\hline 74 & 870 & 5072,0 & 20188 & 87,00 \\
\hline 75 & 865 & 5159,0 & 20275 & 87,00 \\
\hline 76 & 861 & 5246,0 & 20363 & 87,00 \\
\hline 77 & 857 & 5333,0 & 20450 & 87,00 \\
\hline 78 & 824 & 5473,0 & 20450 & 140,00 \\
\hline 79 & 794 & 5613,0 & 20450 & 140,00 \\
\hline 80 & 768 & 5753,0 & 20450 & 140,00 \\
\hline 81 & 740 & 5893,0 & 20450 & 140,00 \\
\hline 82 & 706 & 6033,0 & 20450 & 140,00 \\
\hline 83 & 680 & 6173,0 & 20450 & 140,00 \\
\hline 84 & 652 & 6313,0 & 20450 & 140,00 \\
\hline 85 & 626 & 6453,0 & 20450 & 140,00 \\
\hline 86 & 602 & 6593,0 & 20450 & 140,00 \\
\hline 87 & 577 & 6733,0 & 20450 & 140,00 \\
\hline 88 & 553 & 6873,0 & 20450 & 140,00 \\
\hline 89 & 529 & 7013,0 & 20450 & 140,00 \\
\hline 90 & 511 & 7153,0 & 20450 & 140,00 \\
\hline 91 & 490 & 7293,0 & 20450 & 140,00 \\
\hline 92 & 468 & 7433,0 & 20450 & 140,00 \\
\hline 93 & 449 & 7573,0 & 20450 & 140,00 \\
\hline 94 & 432 & 7713,0 & 20450 & 140,00 \\
\hline 95 & 417 & 7853,0 & 20450 & 140,00 \\
\hline 96 & 401 & 7993,0 & 20450 & 140,00 \\
\hline 97 & 384 & 8133,0 & 20450 & 140,00 \\
\hline 98 & 369 & 8273,0 & 20450 & 140,00 \\
\hline 99 & 355 & 8413,0 & 20450 & 140,00 \\
\hline 100 & 340 & 8553 & 20450 & 140,00 \\
\hline & & & & \\
\hline 76 &
\end{tabular}

\begin{tabular}{|c|c|c|c|}
\hline 398 & 2,36 & 13845 & 14198 \\
\hline 529 & 2,48 & 14552 & 19543 \\
\hline 531 & 2,48 & 24535 & 19898 \\
\hline 402 & 2,59 & 15262 & 15613 \\
\hline 401 & 2,71 & 15965 & 16329 \\
\hline 395 & 2,84 & 16693 & 17069 \\
\hline 384 & 2,96 & 17444 & 17848 \\
\hline 363 & 3,11 & 18251 & 18719 \\
\hline 539 & 3,27 & 19188 & 31974 \\
\hline 737 & 3,29 & 44760 & 46325 \\
\hline 749 & 3,31 & 47890 & 49597 \\
\hline 734 & 3,32 & 51304 & 51446 \\
\hline 538 & 3,34 & 51587 & 40196 \\
\hline 335 & 3,28 & 28804 & 28532 \\
\hline 283 & 3,22 & 28261 & 27986 \\
\hline 242 & 3,15 & 27712 & 27403 \\
\hline 285 & 3,08 & 27094 & 35085 \\
\hline 344 & 3,08 & 43077 & 43078 \\
\hline 343 & 3,08 & 43079 & 43084 \\
\hline 340 & 3,08 & 43088 & 43095 \\
\hline 337 & 3,08 & 43102 & 43111 \\
\hline 331 & 3,08 & 43120 & 43131 \\
\hline 325 & 3,08 & 43142 & 43155 \\
\hline 317 & 3,08 & 43168 & 43183 \\
\hline 309 & 3,09 & 43198 & 43215 \\
\hline 300 & 3,09 & 43231 & 43250 \\
\hline 289 & 3,09 & 43268 & 43289 \\
\hline 277 & 3,10 & 43309 & 43331 \\
\hline 264 & 3,10 & 43352 & 43376 \\
\hline 250 & 3,10 & 43399 & 43425 \\
\hline 235 & 3,11 & 43450 & 43478 \\
\hline 218 & 3,11 & 43505 & 43534 \\
\hline 199 & 3,11 & 43562 & 43593 \\
\hline 179 & 3,12 & 43624 & 43657 \\
\hline 156 & 3,12 & 43691 & 43726 \\
\hline 132 & 3,13 & 43761 & 43799 \\
\hline 107 & 3,13 & 43838 & 43876 \\
\hline 80 & 3,14 & 43915 & 43963 \\
\hline 43 & 3,15 & 44012 & 44077 \\
\hline 11 & 3,16 & 44141 & 22071 \\
\hline
\end{tabular}

\begin{tabular}{|c|c|c|c|}
\hline 98 & 2,38 & 13941 & 14297 \\
\hline 134 & 2,50 & 14652 & 19677 \\
\hline 135 & 2,50 & 24702 & 20033 \\
\hline 104 & 2,61 & 15364 & 15717 \\
\hline 105 & 2,73 & 16070 & 16435 \\
\hline 106 & 2,85 & 16799 & 17175 \\
\hline 105 & 2,98 & 17550 & 17952 \\
\hline 102 & 3,12 & 18355 & 18821 \\
\hline 155 & 3,29 & 19287 & 32129 \\
\hline 214 & 3,31 & 44972 & 46539 \\
\hline 219 & 3,32 & 48106 & 49816 \\
\hline 217 & 3,34 & 51526 & 51662 \\
\hline 159 & 3,36 & 51799 & 40355 \\
\hline 100 & 3,29 & 28911 & 28632 \\
\hline 85 & 3,23 & 28352 & 28071 \\
\hline 73 & 3,16 & 27790 & 27475 \\
\hline 86 & 3,08 & 27161 & 35171 \\
\hline 104 & 3,08 & 43180 & 43182 \\
\hline 104 & 3,08 & 43184 & 43188 \\
\hline 104 & 3,09 & 43192 & 43198 \\
\hline 102 & 3,09 & 43205 & 43213 \\
\hline 101 & 3,09 & 43222 & 43232 \\
\hline 99 & 3,09 & 43242 & 43254 \\
\hline 97 & 3,09 & 43266 & 43280 \\
\hline 95 & 3,09 & 43294 & 43309 \\
\hline 92 & 3,10 & 43324 & 43342 \\
\hline 88 & 3,10 & 43359 & 43377 \\
\hline 84 & 3,10 & 43395 & 43415 \\
\hline 81 & 3,10 & 43435 & 43457 \\
\hline 77 & 3,11 & 43478 & 43502 \\
\hline 71 & 3,11 & 43525 & 43549 \\
\hline 66 & 3,11 & 43574 & 43600 \\
\hline 61 & 3,12 & 43626 & 43654 \\
\hline 56 & 3,12 & 43683 & 43713 \\
\hline 49 & 3,13 & 43743 & 43775 \\
\hline 41 & 3,13 & 43807 & 43841 \\
\hline 33 & 3,14 & 43875 & 43909 \\
\hline 24 & 3,14 & 43943 & 43987 \\
\hline 13 & 3,15 & 44031 & 44090 \\
\hline 4 & 3,16 & 44148 & 22074 \\
\hline
\end{tabular}


Tabela B-4 (9)

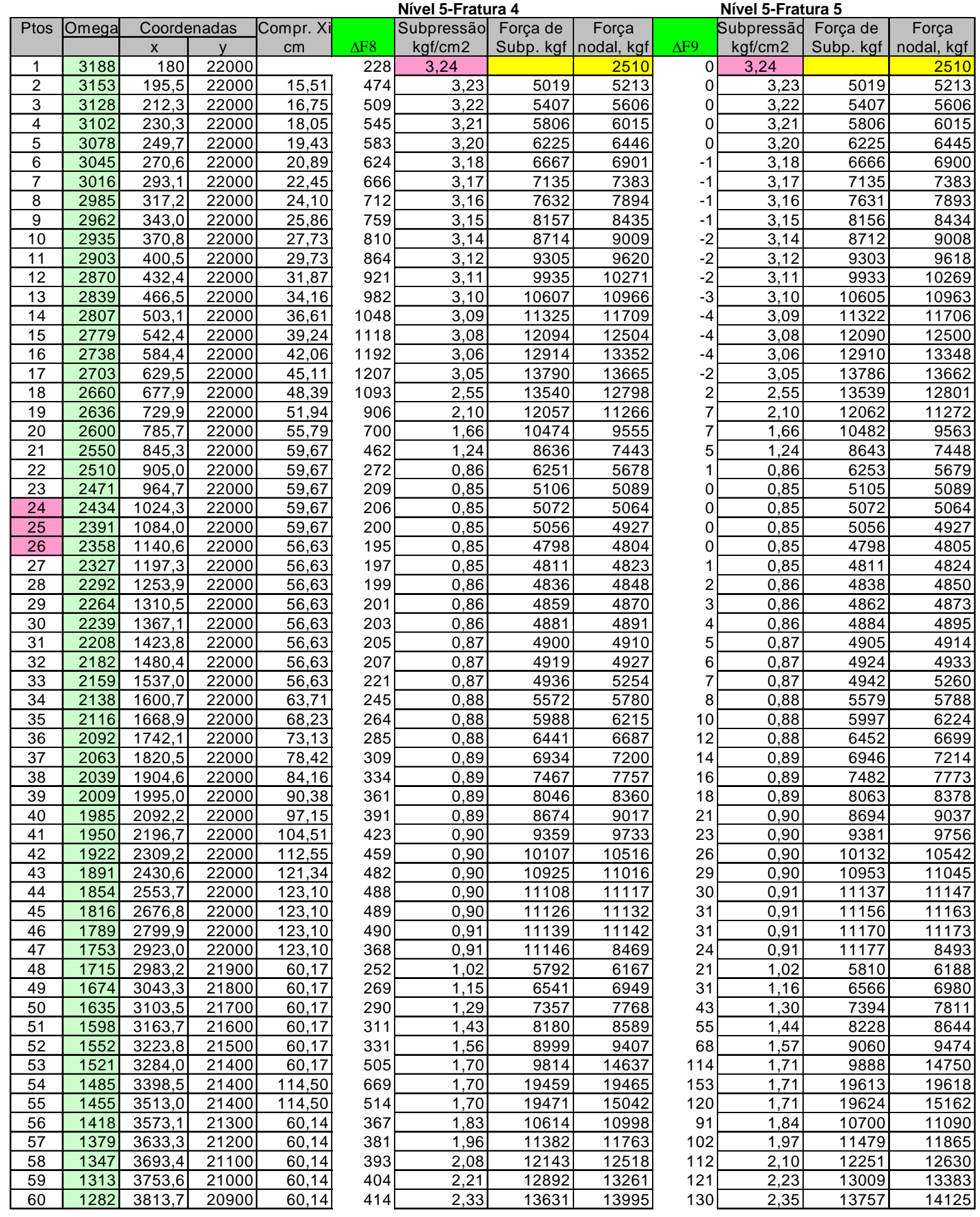


Tabela B-4 (10)

\begin{tabular}{|r|r|r|r|r|}
\hline 61 & 1248 & 3873,9 & 20800 & 60,14 \\
\hline 62 & 1218 & 3934,0 & 20700 & 60,14 \\
\hline 63 & 1191 & 4033,0 & 20700 & 99,00 \\
\hline 64 & 1162 & 4093,2 & 20600 & 60,17 \\
\hline 65 & 1131 & 4153,3 & 20500 & 60,17 \\
\hline 66 & 1098 & 4213,5 & 20400 & 60,17 \\
\hline 67 & 1071 & 4273,7 & 20300 & 60,17 \\
\hline 68 & 1045 & 4333,8 & 20200 & 60,16 \\
\hline 69 & 1010 & 4394,0 & 20100 & 60,17 \\
\hline 70 & 984 & 4530,4 & 20100 & 136,39 \\
\hline 71 & 947 & 4675,6 & 20100 & 145,16 \\
\hline 72 & 916 & 4830,3 & 20100 & 154,72 \\
\hline 73 & 878 & 4985,0 & 20100 & 154,72 \\
\hline 74 & 870 & 5072,0 & 20188 & 87,00 \\
\hline 75 & 865 & 5159,0 & 20275 & 87,00 \\
\hline 76 & 861 & 5246,0 & 20363 & 87,00 \\
\hline 77 & 857 & 5333,0 & 20450 & 87,00 \\
\hline 78 & 824 & 5473,0 & 20450 & 140,00 \\
\hline 79 & 794 & 5613,0 & 20450 & 140,00 \\
\hline 80 & 768 & 5753,0 & 20450 & 140,00 \\
\hline 81 & 740 & 5893,0 & 20450 & 140,00 \\
\hline 82 & 706 & 6033,0 & 20450 & 140,00 \\
\hline 83 & 680 & 6173,0 & 20450 & 140,00 \\
\hline 84 & 652 & 6313,0 & 20450 & 140,00 \\
\hline 85 & 626 & 6453,0 & 20450 & 140,00 \\
\hline 86 & 602 & 6593,0 & 20450 & 140,00 \\
\hline 87 & 577 & 6733,0 & 20450 & 140,00 \\
\hline 88 & 553 & 6873,0 & 20450 & 140,00 \\
\hline 89 & 529 & 7013,0 & 20450 & 140,00 \\
\hline 90 & 511 & 7153,0 & 20450 & 140,00 \\
\hline 91 & 490 & 7293,0 & 20450 & 140,00 \\
\hline 92 & 468 & 7433,0 & 20450 & 140,00 \\
\hline 93 & 449 & 7573,0 & 20450 & 140,00 \\
\hline 94 & 432 & 7713,0 & 20450 & 140,00 \\
\hline 95 & 417 & 7853,0 & 20450 & 140,00 \\
\hline 96 & 401 & 7993,0 & 20450 & 140,00 \\
\hline 97 & 384 & 8133,0 & 20450 & 140,00 \\
\hline 98 & 369 & 8273,0 & 20450 & 140,00 \\
\hline 99 & 355 & 8413,0 & 20450 & 140,00 \\
\hline 100 & 340 & 8553 & 20450 & 140,00 \\
\hline & & & & \\
\hline 69
\end{tabular}

\begin{tabular}{|c|c|c|c|}
\hline 420 & 2,45 & 14359 & 14717 \\
\hline 561 & 2,57 & 15075 & 20238 \\
\hline 562 & 2,57 & 25401 & 20596 \\
\hline 427 & 2,68 & 15790 & 16144 \\
\hline 426 & 2,80 & 16498 & 16861 \\
\hline 421 & 2,92 & 17224 & 17596 \\
\hline 410 & 3,05 & 17967 & 18363 \\
\hline 389 & 3,19 & 18758 & 19209 \\
\hline 580 & 3,35 & 19661 & 32709 \\
\hline 793 & 3,36 & 45757 & 47332 \\
\hline 808 & 3,38 & 48907 & 50624 \\
\hline 793 & 3,39 & 52340 & 52455 \\
\hline 581 & 3,41 & 52569 & 40936 \\
\hline 362 & 3,33 & 29302 & 28994 \\
\hline 306 & 3,26 & 28685 & 28377 \\
\hline 261 & 3,19 & 28069 & 27737 \\
\hline 308 & 3,11 & 27405 & 35479 \\
\hline 372 & 3,11 & 43553 & 43554 \\
\hline 370 & 3,11 & 43555 & 43558 \\
\hline 367 & 3,11 & 43561 & 43566 \\
\hline 363 & 3,11 & 43570 & 43576 \\
\hline 358 & 3,11 & 43582 & 43589 \\
\hline 351 & 3,11 & 43597 & 43605 \\
\hline 343 & 3,12 & 43614 & 43623 \\
\hline 334 & 3,12 & 43632 & 43643 \\
\hline 323 & 3,12 & 43653 & 43665 \\
\hline 312 & 3,12 & 43677 & 43689 \\
\hline 300 & 3,12 & 43702 & 43715 \\
\hline 287 & 3,12 & 43729 & 43743 \\
\hline 271 & 3,13 & 43758 & 43773 \\
\hline 254 & 3,13 & 43788 & 43804 \\
\hline 236 & 3,13 & 43819 & 43836 \\
\hline 216 & 3,13 & 43853 & 43870 \\
\hline 193 & 3,14 & 43888 & 43906 \\
\hline 169 & 3,14 & 43924 & 43944 \\
\hline 143 & 3,14 & 43964 & 43984 \\
\hline 117 & 3,14 & 44005 & 44026 \\
\hline 87 & 3,15 & 44047 & 44074 \\
\hline 47 & 3,15 & 44101 & 44137 \\
\hline 12 & 3,16 & 44173 & 22086 \\
\hline
\end{tabular}

\begin{tabular}{|c|c|c|c|}
\hline 138 & 2,47 & 14494 & 14855 \\
\hline 189 & 2,59 & 15216 & 20427 \\
\hline 192 & 2,59 & 25638 & 20787 \\
\hline 149 & 2,71 & 15937 & 16293 \\
\hline 152 & 2,83 & 16649 & 17013 \\
\hline 154 & 2,95 & 17377 & 17749 \\
\hline 153 & 3,07 & 18121 & 18516 \\
\hline 150 & 3,21 & 18911 & 19359 \\
\hline 231 & 3,37 & 19807 & 32940 \\
\hline 320 & 3,39 & 46074 & 47653 \\
\hline 329 & 3,40 & 49231 & 50952 \\
\hline 325 & 3,41 & 52673 & 52780 \\
\hline 240 & 3,43 & 52887 & 41176 \\
\hline 150 & 3,35 & 29465 & 29144 \\
\hline 127 & 3,28 & 28824 & 28504 \\
\hline 109 & 3,20 & 28185 & 27846 \\
\hline 129 & 3,12 & 27507 & 35608 \\
\hline 156 & 3,12 & 43709 & 43710 \\
\hline 155 & 3,12 & 43711 & 43713 \\
\hline 154 & 3,12 & 43716 & 43720 \\
\hline 152 & 3,12 & 43723 & 43728 \\
\hline 150 & 3,12 & 43733 & 43740 \\
\hline 148 & 3,13 & 43746 & 43753 \\
\hline 145 & 3,13 & 43760 & 43768 \\
\hline 141 & 3,13 & 43775 & 43784 \\
\hline 137 & 3,13 & 43793 & 43802 \\
\hline 133 & 3,13 & 43812 & 43822 \\
\hline 127 & 3,13 & 43832 & 43842 \\
\hline 120 & 3,13 & 43853 & 43864 \\
\hline 114 & 3,13 & 43875 & 43887 \\
\hline 107 & 3,14 & 43898 & 43911 \\
\hline 100 & 3,14 & 43924 & 43936 \\
\hline 91 & 3,14 & 43949 & 43962 \\
\hline 82 & 3,14 & 43975 & 43988 \\
\hline 72 & 3,14 & 44002 & 44016 \\
\hline 61 & 3,15 & 44030 & 44045 \\
\hline 49 & 3,15 & 44059 & 44075 \\
\hline 36 & 3,15 & 44090 & 44111 \\
\hline 20 & 3,15 & 44131 & 44157 \\
\hline 5 & 3,16 & 44183 & 22092 \\
\hline
\end{tabular}


$\underline{\text { Tabela B-4 (11) }}$

\begin{tabular}{|c|c|c|c|c|c|c|c|c|}
\hline \multirow{3}{*}{ Ptos } & \multirow{3}{*}{ Omega } & & & \multicolumn{5}{|c|}{ Nível 6-Fratura 5} \\
\hline & & \multicolumn{2}{|c|}{ Coordenadas } & \multirow{2}{*}{$\begin{array}{c}\text { Compr. Xi } \\
\mathrm{cm}\end{array}$} & \multirow[b]{2}{*}{$\Delta \mathrm{F} 10$} & \multirow{2}{*}{$\begin{array}{c}\text { Subpressãd } \\
\mathrm{kgf} / \mathrm{cm} 2\end{array}$} & \multirow{2}{*}{$\begin{array}{l}\text { Força de } \\
\text { Subp. kgf }\end{array}$} & \multirow{2}{*}{$\begin{array}{c}\text { Força } \\
\text { nodal, kgf }\end{array}$} \\
\hline & & $\mathrm{x}$ & $y$ & & & & & \\
\hline 1 & 3188 & 180 & 22000 & & 304 & 3,63 & & 2814 \\
\hline 2 & 3153 & 195,5 & 22000 & 15,51 & 632 & 3,63 & 5628 & 5844 \\
\hline 3 & 3128 & 212,3 & 22000 & 16,75 & 678 & 3,61 & 6061 & 6285 \\
\hline 4 & 3102 & 230,3 & 22000 & 18,05 & 727 & 3,60 & 6508 & 6742 \\
\hline 5 & 3078 & 249,7 & 22000 & 19,43 & 778 & 3,58 & 6976 & 7223 \\
\hline 6 & 3045 & 270,6 & 22000 & 20,89 & 832 & 3,57 & 7471 & 7732 \\
\hline 7 & 3016 & 293,1 & 22000 & 22,45 & 889 & 3,55 & 7994 & 8271 \\
\hline 8 & 2985 & 317,2 & 22000 & 24,10 & 949 & 3,54 & 8549 & 8842 \\
\hline 9 & 2962 & 343,0 & 22000 & 25,86 & 1013 & 3,53 & 9136 & 9446 \\
\hline 10 & 2935 & 370,8 & 22000 & 27,73 & 1080 & 3,51 & 9757 & 10088 \\
\hline 11 & 2903 & 400,5 & 22000 & 29,73 & 1152 & 3,50 & 10418 & 10770 \\
\hline 12 & 2870 & 432,4 & 22000 & 31,87 & 1228 & 3,48 & 11122 & 11497 \\
\hline 13 & 2839 & 466,5 & 22000 & 34,16 & 1310 & 3,47 & 11872 & 12273 \\
\hline 14 & 2807 & 503,1 & 22000 & 36,61 & 1397 & 3,46 & 12674 & 13103 \\
\hline 15 & 2779 & 542,4 & 22000 & 39,24 & 1490 & 3,44 & 13532 & 13990 \\
\hline 16 & 2738 & 584,4 & 22000 & 42,06 & 1589 & 3,43 & 14448 & 14937 \\
\hline 17 & 2703 & 629,5 & 22000 & 45,11 & 1610 & 3,41 & 15426 & 15272 \\
\hline 18 & 2660 & 677,9 & 22000 & 48,39 & 1458 & 2,84 & 15118 & 14259 \\
\hline 19 & 2636 & 729,9 & 22000 & 51,94 & 1210 & 2,32 & 13400 & 12482 \\
\hline 20 & 2600 & 785,7 & 22000 & 55,79 & 935 & 1,82 & 11563 & 10497 \\
\hline 21 & 2550 & 845,3 & 22000 & 59,67 & 617 & 1,34 & 9431 & 8065 \\
\hline 22 & 2510 & 905,0 & 22000 & 59,67 & 364 & 0,91 & 6700 & 6044 \\
\hline 23 & 2471 & 964,7 & 22000 & 59,67 & 280 & 0,90 & 5388 & 5369 \\
\hline 24 & 2434 & 1024,3 & 22000 & 59,67 & 276 & 0,89 & 5350 & 5340 \\
\hline 25 & 2391 & 1084,0 & 22000 & 59,67 & 268 & 0,89 & 5331 & 5195 \\
\hline 26 & 2358 & 1140,6 & 22000 & 56,63 & 262 & 0,89 & 5059 & 5067 \\
\hline 27 & 2327 & 1197,3 & 22000 & 56,63 & 264 & 0,90 & 5074 & 5089 \\
\hline 28 & 2292 & 1253,9 & 22000 & 56,63 & 268 & 0,90 & 5104 & 5117 \\
\hline 29 & 2264 & 1310,5 & 22000 & 56,63 & 271 & 0,91 & 5131 & 5144 \\
\hline 30 & 2239 & 1367,1 & 22000 & 56,63 & 274 & 0,91 & 5157 & 5168 \\
\hline 31 & 2208 & 1423,8 & 22000 & 56,63 & 276 & 0,92 & 5180 & 5191 \\
\hline 32 & 2182 & 1480,4 & 22000 & 56,63 & 279 & 0,92 & 5201 & 5211 \\
\hline 33 & 2159 & 1537,0 & 22000 & 56,63 & 299 & 0,92 & 5221 & 5559 \\
\hline 34 & 2138 & 1600,7 & 22000 & 63,71 & 330 & 0,93 & 5897 & 6118 \\
\hline 35 & 2116 & 1668,9 & 22000 & 68,23 & 357 & 0,93 & 6340 & 6581 \\
\hline 36 & 2092 & 1742,1 & 22000 & 73,13 & 386 & 0,93 & 6822 & 7085 \\
\hline 37 & 2063 & 1820,5 & 22000 & 78,42 & 417 & 0,94 & 7347 & 7631 \\
\hline 38 & 2039 & 1904,6 & 22000 & 84,16 & 452 & 0,94 & 7916 & 8224 \\
\hline 39 & 2009 & 1995,0 & 22000 & 90,38 & 489 & 0,95 & 8533 & 8867 \\
\hline 40 & 1985 & 2092,2 & 22000 & 97,15 & 529 & 0,95 & 9202 & 9567 \\
\hline 41 & 1950 & 2196,7 & 22000 & 104,51 & 574 & 0,95 & 9931 & 10330 \\
\hline 42 & 1922 & 2309,2 & 22000 & 112,55 & 622 & 0,95 & 10728 & 11164 \\
\hline 43 & 1891 & 2430,6 & 22000 & 121,34 & 653 & 0,96 & 11600 & 11698 \\
\hline 44 & 1854 & 2553,7 & 22000 & 123,10 & 661 & 0,96 & 11797 & 11808 \\
\hline 45 & 1816 & 2676,8 & 22000 & 123,10 & 663 & 0,96 & 11819 & 11826 \\
\hline 46 & 1789 & 2799,9 & 22000 & 123,10 & 664 & 0,96 & 11834 & 11838 \\
\hline 47 & 1753 & 2923,0 & 22000 & 123,10 & 498 & 0,96 & 11842 & 8992 \\
\hline 48 & 1715 & 2983,2 & 21900 & 60,17 & 343 & 1,08 & 6142 & 6531 \\
\hline 49 & 1674 & 3043,3 & 21800 & 60,17 & 369 & 1,22 & 6919 & 7348 \\
\hline 50 & 1635 & 3103,5 & 21700 & 60,17 & 399 & 1,36 & 7777 & 8210 \\
\hline 51 & 1598 & 3163,7 & 21600 & 60,17 & 430 & 1,51 & 8643 & 9074 \\
\hline 52 & 1552 & 3223,8 & 21500 & 60,17 & 460 & 1,65 & 9505 & 9934 \\
\hline 53 & 1521 & 3284,0 & 21400 & 60,17 & 703 & 1,79 & 10363 & 15454 \\
\hline 54 & 1485 & 3398,5 & 21400 & 114,50 & 933 & 1,80 & 20545 & 20551 \\
\hline 55 & 1455 & 3513,0 & 21400 & 114,50 & 718 & 1,80 & 20558 & 15880 \\
\hline 56 & 1418 & 3573,1 & 21300 & 60,14 & 513 & 1,93 & 11202 & 11603 \\
\hline 57 & 1379 & 3633,3 & 21200 & 60,14 & 535 & 2,06 & 12004 & 12400 \\
\hline 58 & 1347 & 3693,4 & 21100 & 60,14 & 556 & 2,19 & 12797 & 13185 \\
\hline 59 & 1313 & 3753,6 & 21000 & 60,14 & 573 & 2,32 & 13574 & 13956 \\
\hline 60 & 1282 & 3813,7 & 20900 & 60,14 & 589 & 2,45 & 14338 & 14714 \\
\hline
\end{tabular}


Tabela B-4 (12)

\begin{tabular}{|c|c|c|c|c|c|c|c|c|}
\hline 61 & 1248 & 3873,9 & 20800 & 60,14 & 601 & 2,57 & 15090 & 15456 \\
\hline 62 & 1218 & 3934,0 & 20700 & 60,14 & 804 & 2,69 & 15822 & 21231 \\
\hline 63 & 1191 & 4033,0 & 20700 & 99,00 & 808 & 2,69 & 26640 & 21595 \\
\hline 64 & 1162 & 4093,2 & 20600 & 60,17 & 615 & 2,81 & 16550 & 16908 \\
\hline 65 & 1131 & 4153,3 & 20500 & 60,17 & 617 & 2,93 & 17267 & 17630 \\
\hline 66 & 1098 & 4213,5 & 20400 & 60,17 & 611 & 3,05 & 17993 & 18361 \\
\hline 67 & 1071 & 4273,7 & 20300 & 60,17 & 598 & 3,17 & 18728 & 19114 \\
\hline 68 & 1045 & 4333,8 & 20200 & 60,16 & 569 & 3,31 & 19500 & 19928 \\
\hline 69 & 1010 & 4394,0 & 20100 & 60,17 & 853 & 3,46 & 20356 & 33793 \\
\hline 70 & 984 & 4530,4 & 20100 & 136,39 & 1169 & 3,47 & 47231 & 48821 \\
\hline 71 & 947 & 4675,6 & 20100 & 145,16 & 1191 & 3,48 & 50412 & 52143 \\
\hline 72 & 916 & 4830,3 & 20100 & 154,72 & 1169 & 3,49 & 53874 & 53949 \\
\hline 73 & 878 & 4985,0 & 20100 & 154,72 & 858 & 3,50 & 54024 & 42034 \\
\hline 74 & 870 & 5072,0 & 20188 & 87,00 & 535 & 3,41 & 30043 & 29680 \\
\hline 75 & 865 & 5159,0 & 20275 & 87,00 & 453 & 3,33 & 29316 & 28958 \\
\hline 76 & 861 & 5246,0 & 20363 & 87,00 & 387 & 3,25 & 28599 & 28233 \\
\hline 77 & 857 & 5333,0 & 20450 & 87,00 & 455 & 3,16 & 27867 & 36063 \\
\hline 78 & 824 & 5473,0 & 20450 & 140,00 & 550 & 3,16 & 44259 & 44260 \\
\hline 79 & 794 & 5613,0 & 20450 & 140,00 & 548 & 3,16 & 44260 & 44261 \\
\hline 80 & 768 & 5753,0 & 20450 & 140,00 & 544 & 3,16 & 44262 & 44264 \\
\hline 81 & 740 & 5893,0 & 20450 & 140,00 & 538 & 3,16 & 44265 & 44267 \\
\hline 82 & 706 & 6033,0 & 20450 & 140,00 & 530 & 3,16 & 44268 & 44270 \\
\hline 83 & 680 & 6173,0 & 20450 & 140,00 & 520 & 3,16 & 44272 & 44273 \\
\hline 84 & 652 & 6313,0 & 20450 & 140,00 & 509 & 3,16 & 44275 & 44276 \\
\hline 85 & 626 & 6453,0 & 20450 & 140,00 & 495 & 3,16 & 44278 & 44279 \\
\hline 86 & 602 & 6593,0 & 20450 & 140,00 & 480 & 3,16 & 44281 & 44282 \\
\hline 87 & 577 & 6733,0 & 20450 & 140,00 & 463 & 3,16 & 44283 & 44285 \\
\hline 88 & 553 & 6873,0 & 20450 & 140,00 & 445 & 3,16 & 44286 & 44287 \\
\hline 89 & 529 & 7013,0 & 20450 & 140,00 & 424 & 3,16 & 44288 & 44288 \\
\hline 90 & 511 & 7153,0 & 20450 & 140,00 & 402 & 3,16 & 44288 & 44288 \\
\hline 91 & 490 & 7293,0 & 20450 & 140,00 & 377 & 3,16 & 44288 & 44288 \\
\hline 92 & 468 & 7433,0 & 20450 & 140,00 & 349 & 3,16 & 44287 & 44286 \\
\hline 93 & 449 & 7573,0 & 20450 & 140,00 & 320 & 3,16 & 44284 & 44282 \\
\hline 94 & 432 & 7713,0 & 20450 & 140,00 & 288 & 3,16 & 44279 & 44276 \\
\hline 95 & 417 & 7853,0 & 20450 & 140,00 & 252 & 3,16 & 44273 & 44268 \\
\hline 96 & 401 & 7993,0 & 20450 & 140,00 & 213 & 3,16 & 44264 & 44258 \\
\hline 97 & 384 & 8133,0 & 20450 & 140,00 & 173 & 3,16 & 44252 & 44247 \\
\hline 98 & 369 & 8273,0 & 20450 & 140,00 & 128 & 3,16 & 44243 & 44239 \\
\hline 99 & 355 & 8413,0 & 20450 & 140,00 & 70 & 3,16 & 44234 & 44227 \\
\hline 100 & 340 & 8553 & 20450 & 140,00 & 18 & 3,16 & 44220 & 22110 \\
\hline
\end{tabular}

